\title{
jen
}

INSTITUTO DE PESQUISAS ENERGÉTICAS E NUCLEARES

Autarquia Associada à Universidade de São Paulo

\section{EFEITO DAS SUBSTITUIÇÕES DE ELEMENTOS DE LIGA NA DECREPITAÇÃO POR HIDROGÊNIO E TRATAMENTOS TÉRMICOS NAS CARACTERÍSTICAS FÍSICO-QUÍMICAS DAS LIGAS DE NI-HM.}

\author{
EDSON PEREIRA SOARES
}

Tese apresentada como parte dos requisitos para obtenção do Grau de Doutor em Ciências na Área de Tecnologia Nuclear - Materiais

Orientador:

Prof. Dr. Hidetoshi Takiishi 
INSTITUTO DE PESQUISAS ENERGÉTICAS E NUCLEARES

Autarquia Associada à Universidade de São Paulo

EFEITO DAS SUBSTITUIÇÕES DE ELEMENTOS DE LIGA NA DECREPITAÇÃO POR HIDROGÊNIO E TRATAMENTOS TÉRMICOS NAS CARACTERÍSTICAS FÍSICO-QUÍMICAS DAS LIGAS DE NI-HM.

$$
\text { Versão Corrigida }
$$

Versão Original disponível no IPEN

\title{
EDSON PEREIRA SOARES
}

\author{
Tese apresentada como parte dos \\ requisitos para obtenção do Grau de \\ Doutor em Ciências na Área \\ de Tecnologia Nuclear - Materiais \\ Orientador: \\ Prof. Dr. Hidetoshi Takiishi
}


Autorizo a reprodução e divulgação total ou parcial deste trabalho, para fins de estudo e pesquisa, desde que citada a fonte

Como citar:

SOARES, E. P. . EFEITO DAS SUBSTITUIÇÕES DE ELEMENTOS DE LIGA NA

DECREPITACÃO POR HIDROGÊNIO E TRATAMENTOS TÉRMICOS NAS

CARACTERISTICAS FÍSICO-QUÍMICAS DAS LIGAS DE NI-HM.. 2019. 199 p. Tese

(Doutorado em Tecnologia Nuclear), Instituto de Pesquisas Energéticas e Nucleares, IPEN-CNEN/SP, São Paulo. Disponível em: (data de consulta no formato:

$\mathrm{dd} / \mathrm{mm} / \mathrm{aaaa})$

Ficha catalográfica elaborada pelo Sistema de geração automática da Biblioteca IPEN/USP, com os dados fornecidos pelo(a) autor(a)

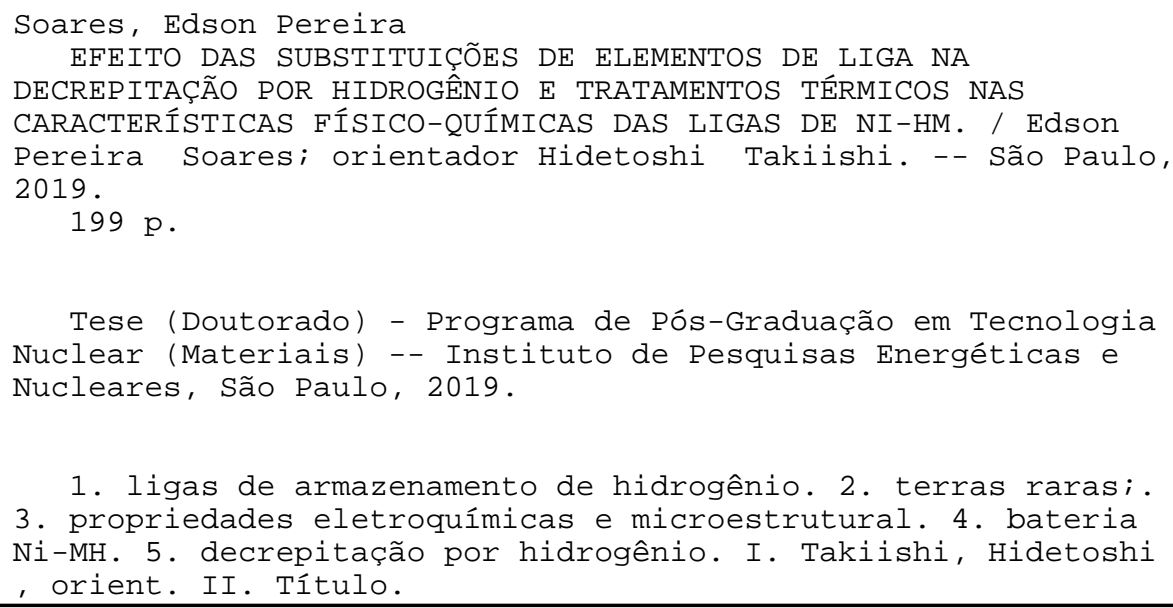


À minha esposa Elizabete que sempre esteve do meu lado, por me apoiar e acreditar neste meu projeto, e me fazer uma pessoa melhor, e as minhas filhas Rebeka e Isabelle que me conduziram até aqui. 
"Éramos todos humanos, até que:

A raça nos desligou;

A religião nos separou;

A politica nos dividiu;

E o dinheiro nos classificou".

Autor: desconhecido 


\section{AGRADECIMENTOS}

A realização de um projeto de Doutorado e todo o trabalho envolvido é um caminho difícil, que não o fiz sozinho, repleto de desafios, alegrias, tristezas, dificuldades e sobre tudo repleto de conquistas.

Caminhei juntamente com pessoas que, de uma forma direta ou indireta contribuíram com o seu melhor na realização deste trabalho.

Que trouxeram consigo conhecimentos, indispensáveis para encontrar o rumo certo neste projeto.

$\mathrm{Na}$ impossibilidade de lembrar-me de todos, aos quais eu expresso a minha profunda gratidão, cito aquelas atuaram de forma direta neste trabalho:

Primeiramente a meu bom Deus por permitir e me capacitar para este trabalho.

Ao Dr. Hidetoshi Takiishi pela orientação e por acreditar na minha capacidade na realização deste trabalho.

Ao Dr. Rubens Nunes de Faria Jr. pela co-orientação, e compreensão ao longo deste trabalho.

Ao Dr. Julio Casini pela cooperação nas discussões técnicas.

A Dra. Luzinete Barbosa pela ajuda e cooperação.

A todos do Laboratório de Materiais Magnéticos pela amizade, companheirismo e incentivo na realização deste trabalho.

Aos companheiros do laboratório de difração de raios-X Dr. Rene e Marcos pela amizade a cooperação nas execuções das análises e ao Dr. Nelson Batista de Lima em todos os refinamentos das analises de difração de raios-X.

Aos colegas do laboratório de materiais particulados Dr. Claudio Rocha, Dr. Railson e ao Dr. Ricardo Leal pela imensa ajuda e cooperação nas analises de PCT e nas discussões sobre os resultados.

A Escola SENAI unidade Osasco na pessoa do Professor André Arakaki na permissão para utilização do equipamento de microscopia e ao Professor Edson Togni pelo esforço e empenho em ajudar nas análises.

A todos os colegas dos demais centros do IPEN que direta ou indiretamente ajudaram na realização deste trabalho. 
A minha esposa Elizabete que esteve sempre do meu lado me apoiando e acreditando em mim.

As minhas filhas Rebeka e Isabelle pela paciência e carinho.

Ao Instituto de Pesquisas Energéticas e Nucleares (IPEN/CNEN) pela oportunidade concedida.

Aos professores que participaram da minha formação desde o ensino básico até 0 final da graduação e pós-graduação.

A todos o meu muito obrigado. 


\title{
EFEITO DAS SUBSTITUIÇÕES DE ELEMENTOS DE LIGA NA DECREPITAÇÃO POR HIDROGÊNIO E TRATAMENTOS TÉRMICOS NAS CARACTERÍSTICAS FÍSICO-QUìMICAS DAS LIGAS DE Ni-MH
}

\author{
Edson Pereira Soares
}

\section{RESUMO}

Neste trabalho, avaliou-se o efeito da substituição parcial do $\mathrm{Ni}$ pelos elementos Co, $\mathrm{Cu}$ e $\mathrm{Sn}$, e do $\mathrm{La}$ e $\mathrm{Mg}$ pelo $\mathrm{Pr}$ em ligas do tipo $\mathrm{AB}_{5}$ para as ligas nominais $\quad \mathrm{La}_{0,7} \mathrm{Mg}_{0,3} \mathrm{Al}_{0,3} \mathrm{Mn}_{0,4} \mathrm{Cu}_{0,5} \mathrm{Ni}_{3,8}, \quad \mathrm{La}_{0,7} \mathrm{Mg}_{0,3} \mathrm{Al}_{0,3} \mathrm{Mn}_{0,4} \mathrm{Co}_{0,5} \mathrm{Ni}_{3,8} \quad$ e $\mathrm{La}_{0,7} \mathrm{Mg}_{0,3} \mathrm{Al}_{0,3} \mathrm{Mn}_{0,4} \mathrm{Sn}_{0,5} \mathrm{Ni}_{3,8}, \quad \mathrm{La}_{0,7} \operatorname{Pr}_{0,3} \mathrm{Al}_{0,3} \mathrm{Mn}_{0,4} \mathrm{Co}_{0,5} \mathrm{Ni}_{3,8}$, $\operatorname{Pr}_{0,7} \mathrm{Mg}_{0,3} \mathrm{Al}_{0,3} \mathrm{Mn}_{0,4} \mathrm{Co}_{0,5} \mathrm{Ni}_{3,8}$ sem e com tratamento térmico de $750^{\circ}$ e $850^{\circ} \mathrm{C}$ por 9 e 16 horas. Estas ligas absorvedoras de hidrogênio foram utilizadas como material ativo em eletrodos negativos de baterias de Ni-HM. Avaliou-se a influência destas substituições e do tratamento térmico na microestrutura e nas propriedades eletroquímicas nas ligas. A substituição parcial do Ni pelo $\mathrm{Co}$ com o tratamento térmico de $750^{\circ} \mathrm{C}$ por 16 horas apresentou duas novas fases $\mathrm{Al}_{6} \mathrm{Mn}$ e $\mathrm{PrCo}_{13} \mathrm{Na}$ substituição parcial do $\mathrm{Ni}$ pelo $\mathrm{Sn}$ formou a fase $\mathrm{LaNi}_{2} \mathrm{Sn}_{2}$ na liga. Utilizou-se caracterização de raios- $X$ com refinamento de Rietveld para quantificar as fases em cada composição. Mediu-se a absorção de hidrogênio utilizando um Aparato Sieverts para obtenção das curvas PCT. Observou-se que as ligas $\mathrm{La}_{0,7} \mathrm{Mg}_{0,3} \mathrm{Al}_{0,3} \mathrm{Mn}_{0,4} \mathrm{Co}_{0,5} \mathrm{Ni}_{3,8}$ e $\mathrm{La}_{0,7} \mathrm{Pr}_{0,3} \mathrm{Al}_{0,3} \mathrm{Mn}_{0,4} \mathrm{Co}_{0,5} \mathrm{Ni}_{3,8}$ apresentaram as melhores capacidades de absorção de hidrogênio. Verificou-se o comportamento destas ligas na capacidade de descarga, estabilidade cíclica das baterias de Ni-HM.

Comparando as ligas, a maior capacidade de descarga medida foi para a substituição parcial do Ni pelo Co, alcançando 406,1 mAh após o tratamento térmico de $850^{\circ} \mathrm{C}$ por 16 horas. A melhor capacidade de absorção obtida na analise de PCT, foi para a liga $\mathrm{La}_{0,7} \mathrm{Pr}_{0,3} \mathrm{Al}_{0,3} \mathrm{Mn}_{0,4} \mathrm{Co}_{0,5} \mathrm{Ni}_{3,8}$ com valor de $\mathrm{H} / \mathrm{M}$ de 0,980 . Também, foi avaliada uma correlação das propriedades eletroquímicas com a capacidade de absorção obtida na analise da curva PCT.

Palavras-chaves: ligas de armazenamento de hidrogênio; terras raras; propriedades eletroquímicas; microestrutura; bateria Ni-MH; decrepitação por hidrogênio 


\title{
EFFECT OF REPLACEMENT OF ALLOYING ELEMENTS IN DECREPTATION BY HYDROGEN AND ANNEALING TREATAMENTS ON PHYSICAL-CHEMISTRY CHARACTERISTCS Ni-MH ALLOYS
}

\author{
Edson Pereira Soares
}

\begin{abstract}
In this work, it was evaluated the effect of the partial substitution of $\mathrm{Ni}$ by the elements $\mathrm{Co}, \mathrm{Cu}$ and $\mathrm{Sn}$ and of the $\mathrm{La}$ and $\mathrm{Mg}$ by the $\mathrm{Pr}$ in type $\mathrm{AB}_{5}$ alloys to the nominal alloys $\mathrm{La}_{0,7} \mathrm{Mg}_{0,3} \mathrm{Al}_{0,3} \mathrm{Mn}_{0,4} \mathrm{Cu}_{0,5} \mathrm{Ni}_{3,8}, \quad \mathrm{La}_{0,7} \mathrm{Mg}_{0,3} \mathrm{Al}_{0,3} \mathrm{Mn}_{0,4} \mathrm{Co}_{0,5} \mathrm{Ni}_{3,8}$, $\mathrm{La}_{0,7} \mathrm{Mg}_{0,3} \mathrm{Al}_{0,3} \mathrm{Mn}_{0,4} \mathrm{Sn}_{0,5} \mathrm{Ni}_{3,8}, \quad \mathrm{La}_{0,7} \mathrm{Pr}_{0,3} \mathrm{Al}_{0,3} \mathrm{Mn}_{0,4} \mathrm{Co}_{0,5} \mathrm{Ni}_{3,8} \quad$ and $\mathrm{Pr}_{0,7} \mathrm{Mg}_{0,3} \mathrm{Al}_{0,3} \mathrm{Mn}_{0,4} \mathrm{Co}_{0,5} \mathrm{Ni}_{3,8}$, as castting and with annealing treatment of $750{ }^{\circ} \mathrm{C}$ and $850{ }^{\circ} \mathrm{C}$ for 9 and 16 hours. These hydrogen-absorbing alloys were used as active material on negative electrodes of $\mathrm{Ni}-\mathrm{HM}$ batteries. The influence of these substitutions and the annealing treatment on the microstructure and on the electrochemical properties in the alloys was evaluated. The partial substitution of $\mathrm{Ni}$ by Co with the annealing treatment of $750^{\circ} \mathrm{C}$ for 16 hours presented two new phases $\mathrm{Al}_{6} \mathrm{Mn}$ and $\mathrm{PrCo}_{13}$. In the partial substitution of $\mathrm{Ni}$ by $\mathrm{Sn}$ formed the $\mathrm{LaNi}_{2} \mathrm{Sn}_{2}$ phase in the alloy. It was characterized by X-ray diffraction using Rietveld's refinement to quantify the phases in each composition. Hydrogen absorption was measured using the Sieverts apparatus to obtain the PCT curves. It was observed that the alloys $\mathrm{La}_{0,7} \mathrm{Mg}_{0,3} \mathrm{Al}_{0,3} \mathrm{Mn}_{0,4} \mathrm{Co}_{0,5} \mathrm{Ni}_{3,8}$ and $\mathrm{La}_{0,7} \mathrm{Pr}_{0,3} \mathrm{Al}_{0,3} \mathrm{Mn}_{0,4} \mathrm{Co}_{0,5} \mathrm{Ni}_{3,8}$, presented the best capacities of hydrogen absorption. The behavior of these alloys in the discharge capacity, the cyclic stability of the Ni-HM batteries, was verified.

Comparing the alloys, the biggest discharge capacity measured was for the partial substitution of $\mathrm{Ni}$ by $\mathrm{Co}$ alloy, reaching $406.1 \mathrm{mAh}$ after the annealing treatment of $850{ }^{\circ} \mathrm{C}$ for 16 hours. The finest absorption capacity obtained in the PCT analysis was for the $\mathrm{La}_{0,7} \mathrm{Pr}_{0,3} \mathrm{Al}_{0,3} \mathrm{Mn}_{0,4} \mathrm{Co}_{0,5} \mathrm{Ni}_{3,8}$ alloy with an $\mathrm{H} / \mathrm{M}$ value of 0.980 . Also, a correlation of the electrochemical properties with the absorption capacity obtained in the analysis of the PCT curve was evaluated.
\end{abstract}

Keywords: hydrogen storage alloy; rare earth based alloys; electrochemical properties; alloys structure; Ni-MH battery; hydrogen decrepitation. 


\section{SUMÁRIO}

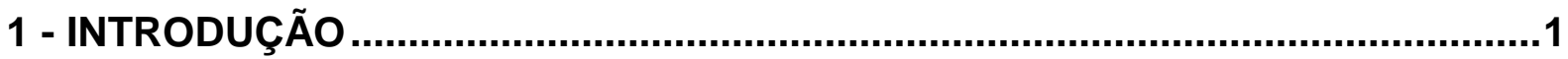

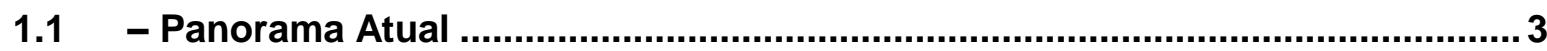

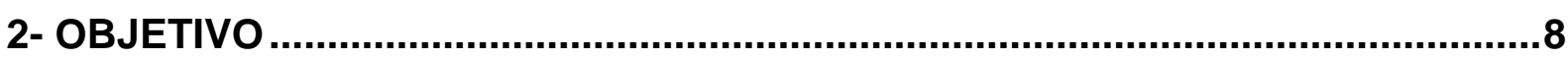

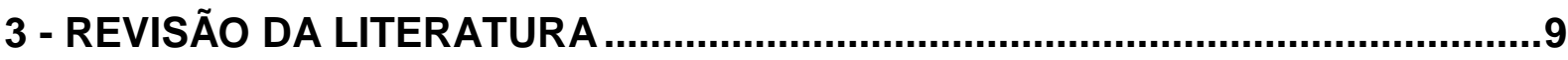

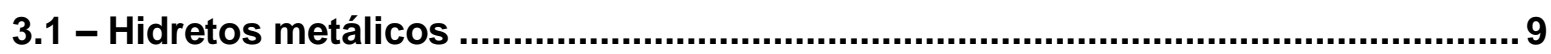

3.2 - Cinética de formação dos hidretos metálicos................................................... 13

3.2.1 - Isotermas de Pressão-Composição-Temperatura (PCT) .............................. 14

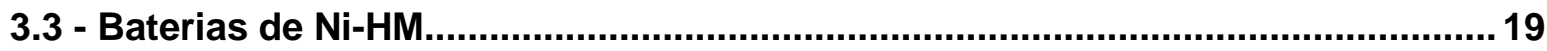

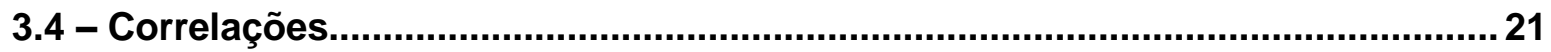

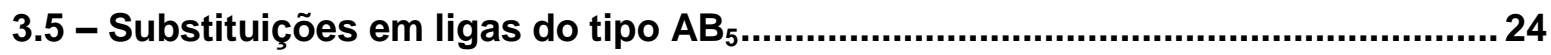

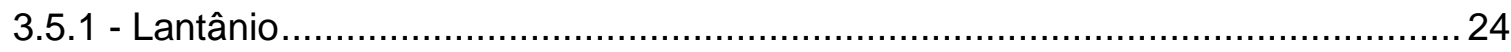

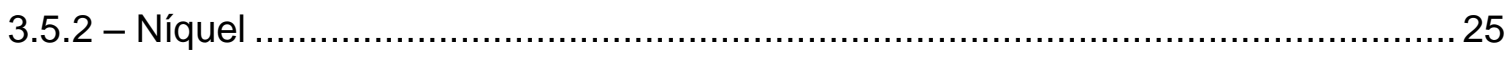

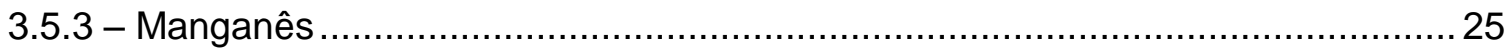

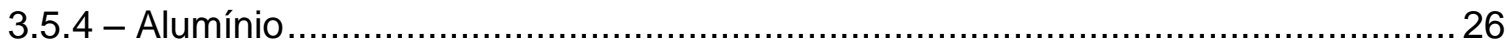

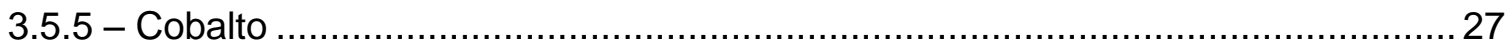

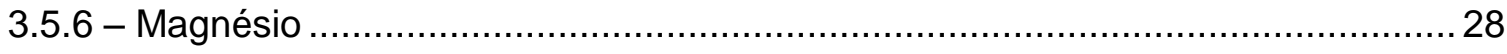

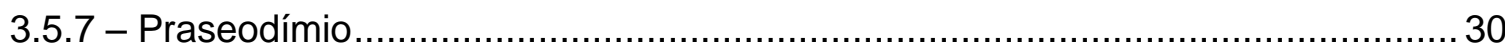

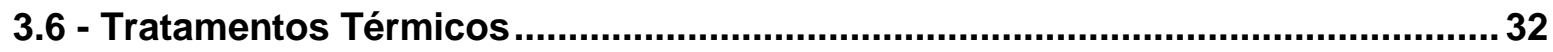

4 - MATERIAIS E MÉTODOS ...........................................................................36

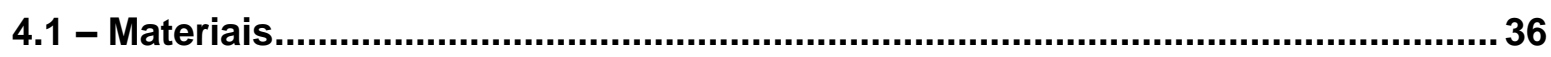

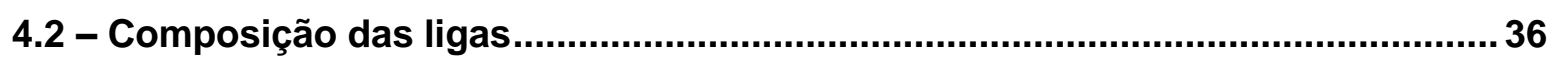

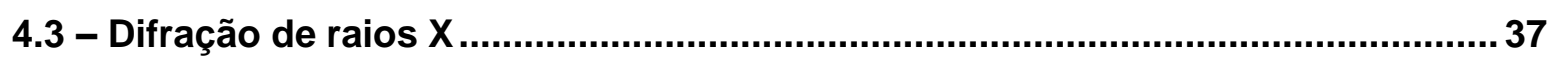

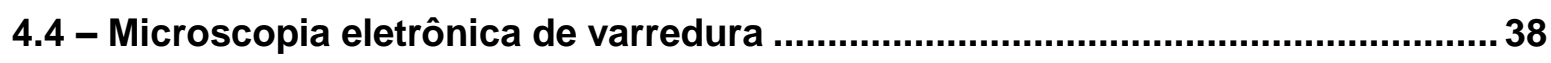

4.5 - Tratamentos térmicos ....................................................................................... 38

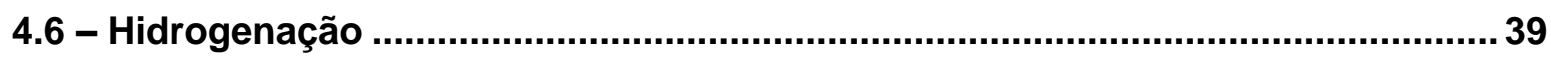

4.6.1 - Fragilização das ligas sem e com tratamento térmico ................................... 40 
4.6.2 - Analise de P-C-T nas ligas sem e com tratamento térmico 40

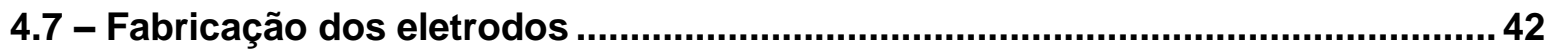

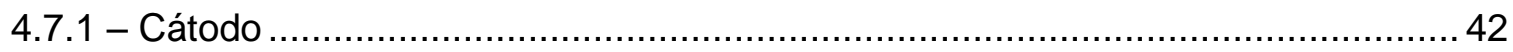

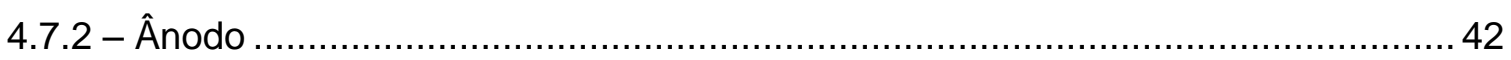

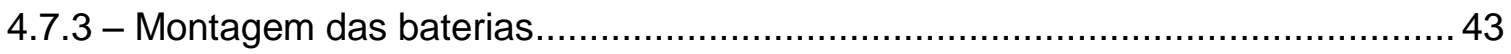

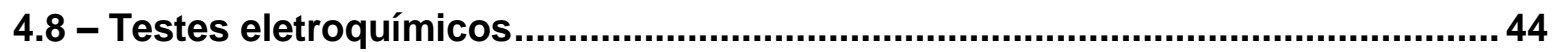

5- RESULTADOS E DISCUSSÃO .......................................................................

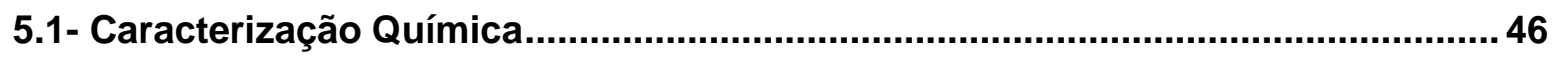

5.2- Caracterização por difração de raios-X com refinamento pelo método de

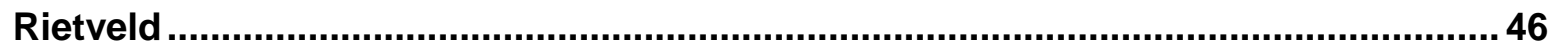

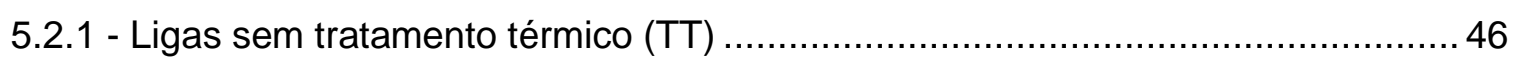

5.2.2 - Liga $\mathrm{La}_{0,7} \mathrm{Mg}_{0,3} \mathrm{Al}_{0,3} \mathrm{Mn}_{0,4} \mathrm{Co}_{0,5} \mathrm{Ni}_{3,8}$ sem e com TT....................................... 49

5.2 .3 - Liga $\mathrm{La}_{0,7} \mathrm{Mg}_{0,3} \mathrm{Al}_{0,3} \mathrm{Mn}_{0,4} \mathrm{Cu}_{0,5} \mathrm{Ni}_{3,8}$ sem e com TT ...................................... 51

5.2.4 - Liga $\mathrm{La}_{0,7} \mathrm{Mg}_{0,3} \mathrm{Al}_{0,3} \mathrm{Mn}_{0,4} \mathrm{Sn}_{0,5} \mathrm{Ni}_{3,8}$ sem e com tratamentos térmicos .................. 52

5.2.5 - Liga $\mathrm{La}_{0,7} \mathrm{Pr}_{0,3} \mathrm{Al}_{0,3} \mathrm{Mn}_{0,4} \mathrm{Co}_{0,5} \mathrm{Ni}_{3,8}$ sem e com tratamentos térmicos.................... 54

5.2.6 - Liga $\operatorname{Pr}_{0,7} \mathrm{Mg}_{0,3} \mathrm{Al}_{0,3} \mathrm{Mn}_{0,4} \mathrm{Co}_{0,5} \mathrm{Ni}_{3,8}$ sem e com tratamentos térmicos...................56

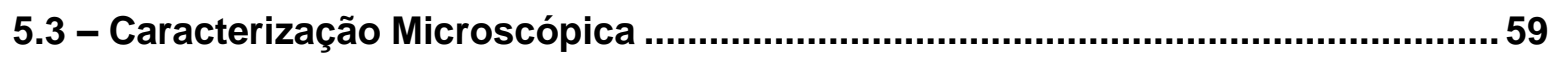

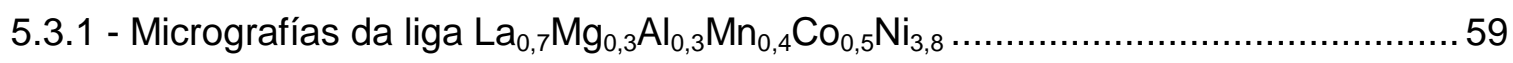

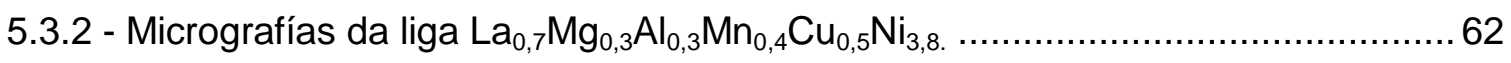

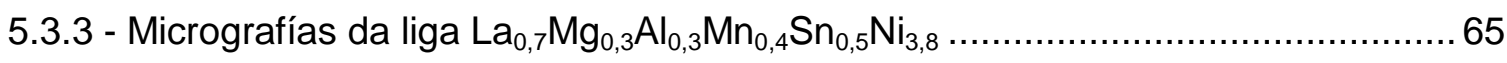

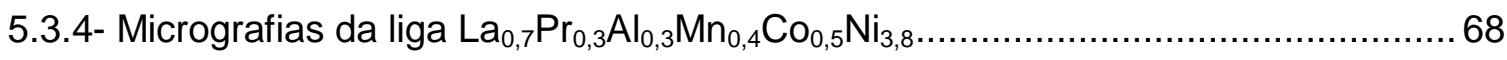

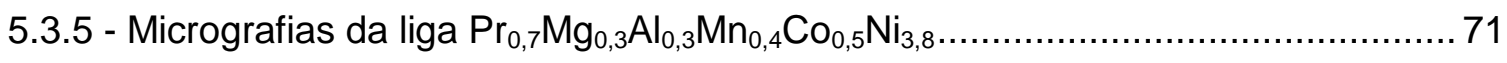

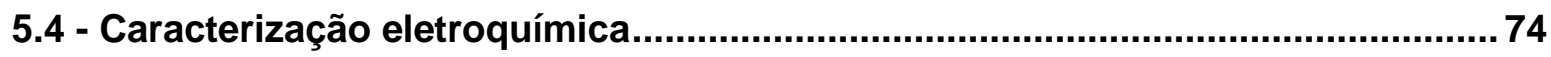

5.4.1 - Caracterização eletroquímica da liga $\mathrm{La}_{0,7} \mathrm{Mg}_{0,3} \mathrm{Al}_{0,3} \mathrm{Mn}_{0,4} \mathrm{Co}_{0,5} \mathrm{Ni}_{3,8}$ sem e com TT

5.4.2 - Caracterização eletroquímica da liga $\mathrm{La}_{0,7} \mathrm{Mg}_{0,3} \mathrm{Al}_{0,3} \mathrm{Mn}_{0,4} \mathrm{Cu}_{0,5} \mathrm{Ni}_{3,8}$ sem e com TT.

5.4.3 - Caracterização eletroquímica da liga $\mathrm{La}_{0,7} \mathrm{Mg}_{0,3} \mathrm{Al}_{0,3} \mathrm{Mn}_{0,4} \mathrm{Sn}_{0,5} \mathrm{Ni}_{3,8}$ sem e com TT.

5.4.4 - Caracterização eletroquímica da liga $\mathrm{La}_{0,7} \operatorname{Pr}_{0,3} \mathrm{Al}_{0,3} \mathrm{Mn}_{0,4} \mathrm{Co}_{0,5} \mathrm{Ni}_{3,8}$ sem e com TT.

5.4.5 - Caracterização eletroquímica da liga $\operatorname{Pr}_{0,7} \mathrm{Mg}_{0,3} \mathrm{Al}_{0,3} \mathrm{Mn}_{0,4} \mathrm{Co}_{0,5} \mathrm{Ni}_{3,8}$ sem e com TT. 


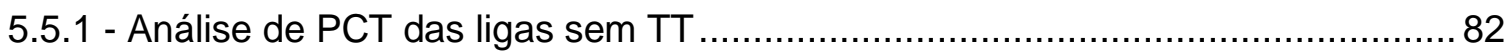

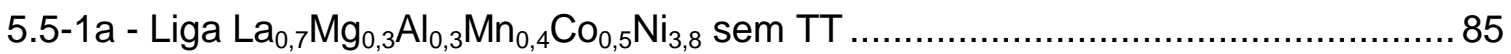

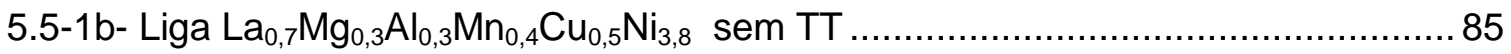

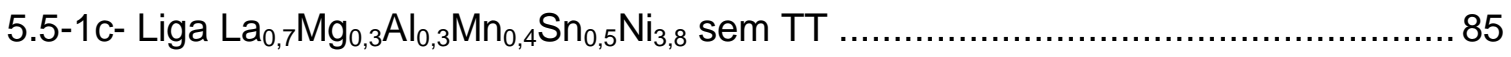

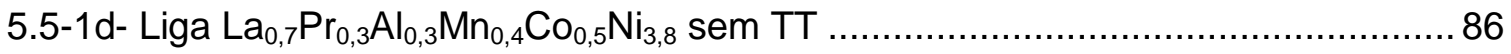

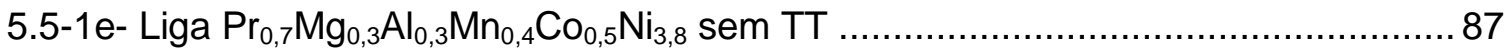

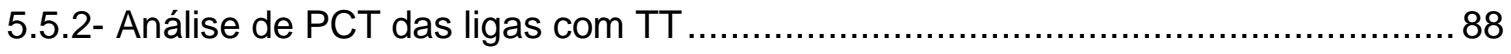

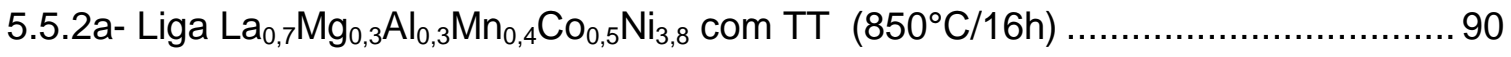

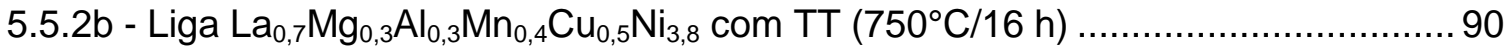

5.5.2c- Liga La ${ }_{0,7} \mathrm{Mg}_{0,3} \mathrm{Al}_{0,3} \mathrm{Mn}_{0,4} \mathrm{Sn}_{0,5} \mathrm{Ni}_{3,8}$ com TT $(750 \%$ 16h) $\ldots \ldots \ldots \ldots \ldots \ldots \ldots \ldots \ldots \ldots \ldots \ldots . . . \ldots 1$

5.5.2d- Liga La ${ }_{0,7} \mathrm{Pr}_{0,3} \mathrm{Al}_{0,3} \mathrm{Mn}_{0,4} \mathrm{Co}_{0,5} \mathrm{Ni}_{3,8}$ com TT (850\%16h) ................................... 91

5.5.2e- Liga $\operatorname{Pr}_{0,7} \mathrm{Mg}_{0,3} \mathrm{Al}_{0,3} \mathrm{Mn}_{0,4} \mathrm{Co}_{0,5} \mathrm{Ni}_{3,8}$ com TT (750\% $\left.9 \mathrm{~h}\right)$..................................... 92

5.5.3 - Absorção de hidrogênio e ciclos de ativação e Análise de PCT das ligas com TT

5.5.3-a - Curvas de Absorção de hidrogênio e ciclos de ativação da liga

$\mathrm{La}_{0,7} \mathrm{Mg}_{0,3} \mathrm{Al}_{0,3} \mathrm{Mn}_{0,4} \mathrm{Co}_{0,5} \mathrm{Ni}_{3,8}$ com TT de $850^{\circ}$ por 16 horas 93

5.5.3-b - Curvas de Absorção de hidrogênio e ciclos de ativação da liga

$\mathrm{La}_{0,7} \mathrm{Mg}_{0,3} \mathrm{Al}_{0,3} \mathrm{Mn}_{0,4} \mathrm{Cu}_{0,5} \mathrm{Ni}_{3,8}$ com TT de $850^{\circ}$ por 16 horas....

5.5.3-c - Curvas de Absorção de hidrogênio e ciclos de ativação da liga

$\mathrm{La}_{0,7} \mathrm{Mg}_{0,3} \mathrm{Al}_{0,3} \mathrm{Mn}_{0,4} \mathrm{Sn}_{0,5} \mathrm{Ni}_{3,8}$ com TT de $850^{\circ}$ por 16 horas.

5.5.3-d - Curvas de Absorção de hidrogênio e ciclos de ativação da liga

$\mathrm{La}_{0,7} \mathrm{Pr}_{0,3} \mathrm{Al}_{0,3} \mathrm{Mn}_{0,4} \mathrm{Co}_{0,5} \mathrm{Ni}_{3,8}$ com TT de $850^{\circ}$ por 16 horas.

5.5.3-e - Curvas de Absorção de hidrogênio e ciclos de ativação da liga

$\mathrm{Pr}_{0,7} \mathrm{Mg}_{0,3} \mathrm{Al}_{0,3} \mathrm{Mn}_{0,4} \mathrm{Co}_{0,5} \mathrm{Ni}_{3,8}$ com TT de $750^{\circ}$ por 9 horas....

5.5.3-f - Análise de PCT das ligas com TT e com quatro ciclos de ativações. . 100

\section{6 - Curvas de absorção e caracterização da morfologia das partículas das ligas} sem e com $\pi$ fragilizadas por hidrogênio.

5.6.1 - Curvas de absorção de hidrogênio e micrografias da liga

$\mathrm{La}_{0,7} \mathrm{Mg}_{0,3} \mathrm{Al}_{0,3} \mathrm{Mn}_{0,4} \mathrm{Co}_{0,5} \mathrm{Ni}_{3,8}$ sem TT..... 104

5.6.2 - Curvas de absorção de hidrogênio e micrografias da liga

$\mathrm{La}_{0,7} \mathrm{Mg}_{0,3} \mathrm{Al}_{0,3} \mathrm{Mn}_{0,4} \mathrm{Co}_{0,5} \mathrm{Ni}_{3,8}$ TT de $750^{\circ} \mathrm{C}$ por 9 horas.... 106

5.6.3 - Curvas de absorção de hidrogênio e micrografias da liga $\mathrm{La}_{0,7} \mathrm{Mg}_{0,3} \mathrm{Al}_{0,3} \mathrm{Mn}_{0,4} \mathrm{Co}_{0,5} \mathrm{Ni}_{3,8} \mathrm{TT}$ de $750^{\circ} \mathrm{C}$ por 16 horas

5.6.4 - Curvas de absorção de hidrogênio e micrografias da liga

$\mathrm{La}_{0,7} \mathrm{Mg}_{0,3} \mathrm{Al}_{0,3} \mathrm{Mn}_{0,4} \mathrm{Co}_{0,5} \mathrm{Ni}_{3,8}$ com TT de $850^{\circ} \mathrm{C}$ por 9 horas

5.6.5 - Curvas de absorção de hidrogênio e micrografias da liga

$\mathrm{La}_{0,7} \mathrm{Mg}_{0,3} \mathrm{Al}_{0,3} \mathrm{Mn}_{0,4} \mathrm{Co}_{0,5} \mathrm{Ni}_{3,8}$ com TT de $850^{\circ} \mathrm{C}$ por 16 horas 
5.6.6 - Curvas de absorção de hidrogênio e micrografias da liga $\mathrm{La}_{0,7} \mathrm{Mg}_{0,3} \mathrm{Al}_{0,3} \mathrm{Mn}_{0,4} \mathrm{Cu}_{0,5} \mathrm{Ni}_{3,8}$ sem TT.

5.6.7 - Curvas de absorção de hidrogênio e micrografias da liga

$\mathrm{La}_{0,7} \mathrm{Mg}_{0,3} \mathrm{Al}_{0,3} \mathrm{Mn}_{0,4} \mathrm{Cu}_{0,5} \mathrm{Ni}_{3,8}$ com tratamento térmico de $750^{\circ} \mathrm{C}$ por 9 horas

5.6.8 - Curvas de absorção de hidrogênio e micrografias da liga

$\mathrm{La}_{0,7} \mathrm{Mg}_{0,3} \mathrm{Al}_{0,3} \mathrm{Mn}_{0,4} \mathrm{Cu}_{0,5} \mathrm{Ni}_{3,8}$ com TT de $750^{\circ} \mathrm{C}$ por 16 horas

5.6.9 - Curvas de absorção de hidrogênio e micrografias da liga

$\mathrm{La}_{0,7} \mathrm{Mg}_{0,3} \mathrm{Al}_{0,3} \mathrm{Mn}_{0,4} \mathrm{Cu}_{0,5} \mathrm{Ni}_{3,8}$ com tratamento térmico de $850^{\circ} \mathrm{C}$ por 9 horas

5.6.10 - Curvas de absorção de hidrogênio e micrografias da liga

$\mathrm{La}_{0,7} \mathrm{Mg}_{0,3} \mathrm{Al}_{0,3} \mathrm{Mn}_{0,4} \mathrm{Cu}_{0,5} \mathrm{Ni}_{3,8}$ com TT de $850^{\circ} \mathrm{C}$ por 16 horas

5.6.11 - Curvas de absorção de hidrogênio e micrografias da liga

$\mathrm{La}_{0,7} \mathrm{Mg}_{0,3} \mathrm{Al}_{0,3} \mathrm{Mn}_{0,4} \mathrm{Sn}_{0,5} \mathrm{Ni}_{3,8}$ sem TT

5.6.12 - Curvas de absorção de hidrogênio e micrografias da liga

$\mathrm{La}_{0,7} \mathrm{Mg}_{0,3} \mathrm{Al}_{0,3} \mathrm{Mn}_{0,4} \mathrm{Sn}_{0,5} \mathrm{Ni}_{3,8}$ com TT de $750^{\circ} \mathrm{C}$ por 9 horas.

5.6.13 - Curvas de absorção de hidrogênio e micrografias da liga

$\mathrm{La}_{0,7} \mathrm{Mg}_{0,3} \mathrm{Al}_{0,3} \mathrm{Mn}_{0,4} \mathrm{Sn}_{0,5} \mathrm{Ni}_{3,8}$ com TT de $750^{\circ} \mathrm{C}$ por 16 horas.

5.6.14 - Curvas de absorção de hidrogênio e micrografias da liga

$\mathrm{La}_{0,7} \mathrm{Mg}_{0,3} \mathrm{Al}_{0,3} \mathrm{Mn}_{0,4} \mathrm{Sn}_{0,5} \mathrm{Ni}_{3,8}$ com TT de $850^{\circ} \mathrm{C}$ por 9 horas.

5.6.15 - Curvas de absorção de hidrogênio e micrografias da liga

$\mathrm{La}_{0,7} \mathrm{Mg}_{0,3} \mathrm{Al}_{0,3} \mathrm{Mn}_{0,4} \mathrm{Sn}_{0,5} \mathrm{Ni}_{3,8}$ com TT de $850^{\circ} \mathrm{C}$ por 16 horas.

5.6.16 - Curvas de absorção de hidrogênio e micrografias da liga

$\mathrm{La}_{0,7} \mathrm{Pr}_{0,3} \mathrm{Al}_{0,3} \mathrm{Mn}_{0,4} \mathrm{Co}_{0,5} \mathrm{Ni}_{3,8}$ sem TT

5.6.17 - Curvas de absorção de hidrogênio e micrografias da liga

$\mathrm{La}_{0,7} \mathrm{Pr}_{0,3} \mathrm{Al}_{0,3} \mathrm{Mn}_{0,4} \mathrm{Co}_{0,5} \mathrm{Ni}_{3,8}$ com TT de $750^{\circ} \mathrm{C}$ por 9 horas.

5.6.18 - Curvas de absorção de hidrogênio e micrografias da liga

$\mathrm{La}_{0,7} \mathrm{Pr}_{0,3} \mathrm{Al}_{0,3} \mathrm{Mn}_{0,4} \mathrm{Co}_{0,5} \mathrm{Ni}_{3,8}$ com TT de $750^{\circ} \mathrm{C}$ por 16 horas.

5.6.19 - Curvas de absorção de hidrogênio e micrografias da liga

$\mathrm{La}_{0,7} \mathrm{Pr}_{0,3} \mathrm{Al}_{0,3} \mathrm{Mn}_{0,4} \mathrm{Co}_{0,5} \mathrm{Ni}_{3,8}$ com TT de $850^{\circ} \mathrm{C}$ por 9 horas.

5.6.20 - Curvas de absorção de hidrogênio e micrografias da liga

$\mathrm{La}_{0,7} \mathrm{Pr}_{0,3} \mathrm{Al}_{0,3} \mathrm{Mn}_{0,4} \mathrm{Co}_{0,5} \mathrm{Ni}_{3,8}$ com TT de $850^{\circ} \mathrm{C}$ por 16 horas.

5.6.21 - Curvas de absorção de hidrogênio e micrografias da liga TT

$\operatorname{Pr}_{0,7} \mathrm{Mg}_{0,3} \mathrm{Al}_{0,3} \mathrm{Mn}_{0,4} \mathrm{Co}_{0,5} \mathrm{Ni}_{3,8}$ sem TT.

5.6.22 - Curvas de absorção de hidrogênio e micrografias da liga TT

$\mathrm{Pr}_{0,7} \mathrm{Mg}_{0,3} \mathrm{Al}_{0,3} \mathrm{Mn}_{0,4} \mathrm{Co}_{0,5} \mathrm{Ni}_{3,8}$ com TT em $750^{\circ} \mathrm{C}$ por 9 horas.

5.6.23 - Curvas de absorção de hidrogênio e micrografias da liga TT

$\operatorname{Pr}_{0,7} \mathrm{Mg}_{0,3} \mathrm{Al}_{0,3} \mathrm{Mn}_{0,4} \mathrm{Co}_{0,5} \mathrm{Ni}_{3,8}$ com TT de $750^{\circ} \mathrm{C}$ por 16 horas.

5.6.24 - Curvas de absorção de hidrogênio e micrografias da liga TT

$\operatorname{Pr}_{0,7} \mathrm{Mg}_{0,3} \mathrm{Al}_{0,3} \mathrm{Mn}_{0,4} \mathrm{Co}_{0,5} \mathrm{Ni}_{3,8}$ com TT $850^{\circ} \mathrm{C}$ por 9 horas.

5.6.25 - Curvas de absorção de hidrogênio e micrografias da liga TT

$\operatorname{Pr}_{0,7} \mathrm{Mg}_{0,3} \mathrm{Al}_{0,3} \mathrm{Mn}_{0,4} \mathrm{Co}_{0,5} \mathrm{Ni}_{3,8}$ com TT de $850^{\circ} \mathrm{C}$ por 16 horas. 
6 - CONCLUSÕES.

APENDICE A -

A influência da adição de rGO e CNT nas propriedades eletroquímicas nas Baterias das Ligas de LaNi. 


\section{LISTA DE FIGURAS}

FIGURA 1 - Usina solar e a estação de baterias de Ni-MH com sistema BPS instalada em uma região próximo Osaka, Japan

FIGURA 2 - Instalação da subestação da rede de alimentação da linha do metro de West Falls Church (BPS).

FIGURA 3 - Carro de competição da FE, com motor elétrico. .5

FIGURA 4 - Comparativo entre a frota de veículos com motores elétricos existentes nos países até 2017.

FIGURA 5 - Projeção para a quantidade de modelos de veículos com motores elétricos pelas principais montadoras até o ano de 2021

FIGURA 6 - Tabela periódica dos elementos, onde: em vermelho estão representados os elementos formadores de hidretos estáveis e em azul os elementos formadores de hidretos instáveis (Zutell, 2007; Dornheim 2011).............10

FIGURA 7 - Diagrama de blocos demonstrando as principais ligas e complexos que formam o hidreto metálico (adaptado de Sandrock, 1999).

FIGURA 8 - Etapas da absorção de hidrogênio em metais, na formação do hidreto.

FIGURA 9 - Um exemplo do perfil de pressão ao longo do tempo durante o ciclo de ativação de hidrogênio em um equipamento Sieverts (adaptado Lim et al 2017).....15

FIGURA 10 - (a) Curvas Pressão-Composição-Temperatura (PCT) para comportamento ideal com elevação da temperatura e (b) representação do decaimento logarítmico da pressão de equilíbrio de hidrogênio em função do inverso da temperatura. (lei de Van't Hoff) (Liao et 2004) 17

FIGURA 11 - Representação esquemática de isotermas de absorção e dessorção, considerando amostra real.

FIGURA 12 - Diagrama de funcionamento de uma bateria de NI-HM (Liu et al 2011b). 
FIGURA 13 - Diagrama de fases do sistema La-Ni.

FIGURA 14 - Sistema de vácuo utilizado na hidrogenação e nos tratamentos térmico das ligas, onde: (a) bomba de vácuo mecânica (b) retorta, vaso de hidrogenação, (c) indicador digital de pressão, (d) indicador digital de alta pressão, (e) medidor de vácuo mecânico pirani, (f). forno (EDG) e (g) válvula para injeção de hidrogênio.....39

FIGURA 15 - Imagem do equipamento do tipo Sieverts construído pelo LMI (CCTM/IPEN): a) Painel de controle central do equipamento, b) retorta de aço utilizada nos estudos das ligas de armazenamento de hidrogênio, c) Reator conectado a bomba auxiliar turbomolecular.

FIGURA 16 - Representação esquemática da montagem final das baterias de $\mathrm{Ni}$ HM.

FIGURA 17 - Equipamento de testes eletroquímicos nas baterias modelo

FIGURA 18 - Esquema da formação da estrutura cristalina no plano espacial da liga do tipo $\mathrm{A}_{2} \mathrm{~B}_{9}$ (adaptado da Base de Estruturas Cristalinas icsd-fiz-karlsruhe de.proxy01.dotlib.com.br)

FIGURA 19 - Difratogramas de raios-X para o refinamento por Rietveld das ligas $\mathrm{La}_{0,7} \mathrm{Mg}_{0,3} \mathrm{Al}_{0,3} \mathrm{Mn}_{0,4} \mathrm{Cu}_{0,5} \mathrm{Ni}_{3,8}, \quad \mathrm{La}_{0,7} \mathrm{Mg}_{0,3} \mathrm{Al}_{0,3} \mathrm{Mn}_{0,4} \mathrm{Co}_{0,5} \mathrm{Ni}_{3,8}$, $\mathrm{La}_{0,7} \mathrm{Mg}_{0,3} \mathrm{Al}_{0,3} \mathrm{Mn}_{0,4} \mathrm{Sn}_{0,5} \mathrm{Ni}_{3,8}$,

FIGURA 20 - Difratogramas de raios $X$ das ligas $L a_{0,7} M_{0,3} A_{0,3} M_{0,4} C_{0,5} \mathrm{Ni}_{3,8}$ sem e com tratamentos térmicos.

FIGURA 21 - Difratogramas de raios- $X$ das ligas $\mathrm{La}_{0,7} \mathrm{Mg}_{0,3} \mathrm{Al}_{0,3} \mathrm{Mn}_{0,4} \mathrm{Cu}_{0,5} \mathrm{Ni}_{3,8}$ com e sem tratamentos térmicos.

FIGURA 22 - Difratogramas de raios-X das ligas $\mathrm{La}_{0,7} \mathrm{Mg}_{0,3} \mathrm{Al}_{0,3} \mathrm{Mn}_{0,4} \mathrm{Sn}_{0,5} \mathrm{Ni}_{3,8}$ sem e com tratamentos térmicos.

FIGURA 23 - Difratogramas de raios $X$ das ligas $\mathrm{La}_{0,7} \mathrm{Pr}_{0,3} \mathrm{Al}_{0,3} \mathrm{Mn}_{0,4} \mathrm{Co}_{0,5} \mathrm{Ni}_{3,8}$ sem e com tratamentos térmicos. .55

FIGURA 24 - Difratogramas de raios $X$ das ligas $\mathrm{Pr}_{0,7} \mathrm{Mg}_{0,3} \mathrm{Al}_{0,3} \mathrm{Mn}_{0,4} \mathrm{Co}_{0,5} \mathrm{Ni}_{3,8}$ sem e com tratamentos térmicos. 
FIGURA 25 - Fração da fase $\mathrm{LaNi}_{5}$ nas ligas $\mathrm{NiMH}$ sem e com tratamentos térmicos.

FIGURA 26 - Fração da fase $\mathrm{LaMg}_{2} \mathrm{Ni}_{9}$ nas ligas $\mathrm{NiMH}$ sem e com tratamentos térmicos.

FIGURA 27 - Micrografias da liga $\mathrm{La}_{0,7} \mathrm{Mg}_{0,3} \mathrm{Al}_{0,3} \mathrm{Mg}_{0,3} \mathrm{Mn}_{0,4} \mathrm{Co}_{0,5} \mathrm{Ni}_{3,8}$ sem e com TT, onde: (a) sem TT, (b) $750^{\circ} \mathrm{C}$ por 9 horas, (c) $750^{\circ} \mathrm{C}$ por 16 horas, (d) $850^{\circ} \mathrm{C}$ por 9 horas, (e) $850^{\circ} \mathrm{C}$ por 16 horas.

Figura 28 - Micrografias da liga $\mathrm{La}_{0,7} \mathrm{Mg}_{0,3} \mathrm{Al}_{0,3} \mathrm{Mg}_{0,3} \mathrm{Mn}_{0,4} \mathrm{Cu}_{0,5} \mathrm{Ni}_{3,8}$ com e sem TT, onde: (a) sem TT, (b) $750^{\circ} \mathrm{C}$ por 9 horas, (c) $750^{\circ} \mathrm{C}$ por 16 horas, (d) $850^{\circ} \mathrm{C}$ por 9 horas, (e) $850^{\circ} \mathrm{C}$ por 16 horas

FIGURA 29 - Micrografias da liga $\mathrm{La}_{0,7} \mathrm{Mg}_{0,3} \mathrm{Al}_{0,3} \mathrm{Mg}_{0,3} \mathrm{Mn}_{0,4} \mathrm{Sn}_{0,5} \mathrm{Ni}_{3,8}$ com e sem TT, onde: (a) sem TT, (b) $750^{\circ} \mathrm{C}$ por 9horas, (c) $750^{\circ} \mathrm{C}$ por 16 horas, (d) $850^{\circ} \mathrm{C}$ por 9 horas, (e) $850^{\circ} \mathrm{C}$ por 16 horas

FIGURA 30 - Micrografias da liga $\mathrm{La}_{0,7} \mathrm{Pr}_{0,3} \mathrm{Al}_{0,3} \mathrm{Mg}_{0,3} \mathrm{Mn}_{0,4} \mathrm{Co}_{0,5} \mathrm{Ni}_{3,8}$ com e sem TT, onde: (a) sem TT, (b) $750^{\circ} \mathrm{C}$ por 9 horas, (c) $750^{\circ} \mathrm{C}$ por 16 horas, (d) $850^{\circ} \mathrm{C}$ por 9 horas, (e) $850^{\circ} \mathrm{C}$ por 16 horas.

FIGURA 31 - Micrografias da liga $\operatorname{Pr}_{0,7} \mathrm{Mg}_{0,3} \mathrm{Al}_{0,3} \mathrm{Mg}_{0,3} \mathrm{Mn}_{0,4} \mathrm{Co}_{0,5} \mathrm{Ni}_{3,8}$ com e sem tratamento térmico, onde: (a) sem tratamento térmico, (b) $750^{\circ} \mathrm{C}$ por 9 horas, (c) $750^{\circ} \mathrm{C}$ por 16 horas, (d) $850^{\circ} \mathrm{C}$ por 9 horas, (e) $850^{\circ} \mathrm{C}$ por 16 horas.

FIGURA 32 - Perfis da capacidade de descarga dos eletrodos negativos fabricados com a liga $\mathrm{La}_{0,7} \mathrm{Mg}_{0,3} \mathrm{Al}_{0,3} \mathrm{Mn}_{0,4} \mathrm{Co}_{0,5} \mathrm{Ni}_{3,8}$ sem e com TT

FIGURA 33 - Perfis da capacidade de descarga dos eletrodos negativos fabricados com a liga $\mathrm{La}_{0,7} \mathrm{Mg}_{0,3} \mathrm{Al}_{0,3} \mathrm{Mn}_{0,4} \mathrm{Cu}_{0,5} \mathrm{Ni}_{3,8}$ sem e com TT.

FIGURA 34 - Perfis da capacidade de descarga dos eletrodos negativos fabricados com a liga $\mathrm{La}_{0,7} \mathrm{Mg}_{0,3} \mathrm{Al}_{0,3} \mathrm{Mn}_{0,4} \mathrm{Sn}_{0,5} \mathrm{Ni}_{3,8}$ sem e com TT . .77

FIGURA 35 - Perfis da capacidade de descarga dos eletrodos negativos fabricados com a liga $\mathrm{La}_{0,7} \mathrm{Pr}_{0,3} \mathrm{Al}_{0,3} \mathrm{Mn}_{0,4} \mathrm{Co}_{0,5} \mathrm{Ni}_{3,8}$ sem e com TT . .79

FIGURA 36 - Perfis de descarga dos eletrodos negativos fabricados com a liga $\mathrm{Pr}_{0,7} \mathrm{Mg}_{0,3} \mathrm{Al}_{0,3} \mathrm{Mn}_{0,4} \mathrm{Co}_{0,5} \mathrm{Ni}_{3,8}$ 
FIGURA 37 - Perfis de descarga dos eletrodos negativos fabricados com as ligas sem e com TT.

FIGURA 38 - Curvas de absorção de hidrogênio pela análise de PCT pelas ligas $\mathrm{La}_{0,7} \mathrm{Mg}_{0,3} \mathrm{Al}_{0,3} \mathrm{Mn}_{0,4} \mathrm{Co}_{0,5} \mathrm{Ni}_{3,8}, \quad \mathrm{La}_{0,7} \mathrm{Mg}_{0,3} \mathrm{Al}_{0,3} \mathrm{Mn}_{0,4} \mathrm{Cu}_{0,5} \mathrm{Ni}_{3,8}$, $\mathrm{La}_{0,7} \mathrm{Mg}_{0,3} \mathrm{Al}_{0,3} \mathrm{Mn}_{0,4} \mathrm{Sn}_{0,5} \mathrm{Ni}_{3,8}$ $\mathrm{Pr}_{0,7} \mathrm{Mg}_{0,3} \mathrm{Al}_{0,3} \mathrm{Mn}_{0,4} \mathrm{Co}_{0,5} \mathrm{Ni}_{3,8} \quad$ sem TT

FIGURA 39 - Curvas de PCT das ligas $\mathrm{La}_{0,7} \mathrm{Mg}_{0,3} \mathrm{Al}_{0,3} \mathrm{Mn}_{0,4} \mathrm{Co}_{0,5} \mathrm{Ni}_{3,8}\left(850^{\circ} \mathrm{C} / 16 \mathrm{~h}\right)$, $\mathrm{La}_{0,7} \mathrm{Mg}_{0,3} \mathrm{Al}_{0,3} \mathrm{Mn}_{0,4} \mathrm{Cu}_{0,5} \mathrm{Ni}_{3,8}\left(750^{\circ} \mathrm{C} / 16 \mathrm{~h}\right) \quad \mathrm{La}_{0,7} \mathrm{Mg}_{0,3} \mathrm{Al}_{0,3} \mathrm{Mn}_{0,4} \mathrm{Sn}_{0,5} \mathrm{Ni}_{3,8} \quad\left(750^{\circ} \mathrm{C} / 16 \mathrm{~h}\right)$, $\mathrm{La}_{0,7} \mathrm{Pr}_{0,3} \mathrm{Al}_{0,3} \mathrm{Mn}_{0,4} \mathrm{Co}_{0,5} \mathrm{Ni}_{3,8}\left(850^{\circ} \mathrm{C} / 16 \mathrm{~h}\right)$ e $\operatorname{Pr}_{0,7} \mathrm{Mg}_{0,3} \mathrm{Al}_{0,3} \mathrm{Mn}_{0,4} \mathrm{Co}_{0,5} \mathrm{Ni}_{3,8}\left(750^{\circ} \mathrm{C} / 9 \mathrm{~h}\right)$.

FIGURA 40 - Curvas de absorção de hidrogênio da liga $\mathrm{La}_{0,7} \mathrm{Mg}_{0,3} \mathrm{Al}_{0,3} \mathrm{Mn}_{0,4} \mathrm{Co}_{0,5} \mathrm{Ni}_{3,8}$ com TT de $850^{\circ} \mathrm{C}$ por 16 horas

FIGURA 41 - Ciclos de ativação da liga $\mathrm{La}_{0,7} \mathrm{Mg}_{0,3} \mathrm{Al}_{0,3} \mathrm{Mn}_{0,4} \mathrm{Co}_{0,5} \mathrm{Ni}_{3,8}$ com tratamento térmico de $850^{\circ} \mathrm{C}$ por 16 horas

FIGURA 42 - Curvas de absorção durante os ciclos de ativação da liga $\mathrm{La}_{0,7} \mathrm{Mg}_{0,3} \mathrm{Al}_{0,3} \mathrm{Mn}_{0,4} \mathrm{Cu}_{0,5} \mathrm{Ni}_{3,8}$ com tratamento térmico de $750^{\circ} \mathrm{C}$ por 16 horas. .95

FIGURA 43 - Ciclos de ativação da liga $\mathrm{La}_{0,7} \mathrm{Mg}_{0,3} \mathrm{Al}_{0,3} \mathrm{Mn}_{0,4} \mathrm{Cu}_{0,5} \mathrm{Ni}_{3,8}$ com tratamento térmico de $750^{\circ} \mathrm{C}$ por 16 horas.

FIGURA 44 - Curvas de absorção durante os ciclos de ativação da liga $\mathrm{La}_{0,7} \mathrm{Mg}_{0,3} \mathrm{Al}_{0,3} \mathrm{Mn}_{0,4} \mathrm{Sn}_{0,5} \mathrm{Ni}_{3,8}$ com tratamento térmico de $750^{\circ} \mathrm{C}$ por 16 horas .96

Figura 45 - Ciclos de ativação da liga $\mathrm{La}_{0,7} \mathrm{Mg}_{0,3} \mathrm{Al}_{0,3} \mathrm{Mn}_{0,4} \mathrm{Sn}_{0,5} \mathrm{Ni}_{3,8}$ com tratamento térmico de $750^{\circ} \mathrm{C}$ por 16 horas .97

Figura 46 - Curvas de absorção durante os ciclos de ativação da liga $\mathrm{La}_{0,7} \mathrm{Pr}_{0,3} \mathrm{Al}_{0,3} \mathrm{Mn}_{0,4} \mathrm{Co}_{0,5} \mathrm{Ni}_{3,8}$ com tratamento térmico de $850^{\circ} \mathrm{C}$ por 16 horas...........98

Figura 47 - Ciclos de ativação da liga $\mathrm{La}_{0,7} \mathrm{Pr}_{0,3} \mathrm{Al}_{0,3} \mathrm{Mn}_{0,4} \mathrm{Co}_{0,5} \mathrm{Ni}_{3,8}$ com tratamento térmico de $850^{\circ} \mathrm{C}$ por 16 horas .98

FIGURA 48 - Curvas de absorção durante os ciclos de ativação da liga $\mathrm{Pr}_{0,7} \mathrm{Mg}_{0,3} \mathrm{Al}_{0,3} \mathrm{Mn}_{0,4} \mathrm{Co}_{0,5} \mathrm{Ni}_{3,8}$ com tratamento térmico de $750^{\circ} \mathrm{C}$ por 9 horas. .99 
FIGURA 49 - Ciclos de ativação da liga $\operatorname{Pr}_{0,7} \mathrm{Mg}_{0,3} \mathrm{Al}_{0,3} \mathrm{Mn}_{0,4} \mathrm{Co}_{0,5} \mathrm{Ni}_{3,8}$ com tratamento térmico de $750^{\circ} \mathrm{C}$ por 9 horas

FIGURA 50 - Curva de PCT das ligas $\mathrm{La}_{0,7} \mathrm{Mg}_{0,3} \mathrm{Al}_{0,3} \mathrm{Mn}_{0,4} \mathrm{Co}_{0,5} \mathrm{Ni}_{3,8} \quad 850 \% / 16 \mathrm{~h}$, $\mathrm{La}_{0,7} \mathrm{Mg}_{0,3} \mathrm{Al}_{0,3} \mathrm{Mn}_{0,4} \mathrm{Cu}_{0,5} \mathrm{Ni}_{3,8} \quad 750^{\circ} \mathrm{C} / 16 \mathrm{~h}, \quad \mathrm{La}_{0,7} \mathrm{Mg}_{0,3} \mathrm{Al}_{0,3} \mathrm{Mn}_{0,4} \mathrm{Sn}_{0,5} \mathrm{Ni}_{3,8} \quad 750^{\circ} \mathrm{C} / 16 \mathrm{~h}$, $\mathrm{La}_{0,7} \mathrm{Pr}_{0,3} \mathrm{Al}_{0,3} \mathrm{Mn}_{0,4} \mathrm{Co}_{0,5} \mathrm{Ni}_{3,8} \quad 850^{\circ} \mathrm{C} / 16 \mathrm{~h}$ e $\operatorname{Pr}_{0,7} \mathrm{Mg}_{0,3} \mathrm{Al}_{0,3} \mathrm{Mn}_{0,4} \mathrm{Co}_{0,5} \mathrm{Ni}_{3,8} \quad 750^{\circ} \mathrm{C} / 9 \mathrm{~h}$ após quatro ciclos de ativação. 101

FIGURA 51 - Curvas de absorção de hidrogênio pela liga $\mathrm{La}_{0,7} \mathrm{Mg}_{0,3} \mathrm{Al}_{0,3} \mathrm{Mn}_{0,4} \mathrm{Co}_{0,5} \mathrm{Ni}_{3,8}$ sem TT na pressão de 2, 4, 6 e 9 bar de hidrogênio por $60 \mathrm{~min}$.

FIGURA 52 - (a) Micrografia da liga La $\mathrm{La}_{0,7} \mathrm{Mg}_{0,3} \mathrm{Al}_{0,3} \mathrm{Mn}_{0,4} \mathrm{Co}_{0,5} \mathrm{Ni}_{3,8}$ bruta de fusão sem TT e (b) a (e) micrografias (500x) da liga fragilizada com pressão de 2, 4, 6 e 9 bar de hidrogênio por 60 minutos, respectivamente.

FIGURA 53 - Curvas de absorção da liga $\mathrm{La}_{0,7} \mathrm{Mg}_{0,3} \mathrm{Al}_{0,3} \mathrm{Mn}_{0,4} \mathrm{Co}_{0,5} \mathrm{Ni}_{3,8}$ com TT de $750^{\circ} \mathrm{C}$ por 9 horas com pressão de 2, 4, 6 e 9 bar de hidrogênio por 60 minutos ...107

FIGURA 54 - Micrografias (500x) da liga $\mathrm{La}_{0,7} \mathrm{Mg}_{0,3} \mathrm{Al}_{0,3} \mathrm{Mn}_{0,4} \mathrm{Co}_{0,5} \mathrm{Ni}_{3,8}$ com TT de $750^{\circ} \mathrm{C}$ por 9 horas fragilizada na pressão de 2, 4, 6 e 9 bar de hidrogênio por 60 min.

FIGURA 55 - Curvas de absorção de hidrogênio pela liga $\mathrm{La}_{0,7} \mathrm{Mg}_{0,3} \mathrm{Al}_{0,3} \mathrm{Mn}_{0,4} \mathrm{Co}_{0,5} \mathrm{Ni}_{3,8}$ com TT de $750^{\circ} \mathrm{C}$ por 16 horas, com pressão de 2, 4, 6 e 9 bar de hidrogênio por 60 minutos 108

FIGURA 56 - Micrografias (500x) da liga $\mathrm{La}_{0,7} \mathrm{Mg}_{0,3} \mathrm{Al}_{0,3} \mathrm{Mn}_{0,4} \mathrm{Co}_{0,5} \mathrm{Ni}_{3,8}$ com TT de $750^{\circ} \mathrm{C}$ por 16 horas fragilizada na pressão de 2, 46 e 9 bar de hidrogênio por 60 min

FIGURA 57 - Curvas de absorção de hidrogênio pela liga $\mathrm{La}_{0,7} \mathrm{Mg}_{0,3} \mathrm{Al}_{0,3} \mathrm{Mn}_{0,4} \mathrm{Co}_{0,5} \mathrm{Ni}_{3,8}$ com TT de $850^{\circ} \mathrm{C}$ por 9 horas com pressão de 2, 4, 6 e 9 bar de hidrogênio por 60 minutos. .110

FIGURA 58 - Micrografias $(500 x)$ da liga $\mathrm{La}_{0,7} \mathrm{Mg}_{0,3} \mathrm{Al}_{0,3} \mathrm{Mn}_{0,4} \mathrm{Co}_{0,5} \mathrm{Ni}_{3,8}$ com TT de $850^{\circ} \mathrm{C}$ por 9 horas fragilizada na pressão de 2, 46 e 9 bar de hidrogênio por 60 min.

FIGURA 59 - Curvas de absorção de hidrogênio pela liga $\mathrm{La}_{0,7} \mathrm{Mg}_{0,3} \mathrm{Al}_{0,3} \mathrm{Mn}_{0,4} \mathrm{Co}_{0,5} \mathrm{Ni}_{3,8}$ com TT de $850^{\circ} \mathrm{C}$ por 16 horas com pressão de 2, 4, 6 e 9 bar de hidrogênio por 60 minutos 
FIGURA 60 - Micrografias (500x) da liga de $\mathrm{La}_{0,7} \mathrm{Mg}_{0,3} \mathrm{Al}_{0,3} \mathrm{Mn}_{0,4} \mathrm{Co}_{0,5} \mathrm{Ni}_{3,8}$ com TT de 850 por 16 horas fragilizada na pressão de 2, 46 e 9 bar de hidrogênio por 60 min.

FIGURA 61 - Curvas de absorção de hidrogênio pela liga $\mathrm{La}_{0,7} \mathrm{Mg}_{0,3} \mathrm{Al}_{0,3} \mathrm{Mn}_{0,4} \mathrm{Cu}_{0,5} \mathrm{Ni}_{3,8}$ sem TT com pressão de 2, 4, 6 e 9 bar de hidrogênio por 60 minutos.

FIGURA 62 - Micrografias (500x) da liga $\mathrm{La}_{0,7} \mathrm{Mg}_{0,3} \mathrm{Al}_{0,3} \mathrm{Mn}_{0,4} \mathrm{Cu}_{0,5} \mathrm{Ni}_{3,8}$ sem TT fragilizada na pressão de 2, 4, 6 e 9 bar de hidrogênio por 60 minutos.

FIGURA 63 - Curvas de absorção de Hidrogênio pela liga $\mathrm{La}_{0,7} \mathrm{Mg}_{0,3} \mathrm{Al}_{0,3} \mathrm{Mn}_{0,4} \mathrm{Cu}_{0,5} \mathrm{Ni}_{3,8}$ com TT de $750^{\circ} \mathrm{C}$ por 9 horas com pressão de 2, 4, 6 e 9 bar de hidrogênio por 60 minutos. .115

FIGURA 64 - Micrografias (500x) da liga $\mathrm{La}_{0,7} \mathrm{Mg}_{0,3} \mathrm{Al}_{0,3} \mathrm{Mn}_{0,4} \mathrm{Cu}_{0,5} \mathrm{Ni}_{3,8}$ com TT de $750^{\circ} \mathrm{C}$ por 9 horas fragilizada em 2, 46 e 9 bar de hidrogênio por 60 minutos........115

FIGURA 65 - Curvas de absorção de hidrogênio pela liga $\mathrm{La}_{0,7} \mathrm{Mg}_{0,3} \mathrm{Al}_{0,3} \mathrm{Mn}_{0,4} \mathrm{Cu}_{0,5} \mathrm{Ni}_{3,8}$ com TT de $750^{\circ} \mathrm{C}$ por 16 horas com pressão de 2, 4, 6 e 9 bar de hidrogênio por 60 minutos.....................................................................116

FIGURA 66 - Micrografias (500x) da liga $\mathrm{La}_{0,7} \mathrm{Mg}_{0,3} \mathrm{Al}_{0,3} \mathrm{Mn}_{0,4} \mathrm{Cu}_{0,5} \mathrm{Ni}_{3,8}$ com TT de $750^{\circ} \mathrm{C}$ por 16 horas fragilizada em 2, 46 e 9 bar de hidrogênio por 60 minutos.....117

FIGURA 67 - Curvas de absorção de hidrogênio pela liga $\mathrm{La}_{0,7} \mathrm{Mg}_{0,3} \mathrm{Al}_{0,3} \mathrm{Mn}_{0,4} \mathrm{Cu}_{0,5} \mathrm{Ni}_{3,8}$ com TT de $850^{\circ} \mathrm{C}$ por 9 horas com pressão de 2, 4, 6 e 9 bar de hidrogênio por 60 minutos 118

FIGURA 68 - Micrografias (500x) da liga $\mathrm{La}_{0,7} \mathrm{Mg}_{0,3} \mathrm{Al}_{0,3} \mathrm{Mn}_{0,4} \mathrm{Cu}_{0,5} \mathrm{Ni}_{3,8}$ com TT de $850^{\circ} \mathrm{C}$ por 9 horas fragilizada em 2, 46 e 9 bar de hidrogênio por 60 minutos.......118

FIGURA 69 - Curvas de absorção de Hidrogênio pela liga $\mathrm{La}_{0,7} \mathrm{Mg}_{0,3} \mathrm{Al}_{0,3} \mathrm{Mn}_{0,4} \mathrm{Cu}_{0,5} \mathrm{Ni}_{3,8}$ com tratamento térmico de $850^{\circ} \mathrm{C}$ por 16 horas. , com pressão de 2, 4, 6 e 9 bar de hidrogênio por 60 minutos.

FIGURA 70 - Micrografia com aumento de 500x da liga $\mathrm{La}_{0,7} \mathrm{Mg}_{0,3} \mathrm{Al}_{0,3} \mathrm{Mn}_{0,4} \mathrm{Cu}_{0,5} \mathrm{Ni}_{3,8}$ fragilizada com tratamento térmico de $850^{\circ} \mathrm{C}$ por 16 horas em 2, 46 e 9 bar de hidrogênio por 60 minutos. 
FIGURA 71 - Curvas de absorção de Hidrogênio pela liga

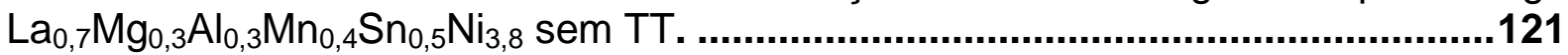

FIGURA 72 - Micrografia com aumento de 500x da liga $\mathrm{La}_{0,7} \mathrm{Mg}_{0,3} \mathrm{Al}_{0,3} \mathrm{Mn}_{0,4} \mathrm{Sn}_{0,5} \mathrm{Ni}_{3,8}$ fragilizada sem TT em 2, 46 e 9 bar de hidrogênio por 60 minutos.

FIGURA 73 - Curvas de absorção de Hidrogênio pela liga $\mathrm{La}_{0,7} \mathrm{Mg}_{0,3} \mathrm{Al}_{0,3} \mathrm{Mn}_{0,4} \mathrm{Sn}_{0,5} \mathrm{Ni}_{3,8}$ com tratamento térmico de $750^{\circ} \mathrm{C}$ por 9 horas..........123

FIGURA 74 - Micrografia com aumento de 500x da liga $\mathrm{La}_{0,7} \mathrm{Mg}_{0,3} \mathrm{Al}_{0,3} \mathrm{Mn}_{0,4} \mathrm{Sn}_{0,5} \mathrm{Ni}_{3,8}$ fragilizada com tratamento térmico de $750^{\circ} \mathrm{C}$ por 9 horas em 2, 46 e 9 bar de hidrogênio por 60 minutos.

123

FIGURA 75 - Curvas de absorção de Hidrogênio pela liga $\mathrm{La}_{0,7} \mathrm{Mg}_{0,3} \mathrm{Al}_{0,3} \mathrm{Mn}_{0,4} \mathrm{Sn}_{0,5} \mathrm{Ni}_{3,8}$ com tratamento térmico de $750^{\circ} \mathrm{C}$ por 16 horas........125

FIGURA 76 - Micrografia com aumento de 500x da liga $\mathrm{La}_{0,7} \mathrm{Mg}_{0,3} \mathrm{Al}_{0,3} \mathrm{Mn}_{0,4} \mathrm{Sn}_{0,5} \mathrm{Ni}_{3,8}$ fragilizada com tratamento térmico de $750^{\circ} \mathrm{C}$ por 16 horas em 2, 46 e 9 bar de hidrogênio por 60 minutos. 125

FIGURA 77 - Curvas de absorção de Hidrogênio pela liga $\mathrm{La}_{0,7} \mathrm{Mg}_{0,3} \mathrm{Al}_{0,3} \mathrm{Mn}_{0,4} \mathrm{Sn}_{0,5} \mathrm{Ni}_{3,8}$ com tratamento térmico de $850^{\circ} \mathrm{C}$ por 9 horas..........126

FIGURA 78 - Micrografia com aumento de 500x da liga $\mathrm{La}_{0,7} \mathrm{Mg}_{0,3} \mathrm{Al}_{0,3} \mathrm{Mn}_{0,4} \mathrm{Sn}_{0,5} \mathrm{Ni}_{3,8}$ fragilizada com tratamento térmico de $850^{\circ} \mathrm{C}$ por 9 horas em 2, 46 e 9 bar de hidrogênio por 60 minutos 126

FIGURA 79 - Curvas de absorção de Hidrogênio pela liga $\mathrm{La}_{0,7} \mathrm{Mg}_{0,3} \mathrm{Al}_{0,3} \mathrm{Mn}_{0,4} \mathrm{Sn}_{0,5} \mathrm{Ni}_{3,8}$ com tratamento térmico de $850^{\circ} \mathrm{C}$ por 16 horas........127

FIGURA 80 - Micrografia com aumento de 500x da liga $\mathrm{La}_{0,7} \mathrm{Mg}_{0,3} \mathrm{Al}_{0,3} \mathrm{Mn}_{0,4} \mathrm{Sn}_{0,5} \mathrm{Ni}_{3,8}$ fragilizada com tratamento térmico de $850^{\circ} \mathrm{C}$ por 16 horas em 2, 46 e 9 bar de hidrogênio por 60 minutos.. 128

FIGURA 81 - Curvas de absorção de hidrogênio pela liga $\mathrm{La}_{0,7} \mathrm{Pr}_{0,3} \mathrm{Al}_{0,3} \mathrm{Mn}_{0,4} \mathrm{Co}_{0,5} \mathrm{Ni}_{3,8}$ sem TT...........................................................129

FIGURA 82 - Micrografia com aumento de 500x da liga $\mathrm{La}_{0,7} \mathrm{Pr}_{0,3} \mathrm{Al}_{0,3} \mathrm{Mn}_{0,4} \mathrm{Co}_{0,5} \mathrm{Ni}_{3,8}$ fragilizada sem tratamento térmico em 2, 46 e 9 bar de hidrogênio por 60 minutos. 
FIGURA 83 - Curvas de absorção de hidrogênio pela liga $\mathrm{La}_{0,7} \mathrm{Pr}_{0,3} \mathrm{Al}_{0,3} \mathrm{Mn}_{0,4} \mathrm{Co}_{0,5} \mathrm{Ni}_{3,8}$ com TT de $750^{\circ} \mathrm{C}$ por 9 horas....................................132

FIGURA 84 - Micrografias (500x) da liga $\mathrm{La}_{0,7} \mathrm{Pr}_{0,3} \mathrm{Al}_{0,3} \mathrm{Mn}_{0,4} \mathrm{Co}_{0,5} \mathrm{Ni}_{3,8}$ com TT de 750 por 9 horas fragilizada em 2, 46 e 9 bar de hidrogênio por 60 minutos.

FIGURA 85 - Curvas de absorção de Hidrogênio pela liga $\mathrm{La}_{0,7} \mathrm{Pr}_{0,3} \mathrm{Al}_{0,3} \mathrm{Mn}_{0,4} \mathrm{Co}_{0,5} \mathrm{Ni}_{3,8}$ com tratamento térmico de $750^{\circ} \mathrm{C}$ por 16 horas. ........133

FIGURA 86 - Micrografia com aumento de 500x da liga $\mathrm{La}_{0,7} \mathrm{Pr}_{0,3} \mathrm{Al}_{0,3} \mathrm{Mn}_{0,4} \mathrm{Co}_{0,5} \mathrm{Ni}_{3,8}$ fragilizada com tratamento térmico de 750 por 16 horas em 2, 46 e 9 bar de hidrogênio por 60 minutos. 133

FIGURA 87 - Curvas de absorção de Hidrogênio pela liga $\mathrm{La}_{0,7} \mathrm{Pr}_{0,3} \mathrm{Al}_{0,3} \mathrm{Mn}_{0,4} \mathrm{Co}_{0,5} \mathrm{Ni}_{3,8}$ com tratamento térmico de $850^{\circ} \mathrm{C}$ por 9 horas ..........135

FIGURA 88 - Micrografia com aumento de 500x da liga $\mathrm{La}_{0,7} \mathrm{Pr}_{0,3} \mathrm{Al}_{0,3} \mathrm{Mn}_{0,4} \mathrm{Co}_{0,5} \mathrm{Ni}_{3,8}$ fragilizada com tratamento térmico de 850 por 9 horas em 2, 46 e 9 bar de hidrogênio por 60 minutos. .135

FIGURA 89 - Curvas de absorção de Hidrogênio pela liga $\mathrm{La}_{0,7} \mathrm{Pr}_{0,3} \mathrm{Al}_{0,3} \mathrm{Mn}_{0,4} \mathrm{Co}_{0,5} \mathrm{Ni}_{3,8}$ com tratamento térmico de $850^{\circ} \mathrm{C}$ por 16 horas. ........136

FIGURA 90 - Micrografia com aumento de 500x da liga $\mathrm{La}_{0,7} \mathrm{Pr}_{0,3} \mathrm{Al}_{0,3} \mathrm{Mn}_{0,4} \mathrm{Co}_{0,5} \mathrm{Ni}_{3,8}$ fragilizada com tratamento térmico de 850 por 16 horas em 2, 46 e 9 bar de hidrogênio por 60 minutos. 136

FIGURA 91 - Curvas de absorção de Hidrogênio pela liga $\operatorname{Pr}_{0,7} \mathrm{Mg}_{0,3} \mathrm{Al}_{0,3} \mathrm{Mn}_{0,4} \mathrm{C}_{0,5} \mathrm{Ni}_{3,8}$ sem tratamento térmico.

FIGURA 92 - Micrografia com aumento de 500x da liga $\operatorname{Pr}_{0,7} \mathrm{Mg}_{0,3} \mathrm{Al}_{0,3} \mathrm{Mn}_{0,4} \mathrm{Co}_{0,5} \mathrm{Ni}_{3,8}$ fragilizada sem tratamento térmico em 6 e 9 bar de hidrogênio por 60 minutos. ....138

FIGURA 93 - Curvas de absorção de Hidrogênio pela liga $\mathrm{Pr}_{0,7} \mathrm{Mg}_{0,3} \mathrm{Al}_{0,3} \mathrm{Mn}_{0,4} \mathrm{Co}_{0,5} \mathrm{Ni}_{3,8}$ com tratamento térmico de $750^{\circ} \mathrm{C}$ por 9 horas..........139 FIGURA 94 - Micrografia com aumento de 500x da liga $\mathrm{Pr}_{0,7} \mathrm{Mg}_{0,3} \mathrm{Al}_{0,3} \mathrm{Mn}_{0,4} \mathrm{Co}_{0,5} \mathrm{Ni}_{3,8}$ fragilizada com tratamento térmico de 750 por 9 horas em 6 e 9 bar de hidrogênio

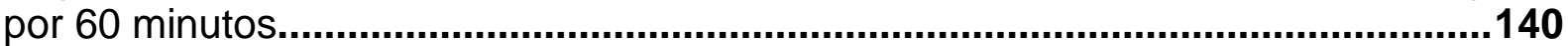

FIGURA 95 - Curvas de absorção de Hidrogênio pela liga $\mathrm{Pr}_{0,7} \mathrm{Mg}_{0,3} \mathrm{Al}_{0,3} \mathrm{Mn}_{0,4} \mathrm{Co}_{0,5} \mathrm{Ni}_{3,8}$ com tratamento térmico de $750^{\circ} \mathrm{C}$ por 16 horas. .......141 
FIGURA 96 - Micrografia com aumento de 500x da liga $\operatorname{Pr}_{0,7} \mathrm{Mg}_{0,3} \mathrm{Al}_{0,3} \mathrm{Mn}_{0,4} \mathrm{Co}_{0,5} \mathrm{Ni}_{3,8}$ fragilizada com tratamento térmico de 750 por 16 horas em 6 e 9 bar de hidrogênio

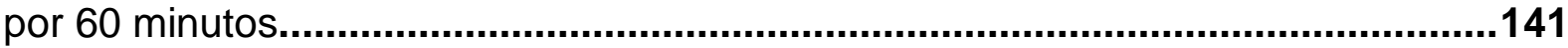

FIGURA 97 - Curvas de absorção de Hidrogênio pela liga $\mathrm{Pr}_{0,7} \mathrm{Mg}_{0,3} \mathrm{Al}_{0,3} \mathrm{Mn}_{0,4} \mathrm{Co}_{0,5} \mathrm{Ni}_{3,8}$ com tratamento térmico de $850^{\circ} \mathrm{C}$ por 9 horas. .........142

FIGURA 98 - Micrografia com aumento de 500x da liga $\operatorname{Pr}_{0,7} \mathrm{Mg}_{0,3} \mathrm{Al}_{0,3} \mathrm{Mn}_{0,4} \mathrm{Co}_{0,5} \mathrm{Ni}_{3,8}$ fragilizada com tratamento térmico de 850 por 9 horas em 6 e 9 bar de hidrogênio por 60 minutos. .143

FIGURA 99 - Curvas de absorção de Hidrogênio pela liga $\mathrm{Pr}_{0,7} \mathrm{Mg}_{0,3} \mathrm{Al}_{0,3} \mathrm{Mn}_{0,4} \mathrm{Co}_{0,5} \mathrm{Ni}_{3,8}$ com tratamento térmico de $850^{\circ} \mathrm{C}$ por 16 horas. .......144

FIGURA 100 - Micrografia com aumento de 500x da liga $\operatorname{Pr}_{0,7} \mathrm{Mg}_{0,3} \mathrm{Al}_{0,3} \mathrm{Mn}_{0,4} \mathrm{Co}_{0,5} \mathrm{Ni}_{3,8}$ fragilizada com tratamento térmico de 850 por 16 horas em 6 e 9 bar de hidrogênio por 60 minutos 


\section{LISTA DE TABELAS}

TABELA 1 - Capacidade de descarga teórica para diferentes tipos de ligas formadoras de hidreto metálico.

TABELA 2 - Descrição dos reagentes químicos utilizados na fabricação das baterias.

TABELA 3 - Composição química das ligas $\mathrm{La}_{0,7} \mathrm{Mg}_{0,3} \mathrm{Al}_{0,3} \mathrm{Mn}_{0,4} \mathrm{Co}_{0,5} \mathrm{Ni}_{3,8}$; $\mathrm{La}_{0,7} \mathrm{Mg}_{0,3} \mathrm{Al}_{0,3} \mathrm{Mn}_{0,4} \mathrm{Cu}_{0,5} \mathrm{Ni}_{3,8} ; \quad \mathrm{La}_{0,7} \mathrm{Mg}_{0,3} \mathrm{Al}_{0,3} \mathrm{Mn}_{0,4} \mathrm{Sn}_{0,5} \mathrm{Ni}_{3,8}$; $\mathrm{La}_{0,7} \mathrm{Pr}_{0,3} \mathrm{Al}_{0,3} \mathrm{Mn}_{0,4} \mathrm{Co}_{0,5} \mathrm{Ni}_{3,8}$ e $\mathrm{Pr}_{0,7} \mathrm{Mg}_{0,3} \mathrm{Al}_{0,3} \mathrm{Mn}_{0,4} \mathrm{Co}_{0,5} \mathrm{Ni}_{3,8}$

TABELA 4 - Lista de materiais para montagem do eletrodo negativo. 42

TABELA 5 - Lista de materiais para montagem do eletrodo positivo

TABELA 6 - Composição química das ligas $\mathrm{La}_{0,7} \mathrm{Mg}_{0,3} \mathrm{Al}_{0,3} \mathrm{Mn}_{0,4} \mathrm{Co}_{0,5} \mathrm{Ni}_{3,8}$; $\mathrm{La}_{0,7} \mathrm{Mg}_{0,3} \mathrm{Al}_{0,3} \mathrm{Mn}_{0,4} \mathrm{Cu}_{0,5} \mathrm{Ni}_{3,8} ; \quad \mathrm{La}_{0,7} \mathrm{Mg}_{0,3} \mathrm{Al}_{0,3} \mathrm{Mn}_{0,4} \mathrm{Sn}_{0,5} \mathrm{Ni}_{3,8}$; $\mathrm{La}_{0,7} \mathrm{Pr}_{0,3} \mathrm{Al}_{0,3} \mathrm{Mn}_{0,4} \mathrm{Co}_{0,5} \mathrm{Ni}_{3,8}$ e $\mathrm{Pr}_{0,7} \mathrm{Mg}_{0,3} \mathrm{Al}_{0,3} \mathrm{Mn}_{0,4} \mathrm{Co}_{0,5} \mathrm{Ni}_{3,8}$ analizadas por ICP-AES.

TABELA 7 - Parâmetros obtidos através do refinamento por Rietveld das ligas $\mathrm{La}_{0,7} \mathrm{Mg}_{0,3} \mathrm{Al}_{0,3} \mathrm{Mn}_{0,4} \mathrm{Cu}_{0,5} \mathrm{Ni}_{3,8}, \quad \mathrm{La}_{0,7} \mathrm{Mg}_{0,3} \mathrm{Al}_{0,3} \mathrm{Mn}_{0,4} \mathrm{Co}_{0,5} \mathrm{Ni}_{3,8}$, $\mathrm{La}_{0,7} \mathrm{Mg}_{0,3} \mathrm{Al}_{0,3} \mathrm{Mn}_{0,4} \mathrm{Sn}_{0,5} \mathrm{Ni}_{3,8}, \quad \mathrm{La}_{0,7} \mathrm{Pr}_{0,3} \mathrm{Al}_{0,3} \mathrm{Mn}_{0,4} \mathrm{Co}_{0,5} \mathrm{Ni}_{3,8}$ $\mathrm{Pr}_{0,7} \mathrm{Mg}_{0,3} \mathrm{Al}_{0,3} \mathrm{Mn}_{0,4} \mathrm{Co}_{0,5} \mathrm{Ni}_{3,8}$ sem TT.

TABELA 8 - Parâmetros obtidos através do refinamento por Rietveld das ligas $\mathrm{La}_{0,7} \mathrm{Mg}_{0,3} \mathrm{Al}_{0,3} \mathrm{Mn}_{0,4} \mathrm{Co}_{0,5} \mathrm{Ni}_{3,8}$ sem e com TT.

TABELA 9 - Parâmetros obtidos através do refinamento por Rietveld das ligas $\mathrm{La}_{0,7} \mathrm{Mg}_{0,3} \mathrm{Al}_{0,3} \mathrm{Mn}_{0,4} \mathrm{Cu}_{0,5} \mathrm{Ni}_{3,8}$ sem e com TT.

TABELA 10 - Parâmetros obtidos através do refinamento por Rietveld das ligas $\mathrm{La}_{0,7} \mathrm{Mg}_{0,3} \mathrm{Al}_{0,3} \mathrm{Mn}_{0,4} \mathrm{Sn}_{0,5} \mathrm{Ni}_{3,8}$ .54

TABELA 11 - Parâmetros obtidos através do refinamento por Rietveld das ligas $\mathrm{La}_{0,7} \mathrm{Pr}_{0,3} \mathrm{Al}_{0,3} \mathrm{Mn}_{0,4} \mathrm{Co}_{0,5} \mathrm{Ni}_{3,8}$

TABELA 12 - Parâmetros obtidos através do refinamento por Rietveld das ligas $\operatorname{Pr}_{0,7} \mathrm{Mg}_{0,3} \mathrm{Al}_{0,3} \mathrm{Mn}_{0,4} \mathrm{Co}_{0,5} \mathrm{Ni}_{3,8}$,

TABELA 13 - Composição química (semi-quantitativa) da liga $\mathrm{La}_{0,7} \mathrm{Mg}_{0,3} \mathrm{Al}_{0,3} \mathrm{Mn}_{0,4} \mathrm{Co}_{0,5} \mathrm{Ni}_{3,8}$, sem TT, analisada por EDS. .61

Tabela 14 - Composição química (semi-quantitativa) da liga $\mathrm{La}_{0,7} \mathrm{Mg}_{0,3} \mathrm{Al}_{0,3} \mathrm{Mn}_{0,4} \mathrm{Co}_{0,5} \mathrm{Ni}_{3,8}$, com TT de 750 por 9 horas, analisada por EDS. .......61 
TABELA 15 - Composição química (semi-quantitativa) da liga $\mathrm{La}_{0,7} \mathrm{Mg}_{0,3} \mathrm{Al}_{0,3} \mathrm{Mn}_{0,4} \mathrm{Co}_{0,5} \mathrm{Ni}_{3,8}$, com TT de 750 por 16 horas, analisada por EDS. .....61

TABELA 16 - Composição química (semi-quantitativa) da liga $\mathrm{La}_{0,7} \mathrm{Mg}_{0,3} \mathrm{Al}_{0,3} \mathrm{Mn}_{0,4} \mathrm{Co}_{0,5} \mathrm{Ni}_{3,8}$, com TT de 850 por 9 horas, analisada por EDS. .......61

TABELA 17 - Composição química (semi-quantitativa) da liga $\mathrm{La}_{0,7} \mathrm{Mg}_{0,3} \mathrm{Al}_{0,3} \mathrm{Mn}_{0,4} \mathrm{Co}_{0,5} \mathrm{Ni}_{3,8}$, com TT de 850 por 16 horas, analisada por EDS. .....61

TABELA 18 - Composição química (semi-quantitativa) da liga $\mathrm{La}_{0,7} \mathrm{Mg}_{0,3} \mathrm{Al}_{0,3} \mathrm{Mn}_{0,4} \mathrm{Cu}_{0,5} \mathrm{Ni}_{3,8}$, sem TT, analisada por EDS.

TABELA 19 - Composição química (semi-quantitativa) da liga $\mathrm{La}_{0,7} \mathrm{Mg}_{0,3} \mathrm{Al}_{0,3} \mathrm{Mn}_{0,4} \mathrm{Cu}_{0,5} \mathrm{Ni}_{3,8}$, com TT $750^{\circ} \mathrm{C}$ por 9 horas, analisada por EDS.

TABELA 20 - Composição química (semi-quantitativa) da liga $\mathrm{La}_{0,7} \mathrm{Mg}_{0,3} \mathrm{Al}_{0,3} \mathrm{Mn}_{0,4} \mathrm{Cu}_{0,5} \mathrm{Ni}_{3,8}$, com TT $750^{\circ} \mathrm{C}$ por 16 horas, analisada por EDS.......64

TABELA 21 - Composição química (semi-quantitativa) da liga $\mathrm{La}_{0,7} \mathrm{Mg}_{0,3} \mathrm{Al}_{0,3} \mathrm{Mn}_{0,4} \mathrm{Cu}_{0,5} \mathrm{Ni}_{3,8}$, com TT $850^{\circ} \mathrm{C}$ por 9 horas, analisada por EDS. ........64

TABELA 22 - Composição química (semi-quantitativa) da liga $\mathrm{La}_{0,7} \mathrm{Mg}_{0,3} \mathrm{Al}_{0,3} \mathrm{Mn}_{0,4} \mathrm{Cu}_{0,5} \mathrm{Ni}_{3,8}$, com TT $850^{\circ} \mathrm{C}$ por 169 horas, analisada por EDS. ....64

TABELA 23 - Composição química (semi-quantitativa) da liga $\mathrm{La}_{0,7} \mathrm{Mg}_{0,3} \mathrm{Al}_{0,3} \mathrm{Mn}_{0,4} \mathrm{Sn}_{0,5} \mathrm{Ni}_{3,8}$, sem TT, analisada por EDS.....................................67

TABELA 24 - Composição química (semi-quantitativa) da liga $\mathrm{La}_{0,7} \mathrm{Mg}_{0,3} \mathrm{Al}_{0,3} \mathrm{Mn}_{0,4} \mathrm{Sn}_{0,5} \mathrm{Ni}_{3,8}$, com TT de 750 por 9 horas, analisada por EDS.........67

TABELA 25 - Composição química (semi-quantitativa) da liga $\mathrm{La}_{0,7} \mathrm{Mg}_{0,3} \mathrm{Al}_{0,3} \mathrm{Mn}_{0,4} \mathrm{Sn}_{0,5} \mathrm{Ni}_{3,8}$, com TT de 750 por 16 horas, analisada por EDS.......67

TABELA 26 - Composição química (semi-quantitativa) da liga $\mathrm{La}_{0,7} \mathrm{Mg}_{0,3} \mathrm{Al}_{0,3} \mathrm{Mn}_{0,4} \mathrm{Sn}_{0,5} \mathrm{Ni}_{3,8}$, com TT de 850 por 9 horas, analisada por EDS.........67

TABELA 27 - Composição química (semi-quantitativa) da liga $\mathrm{La}_{0,7} \mathrm{Mg}_{0,3} \mathrm{Al}_{0,3} \mathrm{Mn}_{0,4} \mathrm{Sn}_{0,5} \mathrm{Ni}_{3,8}$, com TT de 850 por 16 horas, analisada por EDS.......67

TABELA 28 - Composição química (semi-quantitativa) da liga $\mathrm{La}_{0,7} \mathrm{Pr}_{0,3} \mathrm{Al}_{0,3} \mathrm{Mn}_{0,4} \mathrm{Co}_{0,5} \mathrm{Ni}_{3,8}$, sem TT, analisada por EDS.......................................70

TABELA 29 - Composição química (semi-quantitativa) da liga $\mathrm{La}_{0,7} \mathrm{Pr}_{0,3} \mathrm{Al}_{0,3} \mathrm{Mn}_{0,4} \mathrm{Co}_{0,5} \mathrm{Ni}_{3,8}$, com TT de 750 por 9 horas, analisada por EDS...........70

TABELA 30 - Composição química (semi-quantitativa) da liga $\mathrm{La}_{0,7} \mathrm{Pr}_{0,3} \mathrm{Al}_{0,3} \mathrm{Mn}_{0,4} \mathrm{Co}_{0,5} \mathrm{Ni}_{3,8}$, com TT de 750 por 16 horas, analisada por EDS........70 
TABELA 31 - Composição química (semi-quantitativa) da liga $\mathrm{La}_{0,7} \mathrm{Pr}_{0,3} \mathrm{Al}_{0,3} \mathrm{Mn}_{0,4} \mathrm{Co}_{0,5} \mathrm{Ni}_{3,8}$, com TT de 850 por 9 horas, analisada por EDS..........70

Tabela 32 - Composição química (semi-quantitativa) da liga $\mathrm{La}_{0,7} \mathrm{Pr}_{0,3} \mathrm{Al}_{0,3} \mathrm{Mn}_{0,4} \mathrm{Co}_{0,5} \mathrm{Ni}_{3,8}$, com TT de 850 por 16 horas, analisada por EDS........70

TABELA 33 - Composição química (semi-quantitativa) da liga $\mathrm{Pr}_{0,7} \mathrm{Mg}_{0,3} \mathrm{Al}_{0,3} \mathrm{Mn}_{0,4} \mathrm{Co}_{0,5} \mathrm{Ni}_{3,8}$, sem TT, analisada por EDS.....................................73

TABELA 34 - Composição química (semi-quantitativa) da liga $\mathrm{Pr}_{0,7} \mathrm{Mg}_{0,3} \mathrm{Al}_{0,3} \mathrm{Mn}_{0,4} \mathrm{Co}_{0,5} \mathrm{Ni}_{3,8}$, com TT de 750 por 9 horas, analisada por EDS.........73

TABELA 35 - Composição química da liga $\operatorname{Pr}_{0,7} \mathrm{Mg}_{0,3} \mathrm{Al}_{0,3} \mathrm{Mn}_{0,4} \mathrm{Co}_{0,5} \mathrm{Ni}_{3,8}$, com tratamento térmico de 750 por 16 horas, analisada por EDS....................................73

TABELA 36 - Composição química (semi-quantitativa) da liga $\operatorname{Pr}_{0,7} \mathrm{Mg}_{0,3} \mathrm{Al}_{0,3} \mathrm{Mn}_{0,4} \mathrm{Co}_{0,5} \mathrm{Ni}_{3,8}$, com TT de 850 por 9 horas, analisada por EDS.........73

TABELA 37 - Composição química (semi-quantitativa) da liga $\mathrm{Pr}_{0,7} \mathrm{Mg}_{0,3} \mathrm{Al}_{0,3} \mathrm{Mn}_{0,4} \mathrm{Co}_{0,5} \mathrm{Ni}_{3,8}$, com TT de 850 por 16 horas, analisada por EDS.......73

TABELA 38 - Analise das características eletroquímicas da liga $\mathrm{La}_{0,7} \mathrm{Mg}_{0,3} \mathrm{Al}_{0,3} \mathrm{Mn}_{0,4} \mathrm{Co}_{0,5} \mathrm{Ni}_{3,8}$ sem e com tratamentos térmicos................................75

TABELA 39 - Características eletroquímicas da liga $\mathrm{La}_{0,7} \mathrm{Mg}_{0,3} \mathrm{Al}_{0,3} \mathrm{Mn}_{0,4} \mathrm{Cu}_{0,5} \mathrm{Ni}_{3,8}$

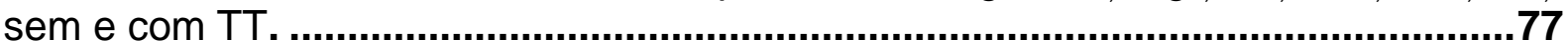

TABELA 40 - Características eletroquímicas da liga $\mathrm{La}_{0,7} \mathrm{Mg}_{0,3} \mathrm{Al}_{0,3} \mathrm{Mn}_{0,4} \mathrm{Sn}_{0,5} \mathrm{Ni}_{3,8}$ sem e com TT.

TABELA 41 - Características eletroquímicas da liga $\mathrm{La}_{0,7} \mathrm{Pr}_{0,3} \mathrm{Al}_{0,3} \mathrm{Mn}_{0,4} \mathrm{Co}_{0,5} \mathrm{Ni}_{3,8}$ sem e com TT.

TABELA 42 - Características eletroquímicas da liga $\operatorname{Pr}_{0,7} \mathrm{Mg}_{0,3} \mathrm{Al}_{0,3} \mathrm{Mn}_{0,4} \mathrm{Co}_{0,5} \mathrm{Ni}_{3,8}$ sem e com TT.

TABELA 43 - Absorção de hidrogênio obtidos das curvas de PCT para as ligas $\mathrm{La}_{0,7} \mathrm{Mg}_{0,3} \mathrm{Al}_{0,3} \mathrm{Mn}_{0,4} \mathrm{Co}_{0,5} \mathrm{Ni}_{3,8}$ $\mathrm{La}_{0,7} \mathrm{Mg}_{0,3} \mathrm{Al}_{0,3} \mathrm{Mn}_{0,4} \mathrm{Sn}_{0,5} \mathrm{Ni}_{3,8}$, $\mathrm{Pr}_{0,7} \mathrm{Mg}_{0,3} \mathrm{Al}_{0,3} \mathrm{Mn}_{0,4} \mathrm{Co}_{0,5} \mathrm{Ni}_{3,8} \quad$ sem TT $\mathrm{La}_{0,7} \mathrm{Mg}_{0,3} \mathrm{Al}_{0,3} \mathrm{Mn}_{0,4} \mathrm{Cu}_{0,5} \mathrm{Ni}_{3,8}$, $\mathrm{La}_{0,7} \mathrm{Pr}_{0,3} \mathrm{Al}_{0,3} \mathrm{Mn}_{0,4} \mathrm{Co}_{0,5} \mathrm{Ni}_{3,8}$

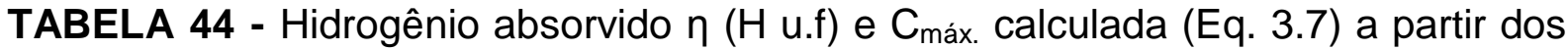
dados obtidos pela curva de PCT para as ligas sem TT.

TABELA 45 - Resultados obtidos das curvas de absorção do PCT das ligas $\mathrm{La}_{0,7} \mathrm{Mg}_{0,3} \mathrm{Al}_{0,3} \mathrm{Mn}_{0,4} \mathrm{Co}_{0,5} \mathrm{Ni}_{3,8} \quad\left(850^{\circ} / 16 \mathrm{~h}\right), \quad \mathrm{La}_{0,7} \mathrm{Mg}_{0,3} \mathrm{Al}_{0,3} \mathrm{Mn}_{0,4} \mathrm{Cu}_{0,5} \mathrm{Ni}_{3,8}\left(750^{\circ} \mathrm{C} / 16\right)$ $\mathrm{La}_{0,7} \mathrm{Mg}_{0,3} \mathrm{Al}_{0,3} \mathrm{Mn}_{0,4} \mathrm{Sn}_{0,5} \mathrm{Ni}_{3,8}\left(750^{\circ} \mathrm{C} / 16 \mathrm{~h}\right), \mathrm{La}_{0,7} \mathrm{Pr}_{0,3} \mathrm{Al}_{0,3} \mathrm{Mn}_{0,4} \mathrm{Co}_{0,5} \mathrm{Ni}_{3,8}\left(850^{\circ} \mathrm{C} / 16 \mathrm{~h}\right)$ e $\mathrm{Pr}_{0,7} \mathrm{Mg}_{0,3} \mathrm{Al}_{0,3} \mathrm{Mn}_{0,4} \mathrm{Co}_{0,5} \mathrm{Ni}_{3,8}\left(750^{\circ} \mathrm{C} / 9 \mathrm{~h}\right)$. 
TABELA 46 - Determinação da $\mathrm{C}_{\max }$ teórica a partir dos dados obtidos através da analise de PCT das ligas $\mathrm{La}_{0,7} \mathrm{Mg}_{0,3} \mathrm{Al}_{0,3} \mathrm{Mn}_{0,4} \mathrm{Co}_{0,5} \mathrm{Ni}_{3,8} \quad\left(850^{\circ} / 16 \mathrm{~h}\right)$, $\mathrm{La}_{0,7} \mathrm{Mg}_{0,3} \mathrm{Al}_{0,3} \mathrm{Mn}_{0,4} \mathrm{Cu}_{0,5} \mathrm{Ni}_{3,8}\left(750^{\circ} \mathrm{C} / 16\right) \quad \mathrm{La}_{0,7} \mathrm{Mg}_{0,3} \mathrm{Al}_{0,3} \mathrm{Mn}_{0,4} \mathrm{Sn}_{0,5} \mathrm{Ni}_{3,8} \quad\left(750^{\circ} \mathrm{C} / 16 \mathrm{~h}\right)$, $\mathrm{La}_{0,7} \mathrm{Pr}_{0,3} \mathrm{Al}_{0,3} \mathrm{Mn}_{0,4} \mathrm{Co}_{0,5} \mathrm{Ni}_{3,8}\left(850^{\circ} \mathrm{C} / 16 \mathrm{~h}\right)$ e $\mathrm{Pr}_{0,7} \mathrm{Mg}_{0,3} \mathrm{Al}_{0,3} \mathrm{Mn}_{0,4} \mathrm{Co}_{0,5} \mathrm{Ni}_{3,8}\left(750^{\circ} \mathrm{C} / 9 \mathrm{~h}\right)$.

TABELA 47 - Resultados obtidos das curvas de absorção do PCT das ligas $\mathrm{La}_{0,7} \mathrm{Mg}_{0,3} \mathrm{Al}_{0,3} \mathrm{Mn}_{0,4} \mathrm{Co}_{0,5} \mathrm{Ni}_{3,8} \quad 850^{\circ} / 16 \mathrm{~h}, \quad \mathrm{La}_{0,7} \mathrm{Mg}_{0,3} \mathrm{Al}_{0,3} \mathrm{Mn}_{0,4} \mathrm{Cu}_{0,5} \mathrm{Ni}_{3,8}, 750^{\circ} \mathrm{C} / 16$ $\mathrm{La}_{0,7} \mathrm{Mg}_{0,3} \mathrm{Al}_{0,3} \mathrm{Mn}_{0,4} \mathrm{Sn}_{0,5} \mathrm{Ni}_{3,8} \quad 750^{\circ} \mathrm{C} / 16 \mathrm{~h}, \quad \mathrm{La}_{0,7} \mathrm{Pr}_{0,3} \mathrm{Al}_{0,3} \mathrm{Mn}_{0,4} \mathrm{Co}_{0,5} \mathrm{Ni}_{3,8} 850^{\circ} \mathrm{C} / 16 \mathrm{~h}$ e $\mathrm{Pr}_{0,7} \mathrm{Mg}_{0,3} \mathrm{Al}_{0,3} \mathrm{Mn}_{0,4} \mathrm{Co}_{0,5} \mathrm{Ni}_{3,8} 750^{\circ} \mathrm{C} / 9 \mathrm{~h}$ com 4 ciclos de ativação...........................102

TABELA 48 - Determinação da $\mathrm{C}_{\max }$ calculada a partir dos dados obtidos através da analise de PCT após os 4 ciclos de ativações, com as ligas com tratamento térmico. 


\section{1 - INTRODUÇÃO}

Nos últimos 200 anos a forma de existir da humanidade tem sofrido drásticas mudanças neste planeta. Desde o início da revolução industrial as formas de produzir e consumir têm estado em expansão constante, e os novos produtos e serviços se introduzem na vida do homem.

A necessidade crescente por energia para atender as aplicações domésticas e industriais, conduziu o homem a utilizar energias não renováveis da terra, tais como carvão e petróleo, que durante muito tempo foram consideradas inesgotáveis.

Atualmente a geração de energia elétrica para as indústrias, residências e transportes dependem principalmente da aplicação de carvão, gás natural e petróleo. Entretanto, com o crescimento populacional aumentou o consumo de combustíveis fósseis e com isso agravou-se o problema da emissão de gases e de poluição ambiental.

Quase todo petróleo produzido pela natureza em milhões de anos foi consumido pela humanidade em apenas 100 anos por causa dessa dependência energética.

Há uma necessidade urgente por pesquisas voltadas a fontes de energias renováveis com eficiência energéticas, limpas e também novas tecnologias associadas com conversão de energia e estocagem. Com essa preocupação aumentou significativamente o número de pesquisas relacionadas à substituição do combustível fóssil por fontes de energia limpas e renováveis, o que inclui o hidrogênio, que é um vetor energético possível para uso diversificado, tanto em sistemas estacionários como em sistemas móveis. Todavia, ainda há um grande número de desafios em aberto, onde as limitações, objetivos e a própria eficiência impulsionam este campo, principalmente no setor de transportes que é fortemente motivado por questões ambientais.

Existem novas aplicações mais efetivas como tecnologias para conversão e estocagem de energia associadas às energias renováveis tais como a solar e eólica, sendo estas armazenadas em baterias para uso posterior. 
Quando necessário, a energia armazenada é convertida em energia elétrica, podendo adequá-las para uma grande variedade de aplicações: desde baterias de grande porte como fontes estacionárias de geração de energia, médio porte onde baterias de Ni-HM têm destaque em aplicação automotiva, a qual é utilizada para alimentar o motor elétrico para veículos elétricos ou híbridos, tendo como vantagem desta aplicação a faixa de temperatura de operação $\left(-30^{\circ} \mathrm{C} \mathrm{a}+75^{\circ} \mathrm{C}\right)$, até as baterias de pequeno porte para aplicação em dispositivos de uso domésticos e eletroeletrônicos, tais como telefones celulares e computadores portáteis (Young, et al., 2014 e Fiori, et al., 2015).

$\mathrm{O}$ uso de ligas metálicas tipo $\mathrm{LaNi}_{5}$ para aplicação em baterias de $\mathrm{Ni}-\mathrm{HM}$, vem sendo objeto constante de estudo, cujo foco principal são as substituições parciais na composição das ligas e tratamentos térmicos pois estes alteram consideravelmente a microestrutura dessas ligas influenciando na capacidade de armazenamento de hidrogênio, capacidade máxima de descarga e na capacidade de retenção cíclica.

A aplicação mais bem sucedida dos hidretos metálicos de terras raras do tipo $A B_{5}$, é sua utilização como material ativo do eletrodo negativo (ânodo) de uma bateria de Ni-HM. 


\section{1 - Panorama Atual}

As grandes potências mundiais têm atualmente, mais que uma preocupação e sim uma necessidade de novas fontes de geração de energia para atender a demanda em sua cadeia produtiva. Desta forma estão reorientando a sua matriz de geração energética, direcionando suas pesquisas para as novas tecnologias e materiais para aplicação em baterias de $\mathrm{Ni}-\mathrm{MH}$, sendo ultimamente o foco de muitas pesquisas por todo o planeta, onde estas tem que atender uma série de requisitos básicos para aplicação tanto como fontes secundarias para uso em automóveis híbridos e elétricos quanto como fontes estacionarias de geração de energia.

O que torna mais interessante é que na matéria publicada pela revista Galileu em abril de 2018, o governo japonês divulgou recentemente na revista Nature, a descoberta de uma reserva mineral de terras raras, na llha de Minamitorishima, localizada no Oceano Pacífico. De acordo com os autores do estudo, há minerais suficientes para atender a demanda global. Por exemplo, há ítrio para cerca de 780 anos, disprósio para 730 anos, európio para 620 anos e térbio para 420 anos. Com esta descoberta poderá promover maior interesse na direção de baterias de $\mathrm{Ni}-\mathrm{MH}$.

Embora aplicações de baterias de Ni-MH já sejam uma realidade, e estão sendo introduzidas como fontes estacionárias de alimentação de energia, em vários programas que estão em funcionamento em empresas no setor público japonês para validar o desempenho do sistema Battery Power System (BPS) com baterias de $\mathrm{Ni}-\mathrm{MH}$ em instalações de energia renovável ligadas à rede de fornecimento de energia elétrica.

A empresa Kansai Electric Power Company (KEPC) projetou e instalou em 2010, na região próximo da cidade de Osaka no Japão o sistema mais antigo, apresentado na FIGURA 1, que consiste em uma bateria que produz $102 \mathrm{~kW} . \mathrm{h}$, e ao lado uma usina solar que gera $10 \mathrm{MW}$ e alimenta a unidade de produção de energia elétrica. 
FIGURA 1 - Usina solar e a estação de baterias de Ni-MH com sistema BPS instalada em uma região próximo Osaka, Japan
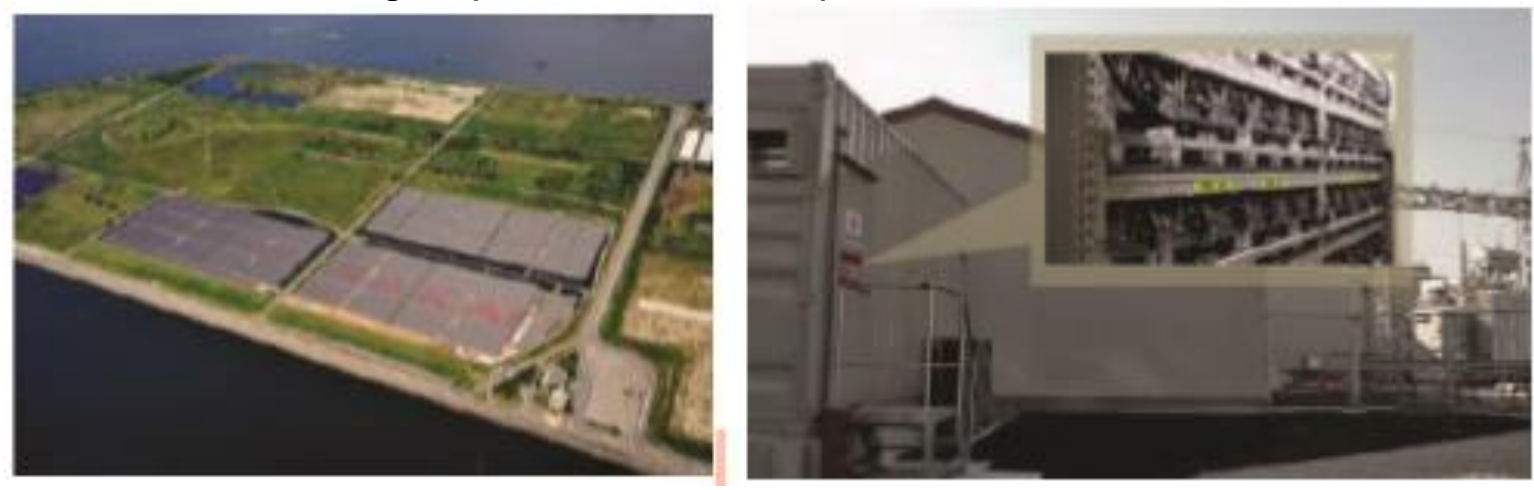

A Autoridade de Transito Metropolitano da área de Washington (WMATA), apresentou em 2015 já em operação, uma unidade estacionaria de baterias de $\mathrm{Ni}-\mathrm{MH}$ na estação de West Falls Church, para alimentar a linha laranja do metrô como esta mostrando na FIGURA 2.

A empresa Kawasaki Heavy Industries desenvolveu a tecnologia (BPS) que produz 400 MW.h, especificamente para aplicações ferroviárias e de trânsito.

FIGURA 2 - Instalação da subestação da rede de alimentação da linha do metro de West Falls Church (BPS).

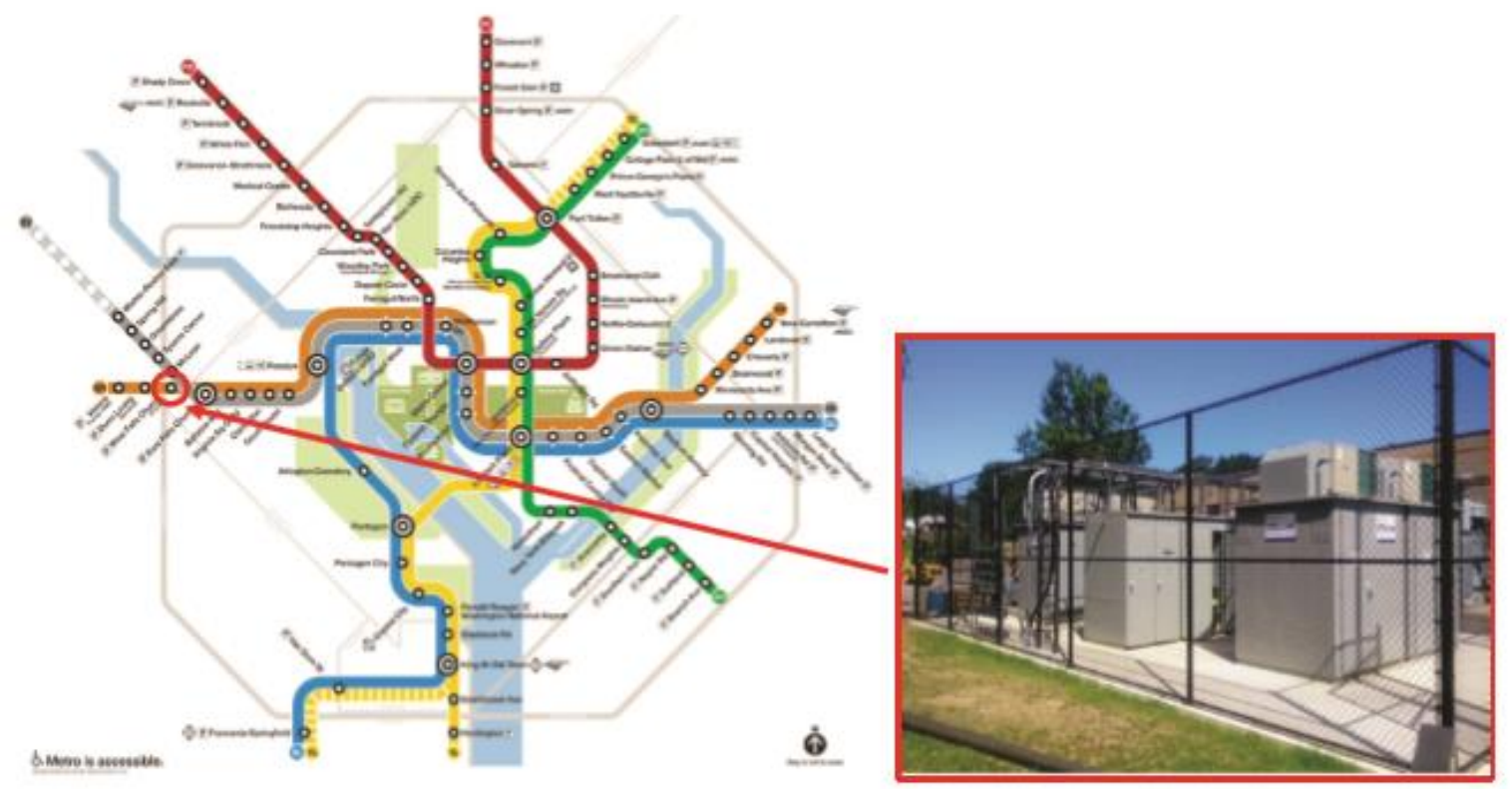

Fonte: Washington Metropolitan Area Transit Authority (WMATA)

Diversas instalações de demonstração e comerciais estão em operação no ambiente ferroviário e de trânsito, incluindo o Departamento de Transporte Municipal 
de Osaka, o Monotrilho de Tóquio, a Ferrovia do Leste do Japão e o Metrô de Nova York.

No mesmo sentido em aplicações de baterias, mas de médio porte para veículos, o circuito de competições automotivas a Federação Internacional de Automobilismo (FIA) criou a Formula E (FE), conforme mostra na FIGURA 3, nada mais do que uma transição para adaptação da Formula 1 (F1), para a concepção de novos conceitos de veículos movidos a motores elétricos, onde um dos seus diretores, declarou que os motores usados hoje na F1 são motores híbridos e possuem um sistema regenerativo, e a perspectiva é de que em aproximadamente cinco anos a competição acontecerá somente com os motores elétricos, portanto o que era esperado e foi uma ideia hoje se tornou uma realidade na aplicação no setor automotivo.

FIGURA 3 - Carro de competição da FE, com motor elétrico.

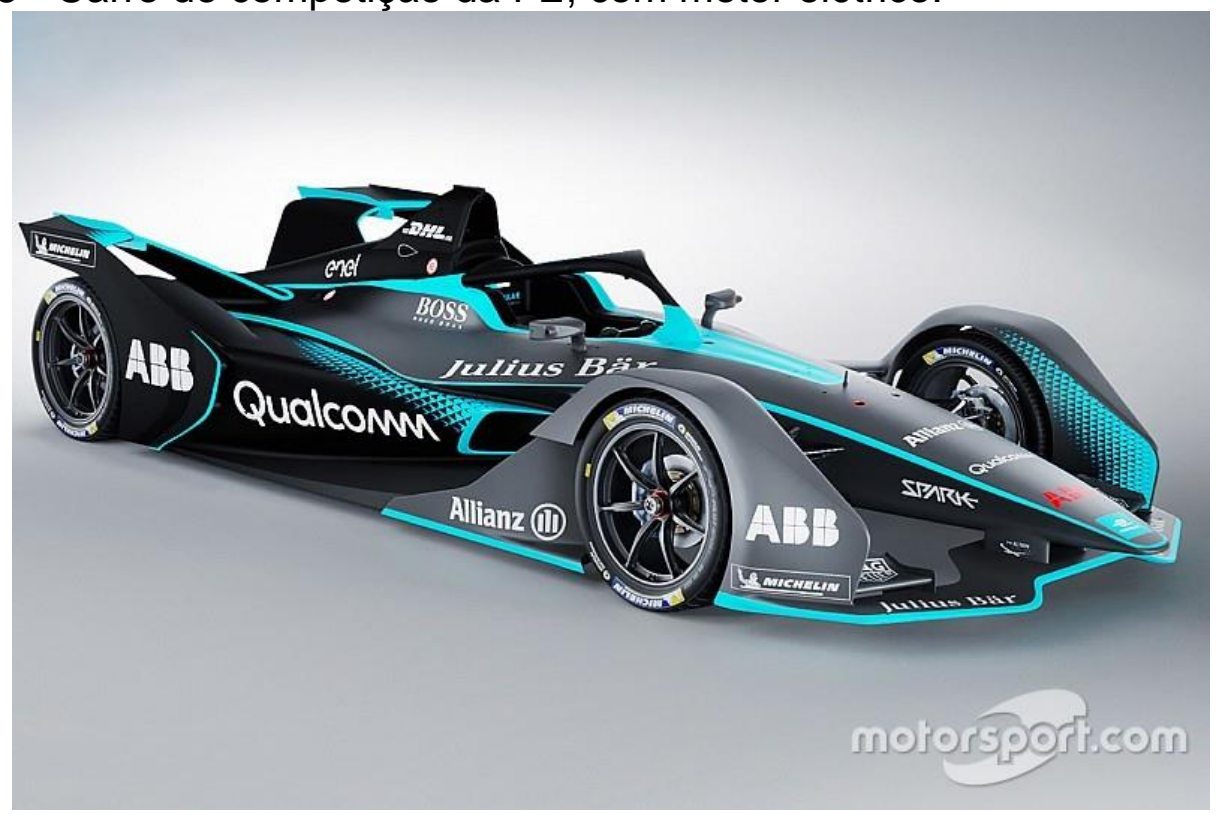

Todas as empresas neste setor estão apresentando e colocando no mercado os seus modelos com este conceito de motor elétrico conforme o reportado pela Associação Nacional dos Fabricantes de Veículos Automotores. (ANFAVEA) e apresentado FIGURA 4.

Diversos países já marcaram data para o fim da produção de carros movidos apenas à gasolina ou diesel. Na Noruega e na Holanda, a indústria não poderá 
colocar esses carros em circulação a partir de 2035. Na Áustria e na Índia, 2030. Na Inglaterra e na França, 2040.

FIGURA 4 - Comparativo entre a frota de veículos com motores elétricos existentes nos países até 2017.

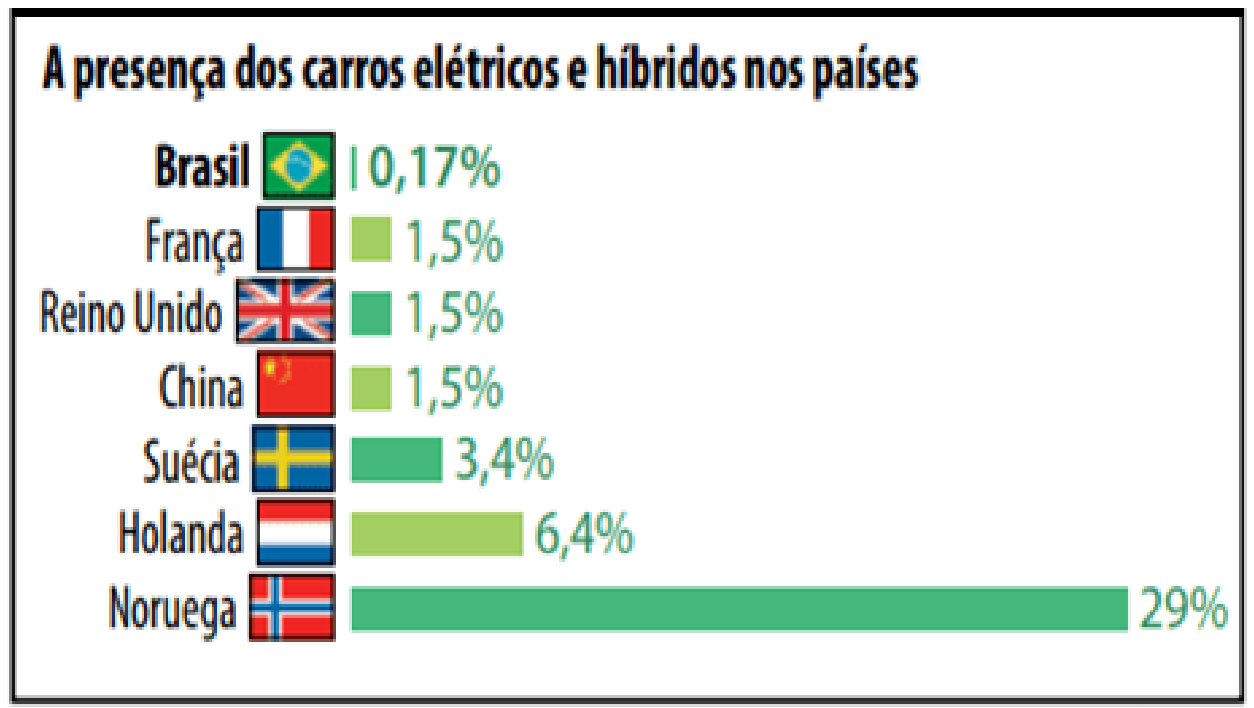

Fontes: Anfovea e Agencia Internacional de Energia

Hoje no Brasil existe projeto de lei que tramita no Senado a PLS 304/2017, o qual fixa prazo até 2030 para as montadoras, para que ocorra a mudança de tecnologia de veículos movidos por motores a combustão para veículos movidos por motores elétricos ou híbridos.

Não há dúvida: a propulsão do carro do futuro é com motor elétrico, em poucos anos se tornara viável e popular. Observando que o mesmo aconteceu com o telefone celular, surgiu como um artigo de luxo, muito caro, tanto na aquisição quanto na utilização, mas se popularizou em pouco tempo.

Segundo dados obtidos do jornal Empresas \& Negócios publicado em 12 de junho de 2018, a tecnologia não é exatamente nova, faz duas décadas que o motor elétrico chegou ao mercado conforme o gráfico mostrado na FIGURA 5 pela revista Transport \& Environment projeta sobre a quantidade de modelos de carros com motor elétrico que estarão no mercado até o ano de 2021. 
Na Noruega, quase $29 \%$ dos veículos são elétricos ou híbridos. Na China, $1,5 \%$ da frota está nessa categoria nada menos do que 450 mil veículos. O Brasil ainda esta começando a passos lentos o processo de implantação de automóveis com motores híbridos ou elétricos na sua frota.

FIGURA 5 - Projeção para a quantidade de modelos de veículos com motores elétricos pelas principais montadoras até o ano de 2021.

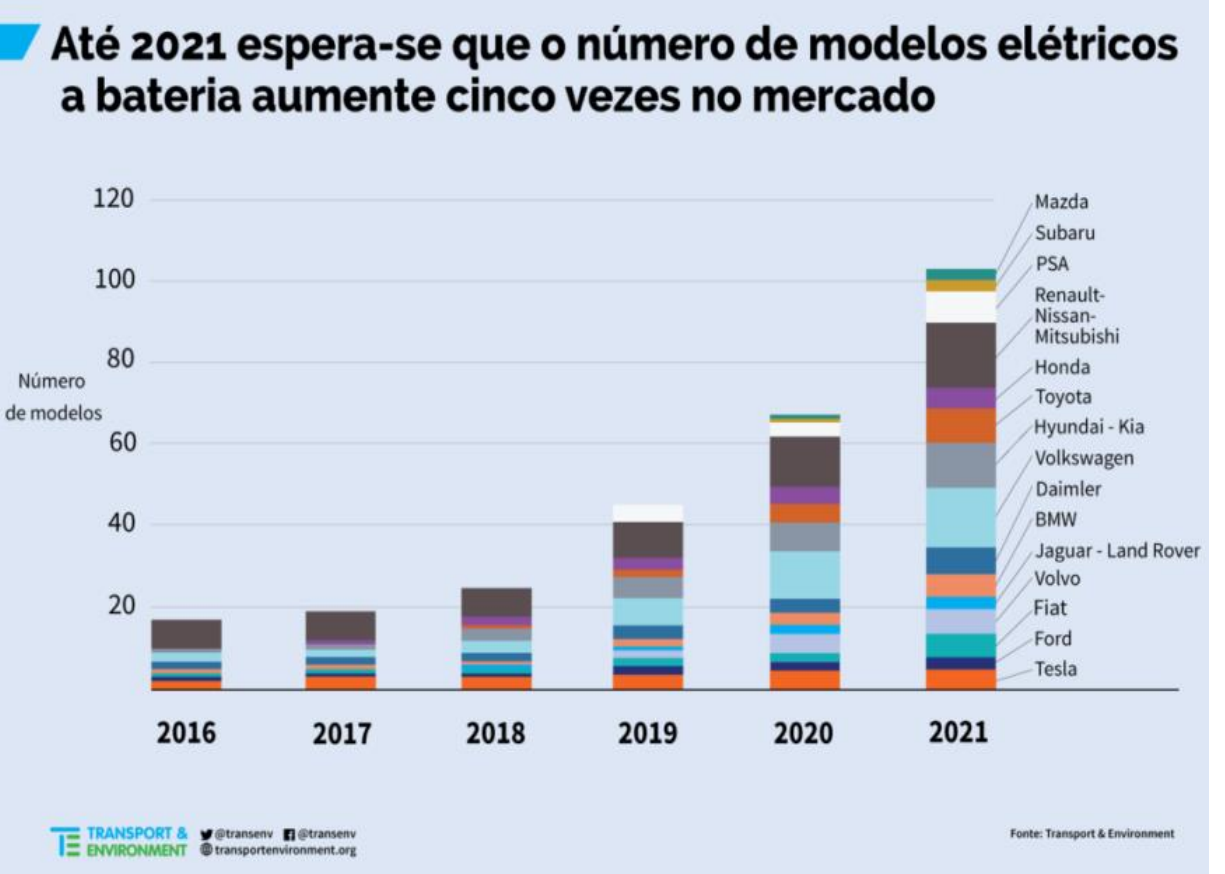




\section{2- OBJETIVO}

O objetivo deste trabalho foi o de avaliar o efeito da substituição parcial do $\mathrm{Ni}$ pelos elementos químicos $\mathrm{Co}, \mathrm{Cu}$ e $\mathrm{Sn}$, e do La e Mg pelo Pr em ligas do tipo $\mathrm{AB}_{5}$ formando as ligas nominais $\mathrm{La}_{0,7} \mathrm{Mg}_{0,3} \mathrm{Al}_{0,3} \mathrm{Mn}_{0,4} \mathrm{Co}_{0,5} \mathrm{Ni}_{3,8}$ $\mathrm{La}_{0,7} \mathrm{Mg}_{0,3} \mathrm{Al}_{0,3} \mathrm{Mn}_{0,4} \mathrm{Cu}_{0,5} \mathrm{Ni}_{3,8}, \quad \mathrm{La}_{0,7} \mathrm{Mg}_{0,3} \mathrm{Al}_{0,3} \mathrm{Mn}_{0,4} \mathrm{Sn}_{0,5} \mathrm{Ni}_{3,8}$, $\mathrm{La}_{0,7} \mathrm{Pr}_{0,3} \mathrm{Al}_{0,3} \mathrm{Mn}_{0,4} \mathrm{Co}_{0,5} \mathrm{Ni}_{3,8}$ e $\operatorname{Pr}_{0,7} \mathrm{Mg}_{0,3} \mathrm{Al}_{0,3} \mathrm{Mn}_{0,4} \mathrm{Co}_{0,5} \mathrm{Ni}_{3,8}$. sem e com tratamento térmico de $750^{\circ}$ e $850^{\circ} \mathrm{C}$ por 9 e 16 horas, nas características microestruturais, capacidade de absorção de hidrogênio, desempenho eletroquímicos das ligas como material ativo do eletrodo negativo. Observar o comportamento das ligas sem e com tratamentos térmicos na análise das curvas de Pressão-ComposiçãoTemperatura (PCT), com as características composicionais e estruturais observadas. As baterias fabricadas com material ativo (ligas) nos eletrodos negativos foram submetidas por 50 ciclos galvanostáticos de carga/descarga, sendo analisados parâmetros como ativação, capacidade de descarga máxima, estabilidade cíclica. Considerando a forte dependência dos parâmetros eletroquímicos nas características do material ativo do eletrodo negativo, adicionalmente à microestrutura e à composição utilizando as técnicas de microscopia eletrônica de varredura/espectroscopia por dispersão de energia de raios $\mathrm{X}$, (MEV/EDS). A caracterização das ligas incluiu estudos referentes à estrutura cristalina (por difração de raios $X$ com refinamento com método de Rietveld), utilizando para identificação das fases o programa CrystallographicaSearch Match versão 2.4 (CSM, PDF 2002) e para refinamento para obtenção dos parâmetros de rede das fases existentes na microestrutura da liga 0 programa General Structure Analysis System (GSAS) 


\section{3 - REVISÃO DA LITERATURA}

\section{1 - Hidretos metálicos}

Hidreto metálico foi definido pela primeira vez por Gibb, T. R. em 1948, da seguinte maneira: "é um composto que possui ligação hidrogênio-metal ou hidrogênio-metaloide", onde o tipo de ligação que é exibido pela maioria dos hidretos é a metálica e possuem alta condutividade térmica e elétrica.

As propriedades químicas, metalúrgicas e tecnológicas dos hidretos são aplicadas nos desenvolvimentos mais recentes. Em 1958, Libowitz et al. descobriram que o composto intermetálico ZrNi pode formar um hidreto ternário, $\mathrm{ZrNiH}_{3}$, o qual, além de ser reversível, tem estabilidade intermediária em relação a seus respectivos hidretos binários, ou seja, o muito estável $\mathrm{ZrH}_{2}$ e o muito instável $\mathrm{NiH}$. Esta descoberta permitiu não apenas um aumento significativo no número de hidretos possíveis, como também melhorar as propriedades e características dos mesmos. No final dos anos 60, com os trabalhos de: Reilly e Wiswall (1974) e Van Vucht et. al (1970), foram descobertos, os hidretos de TiFe e $\mathrm{LaNi}_{5}$ respectivamente. Hidretos que se formam a pressões moderadas e à temperatura ambiente e, apesar de absorverem cerca de 1,5\% em massa de hidrogênio, são utilizados até hoje em sistemas armazenadores.

A FIGURA 6 mostra que quase todos os elementos da tabela periódica podem ser classificados de acordo com a sua afinidade com o hidrogênio. Nesta classificação, há uma separação entre os elementos com elevada (A) ou baixa afinidade (B) com hidrogênio (Sandrock, 1999). 
FIGURA 6 - Tabela periódica dos elementos, onde: em vermelho estão representados os elementos formadores de hidretos estáveis e em azul os elementos formadores de hidretos instáveis (Zutell, 2007; Dornheim 2011).

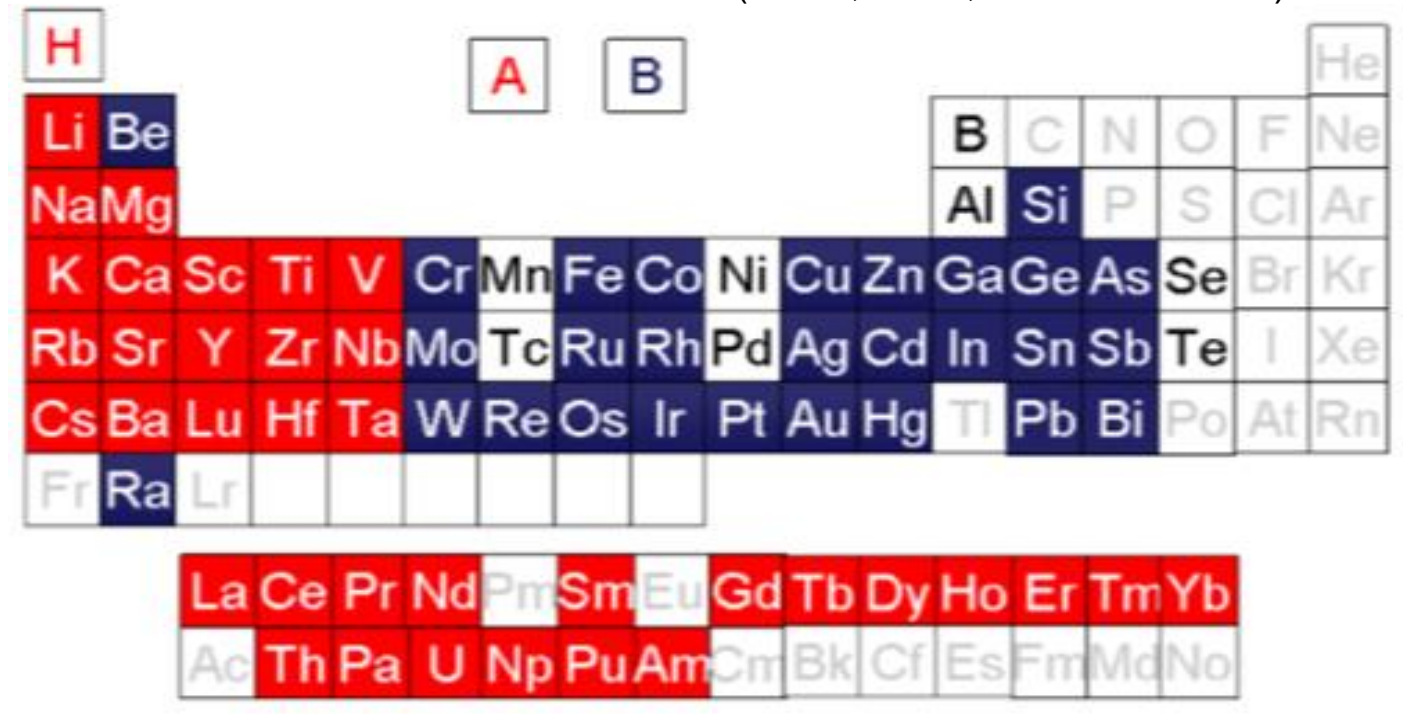

Os elementos do tipo $\mathbf{A}$ formam hidretos termodinamicamente estáveis à pressão e temperatura ambiente, que são as terras raras (TR) e alguns metais de transição. Os elementos do tipo $\mathbf{B}$ com baixa afinidade com hidrogênio. As ligas são constituídas por misturas de elementos do tipo $A$ e $B$ que têm propriedades intermediárias e podem, no caso das composições escolhidas, absorver e dessorver hidrogênio formando um composto intermetálico $A_{a} B_{b}$ que pode reagir reversivelmente com hidrogênio criando um hidreto intermediário $A_{a} B_{b} H_{x}$. Conforme o apresentado na FIGURA 7, os compostos intermetálicos de uso comum são classificados em termos de sua composição estequiométrica em quatro categorias: $A B_{5}, A B_{2}, A B$ e $A_{2} B$ (Schlapbach, L. 1992; Buschow et al, 1982).

Ligas da categoria $A B_{5}$ possuem estrutura hexagonal enquanto as $A B_{2}$ possuem estrutura cúbica. Estas duas categorias são comumente utilizadas para aplicação em baterias de Ni-HM e constantemente são estudadas substituindo ou adicionando elementos formando ligas multicomponentes.

A mudança de elementos permite alterar características específicas, tais como: parâmetro de rede da liga, pressão de equilíbrio de hidrogênio, prevenir formação de óxidos, resistência à corrosão, dentre outros. 
O grande avanço na tecnologia dos hidretos veio no final da década de 1960, com pesquisas na absorção de hidrogênio em ligas do tipo TiFe e $\mathrm{LaNi}_{5}\left(\mathrm{AB}_{5}\right)$ e os resultados mostraram que estes dois tipos de ligas metálicas podem absorver grandes quantidades de hidrogênio (Reilly et al., 1974; Zilstra et al, 1969).

FIGURA 7 - Diagrama de blocos demonstrando as principais ligas e complexos que formam o hidreto metálico (adaptado de Sandrock,1999).

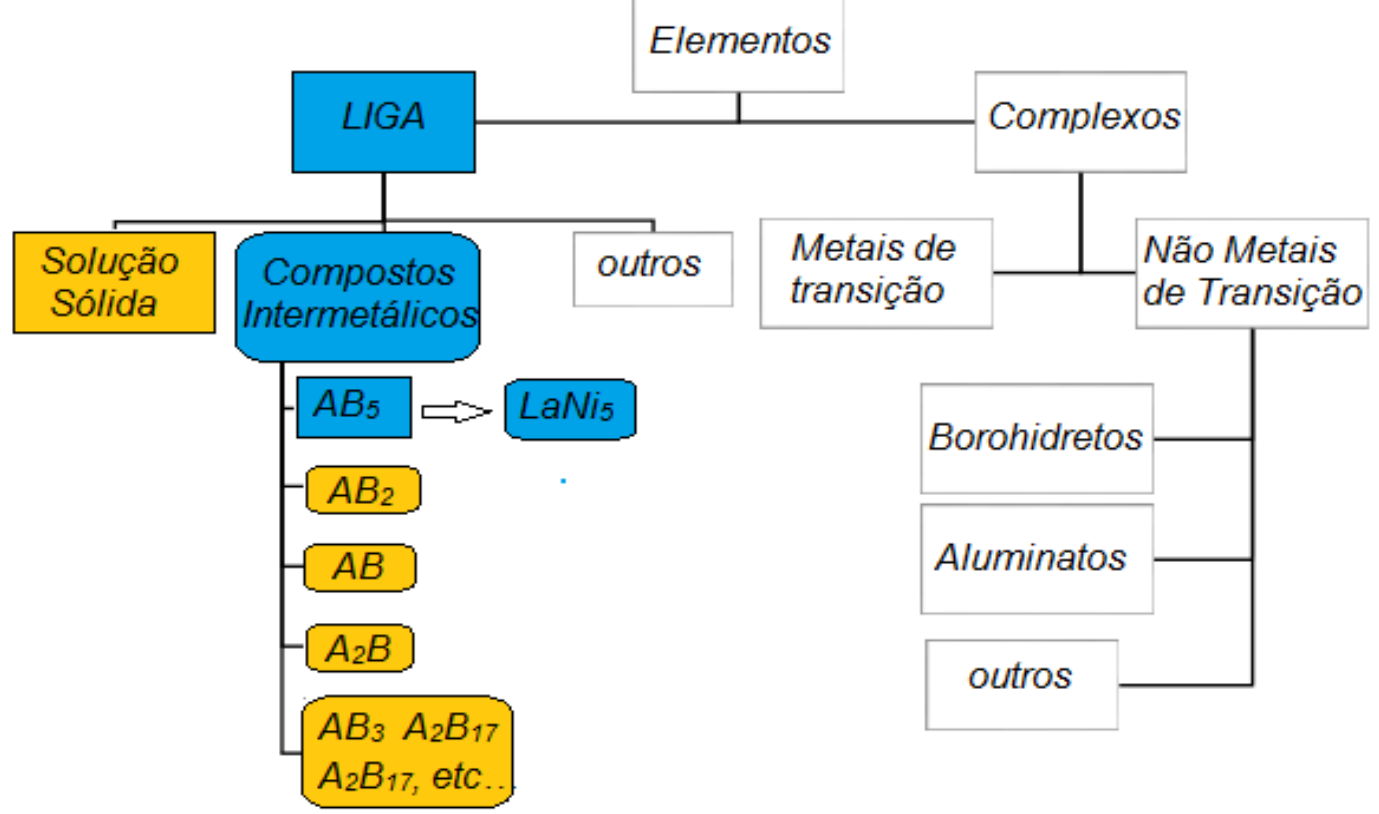

Um novo campo científico e tecnológico foi aberto o qual é chamado de "ligas de armazenamento de hidrogênio". A partir daí estas ligas começaram a ser estudadas em eletrodos negativos em baterias de níquel hidreto metálico, utilizando compostos intermetálicos tais como TiNi e $\mathrm{Ti}_{2} \mathrm{Ni}$ (Justi et al, 1970; Gutjahr et al, 1973), $\mathrm{LaNi}_{5}$ por (Ewe et al,1973) e LaNi ${ }_{5-x} \mathrm{M}_{\mathrm{x}}(\mathrm{M}=\mathrm{Cu}, \mathrm{Al}$, Mn e Cr) por Bronoel et al, 1976). No entanto, esta nova aplicação inicialmente não estimulou muito interesse cientifico e industrial, devido ao baixo desempenho, alto custo para fabricação das ligas e baixo mercado.

No inicio da década de 80 , com o rápido crescimento das áreas de comunicação, computação e eletroeletrônicos surgiu uma necessidade no desenvolvimento de baterias com alta densidade de armazenamento, levando a um crescimento em larga escala na produção destas ligas (Sandrock, G.D., 1995; Kanda et al, 1991). A ciência e a tecnologia de hidretos metálicos reversíveis são temas principais de grandes estudos. O estudo da hidrogenação de ligas para 
aplicação em baterias de Ni-HM pode ser realizado por dois processos, eletroquímico e físico.

Onde o processo eletroquímico consiste em testes destas ligas como eletrodos negativos de baterias de $\mathrm{Ni}-\mathrm{HM}$ e o processo físico em expor o material diretamente a uma atmosfera de hidrogênio (Chen, J. 1999).

Vucht et al (1970), relataram pela primeira vez as propriedades de hidrogenação da liga $\mathrm{LaNi}_{5}$. Eles determinaram que este composto poderia ser facilmente hidrogenado obtendo 6 átomos de hidrogênio por formula unitária $(H / f . u)$, a temperatura ambiente e pressão de 2 bar de hidrogênio.

Os teste com a liga $\mathrm{LaNi}_{5}$ como eletrodo negativo em baterias de $\mathrm{Ni}-\mathrm{HM}$ exibiu alta pressão de equilíbrio de hidrogênio, mas contra partida um baixo número de ciclos para aplicação, igual aos de baterias para aplicações comerciais. A perda da capacidade de descarga em função do número de ciclos das baterias foi atribuída a decomposição da liga em $\mathrm{La}(\mathrm{OH})_{3}$ e partículas de níquel.

Segundo Cassini (2011) e Galdino (2011), relataram ligas pseudo-binárias (ligas multicomponentes) podem ser obtidas a partir da liga $\mathrm{LaNi}_{5}$ do tipo $\left(\mathrm{AB}_{5}\right)$, substituindo parte dos elementos do tipo A lantânio (La) por outras terras raras ou B níquel (Ni) por outros metais de transição. As substituições de elementos envolvem modificações termodinâmicas na formação dos hidretos (pressão de equilíbrio e capacidade de descarga). 


\section{2 - Cinética de formação dos hidretos metálicos}

Zuttel em 2002 descreve o processo de formação de hidretos metálicos é proveniente da absorção de hidrogênio em metais, Schlapbach em 1992 descreve como fenômenos de superfície como apresentado na FIGURA 8, por seis etapas distintas.

FIGURA 8 - Etapas da absorção de hidrogênio em metais, na formação do hidreto.

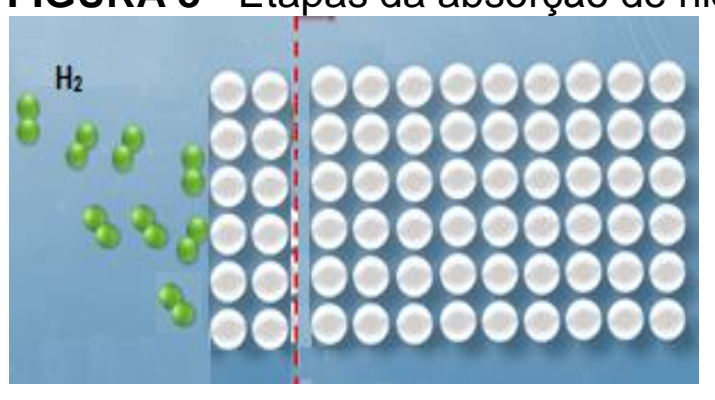

$1^{\text {a }}$ - Interação

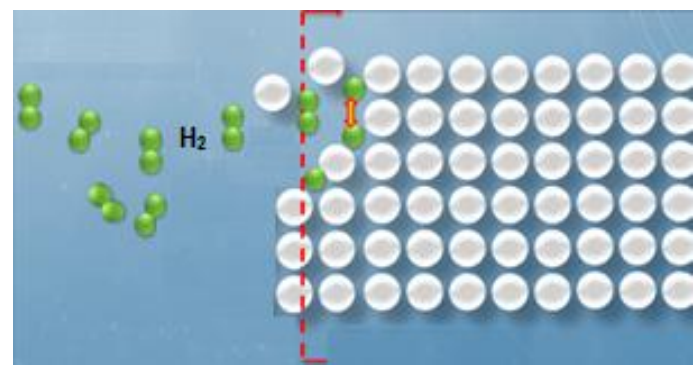

3a - Absorção Química

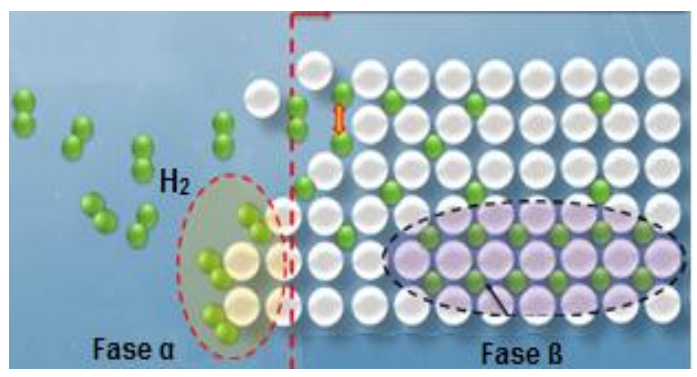

5a - Solução Sólida

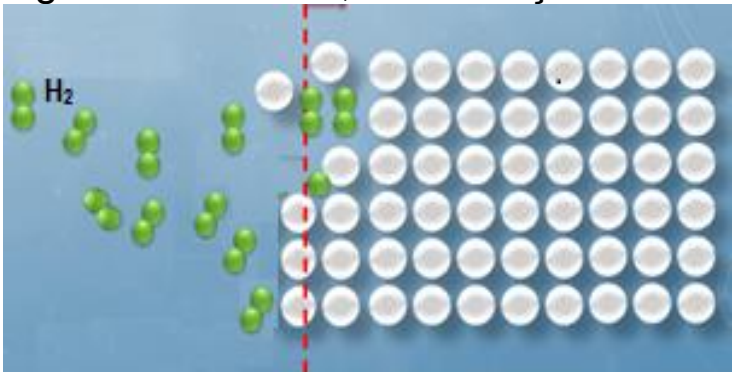

2a - Absorção Física

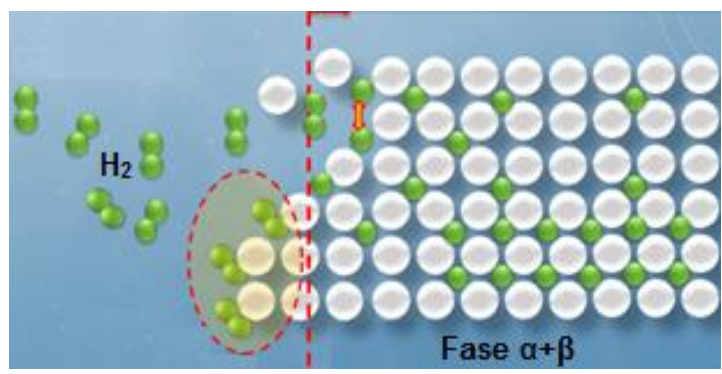

$4^{\mathrm{a}}$ - Difusão

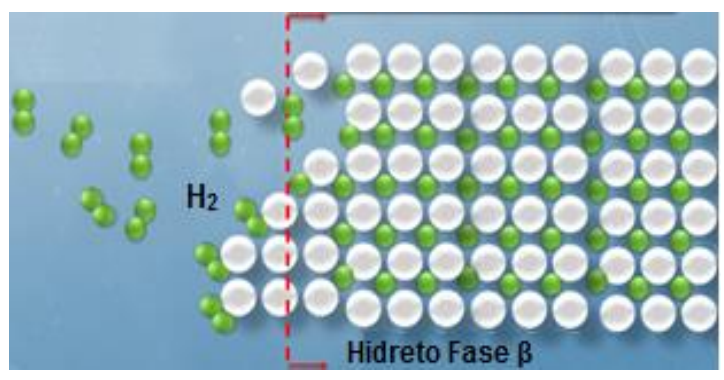

6 - Hidreto

Adaptado de Ribeiro E.S. 2016

Inicialmente observam-se duas partes distintas separadas: metal e gás de hidrogênio. Na segunda etapa as moléculas de hidrogênio estão sendo adsorvidas (van der Waals). Na terceira etapa as moléculas de hidrogênio interagem com os 
elétrons na superfície do metal, e se ligam e se dissociam na superfície do metal para formar o estado de adsorção química. $O$ hidrogênio se difunde na rede cristalina do metal formando solução sólida $(\alpha), 4^{\circ}$ e $5^{\circ}$ etapas. Finalmente, ocorre a expansão da célula unitária e o hidreto $(\beta)$ é formado ( $6^{\circ}$ etapa)

Em 2017 Møller e colaboradores, estudaram a absorção pratica e teórica do hidrogênio onde relataram que hidretos metálicos são hidretos intersticiais, nos quais o hidrogênio ocupa os sítios octaédrico e / ou tetraédrico na estrutura metálica, e que a formação de hidretos metálicos resultará em uma expansão da rede metálica em até 20 - 30 vol\%.

$\mathrm{LaNi}_{5}$, um exemplo representativo de uma liga do tipo $A B_{5}$, foi encontrado para ter a capacidade de absorver e liberar hidrogênio em temperatura e pressão ambiente onde sua composição química foi posteriormente modificada e usada como eletrodos negativos para baterias de $\mathrm{Ni}-\mathrm{MH}$, comercializadas em 1990. Metais e ligas com estrutura cúbica centrada no corpo (CCC) têm estruturas menos compactas quando comparadas com estruturas de face cúbica (CFC) e hexagonal compacta (HCP). Entre os hidretos metálicos conhecidos, as ligas de CCC atingem a maior capacidade de hidrogénio reversível, isto é, até 3\% em peso à temperatura ambiente. Vários tipos de hidretos metálicos foram desenvolvidos com o objetivo de aumentar a capacidade de armazenamento de hidrogênio e melhorar as propriedades termodinâmicas e cinéticas.

Os hidretos metálicos com propriedades apropriadas de absorção e liberação de hidrogênio próximo à temperatura ambiente também são bons candidatos para o armazenamento estacionário de energia, uma solução promissora para o uso eficiente de energias renováveis.

\subsection{1 - Isotermas de Pressão-Composição-Temperatura (PCT)}

Uma das propriedades termodinâmicas dos hidretos é geralmente obtida com a medição da pressão de equilíbrio de hidrogênio em função da quantidade de hidrogênio absorvida $(\mathrm{H} / \mathrm{M})$ a uma determinada temperatura. Esta análise é realizada através de gráficos conhecidos como curvas isotermas de pressãocomposição (PCT), que estabelecem uma relação entre concentração de hidrogênio, pressão e temperatura para o sistema metal hidrogênio. 
No sistema ocorre a formação de duas fases diferentes: a fase a (solução sólida) e a fase $\beta$ (fase hidreto), dependentes da concentração de hidrogênio dissolvida no metal ( $5^{\circ}$ e $6^{\circ}$ etapas da FIGURA 8). A FIGURA 9 ilustra a formação do hidreto a partir da curva P-C-T em seu comportamento ideal.

A ativação é o procedimento necessário para hidretar um metal pela primeira vez e levá-lo à cinética onde se da a capacidade máxima de absorção de $\mathrm{H}_{2} \mathrm{e}$ posterior ocorrendo a dessorção, promovendo um ciclo de hidretação/desidretação representado na FIGURA 9. A facilidade de introdução inicial de hidrogênio depende de estruturas e barreiras superficiais, tais como espécies catalíticas de dissociação e filmes de óxido.

Uma segunda ativação envolve o craqueamento interno em partículas de metal para aumentar a área da superfície de reação. Decrepitação significa diminuição de partículas grandes de metal em pó, um fenômeno comum que resulta de uma combinação entre a mudança de volume de hidretação e a natureza frágil de ligas absorvedoras de hidrogênio (especialmente quando elas já contêm $\mathrm{H}$ em solução).

FIGURA 9 - Um exemplo do perfil de pressão ao longo do tempo durante o ciclo de ativação de hidrogênio em um equipamento Sieverts (adaptado Lim et al 2017).

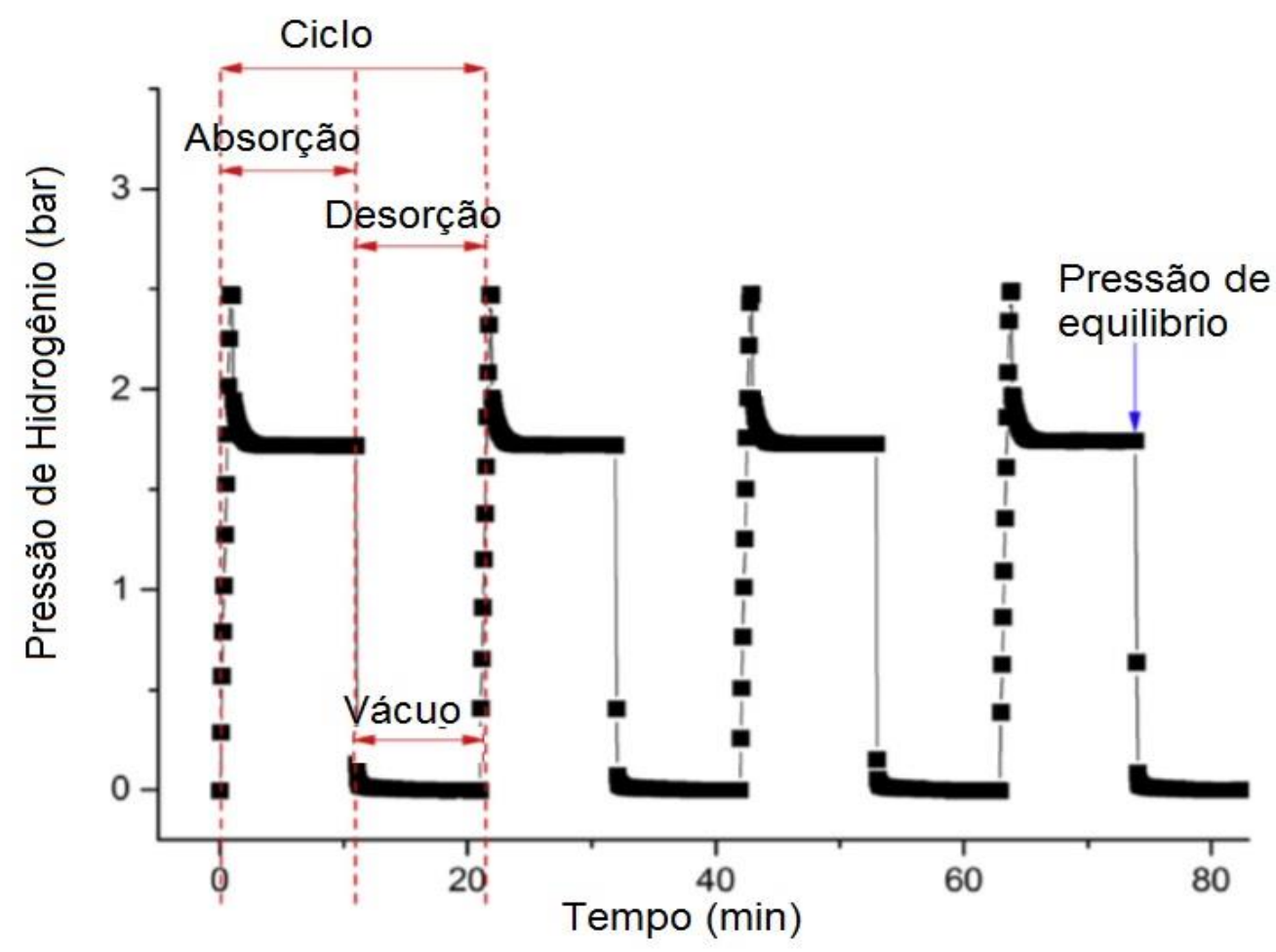


Para tal basta expor de forma direta a liga metálica ao hidrogênio perante certas condições de pressão e temperatura. O processo de absorção de hidrogênio em ligas metálicas pode ser descrito em cinco etapas:

1. Adsorção física das moléculas de hidrogênio;

$$
H_{2 g a s} \leftrightarrow H_{2 a d s}
$$

2. Dissociação das moléculas de hidrogênio;

$$
H_{2 a d s} \leftrightarrow 2 H_{a d s}
$$

3. Penetração na superfície pelos átomos de hidrogênio;

$$
2 H_{a d s} \leftrightarrow 2 H_{a d s}
$$

4. Difusão dos átomos de hidrogênio para o interior da rede do metal, por mecanismos intersticiais ou de lacunas.

5. Formação de hidreto na interface metal-hidreto. A formação do hidreto é um processo exotérmico de reação global (Eq. 3.3):

$$
\mathrm{M}+\frac{\mathrm{x}}{2} \mathrm{H}_{2} \Leftrightarrow \mathrm{MHx}+\Delta \mathrm{Q}
$$

Onde $\Delta Q$ representa o calor liberado durante a absorção de hidrogênio. $A$ absorção de hidrogênio pode alterar significantemente o volume da célula unitária $(\Delta \mathrm{V} / \mathrm{V})$ de 15 a $30 \%$. Esta rápida expansão provoca a pulverização das partículas após alguns ciclos de absorção/dessorção. Este fenômeno é denominado de decrepitação por hidrogênio. As propriedades termodinâmicas dos hidretos são geralmente obtidas através da medição da pressão de equilíbrio de hidrogênio em função da quantidade de hidrogênio absorvida (H/M) a uma determinada temperatura. Esta análise é realizada através de gráficos conhecidos como curvas isotermas de pressão-concentração de hidrogênio (PCT), que estabelecem uma relação entre concentração de hidrogênio, pressão e temperatura para o sistema metal hidrogênio. 
No sistema ocorre a formação de duas fases diferentes: fase a (solução sólida) e fase $\boldsymbol{\beta}$ (fase hidreto), dependentes da concentração de hidrogênio absorvidos no metal. A FIGURA 10 ilustra a formação do hidreto a partir da curva.

FIGURA 10 - (a) Curvas Pressão-Composição-Temperatura (PCT) para comportamento ideal com elevação da temperatura e (b) representação do decaimento logarítmico da pressão de equilíbrio de hidrogênio em função do inverso da temperatura. (lei de Van't Hoff) (Liao et 2004)

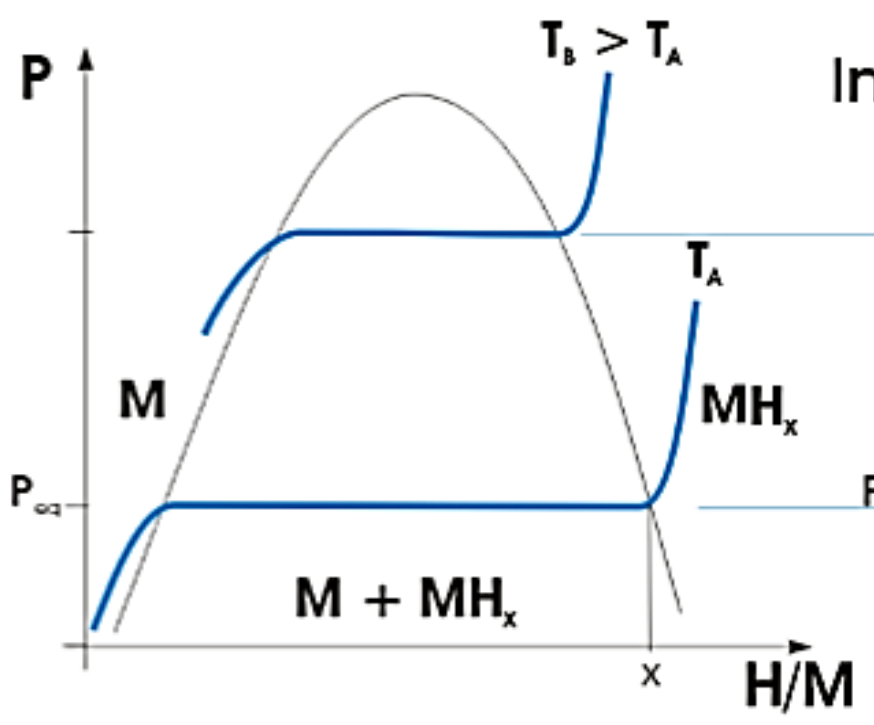

(a)

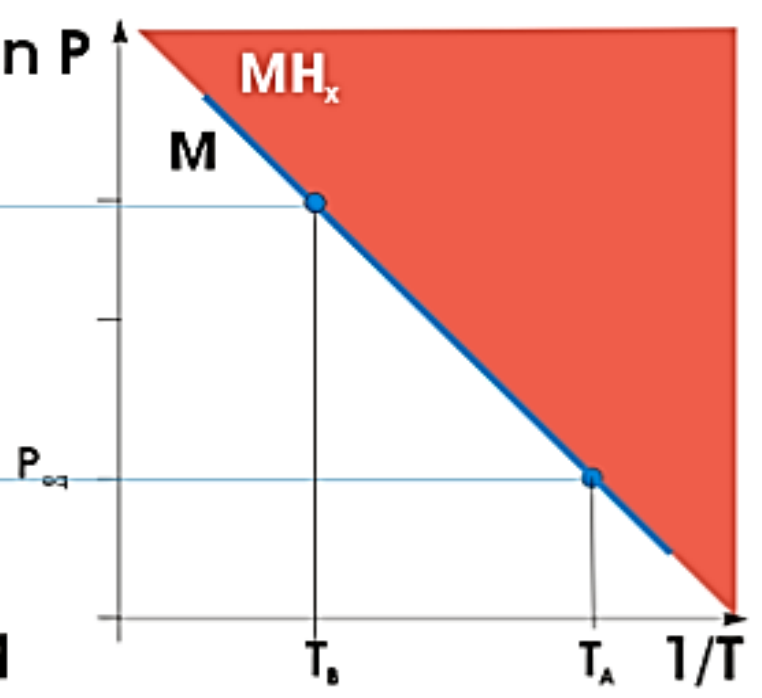

(b)

Através dos dados obtidos das isotermas PCT podemos obter o gráfico de $\ln \mathrm{P}\left(\mathrm{H}_{2}\right)$ versus $1 / T$, com isso é possível determinar os valores de $\Delta \mathrm{H}$ e $\Delta \mathrm{S}$, através dos coeficientes angulares e lineares, respectivamente, da curva resultante. Estas curvas permitem comparar os diferentes graus de estabilidade dos hidretos através de uma simples observação do grau de inclinação da curva plotada (Conceição, M.O. 2010). De fato, a maioria dos compostos intermetálicos que formam hidretos não apresentam isotermas com a formação perfeita de um platô de equilíbrio.

O processo de formação dos hidretos (absorção de hidrogênio) não é coincidente com o processo de dissociação dos hidretos (dessorção de hidrogênio), ou seja, fenômeno de histerese como apresentado na FIGURA 11 é obtido pelo deslocamento entre as curvas absorção e dessorção de hidrogênio. 
FIGURA 11 - Representação esquemática de isotermas de absorção e dessorção, considerando amostra real.

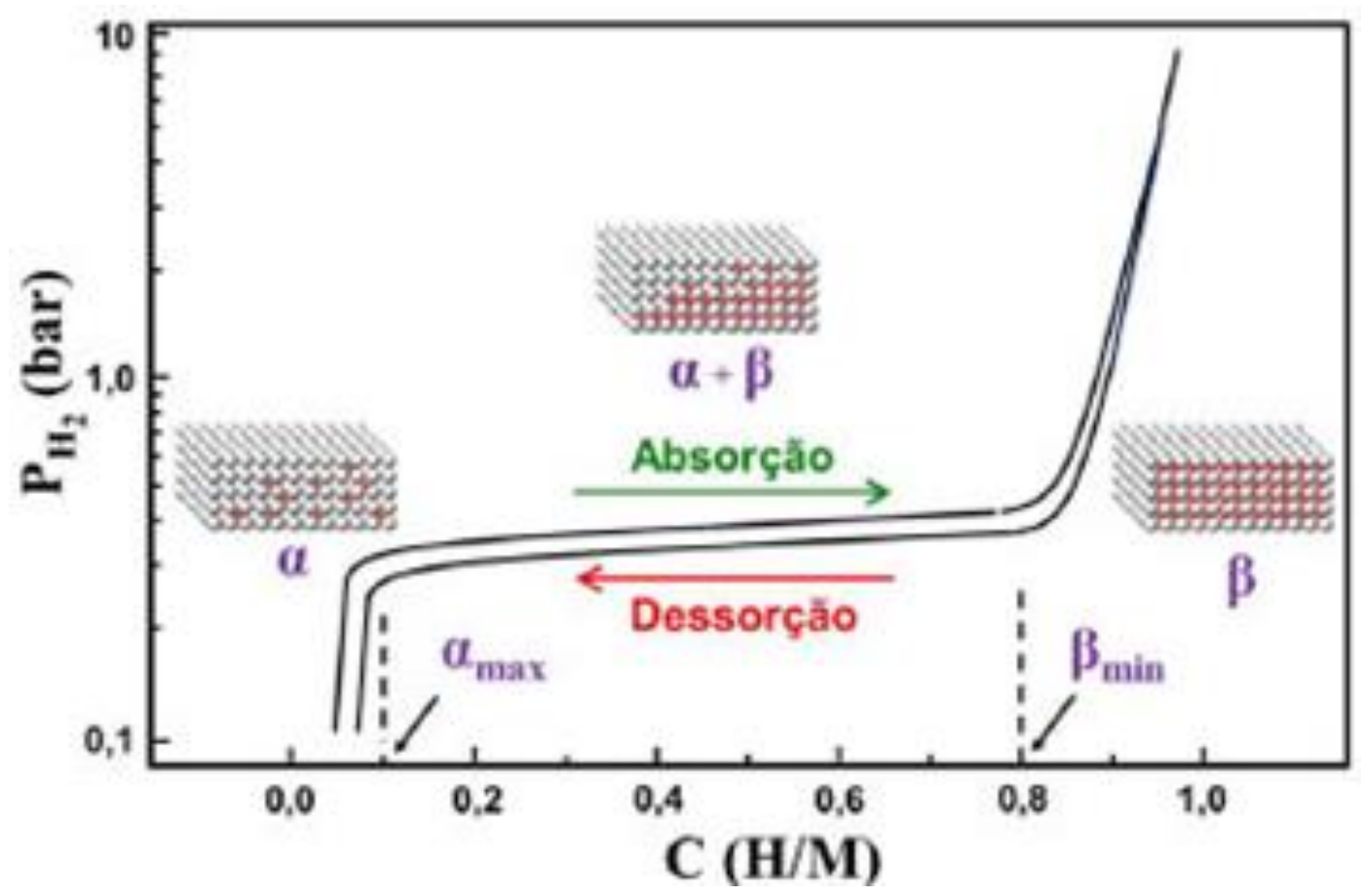

O fenômeno da histerese é manifestado pela não sobreposição das isotermas de absorção e dessorção de hidrogênio. A pressão de equilíbrio de dessorção (Pd) é menor que a pressão de equilíbrio de absorção (Pa). Isto é normalmente atribuído ao excesso de energia necessária para acomodar as limitações associadas à expansão do volume durante a formação do hidreto (Flanagan et al. 1982; Balasubramaniam, R. 1997). 


\section{3 - Baterias de Ni-HM}

O funcionamento teórico do processo que envolve a carga e a descarga das baterias desse tipo de Ni-HM, ou seja, absorção de hidrogênio na liga durante a carga e dessorção de hidrogênio na descarga, liberando elétrons neste último processo.

$\mathrm{Na}$ FIGURA 12, esta representando o processo de transferência de hidrogênio durante o ciclo de carga e descarga de uma bateria de Ni-HM.

FIGURA 12 - Diagrama de funcionamento de uma bateria de NI-HM (Liu et al 2011b).

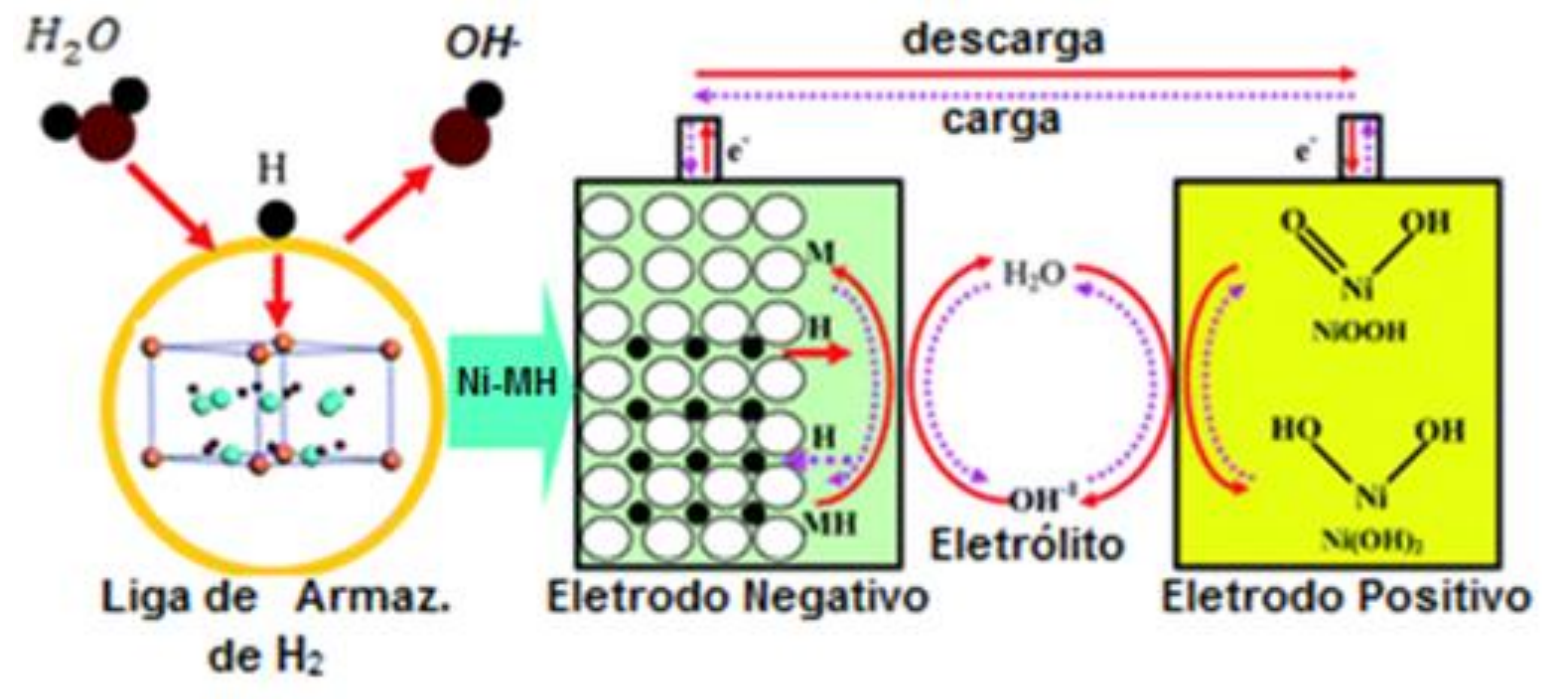

Durante o processo de carga de uma bateria de $\mathrm{Ni}-\mathrm{HM}$, no eletrodo positivo ocorre a combinação do $\mathrm{Ni}(\mathrm{OH})_{2}$ com o hidróxido $\left(\mathrm{OH}^{-}\right)$do eletrólito, gerando o oxihidróxido de níquel $(\mathrm{NiOOH})$, água $\left(\mathrm{H}_{2} \mathrm{O}\right)$ e um elétron $\left(\mathrm{e}^{-}\right)$.

No eletrodo negativo, a liga metálica $(\mathrm{M})$, a água do eletrólito e o elétron interagem para produzir o hidreto metálico (HM). No processo de descarga da bateria de Ni-HM as reações químicas são inversas das que ocorrem no processo de carga. O hidrogênio armazenado como hidreto metálico é liberado no eletrólito para formar água. 
A água do eletrólito libera um íon de hidrogênio que é absorvido pelo eletrodo positivo formando $\mathrm{Ni}(\mathrm{OH})_{2}$. As Eq. 3.4 e 3.5 mostram reações químicas reversíveis que ocorrem na carga e descarga do eletrodo positivo e negativo, respectivamente, e na Eq. 3.6 a reação global da bateria de Ni-HM, todos com respectivos potenciais (Souza, E.C. 2006).

Durante a descarga, no eletrodo positivo, o oxihidróxido de níquel III é reduzido a hidróxido de níquel II,

$\mathrm{NiOOH}+\mathrm{H}_{2} \mathrm{O}+e^{-} \Longleftrightarrow \mathrm{Ni}(\mathrm{OH})_{2}+\mathrm{OH} \quad E^{0}=0,52 \mathrm{~V}$

Enquanto que no eletrodo negativo, o hidreto metálico $\mathrm{MH}$ é oxidado para regenerar a liga metálica $\mathrm{M}$,

$\mathrm{MH}+\mathrm{OH}^{-} \quad \Longleftrightarrow \mathrm{M}+\mathrm{H}_{2} \mathrm{O}+e^{-} \quad E^{0}=0,83 \mathrm{~V}$

Sendo, a reação global de descarga da bateria de níquel-hidreto metálico dada pela reação:

$\mathrm{MH}+\mathrm{NiOOH} \Leftarrow \mathrm{M}+\mathrm{Ni}(\mathrm{OH})_{2} \quad E^{0}=1,35 \mathrm{~V}$

Durante a etapa de carregamento que, o hidrogênio dissocia do $\mathrm{Ni}(\mathrm{OH})_{2}$ então absorvido pela liga metálica. $\mathrm{Na}$ etapa de descarga, o átomo de hidrogênio é liberado da liga metálica e reage com $\mathrm{NiOOH}$ para formar $\mathrm{Ni}(\mathrm{OH})_{2}$. 


\section{4 - Correlações}

As propriedades de absorção e dessorção de hidrogênio em compostos intermetálicos são geralmente descritos pelas isotermas PCT, como mencionado anteriormente. Existe uma relação direta entre a pressão de equilíbrio de hidrogênio $\left(\boldsymbol{P}_{\boldsymbol{H} 2}\right)$ e o potencial do eletrodo de hidreto metálico $(\boldsymbol{E}(\boldsymbol{e}))$, representado pela Eq. 3.7.

$$
\mathbf{E}(\mathrm{e})=\frac{\mathrm{RT}}{\mathrm{nF}}+\ln P \mathrm{H}_{2}
$$

Onde:

$\mathbf{R}$ constante dos gases ideais,

T temperatura,

n número de elétrons envolvidos na reação e

F constante de Faraday (96.485 C).

A capacidade calculada $\left(\mathrm{C}_{\text {calc. }}\right)$ expressa em $\mathrm{mAh} \cdot \mathrm{g}^{-1}$ está relacionada à absorção de hidrogênio medida em uma reação gás-sólido (isotermas PCT) pela Eq. 3.8 (Willens 1984):

$$
C_{\text {calc. }}=\frac{6 \cdot\left(\mathrm{H} / \mathrm{M}_{\text {final }}-\mathrm{H} / \mathrm{M}_{\text {inicial }}\right) \cdot \mathrm{F}}{3,6 . \mathrm{Mw}}
$$

Para:

$\mathbf{6}\left(\mathrm{H} / \mathrm{M}_{\text {final }}-\mathrm{H} / \mathrm{M}_{\text {inicial }}\right)=\boldsymbol{\eta}$ número máximo de átomos de hidrogênio por fórmula unitária (H/f.u.) obtidos de uma reação gás-solido da liga, chamado de platô $(\alpha+\beta)$,

$\mathbf{F}$ é a constante de Faraday,

Mw é a massa molar da liga de hidreto metálico. 
A capacidade de descarga dos eletrodos negativos é obtida de acordo com a equação 3.9:

$$
C_{\left(m A h \cdot g^{-1}\right)}=\frac{\operatorname{Id}(\mathrm{mA}) \cdot \mathrm{td}(\mathrm{h})}{\mathrm{m}(\mathrm{g})}
$$

No qual:

td tempo total de descarga do eletrodo a uma corrente de descarga,

Id potencial de corte $0,6 \mathrm{~V}$ e

m massa de material ativo (liga metálica) do eletrodo negativo.

$\mathrm{Na}$ TABELA 1 estão apresentados os valores de capacidade de descarga teórica de diferentes tipos de ligas de hidreto metálico.

TABELA 1 - Capacidade de descarga teórica para diferentes tipos de ligas formadoras de hidreto metálico.

\begin{tabular}{cccc}
\hline Liga & $\begin{array}{c}\text { Número átomos } \\
\text { de hidrogênio } \\
\text { absorvidos (n) }\end{array}$ & Massa molar & $\begin{array}{c}\mathbf{C}_{\text {teo }} \\
(\mathbf{m A h} / \mathbf{g})\end{array}$ \\
\hline $\mathrm{LaNi}_{5}$ & 6 & 432 & 372 \\
$\mathbf{Z r V}_{2}$ & 5,4 & 193 & 750 \\
$\mathbf{M g}_{2} \mathrm{Ni}$ & 4 & 107 & 1002 \\
$\mathrm{TiNi}$ & 1 & 107 & 250 \\
$\mathrm{TiFe}$ & 2 & 104 & 515 \\
\hline
\end{tabular}


A quantidade de hidrogênio absorvida na liga, expressa como o número de átomos de $\mathrm{H}$ por unidade de fórmula (n), calculada a partir da capacidade máxima de armazenamento (Cmax) usando a Eq. 3.10:

$$
n=\frac{3600 \cdot M w \cdot C_{m a ́ x}}{9,65 \cdot 10^{7}}
$$

Em que:

$\mathbf{C}_{\max }$ capacidade máxima de armazenamento expressa em $(\mathrm{mAh} / \mathrm{g})$, utilizando na equação a constante de Faraday $\left(9,65 \times 10^{7}\right)$.

Mw massa molecular

A capacidade de estabilidade ciclica da bateria é obitida a partir da taxa de retenção ciclica, determina pela equação 3.11 :

$$
\mathrm{S}_{n}=\frac{C_{n}}{C_{\text {máx. }}} .100(\%)
$$

No qual:

$\mathbf{C}_{n}$ capacidade no ultimo ciclo da bateria,

$\mathbf{C}_{\max }$. capacidade máxima de armazenamento expressa em $(\mathrm{mAh} / \mathrm{g})$. 


\section{5 - Substituições em ligas do tipo $\mathrm{AB}_{5}$}

Nessa seção do trabalho será abordado os efeitos da substituição dos elementos da liga $\mathrm{LaNi}_{5}$. Inicialmente será discutida a influência da substituição parte A (La) e da parte B liga (Ni).

O objetivo da modificação da liga metálica com adição de outros elementos é principalmente melhorar o desempenho das baterias, ou seja, obter uma maior capacidade de armazenamento de hidrogênio. A cinética de absorção e dessorção de hidrogênio aumentam:

- o ciclo de vida tornando-os mais longos e estáveis,

- a resistência à corrosão e obter uma ativação inicial mais rápida.

\subsection{1 - Lantânio}

O lantânio (La) é responsável pela formação da liga com o níquel, as taxas de absorção e dessorção do hidrogênio são elevadas e promove um aumento capacidade de descarga, a ativação inicial, mas a estabilidade diminui devida ser susceptível à corrosão e a alta expansão volumétrica da cela unitária (Gao et. al. 2008 e Liu et. al 2011).

Liao et al. 2003 e 2004, prepararam ligas com as seguintes composições $\operatorname{LaxMg}_{3-x} \mathrm{Ni}_{9}(\mathrm{x}=1,0-2,2)$ e descobriram que ligas com alto teor de $\mathrm{La}(\mathrm{x}=1,8-2,1)$ possuem boas propriedades como: capacidade de descarga (400 mAh/g), ativação inicial rápida e alta taxa de descarga. O aumento na razão $\mathrm{La} / \mathrm{Mg}$ em $\mathrm{La}_{0,75}+\mathrm{xMg}_{0,25-\mathrm{x}} \mathrm{Ni}_{3,5} \quad(\mathrm{x}=0-0,1)$ melhorou a o número de ciclos de vida, mas a capacidade de descarga teve uma redução (Dong et. al 2008).

Yasouka et. al 2006, estudaram o ciclo de vida da liga $\mathrm{Mm}_{0,83} \mathrm{Mg}_{0,17} \mathrm{Ni}_{3,1} \mathrm{Al}_{0,2}$ $(\mathrm{Mm}=$ mishmetal, mistura de terras-raras) é 2,5 vezes mais do que da liga $\mathrm{Mm}_{0,7} \mathrm{Mg}_{0,3} \mathrm{Ni}_{3,1} \mathrm{Al}_{0,2}$, para testes nas mesmas condições. Para as ligas $\mathrm{Ml}_{1-x} \mathrm{Mg}_{\mathrm{x}} \mathrm{Ni}_{2,4} \mathrm{CO}_{0,6}(\mathrm{x}=0-0,6)$, com um alto teor de $\mathrm{Mg}$ tende a ter uma maior capacidade de descarga e mais ciclos de vida devido à redução no volume da cela unitária e a diminuição da decrepitação das partículas. 
Para aumentar o número de ciclos e diminuir o custo das ligas à base RMg$\mathrm{Ni}$ (R=terras-raras) o La foi parcialmente substituído por $\mathrm{Ce}$ em $\mathrm{La}_{0,7-\mathrm{x}} \mathrm{Ce}_{\mathrm{x}} \mathrm{Mg}_{0,3} \mathrm{Ni}_{2,875} \mathrm{Co}_{0,525} \mathrm{Mn}_{0,1}(\mathrm{x}=0-0,5)$. Pan e seus colaboradores estudaram o aumento do teor de $\mathrm{Ce}$ fez com que a taxa de decaimento da capacidade diminuísse de 2,65 mAhg ${ }^{-1}(x=0)$ a 0,10 mAhg-1 (x=0,5). O aumento do teor de Ce leva a uma mudança na cela unitária e a formação de uma película na superfície que inibe a oxidação da liga e diminui a taxa de corrosão. No entanto, um grande problema com o aumento do teor de Ce é que a capacidade de descarga é drasticamente diminuída de $382 \mathrm{mAhg}^{-1}(\mathrm{x}=0)$ para 48,6 $\mathrm{mAhg}^{-1}(\mathrm{x}=0,5)$. Fenômeno também observado em as ligas $\mathrm{La}_{0,7-\mathrm{x}} \mathrm{Ce}_{\mathrm{x}} \mathrm{Mg}_{0,3} \mathrm{Ni}_{2,8} \mathrm{Co}_{0,5}$ por Zhang et al. (2005).

\subsection{2 - Níquel}

O níquel ( $\mathrm{Ni}$ ) é um elemento muito utilizado na base das ligas para baterias de hidreto metálico em grandes concentrações. Em uma bateria comercial à base de $\mathrm{LaNi}_{5}$, obtém-se a capacidade de descarga de $320 \mathrm{mAhg}^{-1}$. (Pan et al 2005) Liu e colaboradores em 2011 analisaram a adição dos elementos Mn, Co ou Al em substituição parcial ao Ni em ligas à base de La-Mg-Ni-Co houve uma melhora nas propriedades eletroquímicas, obtendo melhor desempenho em relação à bateria comercial.

Casini et al 2015 estudaram os efeitos das substituições do Co pelo Cu e Sn como elementos de adição em substituição parcial ao $\mathrm{Ni}$ na liga $\mathrm{La}_{0,7} \mathrm{Al}_{0,3} \mathrm{Mg}_{0,3} \mathrm{Mn}_{0,4} \mathrm{Co}_{0,5} \mathrm{Ni}_{3,8}$.

\subsection{3 - Manganês}

Os trabalhos envolvendo a substituição do níquel pelo manganês em ligas do tipo La-Mg-Ni-Co, apresentaram melhorias na ativação, além de aumentarem a capacidade de descarga das baterias. Em estudos realizados por Liu et al. em 2004 nas ligas $\mathrm{La}_{0,7} \mathrm{Mg}_{0,3} \mathrm{Ni}_{2,55-x} \mathrm{Co}_{0,45} \mathrm{Mn}_{\mathrm{x}}(\mathrm{x}=0$ - 0,5) apresentaram somente a presença das fases ( $\mathrm{La}, \mathrm{Mg}) \mathrm{Ni}_{3}$ e $\mathrm{LaNi}_{5}$. A capacidade de descarga das baterias aumentou de $342 \mathrm{mAh} \cdot \mathrm{g}^{-1}(\mathrm{x}=0)$ para $368 \mathrm{mAh} \cdot \mathrm{g}^{-1}(\mathrm{x}=0,3)$ e decaiu para $333 \mathrm{mAh} \cdot \mathrm{g}^{-1}$ quando $\mathrm{x}$ 
$=0,5 . \mathrm{O}$ efeito do manganês nas ligas $\left(\mathrm{La}_{0,7} \mathrm{Ce}_{0,2} \mathrm{Pr}_{0,1}\right) \mathrm{Ni}_{2,6-\mathrm{x}} \mathrm{MnxCo}_{0,9}(\mathrm{x}=0,0 ; 0,225$; $0,45 ; 0,675 ; 0,90)$ mostraram resultados similares. A capacidade de descarga aumenta até uma determinada concentração de manganês e depois decai. A capacidade de descarga máxima obtida foi $352 \mathrm{mAh}^{-1} \mathrm{~g}^{-1}(\mathrm{x}=0,45)$, e depois diminui para $307 \mathrm{mAh} . \mathrm{g}^{-1}$ para $\mathrm{x}=0,9$ (Jiang et al. 2010).

Segundo Zang e colaboradores em 2005 o manganês auxilia com o aumento no coeficiente de difusão do hidrogênio causado pela expansão do volume da célula unitária, consequentemente ocorre o aumento da capacidade de descarga máxima.

\subsection{4 - Alumínio}

O alumínio (Al) é o terceiro elemento mais abundante na terra, depois do oxigênio e o silício. Entretanto, a quantidade de alumínio na maior parte dos minérios é baixa, e a fonte comercial de alumínio, a bauxita é um óxido hidratado impuro e é obtido por meio do processo Bayer.

O alumínio tem baixa densidade, é um metal resistente e um excelente condutor elétrico, embora oxide facilmente é resistente à corrosão, pois sua superfície é apassivada ao ar pela formação de um filme de óxido estável. Acreditase que esta formação da camada é responsável pela melhora da capacidade de descarga e estabilidade cíclica.

Em ligas do tipo $A B_{5}$ trabalhos envolvendo a substituição do $\mathrm{Ni}$ pelo $\mathrm{Al}$ mostram uma melhoria significativa na estabilidade cíclica das baterias de Ni-HM.

Liao e seus colaboradores em 2005 realizaram estudos nas ligas $\mathrm{La}_{2} \mathrm{Mg}\left(\mathrm{Ni}_{1-x} \mathrm{Al}_{\mathrm{x}}\right)_{9} \quad(\mathrm{x}=0-0,05)$, mostraram a presença da fase principal, do tipo$\mathrm{PuNi}_{3}$, e pequenas quantidades da fase $\mathrm{La}_{2} \mathrm{Ni}_{7}$, citada como impureza. A capacidade de descarga das baterias mostrou decréscimo de $400 \mathrm{mAh} \cdot \mathrm{g}^{-1}(\mathrm{x}=0)$ para 374 $\mathrm{mAh} \cdot \mathrm{g}^{-1}(\mathrm{x}=0,02)$, atingindo um ponto mais baixo a $\mathrm{x}=0,05\left(221 \mathrm{mAh} \cdot \mathrm{g}^{-1}\right)$. Pan e colaboradores em 2005 encontraram resultados semelhantes para as ligas $\mathrm{La}_{0,7} \mathrm{Mg}_{0,3} \mathrm{Ni}_{2,65-x} \mathrm{Mn}_{0,1} \mathrm{Co}_{0,75} \mathrm{Al}_{\mathrm{x}}(\mathrm{x}=0-0,5)$.

Pan et al (2005) mostraram uma boa melhoria na estabilidade da capacidade de descarga após 100 ciclos a retenção de carga aumentou de $32 \%(x=0,0)$ para $74 \%(x=0,3)$. 
Liu et al (2005) atribuíram o aumento da estabilidade cíclica à formação de uma camada de óxido de alumínio dificultando a corrosão e decrepitação das partículas durante os ciclos de carga/descarga. Porém, em grandes quantidades de alumínio esta camada de óxido dificulta a difusão do hidrogênio no interior da liga.

\subsection{5 - Cobalto}

O cobalto é um dos elementos de adição com grau de importância elevado para a melhoria nas características das propriedades eletroquímicas de ligas à base de terras raras para eletrodos de baterias de $\mathrm{Ni}-\mathrm{HM}$, especialmente no prolongamento da vida útil (número de ciclos) das baterias.

Liao et al. (2004) estudaram o efeito da substituição do níquel pelo cobalto nas ligas $\mathrm{La}_{2} \mathrm{Mg}\left(\mathrm{Ni}_{1-\mathrm{x}} \mathrm{Co}_{\mathrm{x}}\right)_{9}(\mathrm{x}=0,1-0,5)$. Os resultados de difração de raios $\mathrm{X}$ mostraram a presença da fase principal $(\mathrm{La}, \mathrm{Mg}) \mathrm{Ni}_{3}$ (estrutura romboédrica tipo$\mathrm{PuNi}_{3}$ ) e duas fases em pequenas quantidades ( $\mathrm{LaNi}$ e $\left.\mathrm{La}_{2} \mathrm{Ni}_{7}\right)$. A capacidade de descarga das baterias mostrou um aumento de $400 \mathrm{mAh} \cdot \mathrm{g}^{-1}(\mathrm{x}=0)$ para $404 \mathrm{mAh} \cdot \mathrm{g}^{-1}$ $(\mathrm{x}=0,2)$. Para a liga com $\mathrm{Co}_{0,5}$ a capacidade de descarga diminuiu para $328 \mathrm{mAh} . \mathrm{g}^{-1}$, porém apresentou melhor estabilidade cíclica. Este resultado foi explicado devido à baixa expansão da célula unitária quando se aumenta o teor de cobalto nas ligas, causando uma baixa taxa de decrepitação e corrosão das partículas durante a carga e descarga das baterias.

Liu et al. (2004), mostraram o efeito da substituição do níquel pelo cobalto nas ligas $\mathrm{La}_{0,7} \mathrm{Mg}_{0,3} \mathrm{Ni}_{3,4-x} \mathrm{Mn}_{0,1} \mathrm{Co}_{x}(\mathrm{x}=0-1,6)$. Com o aumento do teor de cobalto a capacidade de descarga máxima das baterias aumenta de $397 \mathrm{mAh} \cdot \mathrm{g}^{-1}(\mathrm{x}=0)$ para 403 mAh. $\mathrm{g}^{-1}(x=0,75)$ e depois diminuiu para $380 \mathrm{mAh} \cdot \mathrm{g}^{-1}(x=1,6)$. Com altos teores de cobalto nas ligas a cinética da reação eletroquímica diminui devido ao baixo coeficiente de difusão do hidrogênio. A melhoria na estabilidade cíclica foi atribuída a menor expansão do volume da célula unitária durante a absorção e dessorção de hidrogênio e o aumento da superfície de passivação durante a carga e descarga das baterias. A substituição adequada do Ni pelo Co melhora a cinética eletroquímica dos eletrodos devido à concentração de $\mathrm{Co}$ e $\mathrm{Ni}$ na superfície das partículas da liga, e com consequente formação de uma fina camada de Ni-Co (Liu et al. 2005). 


\subsection{6 - Magnésio}

O magnésio $(\mathrm{Mg})$ é um metal bastante resistente e leve, produzido pela redução química ou eletrolítica de seus compostos, tem baixo custo em relação aos demais constituintes da liga $A_{5}$ e tem sido relatado como um dos mais promissores elementos químicos para as substituições do $\mathrm{Ni}$.

Oesterricher et. al (1980) estudaram primeiras ligas ternárias La-Mg-Ni obtidas nas composições $\mathrm{La}_{1}{ }_{\mathrm{x}} \mathrm{Mgg}_{\mathrm{x}} \mathrm{Ni}_{2} \quad(\mathrm{x}=0-0,67)$, sinterizadas em um forno de indução em atmosfera de argônio a $1 \mathrm{MPa}$.

Kadir et al. (1999 e 2000) desenvolveram ligas ternárias R-Mg-Ni $(\mathrm{R}=\mathrm{La}, \mathrm{Pr}, \mathrm{Ce}, \mathrm{Nd}, \mathrm{Sm}, \mathrm{Gd}$ e Y) produzidas pela mistura do composto intermetálico $\mathrm{MgNi}_{2}$ com $\mathrm{RNi}_{5}$ sendo logo após sinterizado ou pelo adição dos elementos pela razão atômica $\mathrm{RMg}-\mathrm{Ni}$ (1:2:9) e também sinterizado. O interesse em obtenção deste composto com $\mathrm{RMg}_{2} \mathrm{Ni}_{9}$ foi devido a estrutura apresentar melhor capacidade de estocagem de hidrogênio comparado com composto $\mathrm{LaNi}_{5}$. A estrutura $\mathrm{RMg}_{2} \mathrm{Ni}_{9}$ (tipo $\mathrm{PuNi}_{3}$ romboédrica) pode ser descrito como um empilhamento de $\mathrm{RNi}_{5}$ (R=terra-rara) e $\mathrm{MgCu}_{2}\left(\mathrm{MgZn}_{2}\right)$ ao longo do eixo-c.

Zhang e seus colaboradores em 2005(b) atribuíram a pequena quantidade de Mg pela promoção de uma menor fração da fase secundária, que pode ser a razão para melhora da estabilidade do ciclo.

Zang et al (2007), afirmaram que a oxidação leva a redução da capacidade de descarga das baterias e a redução da capacidade de armazenamento de hidrogênio por causa da dificuldade da absorção do hidrogênio. Na oxidação da superfície do $\mathrm{Mg}$ forma-se o hidróxido de magnésio $\left(\mathrm{Mg}(\mathrm{OH})_{2}\right)$. A oxidação das partículas ocorre durante o processo de carga e descarga devido presença do eletrólito de $\mathrm{KOH}$.

Jain et al (2010) analisaram os hidretos formados com a base de $\mathrm{Mg}$ possuem boas propriedades como: resistência ao calor, aumento da capacidade de descarga máxima e estabilidade cíclica e também aumenta a capacidade de estocagem de hidrogênio nas ligas e é responsável pela diminuição do parâmetro de rede. 
Denys e Yarts em 2011 apresentaram os dados de estudos sistemáticos da influência do magnésio na estrutura cristalina e no comportamento de hidrogenação de $\mathrm{La}_{1-\mathrm{x}} \mathrm{Mgg}_{\mathrm{x}} \mathrm{Ni}_{3}$ do tipo $\mathrm{PuNi}_{3}(\mathrm{x}=0$ - 0,67) ligas intermetálicas.

Estudos de difração de raios $X$ revelaram que substituição de $\mathrm{La}$ em $\mathrm{LaNi}_{3}$ por $\mathrm{Mg}$ se forma maneira ordenada, apenas dentro das camadas do tipo Laves da estrutura cristalina híbrida, construídas a partir das fases do tipo $\mathrm{MgZn}_{2}$ e $\mathrm{CaCu}_{5}$.

Quando o valor de $\mathrm{x}=0,67$, forma a fase $\mathrm{LaMg}_{2} \mathrm{Ni}_{9}\left(2 \mathrm{MgNi}_{2}+\mathrm{LaNi}_{5}\right)$. Com o aumento gradual do teor de $\mathrm{Mg}$ é acompanhada de uma diminuição linear dos volumes das células unitárias. Curiosamente, ocorre uma contração substancial também para as fases do tipo $\mathrm{CaCu}_{5}$ sem teor de $\mathrm{Mg}$. A interação do hidrogênio estudos de pressão-composição-temperatura com as ligas $\mathrm{La}_{1-\mathrm{x}} \mathrm{Mg}_{\mathrm{X}} \mathrm{Ni}_{3}$ foi também investigado in situ por difração de raios $X$ e de nêutrons no sinclotron.

Em toda a faixa de substituição, ligas $\mathrm{La}_{1-x} \mathrm{Mg}_{\times} \mathrm{Ni}_{3}$ formam hidretos intermetálicos com relação $\mathrm{H} / \mathrm{M}$ variando de 0,77 a 1,16. O magnésio influencia as características estruturais da hidrogenação processo e determina vários aspectos da interação do hidrogênio com os intermetálicos de $\mathrm{La}_{1-x} \mathrm{Mg}_{\times} \mathrm{Ni}_{3}$ que causam:

(a) aumento nas pressões de equilíbrio da absorção e dessorção de hidrogênio para as fases ricas em Mg LaMg $\mathrm{Ni}_{9}$ em comparação com o La ${ }_{2,3} \mathrm{Mg}_{0,7} \mathrm{Ni}_{9}$ pobre em Mg e uma modificação substancial da termodinâmica da formaçãodecomposição dos hidretos;

b) aumento das capacidades reversíveis de armazenamento de hidrogénio após o aumento do teor de $\mathrm{Mg}$ no $\mathrm{La}_{1-x} \mathrm{Mg}_{\mathbf{x}} \mathrm{Ni}_{3}$ para 1,5\% em peso para $\mathrm{La}_{2} \mathrm{MgNi}_{9}$;

c) Melhoria da resistência à amorfização e desproporção induzida pelo hidrogénio;

d) mudança do mecanismo de hidrogenação do anisotrópico para o isotrópico.

Zang et al 2014 estudaram o efeito do teor de Mg na transformação dos parâmetros de rede cristalinas e nas características eletroquímicas das ligas $\mathrm{La}_{2-x} \mathrm{Mg}_{x} \mathrm{Ni}_{7} \quad(\mathrm{x}=0,40-0,60)$ estudado. Verificaram que as ligas com estruturas alotrópicas existem nas fases $\mathrm{Ce}_{2} \mathrm{Ni}_{7}(2 \mathrm{H})$ e $\mathrm{Gd}_{2} \mathrm{Co}_{7}$ (3R) numa faixa de concentração de $\mathrm{Mg}$ de 0,48 a 0,50. Além dessa faixa, o aumento adicional do $\mathrm{Mg}$ para 0,60 é favorável para a formação da fase do tipo PuNi3 devido à crescente razão das estruturas do tipo $\left[\mathrm{A}_{2} \mathrm{~B}_{4}\right]$ para o tipo $\left[\mathrm{AB}_{5}\right]$ em relação à demanda de 
átomos de La e Ni para o $\mathrm{Mg}$ formar estruturas do tipo $\left[\mathrm{A}_{2} \mathrm{~B}_{4}\right]$. Por outro lado, o excedente de átomos de La e Ni para Mg na formação da estrutura $\left[\mathrm{A}_{2} \mathrm{~B}_{4}\right]$ reduz a proporção de $\left[A_{2} B_{4}\right]$ para $\left[A B_{5}\right]$, o que ajuda na formação da fase do tipo $\mathrm{CaCu}_{5}$, conforme $\circ \mathrm{Mg}$ diminui para 0,40 . Estudos eletroquímicos mostram que as propriedades eletroquímicas dos eletrodos de liga com fases alotrópicas são superiores na capacidade de descarga $\left(388 \mathrm{mAhg}^{-1}\right.$ ) e estabilidade do ciclo (capacidade de retenção de $78 \%$ no $100^{\circ}$ ciclo).

\subsection{7 - Praseodímio}

Como relatado na literatura à substituição da terra-rara lantânio pelo praseodímio provoca a diminuição dos parâmetros de rede e do volume da célula unitária, diminui a capacidade de absorção e aumenta a capacidade de dessorção do hidrogênio, diminui o valor da capacidade máxima de descarga e melhora estabilidade cíclica. (Gao et. al, 2008; Liao et. al, 2004)

Khono et al (2000) estudaram a introdução do $\operatorname{Pr}$ na liga $\mathrm{La}_{0,65-x} \mathrm{Pr}_{\mathrm{x}} \mathrm{Nd}_{0,12} \mathrm{Mg}_{0,23} \mathrm{Ni}_{3,4} \mathrm{Al}_{0,1} \quad(\mathrm{x}=0,00-0,20)$, e verificaram se a mudança da quantidade faz com que ocorra uma redução do volume da célula unitária das fases presentes na liga. Para altos teores de praseodímio na substituição $(x=0,15$ e $\mathrm{x}=0,20)$. A capacidade caiu de $360 \mathrm{mAhg}^{-1}(\mathrm{x}=0,00)$ para $335 \mathrm{mAhg}^{-1}(\mathrm{x}=0,20)$ (Hiuzong et al 2000).

Pan e colaboradores em 2000 identificaram que conforme o aumento do teor de $\operatorname{Pr}$ nas ligas $\mathrm{La}_{0,7-x} \operatorname{PrxMg}_{0,3} \mathrm{Ni}_{2,45} \mathrm{Co}_{0,75} \mathrm{Mn}_{0,1} \mathrm{Al}_{0,2} \quad(\mathrm{x}=0,00-0,30)$ houve um decréscimo na capacidade de descarga máxima de $366 \mathrm{mAhg}^{-1}(\mathrm{x}=0,00)$ para $346 \mathrm{mAhg}^{-1}(\mathrm{x}=0,30)$ também a presença das fases citadas nos outros trabalhos.

Pan et al. (2007), estudaram ligas $\operatorname{LaPr}_{x} \mathrm{Mg}_{0,3} \mathrm{Ni}_{2,45} \mathrm{Co}_{0,75} \mathrm{Mn}_{0,1} \mathrm{Al}_{0,2}(x=0 \quad 0,3)$ após tratamento térmico a $1173 \mathrm{~K}$ por 8 horas. Verificaram que as ligas com diferentes teores de Pr apresentaram padrão de difração similares e consistiram das fases $(\mathrm{La}, \mathrm{Mg}) \mathrm{Ni}_{3}$ (estrutura romboédrica tipo- $\mathrm{PuNi}_{3}$ ) e $\mathrm{LaNi}_{5}$ (estrutura hexagonal tipo- $\mathrm{CaCu}_{5}$ ) mas, com uma diminuição no parâmetro de rede. O resultado da capacidade de descarga das baterias mostrou decréscimo de $366 \mathrm{mAh} \cdot \mathrm{g}^{-1}(\mathrm{x}=0)$ para $346 \mathrm{mAhg}^{-1}(\mathrm{x}=0,3)$ (Liao et. al, 2004). A diminuição da capacidade máxima de descarga é atribuída a uma formação da fase $(\mathrm{La}, \mathrm{Mg}) \mathrm{Ni}_{3}$. 
Yan H. et al (2009), investigaram o efeito da substituição do La pelo Pr nas propriedades estruturais e de armazenamento de hidrogênio do sistema La-Mg-Ni (tipo $\mathrm{AB}_{3.5}$ ) ligas de armazenamento de hidrogênio, foram preparados das séries de $\mathrm{La}_{0.65-\mathrm{x}} \mathrm{Pr}_{\mathrm{x}} \mathrm{Nd}_{0.12} \mathrm{Mg}_{0.23} \mathrm{Ni}_{3.4} \mathrm{Al}_{0.1} \quad(\mathrm{x}=0,0,10,0,15,0,2)$. Onde as analises de difratometria de raios-X (XRD), microscopia eletrônica de varredura (MEV) e espectrômetro de dispersão de energia (EDS) revelaram que nas ligas $(x=0,0$ e $0,10)$ foram encontradas as composições das fases $(\mathrm{La}, \mathrm{Mg})_{2}(\mathrm{Ni}, \mathrm{Al})_{7}, \mathrm{La}(\mathrm{Ni}, \mathrm{Al})_{5} \mathrm{e}$ ( $\mathrm{La}, \mathrm{Mg}) \mathrm{Ni}_{2}$, enquanto nas ligas $(\mathrm{x}=0,15$ e 0,20$)$ ) consistiu das fases $(\mathrm{La}, \mathrm{Mg})_{2}(\mathrm{Ni}, \mathrm{Al})_{7}, \mathrm{La}(\mathrm{Ni}, \mathrm{Al})_{5},(\mathrm{La}, \mathrm{Mg}) \mathrm{Ni}_{2}$ e $(\mathrm{La}, \mathrm{Mg})(\mathrm{Ni}, \mathrm{Al})_{3}$.

Todas as ligas mostraram, no entanto, apenas um platô de pressão em curvas P-C-T.

A relação $\mathrm{Pr} / \mathrm{La}$ na composição da liga influenciou a capacidade de armazenamento de hidrogênio e as propriedades. Estudos eletroquímicos mostraram que a capacidade de descarga diminuiu à medida que aumentou a concentração de Pr.

Zhang et al. (2009), também verificaram o aumento da fase ( $\mathrm{La}, \mathrm{Mg}) \mathrm{Ni}_{3} \mathrm{e}$ diminuição da fase matriz $\mathrm{LaNi}_{5}$ para as ligas $\mathrm{La}_{0,75-x} \operatorname{Pr}_{x} \mathrm{Mg}_{0,25} \mathrm{Ni}_{3,2} \mathrm{Co}_{0,2} \mathrm{~A}_{10,1}$ $(x=0-0,4)$.

Zhang e colaboradores em 2014 estudaram a substituição parcial de $\mathrm{M}$ ( $\mathrm{M}=$ $\mathrm{Sm}, \mathrm{Nd}, \mathrm{Pr}$ ) por La foi realizada com o objetivo de melhorar o desempenho de armazenamento de hidrogênio eletroquímico de ligas de eletrodo do tipo $A_{2} B_{7}$ à base de RE-Mg-Ni. As ligas de eletrodos $\mathrm{La}_{0,8-\mathrm{x}} \mathrm{M}_{\mathrm{x}} \mathrm{Mg}_{0.2} \mathrm{Ni}_{3.35} \mathrm{Al}_{0.1} \mathrm{Si}_{0.05}(\mathrm{M}=\mathrm{Sm}, \mathrm{Nd}$, $\mathrm{Pr} ; \mathrm{x}=$ 0-0.4) foram fabricadas por fusão e suas microestruturas foram caracterizadas por difração de raios $X(D R X)$. e microscopia eletrônica de varredura (SEM). As principais fases $(\mathrm{La}, \mathrm{Mg})_{2} \mathrm{Ni}_{7}$ com a estrutura do tipo $\mathrm{Ce}_{2} \mathrm{Ni}_{7}$ hexagonal e $\mathrm{LaNi}_{5}$ com a estrutura do tipo $\mathrm{CaCu}_{5}$ hexagonal compõem a microestrutura básica das ligas experimentais. As capacidades de descarga das ligas fundidas e recozidas ganham seus valores máximos com o teor de $M(M=S m, N d, P r)$. A estabilidade do ciclo eletroquímico das ligas fundidas e tratamento térmico melhoram claramente com o aumento da quantidade desses elementos. Além disso, a cinética das reações eletroquímica das ligas, incluindo a uma elevada capacidade de descarga e o coeficiente de difusão de hidrogênio, apresentam uma tendência a diminuir com o aumento da quantidade de adição de $\mathrm{M}(\mathrm{M}=\mathrm{Sm}, \mathrm{Nd}, \mathrm{Pr})$. 


\section{6 - Tratamentos Térmicos}

O tratamento térmico é uma forma eficiente para melhorar as propriedades gerais das ligas de armazenamento de hidrogênio, tais como a capacidade máxima de descarga e estabilidade cíclica (De Negri et.al 2005 e 2007).

Podendo diminuir os defeitos cristalinos e melhorar a homogeneização da composição da liga e, consequentemente, aumentar a capacidade de carga/descarga e a estabilidade cíclica das baterias de Ni-HM. Para melhorar a estabilidade cíclica da liga $\mathrm{La}_{0,7} \mathrm{Mg}_{0,3} \mathrm{Ni}_{2,45} \mathrm{Co}_{0,75} \mathrm{Mn}_{0,1} \mathrm{Al}_{0,2}$ Pan e seus colaboradores em 2005 , estudaram o tratamento térmico a $900^{\circ} \mathrm{C}, 1000^{\circ} \mathrm{C}$ e $1100^{\circ} \mathrm{C}$ por 8 horas.

As análises de difração de raios- $X$ e Rietveld indicaram que a estrutura das ligas manteve a presença das duas principais fases após o tratamento térmico, ou seja, as fases (La, Mg) $\mathrm{Ni}_{3}$ e $\mathrm{LaNi}_{5}$.

Com o aumento da temperatura de tratamento térmico, os parâmetros de rede e os volumes da célula unitária, nas duas fases aumentaram. Porém, houve variação na fração das duas fases, com a redução da fase ( $\mathrm{La}, \mathrm{Mg}) \mathrm{Ni}_{3}$ e consequentemente, aumento da fase $\mathrm{LaNi}_{5}$. Os estudos eletroquímicos indicaram melhorias na estabilidade cíclica devido à maior homogeneização da composição, mostrando um aumento de $65,5 \%$ (liga no estado bruto de fusão) para 75,0\% (liga tratada termicamente a $1100^{\circ} \mathrm{C}$ ) na retenção da capacidade de descarga após 100 ciclos de carga e descarga. A capacidade de descarga máxima da liga no estado bruto de fusão $\left(350 \mathrm{mAhg}^{-1}\right)$ aumentou para $370 \mathrm{mAhg}^{-1}$ após tratamento térmico a $900^{\circ} \mathrm{C}$, reduzindo para $359 \mathrm{mAhg}^{-1}$ a $1100^{\circ} \mathrm{C}$ (De Negri et al 2007).

Ma e colaboradores em 2002 estudaram a microestrutura e as curva de isotermas de PCT da liga tipo $\mathrm{AB}_{5} \mathrm{MNi}_{3,60} \mathrm{Co}_{0,85} \mathrm{Mn}_{0,40} \mathrm{Al}_{0,15}$, tratada termicamente a uma temperatura de $1100^{\circ} \mathrm{C}$, com tempo de espera de 2 a $8 \mathrm{~h}$ e posteriormente resfriadas bruscamente em água. Os resultados de DRX mostraram que a estrutura de fase de todas as amostras investigadas foi a estrutura hexagonal do tipo $\mathrm{CaCu}_{5}$, enquanto que os parâmetros de rede e o FWHM da liga foram modificados por tratamento térmico. A microestrutura metalográfica da liga fundida foi uma estrutura dendrítica e após o tratamento térmico, a microestrutura da liga era uma estrutura colunar. Com um tempo maior de tratamento térmico, o tamanho do grão aumentou, e diminuiu os pontos de segregação distribuídos no interior do grão. Em comparação 
com as P-C-I da liga fundida, após o tratamento térmico, a pressão de formação do platô de absorção de hidrogênio e a histerese diminuíram.

Xiao et al. (2008) identificaram que a modificação da superfície da liga $\mathrm{La}_{0,7} \mathrm{Mg}_{0,3} \mathrm{Ni}_{2,4} \mathrm{Co}_{0,6}$ por tratamento com solução de $\mathrm{KBH}_{4}$ trouxe benefícios à estabilidade cíclica e à cinética do eletrodo.

Zhang e colaboradores em 1991 estabeleceram a temperatura $976^{\circ} \mathrm{C}$ como a temperatura de transição de $\alpha$ para $\beta$ na fase $\mathrm{La}_{2} \mathrm{Ni}_{7}$. Nesse trabalho os autores também citam a fase $\mathrm{LaNi}_{2}$ como uma fase não estequiométrica, mas uma fase incompleta $\mathrm{La}_{0,875} \mathrm{Ni}_{2}\left(\mathrm{LaNi}_{2,28}\right)$. Em 1972, Buschow e colaboradores em 1972 relataram a existência da fase $\mathrm{LaNi}_{1,4}$, que posteriormente foi identificada como $\mathrm{La}_{2} \mathrm{~N}_{3}$. O último diagrama datado foi em 2002 por Okamoto do sistema La-Ni como apresentado na FIGURA 13, embora esse diagrama não está completo.

FIGURA 13 - Diagrama de fases do sistema La-Ni.

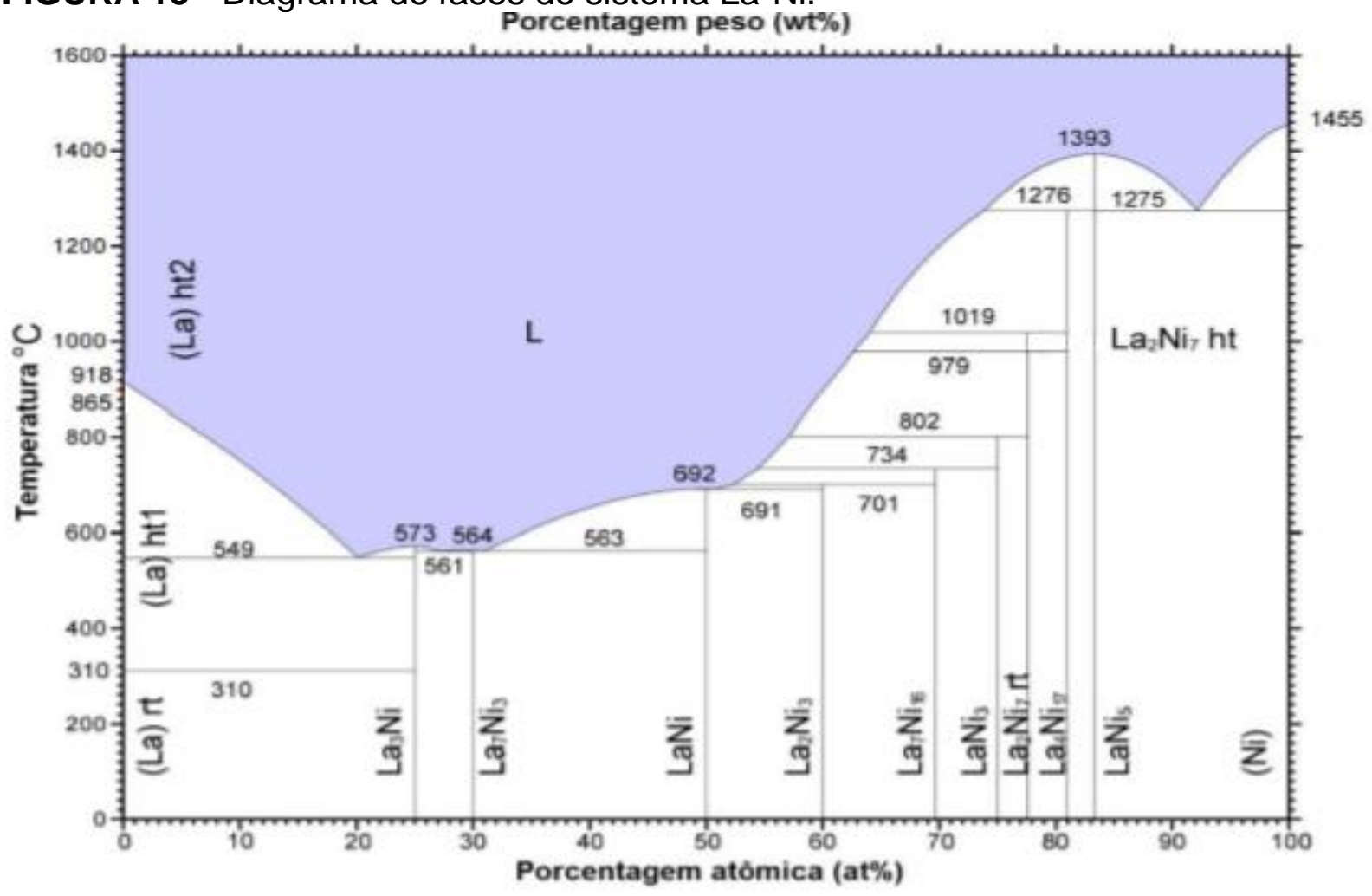

Segundo Zhou et al (2010), "A liga de armazenamento de hidrogênio $\mathrm{MmNi}_{4.2} \mathrm{Co}_{0.3} \mathrm{Mn}_{0.4} \mathrm{Al}_{0.3} \mathrm{Mg}_{0.03}$ foi preparada por melt spinning e submetida a tratamentos térmicos de recozimento por $8 \mathrm{~h}$ em temperaturas de $1133 \mathrm{~K}, 1173 \mathrm{~K}$, $1213 \mathrm{~K}$ e 1253K, respectivamente. Estrutura de ligas, composição de fases, propriedades pressão-composição-temperatura (PCT) e desempenho eletroquímico 
da liga foram investigados por difração de raios $X(X R D)$, microscópio eletrônico de emissão de partículas (FESEM), espectrômetro de dispersão de energia (EDS), onde os experimentos eletroquímicos indicaram que o tratamento de recozimento em $1213 \mathrm{~K}$ estende o ciclo de vida de 193 ciclos para 358 ciclos, aumentou a capacidade máxima de descarga e diminui ligeiramente o comportamento de ativação. Análises da estrutura da liga mostram que a melhoria no ciclo de vida que foi atribuída à formação de uma única estrutura do tipo $\mathrm{CaCu}_{5}$ ou ao aparecimento de uma segunda fase do tipo $\mathrm{AlMnNi}_{2}$ contendo $\mathrm{Mg}$. Os resultados das isotermas da composição da pressão demonstraram que tanto a capacidade de absorção de hidrogênio como o equilíbrio de hidretação melhorou com a temperatura de tratamento térmico."

O estudo de Shen et al. (2012), mostra que a modificação da superfície das partículas da liga $\mathrm{La}_{0,80} \mathrm{Mg}_{0,20} \mathrm{Ni}_{2,70} \mathrm{Mn}_{0,10} \mathrm{Co}_{0,55} \mathrm{Al}_{0,10}$ por recobrimento com polianilina (PANI) proporcionou aumento da estabilidade cíclica e da cinética do eletrodo, com decréscimo da resistência à transferência de carga e aumento na taxa de absorção de hidrogênio. A velocidade de difusão do hidrogênio do interior da liga para a superfície é diminuída. Vários outros exemplos de estudos tratando da influência do tratamento térmico em propriedades eletroquímicas como ativação, capacidade de descarga, estabilidade cíclica e alta taxa de descarga são reportados na literatura (Gao et al., 2012; Li, F. et al., 2009; Peng e Zhu, 2004; Song et al., 2008).

Wei et al (2013), estudaram a liga $\mathrm{La}_{2} \mathrm{MgNi}_{9}$ sem adição de Co, como materiais ativos de eletrodos negativos de níquel-hidreto metálico (NiMH). O efeito do tratamento de recozimento na composição de fases, microestrutura, absorçãodessorção de hidrogênio e propriedades eletroquímicas. A composição estrutural de fase, microestruturas e morfologias das fases foram analisados por difração de raios-X e por microscopia eletrônica de varredura. A temperatura de recozimento de $950^{\circ} \mathrm{C}$ promoveu a uma abundância das fases $\mathrm{La}_{2} \mathrm{MgNi}_{9}$ e $\mathrm{La}_{3} \mathrm{MgNi}_{14}$ e uma eliminação do presente a baixas temperaturas $\mathrm{LaNi}_{5-x}$ e $\mathrm{LaMgNi}_{4}$.

Os comportamentos de absorção e dessorção de hidrogênio, o desempenho eletroquímico e a estabilidade do ciclo eletroquímico melhoram significativamente após o recozimento. Para o eletrodo com, as ligas recozidas obtiveram uma capacidade de descarga de 350-360 mAhg ${ }^{-1}$ em comparação com $325 \mathrm{mAhg}^{-1}$ para a liga sem tratamento térmico. A capacidade de descarga das amostras recozidas 
permaneceu alta, quase $50 \%$ após 300 ciclos com $100 \%$ de profundidade de descarga (DOD) em testes de meia célula. Pedaços dos eletrodos separados da liga tratada e pó de níquel-carbonila apresentaram uma capacidade de descarga de 396 $\mathrm{mAhg}^{-1}$. Também relataram o desempenho de um pequeno protótipo de uma bateria de $\mathrm{NiMH}$, onde a liga tratada foi usada como material ativo no eletrodo negativo e um eletrodo de Ni sinterizado atuou como o eletrodo positivo. Após 300 ciclos com taxas de carga/descarga de $0,2^{\circ} \mathrm{C}$, a célula apresentou uma estabilidade de ciclos muito boa, com sua capacidade cíclica permanecendo na faixa de $87 \%$.

(Ouyang et al., 2014), à ligas tipo La-Mg-Ni mostraram procedimento para a obtenção de eletrodos compósitos que apresentaram melhorias em características eletroquímicas como ativação, capacidade de descarga, estabilidade cíclica e cinética.

Zang e colaboradores em 2015 relataram as transformações de fases e as propriedades eletroquímicas das ligas $\mathrm{La}_{0,70} \mathrm{Mg}_{0,30} \mathrm{Ni}_{3,3}$ obtidas por fusão por indução. Os resultados de refinamento de XRD e Rietveld mostram que a liga no estado bruto de fusão é composta pelas fases $\mathrm{LaNi}_{5}, \mathrm{La}_{4} \mathrm{MgNi}_{19}, \mathrm{La}_{3} \mathrm{MgNi}_{14}$, $\mathrm{La}_{2} \mathrm{MgNi}_{9}$ e $\mathrm{LaMgNi}_{4}$, e a temperatura gradual de recozimento aumenta efetivamente a fase $\mathrm{La}_{3} \mathrm{MgNi}_{14}$ tornando-se abundante. $\mathrm{Em} 1123 \mathrm{~K}, \quad \mathrm{LaNi}_{5}$ e $\mathrm{LaMgNi}_{4}$ desaparecem, transformando-se em fases de super-empilhamento. $\mathrm{O}$ aumento da a temperatura para $1173 \mathrm{~K}$, as fases $\mathrm{La}_{4} \mathrm{MgNi}_{19} \mathrm{e}$ $\mathrm{La}_{2} \mathrm{MgNi}_{9}$ transformaram nas fases $\mathrm{La}_{3} \mathrm{MgNi}_{14}$ e a fase $\mathrm{La}_{4} \mathrm{MgNi}_{19}$ desaparece completamente a $1223 \mathrm{~K}$, o que resulta em $\mathrm{La}_{3} \mathrm{MgNi}_{14}$ como fase principal e $\mathrm{La}_{2} \mathrm{MgNi}_{9}$ como a fase secundaria. Resultados eletroquímicos mostram que com o aumenta da fase abundante $\mathrm{La}_{3} \mathrm{MgNi}_{14}$ melhora significativamente a capacidade de descarga do eletrodo de liga, aumentando de 370 para $401 \mathrm{mAh} \mathrm{g}^{-1}$. Isto é atribuído à formação da fase $\mathrm{La}_{4} \mathrm{MgNi}_{19}$. 


\section{4 - MATERIAIS E MÉTODOS}

\section{1 - Materiais}

$\mathrm{Na}$ Tabela 2 estão relacionados os reagentes químicos utilizados nesse trabalho.

TABELA 2 - Descrição dos reagentes utilizados na fabricação das baterias.

\begin{tabular}{lccc}
\hline \multicolumn{1}{c}{ Nome } & Fórmula & $\begin{array}{c}\text { Grau de } \\
\text { Pureza } \\
(\%)\end{array}$ & Fabricante \\
\hline Fluoreto de polivinilideno (PVDF) & $\left(\mathrm{C}_{2} \mathrm{H}_{2} \mathrm{~F}_{2}\right)_{\mathrm{n}}$ & $\mathrm{n} / \mathrm{a}$ & Sigma Aldrich \\
Hidrogênio (gás) & $\mathrm{H}_{2}$ & $>99,9$ & White Martins \\
Hidróxido de potássio & $\mathrm{KOH}$ & 98,0 & Sigma Aldrich \\
Hidroxilo de níquel & $\mathrm{Ni}(\mathrm{OH})_{2}$ & 99,5 & Sigma Aldrich \\
N-metil-2-pirrolidona (NMP) & $\mathrm{C}_{5} \mathrm{H}_{9} \mathrm{NO}$ & 99,5 & Sigma Aldrich \\
Níquel (pó 3 $\mu \mathrm{m})$ & $\mathrm{Ni}$ & 99,8 & Alfa Aesar \\
Níquel (tela abertura 40) & $\mathrm{Ni}$ & $\mathrm{n} / \mathrm{a}$ & Alfa Aesar \\
\hline
\end{tabular}

\section{2 - Composição das ligas}

As ligas metálicas, no estado bruto de fusão, foram adquiridas pelo projeto CNPQ 472504/2010-0 e fabricadas pela empresa Whole Win Materials Sci. \& Tech. Co. Ltd. utilizando um forno de indução a vácuo. Para todas as matérias primas utilizadas neste trabalho o grau de pureza apresentado foi superior a $99,9 \%$.

- $\mathrm{La}_{0,7} \mathrm{Mg}_{0,3} \mathrm{Al}_{0,3} \mathrm{Mn}_{0,4} \mathrm{Co}_{0,5} \mathrm{Ni}_{3,8}$

- $\mathrm{La}_{0,7} \mathrm{Mg}_{0,3} \mathrm{Al}_{0,3} \mathrm{Mn}_{0,4} \mathrm{Cu}_{0,5} \mathrm{Ni}_{3,8}$

- $\mathrm{La}_{0,7} \mathrm{Mg}_{0,3} \mathrm{Al}_{0,3} \mathrm{Mn}_{0,4} \mathrm{Sn}_{0,5} \mathrm{Ni}_{3,8}$

- $\mathrm{La}_{0,7} \mathrm{Pr}_{0,3} \mathrm{Al}_{0,3} \mathrm{Mn}_{0,4} \mathrm{Co}_{0,5} \mathrm{Ni}_{3,8}$

- $\operatorname{Pr}_{0,7} \mathrm{Mg}_{0,3} \mathrm{Al}_{0,3} \mathrm{Mn}_{0,4} \mathrm{Co}_{0,5} \mathrm{Ni}_{3,8}$

As porcentagens em massa calculadas teoricamente das ligas para estas substituições dos elementos $\mathrm{Co}, \mathrm{Cu}$ e $\mathrm{Sn}$ em relação ao $\mathrm{Ni}$ e $\mathrm{Pr}$ em relação ao La e Mg estão respectivamente apresentadas nas TABELA 3 
TABELA 3 - Composição química nominal das ligas $\mathrm{La}_{0,7} \mathrm{Mg}_{0,3} \mathrm{Al}_{0,3} \mathrm{Mn}_{0,4} \mathrm{Co}_{0,5} \mathrm{Ni}_{3,8}$; $\mathrm{La}_{0,7} \mathrm{Mg}_{0,3} \mathrm{Al}_{0,3} \mathrm{Mn}_{0,4} \mathrm{Cu}_{0,5} \mathrm{Ni}_{3,8}$ $\mathrm{La}_{0,7} \mathrm{Mg}_{0,3} \mathrm{Al}_{0,3} \mathrm{Mn}_{0,4} \mathrm{Sn}_{0,5} \mathrm{Ni}_{3,8}$; $\mathrm{La}_{0,7} \mathrm{Pr}_{0,3} \mathrm{Al}_{0,3} \mathrm{Mn}_{0,4} \mathrm{Co}_{0,5} \mathrm{Ni}_{3,8}$ e $\mathrm{Pr}_{0,7} \mathrm{Mg}_{0,3} \mathrm{Al}_{0,3} \mathrm{Mn}_{0,4} \mathrm{Co}_{0,5} \mathrm{Ni}_{3,8}$

\section{Elementos Químicos (\%massa)}

\begin{tabular}{lccccccccc}
\hline Ligas & La & Pr & Mg & Al & Mn & Cu & Sn & Co & Ni \\
\hline $\mathbf{C o}_{0,5}$ & 25,12 & - & 1,88 & 2,09 & 5,67 & - & - & 7,66 & 57,61 \\
$\mathrm{Cu}_{0,5}$ & 24,97 & - & 1,87 & 2,07 & 5,64 & 8,15 & - & - & 57,27 \\
& & & & & & & & & \\
$\mathbf{S n}_{0,5}$ & 23,32 & - & 1,74 & 1,94 & 5,26 & - & 6.87 & - & 53,48 \\
& & & & & & & & & \\
$\mathbf{L a}_{0,7} \mathbf{P r}_{0,3}$ & 23,04 & 3,04 & - & 1,92 & 5,71 & - & - & 8,07 & 58,22 \\
& & & & & & & & & \\
$\mathbf{P r}_{0,7} \mathbf{M g}_{0,3}$ & - & 23,98 & 1,84 & 2,12 & 5,62 & - & - & 7,92 & 58,43 \\
\hline
\end{tabular}

\section{3 - Difração de raios $X$}

A técnica de difração de raios $X$ foi utilizada para identificação de fases na amostra bem como suas estruturas cristalinas e também avaliar a fração das fases presentes na liga. A preparação de cada amostra para a difração de raios $\mathrm{X}$ partiuse inicialmente da britagem manual do lingote bruto de fusão e posteriormente da moagem mecânica em almofariz de ágata até obter partículas de dimensões inferiores a $75 \mu \mathrm{m}$ (<200 mesh). Utilizou-se um difratômetro modelo multiflex da empresa Rigaku.

Os principais parâmetros operacionais são apresentados a seguir:

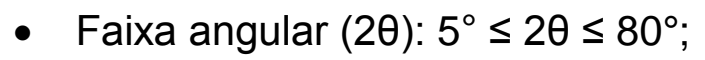

- Velocidade de varredura: $0,22^{\circ} \mathrm{min}^{-1}$;

- Radiação: CuKa

- Passo: 0,02. 
A identificação das fases foi realizada através do programa Crystallographica Search Match versão 2.4 (CSM) utilizando o método Rietveld para o refinamento dos parâmetros de rede das fases presentes nas ligas sem e com tratamentos térmicos, através do programa General Structure Analysis System (GSAS).

\section{4 - Microscopia eletrônica de varredura}

Para a caracterização metalográfica das ligas sem tratamentos térmicos e com tratamentos térmicos, empregaram-se técnicas convencionais. Dentre estas técnicas estão: inicialmente faz-se um corte na secção do lingote, obtendo uma região interna, posteriormente embutimento em resina epóxi e, finalizando com lixamento e polimento. Foram utilizados os microscópios eletrônico de varreduras, o de campo induzido SIGMA ZEISS (FEG) com eletroscopia de energia dispersiva (EDS) da marca FENIX acoplado e o tipo TABLE-TOP da marca RIGAKU modelo MT3000, para analisar as ligas sem e com TT.

\section{5 - Tratamentos térmicos}

Na FIGURA 14 mostra o sistema com forno onde foram realizados tratamentos térmicos nas ligas a fim de analisar e quantificar as mudanças das fases presentes na estrutura das ligas, o material foi introduzido em um vaso de aço inoxidável, e aquecido até $340^{\circ} \mathrm{C}$ por 1 hora em vácuo na ordem de $10^{-2} \mathrm{mbar}$, em seguida é adicionado 1,5 bar de gás Argônio 5.0 analítico, e aumenta a temperatura para o patamar desejado $\left(750\right.$ e $\left.850^{\circ} \mathrm{C}\right)$ durante os tempos de 9 e 16 horas. 
FIGURA 14 - Sistema de vácuo utilizado na hidrogenação e nos tratamentos térmico das ligas, onde: (a) bomba de vácuo mecânica (b) retorta, vaso de hidrogenação, (c) indicador digital de pressão, (d) indicador digital de alta pressão, (e) medidor de vácuo mecânico pirani, (f). forno (EDG) e (g) válvula para injeção de hidrogênio.

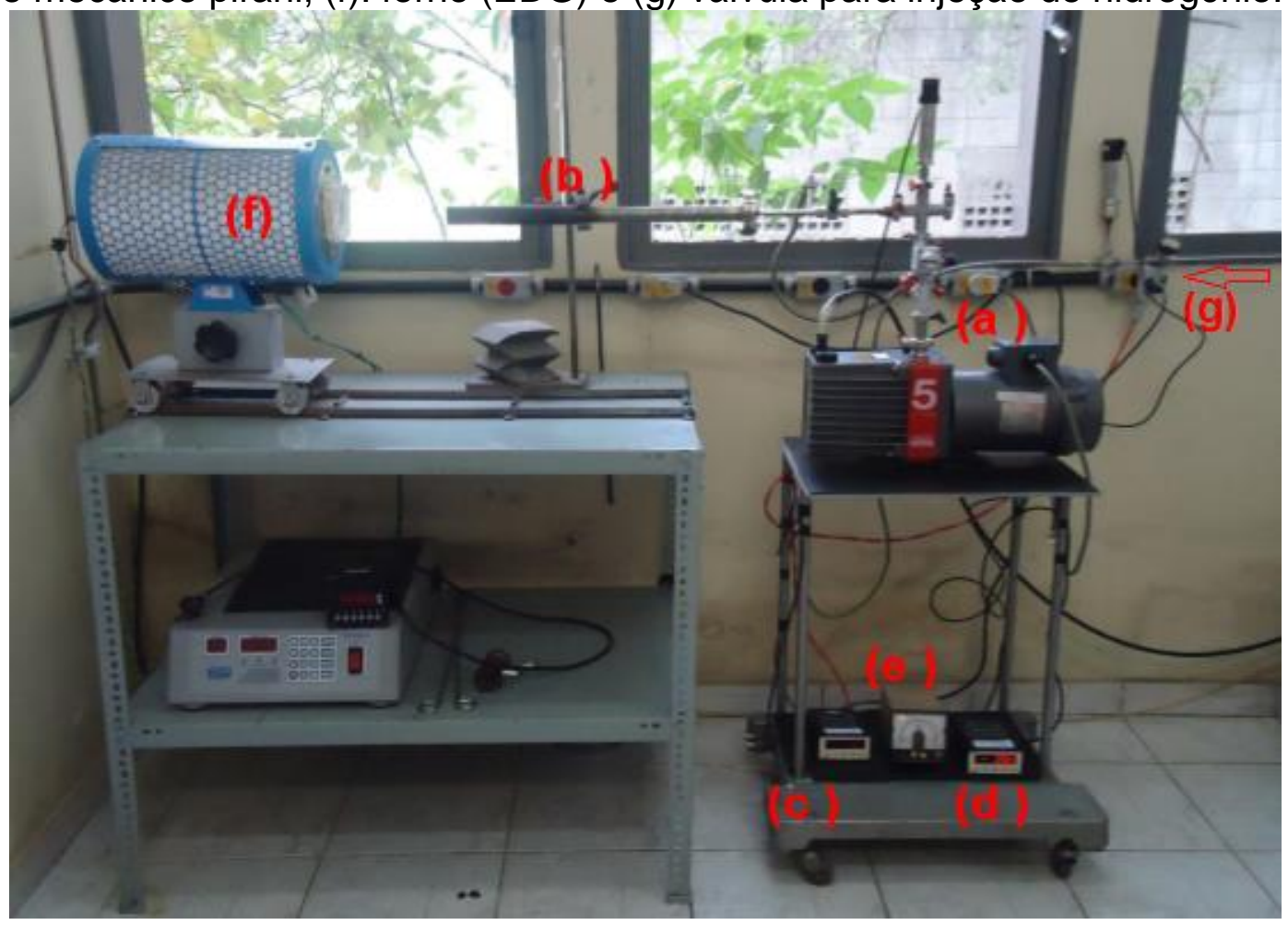

\section{6 - Hidrogenação}

O teste de hidrogenação das ligas se deu em duas formas:

Primeira onde 0 processo direto onde 0 gás de hidrogênio foi aplicado diretamente nas amostras sem e com TT em pressões relativas de 2, 4, 6 e 9 bar, objetivando fragilizar o material para analises morfológicas estes.

Segunda foi a analise de PCT dinâmico no equipamento do laboratório de materiais intermetálicos (GVCM), em um aparato Sieverts, onde as ligas foram analisadas tanto sem quanto com TT, sendo que na etapa do PCT das ligas tratadas termicamente foram também realizados teste sem e com 4 ciclos de ativação. 


\subsection{1 - Fragilização das ligas sem e com tratamento térmico}

Amostras das ligas com e sem TT com massa de $2 \mathrm{~g}$ foram envolvidos em uma malha de aço e colocados dentro de um recipiente de aço inox e, em seguida dentro de um vaso de inconel denominado como retorta, aplicou-se vácuo até a pressão de $2 \times 10^{-2}$ mbar e posteriormente introduziu-se o gás de hidrogênio nas pressões de 2, 4, 6 e 9 bar, onde as amostras foram mantidas nas pressões relativas por 60 minutos, onde os dados foram fornecidos através de barômetro digital e coletados manualmente para posterior confecção dos gráficos das curvas de absorção de hidrogênio.

\subsection{2 - Analise de P-C-T nas ligas sem e com tratamento térmico}

Utilizou-se o aparato Sieverts (dinâmico) mostrado na FIGURA 15 como uma forma de analise, que consiste na determinação da capacidade máxima de absorção de hidrogênio e sua respectiva pressão de saturação máxima PCT.

As analises de PCT das ligas sem tratamento térmico, onde o gás de hidrogênio foi introduzido no equipamento a uma vazão constante de $9 \mathrm{ml} / \mathrm{s}$ até atingir a pressão máxima de 10 bar admitida para estes testes, para quantificar a pressão de hidrogênio necessária para promover o inicio da formação do platô de absorção em cada composição nominal das ligas, os experimentos foram realizados com as ligas previamente reduzidas a pedaços menores que $75 \mu \mathrm{m}$.

A analise de hidrogenação das ligas e sem tratamento térmicos consistiu na determinação da capacidade máxima de absorção de hidrogênio e sua respectiva pressão de saturação máxima que para estas ligas $A B_{5}$ ficou em torno de 3 a 4 bar.

Uma vez conhecida a pressão de formação do platô de inicio de absorção, para as ligas com TT, estabeleceu-se que seria admitida uma pressão máxima de 5 bar de hidrogênio

$\mathrm{Na}$ etapa da analise com ciclos de ativações das ligas tratadas termicamente, que consiste em repetidas injeções e retiradas da pressão de hidrogênio para que ocorresse a denominada ativação do material. Neste trabalho foram realizados 
4 ciclos de ativação, com pressão de 4 bar de hidrogênio, para efeito de comparação dos resultados sem e com ativação nas ligas que obtiveram melhores resultados na analise eletroquímica após os tratamentos térmico. Os experimentos foram executados no laboratório de Intermetálicos e grupo de visualização cientifica em materiais (GVCM), no equipamento de fabricação do projeto FAPESP $n^{\circ}$ 2007/50018-2.

FIGURA 15 - Imagem do equipamento do tipo Sieverts construído pelo LMI (CCTM/IPEN): a) Painel de controle central do equipamento, b) retorta de aço utilizada nos estudos das ligas de armazenamento de hidrogênio, c) Reator conectado a bomba auxiliar turbomolecular.

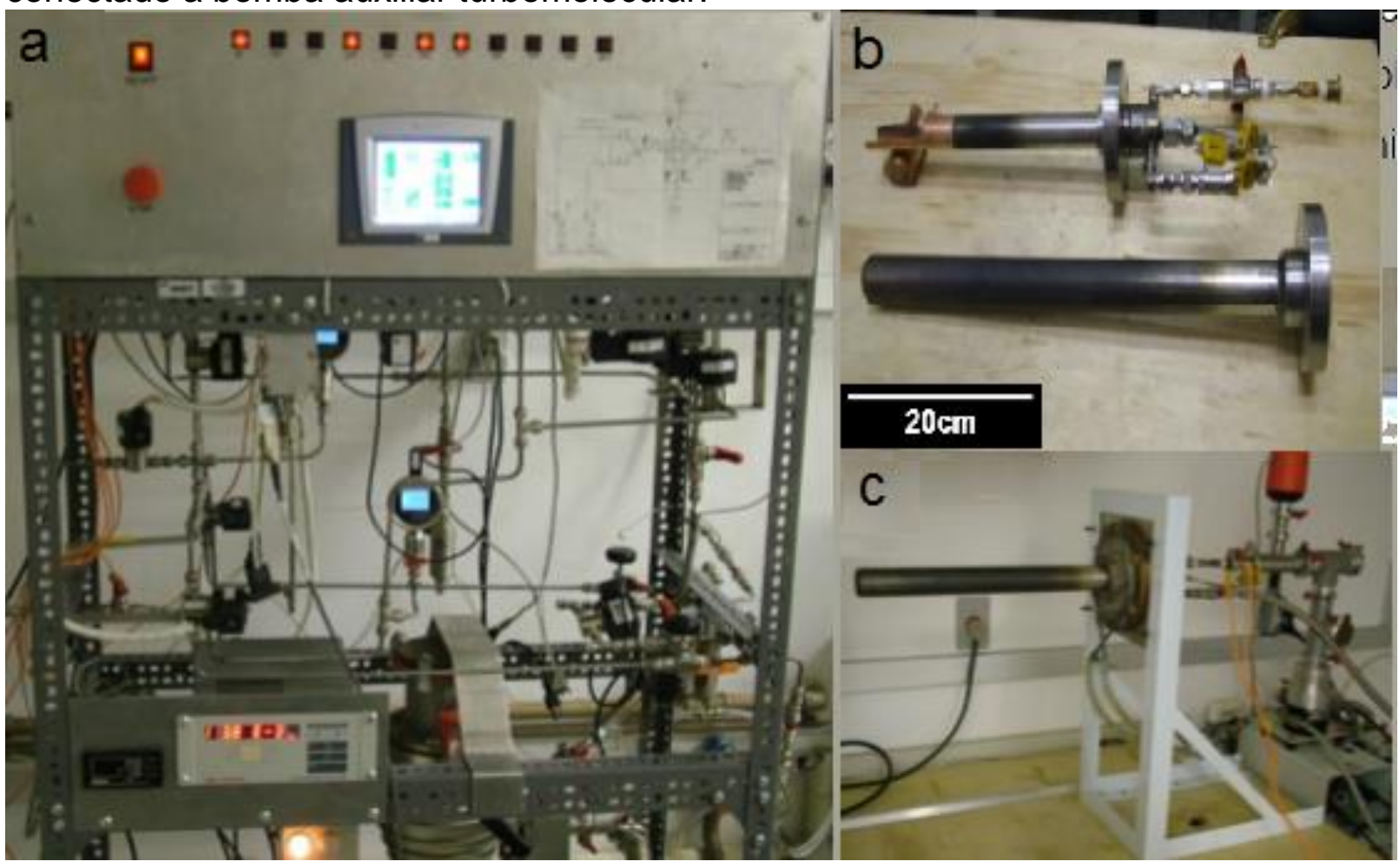




\section{7 - Fabricação dos eletrodos}

Esta seção foi subdividida em duas para melhor entendimento das etapas, na qual a primeira seção mostra os materiais e o processo de fabricação do cátodo e a segunda seção mostra os materiais e o processo de fabricação do ânodo.

\subsection{1 - Cátodo}

Para a montagem desse eletrodo foram utilizados os seguintes materiais descritos na TABELA 4.

TABELA 4 - Lista de materiais para montagem do eletrodo negativo.

\begin{tabular}{cc}
\hline Material & Quantidade $(\mathbf{m g})$ \\
\hline Liga metálica $(<75 \mu \mathrm{m})$ & 100 \\
Níquel em pó & 400 \\
PVDF & 5 \\
\hline
\end{tabular}

A etapa de fabricação do cátodo consiste na mistura desses três materiais em um almofariz de ágata por 30 minutos. Após essa homogeneização adiciona-se aproximadamente $0,1 \mathrm{ml}$ de $\mathrm{N}$-metil-2-pirrolidona (NMP). Esse solvente atua na dissolução do fluoreto de polivinilideno (PVDF) auxiliando na prensagem do material, bem como evitando a fragilização do eletrodo durante os ciclos de carga e descarga, em seguida foi realizada a secagem do eletrodo em uma estufa a $100^{\circ} \mathrm{C}$ por 1 hora.

Finaliza-se, então, a etapa de montagem do eletrodo negativo com a prensagem uniaxial, de 3 toneladas, para a mistura aplicada em uma tela de níquel, com dimensões $1 \times 1 \mathrm{~cm}$.

\subsection{2 - Ânodo}

Para a montagem desse eletrodo foram utilizados os seguintes materiais descritos na TABELA 5.

TABELA 5 - Lista de materiais para montagem do eletrodo positivo.

$\begin{array}{cc}\text { Material } & \text { Quantidade }(\mathbf{m g}) \\ \mathrm{NaOH} & 600 \\ \text { Níquel em pó } & 200 \\ \text { PVDF } & 10\end{array}$


A quantidade de material, descrita na TABELA 5, foi utilizada para a fabricação de dois eletrodos positivos que será mostrada na seção da montagem das baterias. Cabe ressaltar que, a quantidade do eletrodo positivo deve ser no mínimo o dobro do negativo para garantir que todos os resultados obtidos serão efetivamente do eletrodo negativo, e secagem em estufa a $100^{\circ} \mathrm{C}$ por 1 hora.

Finaliza-se, então, a montagem do eletrodo positivo com a prensagem uniaxial, $3 \mathrm{t}$, desta mistura em uma tela de níquel, com dimensões $1 \times 1 \mathrm{~cm}$.

\subsection{3 - Montagem das baterias}

A montagem final das baterias de $\mathrm{Ni}-\mathrm{HM}$ consistiu em colocar o eletrodo negativo em face com os dois eletrodos positivos, utilizando como separadores pedaços de filtros de papel cortados no formato dos eletrodos a fim de manter os eletrodos isolados, conforme representado na FIGURA 16. Posteriormente, o conjunto montado e imerso em um suporte e imerso em eletrólito de $\mathrm{KOH} 6 \mathrm{~mol} / \mathrm{l}$.

FIGURA 16 - Representação esquemática da montagem final das baterias de $\mathrm{Ni}-\mathrm{HM}$.

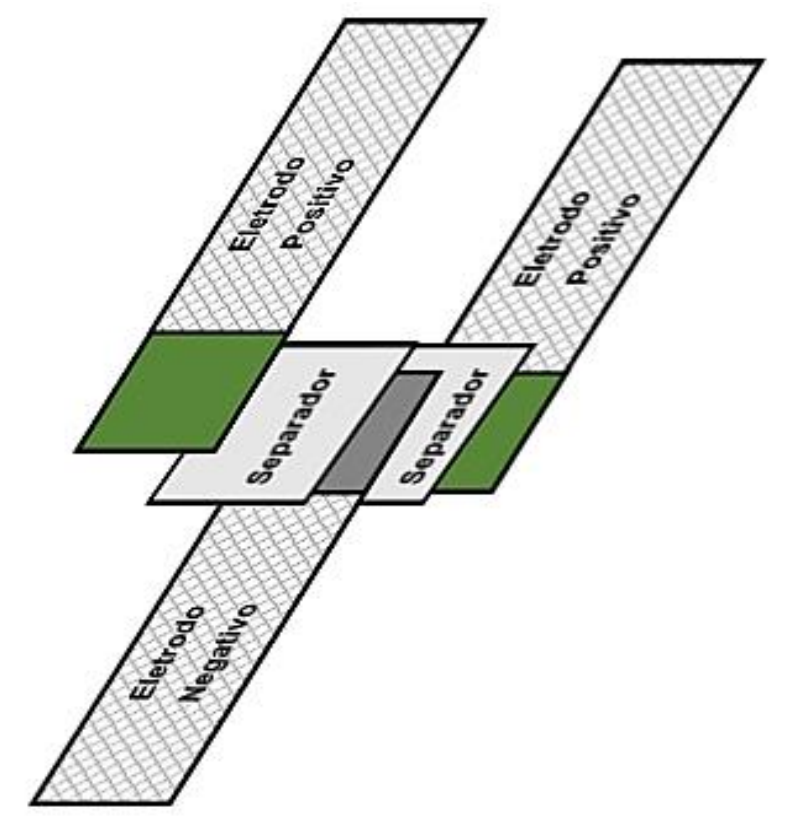




\section{8 - Testes eletroquímicos}

O ciclo de carga-descarga (ciclagem) é a técnica que se utiliza para caracterizar o material ativo diretamente. Trata-se aplicar carga e descarga completa de uma bateria em condições controladas. Para todos os testes elétricos realizados nesse trabalho utilizou-se o método de corrente constante, por um período de tempo suficiente para exceder $20 \%$ na capacidade de descarga nominal da bateria ( 300 $\mathrm{mAh} / \mathrm{g})$.

Os principais parâmetros operacionais são apresentados a seguir:

Carga: $100 \mathrm{~mA} / \mathrm{g}$ por 5 horas;

Descarga: $50 \mathrm{~mA} / \mathrm{g}$ com potencial de corte de 0,6 V.

Todos os testes elétricos foram realizados no equipamento de testes de baterias ARBIN-4 modelo T4 de quatro canais representado na FIGURA 17.

FIGURA 17 - Equipamento de testes eletroquímicos nas baterias modelo

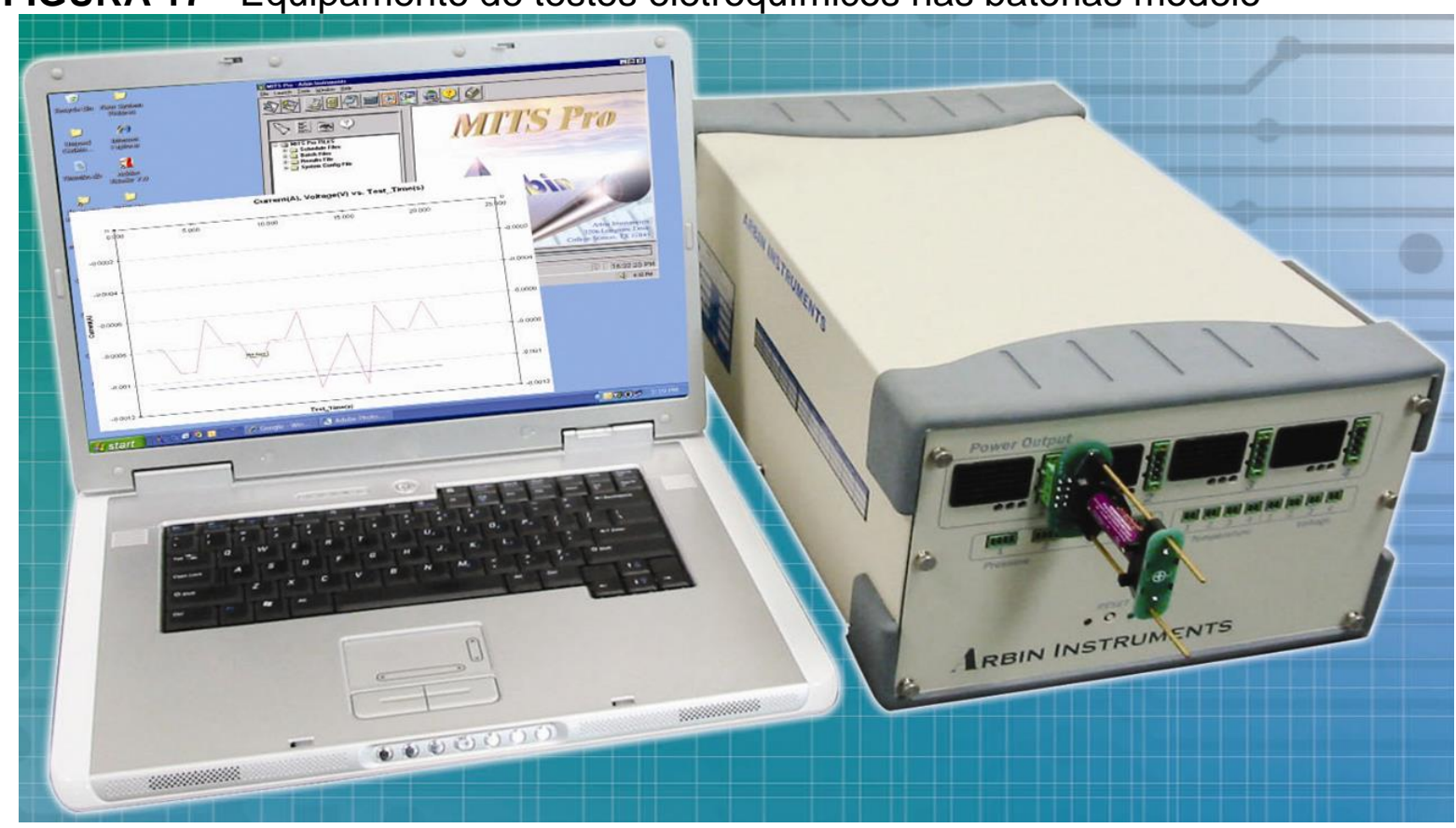




\section{5- RESULTADOS E DISCUSSÃO}

Neste capítulo, apresentam-se os resultados obtidos da seguinte forma:

- 5.1 - Caracterização química por ICP das ligas no estado bruto de fusão.

- 5.2 - Caracterização das ligas sem e após TT por difração de raios-X para determinar os parâmetros de rede das fases presentes por refinamento utilizando o método de Rietveld.

- 5.3 - Microscopia eletrônica de varredura das ligas sem e com tratamento térmico para analise química semiquantitativa por espectroscopia de energia dispersiva (EDS) das fases presentes.

- 5.4 - Reporta a influência dos elementos de adição e tratamentos térmicos no desempenho eletroquímico das baterias na capacidade de descarga das baterias de $\mathrm{NiMH}$.

- 5.5 - Análise de pressão-composição-temperatura (PCT) no patamar de absorção de hidrogênio das ligas, com a substituição química parcial do $\mathrm{Ni}$, sem tratamento térmico (TT). Serão avaliadas as ligas após TT das ligas que apresentaram melhor desempenho eletroquímico. A curva PCT foi realizada após quatro ciclos de ativação com hidrogênio.

- 5.6 - Características morfológicas (MEV) das ligas fragilizadas após hidrogenação com pressões relativas de 9, 6, 4, e 2 bar. 


\section{1- Caracterização Química}

A TABELA 6 apresenta a composição química obtida por ICP das ligas $\mathrm{La}_{0,7} \mathrm{Mg}_{0,3} \mathrm{Al}_{0,3} \mathrm{Mn}_{0,4} \mathrm{Co}_{0,5} \mathrm{Ni}_{3,8}$ $\mathrm{La}_{0,7} \mathrm{Mg}_{0,3} \mathrm{Al}_{0,3} \mathrm{Mn}_{0,4} \mathrm{Cu}_{0,5} \mathrm{Ni}_{3,8}$

$\mathrm{La}_{0,7} \mathrm{Mg}_{0,3} \mathrm{Al}_{0,3} \mathrm{Mn}_{0,4} \mathrm{Sn}_{0,5} \mathrm{Ni}_{3,8}$; $\mathrm{La}_{0,7} \mathrm{Pr}_{0,3} \mathrm{Al}_{0,3} \mathrm{Mn}_{0,4} \mathrm{Co}_{0,5} \mathrm{Ni}_{3,8}$

e $\operatorname{Pr}_{0,7} \mathrm{Mg}_{0,3} \mathrm{Al}_{0,3} \mathrm{Mn}_{0,4} \mathrm{Co}_{0,5} \mathrm{Ni}_{3,8}$.

Os valores determinados pela análise dos elementos químicos constituintes nas ligas permitiram avaliar que as composições são consistentes com as apresentadas na TABELA 3.

TABELA 6 - Composição química das ligas $\mathrm{La}_{0,7} \mathrm{Mg}_{0,3} \mathrm{Al}_{0,3} \mathrm{Mn}_{0,4} \mathrm{Co}_{0,5} \mathrm{Ni}_{3,8}$; $\mathrm{La}_{0,7} \mathrm{Mg}_{0,3} \mathrm{Al}_{0,3} \mathrm{Mn}_{0,4} \mathrm{Cu}_{0,5} \mathrm{Ni}_{3,8}$; $\mathrm{La}_{0,7} \mathrm{Mg}_{0,3} \mathrm{Al}_{0,3} \mathrm{Mn}_{0,4} \mathrm{Sn}_{0,5} \mathrm{Ni}_{3,8}$ $\mathrm{La}_{0,7} \mathrm{Pr}_{0,3} \mathrm{Al}_{0,3} \mathrm{Mn}_{0,4} \mathrm{Co}_{0,5} \mathrm{Ni}_{3,8}$ e $\mathrm{Pr}_{0,7} \mathrm{Mg}_{0,3} \mathrm{Al}_{0,3} \mathrm{Mn}_{0,4} \mathrm{Co}_{0,5} \mathrm{Ni}_{3,8}$ analizadas por ICP-AES.

\section{Elementos Químicos (\% massa)}

\begin{tabular}{lccccccccc}
\hline Ligas & La & Pr & Mg & Al & Mn & Cu & Sn & Co & Ni \\
\hline $\mathbf{C o}_{0,5}$ & 24,94 & - & 1,95 & 2,31 & 6,84 & - & - & 7,01 & 56,95 \\
$\mathbf{C u}_{0,5}$ & 24,97 & - & 1,89 & 2,09 & 5,74 & 8,21 & - & - & 57,10 \\
$\mathbf{S n}_{0,5}$ & 23,42 & - & 1,68 & 1,94 & 5,32 & - & 8,95 & - & 58,69 \\
$\mathbf{L a}_{0,7} \mathbf{P r}_{0,3}$ & 24,53 & 2,54 & - & 2,07 & 5,26 & - & - & 7,98 & 57,62 \\
$\mathbf{P r}_{0,7} \mathbf{M g}_{0,3}$ & - & 24,28 & 1,94 & 2,32 & 5,68 & - & - & 8,02 & 57,76 \\
\hline
\end{tabular}

\section{2- Caracterização por difração de raios-X com refinamento pelo método de} Rietveld

\subsection{1 - Ligas sem tratamento térmico (TT)}

Na Figura 19 estão apresentadas as fases presentes obtidas por difração de raios-X utilizando o método de Rietveld e na Tabela 7 os parâmetros de rede obtidos pelo refinamento. As ligas sem TT, $\mathrm{La}_{0,7} \mathrm{Mg}_{0,3} \mathrm{Al}_{0,3} \mathrm{Mn}_{0,4} \mathrm{Co}_{0,5} \mathrm{Ni}_{3,8}$ e $\mathrm{La}_{0,7} \mathrm{Mg}_{0,3} \mathrm{Al}_{0,3} \mathrm{Mn}_{0,4} \mathrm{Cu}_{0,5} \mathrm{Ni}_{3,8}$, são compostas principalmente pelas fases $\mathrm{LaNi}_{5}$ em 
maior concentração, $\mathrm{MgNi}_{2}$ e $\mathrm{LaMg}_{2} \mathrm{Ni}_{9}$. Na substituição do La pelo $\mathrm{Mg}$ a reação apresentada na equação 5.1 mostra a formação da fase $\mathrm{LaMg}_{2} \mathrm{Ni}_{9}$ fase estudada por Oesterreicher et al (1980) e Kadir et al (1997). Sendo esta fase um subnivel das fases $\mathrm{LaNi}_{5}$ e $\mathrm{MgNi}_{2}$ formada ao longo do eixo $c$ conforme está apresentada na Figura 18 onde mostra os planos espaciais das fases apresentadas na equação 5.1 (Base de Estruturas Cristalinas (dotlib)).

A substituição parcial do $\mathrm{Ni}$ pelo $\mathrm{Sn}$, formando a liga $\mathrm{La}_{0,7} \mathrm{Mg}_{0,3} \mathrm{Al}_{0,3} \mathrm{Mn}_{0,4} \mathrm{Sn}_{0,5} \mathrm{Ni}_{3,8}$, apresentou a fase $\mathrm{LaSn}_{2} \mathrm{Ni}_{2}$, LaNi $\mathrm{La} \mathrm{MgNi}_{2}$. Com a substituição do $\mathrm{Mg}$ pelo $\mathrm{Pr}$, tendo como liga $\mathrm{La}_{0,7} \mathrm{Pr}_{0,3} \mathrm{Al}_{0,3} \mathrm{Mn}_{0,4} \mathrm{Co}_{0,5} \mathrm{Ni}_{3,8}$, aparecendo as fases $\mathrm{LaNi}_{5}$ em maior concentração que $\mathrm{PrNi}_{5}$. A substituição do La pelo $\mathrm{Pr}$, $\mathrm{Pr}_{0,7} \mathrm{Mg}_{0,3} \mathrm{Al}_{0,3} \mathrm{Mn}_{0,4} \mathrm{Co}_{0,5} \mathrm{Ni}_{3,8}$, apresentou as fases $\mathrm{PrNi}_{5}$ em maior concentração, (AIMn) $\mathrm{Ni}_{3}$ e $\mathrm{PrMg}_{2} \mathrm{Ni}_{9}$. A fase $\mathrm{PrMg}_{2} \mathrm{Ni}_{9}$ presente na liga com Pr substituindo o $\mathrm{La}$ também se mostrou presente nas fases obtidas por Zhang Y. et al (2007).

$$
\mathrm{LaNi}_{5}+2\left(\mathrm{MgNi}_{2}\right) \stackrel{900-1100^{\circ} \mathrm{C}}{\longrightarrow} \mathrm{LaMg}_{2} \mathrm{Ni}_{9}
$$

FIGURA 18 - Esquema da formação da estrutura cristalina no plano espacial da liga do tipo $\mathrm{A}_{2} \mathrm{~B}_{9}$ (adaptado da Base de Estruturas Cristalinas icsd-fiz-karlsruhe de.proxy01.dotlib.com.br)

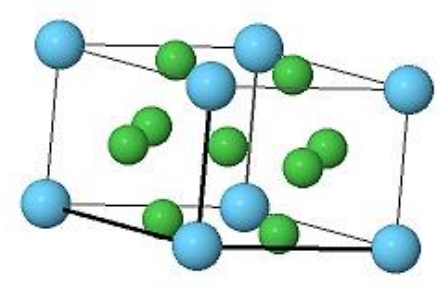

$\mathrm{LaNi}_{5}$

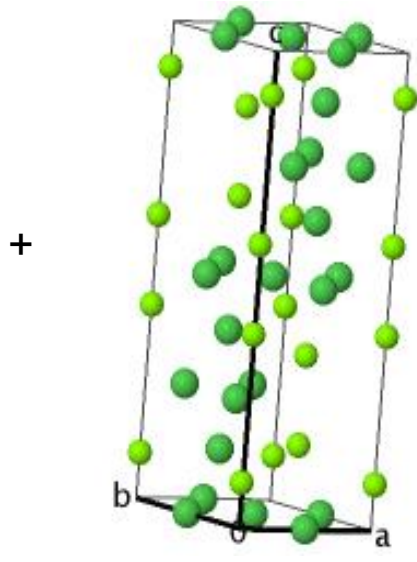

$\mathrm{MgNi}_{2}$

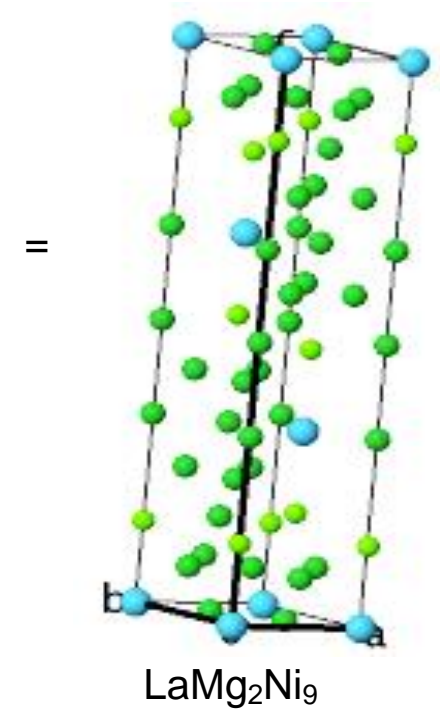


FIGURA 19 - Difratogramas de raios-X para o refinamento por Rietveld das ligas $\mathrm{La}_{0,7} \mathrm{Mg}_{0,3} \mathrm{Al}_{0,3} \mathrm{Mn}_{0,4} \mathrm{Cu}_{0,5} \mathrm{Ni}_{3,8}$, $\mathrm{La}_{0,7} \mathrm{Mg}_{0,3} \mathrm{Al}_{0,3} \mathrm{Mn}_{0,4} \mathrm{Sn}_{0,5} \mathrm{Ni}_{3,8}$, $\mathrm{Pr}_{0,7} \mathrm{Mg}_{0,3} \mathrm{Al}_{0,3} \mathrm{Mn}_{0,4} \mathrm{Co}_{0,5} \mathrm{Ni}_{3,8}$ sem TT. $\mathrm{La}_{0,7} \mathrm{Mg}_{0,3} \mathrm{Al}_{0,3} \mathrm{Mn}_{0,4} \mathrm{Co}_{0,5} \mathrm{Ni}_{3,8}$

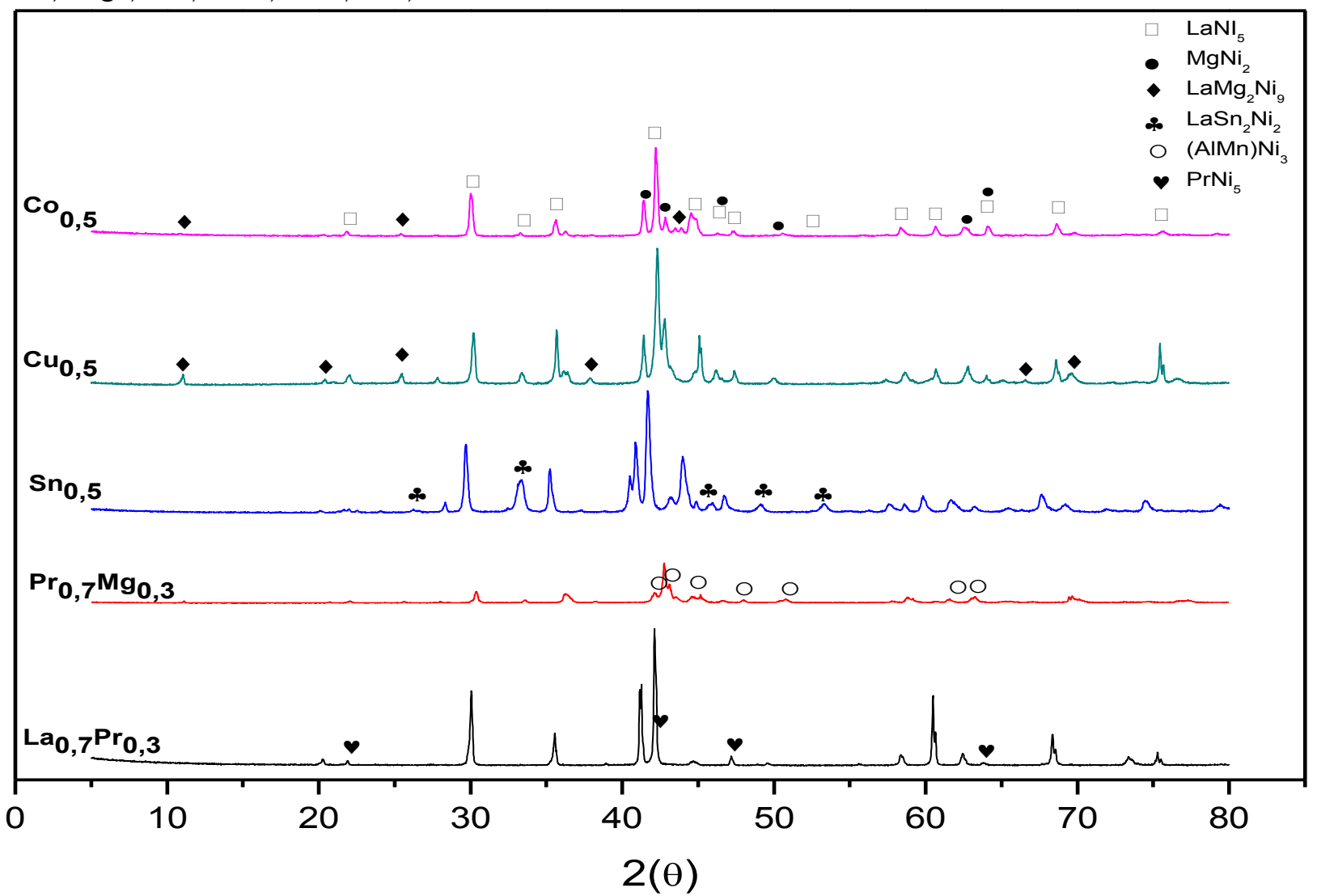

TABELA 7 - Parâmetros obtidos através do refinamento por Rietveld das ligas $\mathrm{La}_{0,7} \mathrm{Mg}_{0,3} \mathrm{Al}_{0,3} \mathrm{Mn}_{0,4} \mathrm{Cu}_{0,5} \mathrm{Ni}_{3,8}$ $\mathrm{La}_{0,7} \mathrm{Mg}_{0,3} \mathrm{Al}_{0,3} \mathrm{Mn}_{0,4} \mathrm{Sn}_{0,5} \mathrm{Ni}_{3,8}$, $\mathrm{La}_{0,7} \mathrm{Mg}_{0,3} \mathrm{Al}_{0,3} \mathrm{Mn}_{0,4} \mathrm{Co}_{0,5} \mathrm{Ni}_{3,8}$, $\mathrm{Pr}_{0,7} \mathrm{Mg}_{0,3} \mathrm{Al}_{0,3} \mathrm{Mn}_{0,4} \mathrm{Co}_{0,5} \mathrm{Ni}_{3,8}$ sem TT.

\begin{tabular}{|c|c|c|c|c|c|c|c|}
\hline \multirow[t]{2}{*}{ Liga } & \multirow[t]{2}{*}{ Fases } & \multirow{2}{*}{$\begin{array}{l}\text { Parâm. de } \\
\text { ajuste }\left(x^{2}\right)\end{array}$} & \multirow{2}{*}{$\begin{array}{c}\text { Fração } \\
\text { da fase } \\
(\% \text { massa) }\end{array}$} & \multicolumn{3}{|c|}{$\begin{array}{c}\text { Parâmetros de } \\
\operatorname{Rede}(\AA)\end{array}$} & \multirow{2}{*}{$\begin{array}{l}\text { Vol. da } \\
\text { célula } \\
\text { unit. }\left(\AA^{3}\right)\end{array}$} \\
\hline & & & & $\mathbf{a}$ & & c & \\
\hline \multirow{3}{*}{$\mathrm{Co}_{0,5}$} & $\mathrm{LaNi}_{5}$ & & 81 & 5,027 & & 4,052 & 88,7 \\
\hline & $\mathrm{LaMg}_{2} \mathrm{Ni}_{9}$ & 6,4 & 12 & 4,944 & & 24,160 & 511,5 \\
\hline & $\mathrm{MgNi}_{2}$ & & 7 & 4,874 & & 15,416 & 317,1 \\
\hline \multirow{3}{*}{$\mathrm{Cu}_{0,5}$} & $\mathrm{LaNi}_{5}$ & & 57 & 5,039 & & 4,033 & 88,7 \\
\hline & $\mathrm{LaMg}_{2} \mathrm{Ni}_{9}$ & 6,2 & 32 & 4,941 & & 24,947 & 516,3 \\
\hline & $\mathrm{MgNiCu}$ & & 11 & 4,903 & & 23,921 & 503,8 \\
\hline \multirow{3}{*}{$\mathrm{Sn}_{0,5}$} & $\mathrm{LaNi}_{5}$ & & 69,3 & 5,094 & & 4,144 & 92,5 \\
\hline & $\mathrm{LaSn}_{2} \mathrm{Ni}_{2}$ & 8,6 & 14 & 4,852 & & 10,803 & 202,3 \\
\hline & $\mathrm{MgNi}_{2}$ & & 17 & 4,819 & & 15,816 & 318,1 \\
\hline \multirow{2}{*}{ LaPr } & $\mathrm{LaNi}_{5}$ & & 77,8 & 5,029 & & 4,051 & 89,9 \\
\hline & $\mathrm{PrNi}_{5}$ & 5,8 & 22,2 & 5,040 & & 4,045 & 89,1 \\
\hline \multirow{3}{*}{ PrMg } & $\mathrm{PrNi}_{5}$ & & 63,1 & 4,962 & & 4,055 & 86,5 \\
\hline & $\mathrm{PrMg}_{2} \mathrm{Ni}_{9}$ & 2,2 & 14,3 & 4,932 & & 24,034 & 506,5 \\
\hline & $\left(\right.$ AIMn) $\mathrm{Ni}_{3}$ & & 22,6 & 3,602 & 3,602 & 3,602 & 46,7 \\
\hline
\end{tabular}




\subsection{2 - Liga $\mathrm{La}_{0,7} \mathrm{Mg}_{0,3} \mathrm{Al}_{0,3} \mathrm{Mn}_{0,4} \mathrm{Co}_{0,5} \mathrm{Ni}_{3,8}$ sem e com TT}

Na FIGURA 20 e TABELA 8 apresentam, respectivamente, os difratogramas de raios- $X$ das ligas $\mathrm{La}_{0,7} \mathrm{Mg}_{0,3} \mathrm{Al}_{0,3} \mathrm{Mn}_{0,4} \mathrm{Co}_{0,5} \mathrm{Ni}_{3,8}$ com TT nas temperaturas de $750 \mathrm{e}$ $850^{\circ} \mathrm{C}$ por 9 e 16 horas e a liga no estado bruto de fusão foi adicionada para comparação dos resultados. Foram identificadas as fases: $\mathrm{LaNi}_{5}$ do tipo $\mathrm{AB}_{5}$ onde a parte A corresponde a $\mathrm{La} \mathrm{e} \mathrm{Mg}$ e na parte $\mathrm{B}$ aos elementos Al, Mn, Co e Ni estrutura hexagonal do grupo espacial: P6/mmm (PDF: 50-7777), presente na microestruturas para as amostras sem TT, mas partir do primeiro TT em $750^{\circ} \mathrm{C}$ por 9 horas identificou-se a fase $\mathrm{LaNi}_{4,7} \mathrm{Mn}_{0,3}$ onde $\circ \mathrm{Mn}$ se soma ao $\mathrm{Ni}$ semelhante a fase $\mathrm{LaNi}_{5}$ também com estrutura hexagonal do grupo espacial P6/mmm com (PDF 65-3852), provavelmente promovida pela mobilidade do $\mathrm{Mn}$, com as mesmas características da fase $\mathrm{LaNi}_{5}$, conforme descrita por Buschow and Van der Goot (1970) e Van Mal et al (1974).

A fase $\mathrm{MgNi}_{2}$ do tipo $A B_{2}$ com estrutura hexagonal do grupo espacial: $\mathrm{P}_{3} / \mathrm{mmc}$ (PDF: 65-3630).

A fase $\mathrm{LaMg}_{2} \mathrm{Ni}_{9}$ tipo $\mathrm{PuNi}_{3}$ de estrutura romboédrica estudada por (Vikar e Raman 1969), TABELA 7 foi observada nas ligas $\mathrm{La}_{0,7} \mathrm{Mg}_{0,3} \mathrm{Al}_{0,3} \mathrm{Mn}_{0,4} \mathrm{Co}_{0,5} \mathrm{Ni}_{3,8}$ sem tratamento térmico e tratadas a $750^{\circ} \mathrm{C}$ por 9 horas, observou-se que a partir do tratamento térmico a $750^{\circ} \mathrm{C}$ por 16 horas inicia o surgimento de uma nova fase $\mathrm{Al}_{6} \mathrm{Mn}$ com estrutura ortorrômbica do grupo espacial C/cmm (PDF: 6-665), substituindo a fase do tipo $\mathrm{A}_{2} \mathrm{~B}_{9}$ até uma aumentando a concentração da fração da fase no tratamento térmico de $850^{\circ} \mathrm{C}$ por 16 horas, nas mesmas condições também ocorre o aparecimento da fase $\mathrm{LaCo}_{13}$ com estrutura cúbica de face centrada do grupo espacial: Fm-3c (PDF: 19-345) estrutura estudada por Wu e colaboradores em 1999. A TABELA 8 apresenta os parâmetros $a, b$ e c, onde o eixo $c$ da fase $A l_{6} M n$ diminui muito em relação ao eixo $c$ da fase $\mathrm{LaMg}_{2} \mathrm{Ni}_{9}$ provocando uma retração no volume da célula unitária, mas frações dessas novas fases aumentaram gradativamente nos tratamentos térmicos de $750^{\circ} \mathrm{C}$ por 16 horas e $850^{\circ} \mathrm{C}$ por 9 e 16 horas e, observou-se também que a fração da fase $\mathrm{LaNi}_{5}$ diminui de $81 \%$ para $68,5 \%$ com esses tratamentos térmicos. Ocorre um aumento da fração da fase $\mathrm{MgNi}_{2}$ até o tratamento térmico em $750^{\circ} \mathrm{C}$ por 9 horas, seguindo de uma diminuição ocasionada pelo surgimento da fase $\mathrm{LaCo}_{13}$ também estudada anteriormente por Liu et al (2016). 
FIGURA 20 - Difratogramas de raios $X$ das ligas $L a_{0,7} \mathrm{Mg}_{0,3} \mathrm{Al}_{0,3} \mathrm{Mn}_{0,4} \mathrm{Co}_{0,5} \mathrm{Ni}_{3,8}$ sem e com tratamentos térmicos.

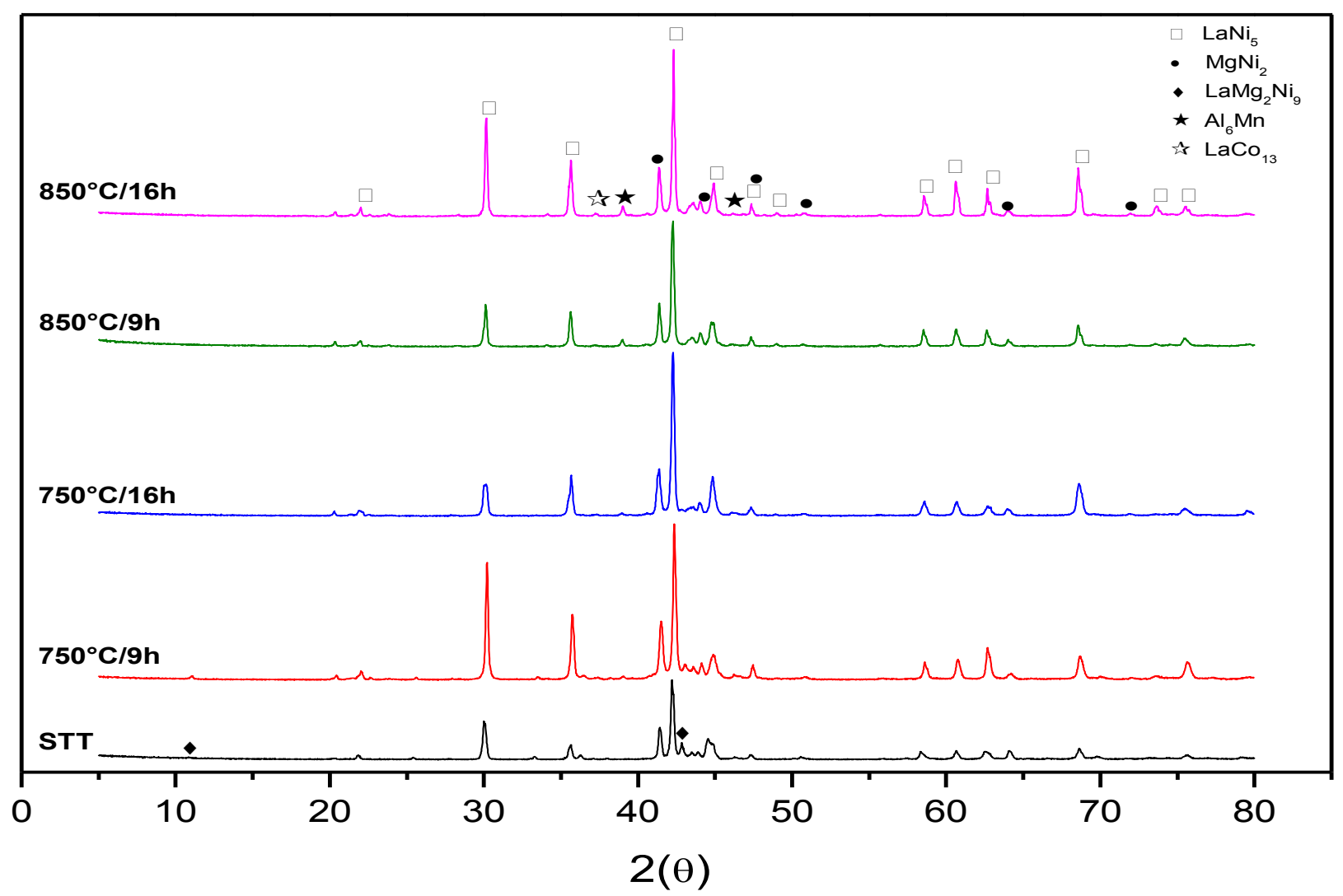

TABELA 8 - Parâmetros obtidos através do refinamento por Rietveld das ligas $\mathrm{La}_{0,7} \mathrm{Mg}_{0,3} \mathrm{Al}_{0,3} \mathrm{Mn}_{0,4} \mathrm{Co}_{0,5} \mathrm{Ni}_{3,8}$ sem e com TT.

\begin{tabular}{|c|c|c|c|c|c|c|c|}
\hline \multirow[t]{2}{*}{ TT } & \multirow[t]{2}{*}{ Fases } & \multirow{2}{*}{$\begin{array}{l}\text { Parâm. de } \\
\text { ajuste }\left(\varkappa^{2}\right)\end{array}$} & \multirow{2}{*}{$\begin{array}{c}\text { Fração } \\
\text { da fase } \\
\text { (\% massa) }\end{array}$} & \multicolumn{3}{|c|}{$\begin{array}{c}\text { Parâmetros de } \\
\text { Rede }(\AA \AA)\end{array}$} & \multirow{2}{*}{$\begin{array}{c}\text { Vol. da } \\
\text { célula } \\
\text { unit. }\left(\AA^{3}\right)\end{array}$} \\
\hline & & & & a & b & c & \\
\hline \multirow{3}{*}{ STT } & $\mathrm{LaNi}_{5}$ & & 81 & 5,027 & & 4,052 & 88,7 \\
\hline & $\mathrm{LaMg}_{2} \mathrm{Ni}_{9}$ & 6,4 & 12 & 4,944 & & 24,160 & 511,5 \\
\hline & $\mathrm{MgNi}_{2}$ & & 7 & 4,874 & & 15,416 & 317,1 \\
\hline \multirow{3}{*}{$750 / 9 h$} & $\mathrm{LaNi}_{5}$ & & 77 & 5,032 & & 4,044 & 88,7 \\
\hline & $\mathrm{LaMg}_{2} \mathrm{Ni}_{9}$ & 5,2 & 6 & 4,930 & & 24,101 & 507,3 \\
\hline & $\mathrm{MgNi}_{2}$ & & 17 & 4,821 & & 15,693 & 315,9 \\
\hline \multirow{4}{*}{ 750/16h } & $\mathrm{LaNi}_{5}$ & & 73 & 5,031 & & 4,035 & 88,5 \\
\hline & $\mathrm{La} \mathrm{Co}_{13}$ & 5,4 & 1 & 11,308 & 11,308 & 11,308 & 1446,1 \\
\hline & $\mathrm{Al}_{6} \mathrm{Mn}$ & & 14 & 7,446 & 6,493 & 8,899 & 430,3 \\
\hline & $\mathrm{MgNi}_{2}$ & & 13 & 4,815 & & 15,680 & 314,8 \\
\hline \multirow{4}{*}{$850 / 9 h$} & $\mathrm{LaNi}_{5}$ & & 64,3 & 5,033 & & 4,040 & 88,6 \\
\hline & $\mathrm{LaCo}_{13}$ & & 2 & 11,307 & 11,307 & 11,307 & 1445,5 \\
\hline & $\mathrm{Al}_{6} \mathrm{Mn}$ & 3,9 & 21,7 & 7,451 & 6,495 & 8,810 & 426,4 \\
\hline & $\mathrm{MgNi}_{2}$ & & 11,8 & 4,811 & & 15,717 & 314,9 \\
\hline \multirow{4}{*}{$850 / 16 h$} & $\mathrm{LaNi}_{5}$ & & 68,5 & 5,035 & & 4,036 & 88,6 \\
\hline & $\mathrm{LaCo}_{13}$ & & 3 & 11,307 & 11,307 & 11,307 & 1445,6 \\
\hline & $\mathrm{Al}_{6} \mathrm{Mn}$ & 4,9 & 18,9 & 7,541 & 6,486 & 8,909 & 435,7 \\
\hline & $\mathrm{MgNi}_{2}$ & & 10,3 & 4,821 & & 15,703 & 316,1 \\
\hline
\end{tabular}




\subsection{3 - Liga $\mathrm{La}_{0,7} \mathrm{Mg}_{0,3} \mathrm{Al}_{0,3} \mathrm{Mn}_{0,4} \mathrm{Cu}_{0,5} \mathrm{Ni}_{3,8}$ sem e com TT}

Na FIGURA 21 e TABELA 9 apresentam, respectivamente, os difratogramas de raios- $X$ das ligas $\mathrm{La}_{0,7} \mathrm{Mg}_{0,3} \mathrm{Al}_{0,3} \mathrm{Mn}_{0,4} \mathrm{Cu}_{0,5} \mathrm{Ni}_{3,8}$ com tratamentos térmicos de $750 \mathrm{e}$ $850^{\circ} \mathrm{C}$ por 9 e 16 horas e a liga estado bruto de fusão adicionada para comparação dos resultados.

Foram identificadas as fases: $\mathrm{LaNi}_{5}$ do tipo $\mathrm{AB}_{5}$ estrutura hexagonal do grupo espacial: $\mathrm{P} 6 / \mathrm{mmm}$ (PDF: $50-7777$ ), $\mathrm{LaMg}_{2} \mathrm{Ni}_{9}$ tipo $\mathrm{PuNi}_{3}$ de estrutura romboédrica do grupo espacial: R-3m (PDF: 50-1454) e MgNiCu do tipo $\mathrm{AB}_{2}$ estrutura hexagonal do grupo espacial: $\mathrm{P}_{3} / \mathrm{mmc}$ (PDF: 25-296), com a entrada do Cu nesta fase ( $\mathrm{MgNi}_{2}$ ) ocorreu um aumento do eixo $c$ de 15, 416 para 23,921 $\AA$ provocando uma ganho no volume da célula unitária consequentemente foi de 317,1 para $503,8 \AA^{3}$, quando comparados aos dados fornecidos na tabela 8 para a fase $\mathrm{MgNi}_{2}$.

A TABELA 9 mostra os parâmetros de rede cristalina das fases estão presentes em todos os tratamentos térmicos.

FIGURA 21 - Difratogramas de raios- $X$ das ligas $\mathrm{La}_{0,7} \mathrm{Mg}_{0,3} \mathrm{Al}_{0,3} \mathrm{Mn}_{0,4} \mathrm{Cu}_{0,5} \mathrm{Ni}_{3,8}$ com e sem tratamentos térmicos.

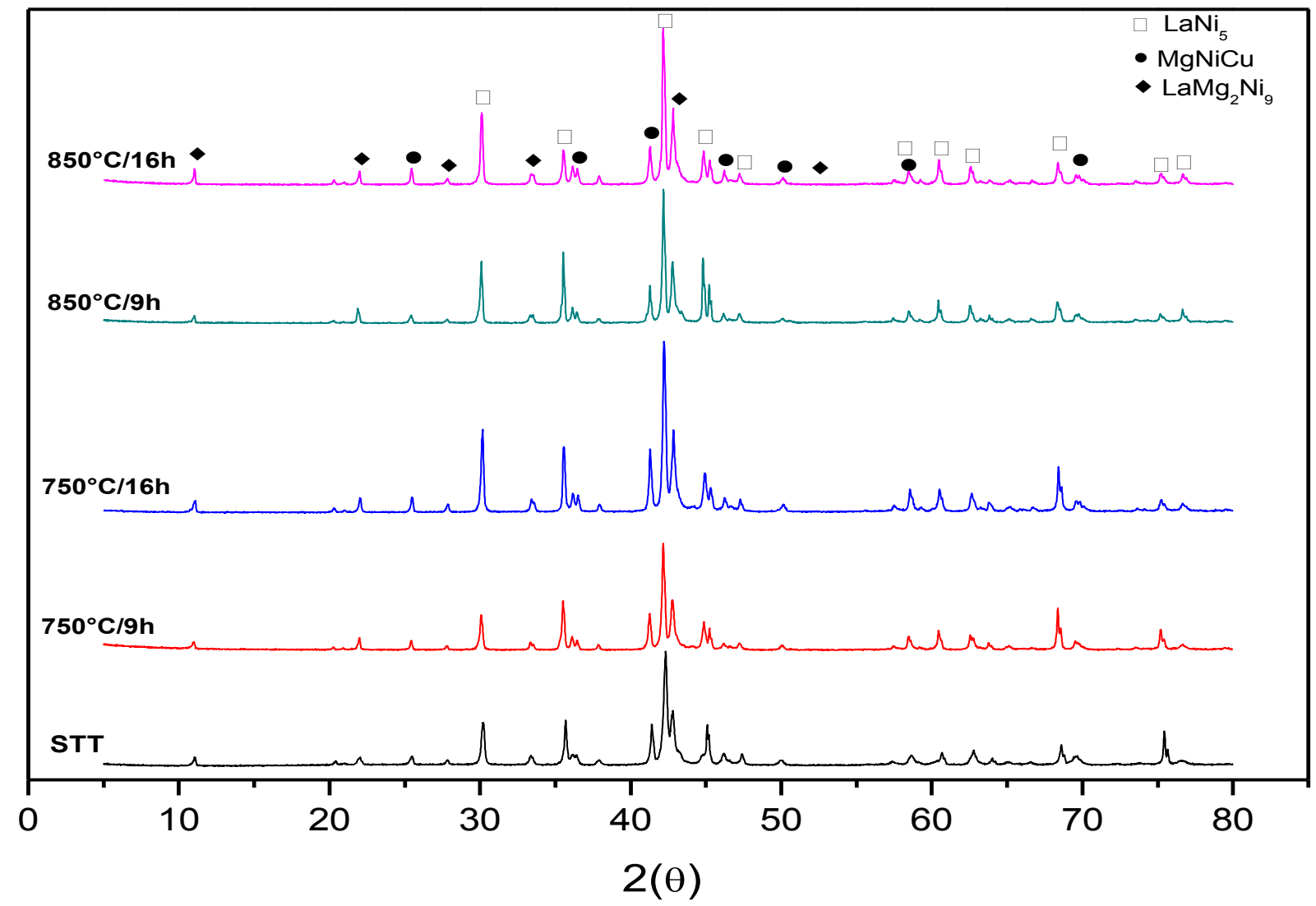


TABELA 9 - Parâmetros obtidos através do refinamento por Rietveld das ligas $\mathrm{La}_{0,7} \mathrm{Mg}_{0,3} \mathrm{Al}_{0,3} \mathrm{Mn}_{0,4} \mathrm{Cu}_{0,5} \mathrm{Ni}_{3,8}$ sem e com TT.

\begin{tabular}{|c|c|c|c|c|c|c|}
\hline \multirow[t]{2}{*}{ TT } & \multirow[t]{2}{*}{ Fases } & \multirow{2}{*}{$\begin{array}{l}\text { Parâm. } \\
\text { de ajuste } \\
\left(\boldsymbol{x}^{2}\right)\end{array}$} & \multirow{2}{*}{$\begin{array}{c}\text { Fração } \\
\text { da fase } \\
(\% \text { massa) }\end{array}$} & \multicolumn{2}{|c|}{$\begin{array}{l}\text { Parâmetros de } \\
\text { rede (Å) }\end{array}$} & \multirow{2}{*}{$\begin{array}{c}\text { Vol. da } \\
\text { célula unit. } \\
\left(\AA^{3}\right)\end{array}$} \\
\hline & & & & $\mathbf{a}$ & b $\quad$ c & \\
\hline \multirow{3}{*}{ STT } & $\mathrm{LaNi}_{5}$ & & 57 & 5,039 & 4,033 & 88,70 \\
\hline & $\mathrm{LaMg}_{2} \mathrm{Ni}_{9}$ & 6,17 & 32 & 4,941 & 24,097 & 516,35 \\
\hline & $\mathrm{MgNiCu}$ & & 11 & 4.903 & 23,921 & 503,80 \\
\hline \multirow{3}{*}{$750 / 9 h$} & $\mathrm{LaNi}_{5}$ & & 57 & 5,048 & 4,036 & 89,10 \\
\hline & $\mathrm{LaMg}_{2} \mathrm{Ni}_{9}$ & 4,56 & 30 & 4,968 & 24,026 & 513,60 \\
\hline & $\mathrm{MgNiCu}$ & & 13 & 4,894 & 24,318 & 504,40 \\
\hline \multirow{3}{*}{$750 / 16 h$} & $\mathrm{LaNi}_{5}$ & & 59 & 5,049 & 4,084 & 89,10 \\
\hline & $\mathrm{LaMg}_{2} \mathrm{Ni}_{9}$ & 4,82 & 31 & 4,968 & 24,013 & 513,20 \\
\hline & $\mathrm{MgNiCu}$ & & 10 & 4,903 & 24,181 & 503,30 \\
\hline \multirow{3}{*}{$850 / 9 \mathrm{~h}$} & $\mathrm{LaNi}_{5}$ & & 55 & 5,049 & 4,040 & 89,20 \\
\hline & $\mathrm{LaMg}_{2} \mathrm{Ni}_{9}$ & 4,19 & 34 & 4.968 & 24.028 & 513,60 \\
\hline & $\mathrm{MgNiC}$ & & 11 & 4,903 & 24,185 & 503,50 \\
\hline \multirow{3}{*}{$850 / 16 h$} & $\mathrm{LaNi}_{5}$ & & 52 & 5,050 & 4,041 & 89,26 \\
\hline & $\mathrm{LaMg}_{2} \mathrm{Ni}_{9}$ & 3,96 & 36,2 & 4.968 & 24.030 & 513,79 \\
\hline & $\mathrm{MgNiCu}$ & & 11,8 & 4,909 & 24,105 & 503,43 \\
\hline
\end{tabular}

\subsection{4 - Liga La ${ }_{0,7} \mathrm{Mg}_{0,3} \mathrm{Al}_{0,3} \mathrm{Mn}_{0,4} \mathrm{Sn}_{0,5} \mathrm{Ni}_{3,8}$ sem e com tratamentos térmicos}

A FIGURA 22 e a TABELA 10 apresentam, respectivamente, os difratogramas de raios- $X$ e os parâmetros de rede das ligas $L a_{0,7} \mathrm{Mg}_{0,3} \mathrm{Al}_{0,3} \mathrm{Mn}_{0,4} \mathrm{Sn}_{0,5} \mathrm{Ni}_{3,8}$ com TT de $750^{\circ}$ e $850^{\circ} \mathrm{C}$ por 9 e 16 horas e a liga no estado bruto de fusão foi adicionada para comparação dos resultados.

Foram identificadas as fases: $\mathrm{LaNi}_{5}$ (grupo espacial: P6/mmm - PDF: 507777), $\mathrm{MgNi}_{2}$ que tem estrutura hexagonal do grupo espacial: P63/mmc (PDF: 653630) e $\mathrm{LaSn}_{2} \mathrm{Ni}_{2}$ estrutura ortorrômbica do grupo espacial: Pnma (PDF: 38-1164).

A fase $\mathrm{LaMg}_{2} \mathrm{Ni}$, presente nas ligas com substituição do Ni pelos elementos $\mathrm{Co}$ e $\mathrm{Cu}$ foi modificada pela presença da substituição parcial do Ni pelo elemento $\mathrm{Sn}$, dando origem a fase $\mathrm{LaSn}_{2} \mathrm{Ni}_{2}$, alterando assim também a sua estrutura cristalina de romboédrica para ortorrômbica. 
Todas as fases obtidas no refinamento pelo método de Rietveld presentes na liga $\mathrm{La}_{0,7} \mathrm{Mg}_{0,3} \mathrm{Al}_{0,3} \mathrm{Mn}_{0,4} \mathrm{Sn}_{0,5} \mathrm{Ni}_{3,8}$ não ocorreram transformações durante os TT, mas há um aumento substancial no volume da célula unitária da fase $\mathrm{LaNi}_{5}$ em decorrência da presença do $S n$ nesta fase, promovido pelo aumento do parâmetros de rede a e c aumentando o volume da célula unitária (TABELA 10).

FIGURA 22 - Difratogramas de raios- $X$ das ligas $\mathrm{La}_{0,7} \mathrm{Mg}_{0,3} \mathrm{Al}_{0,3} \mathrm{Mn}_{0,4} \mathrm{Sn}_{0,5} \mathrm{Ni}_{3,8}$ sem e com tratamentos térmicos.

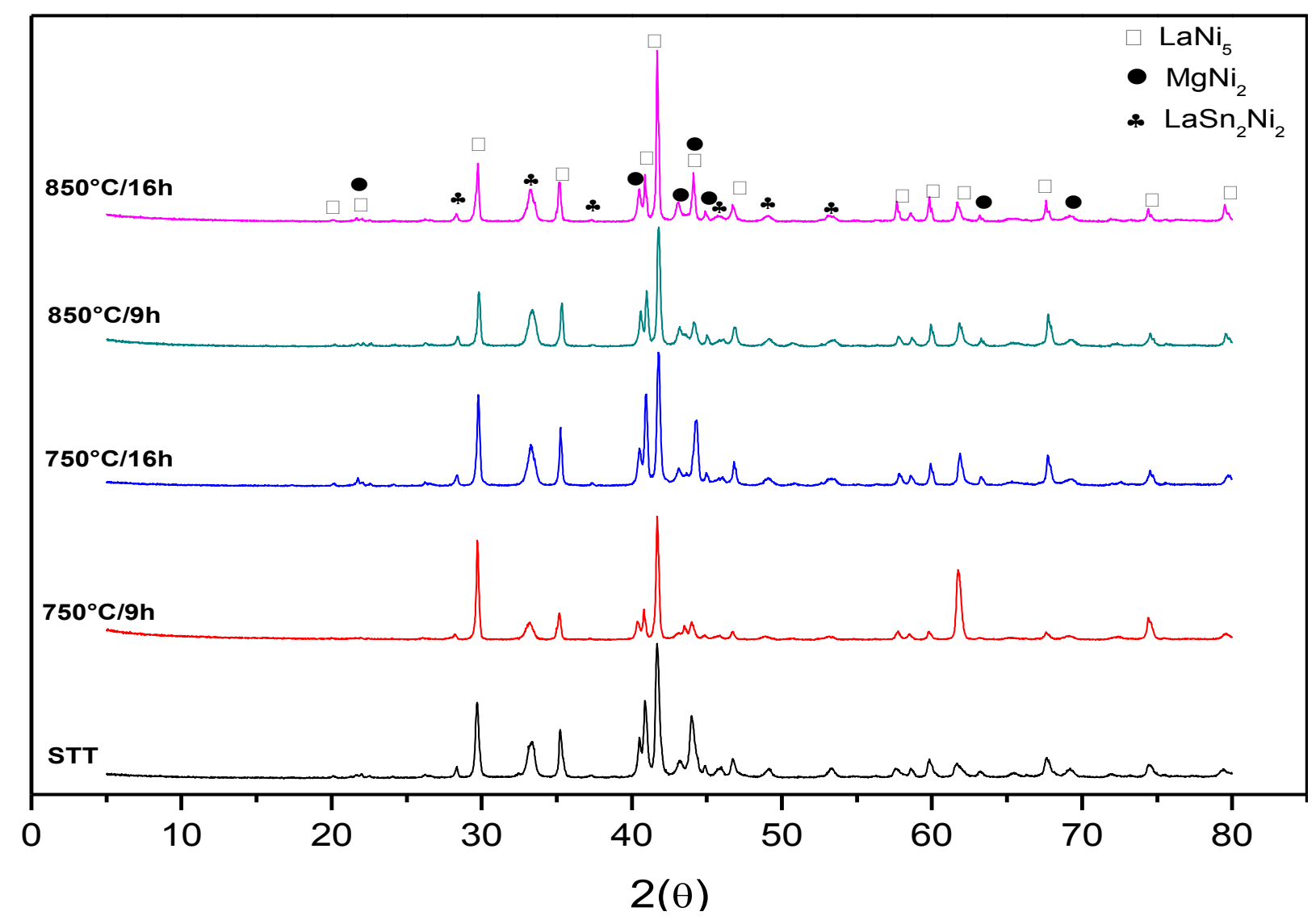


TABELA 10 - Parâmetros obtidos através do refinamento por Rietveld das ligas $\mathrm{La}_{0,7} \mathrm{Mg}_{0,3} \mathrm{Al}_{0,3} \mathrm{Mn}_{0,4} \mathrm{Sn}_{0,5} \mathrm{Ni}_{3,8}$

\begin{tabular}{|c|c|c|c|c|c|c|}
\hline \multirow[t]{2}{*}{ TT } & \multirow[t]{2}{*}{ Fases } & \multirow{2}{*}{$\begin{array}{l}\text { Parâm. de } \\
\text { ajuste }\left(\chi^{2}\right)\end{array}$} & \multirow{2}{*}{$\begin{array}{c}\text { Fração } \\
\text { da fase } \\
(\% \text { massa) }\end{array}$} & \multicolumn{2}{|c|}{$\begin{array}{l}\text { Parâmetros de } \\
\text { rede }(\AA)\end{array}$} & \multirow{2}{*}{$\begin{array}{l}\text { Vol. da } \\
\text { célula unit } \\
\left(\AA^{3}\right)\end{array}$} \\
\hline & & & & a & b & \\
\hline \multirow{3}{*}{ STT } & $\mathrm{LaNi}_{5}$ & & 69,3 & 5,094 & 4,114 & 92,5 \\
\hline & $\mathrm{LaSn}_{2} \mathrm{Ni}_{2}$ & 8,6 & 14,1 & 4,452 & 10,203 & 202,3 \\
\hline & $\mathrm{MgNi}_{2}$ & & 16,6 & 4,819 & 15,816 & 318,1 \\
\hline \multirow{3}{*}{$750 / 9 h$} & $\mathrm{LaNi}_{5}$ & & 66 & 5,093 & 4,091 & 91,9 \\
\hline & $\mathrm{LaSn}_{2} \mathrm{Ni}_{2}$ & 8,2 & 20 & 4,447 & 10,194 & 201,7 \\
\hline & $\mathrm{MgNi}_{2}$ & & 13 & 4,914 & 15,708 & 328,6 \\
\hline \multirow{3}{*}{$750 / 16 h$} & $\mathrm{LaNi}_{5}$ & & 70 & 5,090 & 4,092 & 91,8 \\
\hline & $\mathrm{LaSn}_{2} \mathrm{Ni}_{2}$ & 8,9 & 15 & 4,449 & 10,173 & 201,4 \\
\hline & $\mathrm{MgNi}_{2}$ & & 15 & 4,832 & 14,471 & 292,6 \\
\hline \multirow{3}{*}{$850 / 9 h$} & $\mathrm{LaNi}_{5}$ & & 60,9 & 5,091 & 4,102 & 92,1 \\
\hline & $\operatorname{LaSn}_{2} \mathrm{Ni}_{2}$ & 8,7 & 18,7 & 4,448 & 10,192 & 201,6 \\
\hline & $\mathrm{MgNi}_{2}$ & & 20,4 & 4,912 & 15,696 & 327,9 \\
\hline \multirow{3}{*}{$850 / 16 h$} & $\mathrm{LaNi}_{5}$ & & 65,5 & 5,096 & 4,102 & 92,2 \\
\hline & $\mathrm{LaSn}_{2} \mathrm{Ni}_{2}$ & 7,8 & 17,0 & 4,450 & 10,189 & 201,8 \\
\hline & $\mathrm{MgNi}_{2}$ & & 17,5 & 4,815 & 15,748 & 316,2 \\
\hline
\end{tabular}

\subsection{5 - Liga $\mathrm{La}_{0,7} \mathrm{Pr}_{0,3} \mathrm{Al}_{0,3} \mathrm{Mn}_{0,4} \mathrm{Co}_{0,5} \mathrm{Ni}_{3,8}$ sem e com tratamentos térmicos}

A FIGURA 23 e a TABELA 11 apresentam, respectivamente, os difratogramas de raios- $X$ e os parâmetros de rede das ligas $L a_{0,7} \mathrm{Pr}_{0,3} \mathrm{Al}_{0,3} \mathrm{Mn}_{0,4} \mathrm{Co}_{0,5} \mathrm{Ni}_{3,8}$ no estado bruto de fusão e com tratamentos térmicos de $750^{\circ}$ e $850^{\circ} \mathrm{C}$ por 9 e 16 horas e a liga no estado bruto de fusão foi adicionada para comparação dos resultados.

Foram identificadas as fases: $\mathrm{LaNi}_{5}$ estrutura hexagonal (grupo espacial: P6/mmm - PDF: 50-7777), $\mathrm{PrNi}_{5}$ estrutura hexagonal do grupo espacial: P6/mmm (PDF: 12-502) também observadas por Pan et al (2007).

As fases $\mathrm{LaNi}_{5}$ e $\mathrm{PrNi}_{5}$ (estrutura hexagonal do tipo $\mathrm{CaCu}_{5}$ ) do mesmo grupo espacial.

A FIGURA 20 mostra o padrão de difração de raios-X (XRD) e o padrão de análise da liga $\mathrm{La}_{0,7} \mathrm{Pr}_{0,3} \mathrm{Al}_{0,3} \mathrm{Mn}_{0,4} \mathrm{Co}_{0,5} \mathrm{Ni}_{3,8}$, utilizando o refinamento pelo método de Rietveld, onde os parâmetros de rede, os volumes de célula unitária das fases presentes na liga sem e com TT estão listados na Tabela11. 
FIGURA 23 - Difratogramas de raios $X$ das ligas $\mathrm{La}_{0,7} \mathrm{Pr}_{0,3} \mathrm{Al}_{0,3} \mathrm{Mn}_{0,4} \mathrm{Co}_{0,5} \mathrm{Ni}_{3,8}$ sem e com tratamentos térmicos.

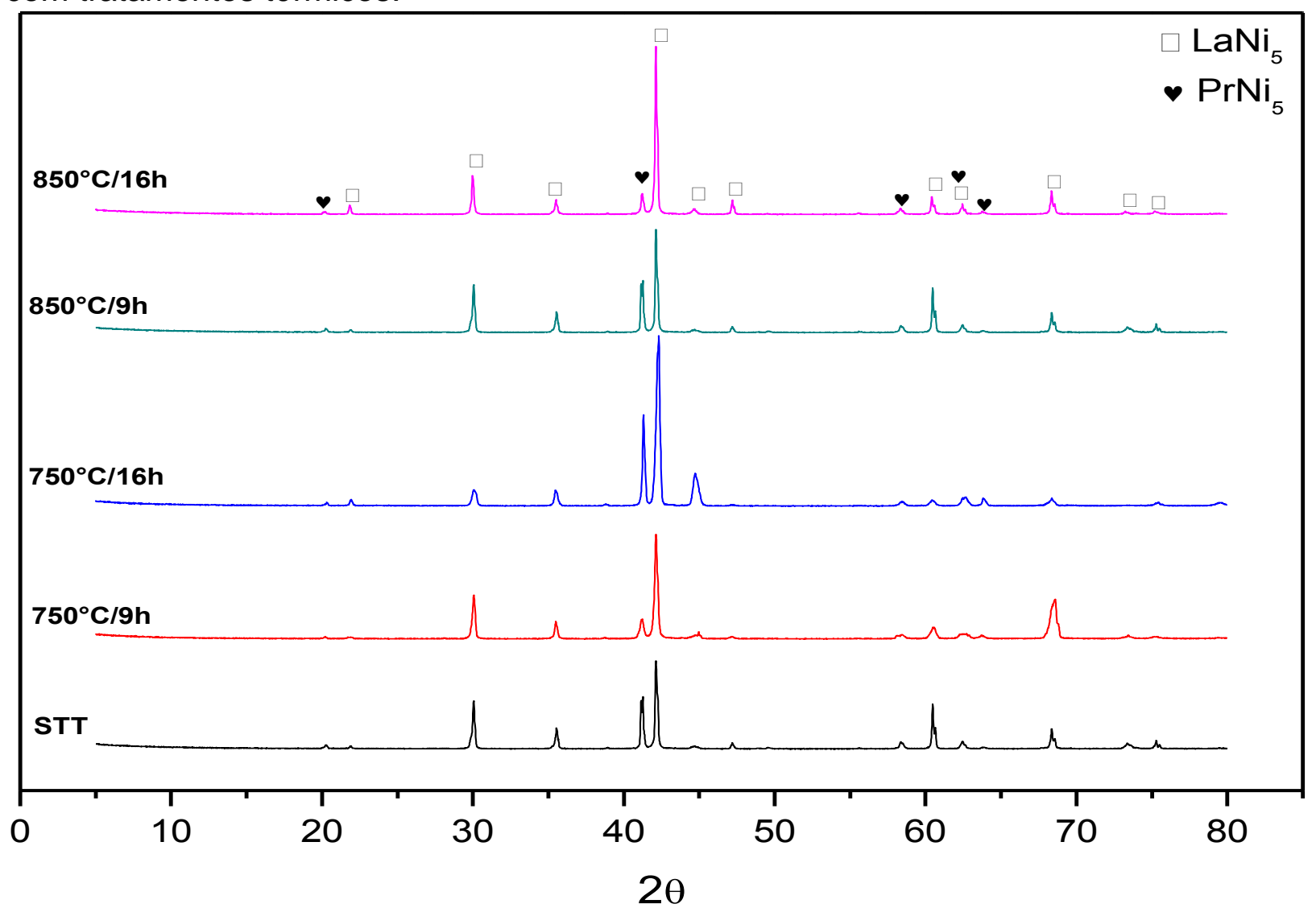

TABELA 11 - Parâmetros obtidos através do refinamento por Rietveld das ligas $\underline{\mathrm{La}_{0,7}} \mathrm{Pr}_{0,3} \mathrm{Al}_{0,3} \mathrm{Mn}_{0,4} \mathrm{Co}_{0,5} \mathrm{Ni}_{3,8}$,

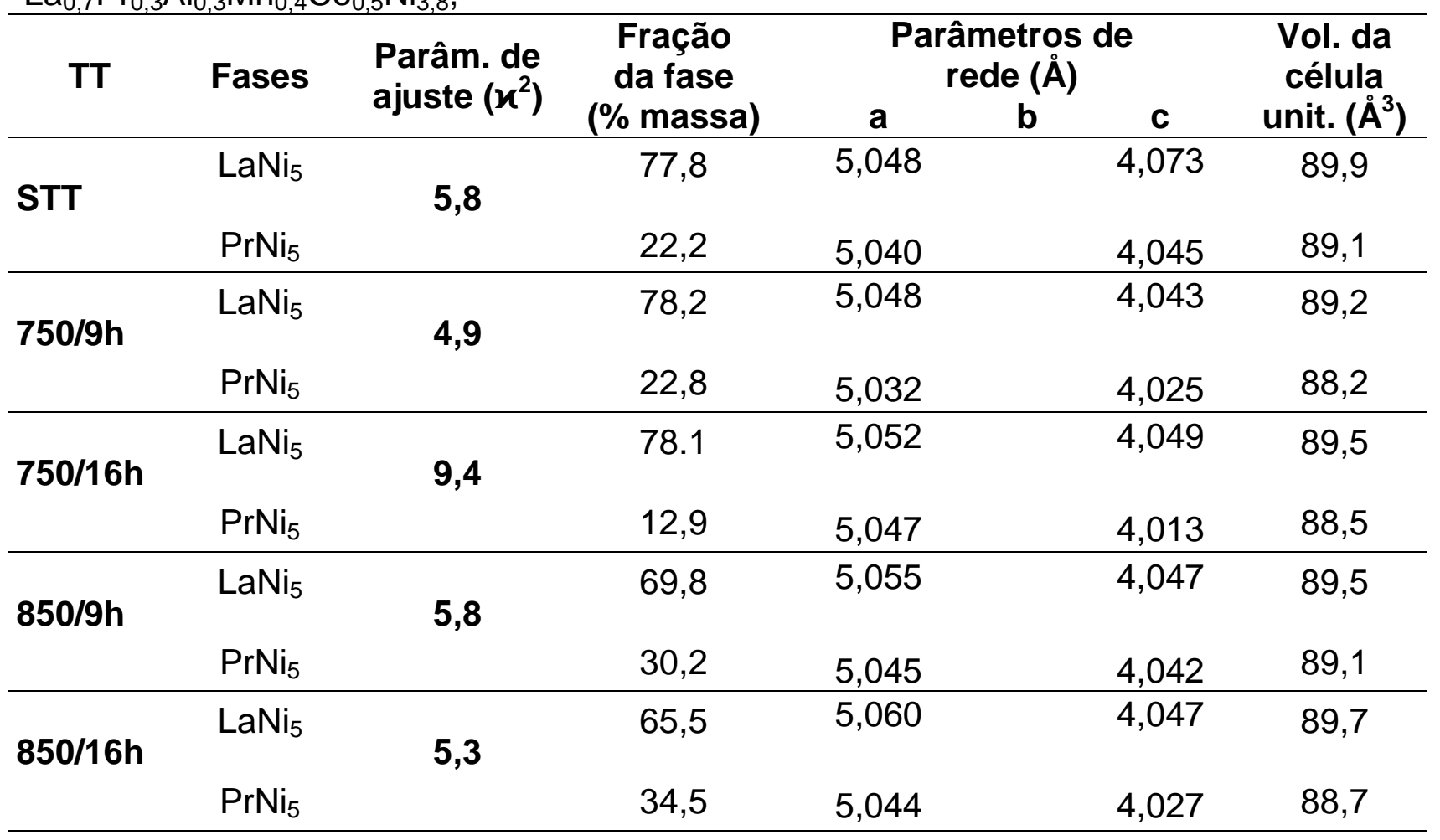




\subsection{6 - Liga $\mathrm{Pr}_{0,7} \mathrm{Mg}_{0,3} \mathrm{Al}_{0,3} \mathrm{Mn}_{0,4} \mathrm{Co}_{0,5} \mathrm{Ni}_{3,8}$ sem e com tratamentos térmicos}

Na FIGURA 24 e a TABELA 12 estão apresentadas os difratogramas de raios-X e os parâmetros de rede obtidos por refinamento utilizando o método de Rietveld da liga $\operatorname{Pr}_{0,7} \mathrm{Mg}_{0,3} \mathrm{Al}_{0,3} \mathrm{Mn}_{0,4} \mathrm{Co}_{0,5} \mathrm{Ni}_{3,8}$ com tratamentos térmicos de $750^{\circ} \mathrm{e}$ $850^{\circ} \mathrm{C}$ por 9 e 16 horas, respectivamente, e a liga no estado bruto de fusão foi adicionada para comparação dos resultados.

Foram identificadas as fases: $\mathrm{PrNi}_{5}$ estrutura hexagonal (grupo espacial: P6/mmm - PDF: 12-502), $\mathrm{PrMg}_{2} \mathrm{Ni}_{9}$ estrutura romboédrica do grupo espacial: R-3m (PDF: 50-1454) também identificadas por Zhou et al (2006), e a fase (AIMn) $\mathrm{Ni}_{3}$ estrutura cúbica de face centrada do grupo espacial Pm-3m

As fases presentes se mantêm sem alterações em todos os TT, mas com aumento da fase $\mathrm{PrMg}_{2} \mathrm{Ni}_{9}$, de 22 a $30 \%$ aproximadamente, e diminuição do volume da célula unitária da fase $\mathrm{PrNi}_{5}\left(86,5 \AA^{3}\right)$ em relação à fase $\operatorname{LaNi}_{5}\left(88,6 \AA^{3}\right)$ obtida para a liga $\mathrm{La}_{0,7} \mathrm{Mg}_{0,3} \mathrm{Al}_{0,3} \mathrm{Mn}_{0,4} \mathrm{Co}_{0,5} \mathrm{Ni}_{3,8}$ (TABELA 8) devido à diminuição dos parâmetros de rede a e c pela substituição do La pelo $\mathrm{Pr}$.

FIGURA 24 - Difratogramas de raios $X$ das ligas $\mathrm{Pr}_{0,7} \mathrm{Mg}_{0,3} \mathrm{Al}_{0,3} \mathrm{Mn}_{0,4} \mathrm{Co}_{0,5} \mathrm{Ni}_{3,8}$ sem e com tratamentos térmicos.

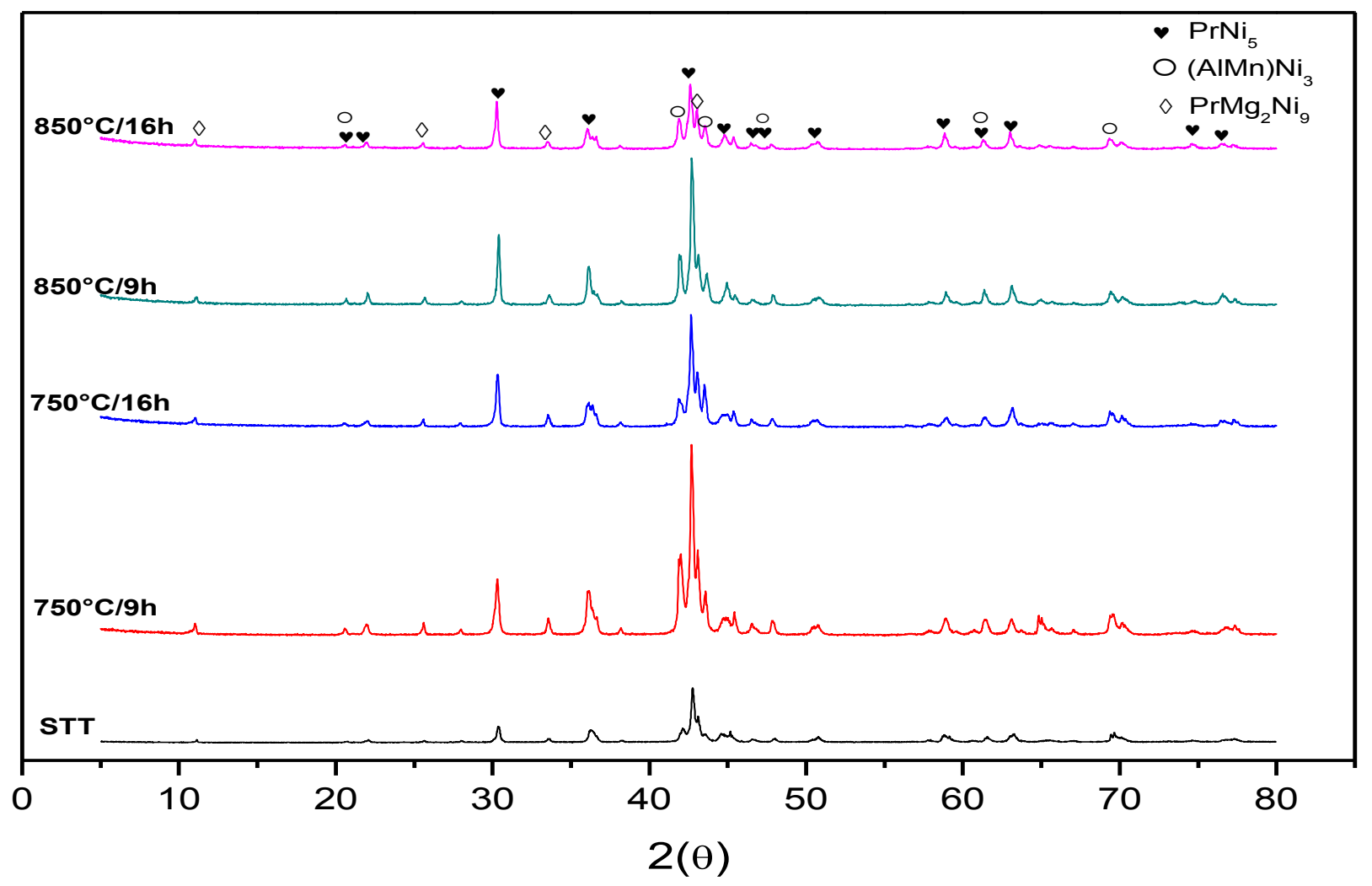


TABELA 12 - Parâmetros obtidos através do refinamento por Rietveld das ligas $\mathrm{Pr}_{0,7} \mathrm{Mg}_{0,3} \mathrm{Al}_{0,3} \mathrm{Mn}_{0,4} \mathrm{Co}_{0,5} \mathrm{Ni}_{3,8}$,

\begin{tabular}{|c|c|c|c|c|c|c|c|}
\hline \multirow[t]{2}{*}{ TT } & \multirow[t]{2}{*}{ Fases } & \multirow{2}{*}{$\begin{array}{l}\text { Parâm. de } \\
\text { ajuste }\left(x^{2}\right)\end{array}$} & \multirow{2}{*}{$\begin{array}{c}\text { Fração } \\
\text { da fase } \\
\text { (\%massa) }\end{array}$} & \multicolumn{3}{|c|}{$\begin{array}{l}\text { Parâmetros de } \\
\text { rede }(A)\end{array}$} & \multirow{2}{*}{$\begin{array}{c}\text { Vol. da } \\
\text { célula } \\
\text { unit. }\left(A^{3}\right.\end{array}$} \\
\hline & & & & $\mathbf{a}$ & b & c & \\
\hline \multirow{3}{*}{ STT } & $\mathrm{PrNi}_{5}$ & & 63,1 & 4,962 & & 4,055 & 86,5 \\
\hline & $\mathrm{PrMg}_{2} \mathrm{Ni}_{9}$ & 2,2 & 22,6 & 4,932 & & 24,034 & 506,5 \\
\hline & (AIMn) $\mathrm{Ni}_{3}$ & & 14,3 & 3,602 & 3,602 & 3,602 & 46,7 \\
\hline \multirow{3}{*}{$750 / 9 \mathrm{~h}$} & $\mathrm{PrNi}_{5}$ & & 60,4 & 4,965 & & 4,044 & 86,4 \\
\hline & $\mathrm{PrMg}_{2} \mathrm{Ni}_{9}$ & 4,3 & 25,3 & 4,929 & & 23,937 & 503,8 \\
\hline & $(\mathrm{AlMn}) \mathrm{Ni}_{3}$ & & 14,3 & 3,595 & 3,595 & 3,595 & 46,5 \\
\hline \multirow{3}{*}{$750 / 16 h$} & $\mathrm{PrNi}_{5}$ & & 71,6 & 4,969 & & 4,041 & 86,4 \\
\hline & $\mathrm{PrMg}_{2} \mathrm{Ni}_{9}$ & 2,0 & 16,5 & 4,927 & & 23,925 & 503,0 \\
\hline & $\left(\right.$ AlMn) $\mathrm{Ni}_{3}$ & & 11,9 & 3,596 & 3,596 & 3,596 & 46,5 \\
\hline \multirow{3}{*}{$850 / 9 h$} & $\mathrm{PrNi}_{5}$ & & 58,8 & 4,979 & & 4,039 & 86,7 \\
\hline & $\mathrm{PrMg}_{2} \mathrm{Ni}_{9}$ & 2,3 & 25,9 & 4,935 & & 23,966 & 505,6 \\
\hline & $(\mathrm{AlMn}) \mathrm{Ni}_{3}$ & & 15,3 & 3,596 & 3,596 & 3,596 & 46,5 \\
\hline \multirow{3}{*}{$850 / 16 h$} & $\mathrm{PrNi}_{5}$ & & 53,1 & 4,975 & & 4,043 & 86,7 \\
\hline & $\mathrm{PrMg}_{2} \mathrm{Ni}_{9}$ & 2,0 & 29,8 & 4,934 & & 23,955 & 505,2 \\
\hline & $(\mathrm{AlMn}) \mathrm{Ni}_{3}$ & & 17,1 & 3,596 & 3,596 & 3,596 & 46,5 \\
\hline
\end{tabular}

Nas FIGURAS 25 e 26 estão mostradas a variação da concentração das fases $\mathrm{LaNi}_{5}$ e $\mathrm{LaMg}_{2} \mathrm{Ni}$, absorvedoras de hidrogênio, mediante aos TT realizados nas ligas, respectivamente. A fase $\mathrm{LaNi}_{5}$ (FIGURA 25) diminui com os TT realizados para todas as ligas. Este comportamento pode influenciar nas propriedades de absorção de hidrogênio e eletroquímicas. A fase $\mathrm{LaMg}_{2} \mathrm{Ni}_{9}$ (FIGURA 26) se mantém somente para as ligas com substituição parcial do Ni pelo $\mathrm{Cu}$ e La pelo Pr após os TT. Nas demais substituições realizadas nas ligas, esta foi substituída por outras fases. O comportamento de absorção de hidrogênio destas novas fases será avaliado nos testes de PCT e eletroquímico. 
FIGURA 25 - Fração da fase $\mathrm{LaNi}_{5}$ nas ligas $\mathrm{NiMH}$ sem e com tratamentos térmicos.

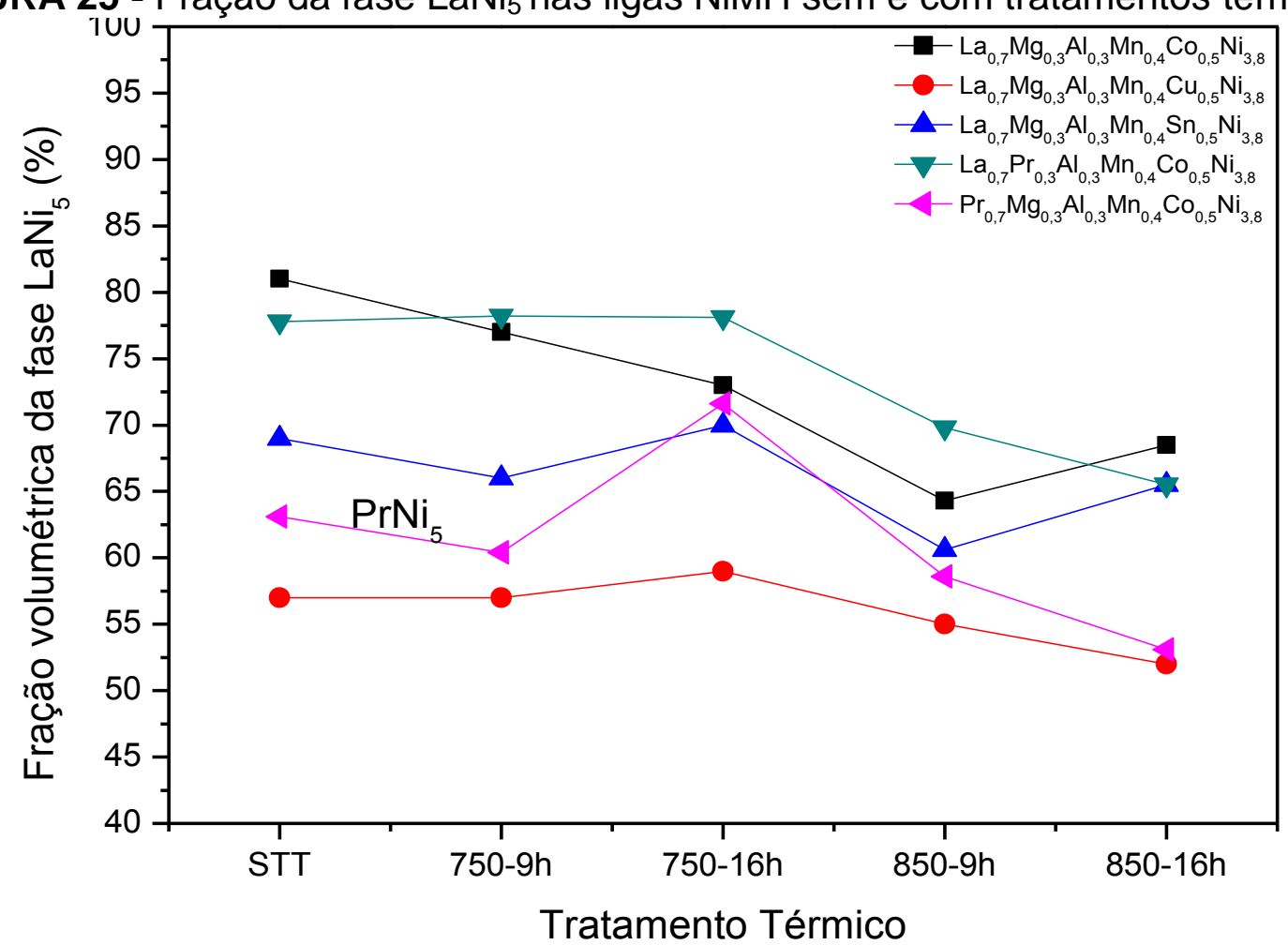

FIGURA 26 - Fração da fase $\mathrm{LaMg}_{2} \mathrm{Ni}_{9}$ nas ligas $\mathrm{NiMH}$ sem e com tratamentos térmicos.

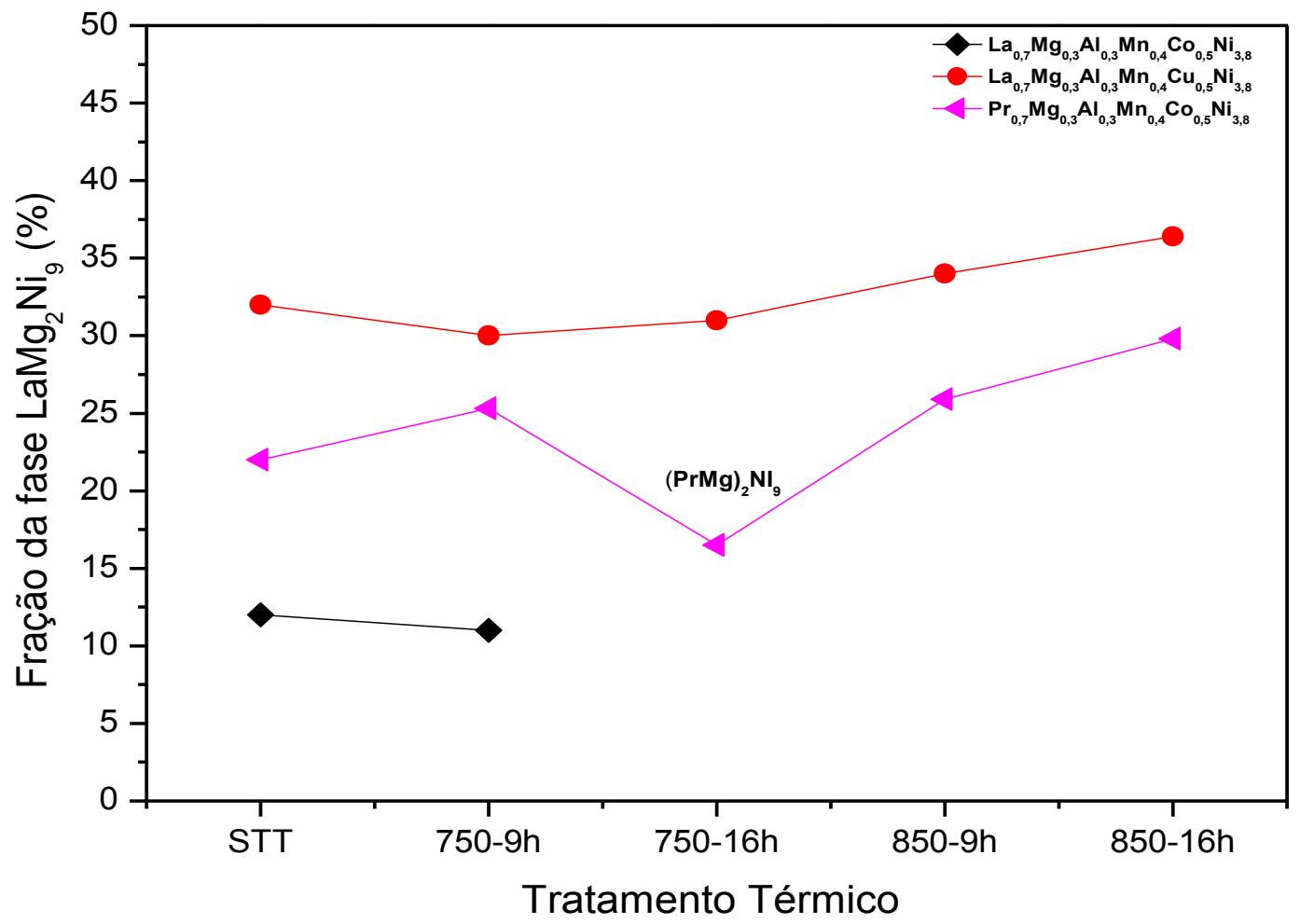




\section{3 - Caracterização Microscópica}

\subsection{1 - Micrografías da liga $\mathrm{La}_{0,7} \mathrm{Mg}_{0,3} \mathrm{Al}_{0,3} \mathrm{Mn}_{0,4} \mathrm{Co}_{0,5} \mathrm{Ni}_{3,8}$}

$\mathrm{Na}$ FIGURA 27 de (a) a (e) estão apresentadas as micrografias (2000x) obtidas por MEV da liga $\mathrm{La}_{0,7} \mathrm{Mg}_{0,3} \mathrm{Al}_{0,3} \mathrm{Mn}_{0,4} \mathrm{Co}_{0,5} \mathrm{Ni}_{3,8}$ sendo: (a) sem tratamento térmico, (b) com tratamento de $750^{\circ} \mathrm{C}$ por 9 horas, (c) com tratamento de $750^{\circ} \mathrm{C}$ por 16 horas, (d) com tratamento de $850^{\circ} \mathrm{C}$ por 9 horas, (e) com tratamento de $850^{\circ} \mathrm{C}$ por 16 horas .

As fases identificadas foram: $\mathrm{LaNi}_{5}$ (matriz), $\mathrm{MgNi}_{2}$ (identificada pelas regiões escuras), e a fase $\mathrm{LaMg}_{2} \mathrm{Ni}_{9}$ (identificadas pelas regiões cinza claro) para a liga sem TT e com TT de $750^{\circ} \mathrm{C}$ por 9 horas. Após TT à $750^{\circ} \mathrm{C}$ por 16 horas a fase $\mathrm{LaMg}_{2} \mathrm{Ni}_{9}$ foi substituída pela fase $\mathrm{Al}_{6} \mathrm{Mn}$, mantendo a cor cinza claro, uma nova fase, $\mathrm{PrCo}_{13}$ (FIGURA 27), foi localizada na superfície da fase $\mathrm{MgNi}_{2}$ (identificada com um tom mais claro nas regiões escuras).

A composição química das fases presentes na liga $\mathrm{La}_{0,7} \mathrm{Mg}_{0,3} \mathrm{Al}_{0,3} \mathrm{Mn}_{0,4} \mathrm{Co}_{0,5} \mathrm{Ni}_{3,8}$ sem e após TT foram obtidas por EDS (análise semiquantitativa) e estão apresentadas nas TABELAS 13 a 17. Todas as fases presentes estão de acordo com as identificadas por difração de raios-X apresentadas na FIGURA 20 e TABELA 8.

Em trabalhos realizados por Liu et al (2004a); Liu et al (2005), Wuang et al (2005), Cheng et al (2008), Ferreira et al (2012), Wei et al (2012), Liu et al (2013) também obtiveram as fases $\mathrm{LaNi}_{5}, \mathrm{MgNi}_{2}$, e a fase $\mathrm{LaMg}_{2} \mathrm{Ni}_{9}$ em ligas sem TT, tipo $\mathrm{AB}_{5}$, com substituições parciais do Ni pelo Co. 
FIGURA 27 - Micrografias da liga $\mathrm{La}_{0,7} \mathrm{Mg}_{0,3} \mathrm{Al}_{0,3} \mathrm{Mg}_{0,3} \mathrm{Mn}_{0,4} \mathrm{Co}_{0,5} \mathrm{Ni}_{3,8}$ sem e com TT, onde: (a) sem TT, (b) $750^{\circ} \mathrm{C}$ por 9 horas, (c) $750^{\circ} \mathrm{C}$ por 16 horas, (d) $850^{\circ} \mathrm{C}$ por 9 horas, (e) $850^{\circ} \mathrm{C}$ por 16 horas.

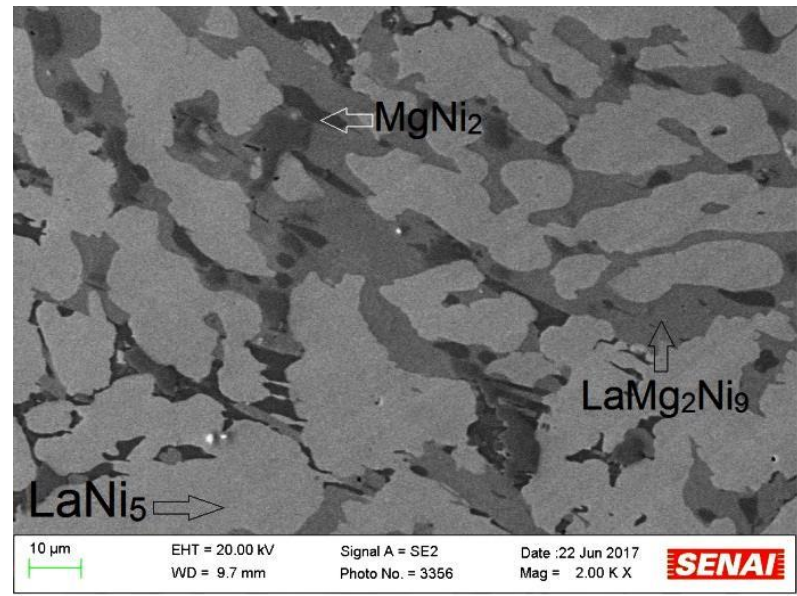

(a)

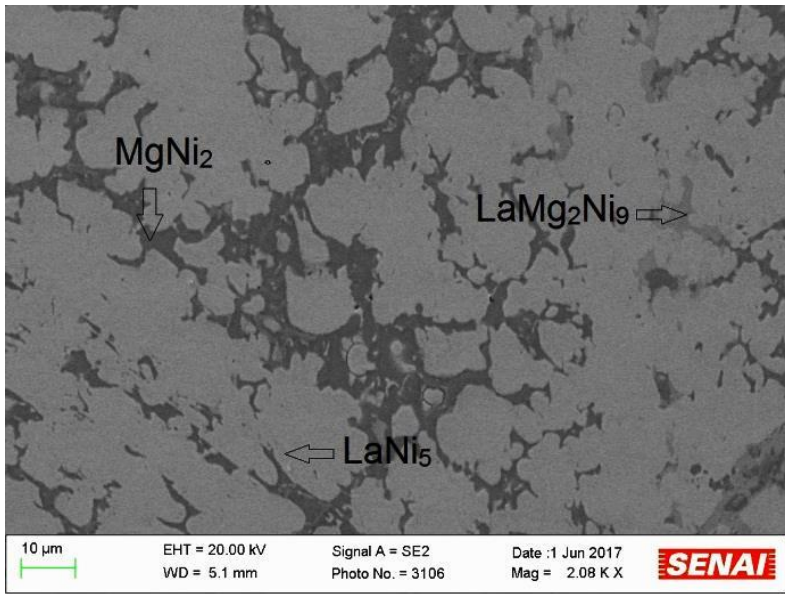

(b)

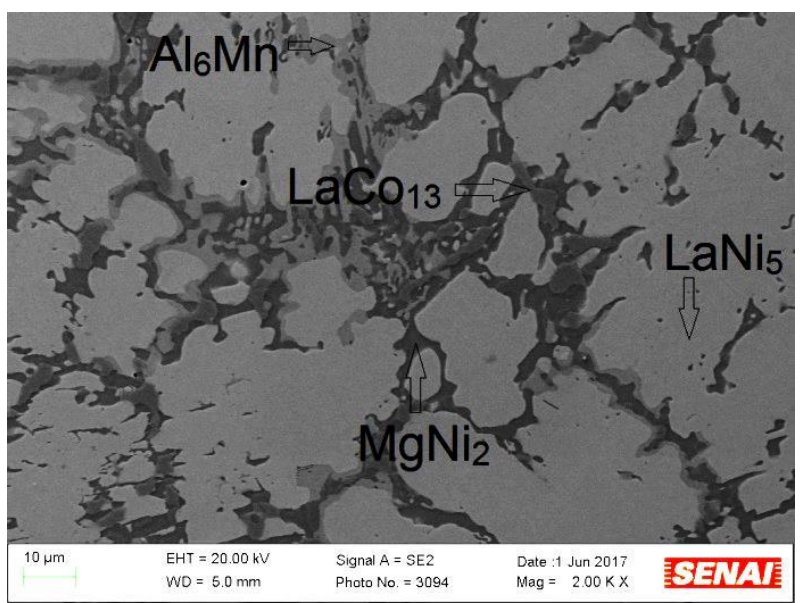

(d)

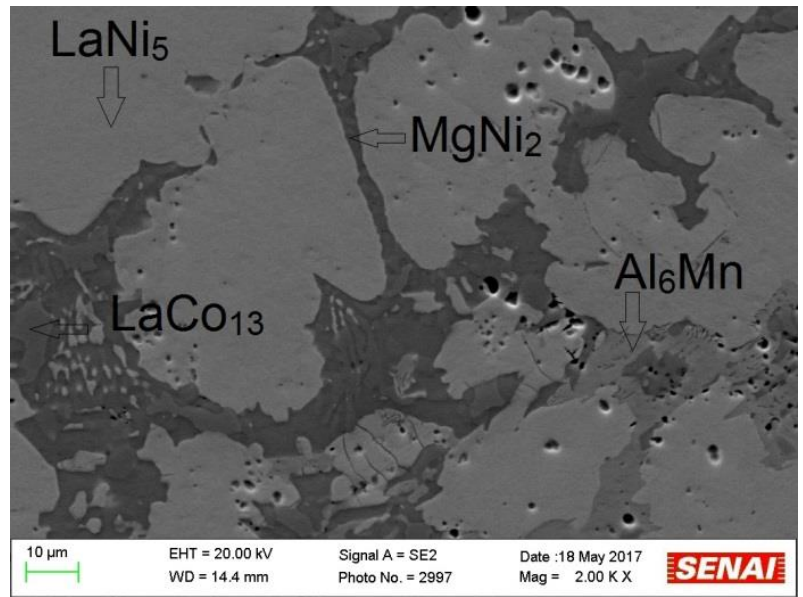

(c)

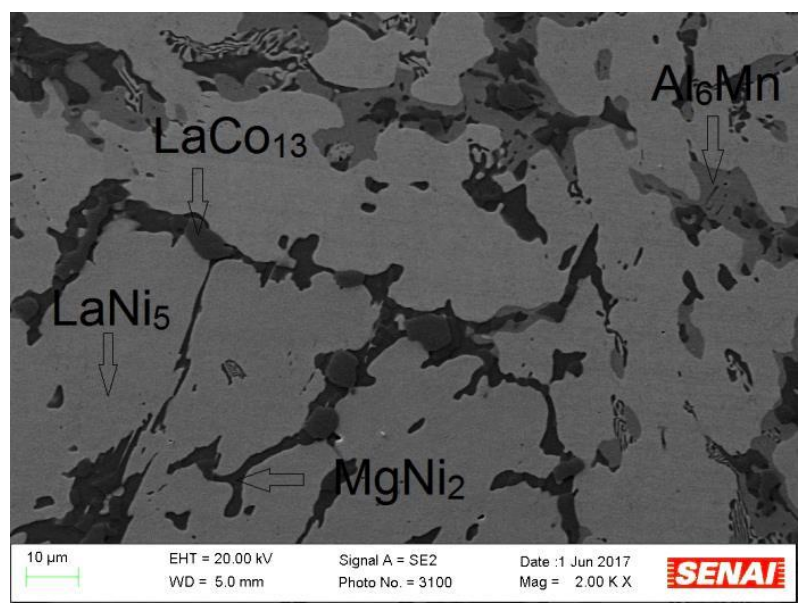

(e) 
TABELA 13 - Composição química (semi-quantitativa) da liga $\mathrm{La}_{0,7} \mathrm{Mg}_{0,3} \mathrm{Al}_{0,3} \mathrm{Mn}_{0,4} \mathrm{Co}_{0,5} \mathrm{Ni}_{3,8}$, sem TT, analisada por EDS.

\begin{tabular}{|c|c|c|c|c|c|c|}
\hline \multicolumn{7}{|c|}{ Composição Química (\% at) } \\
\hline Fases & La & Mg & Al & Mn & Co & $\mathbf{N i}$ \\
\hline $\mathrm{LaNi}_{5}$ & $17,4 \pm 0,3$ & $1,0 \pm 0,1$ & $3,4 \pm 0,1$ & $3,6 \pm 0,1$ & $8,0 \pm 0,2$ & $66,6 \pm 0,3$ \\
\hline $\mathrm{LaMg}_{2} \mathrm{Ni}_{9}$ & $9,5 \pm 0,3$ & $11,7 \pm 0,1$ & $2,1 \pm 0,1$ & $5,4 \pm 0,1$ & $9,8 \pm 0,2$ & $61,5 \pm 0,3$ \\
\hline $\mathrm{MgNi}_{2}$ & $0,9 \pm 0,3$ & $3,6 \pm 0,1$ & $17,0 \pm 0,1$ & $19,9 \pm 0,1$ & $2,4 \pm 0,2$ & $56,2 \pm 0,3$ \\
\hline
\end{tabular}

Tabela 14 - Composição química (semi-quantitativa) da liga La ${ }_{0,7} \mathrm{Mg}_{0,3} \mathrm{Al}_{0,3} \mathrm{Mn}_{0,4} \mathrm{Co}_{0,5} \mathrm{Ni}_{3,8}$, com TT de 750 por 9 horas, analisada por EDS.

\begin{tabular}{lrrrrrr}
\hline \multicolumn{7}{c}{ Composição Química (\% at) } \\
\hline \multicolumn{1}{c}{ Fases } & \multicolumn{1}{c}{ La } & \multicolumn{1}{c}{ Mg } & \multicolumn{1}{c}{ Al } & \multicolumn{1}{c}{ Mn } & \multicolumn{1}{c}{ Co } & \multicolumn{1}{c}{$\mathbf{N i}$} \\
\hline $\mathrm{LaNi}_{5}$ & $16,6 \pm 0,3$ & $1,1 \pm 0,1$ & $3,6 \pm 0,1$ & $3,6 \pm 0,1$ & $7,6 \pm 0,2$ & $67,5 \pm 0,3$ \\
$\mathrm{LaMg}_{2} \mathrm{Ni}_{9}$ & $9,7 \pm 0,3$ & $10,8 \pm 0,1$ & $2,1 \pm 0,1$ & $5,3 \pm 0,1$ & $10,0 \pm 0,2$ & $62,1 \pm 0,3$ \\
$\mathrm{MgNi}_{2}$ & $0,9 \pm 0,3$ & $3,5 \pm 0,1$ & $16,2 \pm 0,1$ & $20,1 \pm 0,1$ & $2,5 \pm 0,2$ & $56,8 \pm 0,3$ \\
\hline
\end{tabular}

TABELA 15 - Composição química (semi-quantitativa) da liga La $a_{0,7} \mathrm{Mg}_{0,3} \mathrm{Al}_{0,3} \mathrm{Mn}_{0,4} \mathrm{Co}_{0,5} \mathrm{Ni}_{3,8}$, com TT de 750 por 16 horas, analisada por EDS.

\begin{tabular}{|c|c|c|c|c|c|c|}
\hline \multicolumn{7}{|c|}{ Composição Química (\% at) } \\
\hline Fases & La & $\mathrm{Mg}$ & Al & Mn & Co & $\mathbf{N i}$ \\
\hline $\mathrm{LaNi}_{5}$ & $15,7 \pm 0,2$ & $3,9 \pm 0,1$ & $4,0 \pm 0,1$ & $4,4 \pm 0,1$ & $7,5 \pm 0,2$ & $64,5 \pm 0,3$ \\
\hline $\mathrm{Al}_{6} \mathrm{Mn}$ & $3,0 \pm 0,2$ & $4,6 \pm 0,1$ & $15,2 \pm 0,1$ & $16,1 \pm 0,1$ & $9,0 \pm 0,2$ & $52,1 \pm 0,3$ \\
\hline $\mathrm{LaCO}_{13}$ & $0,8 \pm 0,1$ & $1,2 \pm 0,1$ & $3,8 \pm 0,1$ & $16,7 \pm 0,1$ & $20,5 \pm 0,2$ & $57,0 \pm 0,3$ \\
\hline $\mathrm{MgNi}_{2}$ & $1,5 \pm 0,2$ & $17,9 \pm 0,1$ & $2,7 \pm 0,1$ & $11,8 \pm 0,1$ & $8,5 \pm 0,2$ & $57,6 \pm 0,3$ \\
\hline
\end{tabular}

TABELA 16 - Composição química (semi-quantitativa) da liga $\mathrm{La}_{0,7} \mathrm{Mg}_{0,3} \mathrm{Al}_{0,3} \mathrm{Mn}_{0,4} \mathrm{Co}_{0,5} \mathrm{Ni}_{3,8}$, com TT de 850 por 9 horas, analisada por EDS.

\begin{tabular}{lrrrrrr}
\hline \multicolumn{7}{c}{ Composição Química (\% at) } \\
\hline \multicolumn{1}{c}{ Fases } & \multicolumn{1}{c}{ La } & \multicolumn{1}{c}{ Mg } & \multicolumn{1}{c}{ Al } & \multicolumn{1}{c}{ Mn } & \multicolumn{1}{c}{ Co } & Ni \\
\hline $\mathrm{LaNi}_{5}$ & $16,3 \pm 0,2$ & $3,4 \pm 0,1$ & $3,6 \pm 0,1$ & $3,2 \pm 0,1$ & $7,6 \pm 0,2$ & $65,9 \pm 0,3$ \\
$\mathrm{Al}_{6} \mathrm{Mn}$ & $2,4 \pm 0,2$ & $5,1 \pm 0,1$ & $15,5 \pm 0,1$ & $17,7 \pm 0,1$ & $9,0 \pm 0,2$ & $51,3 \pm 0,3$ \\
$\mathrm{LaCO}_{13}$ & $0,9 \pm 0,2$ & $0,7 \pm 0,1$ & $3,7 \pm 0,1$ & $16,8 \pm 0,1$ & $20,1 \pm 0,2$ & $57,8 \pm 0,3$ \\
$\mathrm{MgNi}_{2}$ & $1,3 \pm 0,2$ & $20,9 \pm 0,1$ & $1,1 \pm 0,1$ & $11,3 \pm 0,1$ & $8,5 \pm 0,2$ & $56,9 \pm 0,3$ \\
\hline
\end{tabular}

TABELA 17 - Composição química (semi-quantitativa) da liga $\mathrm{La}_{0,7} \mathrm{Mg}_{0,3} \mathrm{Al}_{0,3} \mathrm{Mn}_{0,4} \mathrm{Co}_{0,5} \mathrm{Ni}_{3,8}$, com TT de 850 por 16 horas, analisada por EDS.

\begin{tabular}{lrrrrrr}
\hline \multicolumn{7}{c}{ Composição Química (\% at) } \\
\hline \multicolumn{1}{c}{ Fases } & \multicolumn{1}{c}{ La } & \multicolumn{1}{c}{ Mg } & \multicolumn{1}{c}{ Al } & Mn & \multicolumn{1}{c}{ Co } & \multicolumn{1}{c}{ Ni } \\
\hline $\mathrm{LaNi}_{5}$ & $16,1 \pm 0,2$ & $2,2 \pm 0,1$ & $3,6 \pm 0,1$ & $3,9 \pm 0,1$ & $7,5 \pm 0,2$ & $66,4 \pm 0,3$ \\
$\mathrm{Al}_{6} \mathrm{Mn}$ & $1,21 \pm 0,2$ & $3,2 \pm 0,1$ & $17,1 \pm 0,1$ & $18,0 \pm 0,1$ & $8,5 \pm 0,2$ & $52,0 \pm 0,3$ \\
$\mathrm{LaCo}_{13}$ & $0,8 \pm 0,2$ & $0,8 \pm 0,1$ & $3,8 \pm 0,1$ & $16,6 \pm 0,1$ & $20,4 \pm 0,2$ & $57,6 \pm 0,3$ \\
$\mathrm{MgNi}_{2}$ & $1,5 \pm 0,2$ & $18,7 \pm 0,1$ & $2,7 \pm 0,1$ & $10,8 \pm 0,1$ & $8,9 \pm 0,2$ & $57,4 \pm 0,3$ \\
\hline
\end{tabular}




\subsection{2 - Micrografías da liga $\mathrm{La}_{0,7} \mathrm{Mg}_{0,3} \mathrm{Al}_{0,3} \mathrm{Mn}_{0,4} \mathrm{Cu}_{0,5} \mathrm{Ni}_{3,8}$.}

$\mathrm{Na}$ FIGURA 28 de (a) a (e) estão apresentadas as micrografias (2000x) obtidas por MEV da liga $\mathrm{La}_{0,7} \mathrm{Mg}_{0,3} \mathrm{Al}_{0,3} \mathrm{Mn}_{0,4} \mathrm{Cu}_{0,5} \mathrm{Ni}_{3,8}$ sendo: (a) sem tratamento térmico, (b) com tratamento de $750^{\circ} \mathrm{C}$ por 9 horas, (c) com tratamento de $750^{\circ} \mathrm{C}$ por 16 horas, (d) com tratamento de $850^{\circ} \mathrm{C}$ por 9 horas, (e) com tratamento de $850^{\circ} \mathrm{C}$ por 16 horas .

As fases identificadas na liga sem e com TT de 750 e $850^{\circ} \mathrm{C}$ por 9 e 16 horas foram : $\mathrm{LaNi}_{5}$ (matriz), $\mathrm{MgNiCu}$ identificada como $\mathrm{MgNi}_{2}$ conforme apresentado na figura 21 e tabela 9 estrutura do tipo $A B_{2}$, (região escura), e a fase $\mathrm{LaMg}_{2} \mathrm{Ni}_{9}$ (região cinza claro) também identificadas por Yarts e Denys (2014) .

A composição química das fases presentes na liga $\mathrm{La}_{0,7} \mathrm{Mg}_{0,3} \mathrm{Al}_{0,3} \mathrm{Mn}_{0,4} \mathrm{Cu}_{0,5} \mathrm{Ni}_{3,8}$ sem e após TT foram obtidas por EDS (análise semiquantitativa) estão apresentadas nas TABELAS 18 a 22. Todas as fases presentes estão de acordo com as identificadas por difração de raios-X apresentadas na FIGURA 21 e TABELA 9.

A identificação das regiões nas micrografias realizada por EDS, para verificar as composições químicas presentes nas fases para cada TT, apresenta os resultados para as ligas $\mathrm{La}_{0,7} \mathrm{Mg}_{0,3} \mathrm{Al}_{0,3} \mathrm{Mn}_{0,4} \mathrm{Cu}_{0,5} \mathrm{Ni}_{3,8}$. Estas fases foram identificadas também pelos autores Liao et al 2000 e Huang et al 2012.As fases presentes na liga de $\mathrm{La}_{0,7} \mathrm{Mg}_{0,3} \mathrm{Al}_{0,3} \mathrm{Mn}_{0,4} \mathrm{Cu}_{0,5} \mathrm{Ni}_{3,8}$, sem TT foram observadas anteriormente por Kadir et al (1999), Feng et al (2001), Liu et al (2004), Zhang Y. et al (2013), Casini (2015), Casini et al (2016). 
Figura 28 - Micrografias da liga $\mathrm{La}_{0,7} \mathrm{Mg}_{0,3} \mathrm{Al}_{0,3} \mathrm{Mg}_{0,3} \mathrm{Mn}_{0,4} \mathrm{Cu}_{0,5} \mathrm{Ni}_{3,8}$ com e sem TT, onde: (a) sem TT, (b) $750^{\circ} \mathrm{C}$ por 9 horas, (c) $750^{\circ} \mathrm{C}$ por 16 horas, (d) $850^{\circ} \mathrm{C}$ por 9 horas, (e) $850^{\circ} \mathrm{C}$ por 16 horas

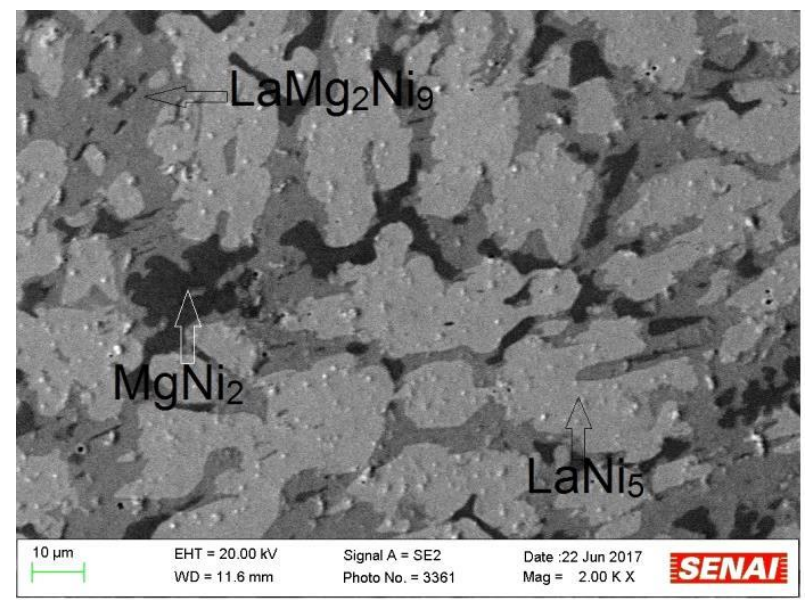

(a)

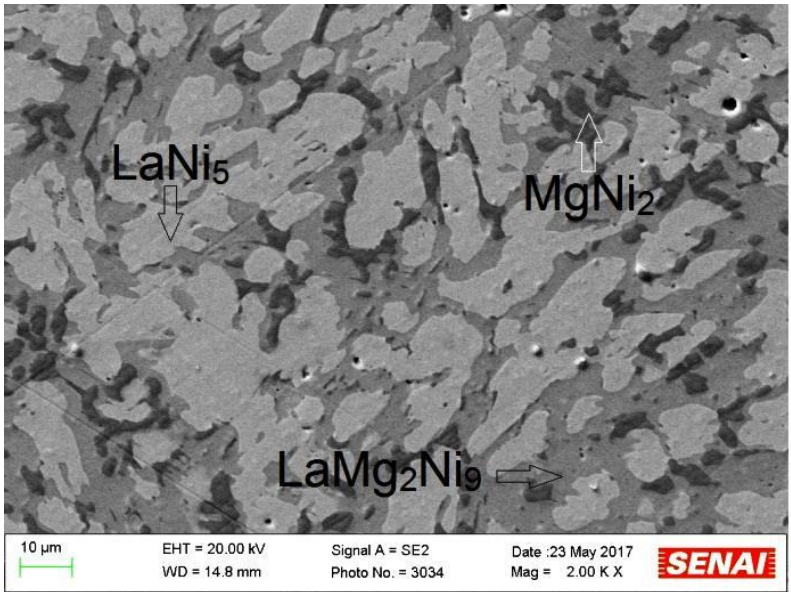

(b)

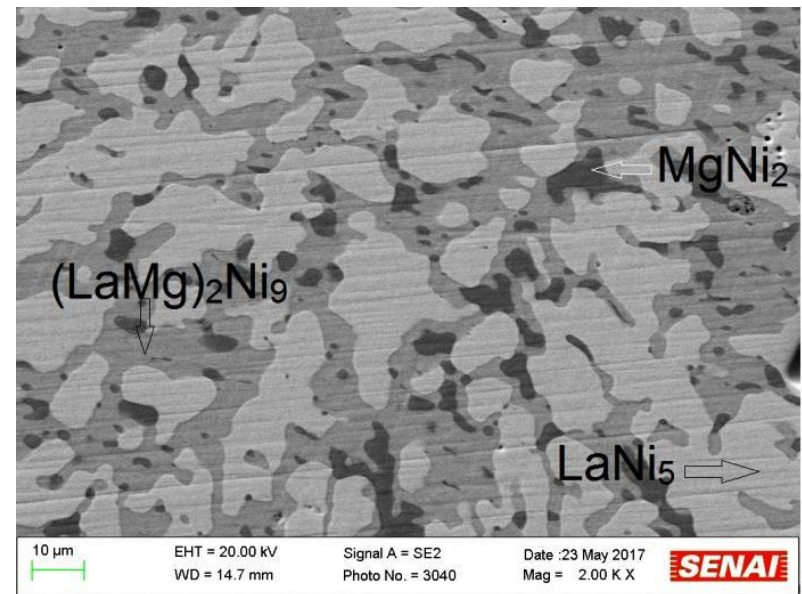

(d)

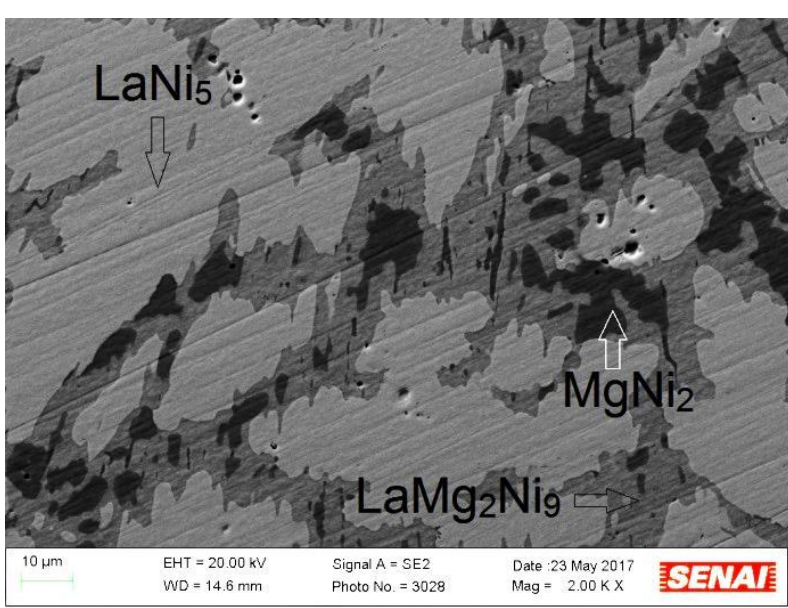

(c)

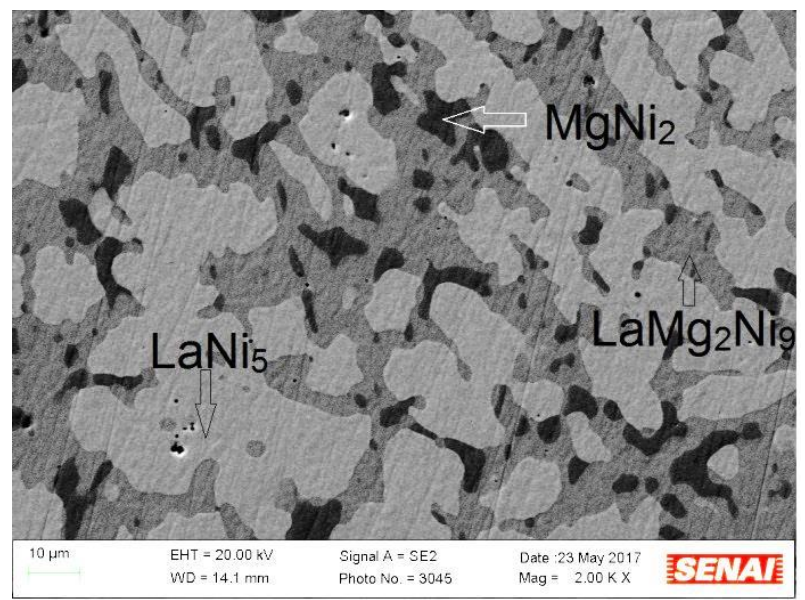

(e) 
TABELA 18 - Composição química (semi-quantitativa) da liga $\mathrm{La}_{0,7} \mathrm{Mg}_{0,3} \mathrm{Al}_{0,3} \mathrm{Mn}_{0,4} \mathrm{Cu}_{0,5} \mathrm{Ni}_{3,8}$, sem TT, analisada por EDS.

\begin{tabular}{lrrrrrc}
\hline \multicolumn{7}{c}{ Composição Química (\% at) } \\
\hline Fases & \multicolumn{1}{c}{ La } & \multicolumn{1}{c}{$\mathbf{M g}$} & \multicolumn{1}{c}{ Al } & \multicolumn{1}{c}{ Mn } & Cu & Ni \\
\hline $\mathrm{LaNi}_{5}$ & $17,2 \pm 0,3$ & $0,4 \pm 0,1$ & $3,4 \pm 0,1$ & $3,6 \pm 0,1$ & $8,9 \pm 0,2$ & $66,5 \pm 0,3$ \\
$\mathrm{LaMg}_{2} \mathrm{Ni}_{9}$ & $9,6 \pm 0,3$ & $11,7 \pm 0,1$ & $2,1 \pm 0,1$ & $5,4 \pm 0,1$ & $9,8 \pm 0,2$ & $61,4 \pm 0,3$ \\
$\mathrm{MgNi}_{2}$ & $0,9 \pm 0,3$ & $3,6 \pm 0,1$ & $17,0 \pm 0,1$ & $20,0 \pm 0,1$ & $2,4 \pm 0,2$ & $56,1 \pm 0,3$ \\
\hline
\end{tabular}

TABELA 19 - Composição química (semi-quantitativa) da liga $\underline{\mathrm{La}}{ }_{0,7} \mathrm{Mg}_{0,3} \mathrm{Al}_{0,3} \mathrm{Mn}_{0,4} \mathrm{Cu}_{0,5} \mathrm{Ni}_{3,8}$, com TT $750^{\circ} \mathrm{C}$ por 9 horas, analisada por EDS.

\begin{tabular}{lrrrrrc}
\hline \multicolumn{7}{c}{ Composição Química (\% at) } \\
\hline Fases & \multicolumn{1}{c}{ La } & \multicolumn{1}{c}{ Mg } & \multicolumn{1}{c}{ Al } & \multicolumn{1}{c}{ Mn } & \multicolumn{1}{c}{ Cu } & Ni \\
\hline $\mathrm{LaNi}_{5}$ & $16,8 \pm 0,3$ & 0,3 & $3,6 \pm 0,1$ & $3,8 \pm 0,1$ & $8,7 \pm 0,2$ & $66,8 \pm 0,3$ \\
$\mathrm{LaMg}_{2} \mathrm{Ni}_{9}$ & $9,7 \pm 0,3$ & $10,8 \pm 0,1$ & $2,1 \pm 0,1$ & $5,3 \pm 0,1$ & $10,0 \pm 0,2$ & $62,1 \pm 0,3$ \\
$\mathrm{MgNi}_{2}$ & $0,9 \pm 0,3$ & $3,5 \pm 0,1$ & $16,3 \pm 0,1$ & $20,1 \pm 0,1$ & $2,5 \pm 0,2$ & $56,7 \pm 0,3$ \\
\hline
\end{tabular}

TABELA 20 - Composição química (semi-quantitativa) da liga $\underline{\mathrm{La}}{ }_{0,7} \mathrm{Mg}_{0,3} \mathrm{Al}_{0,3} \mathrm{Mn}_{0,4} \mathrm{Cu}_{0,5} \mathrm{Ni}_{3,8}$, com TT $750^{\circ} \mathrm{C}$ por 16 horas, analisada por EDS..

\begin{tabular}{lrrrrrc}
\hline \multicolumn{7}{c}{ Composição Química (\% at) } \\
\hline Fases & \multicolumn{1}{c}{ La } & \multicolumn{1}{c}{ Mg } & \multicolumn{1}{c}{ Al } & Mn & Cu & Ni \\
\hline $\mathrm{LaNi}_{5}$ & $17,1 \pm 0,3$ & $0,2 \pm 0,1$ & $3,7 \pm 0,1$ & $3,4 \pm 0,1$ & $8,5 \pm 0,2$ & $67,1 \pm 0,3$ \\
$\mathrm{LaMg}_{2} \mathrm{Ni}_{9}$ & $10,3 \pm 0,3$ & $10,7 \pm 0,1$ & $2,3 \pm 0,1$ & $5,4 \pm 0,1$ & $9,7 \pm 0,2$ & $61,6 \pm 0,3$ \\
$\mathrm{MgNi}_{2}$ & $0,4 \pm 0,3$ & $2,8 \pm 0,1$ & $18,5 \pm 0,1$ & $20,4 \pm 0,1$ & $2,2 \pm 0,2$ & $55,7 \pm 0,3$ \\
\hline
\end{tabular}

TABELA 21 - Composição química (semi-quantitativa) da liga $\underline{\mathrm{La}}{ }_{0,7} \mathrm{Mg}_{0,3} \mathrm{Al}_{0,3} \mathrm{Mn}_{0,4} \mathrm{Cu}_{0,5} \mathrm{Ni}_{3,8}$, com TT $850^{\circ} \mathrm{C}$ por 9 horas, analisada por EDS.

\begin{tabular}{lrrrrrc}
\hline \multicolumn{7}{c}{ Composição Química (\% at) } \\
\hline Fases & \multicolumn{1}{c}{ La } & \multicolumn{1}{c}{ Mg } & \multicolumn{1}{c}{ Al } & \multicolumn{1}{c}{ Mn } & Cu & Ni \\
\hline $\mathrm{LaNi}_{5}$ & $17,3 \pm 0,3$ & $0,4 \pm 0,1$ & $3,2 \pm 0,1$ & $2,6 \pm 0,1$ & $9,1 \pm 0,2$ & $67,4 \pm 0,3$ \\
$(\mathrm{La}, \mathrm{Mg})_{2} \mathrm{Ni}_{9}$ & $9,5 \pm 0,3$ & $11,9 \pm 0,1$ & $2,0 \pm 0,1$ & $5,6 \pm 0,1$ & $9,8 \pm 0,2$ & $61,2 \pm 0,3$ \\
$\mathrm{MgNi}_{2}$ & $0,4 \pm 0,3$ & $3,0 \pm 0,1$ & $17,1 \pm 0,1$ & $20,9 \pm 0,1$ & $2,2 \pm 0,2$ & $56,4 \pm 0,3$ \\
\hline
\end{tabular}

TABELA 22 - Composição química (semi-quantitativa) da liga $\mathrm{La}_{0,7} \mathrm{Mg}_{0,3} \mathrm{Al}_{0,3} \mathrm{Mn}_{0,4} \mathrm{Cu}_{0,5} \mathrm{Ni}_{3,8}$, com TT $850^{\circ} \mathrm{C}$ por 169 horas, analisada por EDS.

\begin{tabular}{lrrrrrc}
\hline \multicolumn{7}{c}{ Composição Química (\% at) } \\
\hline Fases & \multicolumn{1}{c}{ La } & \multicolumn{1}{c}{ Mg } & \multicolumn{1}{c}{ Al } & \multicolumn{1}{c}{ Mn } & Cu & Ni \\
\hline $\mathrm{LaNi}_{5}$ & $16,9 \pm 0,3$ & $0,3 \pm 0,1$ & $3,4 \pm 0,1$ & $3,4 \pm 0,1$ & $8,9 \pm 0,2$ & $67,1 \pm 0,3$ \\
$\mathrm{LaMg}_{2} \mathrm{Ni}_{9}$ & $9,2 \pm 0,3$ & $12,1 \pm 0,1$ & $2,0 \pm 0,1$ & $6,1 \pm 0,1$ & $9,8 \pm 0,2$ & $60,8 \pm 0,3$ \\
$\mathrm{MgNi}_{2}$ & $0,4 \pm 0,3$ & $2,9 \pm 0,1$ & $17,5 \pm 0,1$ & $20,8 \pm 0,1$ & $2,3 \pm 0,2$ & $56,1 \pm 0,3$ \\
\hline
\end{tabular}




\subsection{3 - Micrografías da liga $\mathrm{La}_{0,7} \mathrm{Mg}_{0,3} \mathrm{Al}_{0,3} \mathrm{Mn}_{0,4} \mathrm{Sn}_{0,5} \mathrm{Ni}_{3,8}$}

Na FIGURA 29 de (a) a (e) estão apresentadas as micrografias (2000x) obtidas por MEV da liga $\mathrm{La}_{0,7} \mathrm{Mg}_{0,3} \mathrm{Al}_{0,3} \mathrm{Mn}_{0,4} \mathrm{Sn}_{0,5} \mathrm{Ni}_{3,8}$ sendo: (a) sem tratamento térmico, (b) com tratamento de $750^{\circ} \mathrm{C}$ por 9 horas, (c) com tratamento de $750^{\circ} \mathrm{C}$ por 16 horas, (d) com tratamento de $850^{\circ} \mathrm{C}$ por 9 horas, (e) com tratamento de $850^{\circ} \mathrm{C}$ por 16 horas .

As micrografias apresentam estruturas dendrítica indicando que não houve grandes alterações nos tratamentos térmicos.

As fases identificadas na liga sem e com TT de 750 e $850^{\circ} \mathrm{C}$ por 9 e 16 horas foram : $\mathrm{LaNi}_{5}$ (matriz), $\mathrm{MgNi}_{2}$, (identificada pelas regiões escuras), e a fase LaSn ${ }_{2} \mathrm{Ni}_{2}$ (identificadas pelas regiões brancas) também identificadas pelos autores K. Giza et al (2017) e Borzone et al (2014).

A composição química das fases presentes na liga $\mathrm{La}_{0,7} \mathrm{Mg}_{0,3} \mathrm{Al}_{0,3} \mathrm{Mn}_{0,4} \mathrm{Sn}_{0,5} \mathrm{Ni}_{3,8}$ sem e após TT foram obtidas por EDS (análise semiquantitativa) e estão apresentadas nas TABELAS 23 a 27. Todas as fases presentes estão de acordo com as identificadas por difração de raios-X apresentadas na FIGURA 22 e TABELA 10.

Para a liga de $\mathrm{La}_{0,7} \mathrm{Mg}_{0,3} \mathrm{Al}_{0,3} \mathrm{Mn}_{0,4} \mathrm{Sn}_{0,5} \mathrm{Ni}_{3,8}$, foi identificada a fase $\mathrm{LaSn}_{2} \mathrm{Ni}_{2}$ devido a substituição parcial do Ni pelo Sn, o que também com a foi observado por Casini et al (2016), Blanco et al (2014), Young et al (2009c), Zhuang et al (2004), Liao et al (2000). 
FIGURA 29 - Micrografias da liga $\mathrm{La}_{0,7} \mathrm{Mg}_{0,3} \mathrm{Al}_{0,3} \mathrm{Mg}_{0,3} \mathrm{Mn}_{0,4} \mathrm{Sn}_{0,5} \mathrm{Ni}_{3,8}$ com e sem TT, onde: (a) sem TT, (b) $750^{\circ} \mathrm{C}$ por 9horas, (c) $750^{\circ} \mathrm{C}$ por 16 horas, (d) $850^{\circ} \mathrm{C}$ por 9 horas, (e) $850^{\circ} \mathrm{C}$ por 16 horas

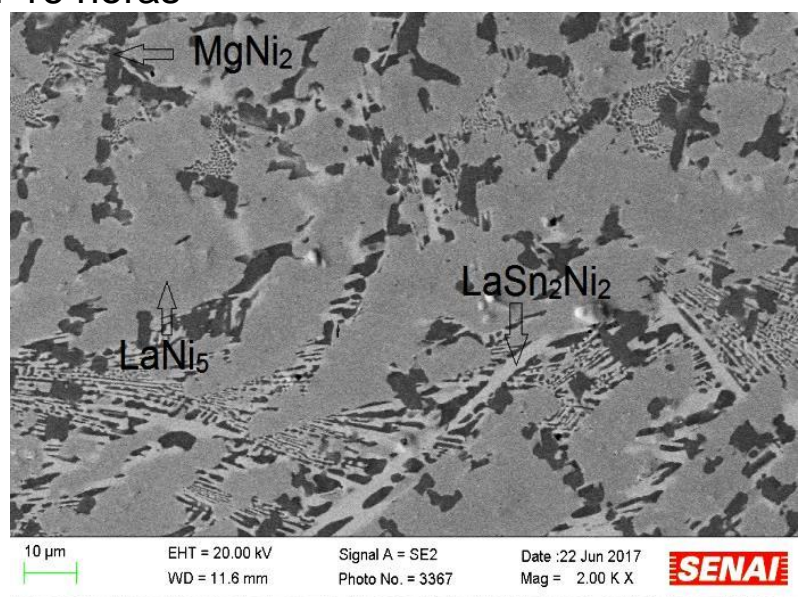

(a)

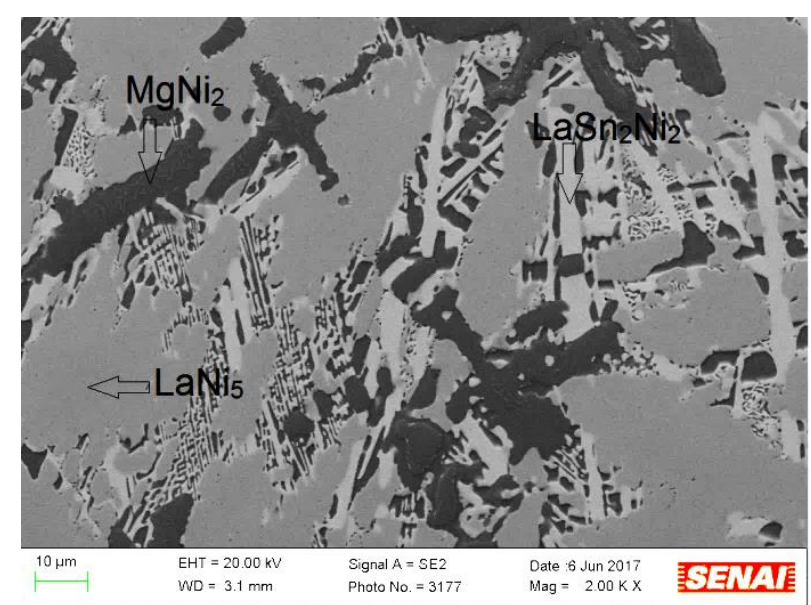

(b)

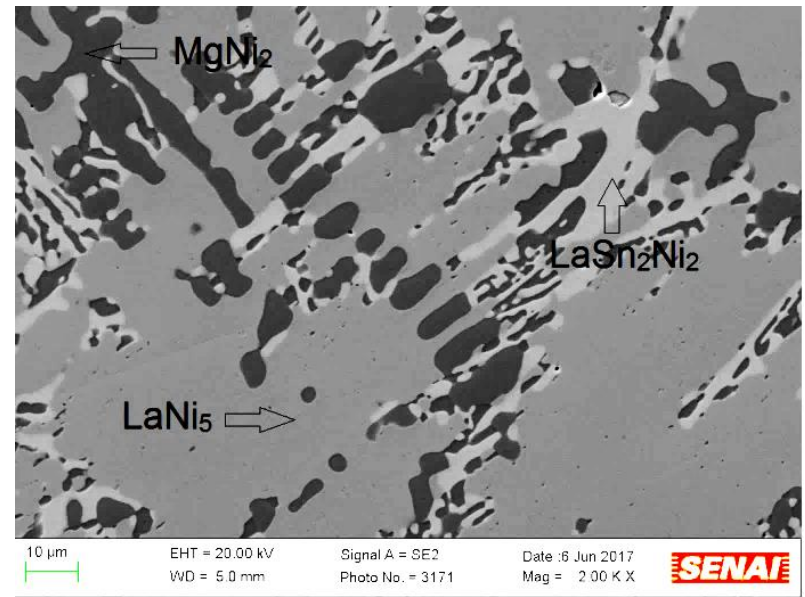

(d)

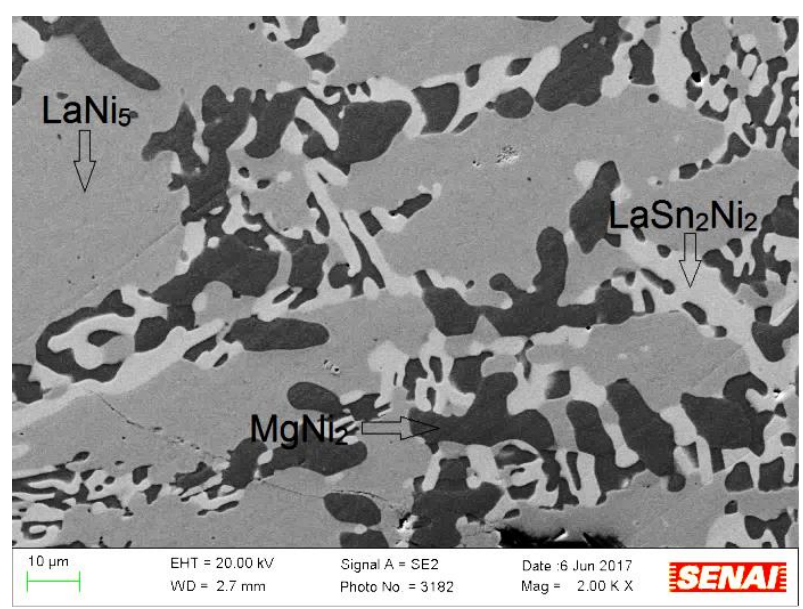

(c)

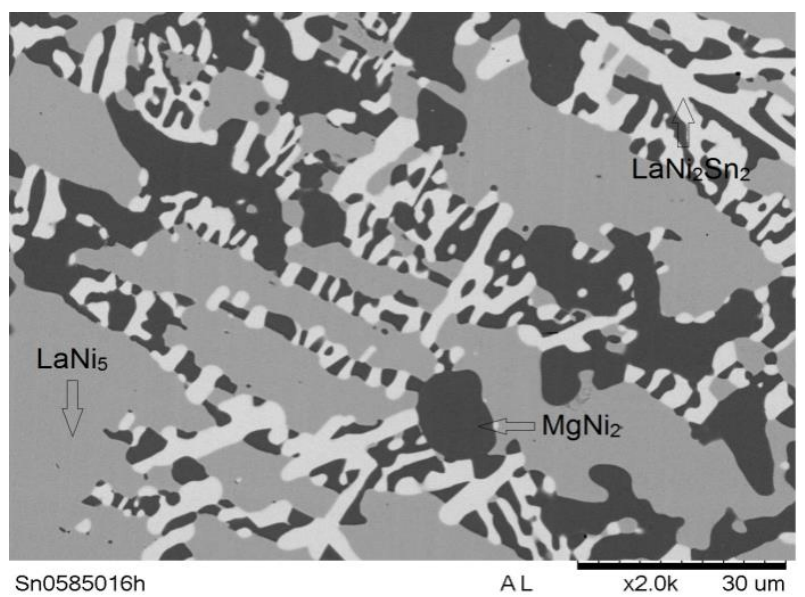

(e) 
TABELA 23 - Composição química (semi-quantitativa) da liga $\mathrm{La}_{0,7} \mathrm{Mg}_{0,3} \mathrm{Al}_{0,3} \mathrm{Mn}_{0,4} \mathrm{Sn}_{0,5} \mathrm{Ni}_{3,8}$, sem TT, analisada por EDS

\begin{tabular}{lrrrrrr}
\hline \multicolumn{7}{c}{ Composição Química (\% at) } \\
\hline \multicolumn{1}{c}{ Fases } & \multicolumn{1}{c}{ La } & \multicolumn{1}{c}{ Mg } & \multicolumn{1}{c}{ Al } & \multicolumn{1}{c}{ Mn } & \multicolumn{1}{c}{ Sn } & \multicolumn{1}{c}{$\mathbf{N i}$} \\
\hline $\mathrm{LaNi}_{5}$ & $16,6 \pm 0,3$ & $0,3 \pm 0,1$ & $2,5 \pm 0,1$ & $3,5 \pm 0,1$ & $6,0 \pm 0,3$ & $71,0 \pm 0,3$ \\
$\mathrm{LaNi}_{2} \mathrm{Sn}_{2}$ & $19,5 \pm 0,3$ & $3,8 \pm 0,1$ & $0,3 \pm 0,1$ & $1,0 \pm 0,1$ & $36,0 \pm 0,3$ & $39,3 \pm 0,3$ \\
$\mathrm{MgNi}_{2}$ & $0,3 \pm 0,3$ & $21,3 \pm 0,1$ & $1,3 \pm 0,1$ & $11,4 \pm 0,1$ & $0,3 \pm 0,3$ & $65,2 \pm 0,3$ \\
\hline
\end{tabular}

TABELA 24 - Composição química (semi-quantitativa) da liga $\mathrm{La}_{0,7} \mathrm{Mg}_{0,3} \mathrm{Al}_{0,3} \mathrm{Mn}_{0,4} \mathrm{Sn}_{0,5} \mathrm{Ni}_{3,8}$, com TT de 750 por 9 horas, analisada por EDS

\begin{tabular}{lrrrrrr}
\hline \multicolumn{7}{c}{ Composição Química (\% at) } \\
\hline \multicolumn{1}{c}{ Fases } & \multicolumn{1}{c}{ La } & \multicolumn{1}{c}{ Mg } & \multicolumn{1}{c}{ Al } & \multicolumn{1}{c}{ Mn } & \multicolumn{1}{c}{ Sn } & \multicolumn{1}{c}{$\mathbf{N i}$} \\
\hline $\mathrm{LaNi}_{5}$ & $16,0 \pm 0,3$ & $3,6 \pm 0,1$ & $2,1 \pm 0,1$ & $3,5 \pm 0,1$ & $5,7 \pm 0,3$ & $69,1 \pm 0,3$ \\
$\mathrm{LaNi}_{2} \mathrm{Sn}_{2}$ & $20,2 \pm 0,3$ & $3,5 \pm 0,1$ & $0,3 \pm 0,1$ & $1,0 \pm 0,1$ & $34,8 \pm 0,3$ & $40,0 \pm 0,3$ \\
$\mathrm{MgNi}_{2}$ & $0,4 \pm 0,3$ & $18,3 \pm 0,1$ & $3,2 \pm 0,1$ & $13,1 \pm 0,1$ & $0,3 \pm 0,3$ & $63,8 \pm 0,3$ \\
\hline
\end{tabular}

TABELA 25 - Composição química (semi-quantitativa) da liga $\mathrm{La}_{0,7} \mathrm{Mg}_{0,3} \mathrm{Al}_{0,3} \mathrm{Mn}_{0,4} \mathrm{Sn}_{0,5} \mathrm{Ni}_{3,8}$, com TT de 750 por 16 horas, analisada por EDS

\begin{tabular}{lrrrrrr}
\hline \multicolumn{7}{c}{ Composição Química (\% at) } \\
\hline \multicolumn{1}{c}{ Fases } & \multicolumn{1}{c}{ La } & \multicolumn{1}{c}{ Mg } & \multicolumn{1}{c}{ Al } & \multicolumn{1}{c}{ Mn } & \multicolumn{1}{c}{ Sn } & \multicolumn{1}{c}{$\mathbf{N i}$} \\
\hline $\mathrm{LaNi}_{5}$ & $16,4 \pm 0,3$ & $0,3 \pm 0,1$ & $2,1 \pm 0,1$ & $3,5 \pm 0,1$ & $6,4 \pm 0,3$ & $71,1 \pm 0,3$ \\
$\mathrm{LaNi}_{2} \mathrm{Sn}_{2}$ & $20,0 \pm 0,3$ & $3,1 \pm 0,1$ & $0,3 \pm 0,1$ & $0,8 \pm 0,1$ & $34,8 \pm 0,3$ & $40,8 \pm 0,3$ \\
$\mathrm{MgNi}_{2}$ & $0,5 \pm 0,3$ & $20,9 \pm 0,1$ & $1,1 \pm 0,1$ & $10,7 \pm 0,1$ & $0,3 \pm 0,3$ & $66,4 \pm 0,3$ \\
\hline
\end{tabular}

TABELA 26 - Composição química (semi-quantitativa) da liga $\mathrm{La}_{0,7} \mathrm{Mg}_{0,3} \mathrm{Al}_{0,3} \mathrm{Mn}_{0,4} \mathrm{Sn}_{0,5} \mathrm{Ni}_{3,8}$, com TT de 850 por 9 horas, analisada por EDS

\begin{tabular}{lrrrrrr}
\hline \multicolumn{7}{c}{ Composição Química (\% at) } \\
\hline \multicolumn{1}{c}{ Fases } & \multicolumn{1}{c}{ La } & \multicolumn{1}{c}{ Mg } & \multicolumn{1}{c}{ Al } & \multicolumn{1}{c}{ Mn } & \multicolumn{1}{c}{ Sn } & \multicolumn{1}{c}{$\mathbf{N i}$} \\
\hline $\mathrm{LaNi}_{5}$ & $16,6 \pm 0,3$ & $0,3 \pm 0,1$ & $2,5 \pm 0,1$ & $3,5 \pm 0,1$ & $6,0 \pm 0,3$ & $71,0 \pm 0,3$ \\
$\mathrm{LaNi}_{2} \mathrm{Sn}_{2}$ & $19,5 \pm 0,3$ & $3,8 \pm 0,1$ & $0,3 \pm 0,1$ & $1,0 \pm 0,1$ & $36,0 \pm 0,3$ & $39,3 \pm 0,3$ \\
$\mathrm{MgNi}_{2}$ & $0,3 \pm 0,3$ & $21,3 \pm 0,1$ & $1,3 \pm 0,1$ & $11,4 \pm 0,1$ & $0,3 \pm 0,3$ & $65,2 \pm 0,3$ \\
\hline
\end{tabular}

TABELA 27 - Composição química (semi-quantitativa) da liga $\mathrm{La}_{0,7} \mathrm{Mg}_{0,3} \mathrm{Al}_{0,3} \mathrm{Mn}_{0,4} \mathrm{Sn}_{0,5} \mathrm{Ni}_{3,8}$, com TT de 850 por 16 horas, analisada por EDS.

\begin{tabular}{lrrrrrr}
\hline \multicolumn{7}{c}{ Composição Química (\% at) } \\
\hline \multicolumn{1}{c}{ Fases } & \multicolumn{1}{c}{ La } & \multicolumn{1}{c}{ Mg } & \multicolumn{1}{c}{ Al } & Mn & \multicolumn{1}{c}{ Sn } & \multicolumn{1}{c}{$\mathbf{N i}$} \\
\hline $\mathrm{LaNi}_{5}$ & $15,1 \pm 0,3$ & $0,3 \pm 0,1$ & $2,2 \pm 0,1$ & $4,8 \pm 0,1$ & $6,1 \pm 0,3$ & $71,1 \pm 0,3$ \\
$\mathrm{LaNi}_{2} \mathrm{Sn}_{2}$ & $13,8 \pm 0,3$ & $2,7 \pm 0,1$ & $4,2 \pm 0,1$ & $8,1 \pm 0,1$ & $28,9 \pm 0,3$ & $42,2 \pm 0,3$ \\
$\mathrm{MgNi}_{2}$ & $0,4 \pm 0,3$ & $23,1 \pm 0,1$ & $1,3 \pm 0,1$ & $13,2 \pm 0,1$ & $0,5 \pm 0,3$ & $61,5 \pm 0,3$ \\
\hline
\end{tabular}




\subsection{4- Micrografias da liga $\mathrm{La}_{0,7} \mathrm{Pr}_{0,3} \mathrm{Al}_{0,3} \mathrm{Mn}_{0,4} \mathrm{Co}_{0,5} \mathrm{Ni}_{3,8}$}

Na FIGURA 30 de (a) a (e) estão apresentadas as micrografias (2000x) obtidas por MEV da liga $\mathrm{La}_{0,7} \mathrm{Pr}_{0,3} \mathrm{Al}_{0,3} \mathrm{Mn}_{0,4} \mathrm{Co}_{0,5} \mathrm{Ni}_{3,8}$ sendo: (a) sem tratamento térmico, (b) com tratamento de $750^{\circ} \mathrm{C}$ por 9 horas, (c) com tratamento de $750^{\circ} \mathrm{C}$ por 16 horas, (d) com tratamento de $850^{\circ} \mathrm{C}$ por 9 horas, (e) com tratamento de $850^{\circ} \mathrm{C}$ por 16 horas .

As fases identificadas foram na liga sem e com TT de 750 e $850^{\circ} \mathrm{C}$ por 9 e 16 horas foram : $\mathrm{LaNi}_{5}$ (matriz), $\mathrm{PrNi}_{5}$, (identificada pelas regiões escuras), também identificadas por Pan et al (2007), Li R. et al (2004) e Kadir et al (1997)

A composição química das fases presentes na liga La $a_{0,7} \mathrm{Pr}_{0,3} \mathrm{Al}_{0,3} \mathrm{Mn}_{0,4} \mathrm{Co}_{0,5} \mathrm{Ni}_{3,8}$ sem e após TT foram obtidas por EDS (análise semiquantitativa) e estão apresentadas nas TABELAS 28 a 32. Todas as fases presentes estão de acordo com as identificadas por difração de raios-X apresentadas na FIGURA 23 e TABELA 11.

As fases presentes na liga $\mathrm{La}_{0,7} \mathrm{Pr}_{0,3} \mathrm{Al}_{0,3} \mathrm{Mn}_{0,4} \mathrm{Co}_{0,5} \mathrm{Ni}_{3,8}$ sem e com TT, mencionadas acima também foram observadas por Xue et al (2016), Liu and Kong (2010) e Peng et al (2004). 
FIGURA 30 - Micrografias da liga $\mathrm{La}_{0,7} \mathrm{Pr}_{0,3} \mathrm{Al}_{0,3} \mathrm{Mgg}_{0,3} \mathrm{Mn}_{0,4} \mathrm{Co}_{0,5} \mathrm{Ni}_{3,8}$ com e sem TT, onde: (a) sem TT, (b) $750^{\circ} \mathrm{C}$ por 9 horas, (c) $750^{\circ} \mathrm{C}$ por 16 horas, (d) $850^{\circ} \mathrm{C}$ por 9 horas, (e) $850^{\circ} \mathrm{C}$ por 16 horas.

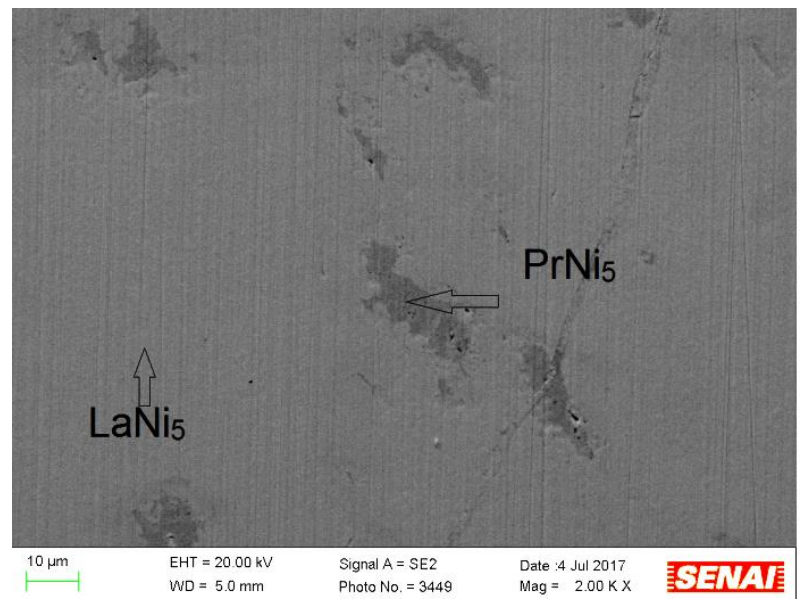

(a)

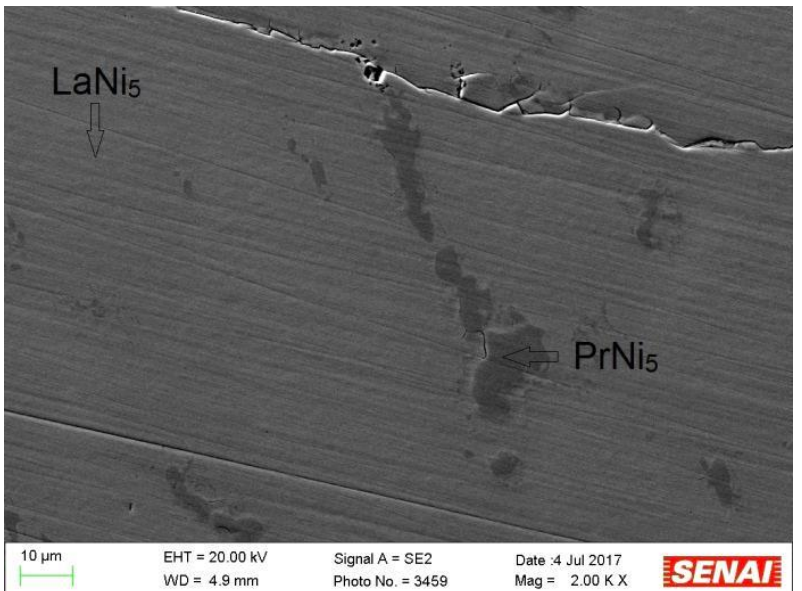

(b)

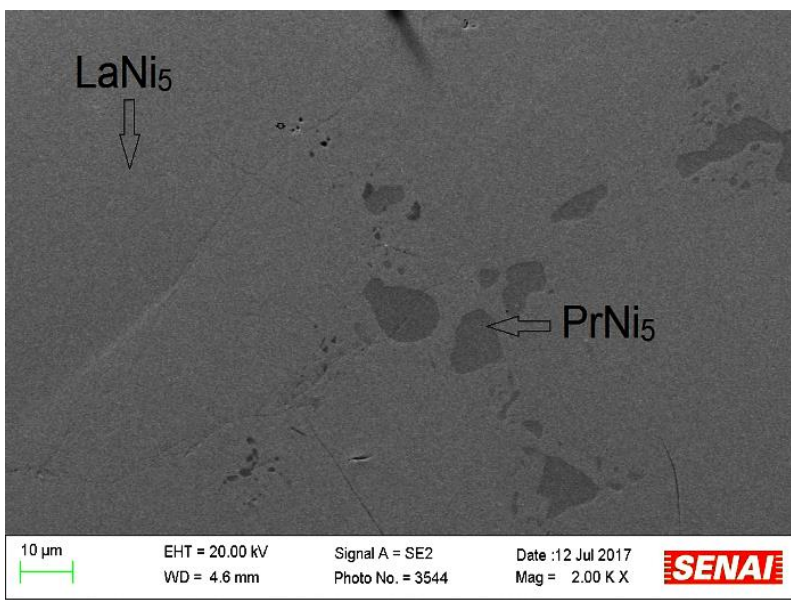

(d)

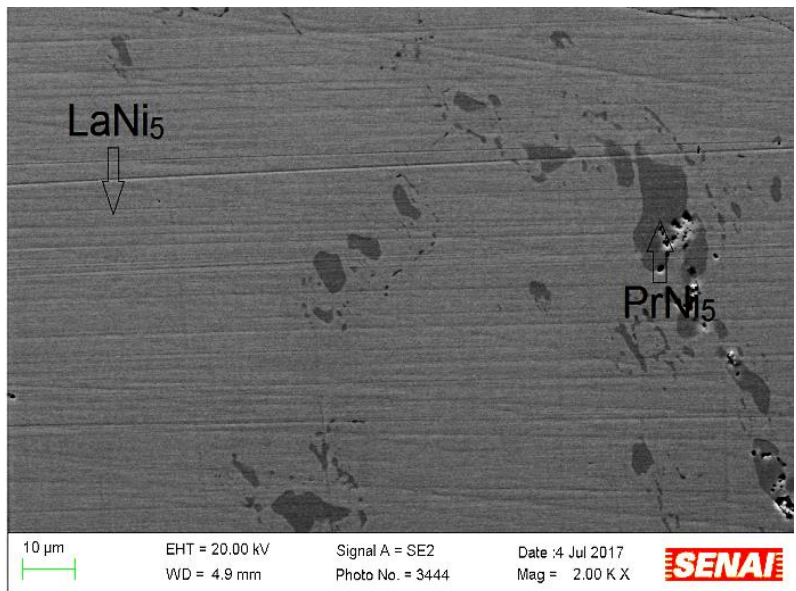

(c)

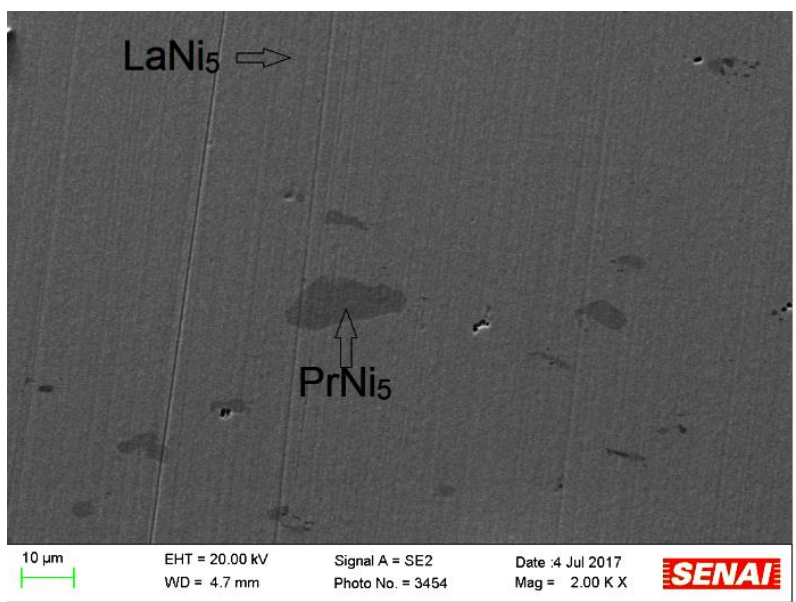

(e) 
TABELA 28 - Composição química (semi-quantitativa) da liga $\mathrm{La}_{0,7} \mathrm{Pr}_{0,3} \mathrm{Al}_{0,3} \mathrm{Mn}_{0,4} \mathrm{Co}_{0,5} \mathrm{Ni}_{3,8}$, sem TT, analisada por EDS.

\begin{tabular}{lrlllll}
\hline \multicolumn{7}{c}{ Composição Química (\% at) } \\
\hline \multicolumn{1}{c}{ Fases } & \multicolumn{1}{c}{ La } & Pr & \multicolumn{1}{c}{ Al } & Mn & \multicolumn{1}{c}{ Co } & Ni \\
\hline $\mathrm{LaNi}_{5}$ & $12,1 \pm 0,2$ & $4,9 \pm 0,3$ & $5,0 \pm 0,1$ & $5,9 \pm 0,2$ & $8,4 \pm 0,2$ & $63,7 \pm 0,3$ \\
$\mathrm{PrNi}_{5}$ & $7,9 \pm 0,2$ & $3,5 \pm 0,3$ & $3,7 \pm 0,1$ & $23,4 \pm 0,2$ & $7,5 \pm 0,2$ & $54,0 \pm 0,3$ \\
\hline
\end{tabular}

TABELA 29 - Composição química (semi-quantitativa) da liga La ${ }_{0,7} \mathrm{Pr}_{0,3} \mathrm{Al}_{0,3} \mathrm{Mn}_{0,4} \mathrm{Co}_{0,5} \mathrm{Ni}_{3,8}$, com TT de 750 por 9 horas, analisada por EDS.

\begin{tabular}{lrlllll}
\hline \multicolumn{7}{c}{ Composição Química (\% at) } \\
\hline \multicolumn{1}{c}{ Fases } & La & Pr & Al & Mn & Co & Ni \\
\hline $\mathrm{LaNi}_{5}$ & $12,1 \pm 0,2$ & $5,0 \pm 0,3$ & $4,2 \pm 0,1$ & $4,6 \pm 0,2$ & $8,7 \pm 0,2$ & $65,3 \pm 0,3$ \\
$\mathrm{PrNi}_{5}$ & $7,3 \pm 0,2$ & $3,5 \pm 0,3$ & $3,1 \pm 0,1$ & $21,3 \pm 0,2$ & $9,3 \pm 0,2$ & $55,5 \pm 0,3$ \\
\hline
\end{tabular}

TABELA $30 \quad$ - Composição química (semi-quantitativa) da liga $\underline{\mathrm{La}_{0,7}} \mathrm{Pr}_{0,3} \mathrm{Al}_{0,3} \mathrm{Mn}_{0,4} \mathrm{Co}_{0,5} \mathrm{Ni}_{3,8}$, com TT de 750 por 16 horas, analisada por EDS.

\begin{tabular}{crlrrrr}
\hline \multicolumn{7}{c}{ Composição Química (\% at) } \\
\hline Fases & La & Pr & Al & Mn & \multicolumn{1}{c}{ Co } & Ni \\
\hline $\mathrm{LaNi}_{5}$ & $12,1 \pm 0,2$ & $5,2 \pm 0,3$ & $3,5 \pm 0,1$ & $4,4 \pm 0,2$ & $8,6 \pm 0,2$ & $66,2 \pm 0,3$ \\
$\mathrm{PrNi}_{5}$ & $7,6 \pm 0,2$ & $3,0 \pm 0,3$ & $3,0 \pm 0,1$ & $21,0 \pm 0,2$ & $10,3 \pm 0,2$ & $55,2 \pm 0,3$ \\
\hline
\end{tabular}

TABELA 31 - Composição química (semi-quantitativa) da liga $\mathrm{La}_{0,7} \mathrm{Pr}_{0,3} \mathrm{Al}_{0,3} \mathrm{Mn}_{0,4} \mathrm{Co}_{0,5} \mathrm{Ni}_{3,8}$, com TT de 850 por 9 horas, analisada por EDS.

\begin{tabular}{ccccccc}
\hline \multicolumn{7}{c}{ Composição Química (\% at) } \\
\hline \multicolumn{1}{c}{ Fases } & La & Pr & \multicolumn{1}{c}{ Al } & Mn & \multicolumn{1}{c}{ Co } & Ni \\
\hline $\mathrm{LaNi}_{5}$ & $12,0 \pm 0,2$ & $4,9 \pm 0,3$ & $5,7 \pm 0,1$ & $6,5 \pm 0,2$ & $8,5 \pm 0,2$ & $62,4 \pm 0,3$ \\
$\mathrm{PrNi}_{5}$ & $7,0 \pm 0,2$ & $2,9 \pm 0,3$ & $4,2 \pm 0,1$ & $20,2 \pm 0,2$ & $10,7 \pm 0,2$ & $54,3 \pm 0,3$ \\
\hline
\end{tabular}

Tabela 32 - Composição química (semi-quantitativa) da liga $\mathrm{La}_{0,7} \mathrm{Pr}_{0,3} \mathrm{Al}_{0,3} \mathrm{Mn}_{0,4} \mathrm{Co}_{0,5} \mathrm{Ni}_{3,8}$, com TT de 850 por 16 horas, analisada por EDS.

\begin{tabular}{crrrrrr}
\hline \multicolumn{7}{c}{ Composição Química (\% at) } \\
\hline \multicolumn{1}{c}{ Fases } & La & Pr & \multicolumn{1}{c}{ Al } & \multicolumn{1}{c}{ Mn } & \multicolumn{1}{c}{ Co } & Ni \\
\hline $\mathrm{LaNi}_{5}$ & $12,1 \pm 0,2$ & $4,9 \pm 0,3$ & $4,72 \pm 0,1$ & $5,66 \pm 0,2$ & $8,8 \pm 0,2$ & $63,8 \pm 0,3$ \\
$\mathrm{PrNi}_{5}$ & $7,1 \pm 0,2$ & $3,2 \pm 0,3$ & $3,63 \pm 0,1$ & $19,00 \pm 0,2$ & $11,5 \pm 0,2$ & $55,5 \pm 0,3$ \\
\hline
\end{tabular}




\subsection{5 - Micrografias da liga $\mathrm{Pr}_{0,7} \mathrm{Mg}_{0,3} \mathrm{Al}_{0,3} \mathrm{Mn}_{0,4} \mathrm{Co}_{0,5} \mathrm{Ni}_{3,8}$}

Na FIGURA 31 de (a) a (e) estão apresentadas as micrografias (2000x) obtidas por MEV da liga $\operatorname{Pr}_{0,7} \mathrm{Mg}_{0,3} \mathrm{Al}_{0,3} \mathrm{Mn}_{0,4} \mathrm{Co}_{0,5} \mathrm{Ni}_{3,8}$ sendo: (a) sem tratamento térmico, (b) com tratamento de $750^{\circ} \mathrm{C}$ por 9 horas, (c) com tratamento de $750^{\circ} \mathrm{C}$ por 16 horas, (d) com tratamento de $850^{\circ} \mathrm{C}$ por 9 horas, (e) com tratamento de $850^{\circ} \mathrm{C}$ por 16 horas .

As micrografias apresentam estruturas dendrítica indicando que não houve grandes alterações com os tratamentos térmicos aplicados na ligas. As fases identificadas na liga sem e com TT de 750 e $850^{\circ} \mathrm{C}$ por 9 e 16 horas foram: $\mathrm{PrNi}_{5}$ (matriz), (AIMn) $\mathrm{Ni}_{3}$ (identificada pelas região escura), e $\mathrm{PrMg}_{2} \mathrm{Ni}_{9}$, (identificada pelas região cinza), também identificadas por Iwase et al (2013) e (2017) e Zhang et al (2016).

A composição química das fases presentes na liga $\operatorname{Pr}_{0,7} \mathrm{Mg}_{0,3} \mathrm{Al}_{0,3} \mathrm{Mn}_{0,4} \mathrm{Co}_{0,5} \mathrm{Ni}_{3,8}$ sem e após TT foram obtidas por EDS (análise semiquantitativa) e estão apresentadas nas TABELAS 33 a 37. Todas as fases presentes estão de acordo com as identificadas por difração de raios-X apresentadas na FIGURA 24 e TABELA 12.

As fases $\mathrm{PrNi}_{5}$ e $\mathrm{PrMg}_{2} \mathrm{Ni}_{9}$ presentes na liga sem TT, também foram identificadas em trabalhos anteriores descrito por Zarpelon et al (2018), Denys and Yartz (2015), Nwakwuo et al (2013), Zang Y. et al (2012), Lemort et al (2011) e Chen et al (1996). 
FIGURA 31 - Micrografias da liga $\operatorname{Pr}_{0,7} \mathrm{Mg}_{0,3} \mathrm{Al}_{0,3} \mathrm{Mg}_{0,3} \mathrm{Mn}_{0,4} \mathrm{Co}_{0,5} \mathrm{Ni}_{3,8}$ com e sem tratamento térmico, onde: (a) sem tratamento térmico, (b) $750^{\circ} \mathrm{C}$ por 9 horas, (c) $750^{\circ} \mathrm{C}$ por 16 horas, (d) $850^{\circ} \mathrm{C}$ por 9 horas, (e) $850^{\circ} \mathrm{C}$ por 16 horas.

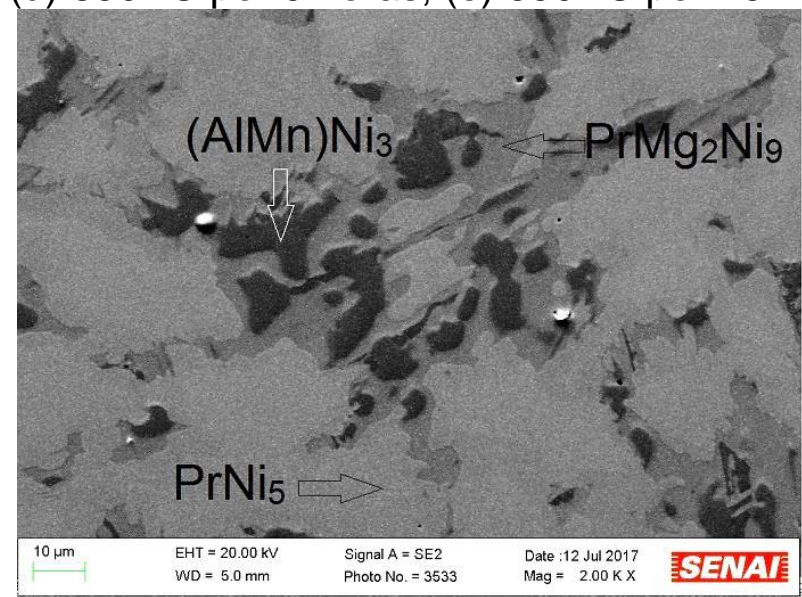

(a)

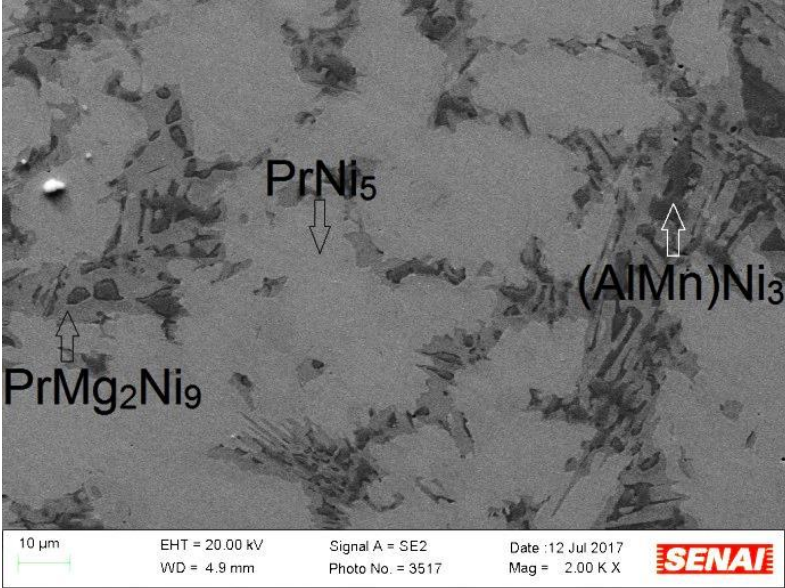

(b)

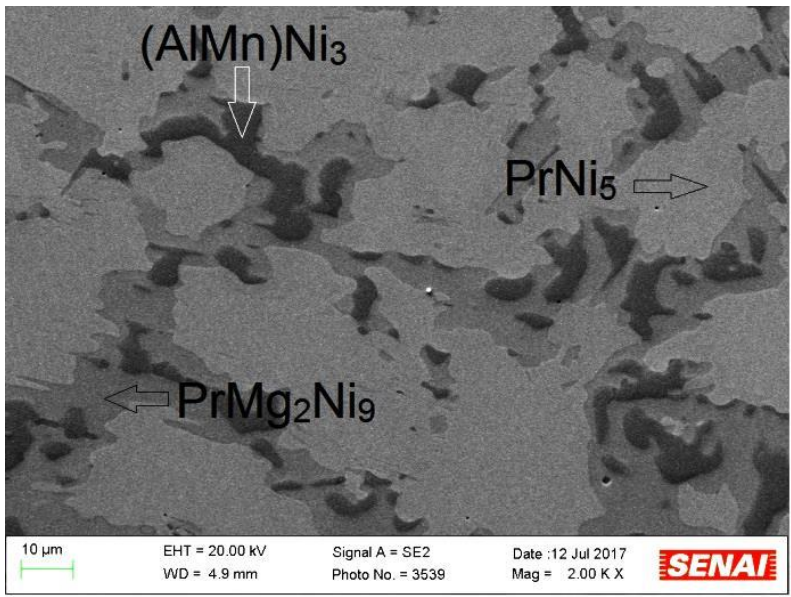

(d)

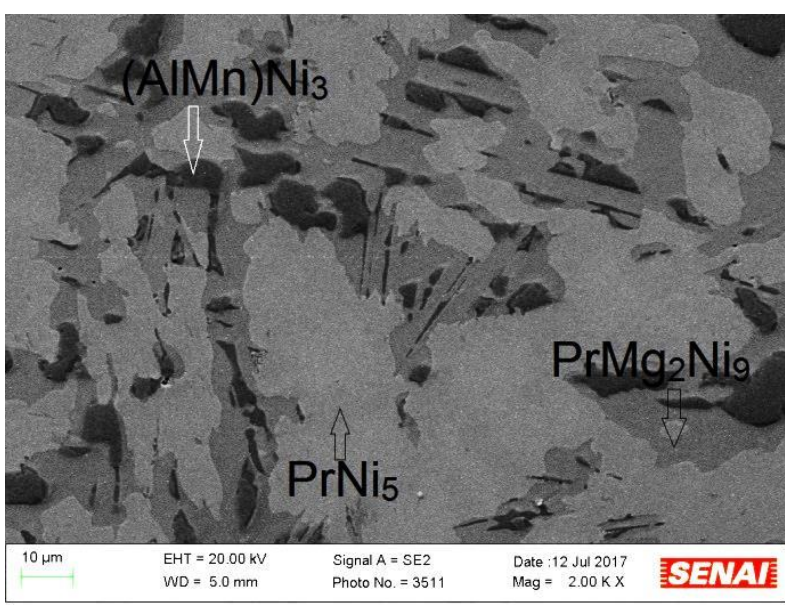

(c)

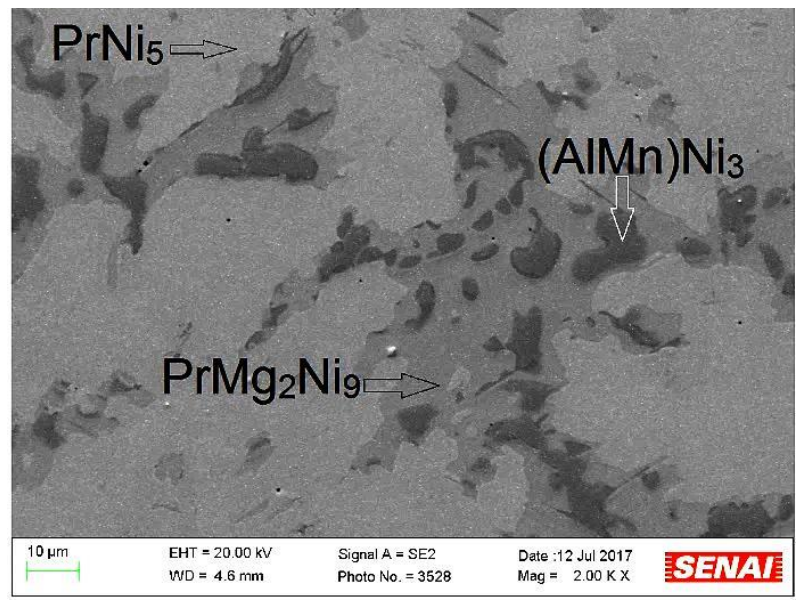

(e) 
TABELA 33 - Composição química (semi-quantitativa) da liga $\operatorname{Pr}_{0,7} \mathrm{Mg}_{0,3} \mathrm{Al}_{0,3} \mathrm{Mn}_{0,4} \mathrm{Co}_{0,5} \mathrm{Ni}_{3,8}$, sem TT, analisada por EDS.

\begin{tabular}{crrrrrr}
\hline \multicolumn{7}{c}{ Composição Química (\% at) } \\
\hline \multicolumn{1}{c}{ Fases } & \multicolumn{1}{c}{$\mathbf{P r}$} & \multicolumn{1}{c}{ Mg } & \multicolumn{1}{c}{ Al } & Mn & \multicolumn{1}{c}{ Co } & Ni \\
\hline $\mathrm{PrNi}_{5}$ & $16,3 \pm 0,3$ & $0,3 \pm 0,1$ & $2,6 \pm 0,1$ & $2,3 \pm 0,2$ & $8,3 \pm 0,2$ & $70,1 \pm 0,3$ \\
$\mathrm{PrMg}_{2} \mathrm{Ni}_{9}$ & $8,9 \pm 0,3$ & $10,1 \pm 0,1$ & $2,7 \pm 0,1$ & $7,7 \pm 0,2$ & $7,9 \pm 0,2$ & $62,5 \pm 0,3$ \\
$(\mathrm{AlMn}) \mathrm{Ni}_{3}$ & $0,7 \pm 0,3$ & $0,9 \pm 0,1$ & $9,8 \pm 0,1$ & $16,6 \pm 0,2$ & $15,5 \pm 0,2$ & $56,6 \pm 0,3$ \\
\hline
\end{tabular}

TABELA 34 - Composição química (semi-quantitativa) da liga $\operatorname{Pr}_{0,7} \mathrm{Mg}_{0,3} \mathrm{Al}_{0,3} \mathrm{Mn}_{0,4} \mathrm{Co}_{0,5} \mathrm{Ni}_{3,8}$, com TT de 750 por 9 horas, analisada por EDS.

\begin{tabular}{lrrrrrr}
\hline \multicolumn{7}{c}{ Composição Química (\% at) } \\
\hline \multicolumn{1}{c}{ Fases } & \multicolumn{1}{c}{$\mathbf{P r}$} & \multicolumn{1}{c}{$\mathbf{M g}$} & \multicolumn{1}{c}{ Al } & \multicolumn{1}{c}{ Mn } & \multicolumn{1}{c}{ Co } & \multicolumn{1}{c}{$\mathbf{N i}$} \\
\hline $\mathrm{PrNi}_{5}$ & $16,1 \pm 0,3$ & $0,3 \pm 0,1$ & $3,4 \pm 0,1$ & $2,9 \pm 0,2$ & $8,4 \pm 0,2$ & $68,8 \pm 0,3$ \\
$\mathrm{PrMg}_{2} \mathrm{Ni}_{9}$ & $10,2 \pm 0,3$ & $10,3 \pm 0,1$ & $2,3 \pm 0,1$ & $6,0 \pm 0,2$ & $7,0 \pm 0,2$ & $64,2 \pm 0,3$ \\
$(\mathrm{AlMn}) \mathrm{Ni}_{3}$ & $0,8 \pm 0,3$ & $0,4 \pm 0,1$ & $9,1 \pm 0,1$ & $18,6 \pm 0,2$ & $15,6 \pm 0,2$ & $55,4 \pm 0,3$ \\
\hline
\end{tabular}

TABELA 35 - Composição química da liga $\operatorname{Pr}_{0,7} \mathrm{Mg}_{0,3} \mathrm{Al}_{0,3} \mathrm{Mn}_{0,4} \mathrm{Co}_{0,5} \mathrm{Ni}_{3,8}$, com tratamento térmico de 750 por 16 horas, analisada por EDS.

\begin{tabular}{lrrrrrr}
\hline \multicolumn{7}{c}{ Composição Química (\% at) } \\
\multicolumn{1}{c}{ Fases } & \multicolumn{1}{c}{ Pr } & \multicolumn{1}{c}{ Mg } & \multicolumn{1}{c}{ Al } & \multicolumn{1}{c}{ Mn } & \multicolumn{1}{c}{ Co } & \multicolumn{1}{c}{$\mathbf{N i}$} \\
\hline $\mathrm{PrNi}_{5}$ & $15,2 \pm 0,3$ & $0,3 \pm 0,1$ & $4,1 \pm 0,1$ & $4,4 \pm 0,2$ & $8,9 \pm 0,2$ & $67,0 \pm 0,3$ \\
$\mathrm{PrMg}_{2} \mathrm{Ni}_{9}$ & $10,1 \pm 0,3$ & $10,3 \pm 0,1$ & $2,1 \pm 0,1$ & $6,8 \pm 0,2$ & $7,5 \pm 0,2$ & $63,2 \pm 0,3$ \\
$(\mathrm{AlMn}) \mathrm{Ni}_{3}$ & $0,3 \pm 0,3$ & $0,6 \pm 0,1$ & $12,5 \pm 0,1$ & $20,0 \pm 0,2$ & $14,6 \pm 0,2$ & $51,9 \pm 0,3$
\end{tabular}

TABELA 36 - Composição química (semi-quantitativa) da liga $\mathrm{Pr}_{0,7} \mathrm{Mg}_{0,3} \mathrm{Al}_{0,3} \mathrm{Mn}_{0,4} \mathrm{Co}_{0,5} \mathrm{Ni}_{3,8}$, com TT de 850 por 9 horas, analisada por EDS.

\begin{tabular}{crrrrrr}
\hline \multicolumn{7}{c}{ Composição Química (\% at) } \\
\hline \multicolumn{1}{c}{ Fases } & \multicolumn{1}{c}{$\mathbf{P r}$} & \multicolumn{1}{c}{ Mg } & \multicolumn{1}{c}{ Al } & \multicolumn{1}{c}{ Mn } & \multicolumn{1}{c}{ Co } & \multicolumn{1}{c}{ Ni } \\
\hline $\mathrm{PrNi}_{5}$ & $16,0 \pm 0,3$ & $0,6 \pm 0,1$ & $4,4 \pm 0,1$ & $3,6 \pm 0,2$ & $7,5 \pm 0,2$ & $67,8 \pm 0,3$ \\
$\mathrm{PrMg}_{2} \mathrm{Ni}_{9}$ & $10,5 \pm 0,3$ & $11,8 \pm 0,1$ & $2,3 \pm 0,1$ & $5,7 \pm 0,2$ & $7,4 \pm 0,2$ & $62,3 \pm 0,3$ \\
$\left(\mathrm{AlMn}_{\mathrm{N}} \mathrm{Ni}_{3}\right.$ & $0,3 \pm 0,3$ & $0,4 \pm 0,1$ & $9,8 \pm 0,1$ & $17,4 \pm 0,2$ & $16,2 \pm 0,2$ & $55,8 \pm 0,3$ \\
\hline
\end{tabular}

TABELA 37 - Composição química (semi-quantitativa) da liga $\mathrm{Pr}_{0,7} \mathrm{Mg}_{0,3} \mathrm{Al}_{0,3} \mathrm{Mn}_{0,4} \mathrm{Co}_{0,5} \mathrm{Ni}_{3,8}$, com TT de 850 por 16 horas, analisada por EDS.

\begin{tabular}{crrrrrc}
\hline \multicolumn{7}{c}{ Composição Química (\% at) } \\
\hline \multicolumn{1}{c}{ Fases } & \multicolumn{1}{c}{ Pr } & \multicolumn{1}{c}{ Mg } & \multicolumn{1}{c}{ Al } & \multicolumn{1}{c}{ Mn } & \multicolumn{1}{c}{ Co } & Ni \\
\hline $\mathrm{PrNi}_{5}$ & $14,6 \pm 0,3$ & $0,3 \pm 0,1$ & $4,3 \pm 0,1$ & $5,5 \pm 0,2$ & $9,1 \pm 0,2$ & $66,1 \pm 0,3$ \\
$\mathrm{PrMg}_{2} \mathrm{Ni}_{9}$ & $9,7 \pm 0,3$ & $10,7 \pm 0,1$ & $2,7 \pm 0,1$ & $7,0 \pm 0,2$ & $7,1 \pm 0,2$ & $62,7 \pm 0,3$ \\
$\left(\mathrm{AlMn}_{9} \mathrm{Ni}_{3}\right.$ & $0,6 \pm 0,3$ & $0,4 \pm 0,1$ & $12,2 \pm 0,1$ & $19,6 \pm 0,2$ & $14,3 \pm 0,2$ & $52,9 \pm 0,3$ \\
\hline
\end{tabular}




\section{4 - Caracterização eletroquímica}

Nas FIGURAS 32 a 37 mostram os resultados das características eletroquímicas de capacidade de descarga das ligas sem e com TT, utilizadas como material ativo do eletrodo negativo nas baterias. Nas TABELAS 38 a 42, apresentam as propriedades eletroquímicas de capacidade de retenção cíclica $(\mathrm{Sn})$ e a quantidade de hidrogênio absorvido por fórmula unitária $(\eta)$ onde se obtém a relação hidrogênio material $(H / M)$ das baterias, a partir das equações 3.10 e 3.11 :

$$
\begin{gathered}
\eta=\frac{3600 \times M w \times C_{\text {máx. }}}{9,65 \times 10^{7}} \\
\mathrm{~S}_{n}=\frac{C_{n}}{C_{\text {máx. }}} \times 100(\%)
\end{gathered}
$$

\subsection{1 - Caracterização eletroquímica da liga $\mathrm{La}_{0,7} \mathrm{Mg}_{0,3} \mathrm{Al}_{0,3} \mathrm{Mn}_{0,4} \mathrm{Co}_{0,5} \mathrm{Ni}_{3,8}$ sem e com TT}

Na FIGURA 32 estão mostradas as curvas de capacidade de descarga em função dos ciclos de carga/descarga para os eletrodos negativos preparados com a liga $\mathrm{La}_{0,7} \mathrm{Mg}_{0,3} \mathrm{Al}_{0,3} \mathrm{Mn}_{0,4} \mathrm{Co}_{0,5} \mathrm{Ni}_{3,8}$ sem e com TT. Os resultados indicaram um aumento da capacidade de descarga para todos os tratamentos térmicos realizados comparados com a liga sem TT. As ligas após TT de $16 \mathrm{~h}$ apresentaram as melhores capacidades de descarga, de 387,6 e 406,1 mAh para as temperaturas de $750^{\circ} \mathrm{e}$ $850^{\circ} \mathrm{C}$, respectivamente.

O aumento inicial da capacidade de descarga (10 primeiros ciclos de carga/descarga) para esta liga sem e com TT pode ser explicado em função de que durante os primeiros ciclos podem ocorrer diversas transformações na superfície da liga, como redução dos óxidos presentes e tamanho das partículas. Esta redução é resultante da dilatação e contração da célula cristalina unitária durante a hidretação/desidretação, aumentando a área ativa da liga o que possibilita uma maior absorção de hidrogênio e consequentemente uma melhor capacidade de 
descarga, observado também por Ambrósio, R. C. e Ticianelli, E. A. (2001), Pan et al (2007), Zhang W. et al (2009), Ferreira et al (2010), Santos S. et al (2013).

FIGURA 32 - Perfis da capacidade de descarga dos eletrodos negativos fabricados com a liga $\mathrm{La}_{0,7} \mathrm{Mg}_{0,3} \mathrm{Al}_{0,3} \mathrm{Mn}_{0,4} \mathrm{Co}_{0,5} \mathrm{Ni}_{3,8}$

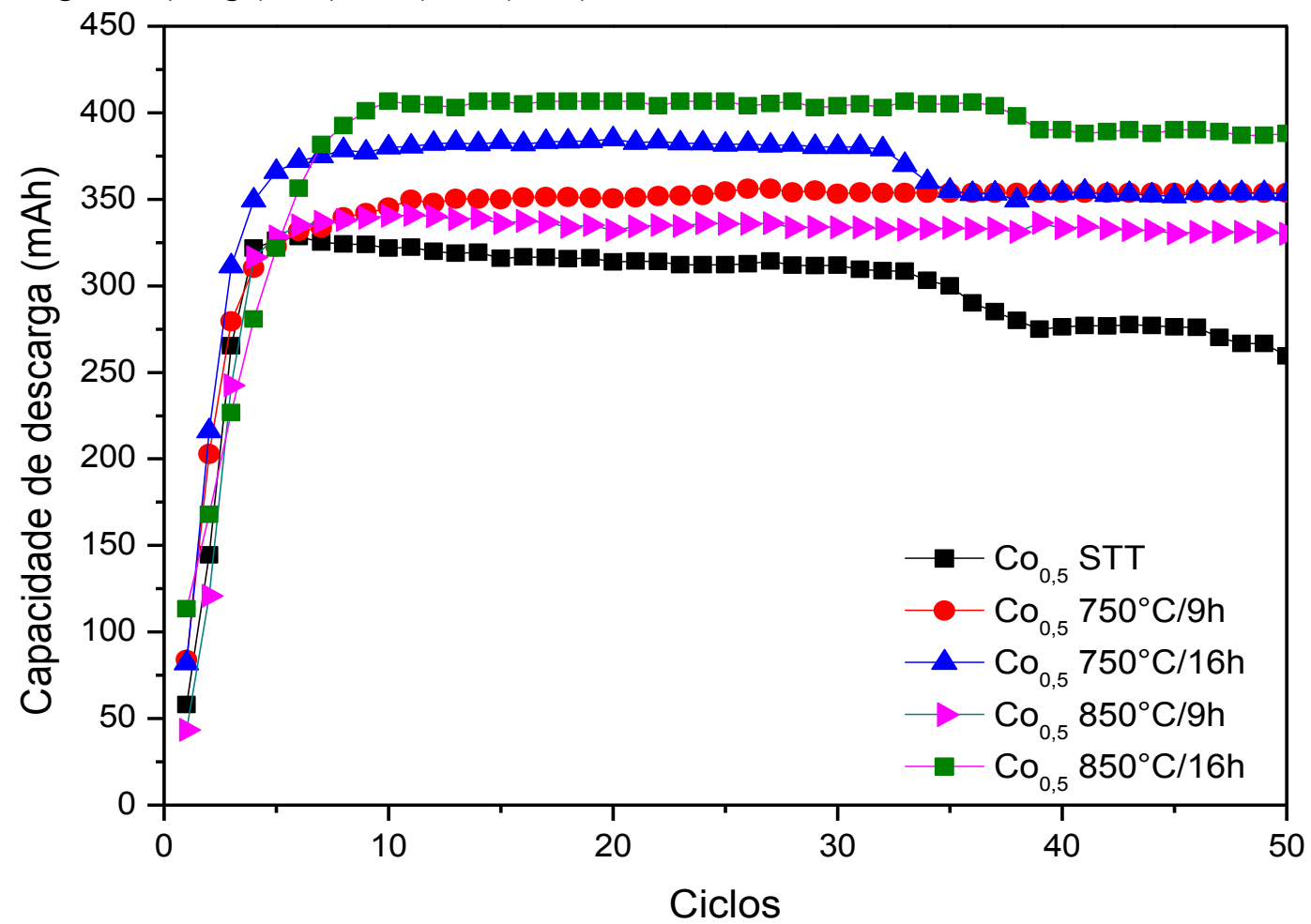

$\mathrm{Na}$ TABELA 38 estão apresentadas as propriedades eletroquímicas da liga $\mathrm{La}_{0,7} \mathrm{Mg}_{0,3} \mathrm{Al}_{0,3} \mathrm{Mn}_{0,4} \mathrm{Co}_{0,5} \mathrm{Ni}_{3,8}$ sem e com TT. A melhor capacidade máxima de descarga e a relação H/M calculado a partir das equações 3.10 e 3.11 (406,1mAh e 0,977 , respectivamente) foram para a liga tratada termicamente a $850^{\circ} \mathrm{C}$ por 16 horas.

TABELA 38 - Analise das características eletroquímicas da liga $\mathrm{La}_{0,7} \mathrm{Mg}_{0,3} \mathrm{Al}_{0,3} \mathrm{Mn}_{0,4} \mathrm{Co}_{0,5} \mathrm{Ni}_{3,8}$ sem e com tratamentos térmicos.

\begin{tabular}{lcccccc}
\hline Trat. Térm. & $\begin{array}{c}\mathbf{C}_{\text {máx. }} \\
\text { (mAh) }\end{array}$ & $\begin{array}{c}\mathbf{M}_{\text {mol. }} \\
(\mathbf{g} / \mathbf{m o l})\end{array}$ & $\begin{array}{c}\mathbf{C}_{50} \\
(\mathbf{m A h})\end{array}$ & $\begin{array}{c}\mathbf{S}_{\mathbf{n}} \\
\mathbf{( \% )}\end{array}$ & $\begin{array}{c}\mathbf{n} \\
(\mathbf{H} \text { u.f) }\end{array}$ & $\begin{array}{c}\mathbf{H} / \mathbf{M} \\
\text { (Calc.) }\end{array}$ \\
\hline STT & 326,0 & 387,1 & 264,2 & 81,0 & 4,7 & 0,785 \\
750/9 h & 355,0 & 387,1 & 343,0 & 96,6 & 5,1 & 0,854 \\
$750 / 16 \mathrm{~h}$ & 387,6 & 387,1 & 353,2 & 91,1 & 5,6 & 0,933 \\
850/9 h & 337,8 & 387,1 & 329,3 & 97,5 & 4,8 & 0,813 \\
$850 / 16 \mathrm{~h}$ & 406.1 & 387,1 & 388,0 & 96,0 & 5,9 & 0,977 \\
\hline
\end{tabular}




\subsection{2 - Caracterização eletroquímica da liga $\mathrm{La}_{0,7} \mathrm{Mg}_{0,3} \mathrm{Al}_{0,3} \mathrm{Mn}_{0,4} \mathrm{Cu}_{0,5} \mathrm{Ni}_{3,8}$ sem e com TT.}

Na FIGURA 33 estão mostradas as curvas de capacidade de descarga em função do número de ciclos de carga/descarga para os eletrodos negativos preparados com a liga $L a_{0,7} \mathrm{Mg}_{0,3} \mathrm{Al}_{0,3} \mathrm{Mn}_{0,4} \mathrm{Cu}_{0,5} \mathrm{Ni}_{3,8}$ sem e com TT. Neste caso, a substituição parcial do Ni pelo $\mathrm{Cu}$ a capacidade de descarga também foi superior após TT a 16 h como na liga com Co (FIGURA 32).

FIGURA 33 - Perfis da capacidade de descarga dos eletrodos negativos fabricados com a liga $\mathrm{La}_{0,7} \mathrm{Mg}_{0,3} \mathrm{Al}_{0,3} \mathrm{Mn}_{0,4} \mathrm{Cu}_{0,5} \mathrm{Ni}_{3,8}$ sem e com TT.

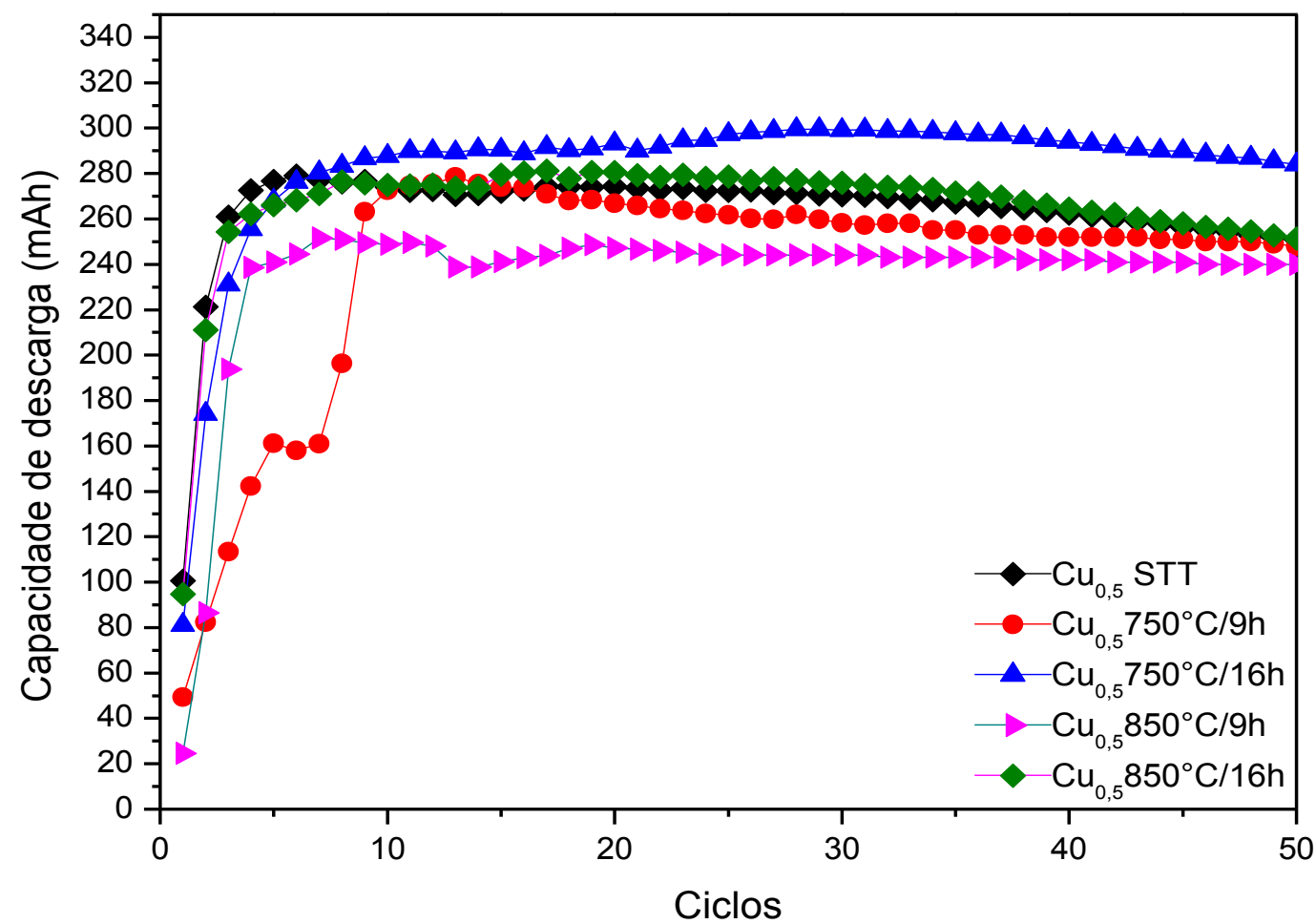

$\mathrm{Na}$ TABELA 39 estão apresentadas as características eletroquímicas da liga $\mathrm{La}_{0,7} \mathrm{Mg}_{0,3} \mathrm{Al}_{0,3} \mathrm{Mn}_{0,4} \mathrm{Cu}_{0,5} \mathrm{Ni}_{3,8}$ sem e com TT, utilizada como material ativo do eletrodo negativo na bateria. A Liga com TT 750/16h apresentou melhores eletroquímicas. A maior capacidade de descarga obtida foi para a liga com TT $750^{\circ} \mathrm{C}$ por 16 horas $(300,1, \mathrm{mAh})$, pode estar relacionados com fração das fases absorvedoras de hidrogênio, $\mathrm{LaNi}_{5}$ de 59\% e $\mathrm{LaMg}_{2} \mathrm{Ni}_{9}$ de $31 \%$, como mostrado na FIGURA 21 e TABELA 9. Fases também observadas por Takasaki et al (2013). 
TABELA 39 - Características eletroquímicas da liga $\mathrm{La}_{0,7} \mathrm{Mg}_{0,3} \mathrm{Al}_{0,3} \mathrm{Mn}_{0,4} \mathrm{Cu}_{0,5} \mathrm{Ni}_{3,8}$ sem e com TT.

\begin{tabular}{lcccccc}
\hline Trat. Térm. & $\begin{array}{c}\mathbf{C}_{\text {máx. }} \\
\text { (mAh) }\end{array}$ & $\begin{array}{c}\mathbf{M}_{\text {mol. }} \\
(\mathbf{g} / \mathbf{m o l})\end{array}$ & $\begin{array}{c}\mathbf{C}_{50} \\
(\mathbf{m A h})\end{array}$ & $\begin{array}{c}\mathbf{S}_{\mathbf{n}} \\
(\%)\end{array}$ & $\begin{array}{c}\mathbf{n} \\
(\mathbf{H} \text { u.f) }\end{array}$ & $\mathbf{H} / \mathbf{M}$ \\
\hline STT & 280,1 & 389,41 & 249,5 & 89,1 & 4,1 & 0,678 \\
$750 / 9 \mathrm{~h}$ & 282,6 & 389,41 & 249,5 & 88,3 & 4,1 & 0,684 \\
$750 / 16 \mathrm{~h}$ & 300,1 & 389,41 & 286,7 & 96,2 & 4,4 & 0,726 \\
850/9 h & 250,7 & 389,41 & 238,7 & 95,2 & 3,6 & 0,607 \\
$850 / 16 \mathrm{~h}$ & 281,4 & 389,41 & 249,5 & 88,7 & 4,1 & 0,681 \\
\hline
\end{tabular}

5.4.3 - Caracterização eletroquímica da liga $\mathrm{La}_{0,7} \mathrm{Mg}_{0,3} \mathrm{Al}_{0,3} \mathrm{Mn}_{0,4} \mathrm{Sn}_{0,5} \mathrm{Ni}_{3,8}$ sem e com TT.

Na FIGURA 34 estão mostradas as curvas de capacidade de descarga em função do número de ciclos de carga/descarga para os eletrodos negativos preparados com a liga $\mathrm{La}_{0,7} \mathrm{Mg}_{0,3} \mathrm{Al}_{0,3} \mathrm{Mn}_{0,4} \mathrm{Sn}_{0,5} \mathrm{Ni}_{3,8}$ sem e com TT.

FIGURA 34 - Perfis da capacidade de descarga dos eletrodos negativos fabricados com a liga $\mathrm{La}_{0,7} \mathrm{Mg}_{0,3} \mathrm{Al}_{0,3} \mathrm{Mn}_{0,4} \mathrm{Sn}_{0,5} \mathrm{Ni}_{3,8}$

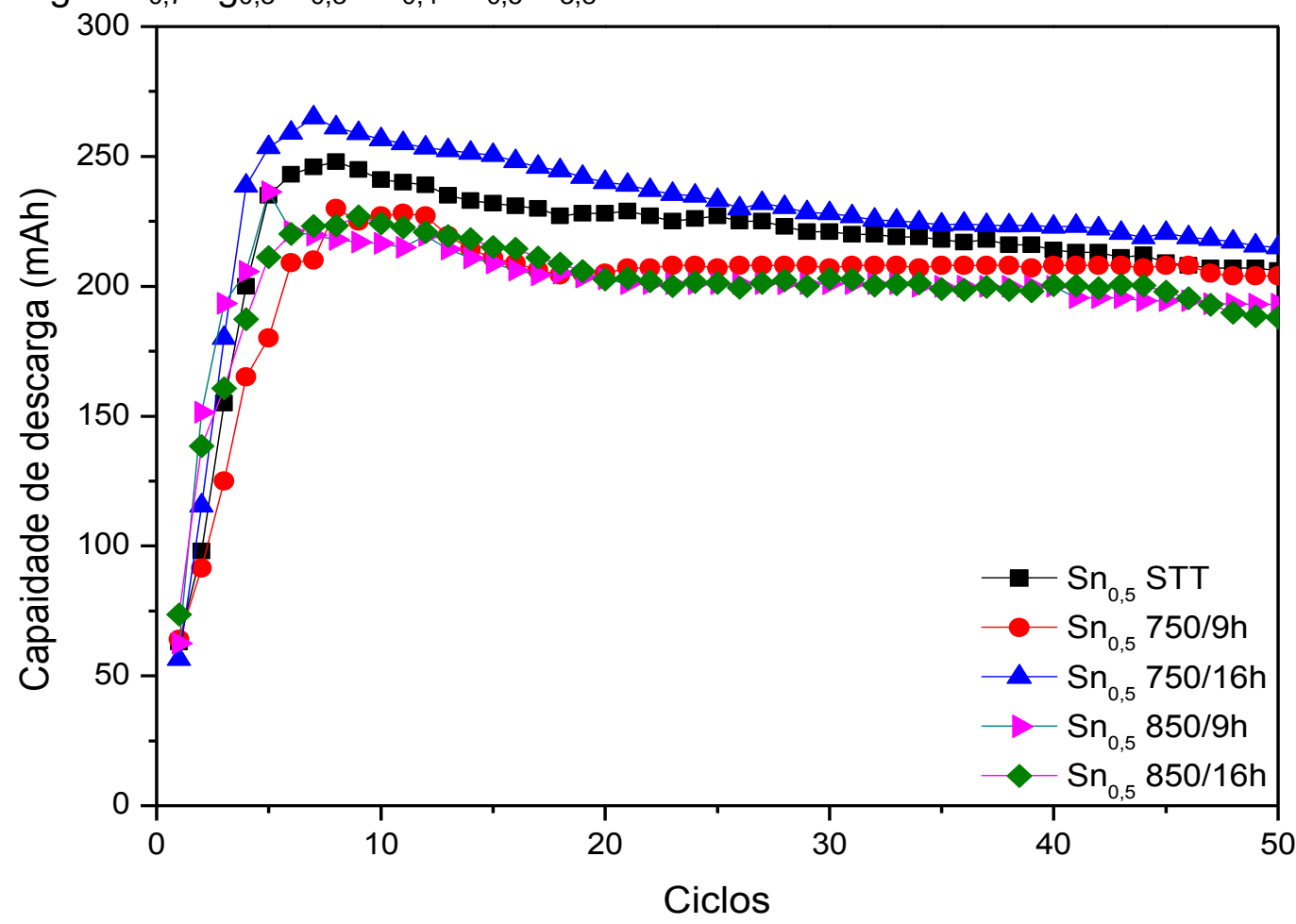


Na TABELA 40 estão apresentadas as características eletroquímicas da liga $\mathrm{La}_{0,7} \mathrm{Mg}_{0,3} \mathrm{Al}_{0,3} \mathrm{Mn}_{0,4} \mathrm{Sn}_{0,5} \mathrm{Ni}_{3,8}$ sem e com TT, utilizada como material ativo do eletrodo negativo. Esta liga apresentou propriedades eletroquímicas inferiores às ligas com substituição do Ni pelo Co e Cu. As propriedades eletroquímicas inferiores obtidas podem estar relacionados com presença da fase $\mathrm{LaSn}_{2} \mathrm{Ni}_{2}$ pela substituição do $\mathrm{Ni}$ pelo Sn.

TABELA 40 - Características eletroquímicas da liga $\mathrm{La}_{0,7} \mathrm{Mg}_{0,3} \mathrm{Al}_{0,3} \mathrm{Mn}_{0,4} \mathrm{Sn}_{0,5} \mathrm{Ni}_{3,8}$ sem e com TT.

\begin{tabular}{lcccccc}
\hline Trat. Térm. & $\begin{array}{c}\mathbf{C}_{\text {máx. }} \\
\text { (mAh) }\end{array}$ & $\begin{array}{c}\mathbf{M}_{\text {mol. }} \\
(\mathbf{g} / \mathbf{m o l})\end{array}$ & $\begin{array}{c}\mathbf{C}_{50} \\
(\mathbf{m A h})\end{array}$ & $\begin{array}{c}\mathbf{S}_{\mathbf{n}} \\
(\%)\end{array}$ & $\begin{array}{c}\mathbf{n} \\
(\mathbf{H} \text { u.f) }\end{array}$ & $\mathbf{H} / \mathbf{M}$ \\
\hline STT & 248,0 & 416,98 & 208,1 & 84,0 & 3,9 & 0,643 \\
$750 / 9 \mathrm{~h}$ & 225,0 & 416,98 & 201,0 & 89,3 & 3,5 & 0,583 \\
$750 / 16 \mathrm{~h}$ & 265,2 & 416,98 & 216,1 & 81,5 & 4,1 & 0,687 \\
850/9 h & 220,0 & 416,98 & 196,6 & 89,4 & 3,4 & 0,570 \\
850/16 h & 226,4 & 416,98 & 190,0 & 84,0 & 3,5 & 0,587 \\
\hline
\end{tabular}

\subsection{4 - Caracterização eletroquímica da liga $\mathrm{La}_{0,7} \mathrm{Pr}_{0,3} \mathrm{Al}_{0,3} \mathrm{Mn}_{0,4} \mathrm{Co}_{0,5} \mathrm{Ni}_{3,8}$ sem e com TT.}

Na FIGURA 35 estão mostradas as curvas de capacidade de descarga em função do número de ciclos de carga/descarga para a liga $\mathrm{La}_{0,7} \mathrm{Pr}_{0,3} \mathrm{Al}_{0,3} \mathrm{Mn}_{0,4} \mathrm{Co}_{0,5} \mathrm{Ni}_{3,8}$ sem e com TT, utilizada como material ativo do eletrodo negativo. Na TABELA 41 estão apresentadas as características eletroquímicas da liga sem e com TT melhores propriedades foram obtidas para a liga com TT a $850^{\circ} \mathrm{C}$ por 16 horas. Nos tratamentos térmicos tanto 750 quanto $850^{\circ} \mathrm{C}$ com tempo de 9 horas, apresentou melhor estabilidade cíclica apesar de promover menor capacidade de descarga, já nos tratamentos térmicos tanto 750 quanto $850^{\circ} \mathrm{C}$ com tempo de 16 horas produziu uma instabilidade cíclica, que poderia ser justificado pelos longos tempos de tratamento podem estar relacionados pela substituição do Mg pelo Pr, mencionados também por Li et al (2004), Li et al (2006); Pan et al (2007); Yan et al (2009); Denys e Yarts (2011) estudaram também as propriedades eletroquímicas de ligas $\mathrm{LaNi}_{5}$ pela substituição do La por terras raras. 
FIGURA 35 - Perfis da capacidade de descarga dos eletrodos negativos fabricados com a liga $\mathrm{La}_{0,7} \mathrm{Pr}_{0,3} \mathrm{Al}_{0,3} \mathrm{Mn}_{0,4} \mathrm{Co}_{0,5} \mathrm{Ni}_{3,8}$

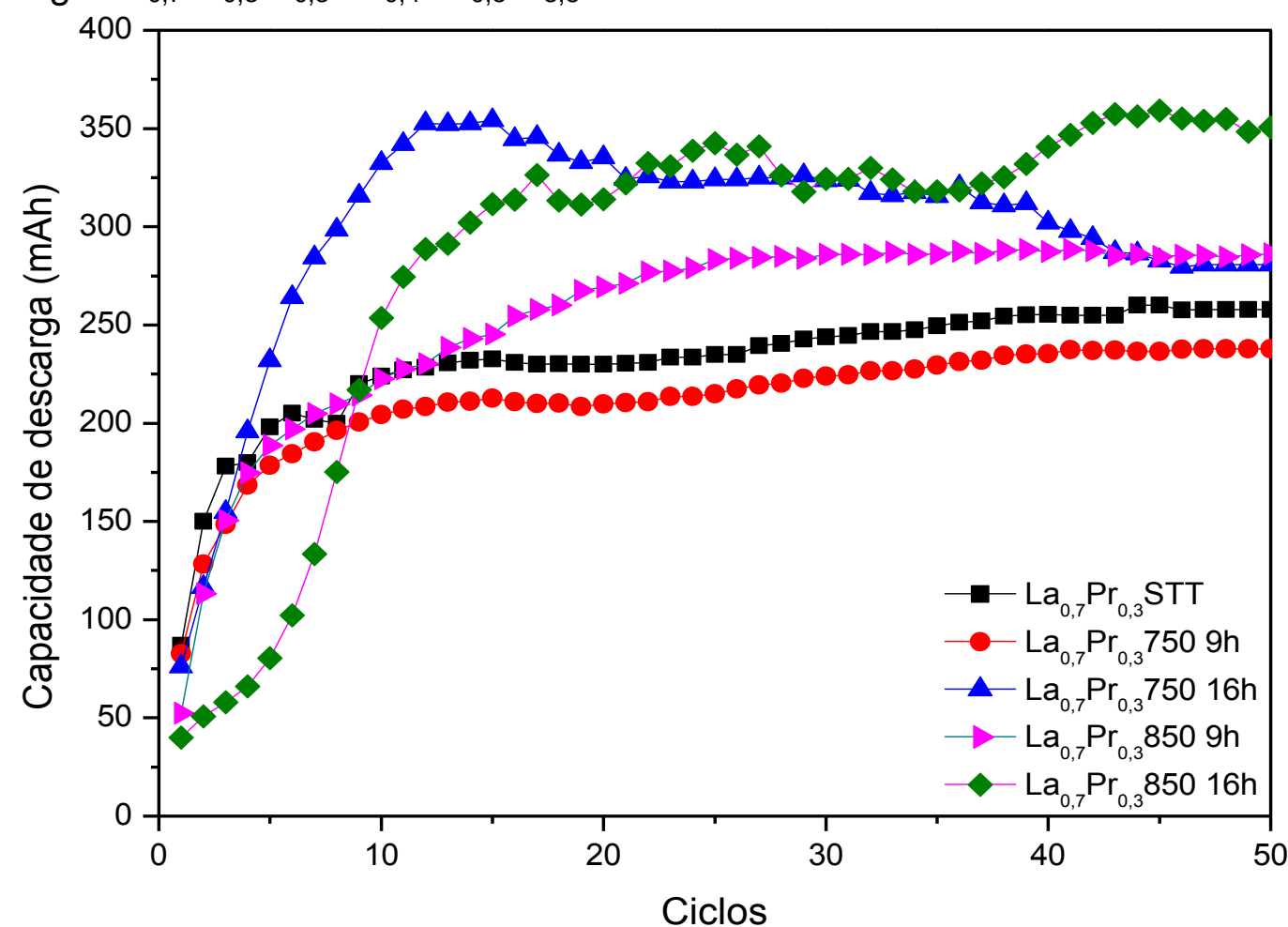

$\mathrm{Na}$ TABELA 41 estão apresentadas as características eletroquímicas da liga $\mathrm{La}_{0,7} \mathrm{Pr}_{0,3} \mathrm{Al}_{0,3} \mathrm{Mn}_{0,4} \mathrm{Co}_{0,5} \mathrm{Ni}_{3,8}$ sem e com TT, utilizada como material ativo do eletrodo negativo. Esta liga apresentou propriedades eletroquímicas bem próximas às das ligas com substituição do Ni pelo Co e $\mathrm{Cu}$.

TABELA 41 - Características eletroquímicas da liga $\mathrm{La}_{0,7} \operatorname{Pr}_{0,3} \mathrm{Al}_{0,3} \mathrm{Mn}_{0,4} \mathrm{Co}_{0,5} \mathrm{Ni}_{3,8}$ sem e com TT.

\begin{tabular}{lcccccc}
\hline Trat. Térm. & $\begin{array}{c}\mathbf{C}_{\text {máx. }} \\
\text { (mAh) }\end{array}$ & $\begin{array}{c}\mathbf{M}_{\text {mol. }} \\
(\mathbf{g} / \mathbf{m o l})\end{array}$ & $\begin{array}{c}\mathbf{C}_{50} \\
(\mathbf{m A h})\end{array}$ & $\begin{array}{c}\mathbf{S}_{\mathbf{n}} \\
\mathbf{( \% )}\end{array}$ & $\begin{array}{c}\mathbf{n} \\
(\mathbf{H} \text { u.f) }\end{array}$ & $\mathbf{H} / \mathbf{M}$ \\
\hline STT & 316,2 & 422,1 & 314 & 99,0 & 4,9 & 0,829 \\
750/9 h & 237,9 & 422,1 & 230 & 97,0 & 3,7 & 0,624 \\
$750 / 16 \mathrm{~h}$ & 358,2 & 422,1 & 280,5 & 78,0 & 5,6 & 0,940 \\
850/9 h & 289,9 & 422,1 & 289,7 & 99,0 & 4,6 & 0,761 \\
850/16 h & 359,7 & 422,1 & 355 & 98,7 & 5,7 & 0.944 \\
\hline
\end{tabular}




\subsection{5 - Caracterização eletroquímica da liga $\operatorname{Pr}_{0,7} \mathrm{Mg}_{0,3} \mathrm{Al}_{0,3} \mathrm{Mn}_{0,4} \mathrm{Co}_{0,5} \mathrm{Ni}_{3,8}$ sem e com TT.}

Na FIGURA 36 estão mostradas as curvas de capacidade de descarga em função do número de ciclos de carga/descarga para os eletrodos negativos preparados com a liga $\operatorname{Pr}_{0,7} \mathrm{Mg}_{0,3} \mathrm{Al}_{0,3} \mathrm{Mn}_{0,4} \mathrm{Co}_{0,5} \mathrm{Ni}_{3,8}$ sem e com TT. A substituição do La pelo Pr apresentou capacidade de descarga bem inferior à todas as ligas com presença de La. Liao et. al (2004); Gao et al (2008); Zarpelon et. al (2008) relataram que a substituição do La pelo Pr provocou uma retração dos parâmetros de rede e do volume da cela unitária, causando baixa absorção do hidrogênio pela liga e diminuição no valor da capacidade máxima de descarga e capacidade de retenção cíclica.

Na TABELA 42 estão apresentadas as características eletroquímicas da liga $\operatorname{Pr}_{0,7} \mathrm{Mg}_{0,3} \mathrm{Al}_{0,3} \mathrm{Mn}_{0,4} \mathrm{Co}_{0,5} \mathrm{Ni}_{3,8}$ sem e com $\mathrm{TT}$, utilizada como material ativo do eletrodo negativo.

FIGURA 36 - Perfis de descarga dos eletrodos negativos fabricados com a liga $\operatorname{Pr}_{0,7} \mathrm{Mg}_{0,3} \mathrm{Al}_{0,3} \mathrm{Mn}_{0,4} \mathrm{Co}_{0,5} \mathrm{Ni}_{3,8}$.

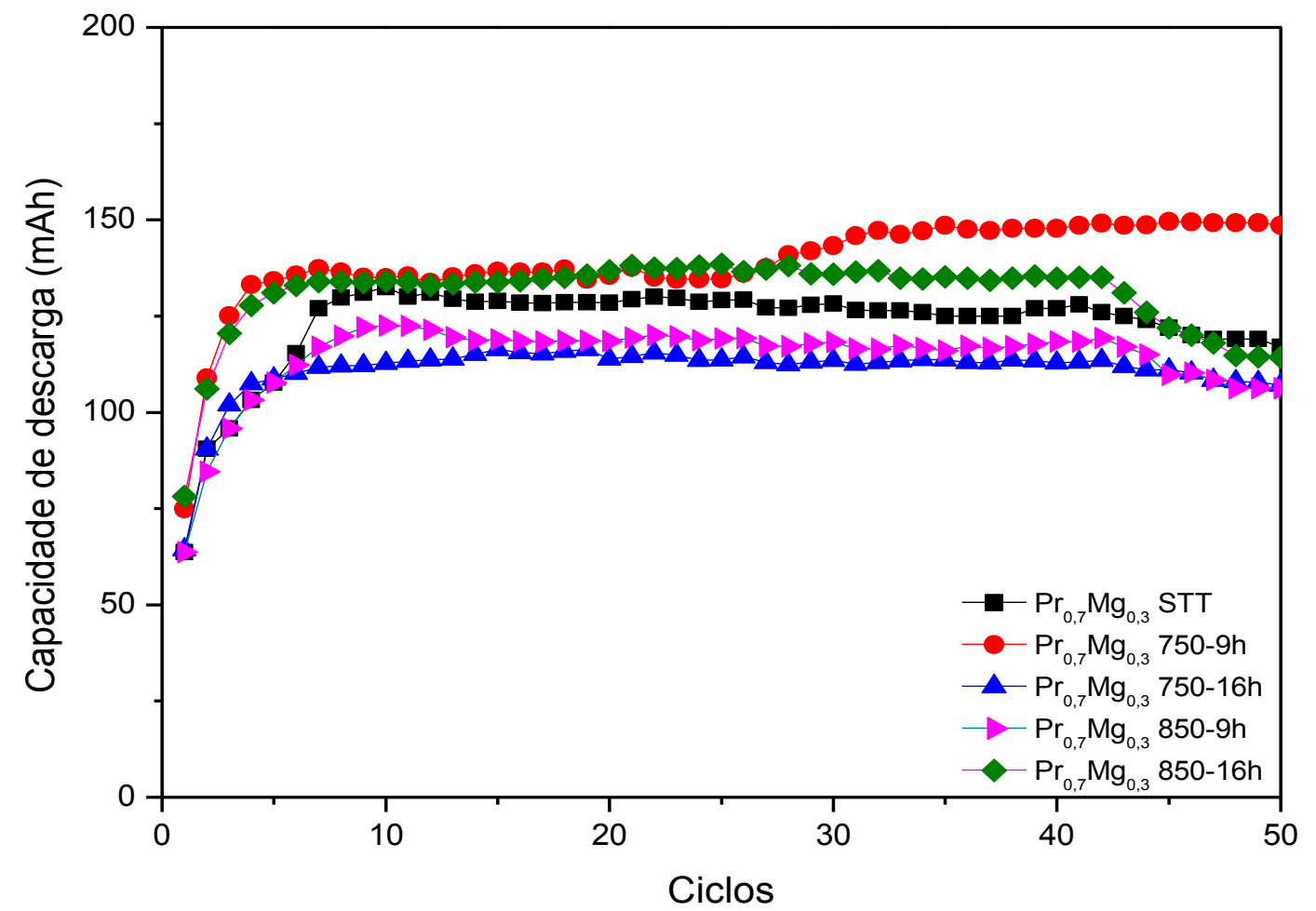


TABELA 42 - Características eletroquímicas da liga $\operatorname{Pr}_{0,7} \mathrm{Mg}_{0,3} \mathrm{Al}_{0,3} \mathrm{Mn}_{0,4} \mathrm{Co}_{0,5} \mathrm{Ni}_{3,8}$ sem e com TT.

\begin{tabular}{lcccccc}
\hline Trat. Térm. & $\begin{array}{c}\mathbf{C}_{\text {máx. }} \\
\text { (mAh) }\end{array}$ & $\begin{array}{c}\mathbf{M}_{\text {mol. }} \\
(\mathbf{g} / \mathbf{m o l})\end{array}$ & $\begin{array}{c}\mathbf{C}_{50} \\
(\mathbf{m A h})\end{array}$ & $\begin{array}{c}\mathbf{S}_{\mathbf{n}} \\
(\%)\end{array}$ & $\begin{array}{c}\mathbf{n} \\
(\mathbf{H ~ u . f )}\end{array}$ & $\mathbf{H} / \mathbf{M}$ \\
\hline STT & 124,2 & 388,5 & 122,0 & 98,0 & 1,8 & 0,300 \\
$750 / 9 \mathrm{~h}$ & 148,7 & 388,5 & 147,0 & 99,0 & 2,1 & 0,359 \\
$750 / 16 \mathrm{~h}$ & 113,4 & 388,5 & 108,5 & 96,0 & 1,6 & 0,274 \\
850/9 h & 123,7 & 388,5 & 106,2 & 86,0 & 1,8 & 0,299 \\
850/16 h & 139,6 & 388,5 & 114,6 & 83,1 & 2,0 & 0,337 \\
\hline
\end{tabular}

A FIGURA 37 mostra os resultados de capacidade máxima de descarga das baterias para todas as ligas sem e com TT.

As baterias fabricadas com a liga com substituição parcial do Ni pelo Co como material ativo no eletrodo negativo apresentaram os melhores valores de capacidade de descarga quando comparados às outras substituições. Os TT realizados a $750 \mathrm{e}$ $850^{\circ} \mathrm{C}$ por 16 horas, melhoraram as capacidades de descarga em relação à liga sem TT em quase todos os casos, com exceção da liga com a substituição do La pelo Pr.

FIGURA 37 - Perfis de descarga dos eletrodos negativos fabricados com as ligas sem e com TT.

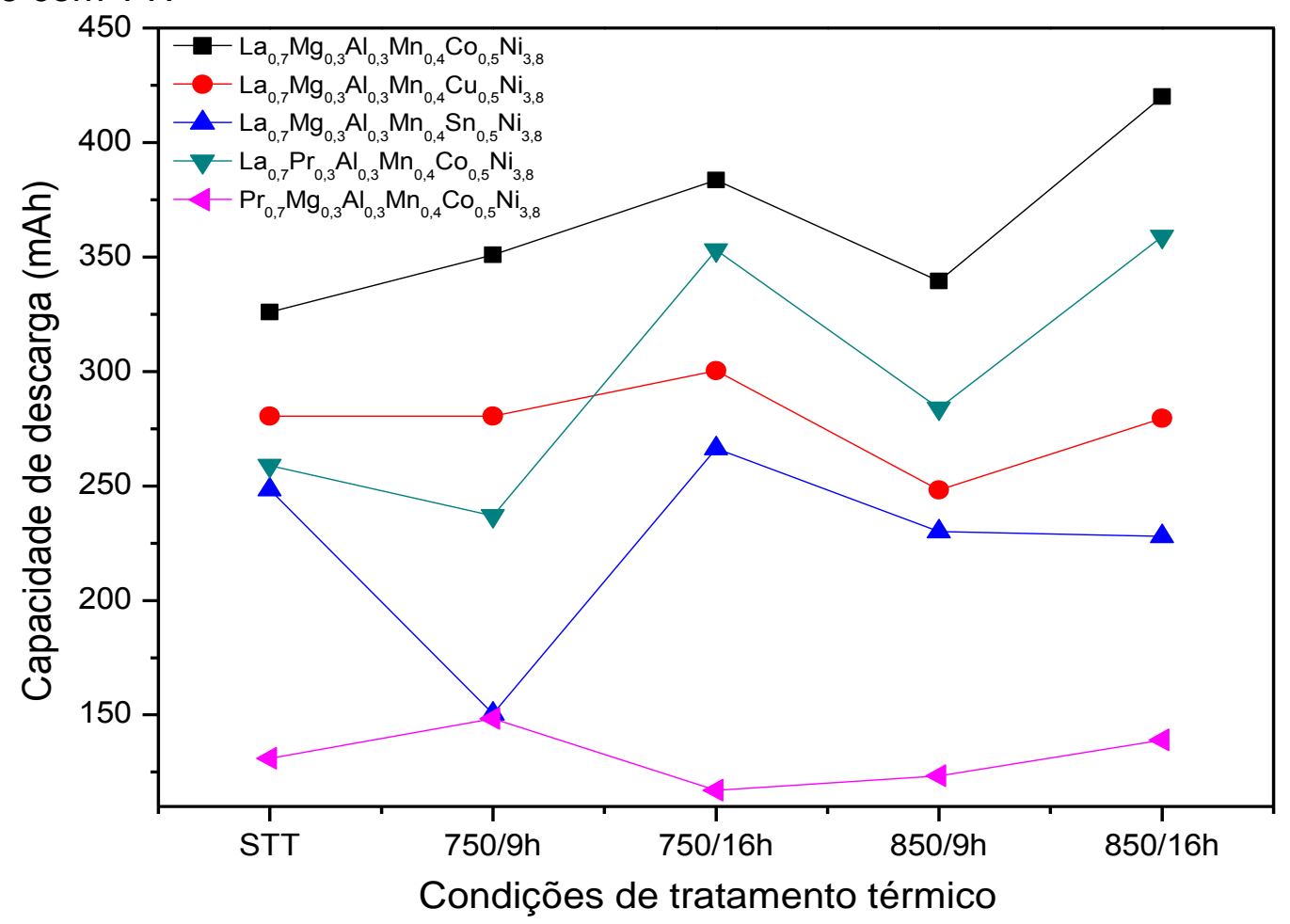




\section{5 - Curvas de PCT}

Para avaliar as curvas de pressão composição temperatura (PCT), esta fase do estudo foi dividida em 3 partes distintas:

$\mathrm{Na}$ primeira parte estudou-se a pressão de inicio de formação da fase a também denominada inicio de formação do platô de equilíbrio, até a formação da fase $\beta$ e saturação com as ligas de $\mathrm{NiMH}$ sem TT. Na segunda, foram obtidas as curvas de PCT para cada substituição do Ni (Co,Cu e Sn), e do La e Mg (Pr) das ligas com TT que apresentaram melhores resultados durante a caracterização eletroquímica. A terceira foi realizada nas ligas com TT que apresentaram melhores resultados na caracterização eletroquímica quatro ciclos de ativação seguidos pelo teste de PCT. A capacidade máxima de descarga calculada $\left(\mathrm{C}_{\text {calc. }}\right)$ do material ativo nesta etapa foram obtidos pela EQUAÇÃO 3.8 .

$$
C_{\text {calc. }}=\frac{6\left(\mathrm{H} / \mathrm{M}_{\text {final }}-\mathrm{H} / \mathrm{M}_{\text {inicial }}\right) \times \mathrm{F}}{3,6 \times \mathrm{Mw}}
$$

\subsection{1 - Análise de PCT das ligas sem TT}

Na FIGURA 38 estão apresentadas as isotermas de pressão-composiçãotemperatura (PCT) realizadas nas ligas sem TT. Com a finalidade de aplicação em baterias recarregáveis de $\mathrm{Ni}-\mathrm{MH}$.

As ligas de armazenamento de hidrogênio devem possuir alta capacidade de hidrogênio e moderada estabilidade do hidreto. A pressão de inicio do platô de equilíbrio de hidrogênio foi utilizada para prever o potencial eletroquímico do eletrodo e a extensão do platô para a liga de armazenamento é usado para estimar a capacidade máxima de descarga calculada das baterias com ligas de Ni-MH através da EQUAÇÃO 3.8: 
FIGURA 38 - Curvas de absorção de hidrogênio pela análise de PCT pelas ligas $\mathrm{La}_{0,7} \mathrm{Mg}_{0,3} \mathrm{Al}_{0,3} \mathrm{Mn}_{0,4} \mathrm{Co}_{0,5} \mathrm{Ni}_{3,8}$, $\mathrm{La}_{0,7} \mathrm{Mg}_{0,3} \mathrm{Al}_{0,3} \mathrm{Mn}_{0,4} \mathrm{Sn}_{0,5} \mathrm{Ni}_{3,8}$, $\mathrm{Pr}_{0,7} \mathrm{Mg}_{0,3} \mathrm{Al}_{0,3} \mathrm{Mn}_{0,4} \mathrm{Co}_{0,5} \mathrm{Ni}_{3,8}$ sem TT.

$\mathrm{La}_{0,7} \mathrm{Mg}_{0,3} \mathrm{Al}_{0,3} \mathrm{Mn}_{0,4} \mathrm{Cu}_{0,5} \mathrm{Ni}_{3,8}$ $\mathrm{La}_{0,7} \mathrm{Pr}_{0,3} \mathrm{Al}_{0,3} \mathrm{Mn}_{0,4} \mathrm{Co}_{0,5} \mathrm{Ni}_{3,8}$

e

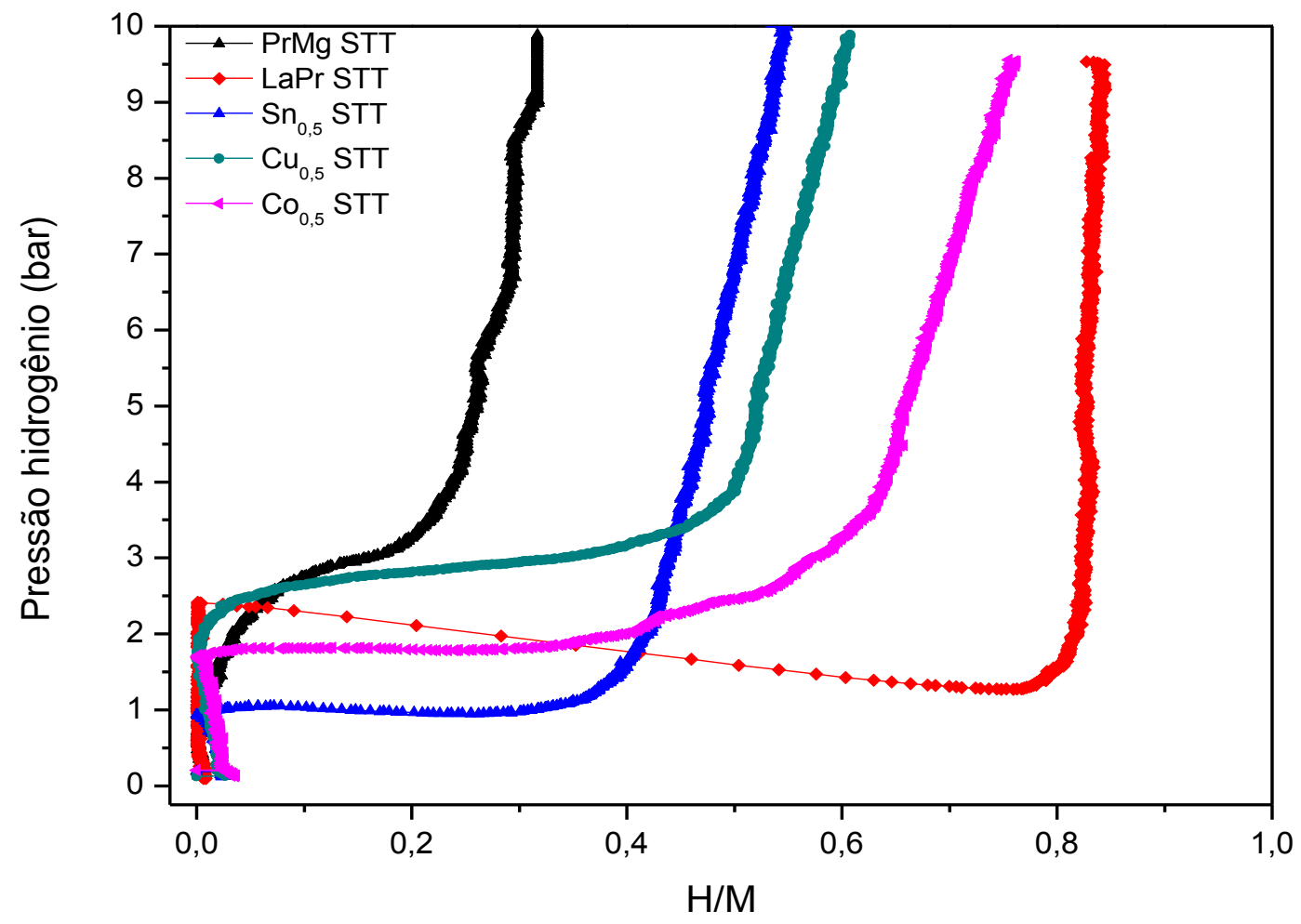

Na TABELA 43 estão apresentados os resultados da absorção de hidrogênio obtidos no teste de PCT e na TABELA 44 a capacidade máxima de descarga calculada obtidos nas ligas sem TT a partir dos dados fornecidos e aplicados na EQUAÇÂO 3.8. 
TABELA 43 - Absorção de hidrogênio obtidos das curvas de PCT para as ligas $\mathrm{La}_{0,7} \mathrm{Mg}_{0,3} \mathrm{Al}_{0,3} \mathrm{Mn}_{0,4} \mathrm{Co}_{0,5} \mathrm{Ni}_{3,8}$, $\mathrm{La}_{0,7} \mathrm{Mg}_{0,3} \mathrm{Al}_{0,3} \mathrm{Mn}_{0,4} \mathrm{Sn}_{0,5} \mathrm{Ni}_{3,8}$, $\mathrm{Pr}_{0,7} \mathrm{Mg}_{0,3} \mathrm{Al}_{0,3} \mathrm{Mn}_{0,4} \mathrm{Co}_{0,5} \mathrm{Ni}_{3,8}$ sem TT.

\begin{tabular}{|c|c|c|c|c|}
\hline Liga & Fase & $\begin{array}{c}<\phi_{\mathrm{abs}}> \pm \sigma<\phi_{\mathrm{abs}}> \\
\left(\mathrm{cm}^{3} / \mathrm{min}^{2} \mathrm{~g}\right)\end{array}$ & $\mathrm{H}: \mathrm{M} \pm 0,016$ & $\begin{array}{c}\mathrm{H} \pm 0,024 \\
(\% \text { em massa) }\end{array}$ \\
\hline $\mathrm{Co}_{0,5}$ & $\alpha$ & $0,03 \pm 0,08$ & 0,004 & 0,007 \\
\hline $\mathrm{Co}_{0,5}$ & $\beta+\alpha$ & $2,30 \pm 0,06$ & 0,603 & 0,933 \\
\hline $\mathrm{Co}_{0,5}$ & $\beta$ & $0,083 \pm 0,016$ & 0,076 & 0,119 \\
\hline Total & - & $0,505 \pm 0,011$ & 0,683 & 1,056 \\
\hline $\mathrm{Cu}_{0,5}$ & $\alpha$ & $0,03 \pm 0,06$ & 0,009 & 0,014 \\
\hline $\mathrm{Cu}_{0,5}$ & $\beta+\alpha$ & $2,71 \pm 0,09$ & 0,468 & 0,721 \\
\hline $\mathrm{Cu}_{0,5}$ & $\beta$ & $0,042 \pm 0,017$ & 0,037 & 0,058 \\
\hline Total & - & $0,387 \pm 0,011$ & 0,514 & 0,793 \\
\hline $\mathrm{Sn}_{0,5}$ & $\alpha$ & $0,03 \pm 0,15$ & 0,003 & 0,005 \\
\hline$S n_{0,5}$ & $\beta+\alpha$ & $6,51 \pm 0,25$ & 0,423 & 0,610 \\
\hline$S n_{0,5}$ & $\beta$ & $0,032 \pm 0,013$ & 0,039 & 0,057 \\
\hline Total & - & $0,335 \pm 0,012$ & 0,466 & 0,671 \\
\hline $\mathrm{LaPr}$ & $\alpha$ & $0,03 \pm 0,06$ & 0,004 & 0,006 \\
\hline LaPr & $\beta+\alpha$ & $2,91 \pm 0,09$ & 0,738 & 1,081 \\
\hline LaPr & $\beta$ & $0,027 \pm 0,016$ & 0,038 & 0,078 \\
\hline Total & - & $0,428 \pm 0,011$ & 0,784 & 1,165 \\
\hline PrMg & $\alpha$ & $0,03 \pm 0,15$ & 0,003 & 0,005 \\
\hline PrMg & $\beta+\alpha$ & $7,53 \pm 0,25$ & 0,223 & 0,315 \\
\hline PrMg & $\beta$ & $0,052 \pm 0,013$ & 0,021 & 0,047 \\
\hline Total & - & $0,425 \pm 0,011$ & 0,247 & 0,367 \\
\hline
\end{tabular}

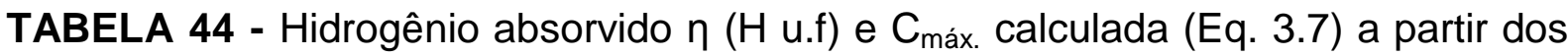
dados obtidos pela curva de PCT para as ligas sem TT.

\begin{tabular}{lcccc}
\hline Liga & $\mathbf{H} / \mathbf{M}$ & $\begin{array}{c}\mathbf{n} \\
\mathbf{H ~ u . f})\end{array}$ & $\begin{array}{c}\mathbf{M}_{\text {mol. }} \\
(\mathbf{g} / \mathbf{m o l})\end{array}$ & $\begin{array}{c}\mathbf{C}_{\text {máx. calc. }} \\
\text { (mAh) }\end{array}$ \\
\hline $\mathrm{Co}_{0,5}$ STT & 0,683 & 4,1 & 387,1 & 284,0 \\
$\mathrm{Cu}_{0,5}$ STT & 0,514 & 3,1 & 389,4 & 212,3 \\
$\mathrm{Sn}_{0,5}$ STT & 0,466 & 2,8 & 416,98 & 179,7 \\
$\mathrm{LaPr}$ STT & 0,832 & 5,0 & 422,1 & 317,0 \\
PrMg STT & 0,247 & 1,5 & 388,5 & 102,0 \\
\hline
\end{tabular}




\section{5-1a - Liga La ${ }_{0,7} \mathrm{Mg}_{0,3} \mathrm{Al}_{0,3} \mathrm{Mn}_{0,4} \mathrm{Co}_{0,5} \mathrm{Ni}_{3,8}$ sem $\mathrm{TT}$}

Na TABELA 43 está apresentado o valor de H/M de 0,683 e na TABELA 44 a capacidade máxima de descarga calculada a partir da equação 3.7 de $284 \mathrm{mAh}$ para a liga $\mathrm{La}_{0,7} \mathrm{Mg}_{0,3} \mathrm{Al}_{0,3} \mathrm{Mn}_{0,4} \mathrm{Co}_{0,5} \mathrm{Ni}_{3,8}$ sem TT. Comparando estes resultados com os obtidos no teste eletroquímico os valores de $\mathrm{H} / \mathrm{M}$ e da capacidade máxima de descarga foram inferiores em $12 \%$ para esta liga (0,780 e 326 mAh TABELA 38).

Estudos realizados por Lim et al (2015) em ligas do tipo $A B_{5}$ armazenamento de hidrogênio sem e com tratamentos verificando sua capacidade de manutenção na absorção.

\section{5-1b- Liga La $0,7 \mathrm{Mg}_{0,3} \mathrm{Al}_{0,3} \mathrm{Mn}_{0,4} \mathrm{Cu}_{0,5} \mathrm{Ni}_{3,8}$ sem TT}

A relação $\mathrm{H} / \mathrm{M}$ e a capacidade máxima de descarga, calculada a partir da Equação 3.8, para a liga $\mathrm{La}_{0,7} \mathrm{Mg}_{0,3} \mathrm{Al}_{0,3} \mathrm{Mn}_{0,4} \mathrm{Cu}_{0,5} \mathrm{Ni}_{3,8}$ sem TT mostradas nas TABELAS 43 e 44 foram de 0,514 e 212,3 mAh, respectivamente. Comparando estes resultados com os obtidos no teste eletroquímico os valores de $\mathrm{H} / \mathrm{M}$ e da capacidade máxima de descarga foram inferiores aproximadamente $24 \%$ para esta liga, de 0,678 e 280,1 mAh apresentados na TABELA 39, respectivamente.

Conforme o relatado por Kadir et al (1999), substituição também estudada por Liao e seus colaboradores em 2004.

\section{5-1c- Liga La $a_{0,7} \mathrm{Mg}_{0,3} \mathrm{Al}_{0,3} \mathrm{Mn}_{0,4} \mathrm{Sn}_{0,5} \mathrm{Ni}_{3,8}$ sem TT}

Na TABELA 43 está apresentado o valor de H/M de 0,466 e na TABELA 44 a capacidade máxima de descarga calculada a partir da Equação 3.8 de 179,7 mAh para a liga $\mathrm{La}_{0,7} \mathrm{Mg}_{0,3} \mathrm{Al}_{0,3} \mathrm{Mn}_{0,4} \mathrm{Sn}_{0,5} \mathrm{Ni}_{3,8}$ sem TT. Comparando estes resultados com os obtidos no teste eletroquímico os valores de $\mathrm{H} / \mathrm{M}$ e da capacidade máxima de 
descarga foram inferiores aproximadamente $27,5 \%$ para esta liga, de 0,643 e 248 mAh apresentados na TABELA 40, respectivamente.

Os resultados obtidos no refinamento pelo método de Rietived mostrados na TABELA 10 onde a presença da fase $\mathrm{LaSn}_{2} \mathrm{Ni}_{2}$ estrutura ortorrômbica podem ter contribuído para formação do platô de pressão de hidrogênio menor obtido na analise de PCT da liga $\mathrm{La}_{0,7} \mathrm{Mg}_{0,3} \mathrm{Al}_{0,3} \mathrm{Mn}_{0,4} \mathrm{Sn}_{0,5} \mathrm{Ni}_{3,8}$.

\section{5-1d- Liga La ${ }_{0,7} \mathrm{Pr}_{0,3} \mathrm{Al}_{0,3} \mathrm{Mn}_{0,4} \mathrm{Co}_{0,5} \mathrm{Ni}_{3,8}$ sem $\mathrm{TT}$}

Na TABELA 43 está apresentado o valor de H/M de 0,832 e na TABELA 44 a capacidade máxima de descarga calculada a partir da Equação 3.8 de 317,0 mAh para a liga $\mathrm{La}_{0,7} \mathrm{Pr}_{0,3} \mathrm{Al}_{0,3} \mathrm{Mn}_{0,4} \mathrm{Co}_{0,5} \mathrm{Ni}_{3,8}$ sem TT. Comparando estes resultados com os obtidos no teste eletroquímico os valores de $\mathrm{H} / \mathrm{M}$ e da capacidade máxima de descarga foram inferiores aproximadamente $27,5 \%$ para esta liga, de 0,839 e 316,2 mAh apresentados na TABELA 41, respectivamente.

Os resultados obtidos no refinamento pelo método de Rietived mostrados na TABELA 11 indicou a presença da fase $\mathrm{LaNi}_{5}$ estrutura hexagonal com eixo $\mathrm{c}$ semelhante ao da fase $\mathrm{PrNi}_{5}$ em 4,053 $\AA$ para as duas fases existentes na microestrutura da liga na o que possibilitou uma manutenção do volume da célula unitária de $89 \AA^{3}$ com uma fração das fases para $\mathrm{LaNi}_{5}$ em $77.8 \%$ e $\mathrm{PrNi}_{5}$ em $22,2 \%$ esses fatores provavelmente podem ter contribuído para a formação do platô de pressão da liga $\mathrm{La}_{0,7} \mathrm{Pr}_{0,3} \mathrm{Al}_{0,3} \mathrm{Mn}_{0,4} \mathrm{Co}_{0,5} \mathrm{Ni}_{3,8}$, onde se observou que a uma inclinação no sentido contrario invertendo a inclinação do platô, pode ter sido por causa da alimentação do processo dinâmico ter sido padronizado em $9 \mathrm{ml} / \mathrm{s}$ e a liga La $a_{0,7} \mathrm{Pr}_{0,3} \mathrm{Al}_{0,3} \mathrm{Mn}_{0,4} \mathrm{Co}_{0,5} \mathrm{Ni}_{3,8}$ ter uma capacidade de absorção superior a vazão de alimentação do sistema. 


\section{5-1e- Liga $\mathrm{Pr}_{0,7} \mathrm{Mg}_{0,3} \mathrm{Al}_{0,3} \mathrm{Mn}_{0,4} \mathrm{Co}_{0,5} \mathrm{Ni}_{3,8}$ sem TT}

Na TABELA 43 está apresentado o valor de H/M de 0,247 e na TABELA 44 a capacidade máxima de descarga calculada a partir da EQUAÇÃO 3.8 de 102 mAh para a liga $\mathrm{Pr}_{0,7} \mathrm{Mg}_{0,3} \mathrm{Al}_{0,3} \mathrm{Mn}_{0,4} \mathrm{Co}_{0,5} \mathrm{Ni}_{3,8}$ sem TT. Comparando estes resultados com os obtidos no teste eletroquímico os valores de $\mathrm{H} / \mathrm{M}$ e da capacidade máxima de descarga foram inferiores aproximadamente $27,5 \%$ para esta liga, de 0,300 e 124,2 mAh apresentados na TABELA 42, respectivamente.

Onde a propriedade de absorção do hidrogênio pela liga com substituição por Pr foi estudada por Iwase e seus colaboradores em 2012.

Estes valores podem ser justificado pelos resultados obtidos no refinamento pelo método de Rietived através dos valores mostrados na TABELA 12 indica a presença da fase (AIMn) $\mathrm{Ni}_{3}$ estrutura cúbica com volume de célula unitária menor o que, provavelmente provocou um aumento na pressão da formação do platô para liga $\operatorname{Pr}_{0,7} \mathrm{Mg}_{0,3} \mathrm{Al}_{0,3} \mathrm{Mn}_{0,4} \mathrm{Co}_{0,5} \mathrm{Ni}_{3,8}$, diminuindo assim a sua capacidade de absorção de hidrogênio e seu desempenho eletroquímica na capacidade de descarga o que também foi mostrado por Zeng e colaboradores em 2003, durante o estudo que avaliou o comportamento das propriedades de absorção e eletroquímicas perante as substituições de terras raras. 


\subsection{2- Curvas de PCT das ligas com TT}

Nessa etapa as curvas de PCT apresentadas na FIGURA 39 foram realizadas nas ligas com TT $\mathrm{La}_{0,7} \mathrm{Mg}_{0,3} \mathrm{Al}_{0,3} \mathrm{Mn}_{0,4} \mathrm{Co}_{0,5} \mathrm{Ni}_{3,8} \quad\left(850^{\circ} \mathrm{C} / 16 \mathrm{~h}\right)$, $\mathrm{La}_{0,7} \mathrm{Mg}_{0,3} \mathrm{Al}_{0,3} \mathrm{Mn}_{0,4} \mathrm{Cu}_{0,5} \mathrm{Ni}_{3,8}\left(750^{\circ} \mathrm{C} / 16 \mathrm{~h}\right), \quad \mathrm{La}_{0,7} \mathrm{Mg}_{0,3} \mathrm{Al}_{0,3} \mathrm{Mn}_{0,4} \mathrm{Sn}_{0,5} \mathrm{Ni}_{3,8} \quad\left(750^{\circ} \mathrm{C} / 16 \mathrm{~h}\right)$, $\mathrm{La}_{0,7} \mathrm{Pr}_{0,3} \mathrm{Al}_{0,3} \mathrm{Mn}_{0,4} \mathrm{Co}_{0,5} \mathrm{Ni}_{3,8} \quad\left(850^{\circ} \mathrm{C} / 16 \mathrm{~h}\right)$ e $\mathrm{Pr}_{0,7} \mathrm{Mg}_{0,3} \mathrm{Al}_{0,3} \mathrm{Mn}_{0,4} \mathrm{Co}_{0,5} \mathrm{Ni}_{3,8}\left(750^{\circ} \mathrm{C} / 9 \mathrm{~h}\right)$ que apresentaram melhores resultados na capacidade de descarga das baterias apresentadas nas TABELAS 40 a 44, respectivamente. Nas TABELAS 45 e 46 estão apresentados os resultados da absorção de hidrogênio das ligas com TT obtidas da curva de PCT e da capacidade máxima calculada obtida pela EQUAÇÂO 3.8.

FIGURA 39 - Curvas de PCT das ligas $\mathrm{La}_{0,7} \mathrm{Mg}_{0,3} \mathrm{Al}_{0,3} \mathrm{Mn}_{0,4} \mathrm{Co}_{0,5} \mathrm{Ni}_{3,8}\left(850^{\circ} \mathrm{C} / 16 \mathrm{~h}\right)$, $\mathrm{La}_{0,7} \mathrm{Mg}_{0,3} \mathrm{Al}_{0,3} \mathrm{Mn}_{0,4} \mathrm{Cu}_{0,5} \mathrm{Ni}_{3,8}\left(750^{\circ} \mathrm{C} / 16 \mathrm{~h}\right) \quad \mathrm{La}_{0,7} \mathrm{Mg}_{0,3} \mathrm{Al}_{0,3} \mathrm{Mn}_{0,4} \mathrm{Sn}_{0,5} \mathrm{Ni}_{3,8} \quad\left(750^{\circ} \mathrm{C} / 16 \mathrm{~h}\right)$, $\mathrm{La}_{0,7} \mathrm{Pr}_{0,3} \mathrm{Al}_{0,3} \mathrm{Mn}_{0,4} \mathrm{Co}_{0,5} \mathrm{Ni}_{3,8}\left(850^{\circ} \mathrm{C} / 16 \mathrm{~h}\right)$ e $\mathrm{Pr}_{0,7} \mathrm{Mg}_{0,3} \mathrm{Al}_{0,3} \mathrm{Mn}_{0,4} \mathrm{Co}_{0,5} \mathrm{Ni}_{3,8}\left(750^{\circ} \mathrm{C} / 9 \mathrm{~h}\right)$.

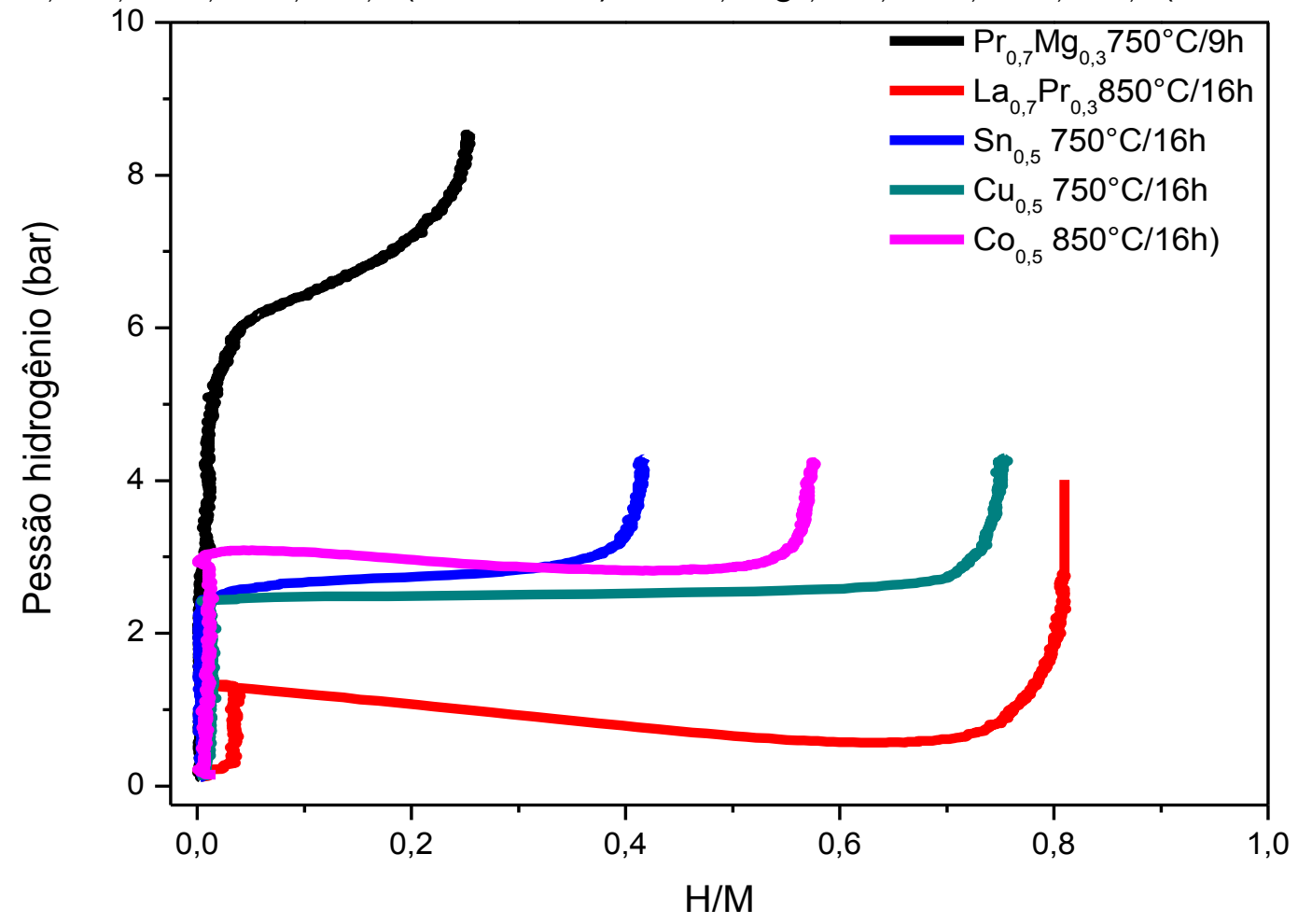


TABELA 45 - Resultados obtidos das curvas de absorção do PCT das ligas $\mathrm{La}_{0,7} \mathrm{Mg}_{0,3} \mathrm{Al}_{0,3} \mathrm{Mn}_{0,4} \mathrm{Co}_{0,5} \mathrm{Ni}_{3,8} \quad\left(850^{\circ} / 16 \mathrm{~h}\right), \quad \mathrm{La}_{0,7} \mathrm{Mg}_{0,3} \mathrm{Al}_{0,3} \mathrm{Mn}_{0,4} \mathrm{Cu}_{0,5} \mathrm{Ni}_{3,8}\left(750^{\circ} \mathrm{C} / 16\right)$ $\mathrm{La}_{0,7} \mathrm{Mg}_{0,3} \mathrm{Al}_{0,3} \mathrm{Mn}_{0,4} \mathrm{Sn}_{0,5} \mathrm{Ni}_{3,8}\left(750^{\circ} \mathrm{C} / 16 \mathrm{~h}\right), \mathrm{La}_{0,7} \mathrm{Pr}_{0,3} \mathrm{Al}_{0,3} \mathrm{Mn}_{0,4} \mathrm{Co}_{0,5} \mathrm{Ni}_{3,8}\left(850^{\circ} \mathrm{C} / 16 \mathrm{~h}\right)$ e $\mathrm{Pr}_{0,7} \mathrm{Mg}_{0,3} \mathrm{Al}_{0,3} \mathrm{Mn}_{0,4} \mathrm{Co}_{0,5} \mathrm{Ni}_{3,8}\left(750^{\circ} \mathrm{C} / 9 \mathrm{~h}\right)$.

\begin{tabular}{|c|c|c|c|c|}
\hline Amostra & Fase & $\begin{array}{c}<\phi_{\mathrm{abs}}> \pm \sigma<\phi_{\mathrm{abs}}> \\
\left(\mathrm{cm}^{3} / \mathrm{min} . \mathrm{g}\right)\end{array}$ & $\mathrm{H} / \mathrm{M} \pm 0,014$ & $\begin{array}{c}\mathrm{H} \pm 0,025 \\
\text { (\% em } \\
\text { massa) }\end{array}$ \\
\hline $\mathrm{Co}_{0,5} 850 / 16 \mathrm{~h}$ & $\alpha$ & $0,06 \pm 0,09$ & 0,005 & 0,006 \\
\hline $\mathrm{Co}_{0,5} 850 / 16 \mathrm{~h}$ & $\alpha+\beta$ & $2,55 \pm 0,06$ & 0,559 & 0,934 \\
\hline $\mathrm{Co}_{0,5} 850 / 16 \mathrm{~h}$ & $\beta$ & $0,083 \pm 0,016$ & 0,034 & 0,049 \\
\hline Total & - & $0,505 \pm 0,011$ & 0,598 & 0,989 \\
\hline $\mathrm{Cu}_{0,5} 750 / 16 \mathrm{~h}$ & $\alpha$ & $0,06 \pm 0,08$ & 0,010 & 0,013 \\
\hline $\mathrm{Cu}_{0,5} 750 / 16 \mathrm{~h}$ & $\alpha+\beta$ & $2,77 \pm 0,09$ & 0,689 & 1,094 \\
\hline $\mathrm{Cu}_{0,5} 750 / 16 \mathrm{~h}$ & $\beta$ & $0,045 \pm 0,017$ & 0,058 & 0,055 \\
\hline Total & - & $0,387 \pm 0,011$ & 0,757 & 1,162 \\
\hline $\mathrm{Sn}_{0,5} 750 / 16 \mathrm{~h}$ & $\alpha$ & $0,03 \pm 0,15$ & 0,005 & 0,007 \\
\hline $\mathrm{Sn}_{0,5} 750 / 16 \mathrm{~h}$ & $\alpha+\beta$ & $6,54 \pm 0,25$ & 0,406 & 0,599 \\
\hline$S n_{0,5} 750 / 16 h$ & $\beta$ & $0,032 \pm 0,013$ & 0,017 & 0,010 \\
\hline Total & - & $0,335 \pm 0,012$ & 0,428 & 0,616 \\
\hline LaPr 850/16h & $\alpha$ & $0,03 \pm 0,06$ & 0,007 & 0,009 \\
\hline LaPr 850/16h & $\alpha+\beta$ & $2,91 \pm 0,09$ & 0,753 & 1,087 \\
\hline LaPr 850/16h & $\beta$ & $0,027 \pm 0,016$ & 0,050 & 0,051 \\
\hline Total & - & $0,438 \pm 0,011$ & 0,810 & 1,147 \\
\hline PrMg 750/9h & $\alpha$ & $0,03 \pm 0,15$ & 0,005 & 0,008 \\
\hline PrMg 750/9h & $\alpha+\beta$ & $7,65 \pm 0,25$ & 0,253 & 0,402 \\
\hline PrMg 750/9h & $\beta$ & $0,047 \pm 0,013$ & 0,022 & 0,024 \\
\hline Total & - & $0,445 \pm 0,011$ & 0,280 & 0,434 \\
\hline
\end{tabular}

TABELA 46 - Determinação da $\mathrm{C}_{\max }$ calculada a partir dos dados obtidos através da analise de PCT das ligas $\mathrm{La}_{0,7} \mathrm{Mg}_{0,3} \mathrm{Al}_{0,3} \mathrm{Mn}_{0,4} \mathrm{Co}_{0,5} \mathrm{Ni}_{3,8} \quad(850 \%$ 16h), $\mathrm{La}_{0,7} \mathrm{Mg}_{0,3} \mathrm{Al}_{0,3} \mathrm{Mn}_{0,4} \mathrm{Cu}_{0,5} \mathrm{Ni}_{3,8}\left(750^{\circ} \mathrm{C} / 16\right) \quad \mathrm{La}_{0,7} \mathrm{Mg}_{0,3} \mathrm{Al}_{0,3} \mathrm{Mn}_{0,4} \mathrm{Sn}_{0,5} \mathrm{Ni}_{3,8} \quad\left(750^{\circ} \mathrm{C} / 16 \mathrm{~h}\right)$, $\underline{\mathrm{La}_{0,7} \mathrm{Pr}_{0,3} \mathrm{Al}_{0,3} \mathrm{Mn}_{0,4} \mathrm{Co}_{0,5} \mathrm{Ni}_{3,8}\left(850^{\circ} \mathrm{C} / 16 \mathrm{~h}\right) \text { e } \mathrm{Pr}_{0,7} \mathrm{Mg}_{0,3} \mathrm{Al}_{0,3} \mathrm{Mn}_{0,4} \mathrm{Co}_{0,5} \mathrm{Ni}_{3,8}\left(750^{\circ} \mathrm{C} / 9 \mathrm{~h}\right) .}$

\begin{tabular}{lcccc}
\hline Liga & $\mathbf{H} / \mathbf{M}$ & $\begin{array}{c}\mathbf{n} \\
\text { (H u.f) }\end{array}$ & $\begin{array}{c}\mathbf{M}_{\text {mol. }} \\
(\mathbf{g} / \mathbf{m o l})\end{array}$ & $\begin{array}{c}\mathbf{C}_{\text {máx.calc. }} \\
\text { (mAh) }\end{array}$ \\
\hline $\mathrm{Co}_{0,5} 850^{\circ} \mathrm{C} / 16 \mathrm{~h}$ & 0,598 & 3,83 & 387,1 & 248,4 \\
$\mathrm{Cu}_{0,5} 750^{\circ} \mathrm{C} / 16 \mathrm{~h}$ & 0,757 & 4,54 & 389,4 & 312,6 \\
$\mathrm{Sn}_{0,5} 750^{\circ} \mathrm{C} / 16 \mathrm{~h}$ & 0,428 & 2,57 & 416,98 & 165,1 \\
$\mathrm{LaPr} 850^{\circ} \mathrm{C} / 16 \mathrm{~h}$ & 0,810 & 4,86 & 422,1 & 308,6 \\
$\mathrm{PrMg} 750^{\circ} \mathrm{C} / 9 \mathrm{~h}$ & 0,280 & 1,7 & 388,5 & 115,9 \\
\hline
\end{tabular}




\subsection{2a- Liga La ${ }_{0,7} \mathrm{Mg}_{0,3} \mathrm{Al}_{0,3} \mathrm{Mn}_{0,4} \mathrm{Co}_{0,5} \mathrm{Ni}_{3,8}$ com TT $\left(850^{\circ} \mathrm{C} / 16 \mathrm{~h}\right)$}

A relação $\mathrm{H} / \mathrm{M}$ e a capacidade máxima de descarga, calculada empregando a EQUAÇÃO 3.8, para a liga $\mathrm{La}_{0,7} \mathrm{Mg}_{0,3} \mathrm{Al}_{0,3} \mathrm{Mn}_{0,4} \mathrm{Co}_{0,5} \mathrm{Ni}_{3,8}$ com $\mathrm{TT}\left(850^{\circ} / 16 \mathrm{~h}\right)$ mostradas nas TABELAS 45 e 46 foram de 0,598 e 248,4 mAh, respectivamente. Comparando estes resultados com os obtidos no teste eletroquímico da liga os valores de $\mathrm{H} / \mathrm{M}$ e da capacidade máxima de descarga foram inferiores em $39 \%$ para esta liga com TT (850\%16h) de 0,977 e 406,1 mAh apresentados na TABELA 38, respectivamente.

Os valores dos resultados do teste de PCT foram obtidos a partir do material ativo, enquanto que os valores da capacidade de descarga nos testes eletroquímicos foram a partir das baterias, fabricadas com dois eletrodos positivo e negativo e imersa num meio aquoso $\mathrm{KOH} 6 \mathrm{~mol}$, onde provavelmente as reações químicas promovidas durante o processo de carga/descarga na bateria possa ter influenciado nos resultados.

\subsection{2b - Liga $\mathrm{La}_{0,7} \mathrm{Mg}_{0,3} \mathrm{Al}_{0,3} \mathrm{Mn}_{0,4} \mathrm{Cu}_{0,5} \mathrm{Ni}_{3,8} \operatorname{com~} \mathrm{TT}\left(750^{\circ} \mathrm{C} / 16 \mathrm{~h}\right)$}

A relação $\mathrm{H} / \mathrm{M}$ e a capacidade máxima de descarga, calculada a partir da EQUAÇÃO 3.8, para a liga $\mathrm{La}_{0,7} \mathrm{Mg}_{0,3} \mathrm{Al}_{0,3} \mathrm{Mn}_{0,4} \mathrm{Cu}_{0,5} \mathrm{Ni}_{3,8}$ com TT $\left(750^{\circ} / 16 \mathrm{~h}\right)$ mostradas nas TABELAS 45 e 46 foram de 0,757 e 312,6 mAh, respectivamente. Comparando estes resultados com os obtidos no teste eletroquímico da liga os valores de $\mathrm{H} / \mathrm{M}$ e da capacidade máxima de descarga foram superiores em 4,2\% para esta liga com TT $(750 \% / 16 h)$ de 0,726 e 300,1 mAh apresentados na TABELA 39, respectivamente.

Isto pode ser justificado pelos resultados obtidos no refinamento da analise de difração de raios-X empregando o método de Rietived para os valores apresentados na TABELA 9 mostrando as fases, $\mathrm{LaNi}_{5}$ e $\mathrm{LaMg}_{2} \mathrm{Ni}_{9}$ que para esta liga são em maior fração, são fases absorvedoras. 


\subsection{2c- Liga La ${ }_{0,7} \mathrm{Mg}_{0,3} \mathrm{Al}_{0,3} \mathrm{Mn}_{0,4} \mathrm{Sn}_{0,5} \mathrm{Ni}_{3,8} \operatorname{com} \mathrm{TT}\left(750^{\circ} \mathrm{C} / 16 \mathrm{~h}\right)$}

A relação $\mathrm{H} / \mathrm{M}$ e a capacidade máxima de descarga, calculada a partir da EQUAÇÃO 3.8, para a liga $\mathrm{La}_{0,7} \mathrm{Mg}_{0,3} \mathrm{Al}_{0,3} \mathrm{Mn}_{0,4} \mathrm{Sn}_{0,5} \mathrm{Ni}_{3,8}$ com TT $(750 \%$ 16h) mostradas nas TABELAS 45 e 46 foram de 0,428 e 165,1 mAh, respectivamente. Comparando estes resultados com os obtidos no teste eletroquímico da liga os valores de $\mathrm{H} / \mathrm{M}$ e da capacidade máxima de descarga foram inferiores em $38 \%$ para esta liga com TT (750\%/16h) de 0,687 e 265,2 mAh apresentados na TABELA 40, respectivamente.

Os resultados obtidos no refinamento pelo método de Rietived observados na TABELA 10 mostram a presença das fases $\mathrm{LaSn}_{2} \mathrm{Ni}_{2}$ e $\mathrm{MgNi}_{2}$ que podem ter contribuído na pressão de formação do platô durante o teste de PCT da liga tratada termicamente a $750^{\circ} \mathrm{C}$ por 16 horas.

\subsection{2d- Liga La $\mathrm{La}_{0,7} \mathrm{Pr}_{0,3} \mathrm{Al}_{0,3} \mathrm{Mn}_{0,4} \mathrm{Co}_{0,5} \mathrm{Ni}_{3,8} \operatorname{com~TT}\left(850^{\circ} \mathrm{C} / 16 \mathrm{~h}\right)$}

A relação $\mathrm{H} / \mathrm{M}$ e a capacidade máxima de descarga, calculada a partir da EQUAÇÃO 3.8, para a liga La $\mathrm{La}_{0,7} \mathrm{Pr}_{0,3} \mathrm{Al}_{0,3} \mathrm{Mn}_{0,4} \mathrm{Co}_{0,5} \mathrm{Ni}_{3,8}$ com TT $(850 \%$ 16h) mostradas nas TABELAS 45 e 46 foram de 0,810 e 308,6 mAh, respectivamente. Comparando estes resultados com os obtidos no teste eletroquímico da liga como material ativo do eletrodo negativo na bateria, os valores de $\mathrm{H} / \mathrm{M}$ e da capacidade máxima de descarga foram inferiores em 14,2\% para esta liga com TT (850\%/16h) de 0,944 e 359,7 mAh apresentados na TABELA 41, respectivamente

No teste de PCT da liga $\mathrm{La}_{0,7} \mathrm{Pr}_{0,3} \mathrm{Al}_{0,3} \mathrm{Mn}_{0,4} \mathrm{Co}_{0,5} \mathrm{Ni}_{3,8}$, observou-se que a uma inclinação no sentido contrario invertendo a inclinação do platô, continua existindo, como já foi mencionado para a liga sem TT, pode ter sido por causado porque a liga com maior capacidade de absorção do que a vazão de alimentação proposta para estes testes de PCT dinâmico mantendo a vazão de alimentação em $9 \mathrm{ml} / \mathrm{s}$, e a liga manter após o TT capacidade de absorção. 


\subsection{2e- Liga $\mathrm{Pr}_{0,7} \mathrm{Mg}_{0,3} \mathrm{Al}_{0,3} \mathrm{Mn}_{0,4} \mathrm{Co}_{0,5} \mathrm{Ni}_{3,8}$ com TT $\left(750^{\circ} \mathrm{C} / 9 \mathrm{~h}\right)$}

A relação $\mathrm{H} / \mathrm{M}$ e a capacidade máxima de descarga, calculada a partir da EQUAÇÃO 3.8, para a liga $\operatorname{Pr}_{0,7} \mathrm{Mg}_{0,3} \mathrm{Al}_{0,3} \mathrm{Mn}_{0,4} \mathrm{Co}_{0,5} \mathrm{Ni}_{3,8}$ com TT (750\%9h) mostradas nas TABELAS 45 e 46 foram de 0,280 e 115,9 mAh, respectivamente. Comparando estes resultados com os obtidos no teste eletroquímico da liga os valores de $\mathrm{H} / \mathrm{M} \mathrm{e}$ da capacidade máxima de descarga foram inferiores em $22 \%$ para esta liga com TT (750\%/9h) de 0,359 e 148,7 mAh apresentados na TABELA 42, respectivamente.

Diferentemente dos outros ensaios de PCT para esta liga a pressão final de hidrogênio foi alterada para 8 bar, pois a substituição do La pelo $\operatorname{Pr}$ dificulta a absorção pois a fase (AIMn) $\mathrm{Ni}_{3}$ presente na estrutura da liga com TT conforme a FIGURA 24 e TABELA 12, possui uma estrutura cúbica de face centrada com retração nos eixos e consequentemente menor volume de célula unitária diminuindo assim a capacidade de absorção da liga nestas condições.

\subsection{3 - Absorção de hidrogênio e ciclos de ativação e Análise de PCT das ligas com TT}

Nessa etapa foram realizadas 4 curvas de absorção de hidrogênio e ciclos de ativação nas ligas com TT $\mathrm{La}_{0,7} \mathrm{Mg}_{0,3} \mathrm{Al}_{0,3} \mathrm{Mn}_{0,4} \mathrm{Co}_{0,5} \mathrm{Ni}_{3,8} \quad(850 \% 16 \mathrm{~h})$, $\mathrm{La}_{0,7} \mathrm{Mg}_{0,3} \mathrm{Al}_{0,3} \mathrm{Mn}_{0,4} \mathrm{Cu}_{0,5} \mathrm{Ni}_{3,8}\left(750^{\circ} \mathrm{C} / 16 \mathrm{~h}\right), \quad \mathrm{La}_{0,7} \mathrm{Mg}_{0,3} \mathrm{Al}_{0,3} \mathrm{Mn}_{0,4} \mathrm{Sn}_{0,5} \mathrm{Ni}_{3,8} \quad\left(750^{\circ} \mathrm{C} / 16 \mathrm{~h}\right)$, $\mathrm{La}_{0,7} \mathrm{Pr}_{0,3} \mathrm{Al}_{0,3} \mathrm{Mn}_{0,4} \mathrm{Co}_{0,5} \mathrm{Ni}_{3,8} \quad\left(850^{\circ} \mathrm{C} / 16 \mathrm{~h}\right)$ e $\mathrm{Pr}_{0,7} \mathrm{Mg}_{0,3} \mathrm{Al}_{0,3} \mathrm{Mn}_{0,4} \mathrm{Co}_{0,5} \mathrm{Ni}_{3,8}\left(750^{\circ} \mathrm{C} / 9 \mathrm{~h}\right)$ que apresentaram melhores resultados na capacidade de descarga das baterias apresentadas nas TABELAS 38 a 42, respectivamente. Esta ativação procura maximizar a capacidade de armazenamento e a cinética de dessorção de hidrogênio na liga.

Foi observado por Li. S e seus colaboradores em 2012, a expansão e a contração interna do hidreto metálico conduzem à pulverização das partículas do metal em "pó" (decrepitação), maximizando a relação área superficial e volume para a consequente adsorção de hidrogênio, promovendo assim um aumento no volume da rede cristalina do material formando a o hidreto o que também foi descrito por Lim et al (2017). 


\subsection{3-a - Curvas de Absorção de hidrogênio e ciclos de ativação da liga $\mathrm{La}_{0,7} \mathrm{Mg}_{0,3} \mathrm{Al}_{0,3} \mathrm{Mn}_{0,4} \mathrm{Co}_{0,5} \mathrm{Ni}_{3,8}$ com TT de $850^{\circ} \mathrm{C}$ por 16 horas}

Nas FIGURAS 40 e 41 estão mostrados as 4 curvas de absorção de hidrogênio e os ciclos de ativação da liga $\mathrm{La}_{0,7} \mathrm{Mg}_{0,3} \mathrm{Al}_{0,3} \mathrm{Mn}_{0,4} \mathrm{Co}_{0,5} \mathrm{Ni}_{3,8}$ com TT de $850^{\circ} \mathrm{C}$ por 16 horas, respectivamente. Para esta liga observou-se que o primeiro ciclo a absorção foi eficiente para ativação da liga, pois nos próximos ciclos de ativação observa-se uma diminuição na absorção do hidrogênio pela liga indicando a presença de uma fase de dessorção lenta, sendo esta fase identificada como $\mathrm{MgNi}_{2}$, a qual liberaria o hidrogênio somente mediante a um aquecimento o que fere o propósito deste ensaio.

FIGURA 40 - Curvas de absorção de hidrogênio da liga $\mathrm{La}_{0,7} \mathrm{Mg}_{0,3} \mathrm{Al}_{0,3} \mathrm{Mn}_{0,4} \mathrm{Co}_{0,5} \mathrm{Ni}_{3,8}$ com TT de $850^{\circ} \mathrm{C}$ por 16 horas

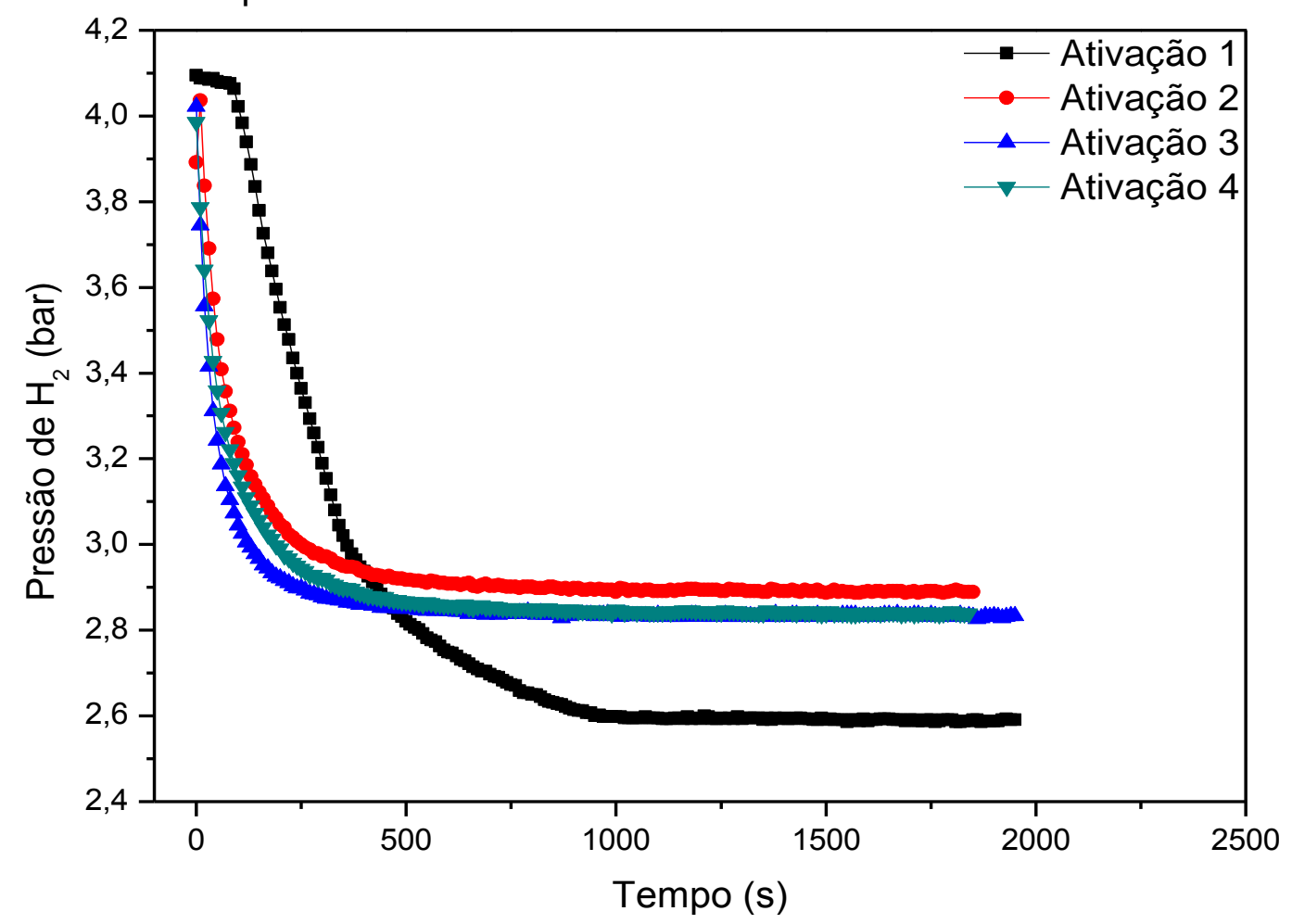


FIGURA 41 - Ciclos de ativação da liga $\mathrm{La}_{0,7} \mathrm{Mg}_{0,3} \mathrm{Al}_{0,3} \mathrm{Mn}_{0,4} \mathrm{Co}_{0,5} \mathrm{Ni}_{3,8}$ com tratamento térmico de $850^{\circ} \mathrm{C}$ por 16 horas .

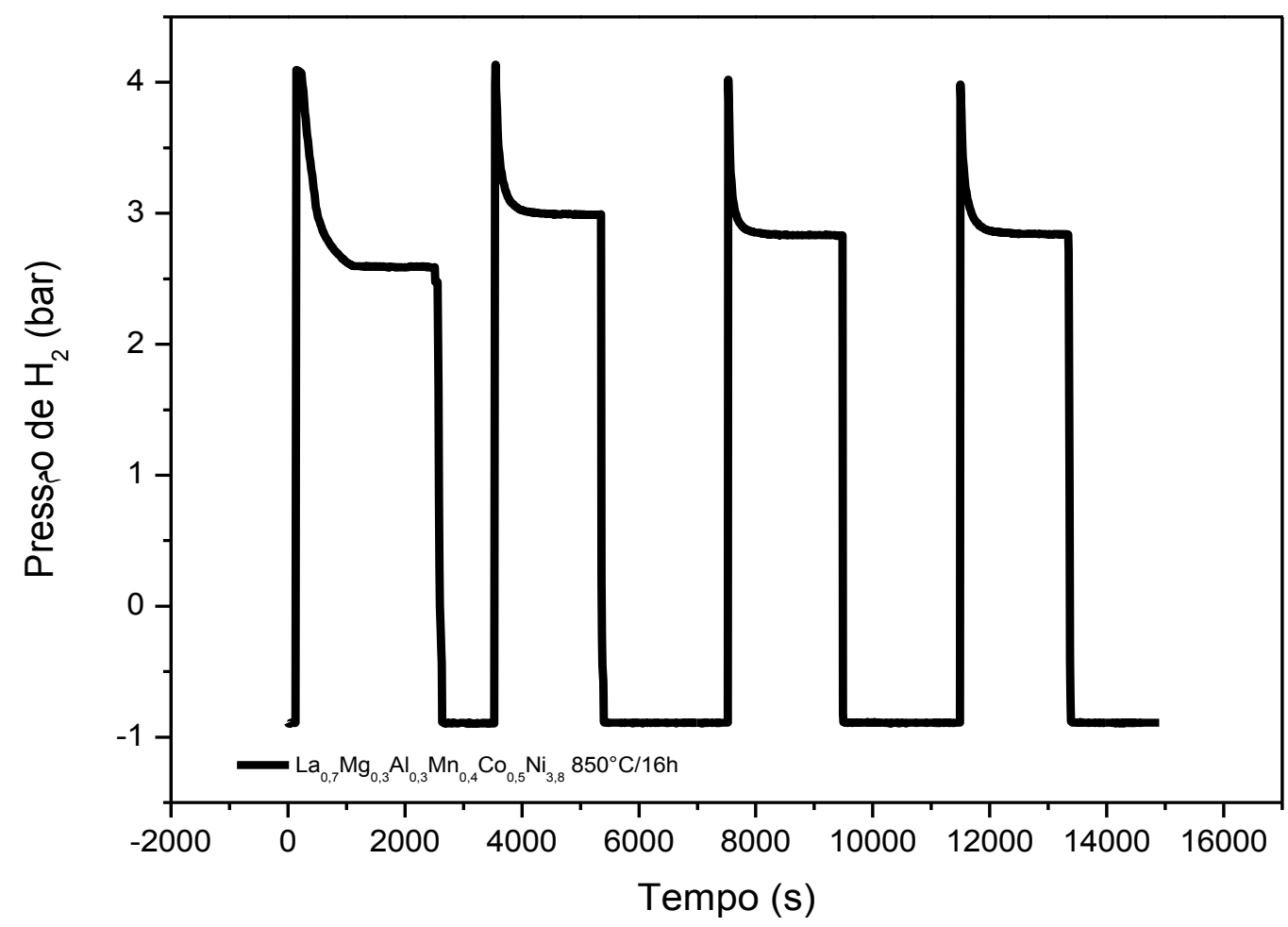

\subsection{3-b - Curvas de Absorção de hidrogênio e ciclos de ativação da liga $\mathrm{La}_{0,7} \mathrm{Mg}_{0,3} \mathrm{Al}_{0,3} \mathrm{Mn}_{0,4} \mathrm{Cu}_{0,5} \mathrm{Ni}_{3,8}$ com TT de $750^{\circ} \mathrm{C}$ por 16 horas}

Nas FIGURAS 42 e 43 estão mostrados as 4 curvas de absorção de hidrogênio e os ciclos de ativação da liga $\mathrm{La}_{0,7} \mathrm{Mg}_{0,3} \mathrm{Al}_{0,3} \mathrm{Mn}_{0,4} \mathrm{Cu}_{0,5} \mathrm{Ni}_{3,8}$ com TT de $750^{\circ} \mathrm{C}$ por 16 horas, respectivamente.

Nas curvas de absorção dos ciclos de ativação da liga no primeiro ciclo de ativação o tempo de espera para que promovesse a absorção foi de aproximadamente 4 horas, provavelmente, isto se deve a uma fina camada de óxidos existentes na superfície do material formada pelas condições de TT da liga, o que também foi estudado por Salvam e colaboradores em 1990.

Observou-se que o primeiro ciclo a absorção foi eficiente para ativação da liga. 
FIGURA 42 - Curvas de absorção durante os ciclos de ativação da liga $\mathrm{La}_{0,7} \mathrm{Mg}_{0,3} \mathrm{Al}_{0,3} \mathrm{Mn}_{0,4} \mathrm{Cu}_{0,5} \mathrm{Ni}_{3,8}$ com tratamento térmico de $750^{\circ} \mathrm{C}$ por 16 horas.

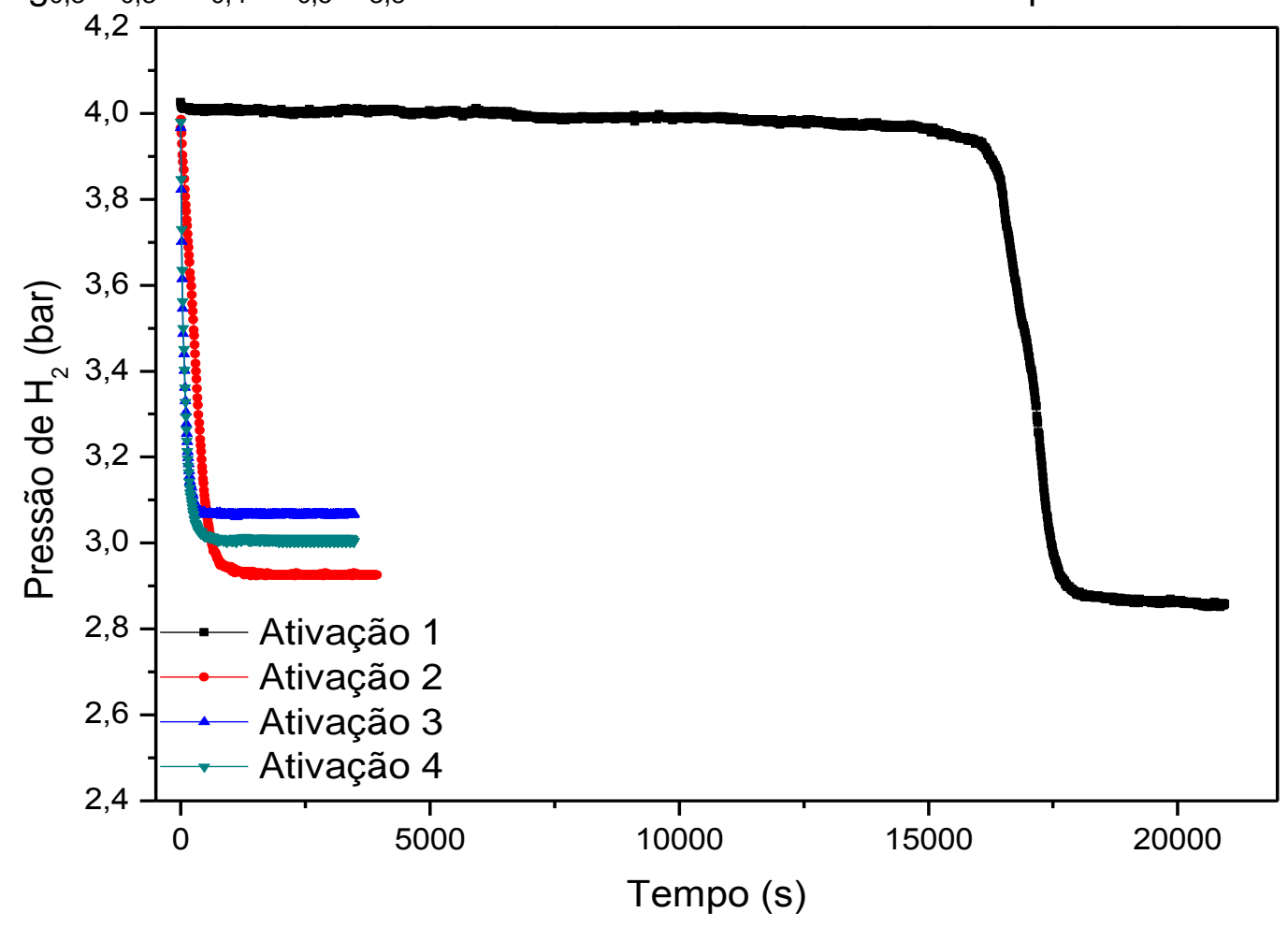

FIGURA 43 - Ciclos de ativação da liga $\mathrm{La}_{0,7} \mathrm{Mg}_{0,3} \mathrm{Al}_{0,3} \mathrm{Mn}_{0,4} \mathrm{Cu}_{0,5} \mathrm{Ni}_{3,8}$ com tratamento térmico de $750^{\circ} \mathrm{C}$ por 16 horas.

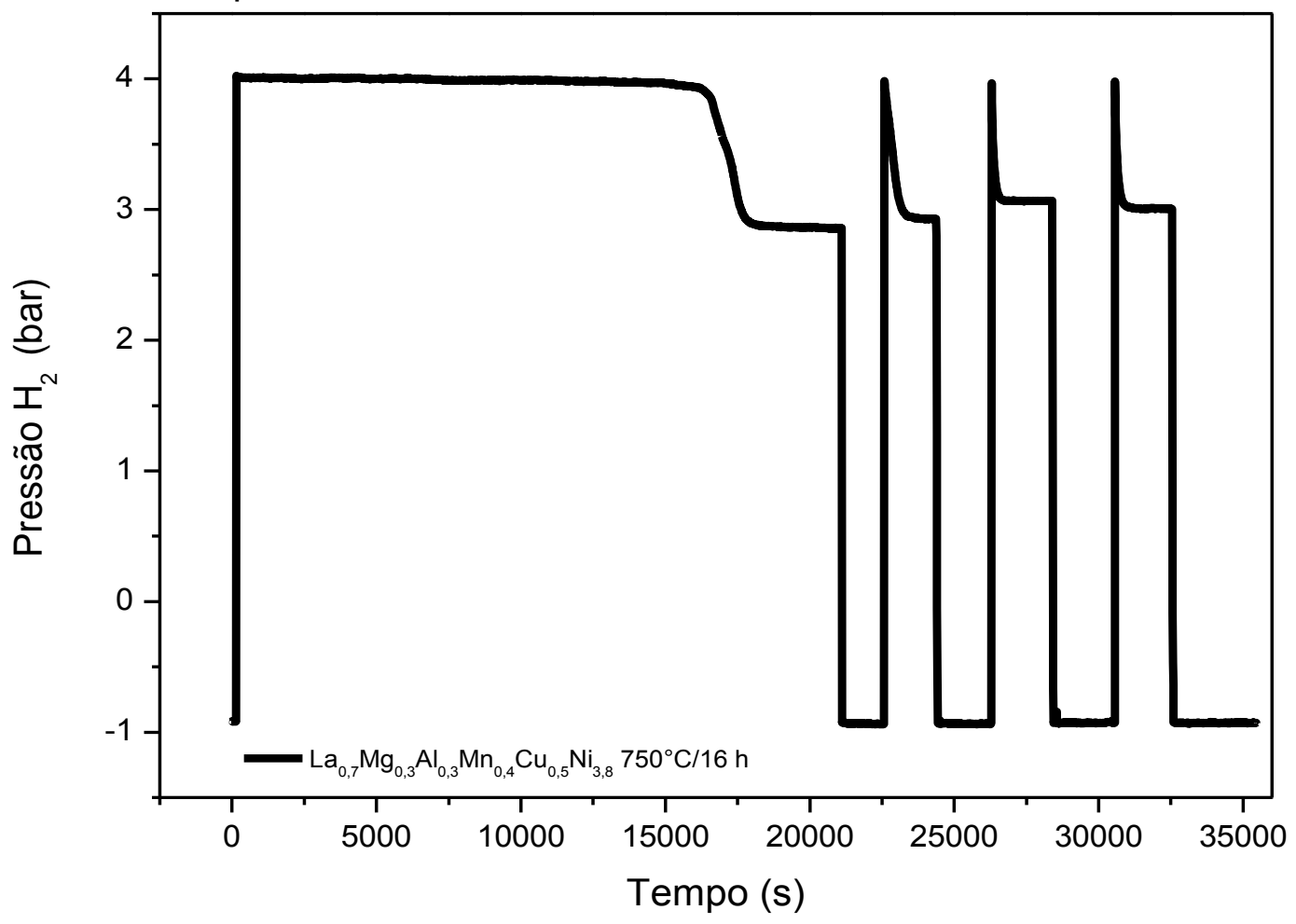




\subsection{3-c - Curvas de Absorção de hidrogênio e ciclos de ativação da liga $\mathrm{La}_{0,7} \mathrm{Mg}_{0,3} \mathrm{Al}_{0,3} \mathrm{Mn}_{0,4} \mathrm{Sn}_{0,5} \mathrm{Ni}_{3,8}$ com TT de $750^{\circ} \mathrm{C}$ por 16 horas}

Para a ativação da liga $\mathrm{La}_{0,7} \mathrm{Mg}_{0,3} \mathrm{Al}_{0,3} \mathrm{Mn}_{0,4} \mathrm{Sn}_{0,5} \mathrm{Ni}_{3,8}$ com TT a $750^{\circ} \mathrm{C}$ por 16 horas nas FIGURAS 44 e 45, no primeiro ciclo de ativação o tempo de espera para que promovesse primeira a absorção foi de aproximadamente 50 minutos, isto se deve à camada do filme de óxidos existentes no material formada pelas condições de estoque das ligas após de tratamento térmico da liga o que também foi observado por Salvam et al em 1990.

As demais ativações ocorrem quase no mesmo instante em que o hidrogênio esta sendo adicionado, isto se deve ao fato barreira da camada de óxido já ter sido ultrapassada e também, motivado pelo fato do material já estar fragilizado e os tamanhos de partículas menores, aumentando assim sua área de superfície o que favorece a velocidade a absorção do hidrogênio pela liga comportamento avaliado por Young et al (2009a; 2009b)

Observou-se que o primeiro ciclo a absorção foi eficiente para ativação da liga.

FIGURA 44 - Curvas de absorção durante os ciclos de ativação da liga $\mathrm{La}_{0,7} \mathrm{Mg}_{0,3} \mathrm{Al}_{0,3} \mathrm{Mn}_{0,4} \mathrm{Sn}_{0,5} \mathrm{Ni}_{3,8}$ com tratamento térmico de $750^{\circ} \mathrm{C}$ por 16 horas

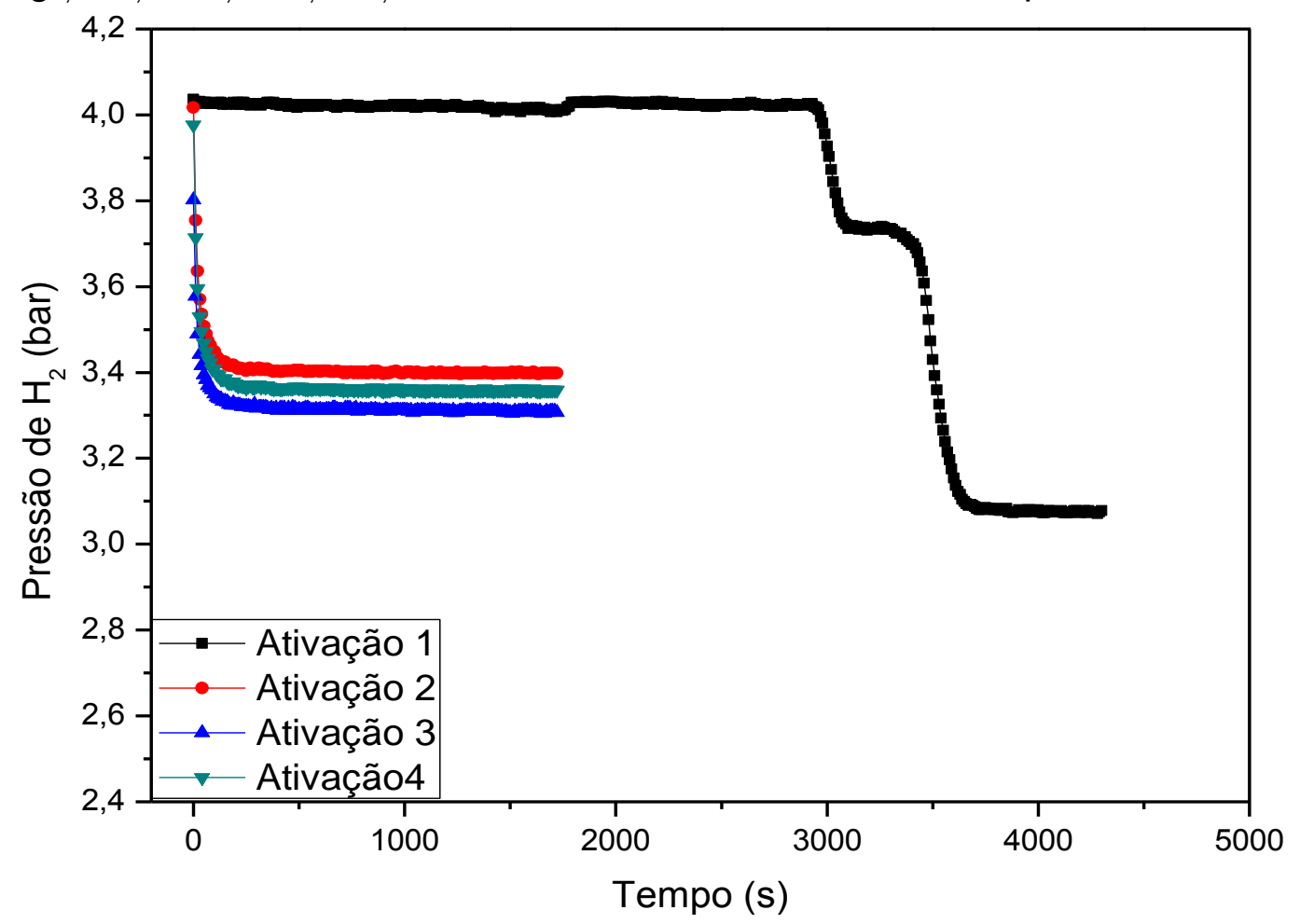


Figura 45 - Ciclos de ativação da liga $\mathrm{La}_{0,7} \mathrm{Mg}_{0,3} \mathrm{Al}_{0,3} \mathrm{Mn}_{0,4} \mathrm{Sn}_{0,5} \mathrm{Ni}_{3,8}$ com tratamento térmico de $750^{\circ} \mathrm{C}$ por 16 horas.

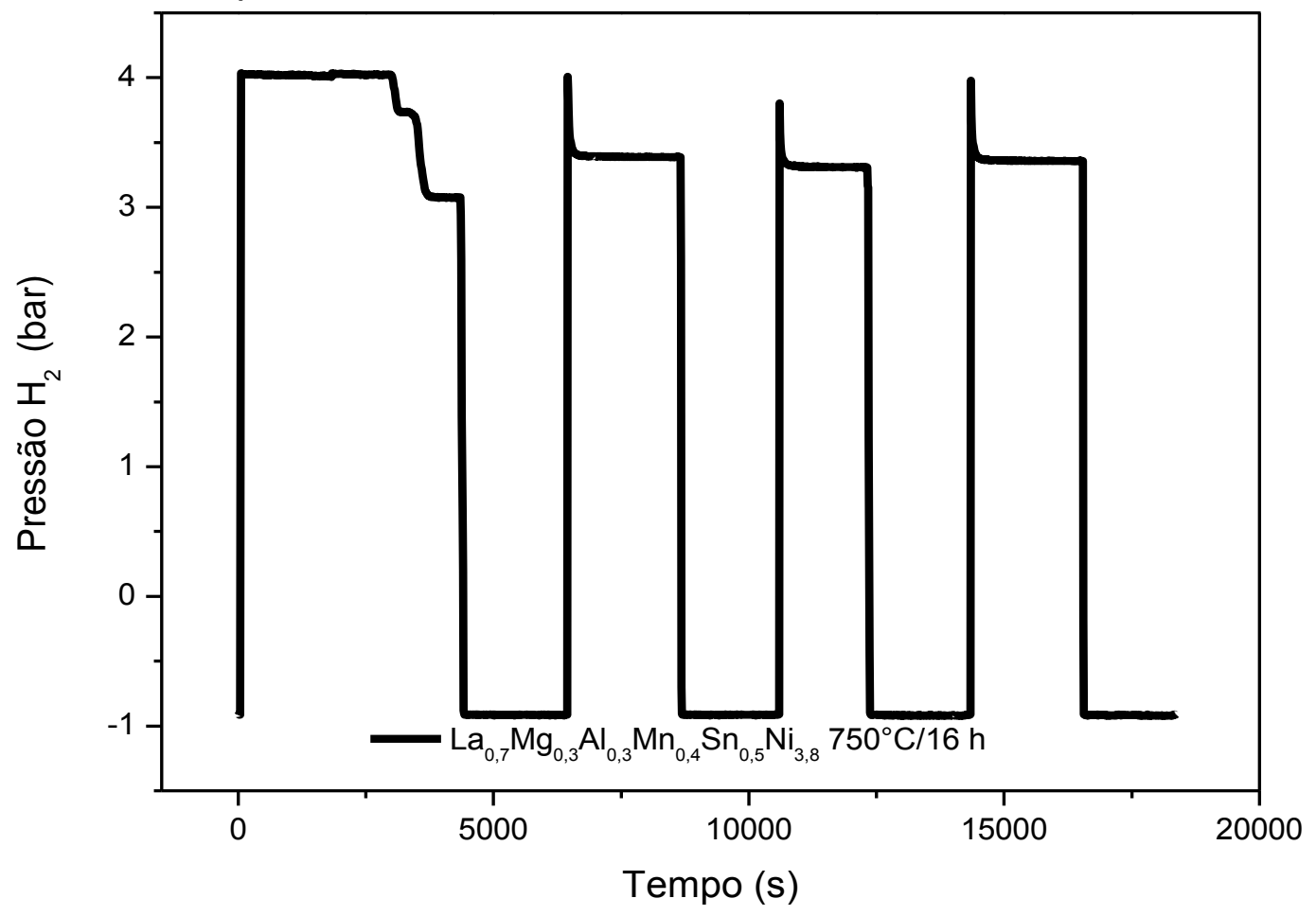

5.5.3-d - Curvas de Absorção de hidrogênio e ciclos de ativação da liga $\mathrm{La}_{0,7} \mathrm{Pr}_{0,3} \mathrm{Al}_{0,3} \mathrm{Mn}_{0,4} \mathrm{Co}_{0,5} \mathrm{Ni}_{3,8}$ com TT de $850^{\circ} \mathrm{C}$ por 16 horas

Nas FIGURAS 46 e 47 estão mostrados as 4 curvas de absorção de hidrogênio e os ciclos de ativação da liga $\mathrm{La}_{0,7} \mathrm{Pr}_{0,3} \mathrm{Al}_{0,3} \mathrm{Mn}_{0,4} \mathrm{Co}_{0,5} \mathrm{Ni}_{3,8}$ com TT de $850^{\circ} \mathrm{C}$ por 16 horas, respectivamente.

Após o primeiro ciclo de ativação, as absorções do hidrogênio pela liga no segundo, terceiro e quarto ciclo ocorreram extremamente rápido acontecendo no instante que o gás hidrogênio foi injetado, provavelmente isto se deve ao fato de que o primeiro ciclo a absorção foi suficiente para ativação da liga, também observado por Denis e seus colaboradores em 2011. 
Figura 46 - Curvas de absorção durante os ciclos de ativação da liga $\mathrm{La}_{0,7} \mathrm{Pr}_{0,3} \mathrm{Al}_{0,3} \mathrm{Mn}_{0,4} \mathrm{Co}_{0,5} \mathrm{Ni}_{3,8}$ com tratamento térmico de $850^{\circ} \mathrm{C}$ por 16 horas.

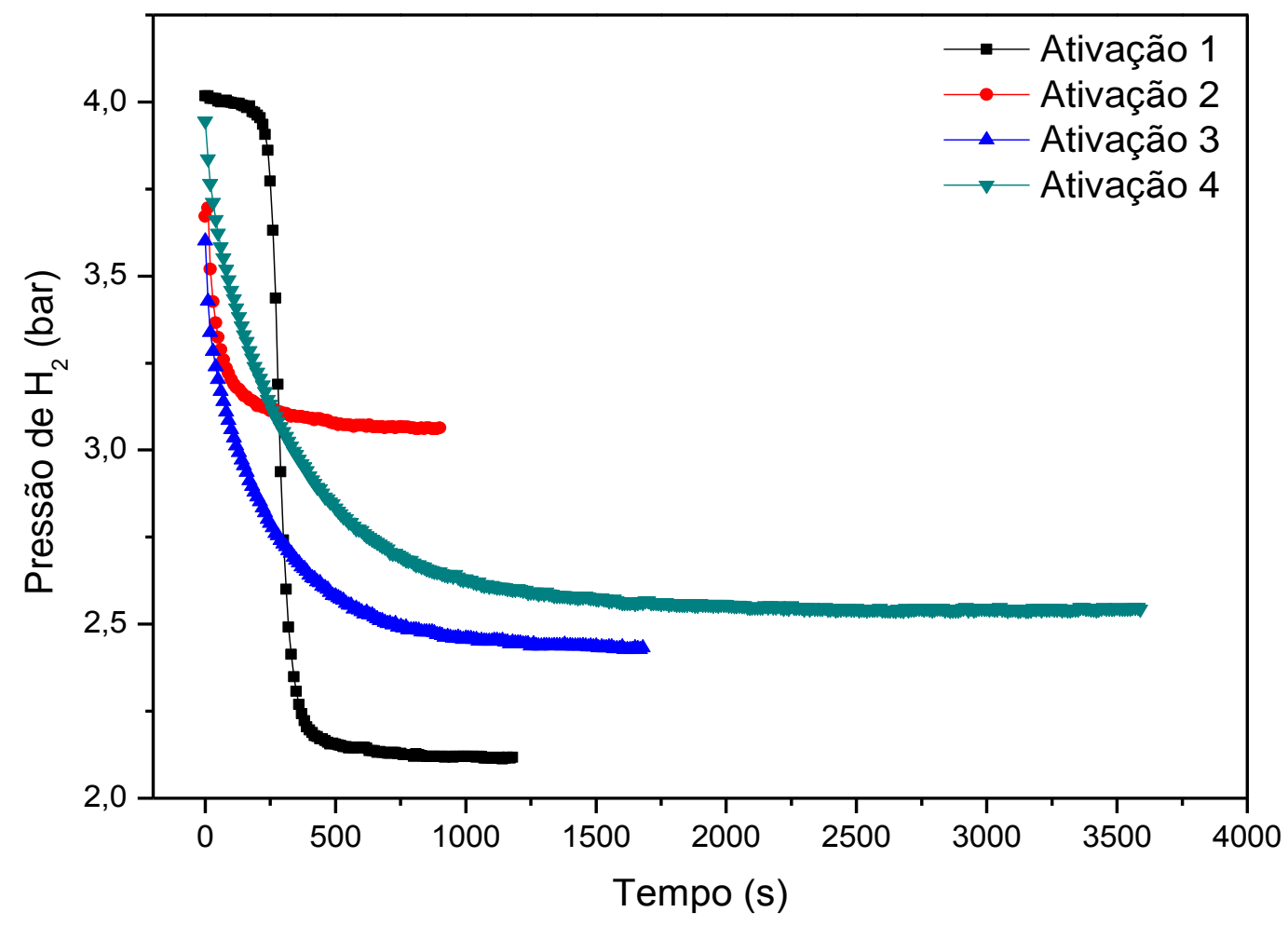

Figura 47 - Ciclos de ativação da liga $\mathrm{La}_{0,7} \mathrm{Pr}_{0,3} \mathrm{Al}_{0,3} \mathrm{Mn}_{0,4} \mathrm{Co}_{0,5} \mathrm{Ni}_{3,8}$ com tratamento térmico de $850^{\circ} \mathrm{C}$ por 16 horas.

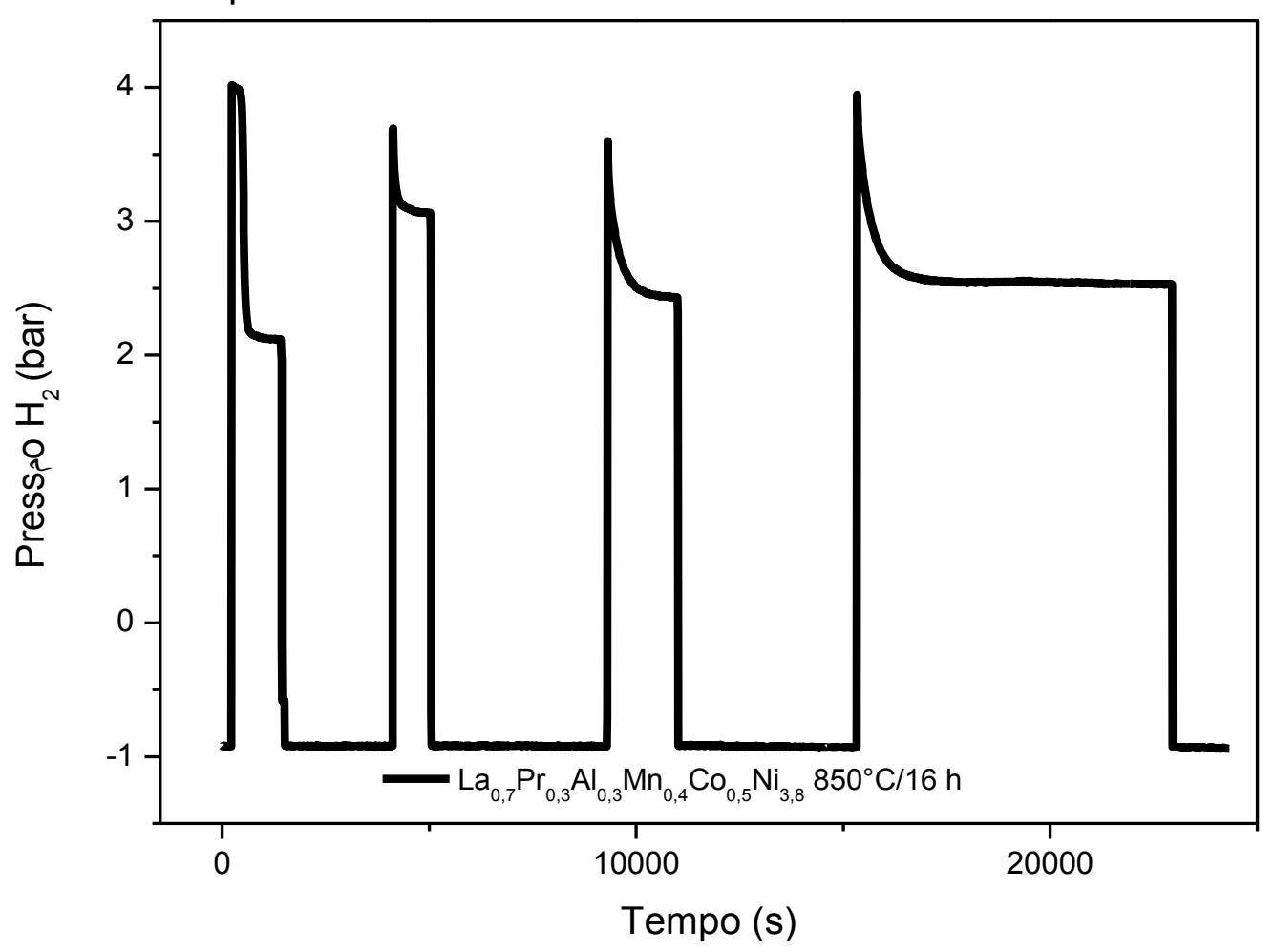




\subsection{3-e - Curvas de Absorção de hidrogênio e ciclos de ativação da liga $\mathrm{Pr}_{0,7} \mathrm{Mg}_{0,3} \mathrm{Al}_{0,3} \mathrm{Mn}_{0,4} \mathrm{Co}_{0,5} \mathrm{Ni}_{3,8}$ com TT de $750^{\circ} \mathrm{C}$ por 9 horas}

Nas FIGURAS 48 e 49 estão mostrados as 4 curvas de absorção de hidrogênio, e os ciclos de ativação com pressão de 6 bar, da liga $\mathrm{Pr}_{0,7} \mathrm{Mg}_{0,3} \mathrm{Al}_{0,3} \mathrm{Mn}_{0,4} \mathrm{Co}_{0,5} \mathrm{Ni}_{3,8}$ com TT de $750^{\circ} \mathrm{C}$ por 9 horas, respectivamente. Observou-se que durante os ciclos não ocorreu absorção suficiente para ativação da liga, substituição que também foi estudado em outras ligas com composições nominais diferentes por Denys et al (2008).

A menor absorção do hidrogênio pela liga, provavelmente foi ocasionada pela substituição do La pelo $\operatorname{Pr}$, onde as fases formadas na microestrutura da liga e identificada pelo refinamento de Rietivel apresentado na TABELA 13, identifica a presença das fases $\mathrm{PrNI}_{5}$, (AIMn) $\mathrm{Ni}_{3}$ e (PrMg) ${ }_{2} \mathrm{Ni}_{9}$ na liga. A fase (AIMn) $\mathrm{Ni}_{3}$ tem volume da célula unitária muito baixo o que reduz bastante a absorção de hidrogênio (Gao et al 2008 e Liao et al 2004)

FIGURA 48 - Curvas de absorção durante os ciclos de ativação da liga $\mathrm{Pr}_{0,7} \mathrm{Mg}_{0,3} \mathrm{Al}_{0,3} \mathrm{Mn}_{0,4} \mathrm{Co}_{0,5} \mathrm{Ni}_{3,8}$ com tratamento térmico de $750^{\circ} \mathrm{C}$ por 9 horas.

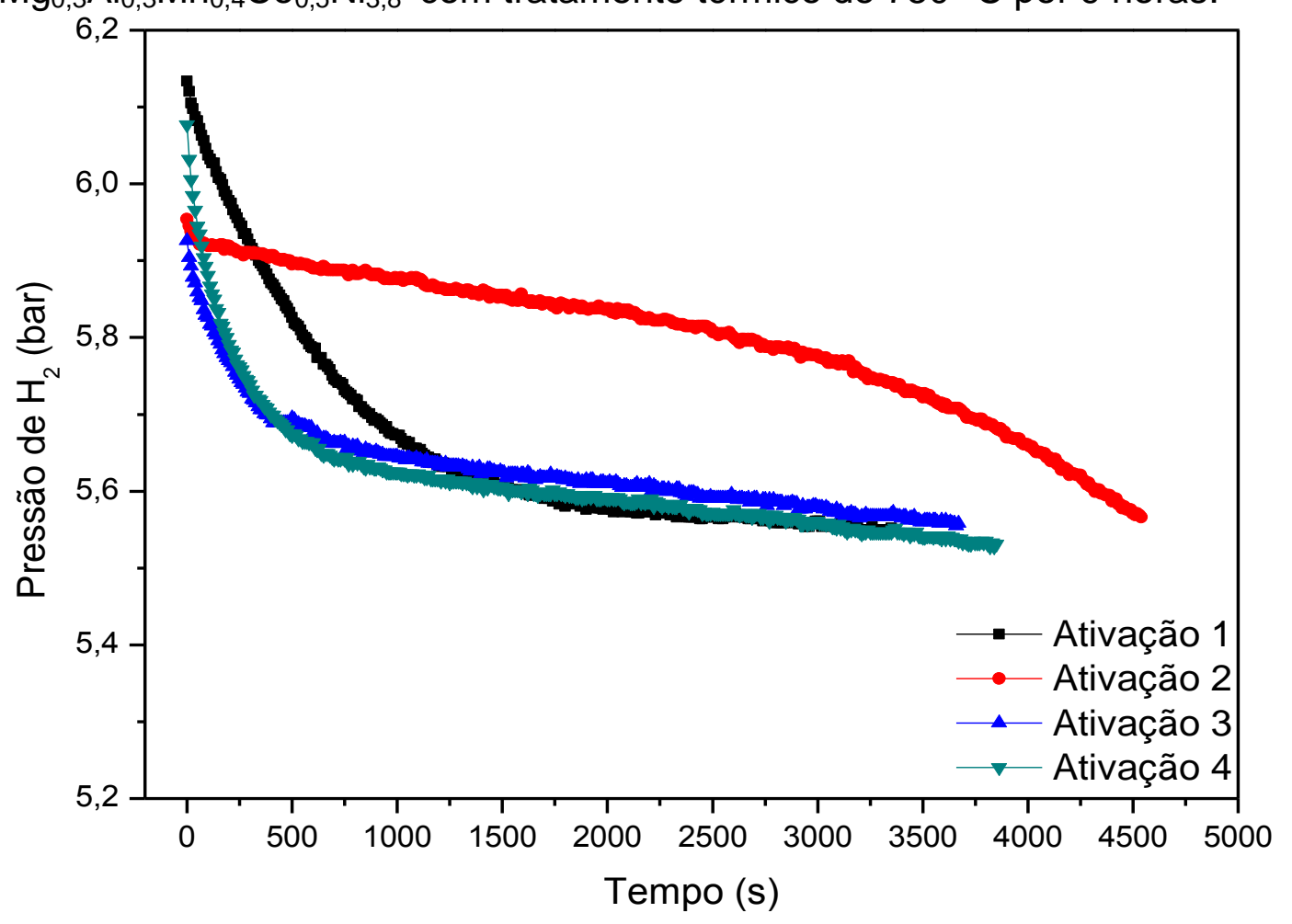


FIGURA 49 - Ciclos de ativação da liga $\operatorname{Pr}_{0,7} \mathrm{Mg}_{0,3} \mathrm{Al}_{0,3} \mathrm{Mn}_{0,4} \mathrm{Co}_{0,5} \mathrm{Ni}_{3,8}$ com tratamento térmico de $750^{\circ} \mathrm{C}$ por 9 horas.

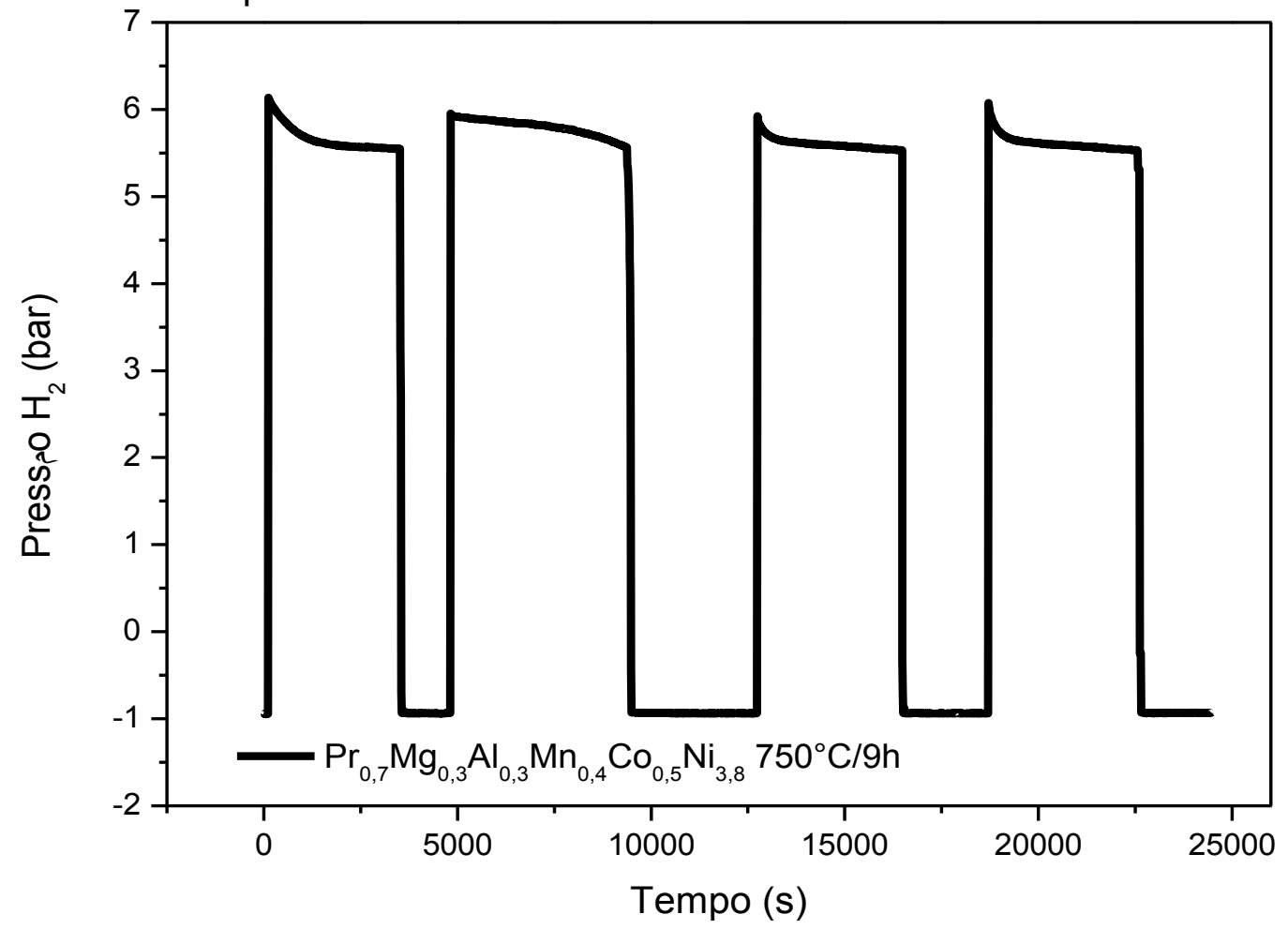

\subsection{3-f - Análise de PCT das ligas com TT e com quatro ciclos de ativações.}

A FIGURA 50 mostra as curvas de absorção PCT das ligas com TT, o início de formação do platô de equilíbrio ocorre quase instantaneamente, pois as ligas $\mathrm{La}_{0,7} \mathrm{Mg}_{0,3} \mathrm{Al}_{0,3} \mathrm{Mn}_{0,4} \mathrm{Co}_{0,5} \mathrm{Ni}_{3,8} \quad 850^{\circ} \mathrm{C} / 16 \mathrm{~h}, \quad \mathrm{La}_{0,7} \mathrm{Mg}_{0,3} \mathrm{Al}_{0,3} \mathrm{Mn}_{0,4} \mathrm{Cu}_{0,5} \mathrm{Ni}_{3,8} \quad 750^{\circ} \mathrm{C} / 16 \mathrm{~h}$, $\mathrm{La}_{0,7} \mathrm{Mg}_{0,3} \mathrm{Al}_{0,3} \mathrm{Mn}_{0,4} \mathrm{Sn}_{0,5} \mathrm{Ni}_{3,8} 750^{\circ} \mathrm{C} / 16 \mathrm{~h}$ e $\mathrm{La}_{0,7} \mathrm{Pr}_{0,3} \mathrm{Al}_{0,3} \mathrm{Mn}_{0,4} \mathrm{Co}_{0,5} \mathrm{Ni}_{3,8} 850^{\circ} \mathrm{C} / 16 \mathrm{~h}$ já estavam ativadas favorecendo o processo de absorção.

Na liga $\operatorname{Pr}_{0,7} \mathrm{Mg}_{0,3} \mathrm{Al}_{0,3} \mathrm{Mn}_{0,4} \mathrm{Co}_{0,5} \mathrm{Ni}_{3,8}$ com TT em $750^{\circ} \mathrm{C}$ por 9 horas observouse que foi necessário uma maior pressão de hidrogênio em relação às outras ligas, para que ocorresse o inicio da formação do platô de absorção, isto se deve a substituição do La pelo Pr e também provavelmente pela a fase (AIMn) $\mathrm{Ni}_{3}$ presente na liga mostrada na FIGURA 24, e identificada nos parâmetros de rede obtidos pelo refinamento pelo método de Rietveld na TABELA 12 onde se observou uma diminuição significativa no volume da célula unitária para esta fase, embora tenham sido aplicado os mesmos 4 ciclos de ativação, o comportamento de absorção desta liga com TT não foi alterado. 
FIGURA 50 - Curva de PCT das ligas $\mathrm{La}_{0,7} \mathrm{Mg}_{0,3} \mathrm{Al}_{0,3} \mathrm{Mn}_{0,4} \mathrm{Co}_{0,5} \mathrm{Ni}_{3,8} \quad 850^{\circ} / 16 \mathrm{~h}$, $\mathrm{La}_{0,7} \mathrm{Mg}_{0,3} \mathrm{Al}_{0,3} \mathrm{Mn}_{0,4} \mathrm{Cu}_{0,5} \mathrm{Ni}_{3,8} \quad 750^{\circ} \mathrm{C} / 16 \mathrm{~h}, \quad \mathrm{La}_{0,7} \mathrm{Mg}_{0,3} \mathrm{Al}_{0,3} \mathrm{Mn}_{0,4} \mathrm{Sn}_{0,5} \mathrm{Ni}_{3,8} \quad 750^{\circ} \mathrm{C} / 16 \mathrm{~h}$, $\mathrm{La}_{0,7} \mathrm{Pr}_{0,3} \mathrm{Al}_{0,3} \mathrm{Mn}_{0,4} \mathrm{Co}_{0,5} \mathrm{Ni}_{3,8} \quad 850^{\circ} \mathrm{C} / 16 \mathrm{~h}$ e $\mathrm{Pr}_{0,7} \mathrm{Mg}_{0,3} \mathrm{Al}_{0,3} \mathrm{Mn}_{0,4} \mathrm{Co}_{0,5} \mathrm{Ni}_{3,8} \quad 750^{\circ} \mathrm{C} / 9 \mathrm{~h}$ após quatro ciclos de ativação.

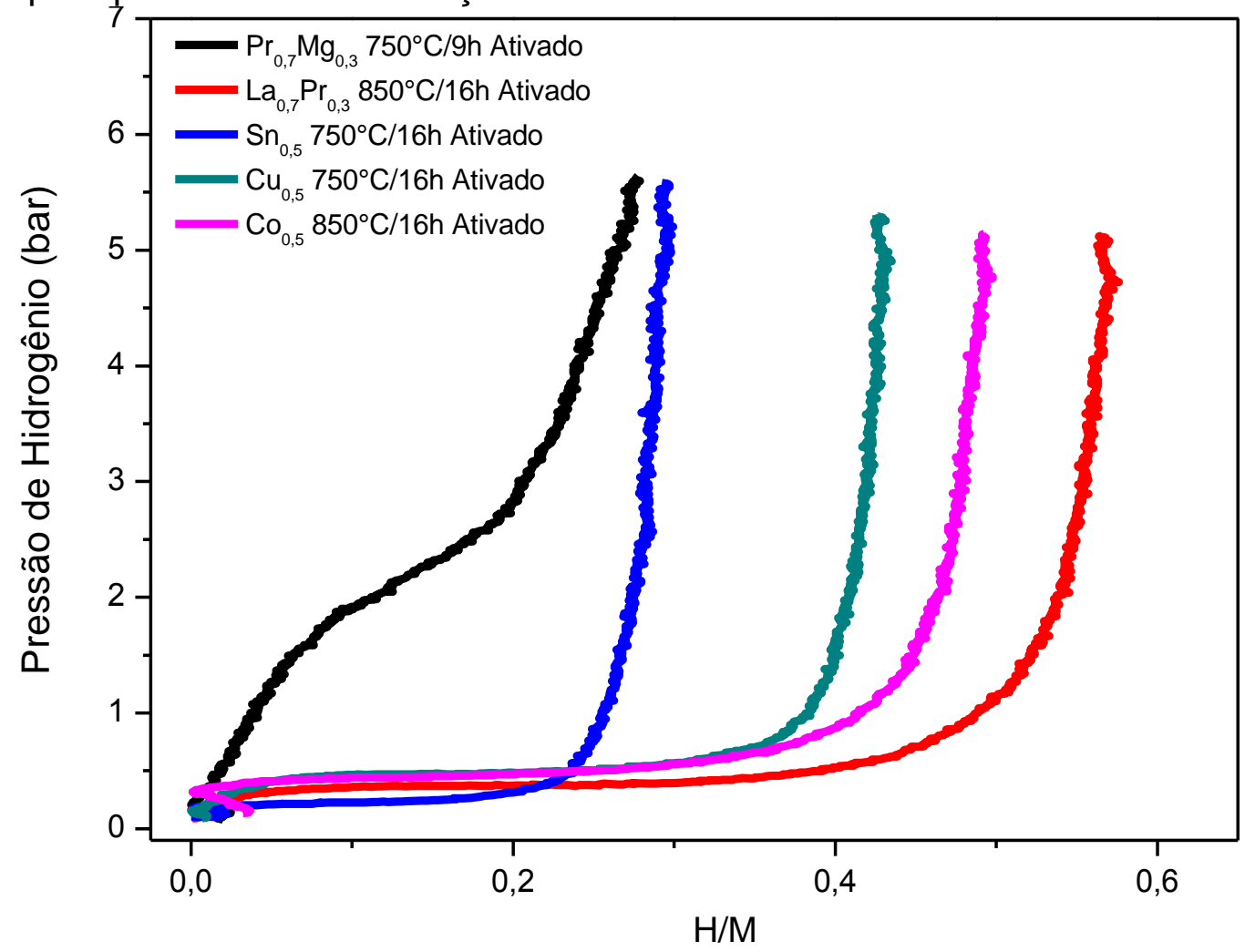

Relação entre analise de PCT mostrado na FIGURA 50, as ligas com TT para melhores resultados obtidos nos testes eletroquímicos, ou seja, os maiores valores de capacidade de descarga nas baterias, na secção 5.3 estão apresentados na TABELA 48.

Observando os resultados da TABELA 48 comparando com os valores da TABELA 46 observamos uma diminuição da capacidade de descarga de todas as ligas o que sugere que o material se deteriora mais rapidamente na presença das ativações o que foi mencionado por CASINI 2015, onde foi avaliado o desempenho eletroquímico das baterias fabricadas com as ligas usadas para o material ativo do eletrodo negativo e suas ativações ocorreram quase que instantaneamente, atingindo as suas capacidades máximas de descarga mais rapidamente, mas por outro lado depois de atingirem a capacidade máxima de descarga o desempenho das características das ligas não foi bom, pois tiveram sua queda quase que vertiginosa logo em seguida diminuindo muito as suas capacidades de estabilidade cíclica. 
TABELA 47 - Resultados obtidos das curvas de absorção do PCT das ligas $\mathrm{La}_{0,7} \mathrm{Mg}_{0,3} \mathrm{Al}_{0,3} \mathrm{Mn}_{0,4} \mathrm{Co}_{0,5} \mathrm{Ni}_{3,8} \quad 850^{\circ} / 16 \mathrm{~h}, \quad \mathrm{La}_{0,7} \mathrm{Mg}_{0,3} \mathrm{Al}_{0,3} \mathrm{Mn}_{0,4} \mathrm{Cu}_{0,5} \mathrm{Ni}_{3,8}, 750^{\circ} \mathrm{C} / 16$ $\mathrm{La}_{0,7} \mathrm{Mg}_{0,3} \mathrm{Al}_{0,3} \mathrm{Mn}_{0,4} \mathrm{Sn}_{0,5} \mathrm{Ni}_{3,8} 750^{\circ} \mathrm{C} / 16 \mathrm{~h}, \mathrm{La}_{0,7} \mathrm{Pr}_{0,3} \mathrm{Al}_{0,3} \mathrm{Mn}_{0,4} \mathrm{Co}_{0,5} \mathrm{Ni}_{3,8} 850^{\circ} \mathrm{C} / 16 \mathrm{~h}$ e $\operatorname{Pr}_{0,7} \mathrm{Mg}_{0,3} \mathrm{Al}_{0,3} \mathrm{Mn}_{0,4} \mathrm{Co}_{0,5} \mathrm{Ni}_{3,8} 750^{\circ} \mathrm{C} / 9 \mathrm{~h}$ com 4 ciclos de ativação.

\begin{tabular}{|c|c|c|c|c|}
\hline Amostra & Fase & $\begin{array}{c}<\phi_{\text {abs }}> \pm \sigma<\phi_{\text {abs }}> \\
\left(\mathrm{cm}^{3} / \mathrm{min} . \mathbf{g}\right)\end{array}$ & $\mathrm{H} / \mathrm{M} \pm 0,014$ & $\begin{array}{c}\mathrm{H} \pm 0,022 \\
(\% \text { em massa })\end{array}$ \\
\hline $\mathrm{Co}_{0,5} 850 / 16 \mathrm{~h}_{\text {ativ. }}$ & $\alpha$ & $0,06 \pm 0,08$ & 0,005 & 0,006 \\
\hline $\mathrm{Co}_{0,5} 850 / 16 \mathrm{~h}_{\text {ativ. }}$ & $\beta+\alpha$ & $2,20 \pm 0,07$ & 0,489 & 0,789 \\
\hline $\mathrm{Co}_{0,5} 850 / 16 \mathrm{~h}_{\text {ativ. }}$ & $\beta$ & $0,083 \pm 0,015$ & 0,032 & 0,019 \\
\hline Total & & $0,504 \pm 0,0101$ & 0,526 & 0,815 \\
\hline $\mathrm{Cu}_{0,5} 750 / 16 \mathrm{~h}_{\text {ativ }}$ & $\alpha$ & $0,06 \pm 0,08$ & 0,010 & 0,011 \\
\hline $\mathrm{Cu}_{0,5} 750 / 16 \mathrm{~h}_{\text {ativ }}$ & $\beta+\alpha$ & $2,54 \pm 0,09$ & 0,389 & 0,627 \\
\hline $\mathrm{Cu}_{0,5} 750 / 16 \mathrm{~h}_{\text {ativ }}$ & $\beta$ & $0,043 \pm 0,015$ & 0,026 & 0,018 \\
\hline Total & & $0,387 \pm 0,011$ & 0,425 & 0,656 \\
\hline $\mathrm{Sn}_{0,5} 750 / 16 \mathrm{~h}_{\text {ativ }}$ & $\alpha$ & $0,03 \pm 0,15$ & 0,005 & 0,007 \\
\hline $\mathrm{Sn}_{0,5} 750 / 16 \mathrm{~h}_{\text {ativ }}$ & $\beta+\alpha$ & $6,51 \pm 0,25$ & 0,302 & 0,476 \\
\hline $\mathrm{Sn}_{0,5} 750 / 16 \mathrm{~h}_{\text {ativ }}$ & $\beta$ & $0,032 \pm 0,012$ & 0,034 & 0,011 \\
\hline Total & & $0,335 \pm 0,012$ & 0,341 & 0,492 \\
\hline LaPr $850 / 16 h_{\text {ativ. }}$ & $\alpha$ & $0,03 \pm 0,06$ & 0,007 & 0,008 \\
\hline LaPr $850 / 16 h_{\text {ativ.. }}$ & $\beta+\alpha$ & $2,91 \pm 0,09$ & 0,543 & 0,797 \\
\hline LaPr $850 / 16 h_{\text {ativ.. }}$ & $\beta$ & $0,027 \pm 0,014$ & 0,030 & 0,015 \\
\hline Total & & $0,456 \pm 0,011$ & 0,580 & 0,820 \\
\hline $\operatorname{PrMg} 750 / 9 \mathrm{~h}_{\text {ativ. }}$ & $\alpha$ & $0,03 \pm 0,15$ & 0,005 & 0,006 \\
\hline PrMg 750/9h ativ. & $\beta+\alpha$ & $7,53 \pm 0,28$ & 0,303 & 0,422 \\
\hline PrMg 750/9h ativ. & $\beta$ & $0,052 \pm 0,013$ & 0,018 & 0,042 \\
\hline Total & & $0,312 \pm 0,010$ & 0,326 & 0,470 \\
\hline
\end{tabular}

TABELA 48 - Determinação da $\mathrm{C}_{\max }$ calculada a partir dos dados obtidos através da analise de PCT após os 4 ciclos de ativações, com as ligas com tratamento térmico.

\begin{tabular}{lcccc}
\hline Liga & $\mathbf{H} / \mathbf{M}$ & $\begin{array}{c}\mathbf{\eta} \\
(\mathbf{H ~ u . f})\end{array}$ & $\begin{array}{c}\mathbf{M}_{\mathbf{w}} \\
(\mathbf{g} / \mathbf{m o l})\end{array}$ & $\begin{array}{c}\mathbf{C}_{\text {máx. calc. }} \\
\text { (mAh) }\end{array}$ \\
\hline $\mathrm{Co}_{0,5} 850 / 16 \mathrm{~h}_{\text {ativ. }}$ & 0,526 & 3,16 & 387,1 & 218,5 \\
$\mathrm{Cu}_{0,5} 750 / 16 \mathrm{~h}_{\text {ativ }}$ & 0,425 & 2,55 & 389,4 & 175,5 \\
$\mathrm{Sn}_{0,5} 750 / 16 \mathrm{~h}_{\text {ativ }}$ & 0,341 & 2,04 & 416,98 & 131,5 \\
$\mathrm{LaPr} 850 / 16 \mathrm{~h}_{\text {ativ }}$ & 0,580 & 3,48 & 422,1 & 221,0 \\
$\mathrm{PrMg} \mathrm{750/9h_{ \text {ativ } }}$ & 0,326 & 1,96 & 388,5 & 134,9 \\
\hline
\end{tabular}




\section{6 - Curvas de absorção e caracterização da morfologia das partículas das ligas sem e com TT fragilizadas por hidrogênio.}

Para verificar o efeito das substituições parciais do Ni pelos elementos $\mathrm{Co}$, $\mathrm{Cu}$, e $\mathrm{Sn}$ na parte $\mathrm{B}$ e do $\mathrm{La}$ e $\mathrm{Mg}$ por $\mathrm{Pr}$ na parte $\mathrm{A}$ ligas armazenadoras de hidrogênio do tipo $A B_{5},\left(\mathrm{La}_{0,7} \mathrm{Mg}_{0,3} \mathrm{Al}_{0,3} \mathrm{Mn}_{0,4} \mathrm{Co}_{0,5} \mathrm{Ni}_{3,8}, \mathrm{La}_{0,7} \mathrm{Mg}_{0,3} \mathrm{Al}_{0,3} \mathrm{Mn}_{0,4} \mathrm{Cu}_{0,5} \mathrm{Ni}_{3,8}\right.$, $\mathrm{La}_{0,7} \mathrm{Mg}_{0,3} \mathrm{Al}_{0,3} \mathrm{Mn}_{0,4} \mathrm{Sn}_{0,5} \mathrm{Ni}_{3,8}$, $\mathrm{La}_{0,7} \mathrm{Pr}_{0,3} \mathrm{Al}_{0,3} \mathrm{Mn}_{0,4} \mathrm{Co}_{0,5} \mathrm{Ni}_{3,8}$ e $\operatorname{Pr}_{0,7} \mathrm{Mg}_{0,3} \mathrm{Al}_{0,3} \mathrm{Mn}_{0,4} \mathrm{Co}_{0,5} \mathrm{Ni}_{3,8}$ ) sem e com tratamento térmico foram expostas a um ciclo de ativação nas pressões pré-determinadas de 2, 4, 6 e 9 bar de hidrogênio por 60 minutos, para avaliar a morfologia das partículas após fragilização por hidrogênio. $A$ capacidade de absorção de hidrogênio por uma liga do tipo $A B_{5}$ também foi estudada por Sandrock (1999) e Schlapbach (2001).

Observou-se que para todas as substituições ocorreram absorções, revelando um aspecto frágil na microestrutura do material analisado. (Yang, et al., 2000; Yang, et al., 2006, Prior, et al., 2013; Li et al 2009).

Somente a liga com a substituição do La pelo $\operatorname{Pr}$ não obedeceu este comportamento de fragilização, mas mesmo sem pulverizar foi observado um aspecto de absorção do material. 
5.6.1 - Curvas de absorção de hidrogênio e micrografias da liga $\mathrm{La}_{0,7} \mathrm{Mg}_{0,3} \mathrm{Al}_{0,3} \mathrm{Mn}_{0,4} \mathrm{Co}_{0,5} \mathrm{Ni}_{3,8}$ sem TT

$\mathrm{Na}$ FIGURA 51 estão mostradas as curvas de absorção pela liga $\mathrm{La}_{0,7} \mathrm{Mg}_{0,3} \mathrm{Al}_{0,3} \mathrm{Mn}_{0,4} \mathrm{Co}_{0,5} \mathrm{Ni}_{3,8}$ sem TT com variação da pressão de hidrogênio. $\mathrm{Na}$ FIGURA 52, de (a) até (e) estão mostradas as micrografias da liga sendo: (a) bruta de fusão em pedaços dimensionados de 5 a $10 \mathrm{~mm}$, e após a fragilização por hidrogênio (micrografias, aumento 500x), (b) pressão de hidrogênio de 2000 mbar, (c) pressão de hidrogênio de 4000 mbar, (d) pressão de hidrogênio de 6000 mbar e (e) com pressão de hidrogênio de 9000 mbar.

A liga fragiliza, tanto à baixa pressão (2000 bar) como a alta pressão (9000 mbar) de hidrogênio, da mesma maneira. Após absorção de hidrogênio pelas fases presentes na microestrutura, defeitos intersticiais e estruturais da liga, as partículas se desprendem em escamas na superfície da liga, que são facilmente cominuídas manualmente. E mantém um aspecto morfológico para todas as pressões utilizadas na fragilização da liga.

FIGURA 51 - Curvas de absorção de hidrogênio pela liga $\mathrm{La}_{0,7} \mathrm{Mg}_{0,3} \mathrm{Al}_{0,3} \mathrm{Mn}_{0,4} \mathrm{Co}_{0,5} \mathrm{Ni}_{3,8}$ sem TT na pressão de 2, 4, 6 e 9 bar de hidrogênio por 60 min.

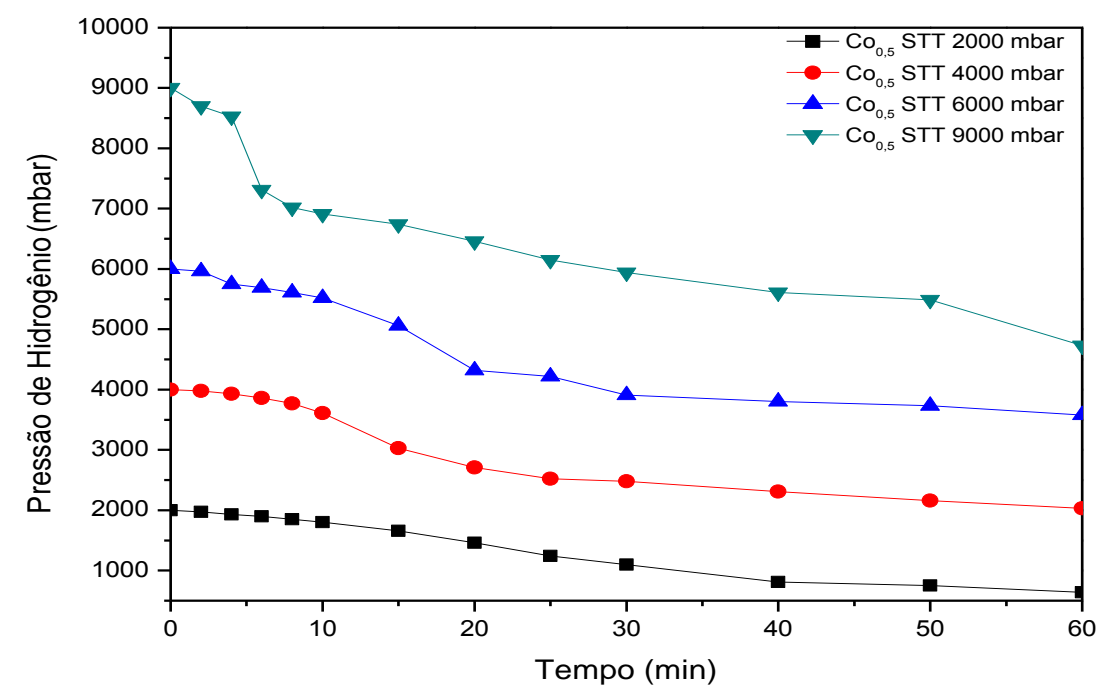


FIGURA 52 - (a) Micrografia da liga $\mathrm{La}_{0,7} \mathrm{Mg}_{0,3} \mathrm{Al}_{0,3} \mathrm{Mn}_{0,4} \mathrm{Co}_{0,5} \mathrm{Ni}_{3,8}$ bruta de fusão e (b) a (e) micrografias (500x) da liga fragilizada com pressão de 2, 4, 6 e 9 bar de hidrogênio por 60 minutos, respectivamente.

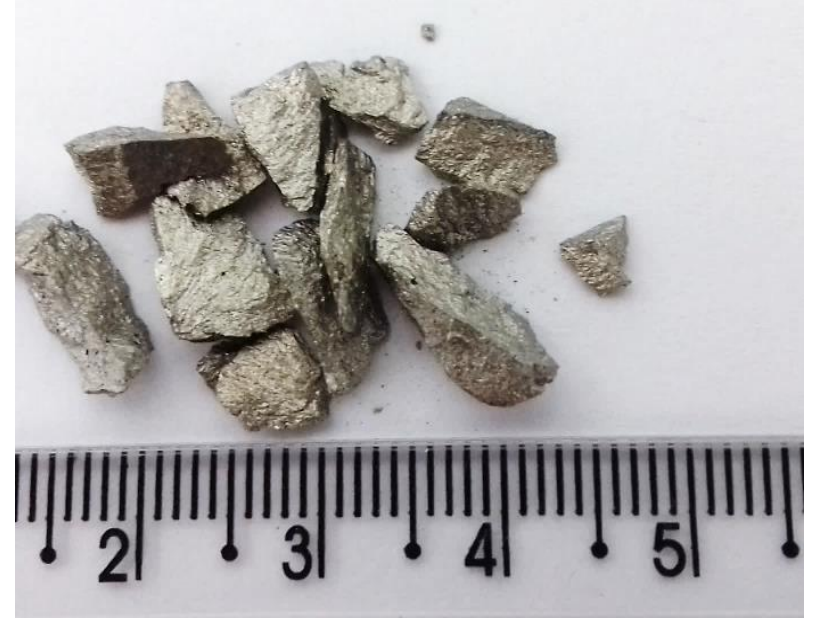

a)

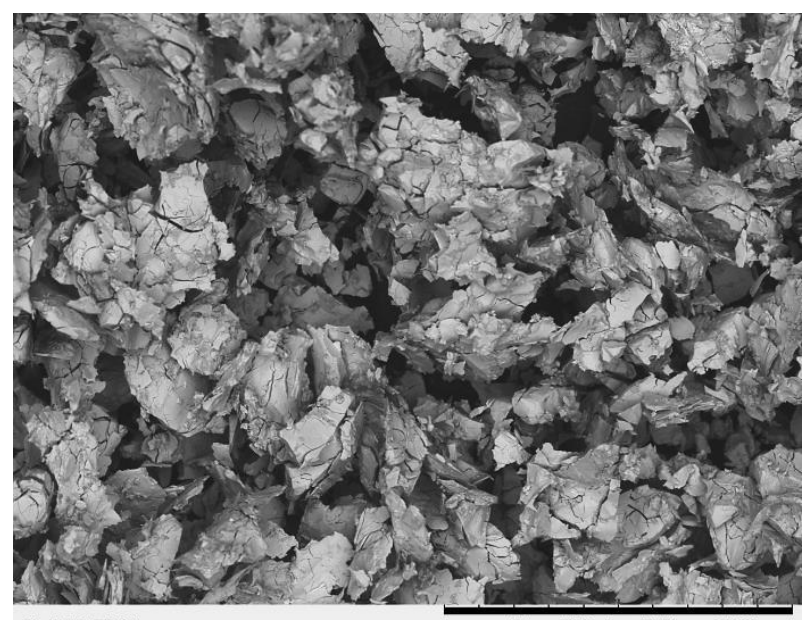

Co05STT2ba

b)

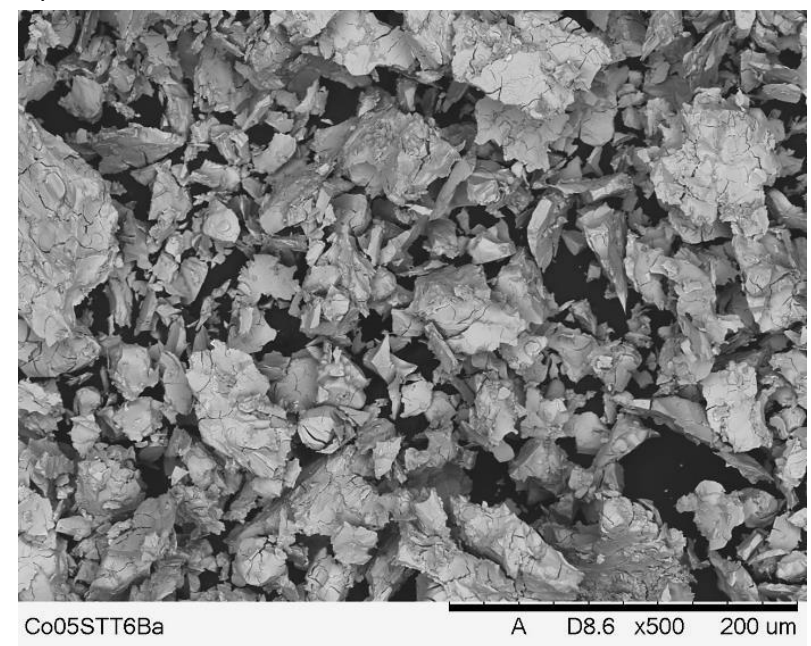

d)

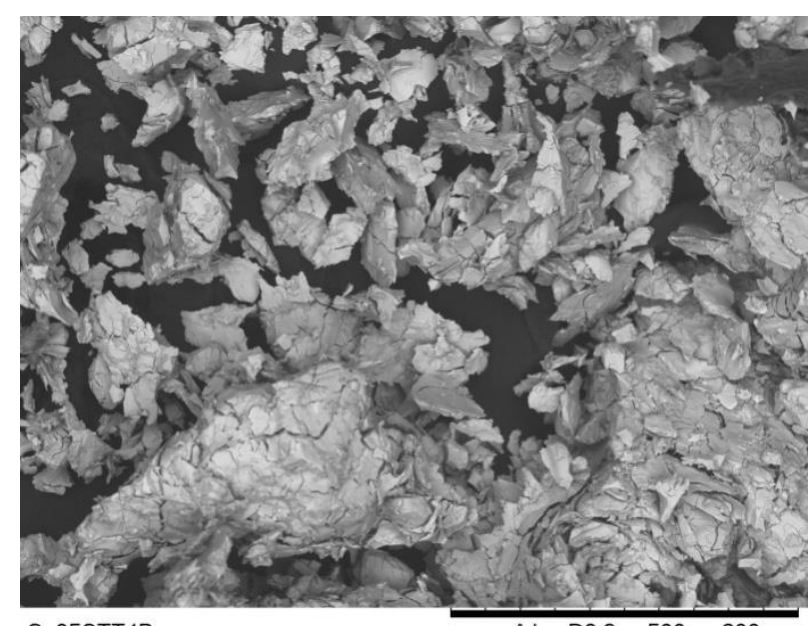

Co05STT4Ba

AL $\quad$ D9.3 $\times 500 \quad 200$ um

c)

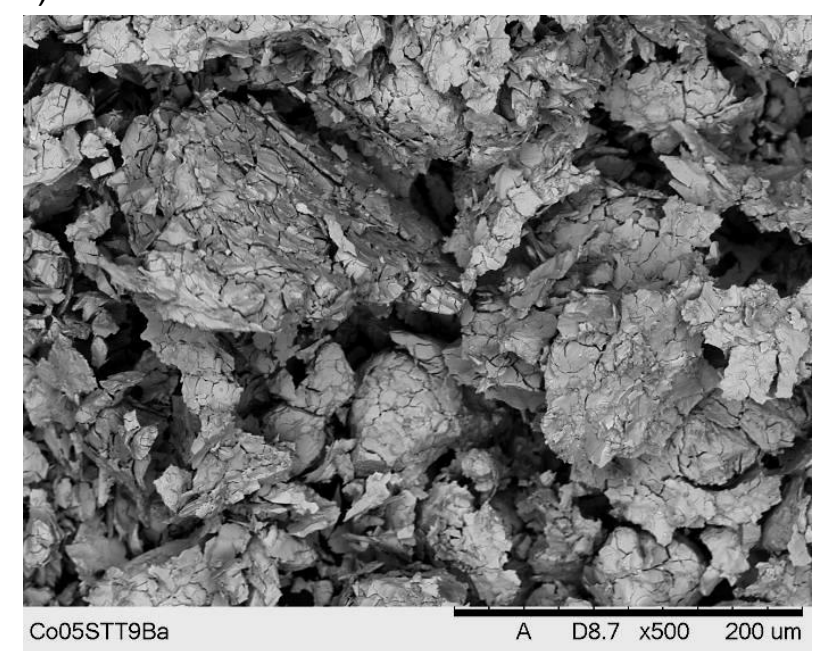

e) 
A liga $\mathrm{La}_{0,7} \mathrm{Mg}_{0,3} \mathrm{Al}_{0,3} \mathrm{Mn}_{0,4} \mathrm{Co}_{0,5} \mathrm{Ni}_{3,8}$ sem TT, fragiliza tanto a baixa pressão (2000 bar) como a alta pressão (9000 mbar) de hidrogênio, com a mesma intensidade diferenciando na quantidade de hidrogênio absorvido, sendo maior para pressões elevadas. Após absorção de hidrogênio pelas fases, interstícios e defeitos estruturais da liga, partículas se desprendem em escamas na superfície da liga, que são facilmente cominuídas manualmente. As partículas mantêm a mesma morfologia para todas as pressões utilizadas na fragilização da liga.

\subsection{2 - Curvas de absorção de hidrogênio e micrografias da liga $\mathrm{La}_{0,7} \mathrm{Mg}_{0,3} \mathrm{Al}_{0,3} \mathrm{Mn}_{0,4} \mathrm{Co}_{0,5} \mathrm{Ni}_{3,8} \mathrm{TT}$ de $750^{\circ} \mathrm{C}$ por 9 horas}

Na FIGURA 53 estão mostradas as curvas de absorção de hidrogênio pela liga $\mathrm{La}_{0,7} \mathrm{Mg}_{0,3} \mathrm{Al}_{0,3} \mathrm{Mn}_{0,4} \mathrm{Co}_{0,5} \mathrm{Ni}_{3,8}$ com TT de $750^{\circ} \mathrm{C}$ por 9 horas e na FIGURA 54 de (a) até (d) estão apresentadas as micrografias (500x), obtidas por MEV da liga após fragilização sendo: (a) pressão de hidrogênio de 2000 mbar, (b) pressão de hidrogênio de 4000 mbar, (c) pressão de hidrogênio de 6000 mbar e (d) com pressão de hidrogênio de 9000 mbar. Comparando com o gráfico de absorção de hidrogênio com a liga sem TT, apresentada no gráfico da FIGURA 51, a absorção foi inferior para a liga após TT em todas as pressões de hidrogênio, provavelmente pela eliminação dos defeitos estruturais existentes na liga bruta de fusão sendo, portanto, a absorção de hidrogênio promovida preferencialmente pelas fases absorvedoras de hidrogênio da liga. As ligas foram fragilizadas como a liga sem TT. Quanto ao aspecto morfológico das partículas, são todas semelhantes após absorção final da liga. 
FIGURA 53 - Curvas de absorção da liga $\mathrm{La}_{0,7} \mathrm{Mg}_{0,3} \mathrm{Al}_{0,3} \mathrm{Mn}_{0,4} \mathrm{Co}_{0,5} \mathrm{Ni}_{3,8}$ com TT de $750^{\circ} \mathrm{C}$ por 9 horas com pressão de 2, 4, 6 e 9 bar de hidrogênio por 60 minutos

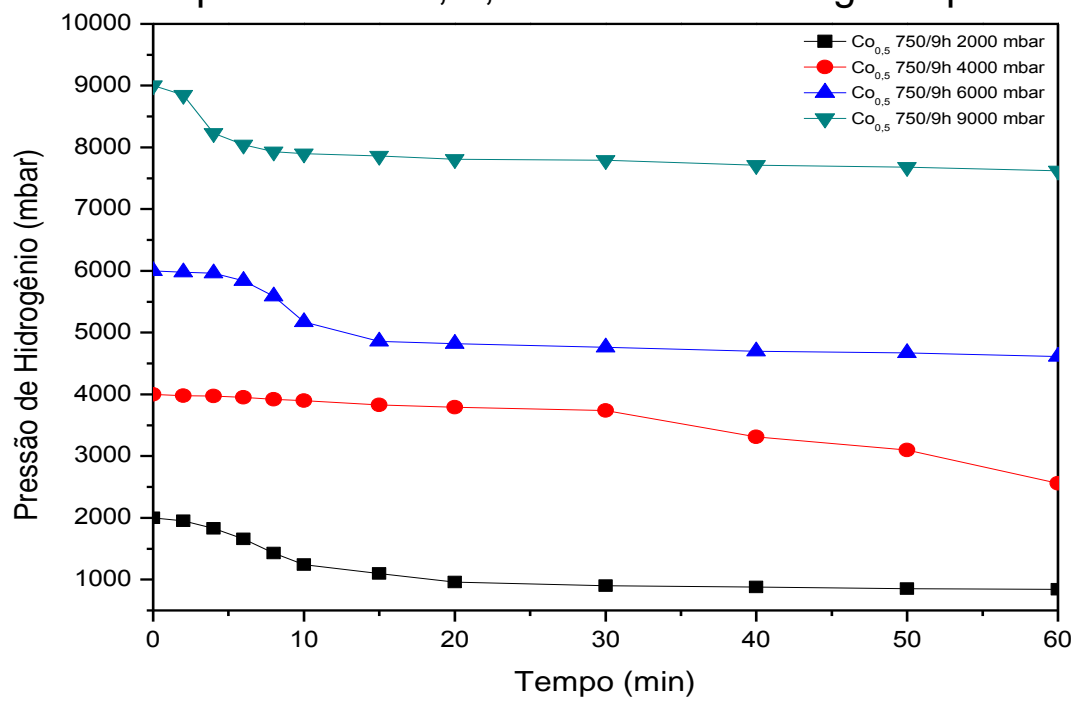

FIGURA 54 - Micrografias (500x) da liga $\mathrm{La}_{0,7} \mathrm{Mg}_{0,3} \mathrm{Al}_{0,3} \mathrm{Mn}_{0,4} \mathrm{Co}_{0,5} \mathrm{Ni}_{3,8}$ com TT de $750^{\circ} \mathrm{C}$ por 9 horas fragilizada na pressão de 2, 4, 6 e 9 bar de hidrogênio por 60 min.
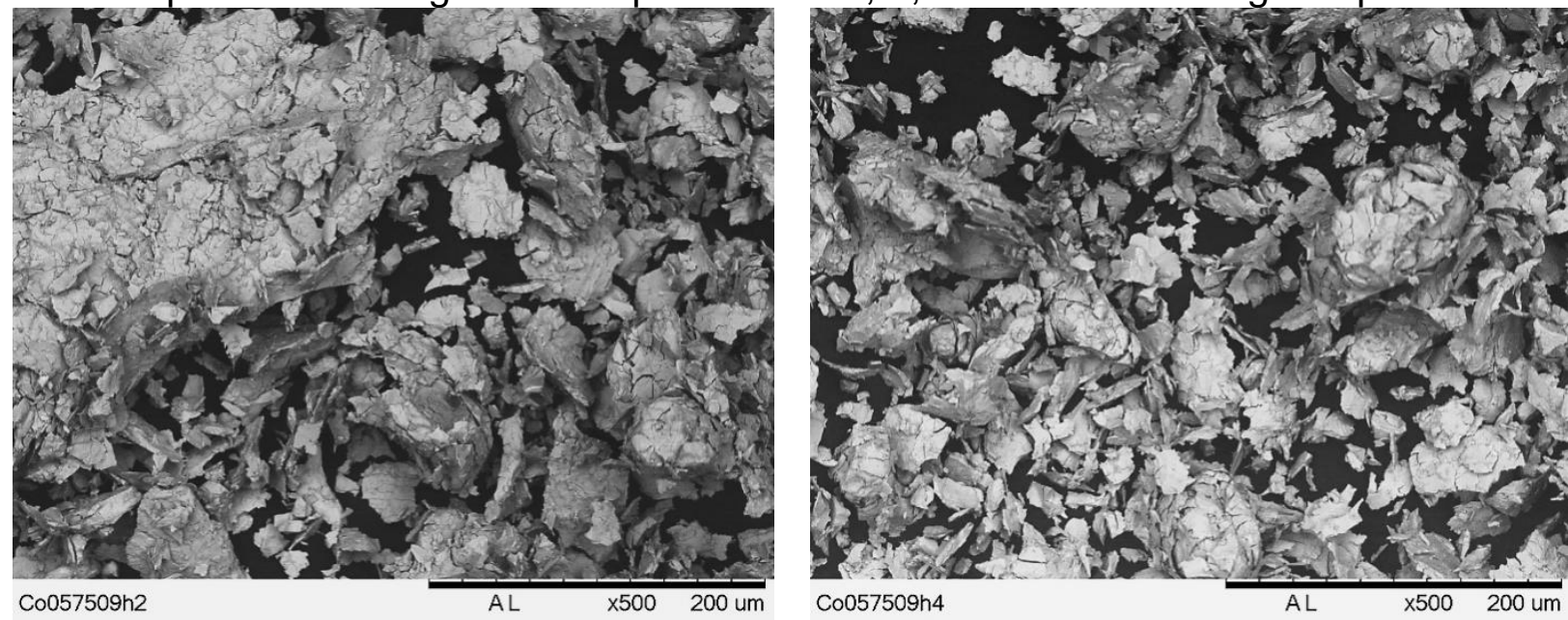

a)

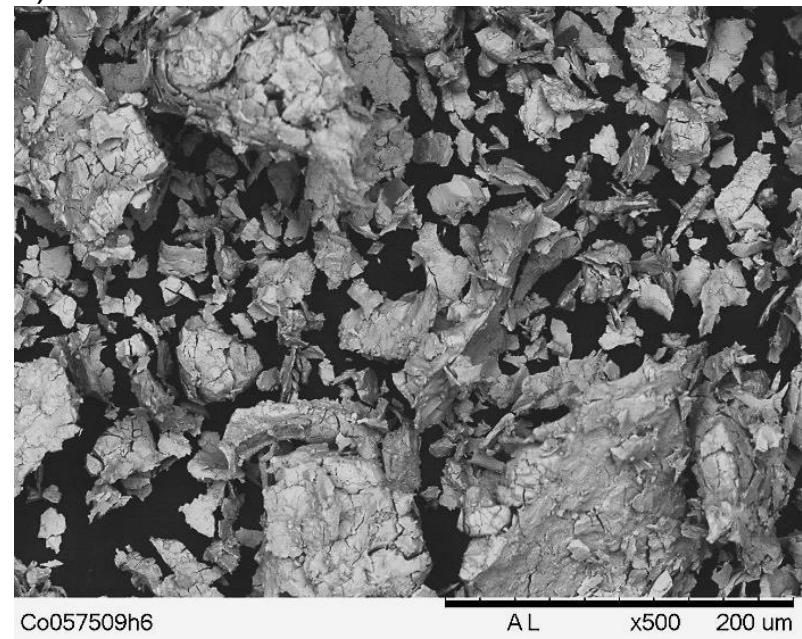

b)

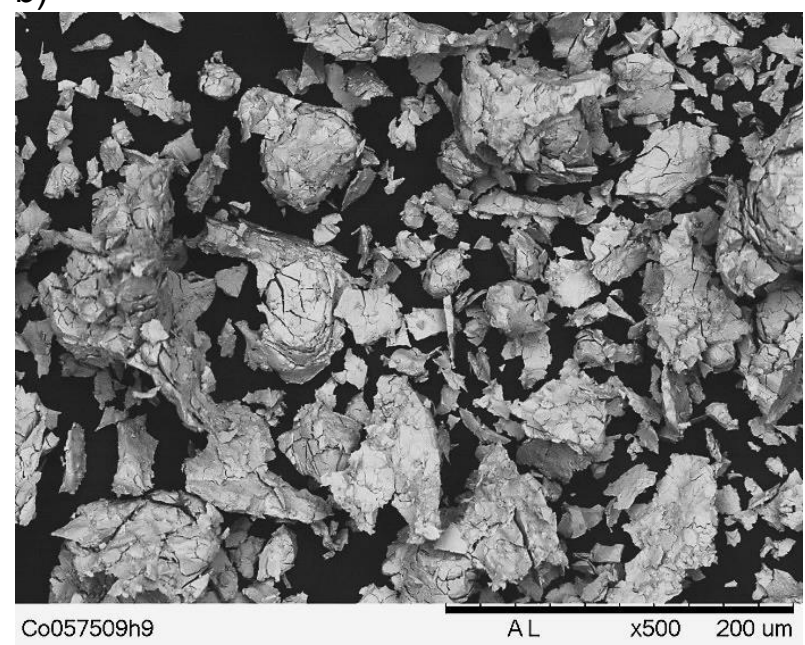

c)

d) 
5.6.3 - Curvas de absorção de hidrogênio e micrografias da liga $\mathrm{La}_{0,7} \mathrm{Mg}_{0,3} \mathrm{Al}_{0,3} \mathrm{Mn}_{0,4} \mathrm{Co}_{0,5} \mathrm{Ni}_{3,8} \mathrm{TT}$ de $750^{\circ} \mathrm{C}$ por 16 horas

Na FIGURA 55 estão mostradas as curvas de absorção de hidrogênio pela liga $\mathrm{La}_{0,7} \mathrm{Mg}_{0,3} \mathrm{Al}_{0,3} \mathrm{Mn}_{0,4} \mathrm{Co}_{0,5} \mathrm{Ni}_{3,8}$ com TT de $750^{\circ} \mathrm{C}$ por 16 horas e na FIGURA 56 de (a) até (d) estão apresentadas as micrografias (500x), obtidas por MEV da liga após fragilização sendo: (a) pressão de hidrogênio de 2000 mbar, (b) pressão de hidrogênio de 4000 mbar, (c) pressão de hidrogênio de 6000 mbar e (d) com pressão de hidrogênio de 9000 mbar.

A morfologia das partículas não foi alterada também para esta liga neste TT.

FIGURA 55 - Curvas de absorção de hidrogênio pela liga $\mathrm{La}_{0,7} \mathrm{Mg}_{0,3} \mathrm{Al}_{0,3} \mathrm{Mn}_{0,4} \mathrm{Co}_{0,5} \mathrm{Ni}_{3,8}$ com TT de $750^{\circ} \mathrm{C}$ por 16 horas, com pressão de 2, 4, 6 e 9 bar de hidrogênio por 60 minutos

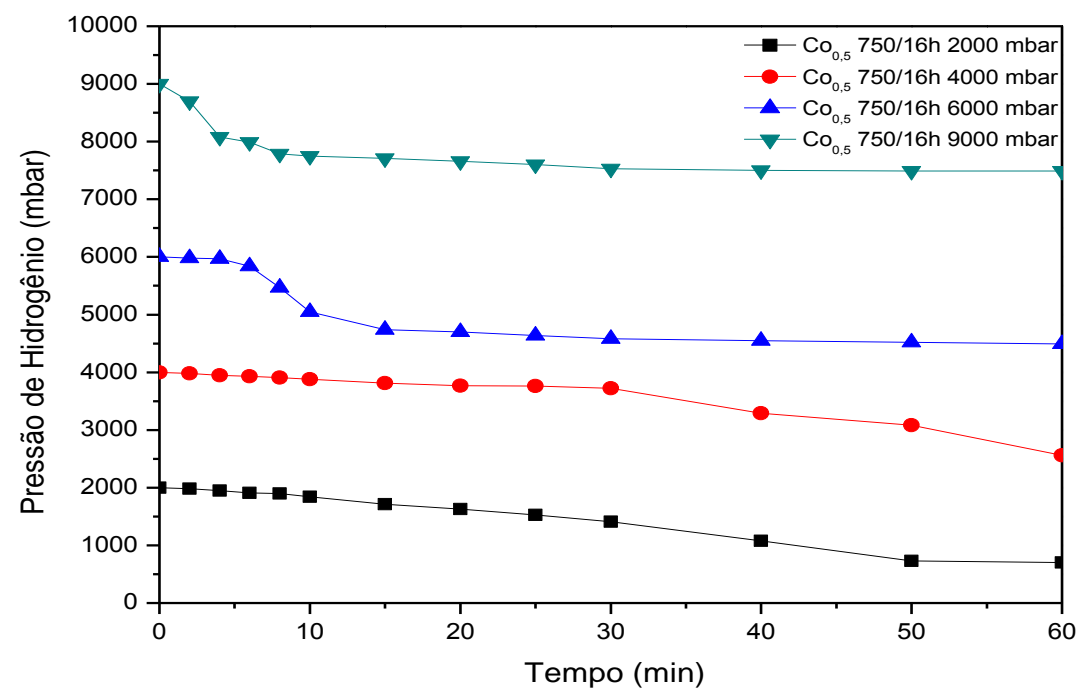


FIGURA 56 - Micrografias (500x) da liga $\mathrm{La}_{0,7} \mathrm{Mg}_{0,3} \mathrm{Al}_{0,3} \mathrm{Mn}_{0,4} \mathrm{Co}_{0,5} \mathrm{Ni}_{3,8}$ com TT de $750^{\circ} \mathrm{C}$ por 16 horas fragilizada na pressão de 2, 46 e 9 bar de hidrogênio por 60 min
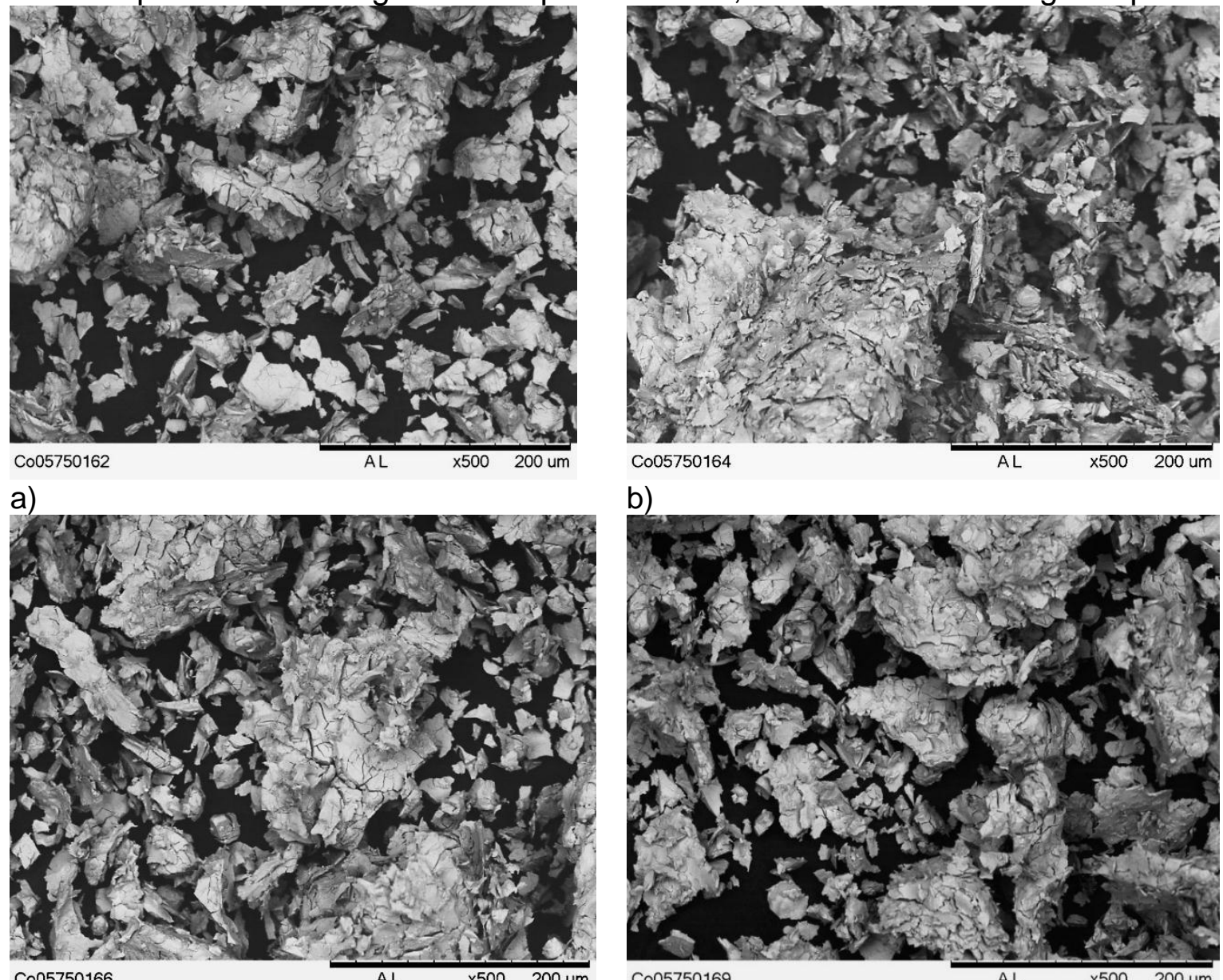

c)

b)

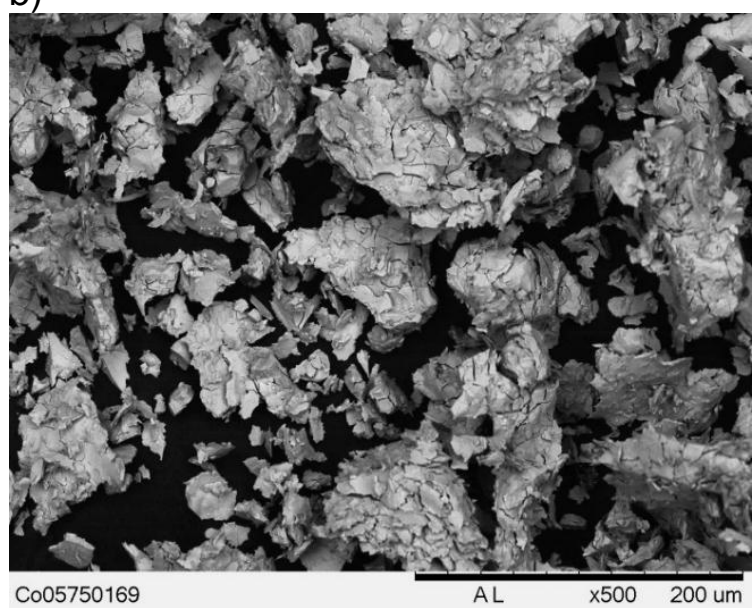

d)

5.6.4 - Curvas de absorção de hidrogênio e micrografias da liga $\mathrm{La}_{0,7} \mathrm{Mg}_{0,3} \mathrm{Al}_{0,3} \mathrm{Mn}_{0,4} \mathrm{Co}_{0,5} \mathrm{Ni}_{3,8}$ com TT de $850^{\circ} \mathrm{C}$ por 9 horas

Na FIGURA 57 estão mostradas as curvas de absorção de hidrogênio pela liga $\mathrm{La}_{0,7} \mathrm{Mg}_{0,3} \mathrm{Al}_{0,3} \mathrm{Mn}_{0,4} \mathrm{Co}_{0,5} \mathrm{Ni}_{3,8}$ com TT de $850^{\circ} \mathrm{C}$ por 9 horas e na FIGURA 58 de (a) até (d) estão apresentadas as micrografias (500x), obtidas por MEV da liga após fragilização sendo: (a) pressão de hidrogênio de 2000 mbar, (b) pressão de hidrogênio de 4000 mbar, (c) pressão de hidrogênio de 6000 mbar e (d) com pressão de hidrogênio de 9000 mbar. A morfologia das partículas também não foi alterada para esta liga. 
FIGURA 57 - Curvas de absorção de hidrogênio pela liga $\mathrm{La}_{0,7} \mathrm{Mg}_{0,3} \mathrm{Al}_{0,3} \mathrm{Mn}_{0,4} \mathrm{Co}_{0,5} \mathrm{Ni}_{3,8}$ com TT de $850^{\circ} \mathrm{C}$ por 9 horas com pressão de 2, 4, 6 e 9 bar de hidrogênio por 60 minutos.

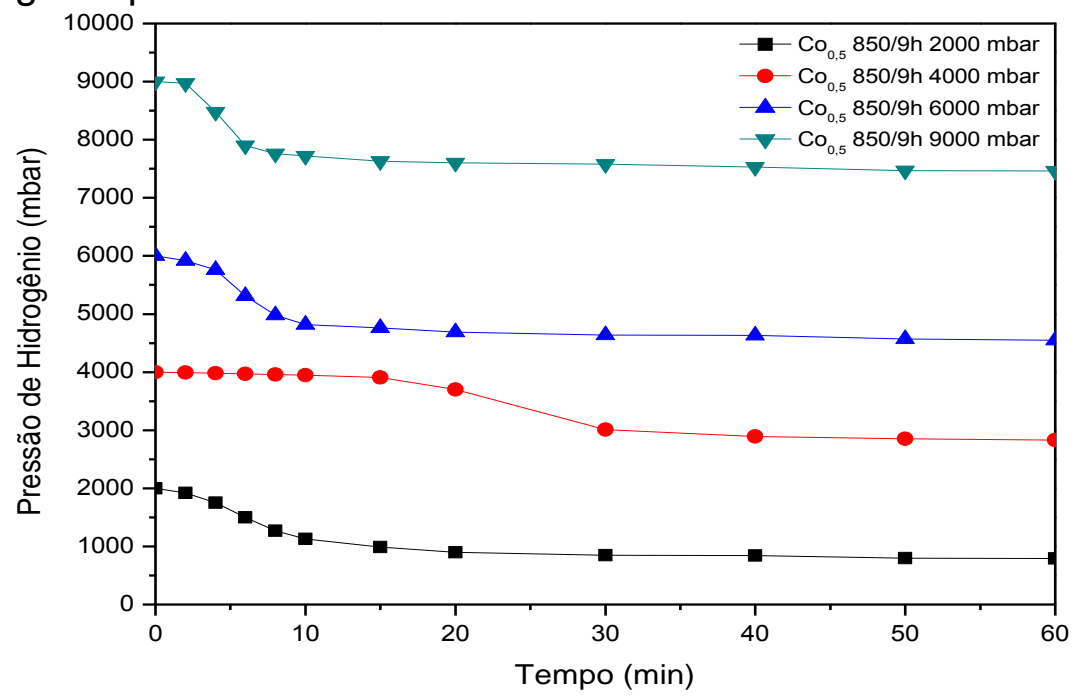

FIGURA 58 - Micrografias (500x) da liga $\mathrm{La}_{0,7} \mathrm{Mg}_{0,3} \mathrm{Al}_{0,3} \mathrm{Mn}_{0,4} \mathrm{Co}_{0,5} \mathrm{Ni}_{3,8}$ com TT de $850^{\circ} \mathrm{C}$ por 9 horas fragilizada na pressão de 2, 46 e 9 bar de hidrogênio por 60 min.
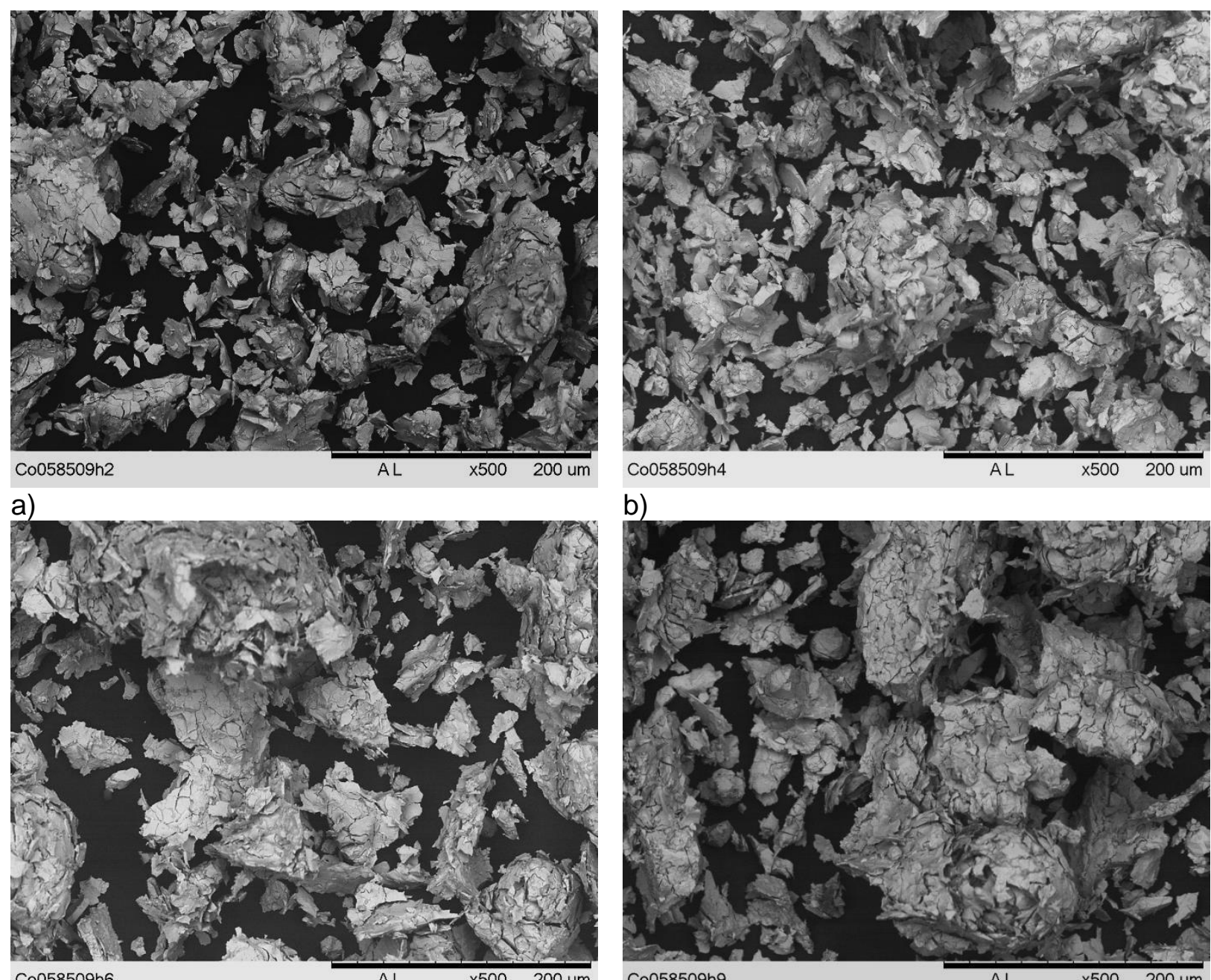

c)

b)

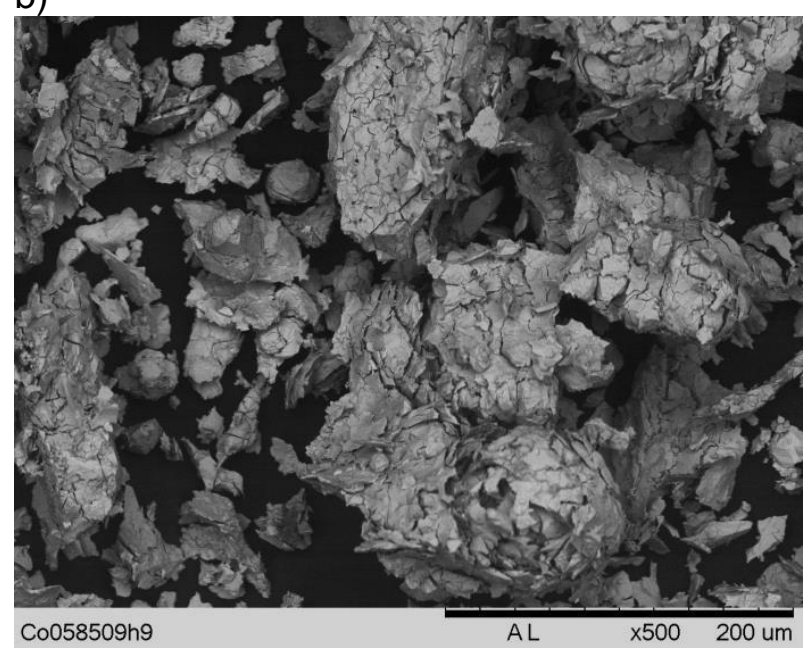

d) 
5.6.5 - Curvas de absorção de hidrogênio e micrografias da liga $\mathrm{La}_{0,7} \mathrm{Mg}_{0,3} \mathrm{Al}_{0,3} \mathrm{Mn}_{0,4} \mathrm{Co}_{0,5} \mathrm{Ni}_{3,8}$ com TT de $850^{\circ} \mathrm{C}$ por 16 horas

Na FIGURA 59 estão mostradas as curvas de absorção de hidrogênio pela liga $\mathrm{La}_{0,7} \mathrm{Mg}_{0,3} \mathrm{Al}_{0,3} \mathrm{Mn}_{0,4} \mathrm{Co}_{0,5} \mathrm{Ni}_{3,8}$ com TT de $850^{\circ} \mathrm{C}$ por 16 horas e na FIGURA 60 de (a) até (d) estão apresentadas as micrografias (500x), obtidas por MEV da liga após fragilização sendo: (a) pressão de hidrogênio de 2000 mbar, (b) pressão de hidrogênio de 4000 mbar, (c) pressão de hidrogênio de 6000 mbar e (d) com pressão de hidrogênio de 9000 mbar. A morfologia das partículas também não foi alterada para esta liga.

Comparando as curvas de absorção de hidrogênio da liga com substituição parcial do Ni pelo Co com TT (FIGURAS 53, 55, 57 e 59) com a liga sem TT (FIGURA 51), mostrou uma absorção inferior para a liga após TT em todas as pressões utilizadas de hidrogênio, provavelmente tenha ocorrido pela diminuição dos defeitos estruturais existentes na liga no estado bruto de fusão sendo, portanto, a absorção de hidrogênio promovida preferencialmente pelas fases absorvedoras de hidrogênio presentes na liga. $\mathrm{O}$ aparecimento das fases $\mathrm{AlMn}_{6}$ e $\mathrm{LaCo}_{3}$ após TT não influenciaram na absorção de hidrogênio nesta liga (TABELAS 15 A 17). Para todos os TT realizados na liga, promoveram fragilização na presença de hidrogênio com certa facilidade, assim como a liga sem TT apresentou o mesmo comportamento. Quanto ao aspecto morfológico das partículas, todas mostraram aspectos semelhantes após absorção de hidrogênio pela liga. 
FIGURA 59 - Curvas de absorção de hidrogênio pela liga $\mathrm{La}_{0,7} \mathrm{Mg}_{0,3} \mathrm{Al}_{0,3} \mathrm{Mn}_{0,4} \mathrm{Co}_{0,5} \mathrm{Ni}_{3,8}$ com TT de $850^{\circ} \mathrm{C}$ por 16 horas com pressão de 2, 4, 6 e 9 bar de hidrogênio por 60 minutos

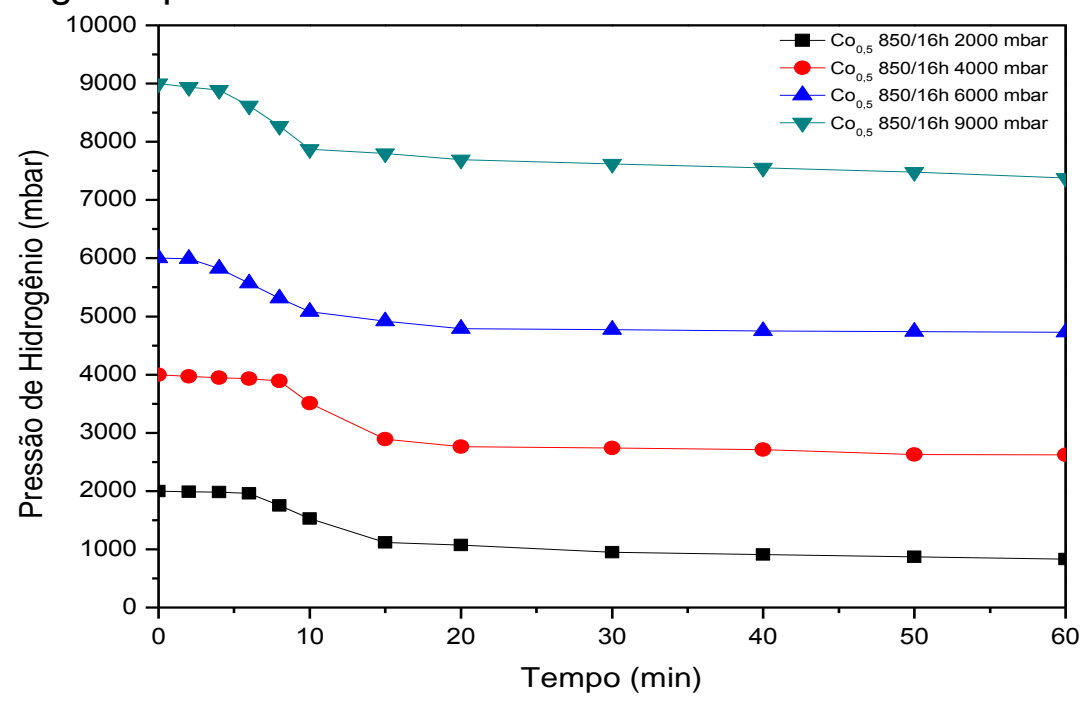

FIGURA 60 - Micrografias (500x) da liga de $\mathrm{La}_{0,7} \mathrm{Mg}_{0,3} \mathrm{Al}_{0,3} \mathrm{Mn}_{0,4} \mathrm{Co}_{0,5} \mathrm{Ni}_{3,8}$ com TT de 850 por 16 horas fragilizada na pressão de 2, 46 e 9 bar de hidrogênio por 60 min.
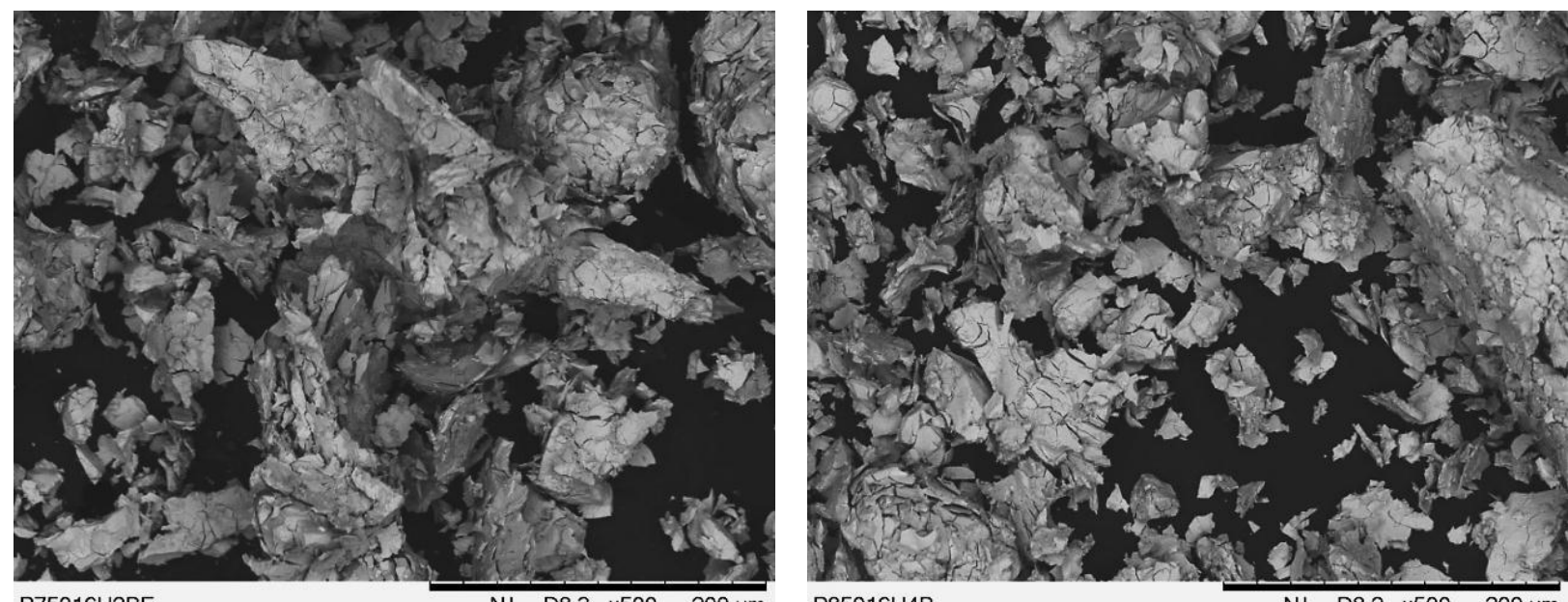

a)

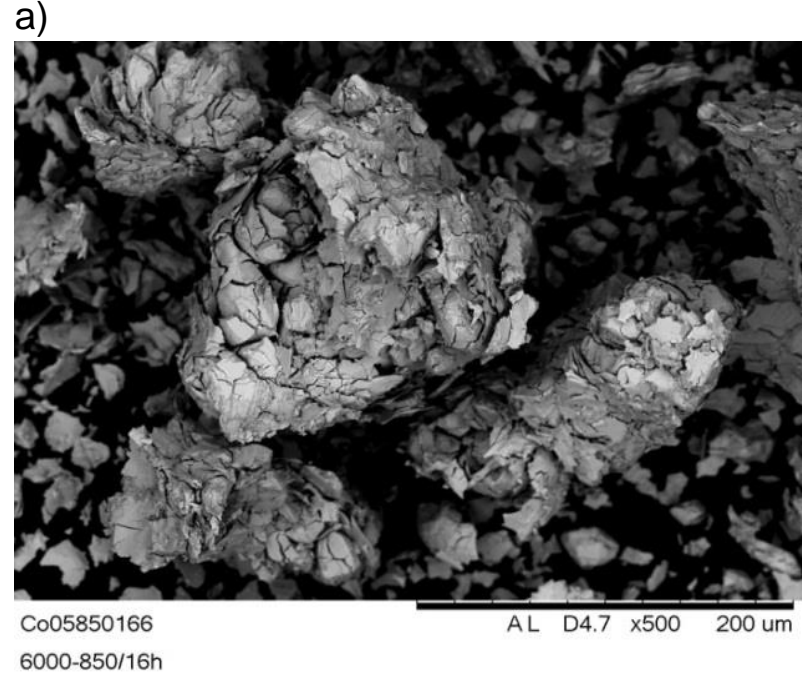

b)

c)

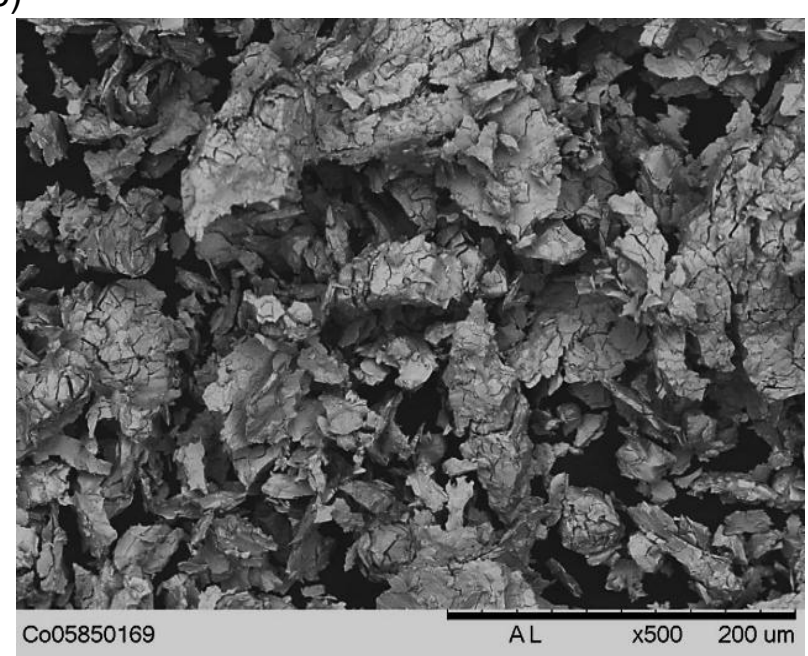

d) 
5.6.6 - Curvas de absorção de hidrogênio e micrografias da liga $\mathrm{La}_{0,7} \mathrm{Mg}_{0,3} \mathrm{Al}_{0,3} \mathrm{Mn}_{0,4} \mathrm{Cu}_{0,5} \mathrm{Ni}_{3,8}$ sem TT

Na FIGURA 61 estão mostradas as curvas de absorção de hidrogênio pela liga $\mathrm{La}_{0,7} \mathrm{Mg}_{0,3} \mathrm{Al}_{0,3} \mathrm{Mn}_{0,4} \mathrm{Cu}_{0,5} \mathrm{Ni}_{3,8}$ sem TT e na FIGURA 62 de (a) até (d) estão apresentadas as micrografias (500x), obtidas por MEV da liga após fragilização sendo: (a) pressão de hidrogênio de 2000 mbar, (b) pressão de hidrogênio de 4000 mbar, (c) pressão de hidrogênio de 6000 mbar e (d) com pressão de hidrogênio de 9000 mbar. O aspecto da morfologia das partículas também não foi alterado para esta liga após absorção de hidrogênio.

FIGURA 61 - Curvas de absorção de hidrogênio pela liga $\mathrm{La}_{0,7} \mathrm{Mg}_{0,3} \mathrm{Al}_{0,3} \mathrm{Mn}_{0,4} \mathrm{Cu}_{0,5} \mathrm{Ni}_{3,8}$ sem TT com pressão de 2, 4, 6 e 9 bar de hidrogênio por 60 minutos.

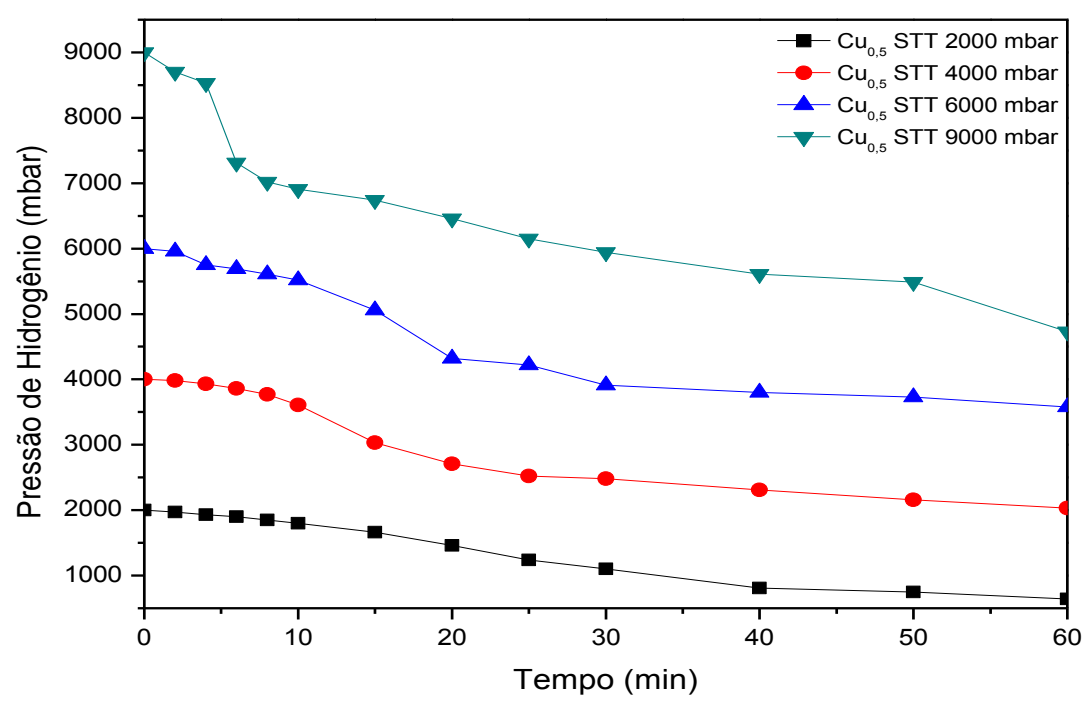


FIGURA 62 - Micrografias (500x) da liga $\mathrm{La}_{0,7} \mathrm{Mg}_{0,3} \mathrm{Al}_{0,3} \mathrm{Mn}_{0,4} \mathrm{Cu}_{0,5} \mathrm{Ni}_{3,8}$ sem TT fragilizada na pressão de 2, 4, 6 e 9 bar de hidrogênio por 60 minutos.

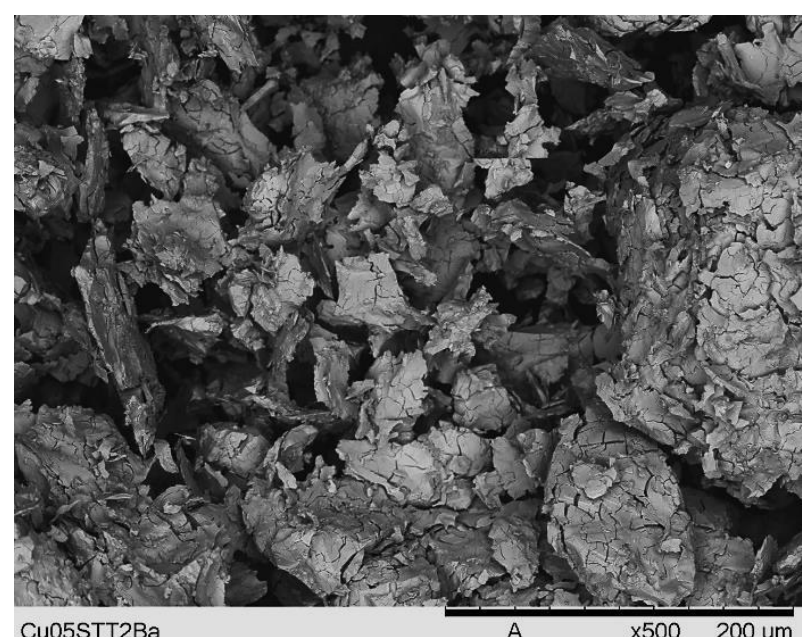

a)

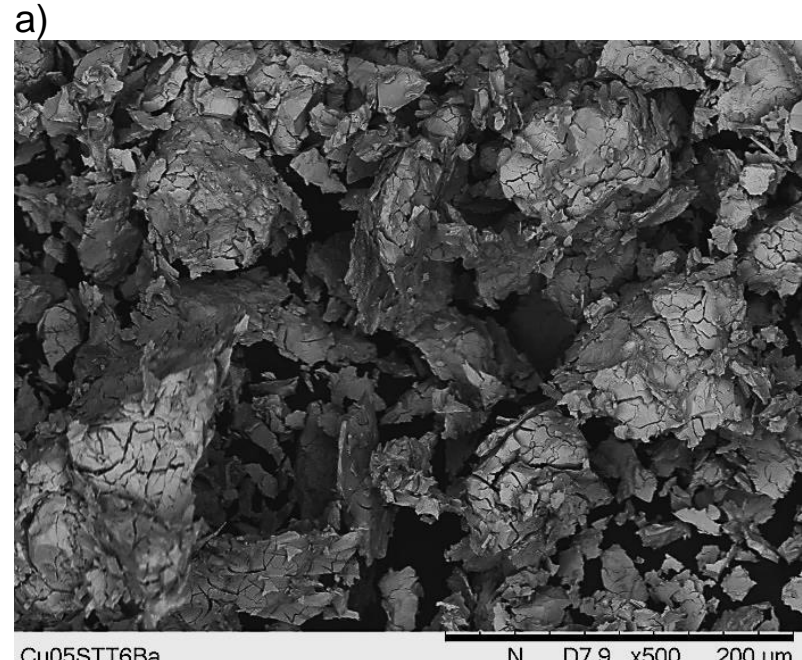

c)

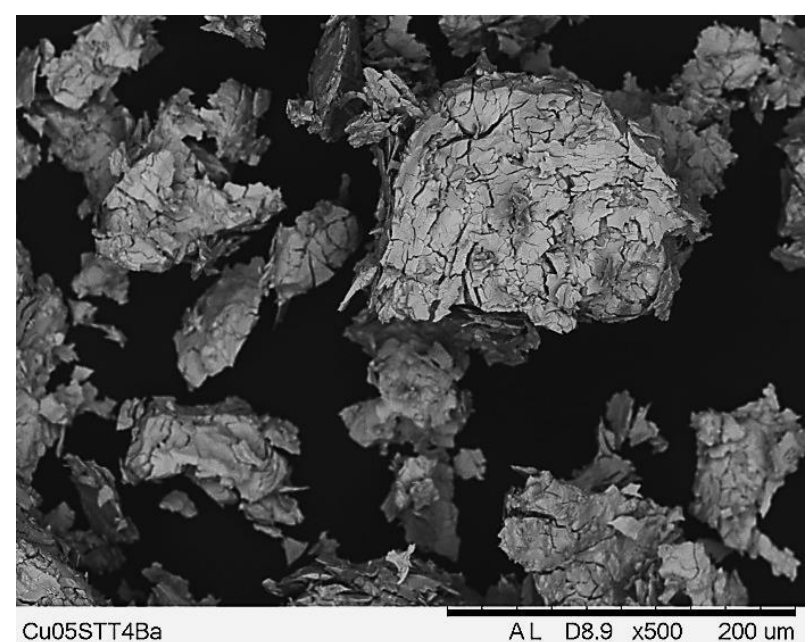

b)

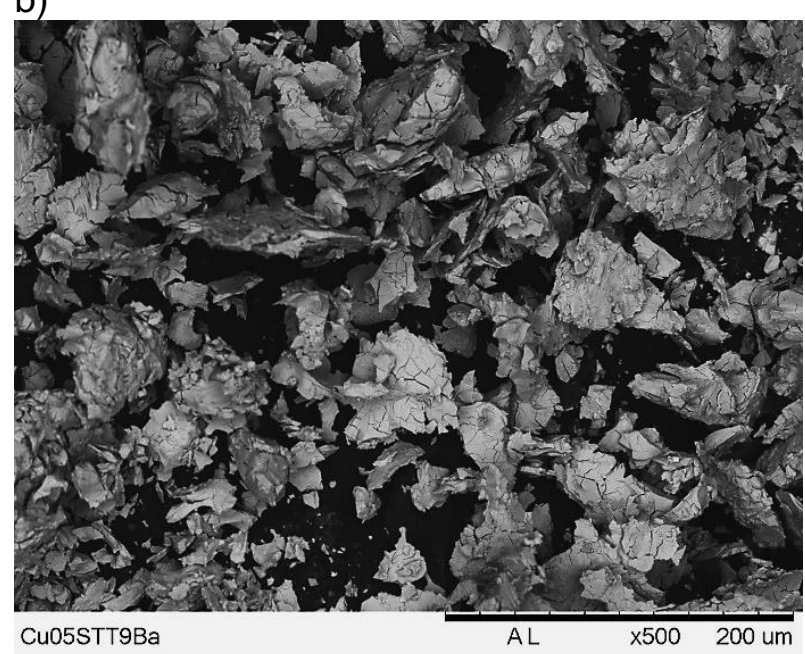

d)

5.6.7 - Curvas de absorção de hidrogênio e micrografias da liga $\mathrm{La}_{0,7} \mathrm{Mg}_{0,3} \mathrm{Al}_{0,3} \mathrm{Mn}_{0,4} \mathrm{Cu}_{0,5} \mathrm{Ni}_{3,8}$ com tratamento térmico de $750^{\circ} \mathrm{C}$ por 9 horas

Na FIGURA 63 estão mostradas as curvas de absorção de hidrogênio pela liga $\mathrm{La}_{0,7} \mathrm{Mg}_{0,3} \mathrm{Al}_{0,3} \mathrm{Mn}_{0,4} \mathrm{Cu}_{0,5} \mathrm{Ni}_{3,8}$ com TT de $750^{\circ} \mathrm{C}$ por 9 horas. e na FIGURA 64 de (a) até (d) estão apresentadas as micrografias (500x), obtidas por MEV da liga após fragilização sendo: (a) pressão de hidrogênio de 2000 mbar, (b) pressão de hidrogênio de 4000 mbar, (c) pressão de hidrogênio de 6000 mbar e (d) com pressão de hidrogênio de 9000 mbar. O aspecto da morfologia das partículas também não foi alterado para esta liga após absorção de hidrogênio. 
FIGURA 63 - Curvas de absorção de Hidrogênio pela liga $\mathrm{La}_{0,7} \mathrm{Mg}_{0,3} \mathrm{Al}_{0,3} \mathrm{Mn}_{0,4} \mathrm{Cu}_{0,5} \mathrm{Ni}_{3,8}$ com TT de $750^{\circ} \mathrm{C}$ por 9 horas com pressão de 2, 4, 6 e 9 bar de hidrogênio por 60 minutos.

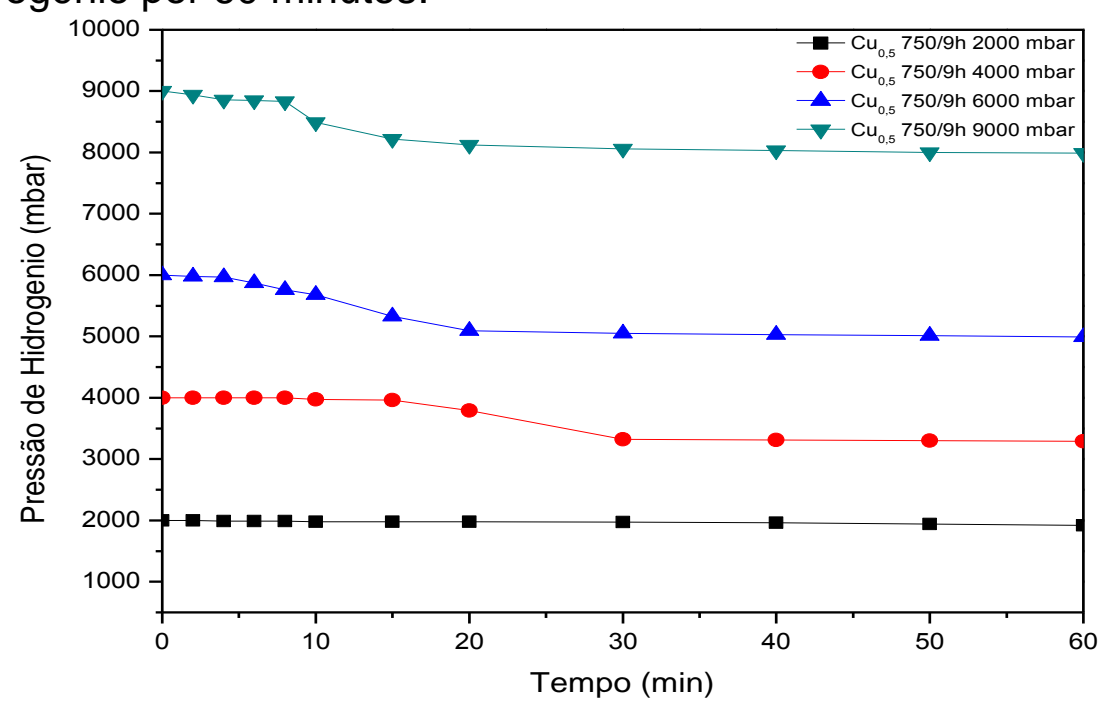

FIGURA 64 - Micrografias (500x) da liga $\mathrm{La}_{0,7} \mathrm{Mg}_{0,3} \mathrm{Al}_{0,3} \mathrm{Mn}_{0,4} \mathrm{Cu}_{0,5} \mathrm{Ni}_{3,8}$ com TT de $750^{\circ} \mathrm{C}$ por 9 horas fragilizada em 2, 46 e 9 bar de hidrogênio por 60 minutos.

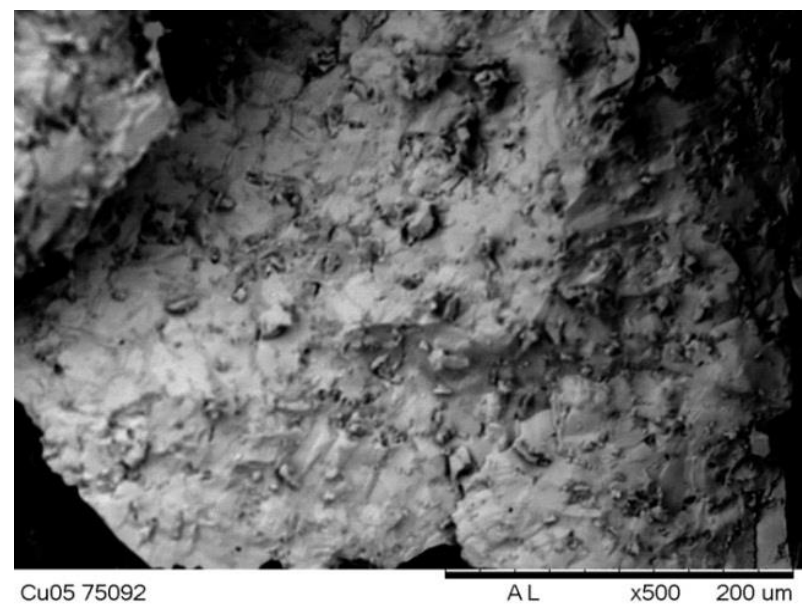

Cu05 750-9h 2000 mbar

a)

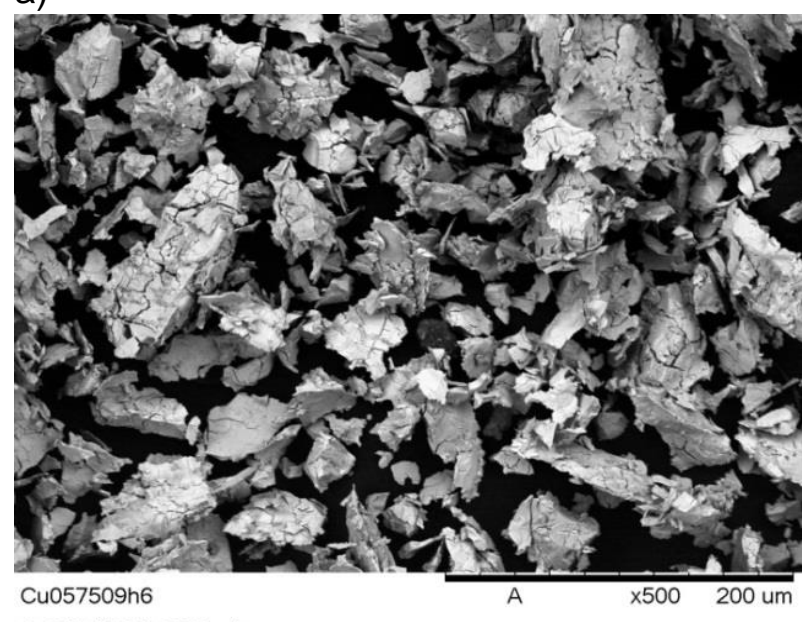

Cu05 750 9h 6000 mbar

c)

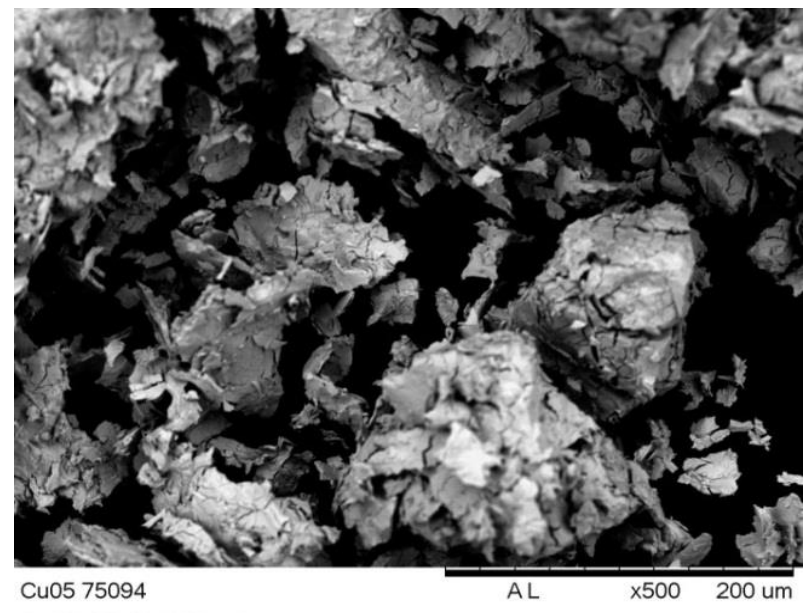

Cu05 750-9h 4000 mbar

b)

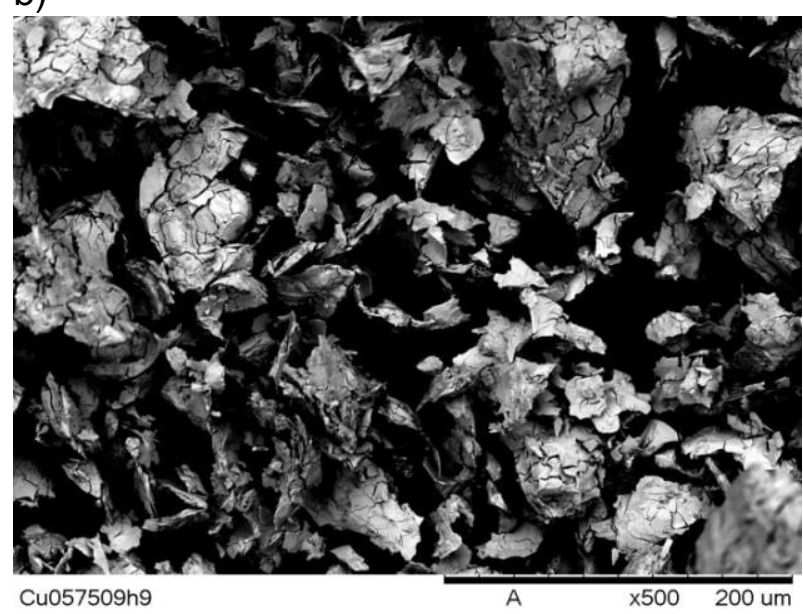

Cu05 750 9h 9000 mbar

d) 
5.6.8 - Curvas de absorção de hidrogênio e micrografias da liga $\mathrm{La}_{0,7} \mathrm{Mg}_{0,3} \mathrm{Al}_{0,3} \mathrm{Mn}_{0,4} \mathrm{Cu}_{0,5} \mathrm{Ni}_{3,8}$ com TT de $750^{\circ} \mathrm{C}$ por 16 horas

Na FIGURA 65 estão mostradas as curvas de absorção de hidrogênio pela liga $\mathrm{La}_{0,7} \mathrm{Mg}_{0,3} \mathrm{Al}_{0,3} \mathrm{Mn}_{0,4} \mathrm{Cu}_{0,5} \mathrm{Ni}_{3,8}$ com TT de $750^{\circ} \mathrm{C}$ por 16 horas. e na FIGURA 66 de (a) até (d) estão apresentadas as micrografias (500x), obtidas por MEV da liga após fragilização sendo: (a) pressão de hidrogênio de 2000 mbar, (b) pressão de hidrogênio de 4000 mbar, (c) pressão de hidrogênio de 6000 mbar e (d) com pressão de hidrogênio de 9000 mbar. O aspecto da morfologia das partículas também não foi alterado para esta liga após absorção de hidrogênio.

FIGURA 65 - Curvas de absorção de hidrogênio pela liga $\mathrm{La}_{0,7} \mathrm{Mg}_{0,3} \mathrm{Al}_{0,3} \mathrm{Mn}_{0,4} \mathrm{Cu}_{0,5} \mathrm{Ni}_{3,8}$ com TT de $750^{\circ} \mathrm{C}$ por 16 horas com pressão de 2, 4, 6 e 9 bar de hidrogênio por 60 minutos.

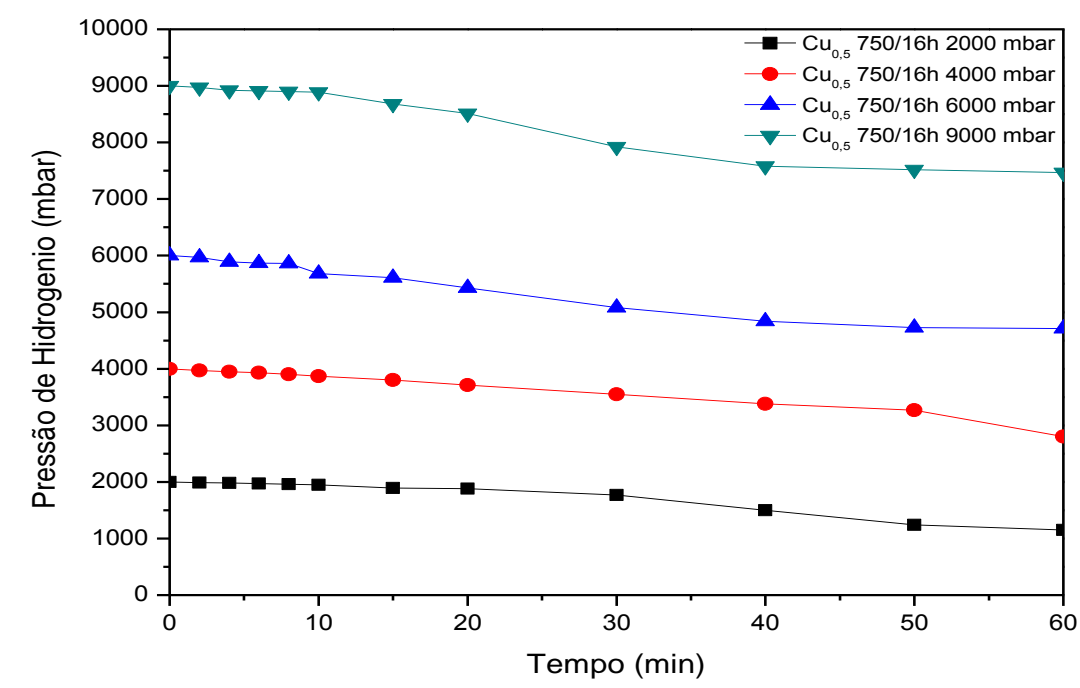


FIGURA 66 - Micrografias (500x) da liga $\mathrm{La}_{0,7} \mathrm{Mg}_{0,3} \mathrm{Al}_{0,3} \mathrm{Mn}_{0,4} \mathrm{Cu}_{0,5} \mathrm{Ni}_{3,8}$ com TT de $750^{\circ} \mathrm{C}$ por 16 horas fragilizada em 2, 46 e 9 bar de hidrogênio por 60 minutos.
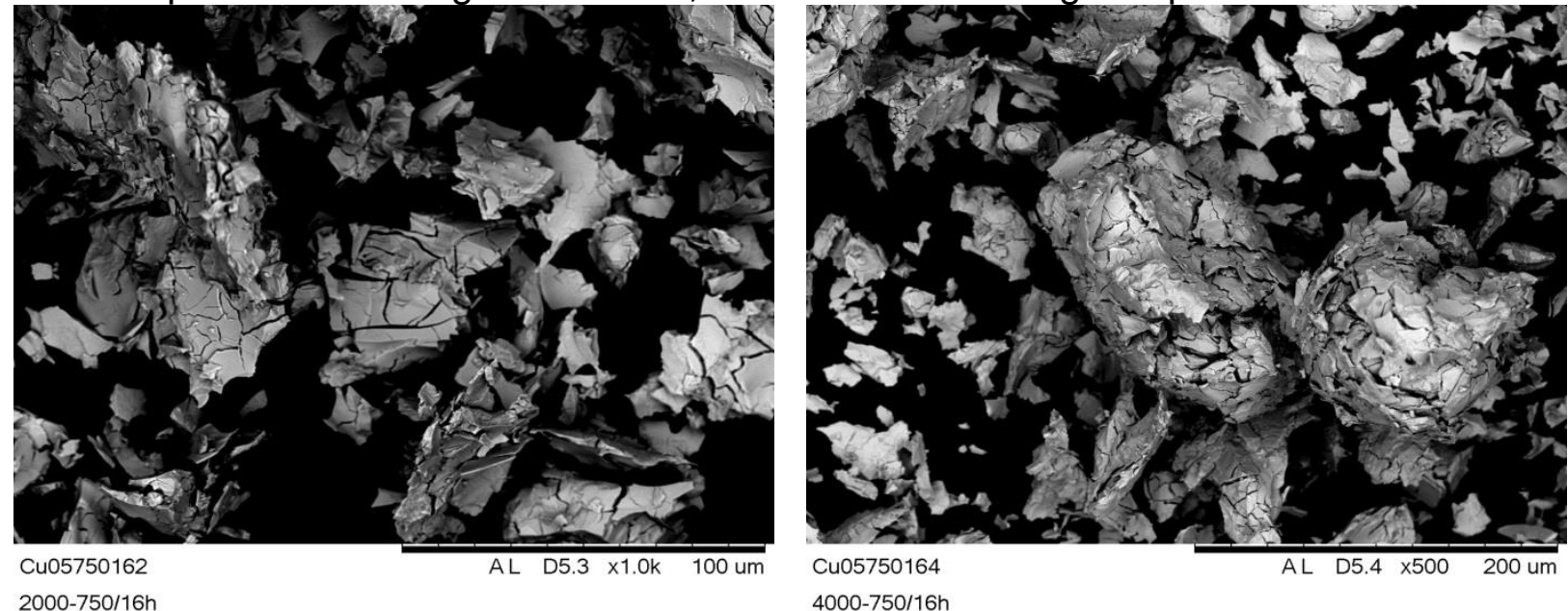

a)

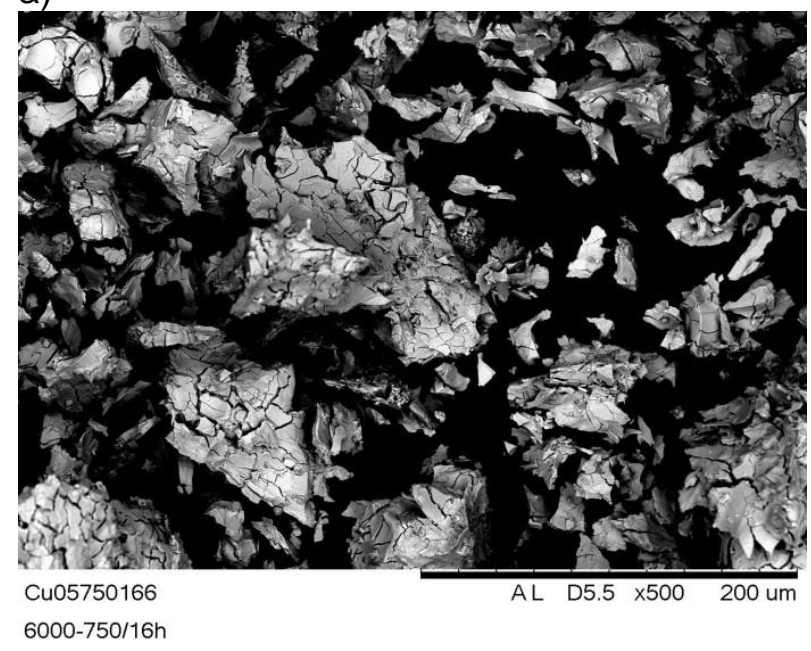

b)

c)

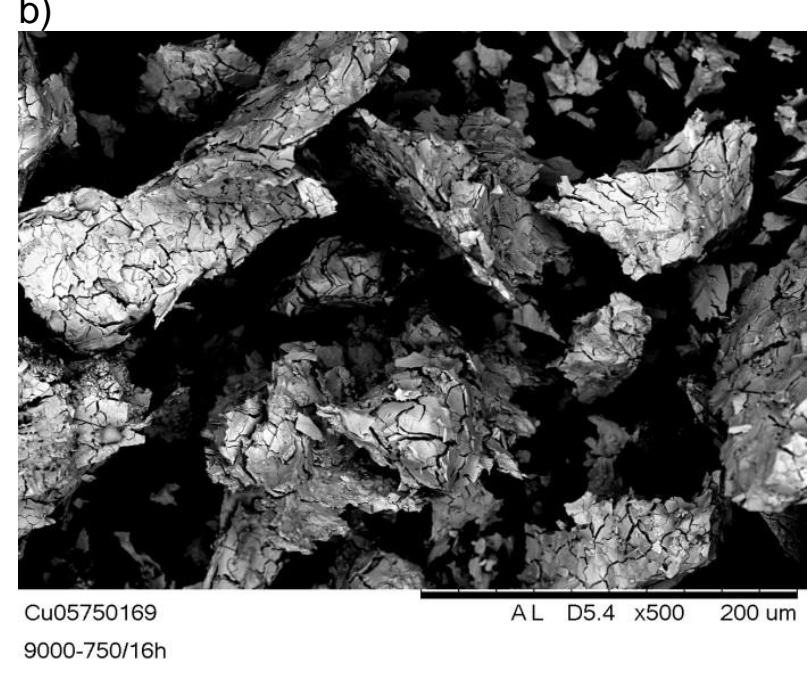

d)

5.6.9 - Curvas de absorção de hidrogênio e micrografias da liga $\mathrm{La}_{0,7} \mathrm{Mg}_{0,3} \mathrm{Al}_{0,3} \mathrm{Mn}_{0,4} \mathrm{Cu}_{0,5} \mathrm{Ni}_{3,8}$ com tratamento térmico de $850^{\circ} \mathrm{C}$ por 9 horas

Na FIGURA 67 estão mostradas as curvas de absorção de hidrogênio pela liga $\mathrm{La}_{0,7} \mathrm{Mg}_{0,3} \mathrm{Al}_{0,3} \mathrm{Mn}_{0,4} \mathrm{Cu}_{0,5} \mathrm{Ni}_{3,8}$ com TT de $850^{\circ} \mathrm{C}$ por 9 horas e na FIGURA 68 de (a) até (d) estão apresentadas as micrografias (500x), obtidas por MEV da liga após fragilização sendo: (a) pressão de hidrogênio de 2000 mbar, (b) pressão de hidrogênio de 4000 mbar, (c) pressão de hidrogênio de 6000 mbar e (d) com pressão de hidrogênio de 9000 mbar. O aspecto da morfologia das partículas também não foi alterado para esta liga após absorção de hidrogênio. 
FIGURA 67 - Curvas de absorção de hidrogênio pela liga $\mathrm{La}_{0,7} \mathrm{Mg}_{0,3} \mathrm{Al}_{0,3} \mathrm{Mn}_{0,4} \mathrm{Cu}_{0,5} \mathrm{Ni}_{3,8}$ com TT de $850^{\circ} \mathrm{C}$ por 9 horas com pressão de 2, 4, 6 e 9 bar de hidrogênio por 60 minutos.

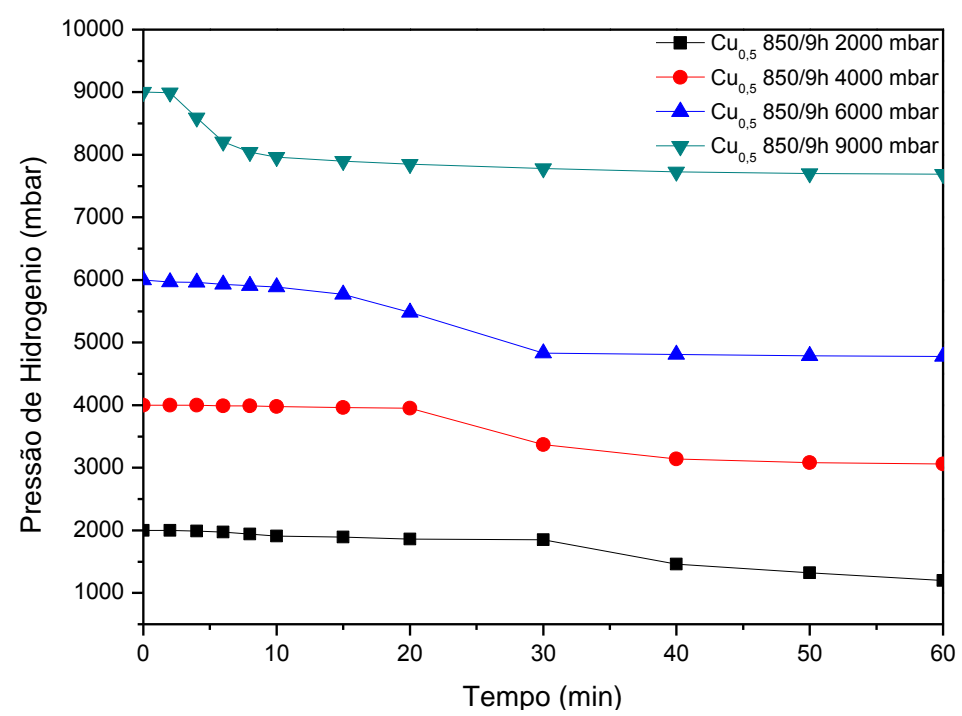

FIGURA 68 - Micrografias (500x) da liga $\mathrm{La}_{0,7} \mathrm{Mg}_{0,3} \mathrm{Al}_{0,3} \mathrm{Mn}_{0,4} \mathrm{Cu}_{0,5} \mathrm{Ni}_{3,8}$ com TT de $850^{\circ} \mathrm{C}$ por 9 horas fragilizada em 2, 46 e 9 bar de hidrogênio por 60 minutos.

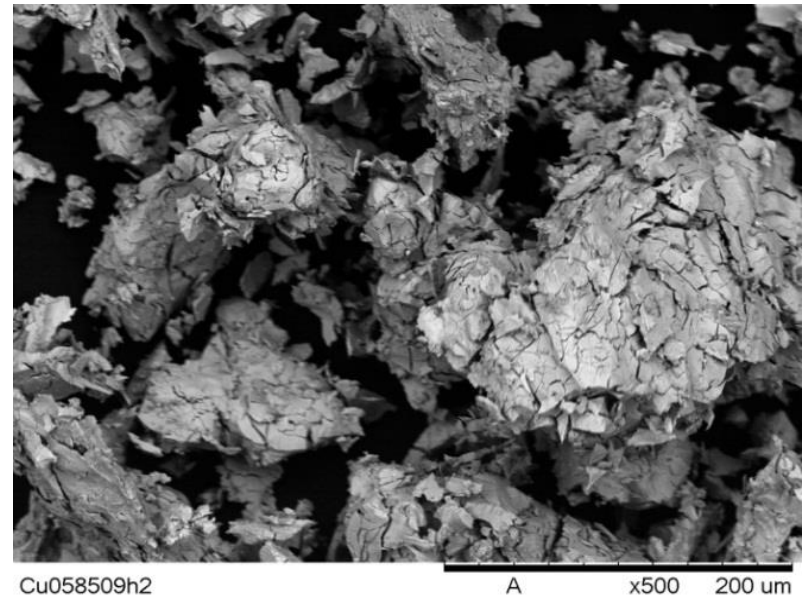

Cu05 850-9h 2000 mbar

a)

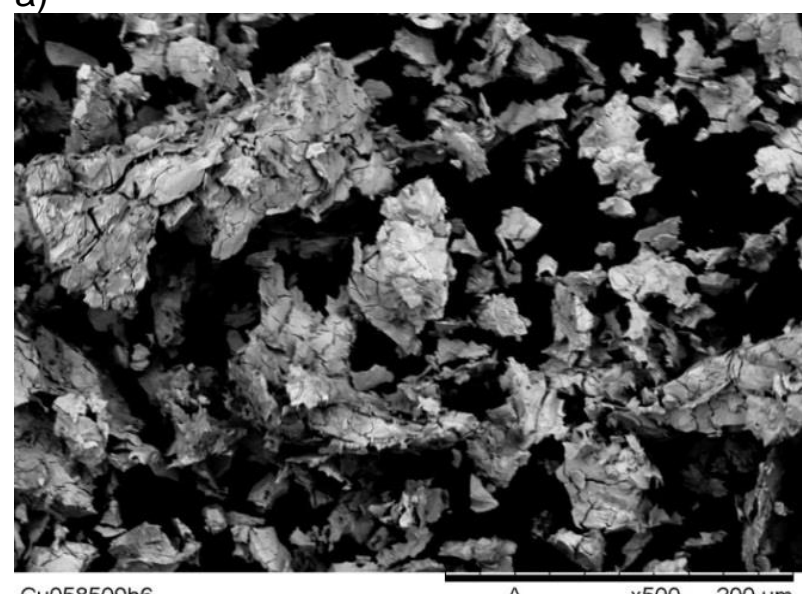

Cu058509h6

Cu05 850 9h 6000 mbar

c)

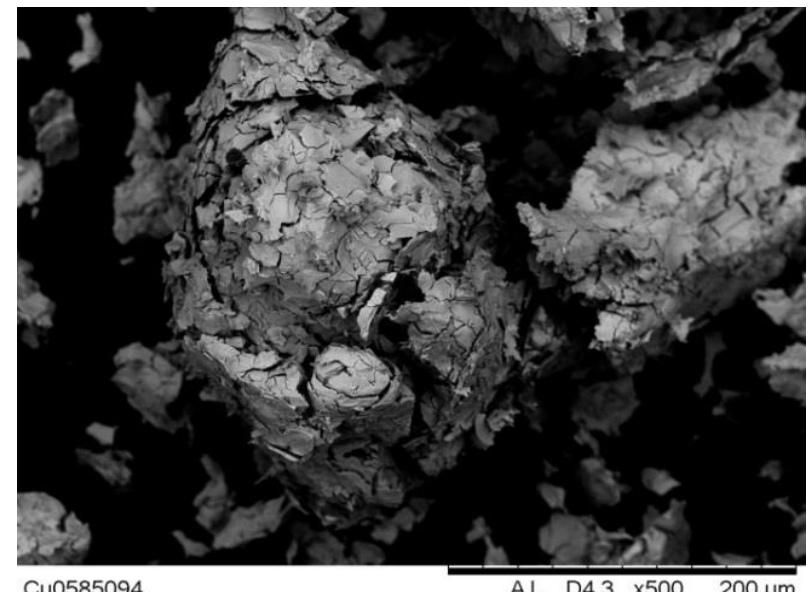

Cu0585094

Cu05 850-9h 4000 mbar

b)

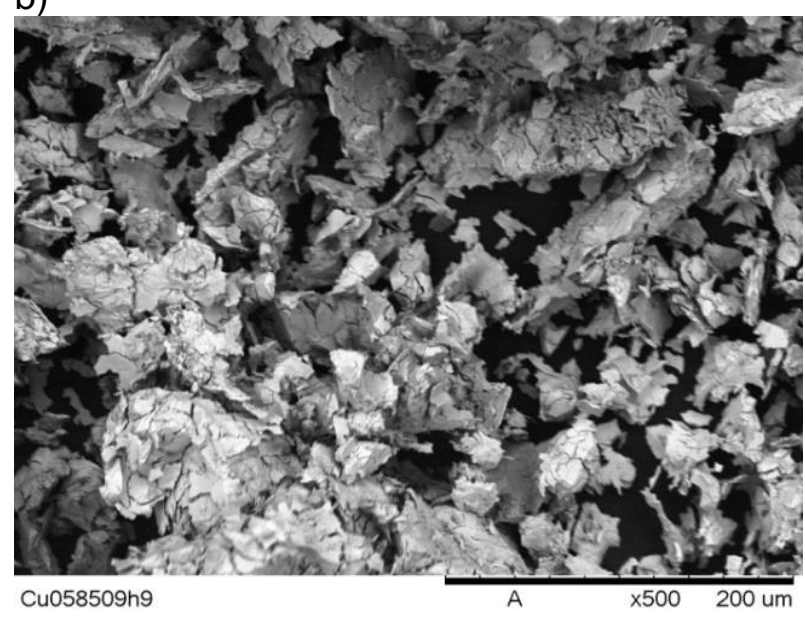

Cu05 850 9h 9000 mbar

d) 
5.6.10 - Curvas de absorção de hidrogênio e micrografias da liga $\mathrm{La}_{0,7} \mathrm{Mg}_{0,3} \mathrm{Al}_{0,3} \mathrm{Mn}_{0,4} \mathrm{Cu}_{0,5} \mathrm{Ni}_{3,8}$ com TT de $850^{\circ} \mathrm{C}$ por 16 horas

Na FIGURA 69 estão mostradas as curvas de absorção de hidrogênio pela liga $\mathrm{La}_{0,7} \mathrm{Mg}_{0,3} \mathrm{Al}_{0,3} \mathrm{Mn}_{0,4} \mathrm{Cu}_{0,5} \mathrm{Ni}_{3,8}$ com TT de $850^{\circ} \mathrm{C}$ por 16 horas e na FIGURA 70 de (a) até (d) estão apresentadas as micrografias (500x), obtidas por MEV da liga após fragilização sendo: (a) pressão de hidrogênio de 2000 mbar, (b) pressão de hidrogênio de 4000 mbar, (c) pressão de hidrogênio de 6000 mbar e (d) com pressão de hidrogênio de 9000 mbar. Todas as pressões promoveram a fragilização desta liga nesta condição de TT.

Comparando as curvas de absorção de hidrogênio da liga com TT (FIGURAS 63, 65, 67 e 69) com a liga sem TT (FIGURA 61), a absorção foi inferior para a liga após TT em todas as pressões utilizadas de hidrogênio, provavelmente pela eliminação dos defeitos estruturais existentes na liga bruta de fusão sendo, portanto, a absorção de hidrogênio promovida preferencialmente pelas fases absorvedoras de hidrogênio da liga. A presença do $\mathrm{Cu}$ nas fases absorvedoras de hidrogênio $\mathrm{LaNi}_{5}$ e $\mathrm{LaMg}_{2} \mathrm{Ni}_{9}$ mostradas nas TABELAS 18 a 22 também influenciaram na baixa absorção de hidrogênio quando comparado com a liga $\mathrm{La}_{0,7} \mathrm{Mg}_{0,3} \mathrm{Al}_{0,3} \mathrm{Mn}_{0,4} \mathrm{Cu}_{0,5} \mathrm{Ni}_{3,8}$. Quanto ao aspecto morfológico das partículas, todas foram semelhantes após absorção de hidrogênio pela liga. 
FIGURA 69 - Curvas de absorção de Hidrogênio pela liga $\mathrm{La}_{0,7} \mathrm{Mg}_{0,3} \mathrm{Al}_{0,3} \mathrm{Mn}_{0,4} \mathrm{Cu}_{0,5} \mathrm{Ni}_{3,8}$ com tratamento térmico de $850^{\circ} \mathrm{C}$ por 16 horas. , com pressão de 2, 4, 6 e 9 bar de hidrogênio por 60 minutos.

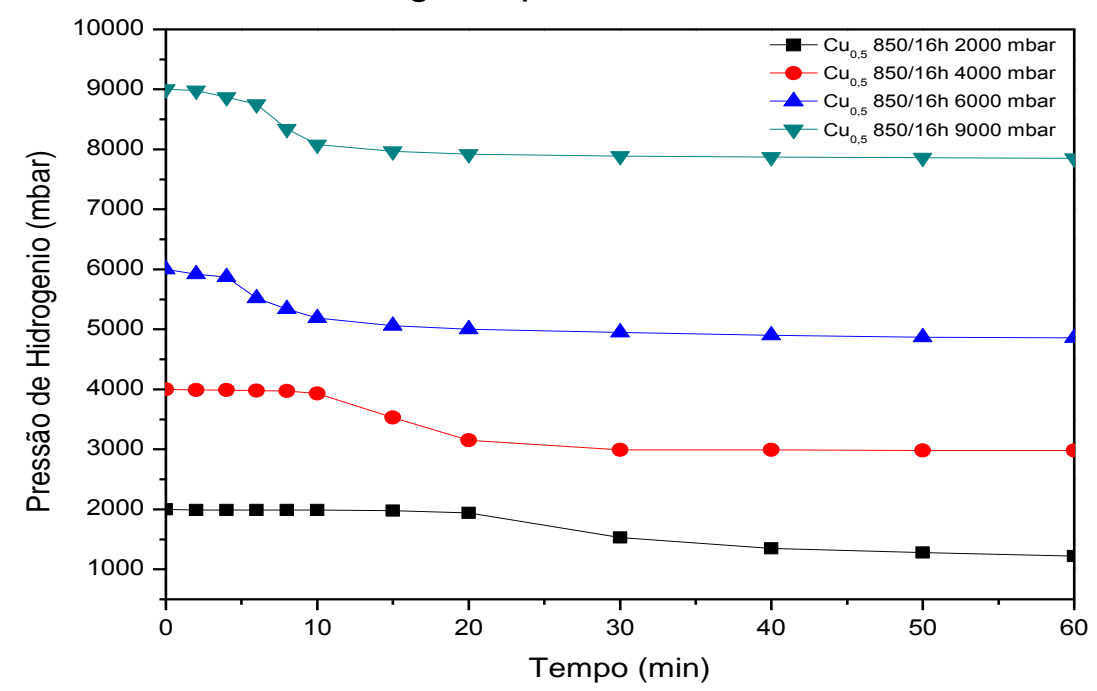

FIGURA 70 - Micrografia com aumento de 500x da liga $\mathrm{La}_{0,7} \mathrm{Mg}_{0,3} \mathrm{Al}_{0,3} \mathrm{Mn}_{0,4} \mathrm{Cu}_{0,5} \mathrm{Ni}_{3,8}$ fragilizada com tratamento térmico de $850^{\circ} \mathrm{C}$ por 16 horas em 2, 46 e 9 bar de hidrogênio por 60 minutos.

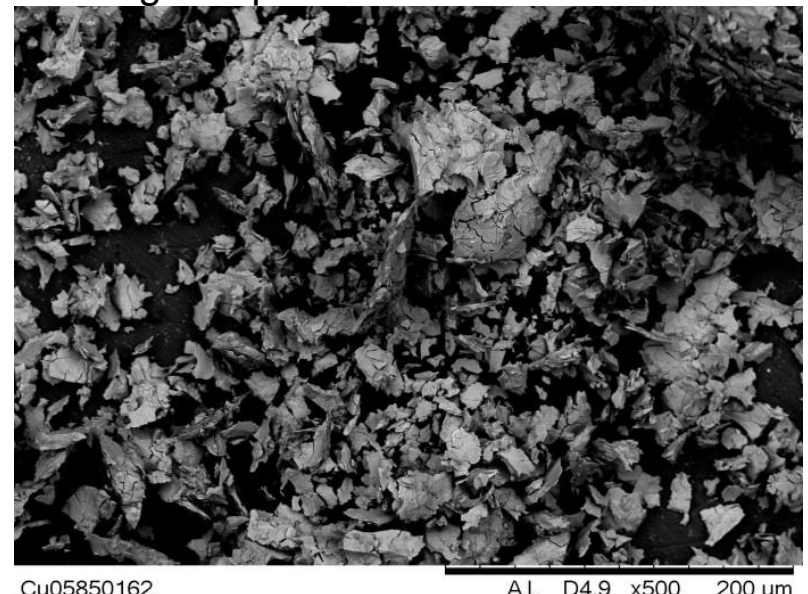

Cu05850162

Cu05 850-16h 2000 mbar

a)

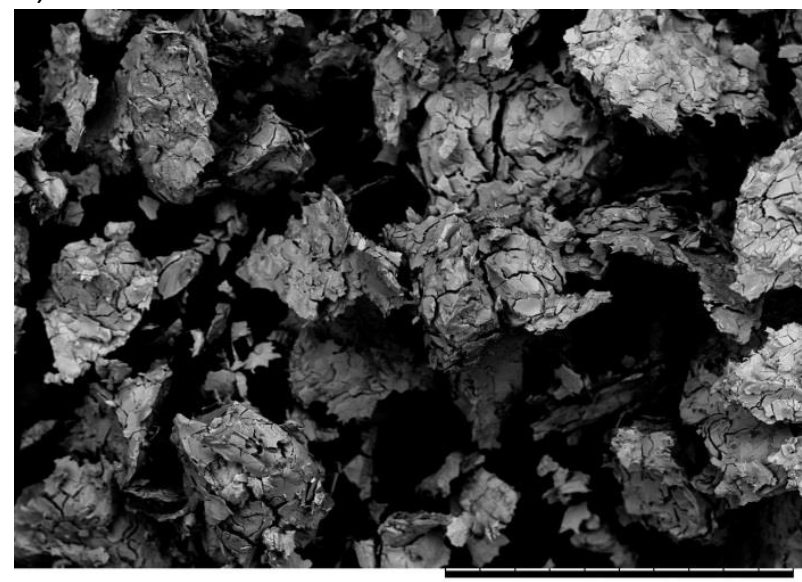

Cu05850166

AL $\quad$ D4.4 $\times 500 \quad 200$ um

Cu05 850-16h 6000 mbar

C)

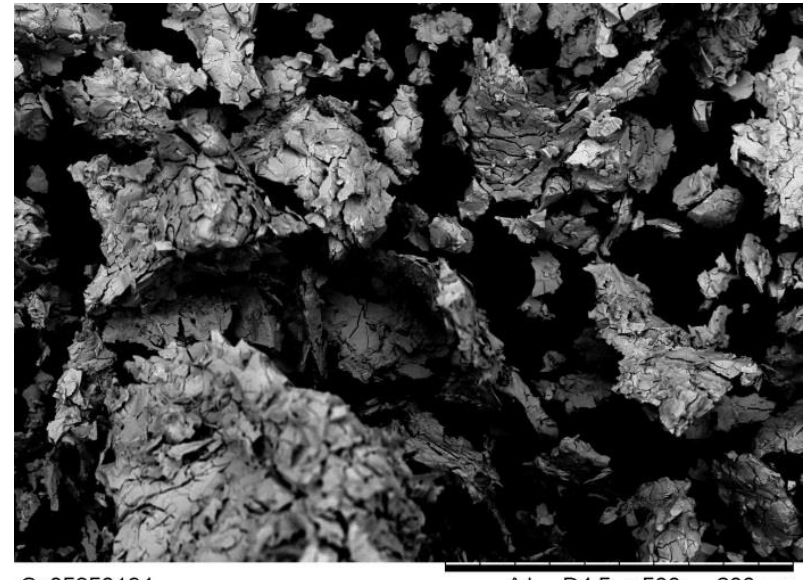

Cu05850164

Cu05 850-16h 4000 mbar

b)

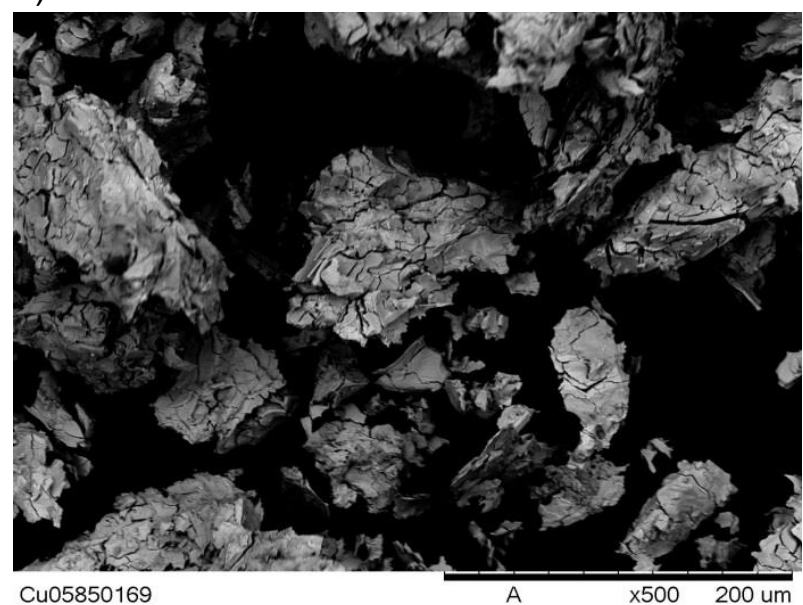

Cu05850169

Cu05 850-16h 9000 mbar

d) 


\subsubsection{1 - Curvas de absorção de hidrogênio e micrografias da liga}

$\mathrm{La}_{0,7} \mathrm{Mg}_{0,3} \mathrm{Al}_{0,3} \mathrm{Mn}_{0,4} \mathrm{Sn}_{0,5} \mathrm{Ni}_{3,8}$ sem TT

Na FIGURA 71 estão mostradas as curvas de absorção de hidrogênio pela liga $\mathrm{La}_{0,7} \mathrm{Mg}_{0,3} \mathrm{Al}_{0,3} \mathrm{Mn}_{0,4} \mathrm{Cu}_{0,5} \mathrm{Ni}_{3,8}$ sem TT e na FIGURA 72 de (a) até (d) estão apresentadas as micrografias (500x), obtidas por MEV da liga após fragilização sendo: (a) pressão de hidrogênio de 2000 mbar, (b) pressão de hidrogênio de 4000 mbar, (c) pressão de hidrogênio de 6000 mbar e (d) com pressão de hidrogênio de 9000 mbar. Todas as pressões promoveram a fragilização desta liga nesta condição de TT.

Comparando as curvas de absorção das ligas com substituição do Ni pelo Co e Cu para as ligas sem TT mostradas nas FIGURAS 51 e 61, respectivamente, pode ser verificado que a substituição do Ni pelo Sn levou a uma baixa absorção de hidrogênio. Neste caso, provavelmente a presença do Sn na fase absorvedora de hidrogênio $\mathrm{LaNi}_{5}$, aumentando os parâmetros de rede a e $\mathrm{c}$ e $\mathrm{o}$ volume da célula unitária (TABELA 10) e da fase $\mathrm{LaSn}_{2} \mathrm{Ni}_{2}$ (substituindo a fase $\mathrm{LaMg}_{2} \mathrm{Ni}_{9}$ influenciaram a absorção de hidrogênio pela liga.

FIGURA 71 - Curvas de absorção de Hidrogênio pela liga $\mathrm{La}_{0,7} \mathrm{Mg}_{0,3} \mathrm{Al}_{0,3} \mathrm{Mn}_{0,4} \mathrm{Sn}_{0,5} \mathrm{Ni}_{3,8}$ sem TT.

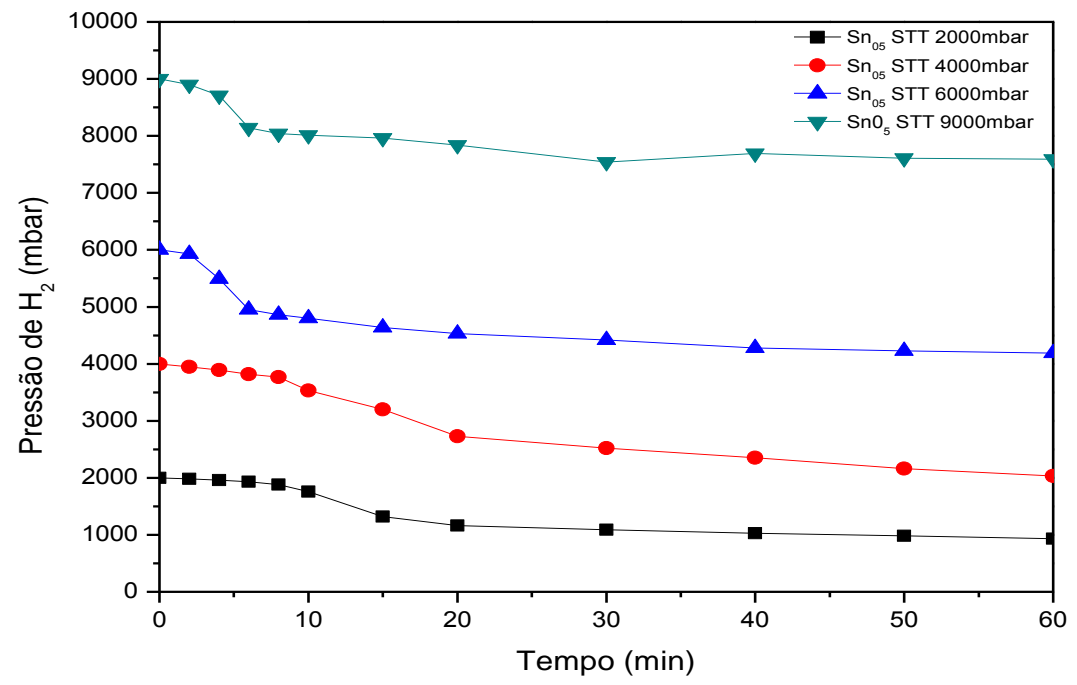


FIGURA 72 - Micrografia com aumento de 500x da liga $\mathrm{La}_{0,7} \mathrm{Mg}_{0,3} \mathrm{Al}_{0,3} \mathrm{Mn}_{0,4} \mathrm{Sn}_{0,5} \mathrm{Ni}_{3,8}$ fragilizada sem TT em 2, 46 e 9 bar de hidrogênio por 60 minutos.
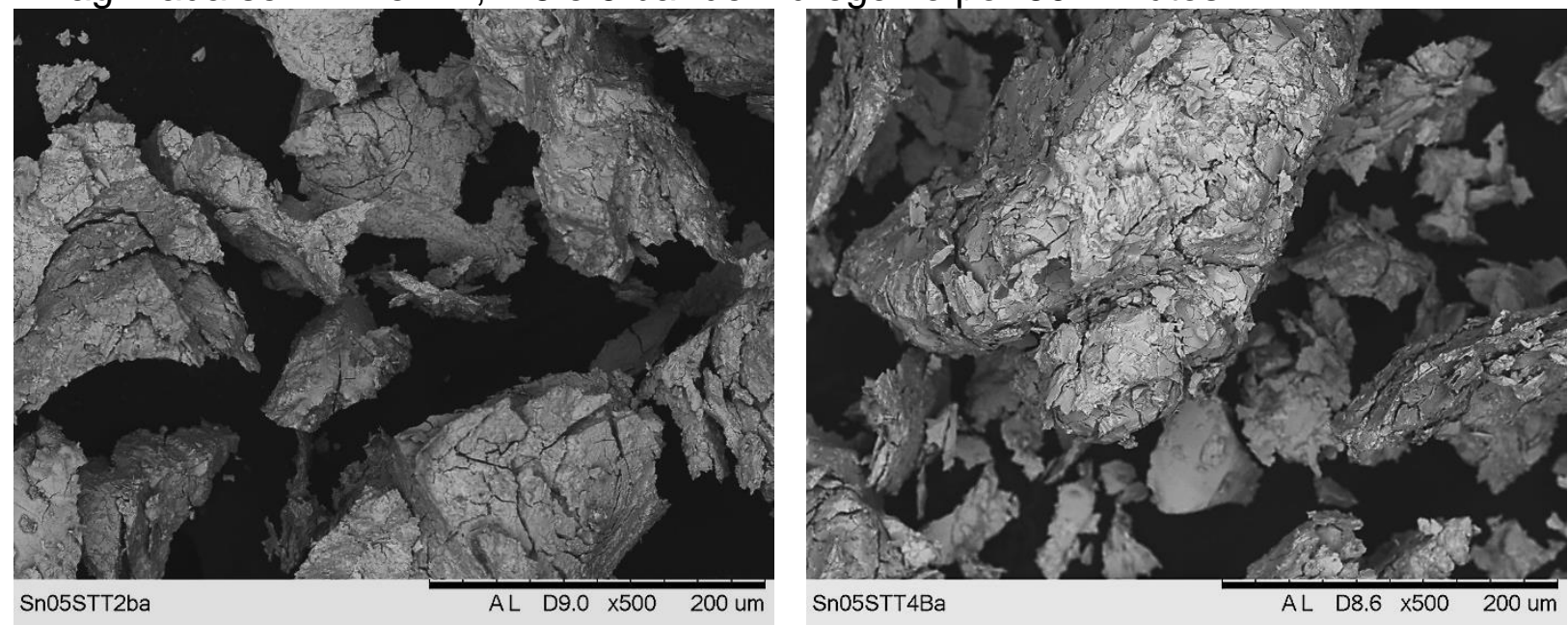

a)

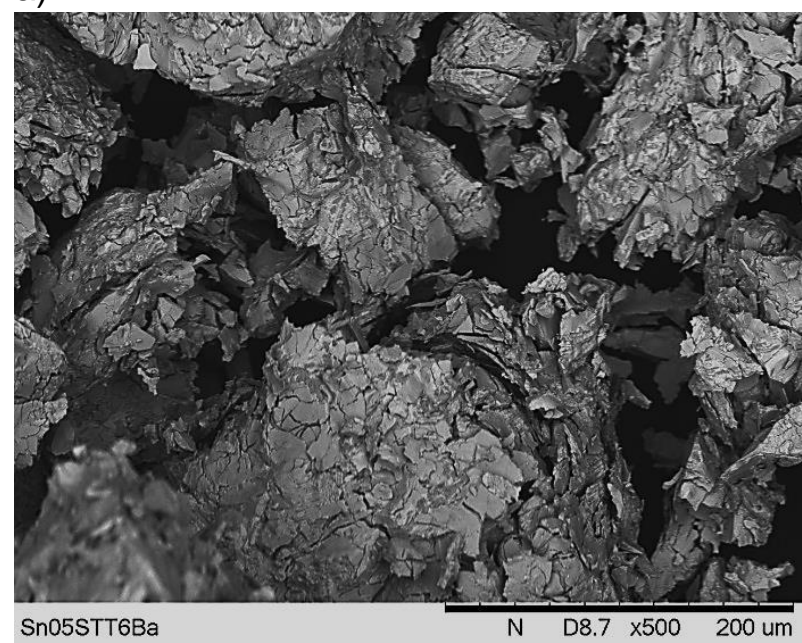

b)

c)

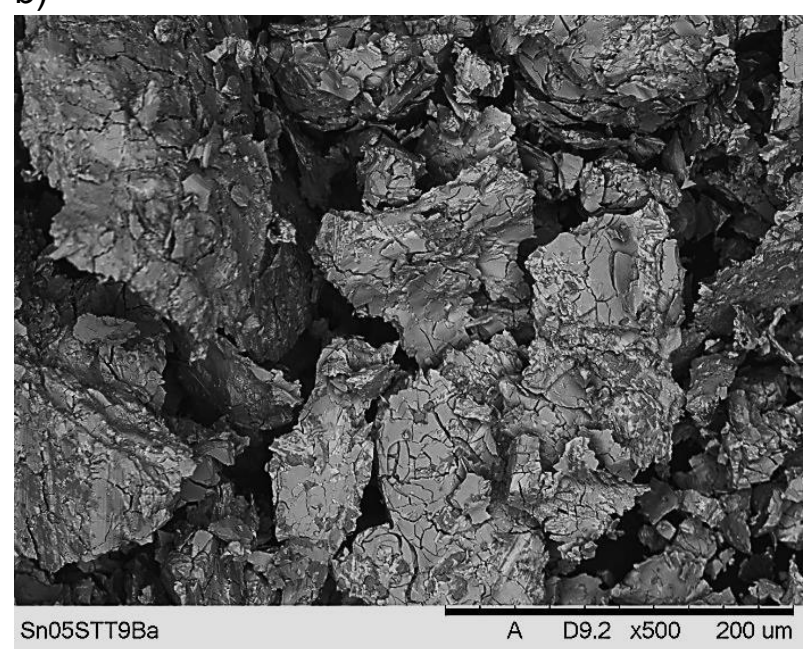

d)

5.6.12 - Curvas de absorção de hidrogênio e micrografias da liga $\mathrm{La}_{0,7} \mathrm{Mg}_{0,3} \mathrm{Al}_{0,3} \mathrm{Mn}_{0,4} \mathrm{Sn}_{0,5} \mathrm{Ni}_{3,8}$ com TT de $750^{\circ} \mathrm{C}$ por 9 horas.

Na FIGURA 73 estão mostradas as curvas de absorção de hidrogênio pela liga $\mathrm{La}_{0,7} \mathrm{Mg}_{0,3} \mathrm{Al}_{0,3} \mathrm{Mn}_{0,4} \mathrm{Cu}_{0,5} \mathrm{Ni}_{3,8}$ com TT de $750^{\circ} \mathrm{C}$ por 9 horas e na FIGURA 74 de (a) até (d) estão apresentadas as micrografias (500x), obtidas por MEV da liga após fragilização sendo: (a) pressão de hidrogênio de 2000 mbar, (b) pressão de hidrogênio de 4000 mbar, (c) pressão de hidrogênio de 6000 mbar e (d) com pressão de hidrogênio de 9000 mbar.

Todas as pressões promoveram a fragilização desta liga nesta condição de TT. 
FIGURA 73 - Curvas de absorção de Hidrogênio pela liga $\mathrm{La}_{0,7} \mathrm{Mg}_{0,3} \mathrm{Al}_{0,3} \mathrm{Mn}_{0,4} \mathrm{Sn}_{0,5} \mathrm{Ni}_{3,8}$ com tratamento térmico de $750^{\circ} \mathrm{C}$ por 9 horas.

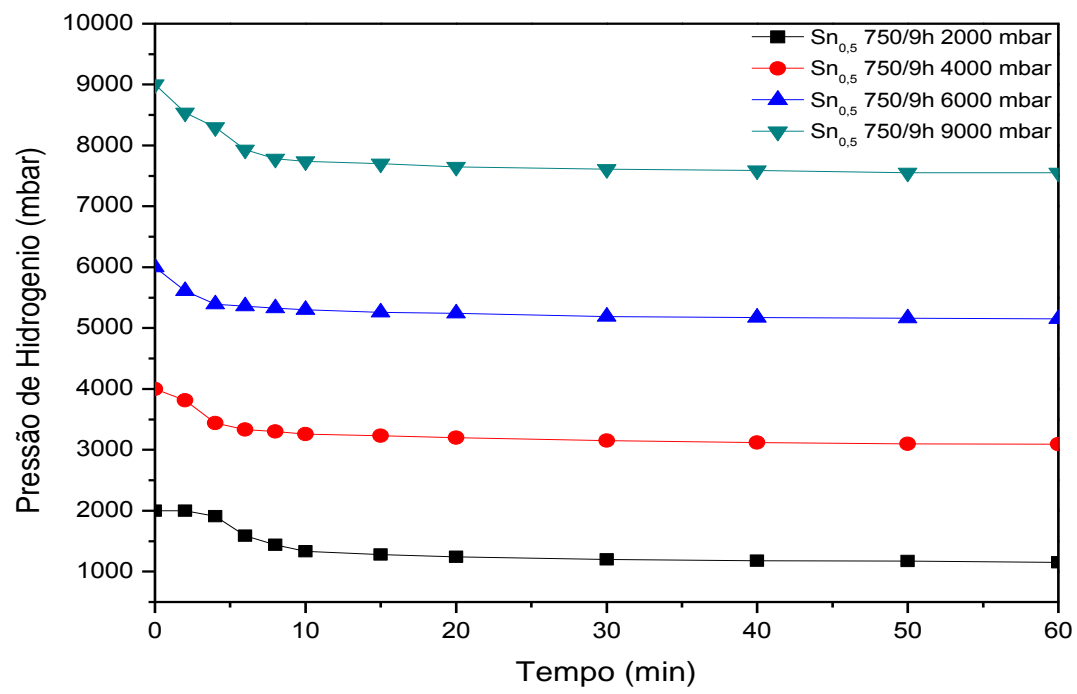

FIGURA 74 - Micrografia com aumento de 500x da liga $\mathrm{La}_{0,7} \mathrm{Mg}_{0,3} \mathrm{Al}_{0,3} \mathrm{Mn}_{0,4} \mathrm{Sn}_{0,5} \mathrm{Ni}_{3,8}$ fragilizada com tratamento térmico de $750^{\circ} \mathrm{C}$ por 9 horas em 2, 46 e 9 bar de hidrogênio por 60 minutos.

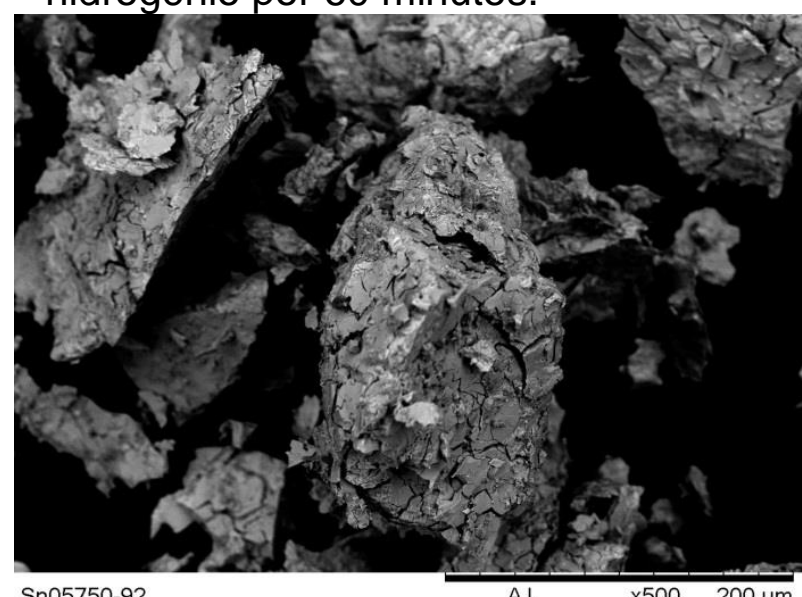

Sn05750-92

Sn05 750-9h 2000 mbar

a)

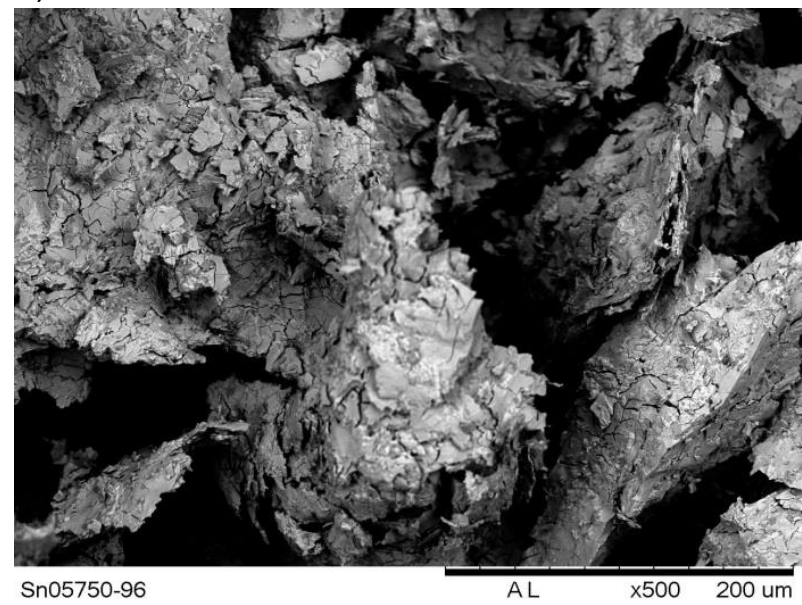

Sn05 750-9h 6000 mbar

C)

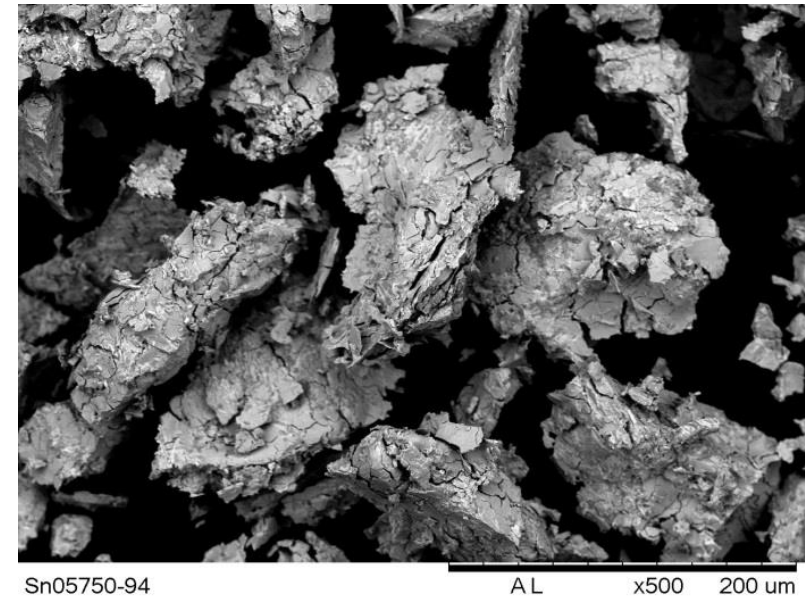

Sn05 750-9h 4000 mbar

b)

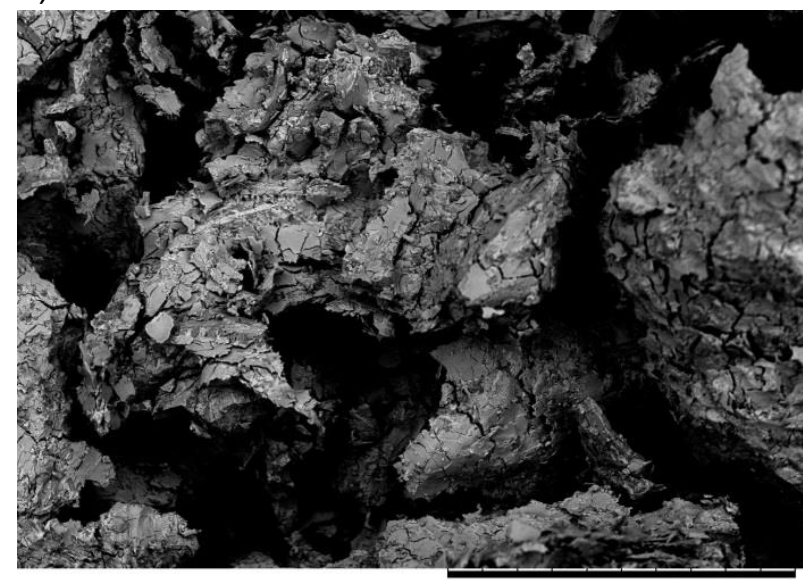

Sn05750-99

$A L$

x500 200 um

Sn05 750-9h 9000 mbar

d) 
5.6.13 - Curvas de absorção de hidrogênio e micrografias da liga $\mathrm{La}_{0,7} \mathrm{Mg}_{0,3} \mathrm{Al}_{0,3} \mathrm{Mn}_{0,4} \mathrm{Sn}_{0,5} \mathrm{Ni}_{3,8}$ com TT de $750^{\circ} \mathrm{C}$ por 16 horas.

Na FIGURA 75 estão mostradas as curvas de absorção de hidrogênio pela liga $\mathrm{La}_{0,7} \mathrm{Mg}_{0,3} \mathrm{Al}_{0,3} \mathrm{Mn}_{0,4} \mathrm{Cu}_{0,5} \mathrm{Ni}_{3,8}$ com TT de $750^{\circ} \mathrm{C}$ por 16 horas e na FIGURA 76 de (a) até (d) estão apresentadas as micrografias (500x), obtidas por MEV da liga após fragilização sendo: (a) pressão de hidrogênio de 2000 mbar, (b) pressão de hidrogênio de 4000 mbar, (c) pressão de hidrogênio de 6000 mbar e (d) com pressão de hidrogênio de 9000 mbar.

Todas as pressões promoveram a fragilização, mas em fragmentos maiores da liga nesta condição de TT.

5.6.14 - Curvas de absorção de hidrogênio e micrografias da liga $\mathrm{La}_{0,7} \mathrm{Mg}_{0,3} \mathrm{Al}_{0,3} \mathrm{Mn}_{0,4} \mathrm{Sn}_{0,5} \mathrm{Ni}_{3,8}$ com TT de $850^{\circ} \mathrm{C}$ por 9 horas.

$\mathrm{Na}$ FIGURA 78 de (a) até (d) estão apresentadas as microestruturas com magnitude 500x, obtidas por MEV das ligas $\mathrm{La}_{0,7} \mathrm{Mg}_{0,3} \mathrm{Al}_{0,3} \mathrm{Mn}_{0,4} \mathrm{Sn}_{0,5} \mathrm{Ni}_{3,8}$ com tratamento térmico de $850^{\circ} \mathrm{C}$ por 9 horas. Sendo que para (a) com pressão de Hidrogênio de 2000 mbar, (b) com pressão de Hidrogênio de 4000 mbar, (c) com pressão de Hidrogênio de 6000 mbar, (d) com pressão de Hidrogênio de 9000 mbar.

Sendo que estas são pressões relativas e não absolutas, como já foi mencionado anteriormente no capitulo 5.6 em materiais e métodos.

Foi possível observar no gráfico da FIGURA 77 que em 2000 mba de pressão de hidrogênio aconteceu um tempo de espera para começo da absorção, mas todas as pressões promoveram a fragilização desta liga para este tratamento térmico. 
FIGURA 75 - Curvas de absorção de Hidrogênio pela liga $\mathrm{La}_{0,7} \mathrm{Mg}_{0,3} \mathrm{Al}_{0,3} \mathrm{Mn}_{0,4} \mathrm{Sn}_{0,5} \mathrm{Ni}_{3,8}$ com tratamento térmico de $750^{\circ} \mathrm{C}$ por 16 horas.

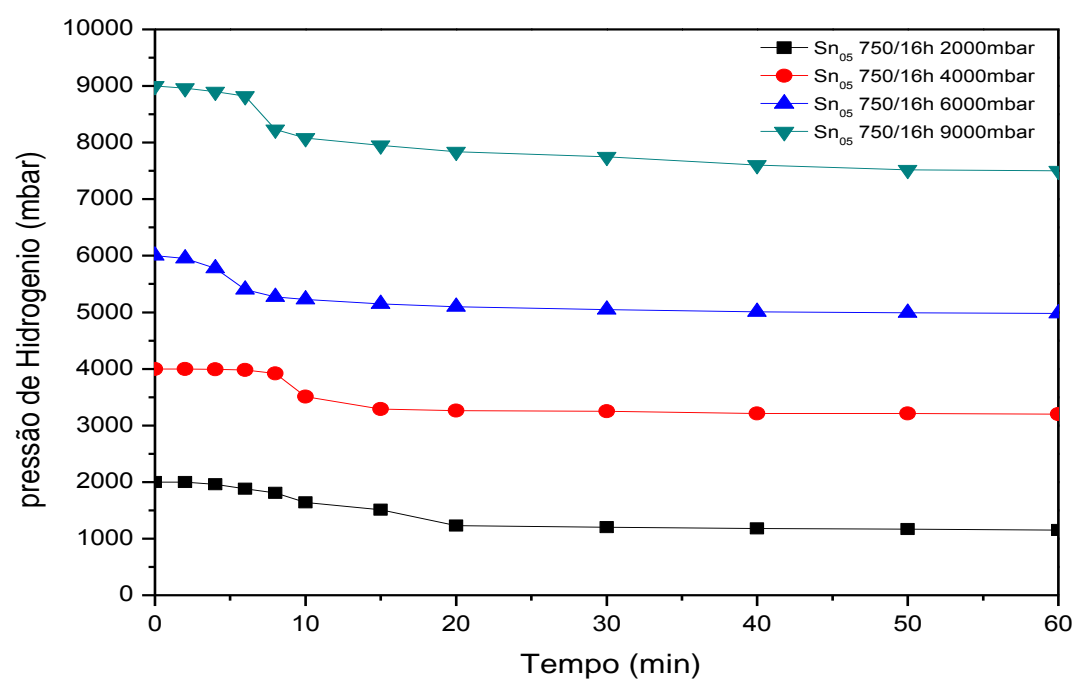

FIGURA 76 - Micrografia com aumento de 500x da liga $\mathrm{La}_{0,7} \mathrm{Mg}_{0,3} \mathrm{Al}_{0,3} \mathrm{Mn}_{0,4} \mathrm{Sn}_{0,5} \mathrm{Ni}_{3,8}$ fragilizada com tratamento térmico de $750^{\circ} \mathrm{C}$ por 16 horas em 2, 46 e 9 bar de hidrogênio por 60 minutos.
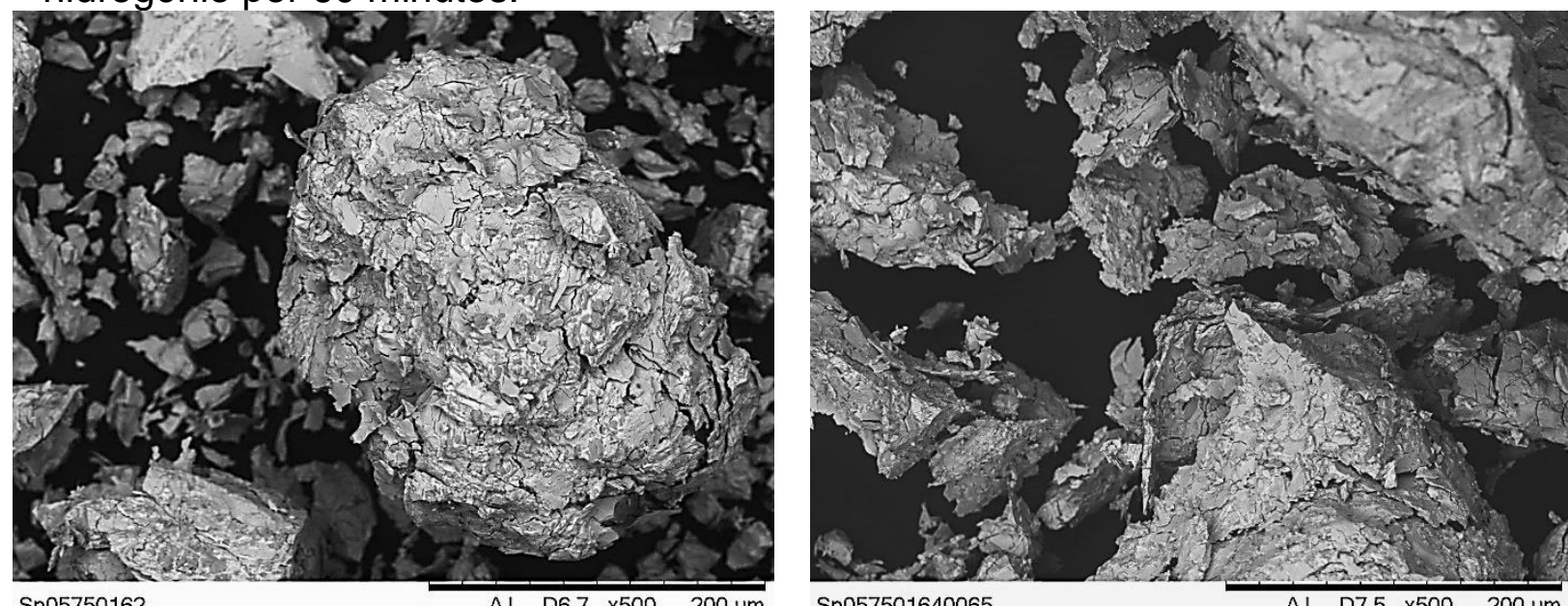

a)

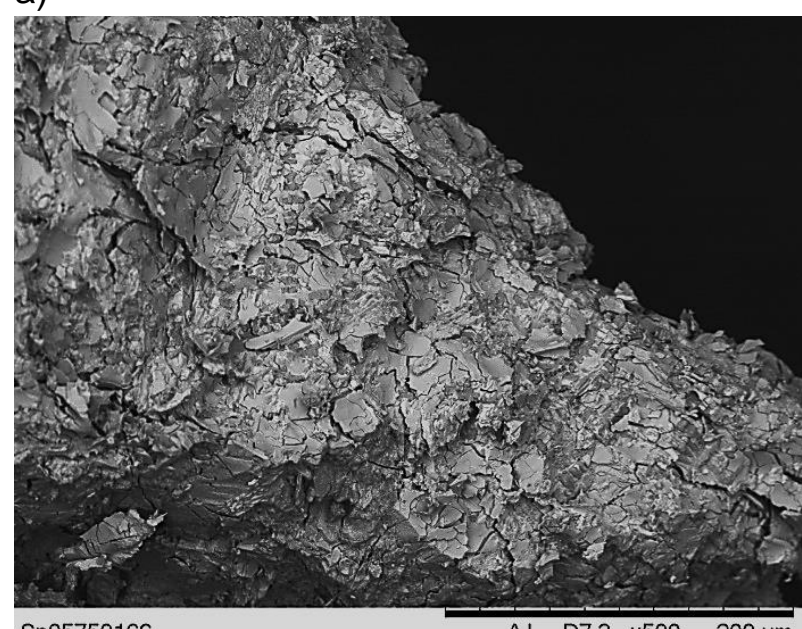

Sn05750166

AL $\quad$ D7.3 $\times 500 \quad 200$ um

c)

b)

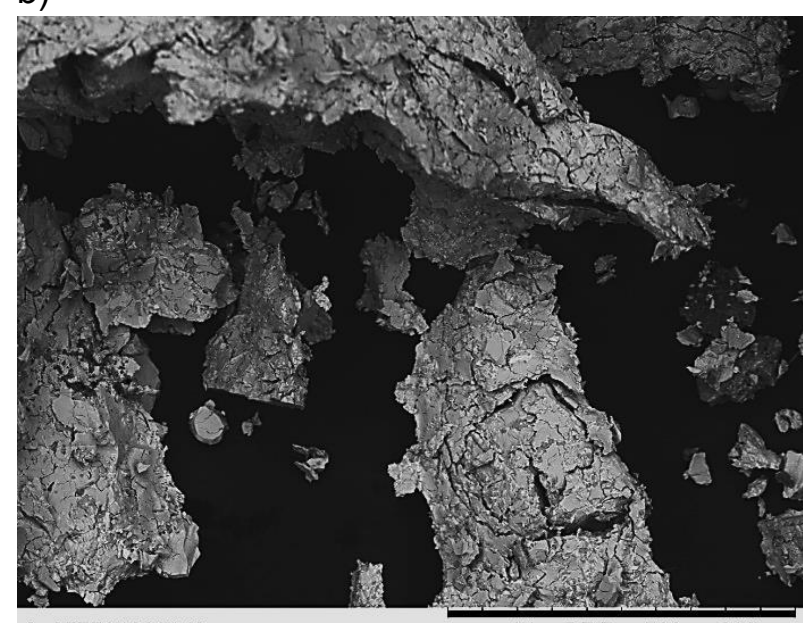

Sn057501690043

AL $\quad$ D7.7 $\times 500 \quad 200$ um

d) 
FIGURA 77 - Curvas de absorção de Hidrogênio pela liga $\mathrm{La}_{0,7} \mathrm{Mg}_{0,3} \mathrm{Al}_{0,3} \mathrm{Mn}_{0,4} \mathrm{Sn}_{0,5} \mathrm{Ni}_{3,8}$ com tratamento térmico de $850^{\circ} \mathrm{C}$ por 9 horas.

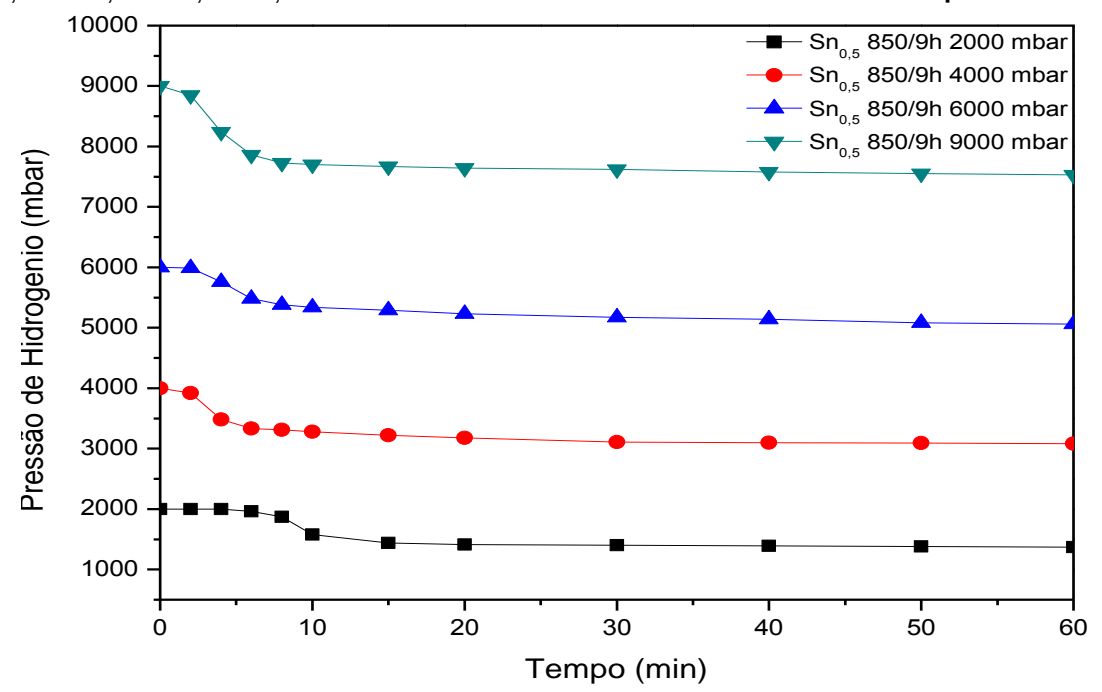

FIGURA 78 - Micrografia com aumento de 500x da liga $\mathrm{La}_{0,7} \mathrm{Mg}_{0,3} \mathrm{Al}_{0,3} \mathrm{Mn}_{0,4} \mathrm{Sn}_{0,5} \mathrm{Ni}_{3,8}$ fragilizada com tratamento térmico de $850^{\circ} \mathrm{C}$ por 9 horas em 2,46 e 9 bar de hidrogênio por 60 minutos
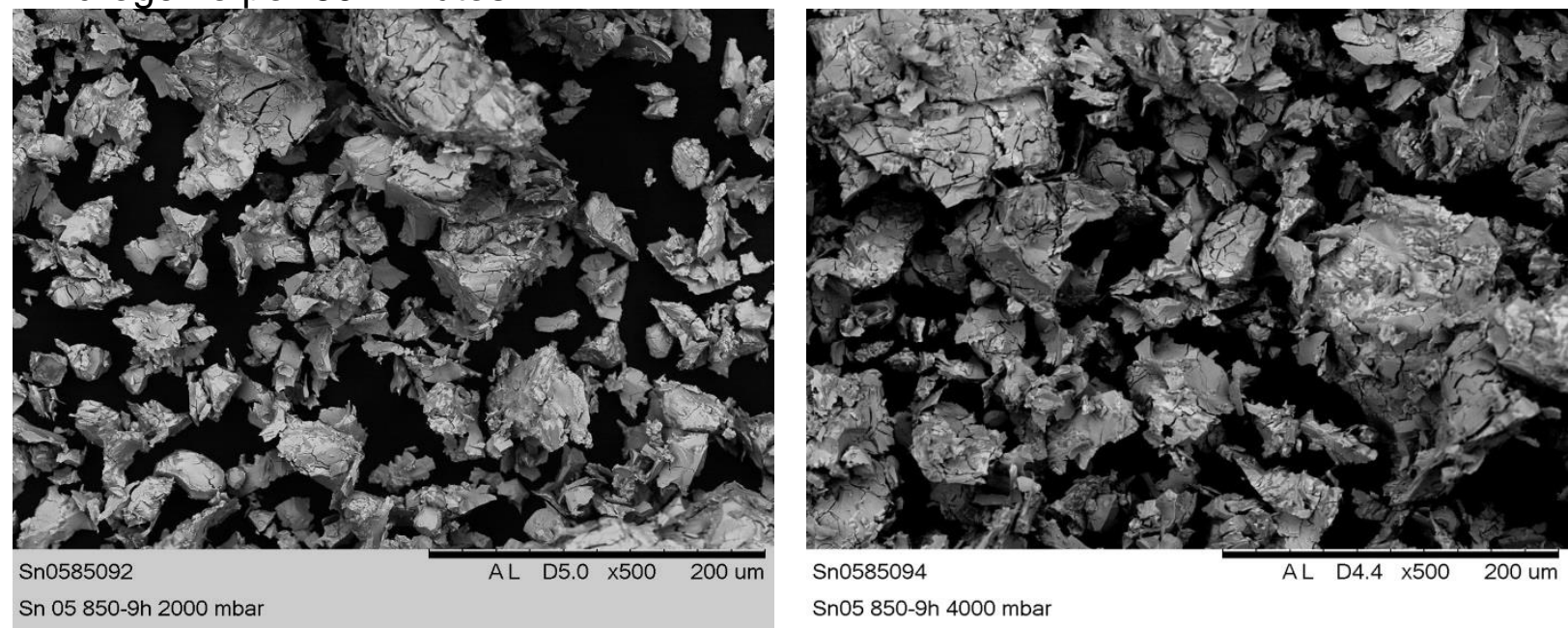

a)

b)

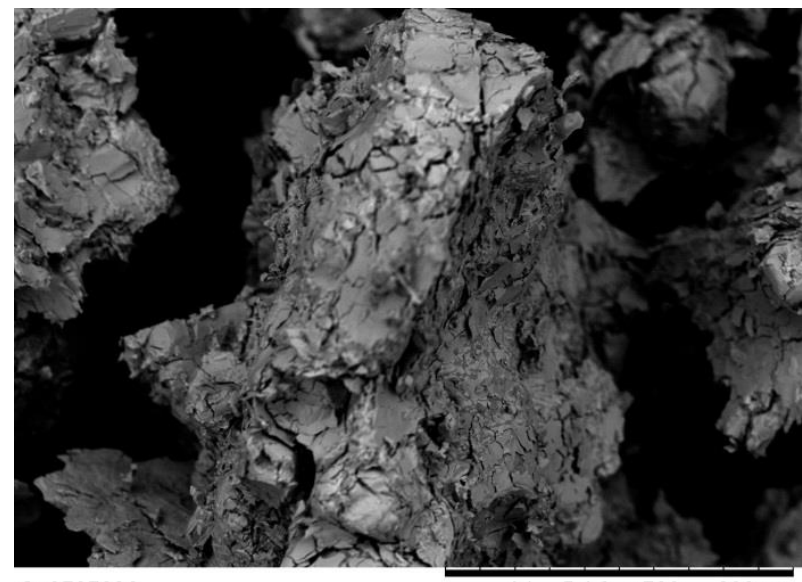

AL $\quad$ D4.0 $\times 500 \quad 200$ um

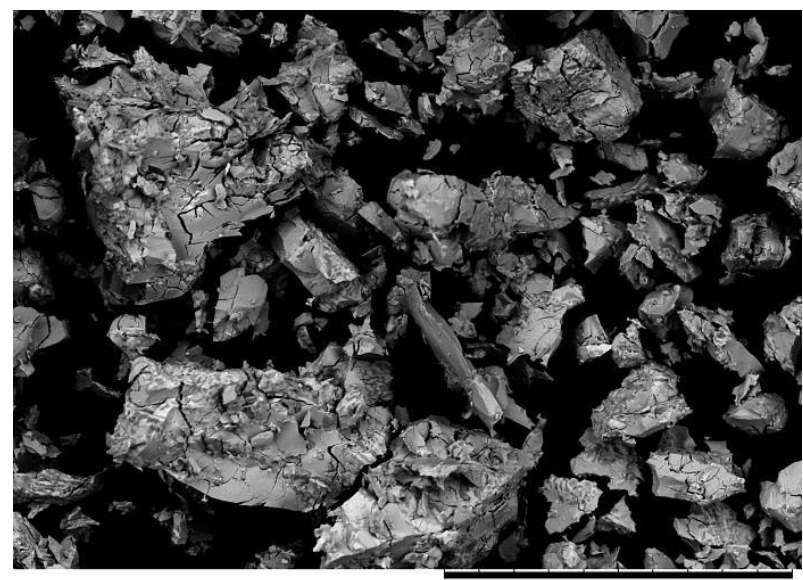

AL $\quad$ D4.4 ×500 200 um

c)

d) 
5.6.15 - Curvas de absorção de hidrogênio e micrografias da liga $\mathrm{La}_{0,7} \mathrm{Mg}_{0,3} \mathrm{Al}_{0,3} \mathrm{Mn}_{0,4} \mathrm{Sn}_{0,5} \mathrm{Ni}_{3,8}$ com TT de $850^{\circ} \mathrm{C}$ por 16 horas.

$\mathrm{Na}$ FIGURA 80 de (a) até (d) estão apresentadas as microestruturas com magnitude 500x, obtidas por MEV das ligas $\mathrm{La}_{0,7} \mathrm{Mg}_{0,3} \mathrm{Al}_{0,3} \mathrm{Mn}_{0,4} \mathrm{Sn}_{0,5} \mathrm{Ni}_{3,8}$ com tratamento térmico de $850^{\circ} \mathrm{C}$ por 16 horas. Sendo que para (a) com pressão de Hidrogênio de 2000 mbar, (b) com pressão de Hidrogênio de 4000 mbar, (c) com pressão de Hidrogênio de 6000 mbar, (d) com pressão de Hidrogênio de 9000 mbar., Todas as pressões promoveram a fragilização desta liga para este tratamento térmico.

Comparando as curvas de absorção para esta liga sem e com TT as curvas de absorção (FIGURAS 71, 73, 75, 772 79) apresentaram mesmas características nas pressões de hidrogênio utilizadas. A diminuição dos defeitos estruturais após TT não influenciaram na absorção de hidrogênio para esta liga.

FIGURA 79 - Curvas de absorção de Hidrogênio pela liga $\mathrm{La}_{0,7} \mathrm{Mg}_{0,3} \mathrm{Al}_{0,3} \mathrm{Mn}_{0,4} \mathrm{Sn}_{0,5} \mathrm{Ni}_{3,8}$ com tratamento térmico de $850^{\circ} \mathrm{C}$ por 16 horas.

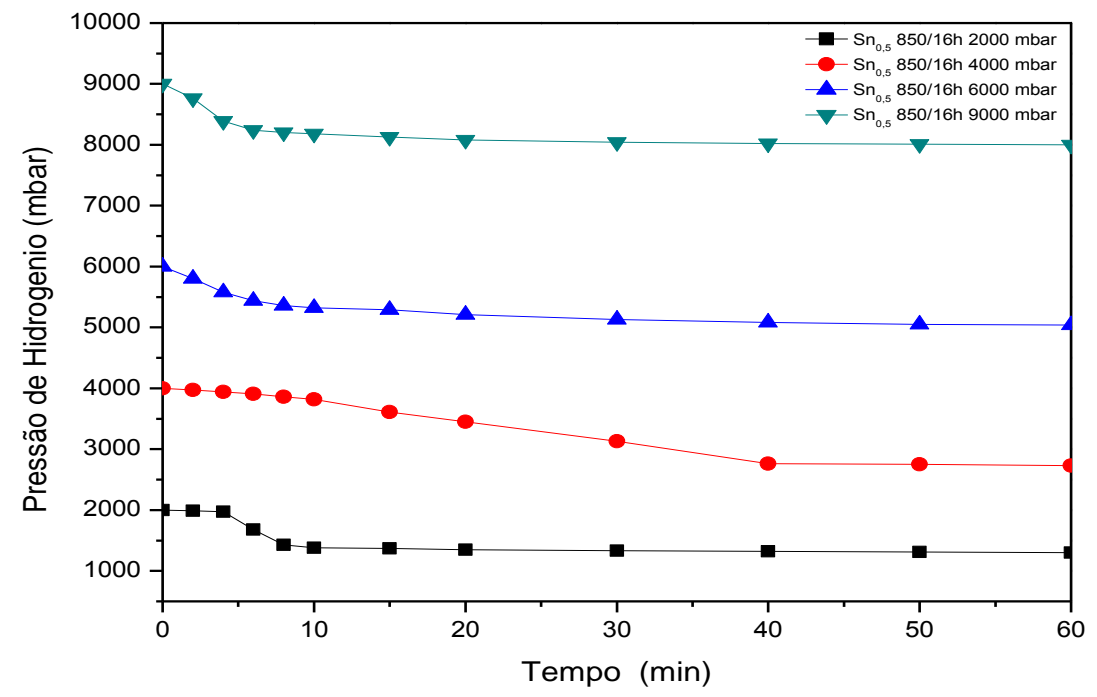


FIGURA 80 - Micrografia com aumento de $500 x$ da liga $\mathrm{La}_{0,7} \mathrm{Mg}_{0,3} \mathrm{Al}_{0,3} \mathrm{Mn}_{0,4} \mathrm{Sn}_{0,5} \mathrm{Ni}_{3,8}$ fragilizada com tratamento térmico de $850^{\circ} \mathrm{C}$ por 16 horas em 2, 46 e 9 bar de hidrogênio por 60 minutos.

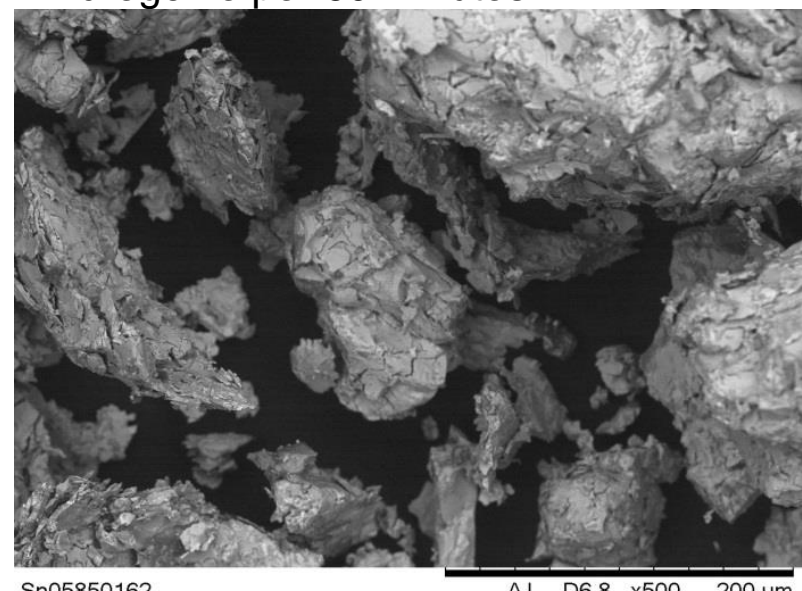

Sn05850162

AL $\quad 06.8 \times 500 \quad 200$ um Sn 05 850-16h 2000 mbar

a)

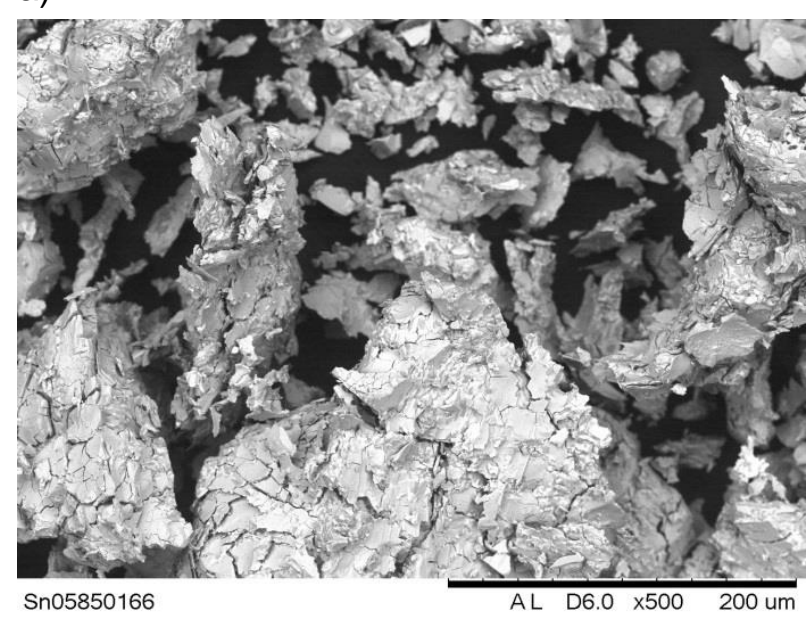
Sn 05 850-16h 6000 mbar

c)

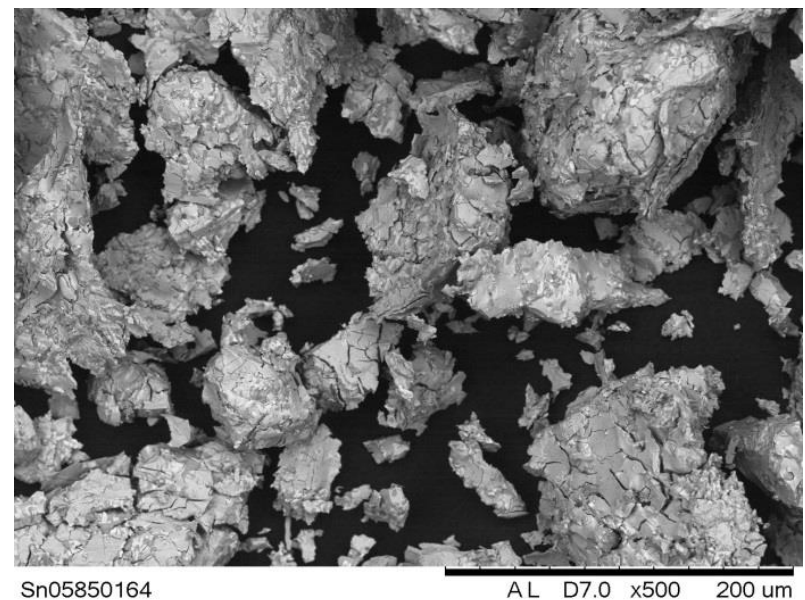

Sn 05 850-16h 4000 mbar

b)

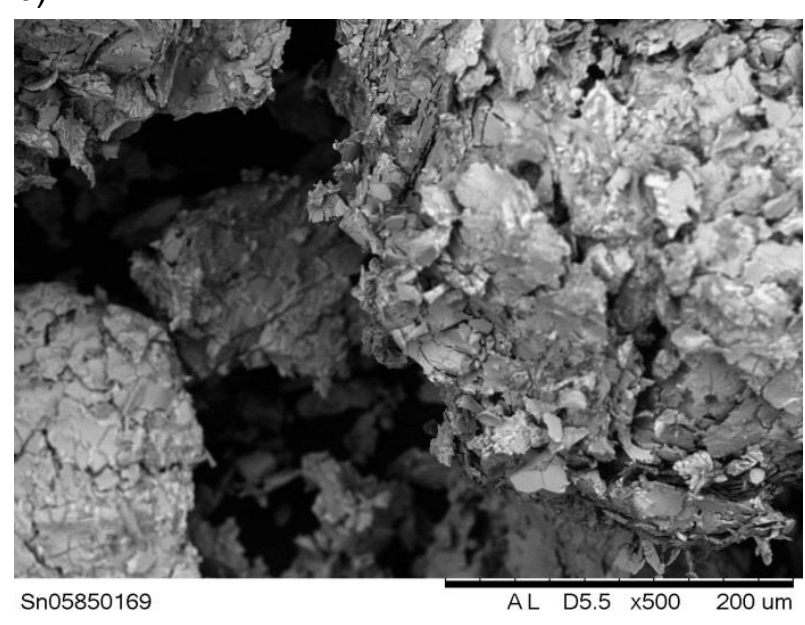

Sn 05 850-16h 9000 mbar

d)

5.6.16 - Curvas de absorção de hidrogênio e micrografias da liga $\mathrm{La}_{0,7} \mathrm{Pr}_{0,3} \mathrm{Al}_{0,3} \mathrm{Mn}_{0,4} \mathrm{Co}_{0,5} \mathrm{Ni}_{3,8}$ sem TT

Na FIGURA 81 estão mostradas as curvas de absorção de hidrogênio pela liga $\mathrm{La}_{0,7} \mathrm{Pr}_{0,3} \mathrm{Al}_{0,3} \mathrm{Mn}_{0,4} \mathrm{Co}_{0,5} \mathrm{Ni}_{3,8}$ sem TT e na FIGURA 82 de (a) até (d) estão apresentadas as micrografias (500x), obtidas por MEV da liga após fragilização sendo: (a) pressão de hidrogênio de 2000 mbar, (b) pressão de hidrogênio de 4000 mbar, (c) pressão de hidrogênio de 6000 mbar e (d) com pressão de hidrogênio de 9000 mbar. 
Pode ser observado que a substituição do $\mathrm{Mg}$ pelo $\operatorname{Pr}$ aumenta o teor de terras raras proporcionando um aumento das fases absorvedoras de hidrogênio, neste caso $\mathrm{LaNi}_{5}$ e $\mathrm{PrNi}_{5}$, como apresentado na TABELA 28. A presença somente destas fases proporcionaram pulverização da liga em tamanhos de partículas menores que $50 \mu \mathrm{m}$, diferente dos resultados obtidos anteriormente.

FIGURA 81 - Curvas de absorção de hidrogênio pela liga $\mathrm{La}_{0,7} \mathrm{Pr}_{0,3} \mathrm{Al}_{0,3} \mathrm{Mn}_{0,4} \mathrm{Co}_{0,5} \mathrm{Ni}_{3,8}$ sem TT.

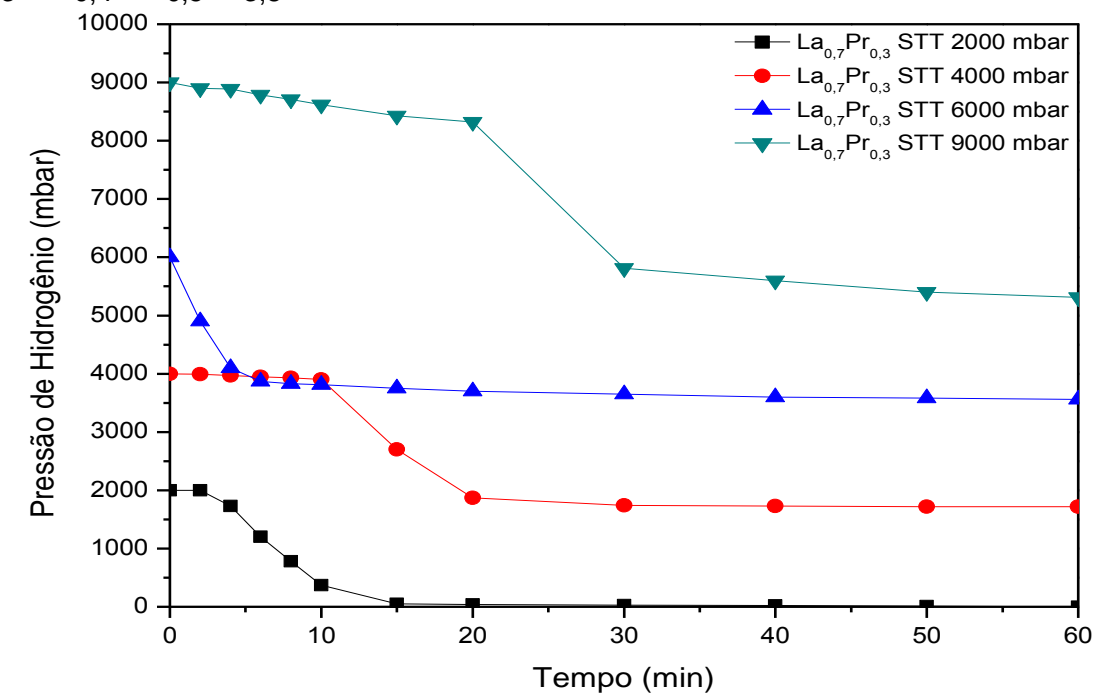


FIGURA 82 - Micrografia com aumento de 500x da liga $\mathrm{La}_{0,7} \mathrm{Pr}_{0,3} \mathrm{Al}_{0,3} \mathrm{Mn}_{0,4} \mathrm{Co}_{0,5} \mathrm{Ni}_{3,8}$ fragilizada sem tratamento térmico em 2, 46 e 9 bar de hidrogênio por 60 minutos.
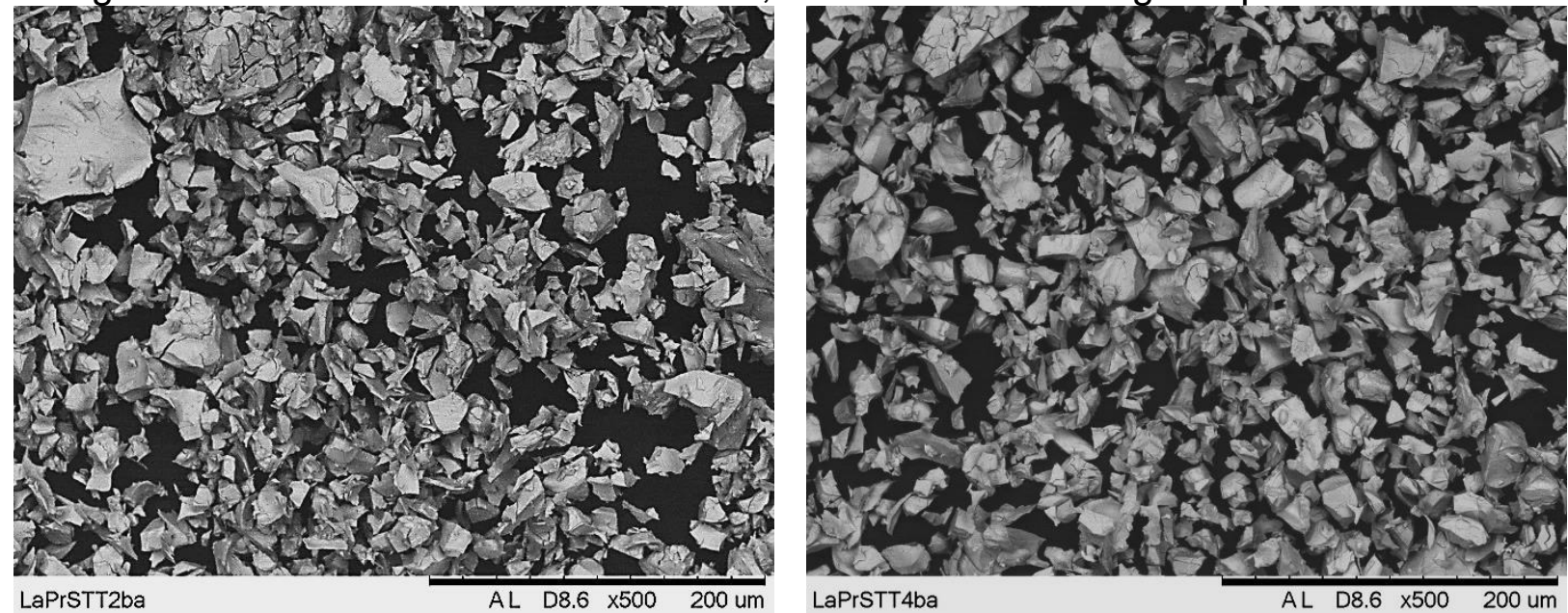

a)

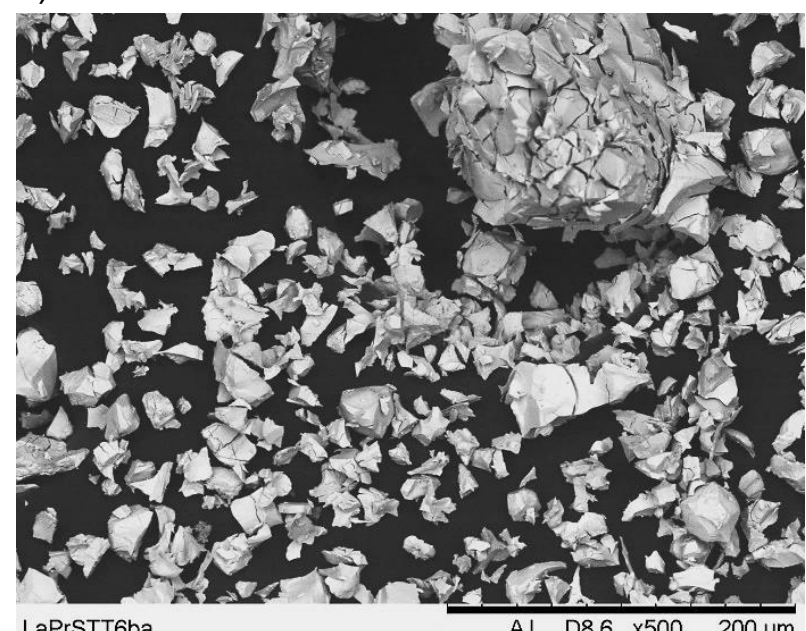

c)

b)

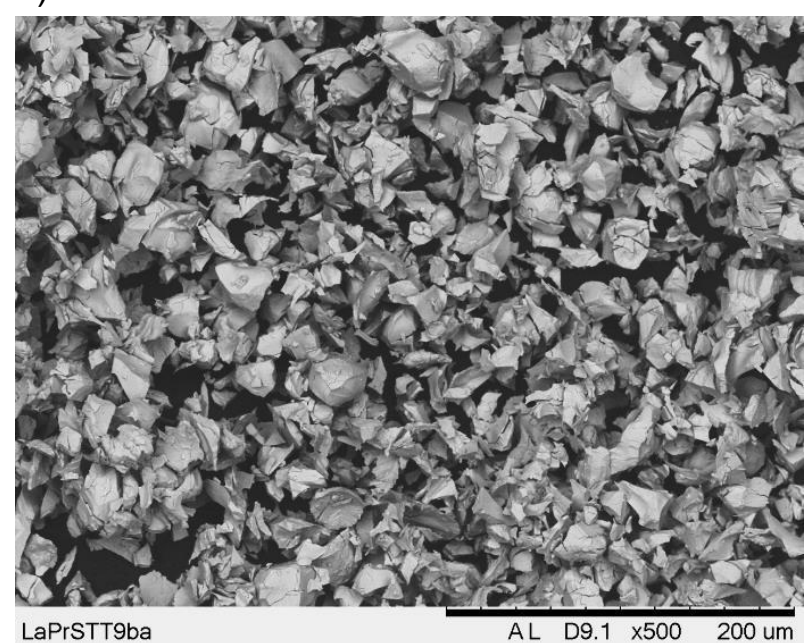

d)

5.6.17 - Curvas de absorção de hidrogênio e micrografias da liga $\mathrm{La}_{0,7} \mathrm{Pr}_{0,3} \mathrm{Al}_{0,3} \mathrm{Mn}_{0,4} \mathrm{Co}_{0,5} \mathrm{Ni}_{3,8}$ com TT de $750^{\circ} \mathrm{C}$ por 9 horas

Na FIGURA 83 estão mostradas as curvas de absorção de hidrogênio pela liga $\mathrm{La}_{0,7} \mathrm{Pr}_{0,3} \mathrm{Al}_{0,3} \mathrm{Mn}_{0,4} \mathrm{Co}_{0,5} \mathrm{Ni}_{3,8}$ com TT de $750^{\circ} \mathrm{C}$ por 9 horas e na FIGURA 84 de (a) até (d) estão apresentadas as micrografias (500x), obtidas por MEV da liga após fragilização sendo: (a) pressão de hidrogênio de 2000 mbar, (b) pressão de hidrogênio de 4000 mbar, (c) pressão de hidrogênio de 6000 mbar e (d) com pressão de hidrogênio de 9000 mbar. 
Pode ser observado que a substituição do $\mathrm{Mg}$ pelo $\operatorname{Pr}$ aumenta o teor de terras raras proporcionando um aumento das fases absorvedoras de hidrogênio, neste caso $\mathrm{LaNi}_{5}$ e $\mathrm{PrNi}_{5}$, como apresentado na TABELA 29. A presença somente destas fases proporcionaram pulverização da liga em tamanhos de partículas menores que $50 \mu \mathrm{m}$.

Comparando o teor de hidrogênio absorvido pela liga com TT foi menor do que para a liga sem TT, decorrente provavelmente pela diminuição dos defeitos estruturais na liga bruta de fusão após TT.

\subsubsection{8 - Curvas de absorção de hidrogênio e micrografias da liga La $0,7 \mathrm{Pr}_{0,3} \mathrm{Al}_{0,3} \mathrm{Mn}_{0,4} \mathrm{Co}_{0,5} \mathrm{Ni}_{3,8}$ com TT de $750^{\circ} \mathrm{C}$ por 16 horas.}

Na FIGURA 85 estão mostradas as curvas de absorção de hidrogênio pela liga $\mathrm{La}_{0,7} \mathrm{Pr}_{0,3} \mathrm{Al}_{0,3} \mathrm{Mn}_{0,4} \mathrm{Co}_{0,5} \mathrm{Ni}_{3,8}$ com TT de $750^{\circ} \mathrm{C}$ por 16 horas e na FIGURA 86 de (a) até (d) estão apresentadas as micrografias (500x), obtidas por MEV da liga após fragilização sendo: (a) pressão de hidrogênio de 2000 mbar, (b) pressão de hidrogênio de 4000 mbar, (c) pressão de hidrogênio de 6000 mbar e (d) com pressão de hidrogênio de 9000 mbar.

Observou-se que a substituição do Mg pelo $\operatorname{Pr}$ aumenta o teor de terras raras proporcionando um aumento da fração das fases absorvedoras de hidrogênio, $\mathrm{LaNi}_{5}$ e $\mathrm{PrNi}_{5}$, como apresentado na TABELA 30 após o refinamento obtido pelo método de Rietveld. A presença somente destas fases proporcionaram uma maior velocidade de fragilização, pulverizando a liga em tamanhos de partículas menores que $50 \mu \mathrm{m}$, diferente dos resultados obtidos anteriormente. 
FIGURA 83 - Curvas de absorção de hidrogênio pela liga $\mathrm{La}_{0,7} \mathrm{Pr}_{0,3} \mathrm{Al}_{0,3} \mathrm{Mn}_{0,4} \mathrm{Co}_{0,5} \mathrm{Ni}_{3,8}$ com TT de $750^{\circ} \mathrm{C}$ por 9 horas.

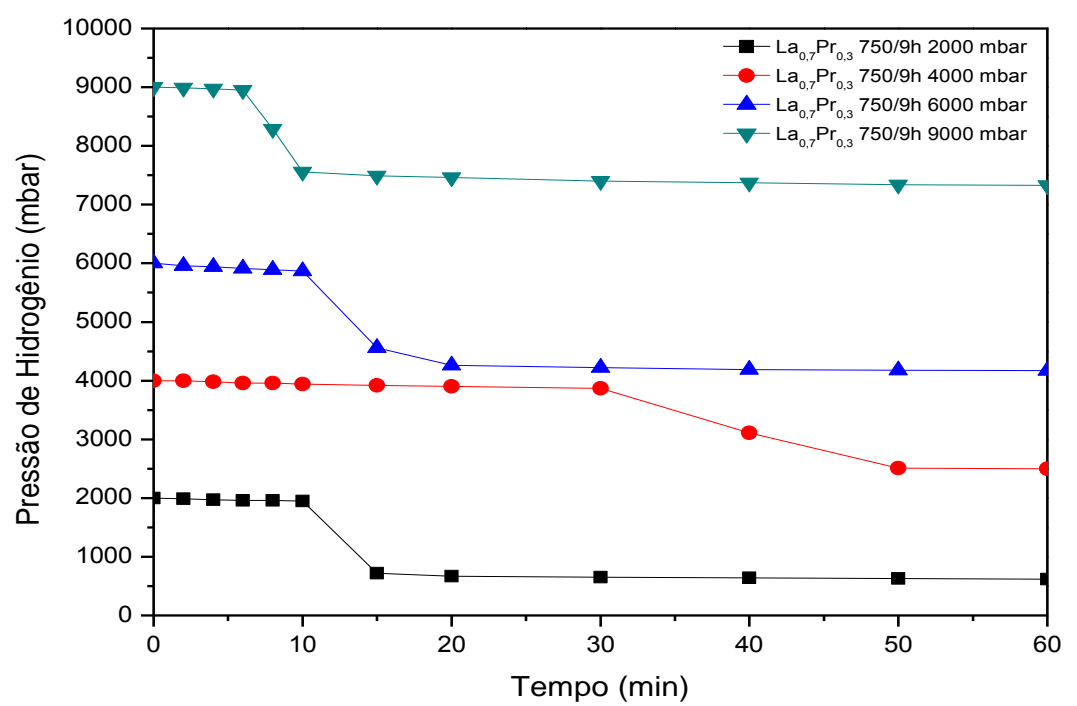

FIGURA 84 - Micrografias $(500 x)$ da liga $\mathrm{La}_{0,7} \mathrm{Pr}_{0,3} \mathrm{Al}_{0,3} \mathrm{Mn}_{0,4} \mathrm{Co}_{0,5} \mathrm{Ni}_{3,8}$ com TT de 750 por 9 horas fragilizada em 2, 46 e 9 bar de hidrogênio por 60 minutos.
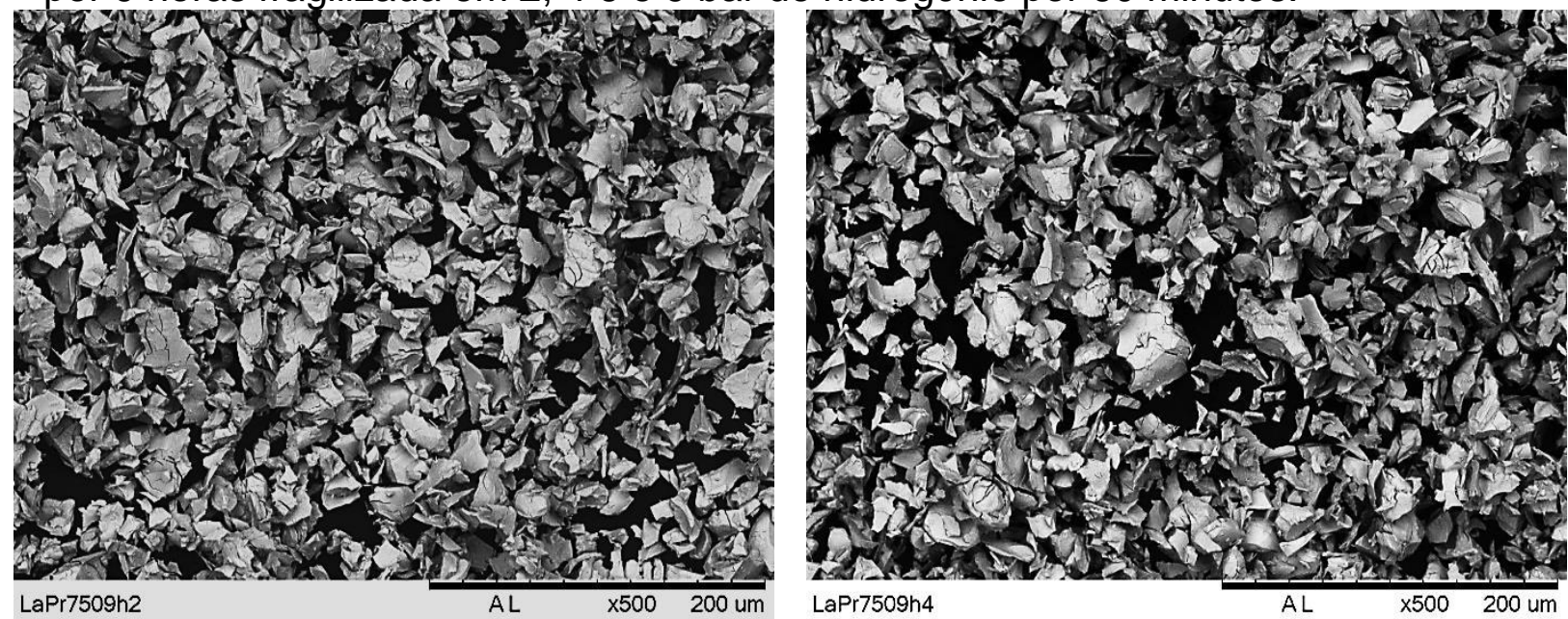

a)

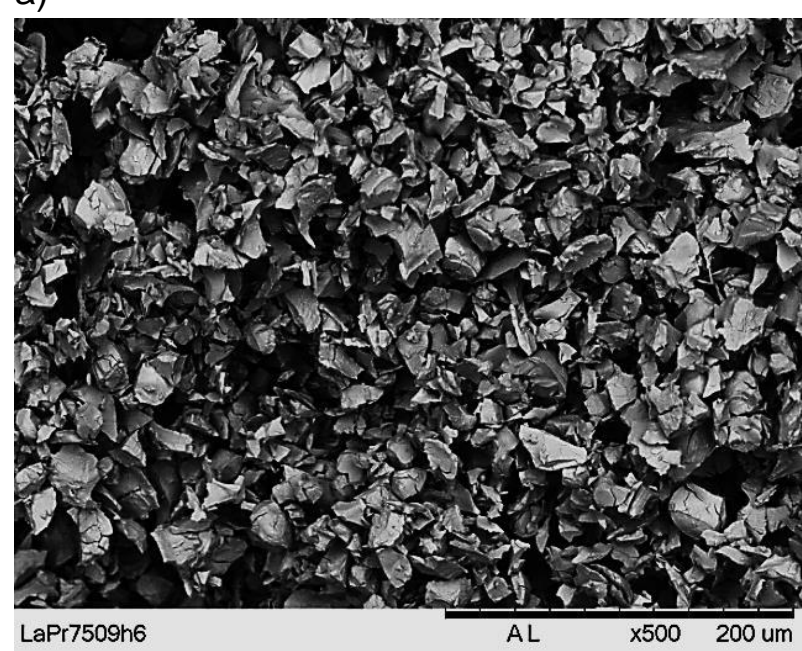

b)

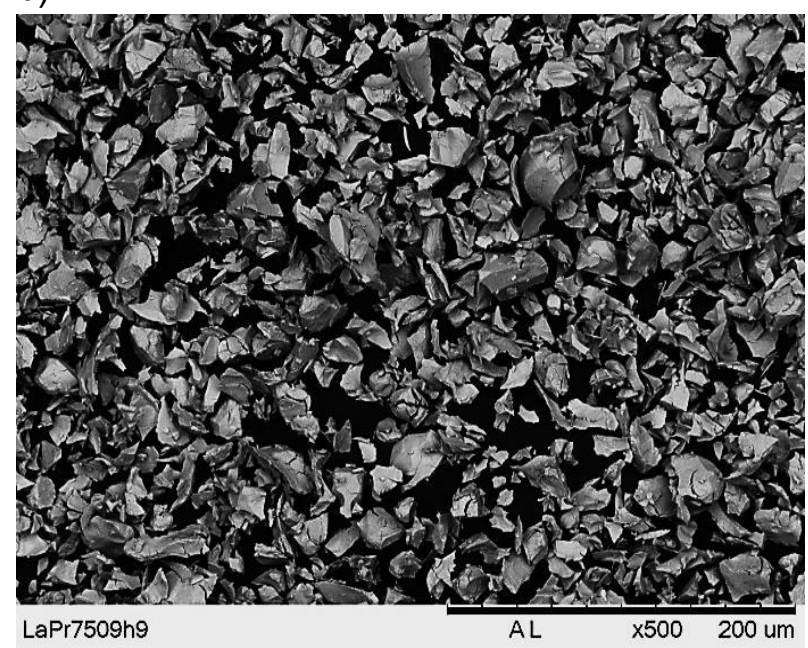

C)

d) 
FIGURA 85 - Curvas de absorção de Hidrogênio pela liga $\mathrm{La}_{0,7} \mathrm{Pr}_{0,3} \mathrm{Al}_{0,3} \mathrm{Mn}_{0,4} \mathrm{Co}_{0,5} \mathrm{Ni}_{3,8}$ com tratamento térmico de $750^{\circ} \mathrm{C}$ por 16 horas.

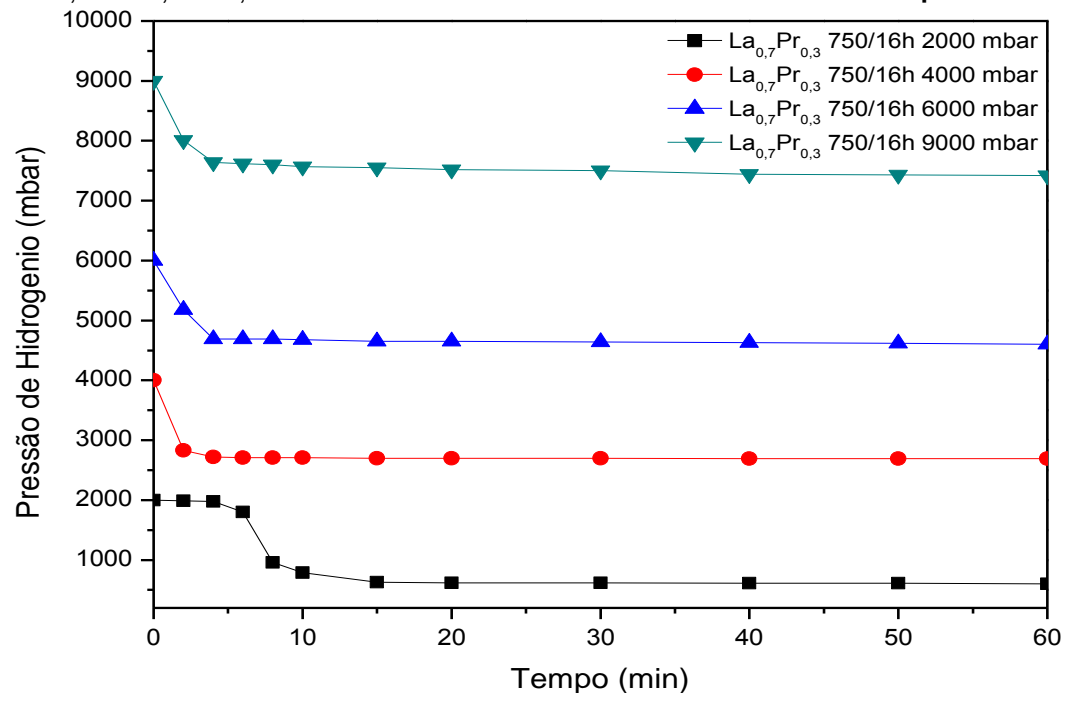

FIGURA 86 - Micrografia com aumento de 500x da liga $\mathrm{La}_{0,7} \mathrm{Pr}_{0,3} \mathrm{Al}_{0,3} \mathrm{Mn}_{0,4} \mathrm{Co}_{0,5} \mathrm{Ni}_{3,8}$ fragilizada com tratamento térmico de 750 por 16 horas em 2, 46 e 9 bar de hidrogênio por 60 minutos.
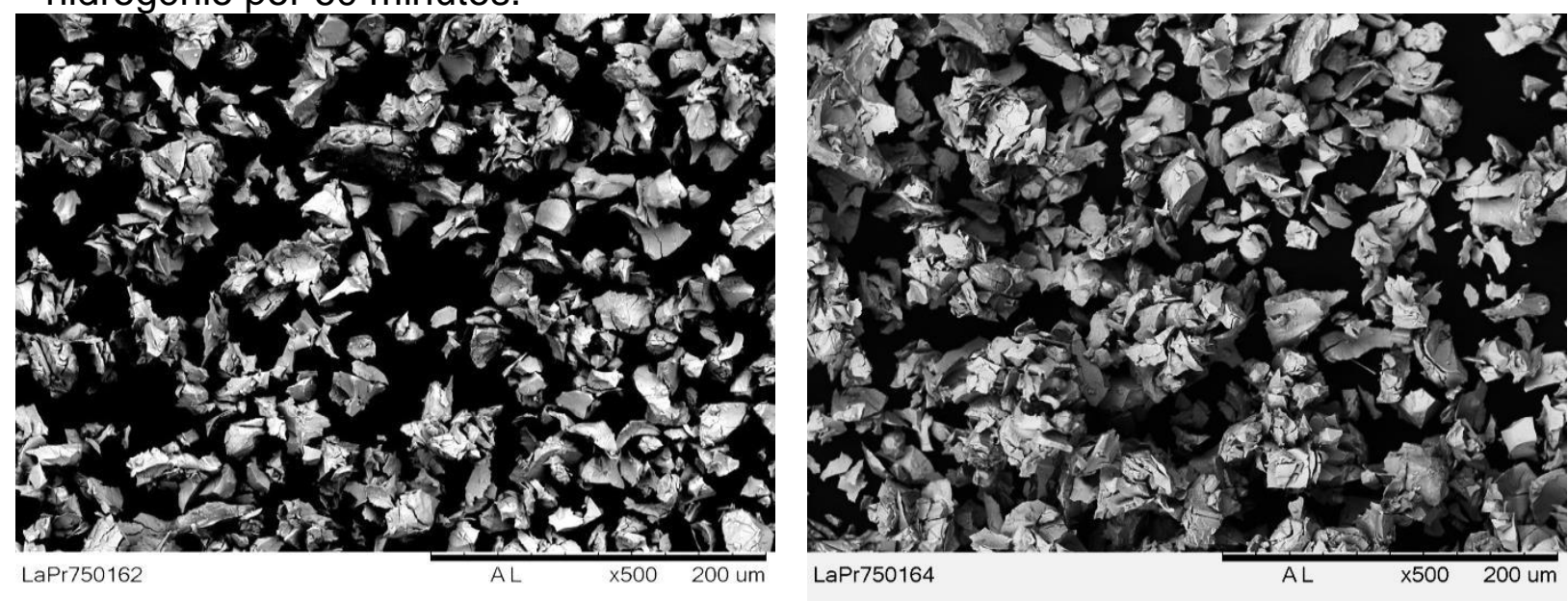

LaPr 750-16h 2000 mbar

a)

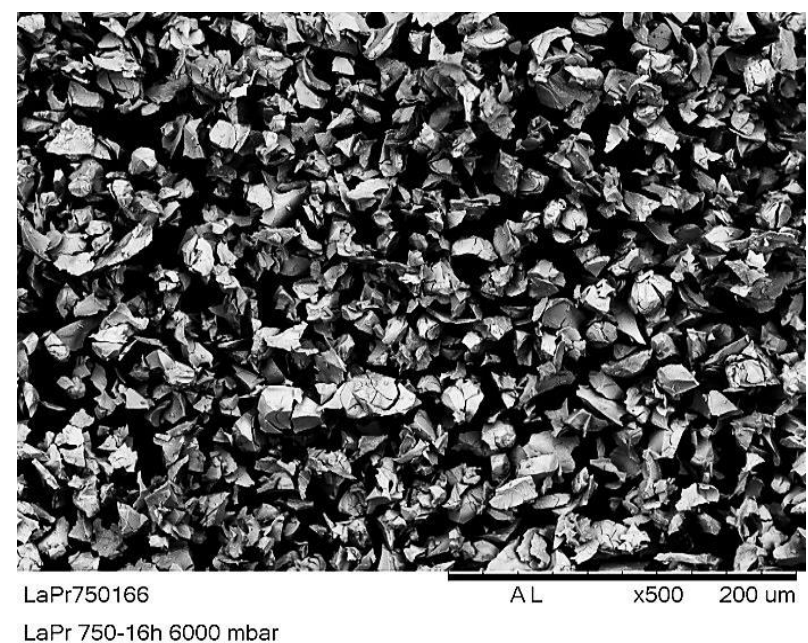

LaPr 750-16h 4000 mbar

b)

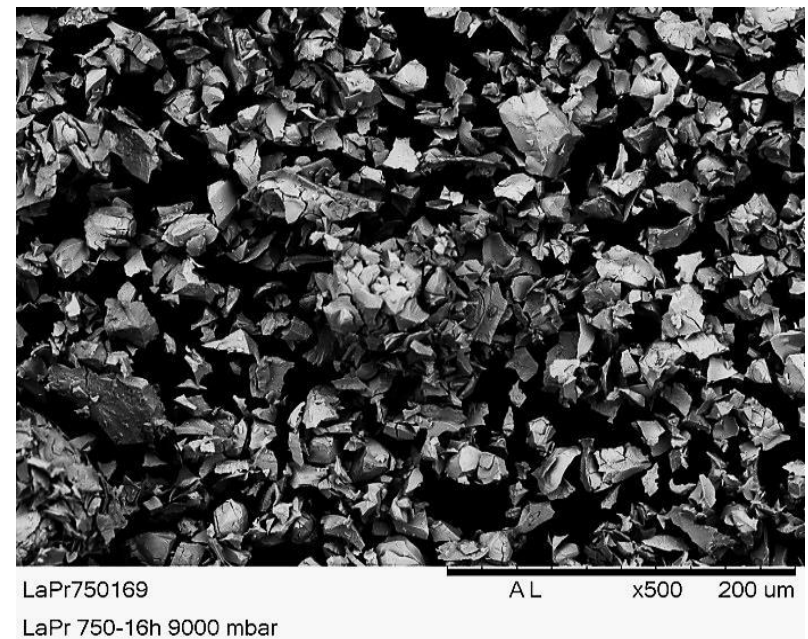

C)

d) 
5.6.19 - Curvas de absorção de hidrogênio e micrografias da liga $\mathrm{La}_{0,7} \mathrm{Pr}_{0,3} \mathrm{Al}_{0,3} \mathrm{Mn}_{0,4} \mathrm{Co}_{0,5} \mathrm{Ni}_{3,8}$ com TT de $850^{\circ} \mathrm{C}$ por 9 horas.

Na FIGURA 87 estão mostradas as curvas de absorção de hidrogênio pela liga $\mathrm{La}_{0,7} \mathrm{Pr}_{0,3} \mathrm{Al}_{0,3} \mathrm{Mn}_{0,4} \mathrm{Co}_{0,5} \mathrm{Ni}_{3,8}$ com TT de $850^{\circ} \mathrm{C}$ por 9 horas e na FIGURA $88 \mathrm{de}$ (a) até (d) estão apresentadas as micrografias (500x), obtidas por MEV da liga após fragilização sendo: (a) pressão de hidrogênio de 2000 mbar, (b) pressão de hidrogênio de 4000 mbar, (c) pressão de hidrogênio de 6000 mbar e (d) com pressão de hidrogênio de 9000 mbar.

Pode ser observado que a substituição do Mg pelo Pr aumenta o teor de terras raras proporcionando um aumento das fases absorvedoras de hidrogênio, neste caso $\mathrm{LaNi}_{5}$ e $\mathrm{PrNi}_{5}$, como apresentado na TABELA 31. A presença somente destas fases proporcionaram pulverização da liga em tamanhos de partículas menores que $50 \mu \mathrm{m}$, diferente dos resultados obtidos anteriormente.

5.6.20 - Curvas de absorção de hidrogênio e micrografias da liga $\mathrm{La}_{0,7} \mathrm{Pr}_{0,3} \mathrm{Al}_{0,3} \mathrm{Mn}_{0,4} \mathrm{Co}_{0,5} \mathrm{Ni}_{3,8}$ com TT de $850^{\circ} \mathrm{C}$ por 16 horas.

Na FIGURA 89 estão mostradas as curvas de absorção de hidrogênio pela liga La ${ }_{0,7} \mathrm{Pr}_{0,3} \mathrm{Al}_{0,3} \mathrm{Mn}_{0,4} \mathrm{Co}_{0,5} \mathrm{Ni}_{3,8}$ com TT de $850^{\circ} \mathrm{C}$ por 16 horas e na FIGURA 90 de (a) até (d) estão apresentadas as micrografias (500x), obtidas por MEV da liga após fragilização sendo: (a) pressão de hidrogênio de 2000 mbar, (b) pressão de hidrogênio de 4000 mbar, (c) pressão de hidrogênio de 6000 mbar e (d) com pressão de hidrogênio de 9000 mbar.

Neste TT o resultado da absorção de hidrogênio manteve o comportamento de absorção semelhante a todos os TT realizados para esta liga proporcionando sua pulverização em tamanhos de partículas menores que $50 \mu \mathrm{m}$. 
FIGURA 87 - Curvas de absorção de Hidrogênio pela liga $\mathrm{La}_{0,7} \mathrm{Pr}_{0,3} \mathrm{Al}_{0,3} \mathrm{Mn}_{0,4} \mathrm{Co}_{0,5} \mathrm{Ni}_{3,8}$ com tratamento térmico de $850^{\circ} \mathrm{C}$ por 9 horas

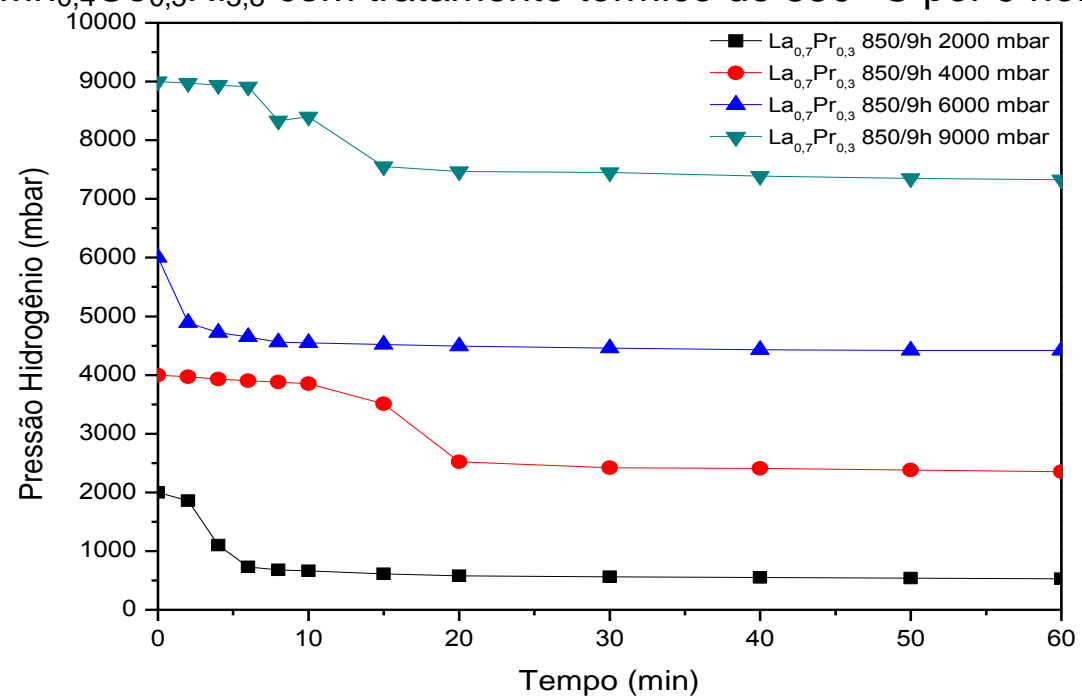

FIGURA 88 - Micrografia com aumento de 500x da liga $\mathrm{La}_{0,7} \mathrm{Pr}_{0,3} \mathrm{Al}_{0,3} \mathrm{Mn}_{0,4} \mathrm{Co}_{0,5} \mathrm{Ni}_{3,8}$ fragilizada com tratamento térmico de 850 por 9 horas em 2, 46 e 9 bar de hidrogênio por 60 minutos.

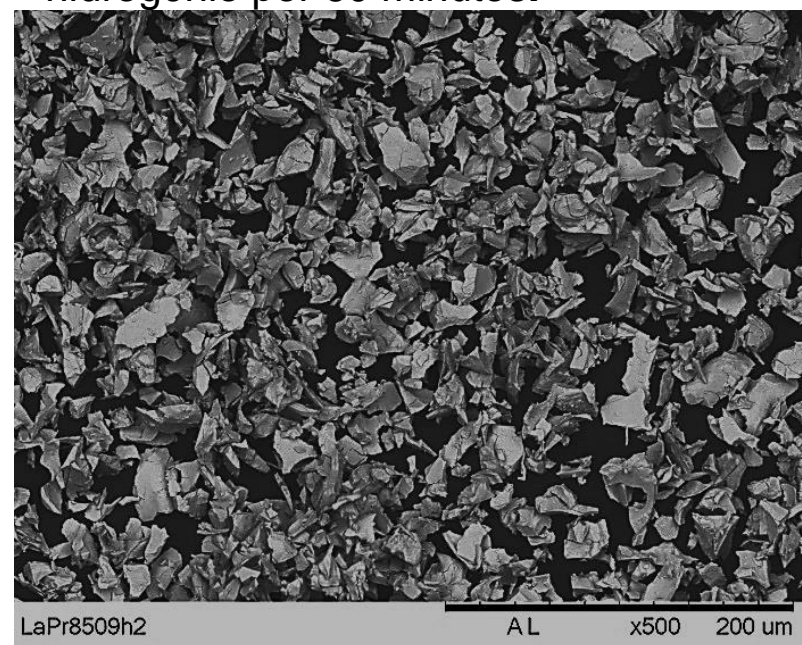

a)

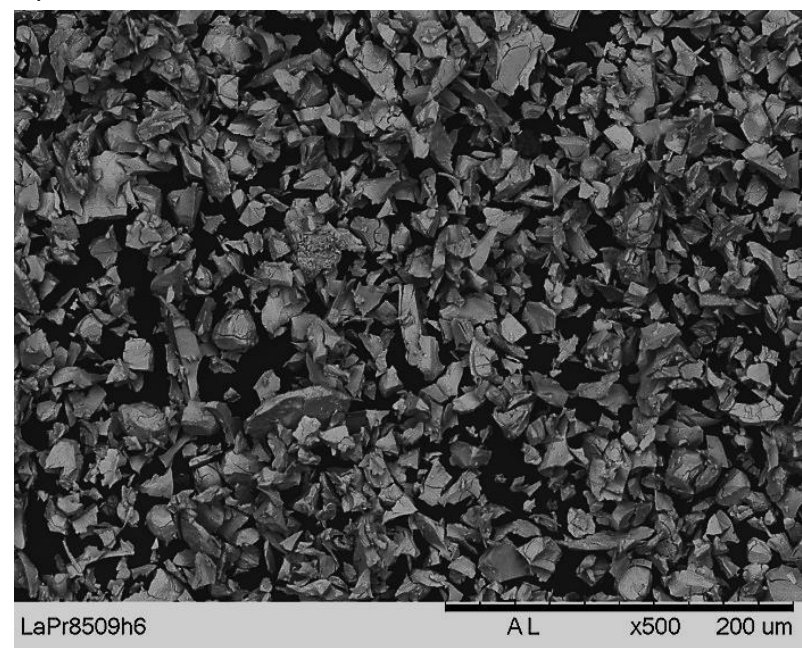

C)

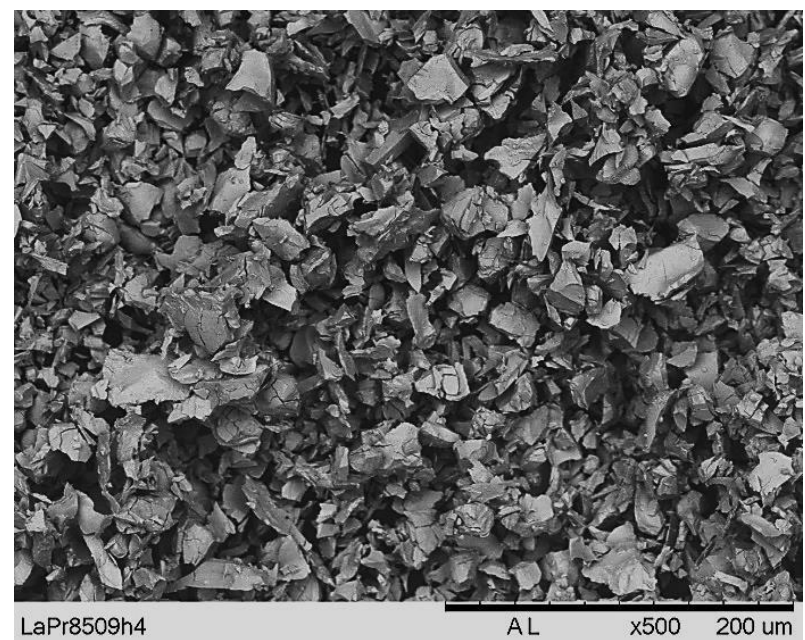

b)

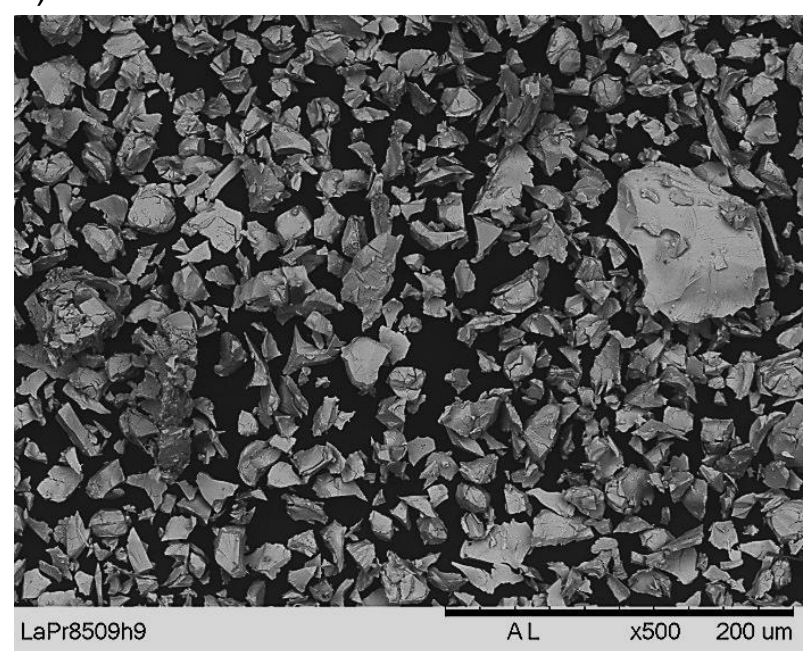

d) 
FIGURA 89 - Curvas de absorção de Hidrogênio pela liga $\mathrm{La}_{0,7} \mathrm{Pr}_{0,3} \mathrm{Al}_{0,3} \mathrm{Mn}_{0,4} \mathrm{Co}_{0,5} \mathrm{Ni}_{3,8}$ com tratamento térmico de $850^{\circ} \mathrm{C}$ por 16 horas.

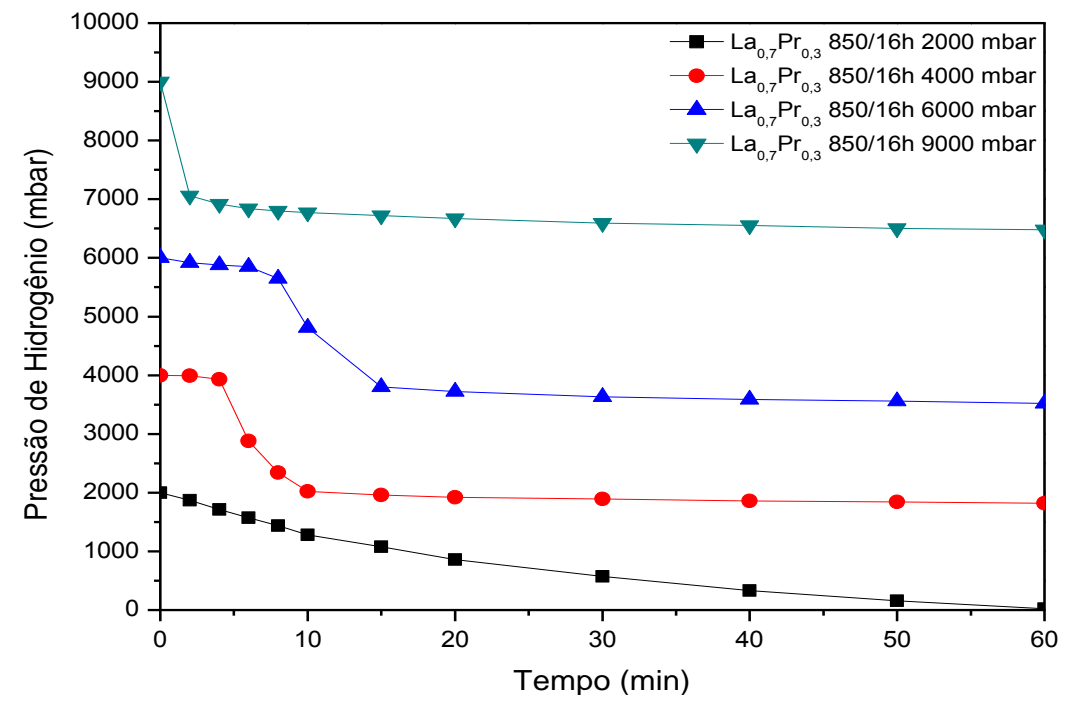

FIGURA 90 - Micrografia com aumento de 500x da liga $\mathrm{La}_{0,7} \mathrm{Pr}_{0,3} \mathrm{Al}_{0,3} \mathrm{Mn}_{0,4} \mathrm{Co}_{0,5} \mathrm{Ni}_{3,8}$ fragilizada com tratamento térmico de 850 por 16 horas em 2, 46 e 9 bar de hidrogênio por 60 minutos.

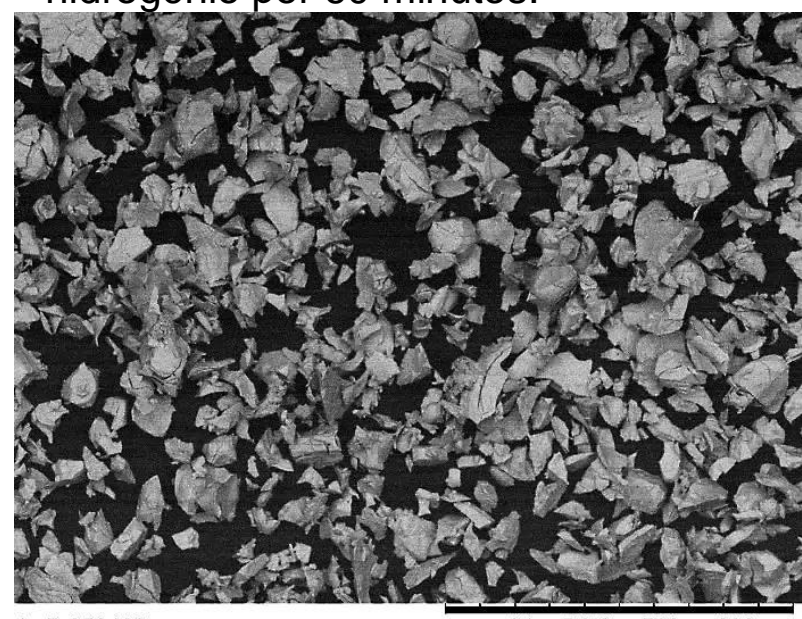

LaPr850162

a)

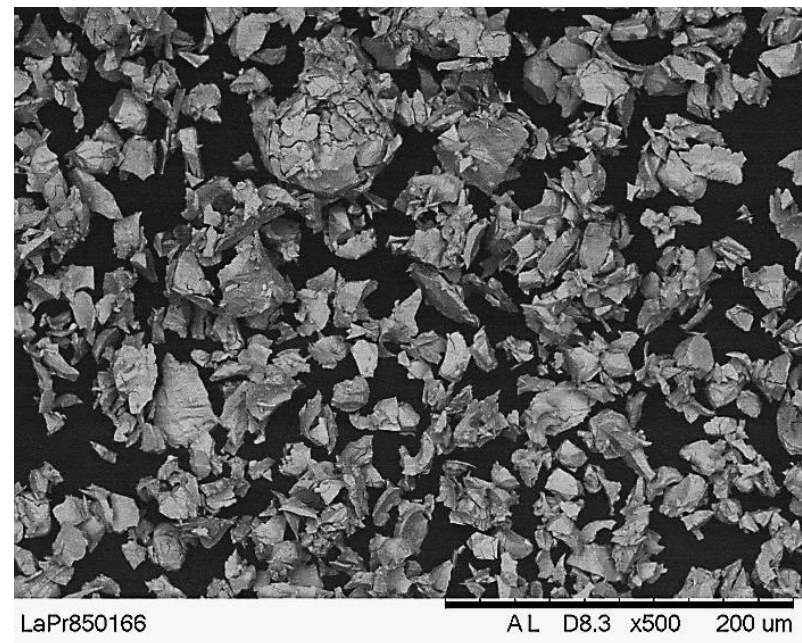

c)

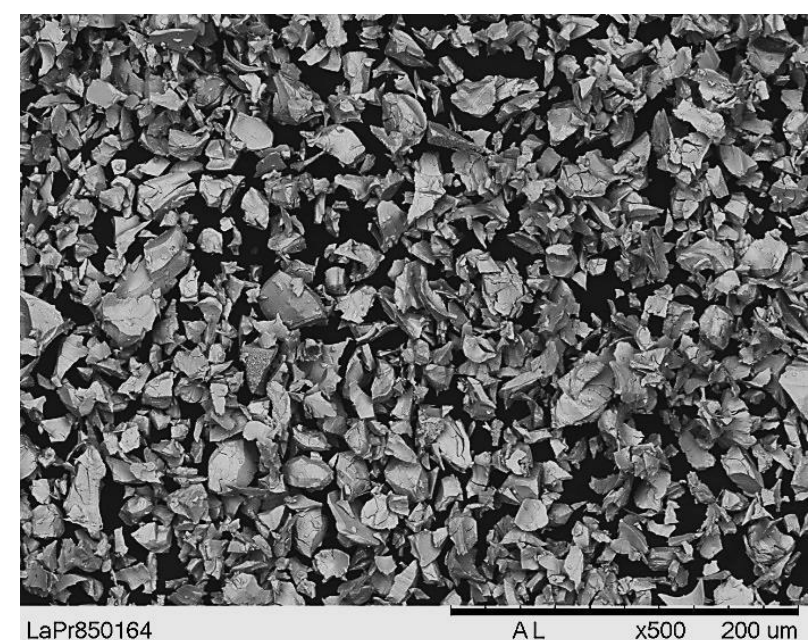

b)

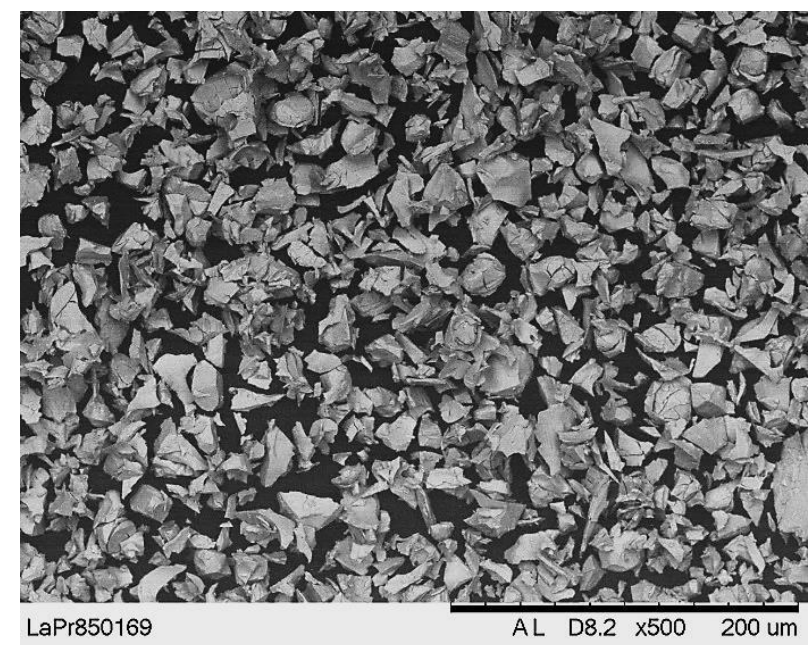

d) 


\subsubsection{1 - Curvas de absorção de hidrogênio e micrografias da liga TT $\mathrm{Pr}_{0,7} \mathrm{Mg}_{0,3} \mathrm{Al}_{0,3} \mathrm{Mn}_{0,4} \mathrm{Co}_{0,5} \mathrm{Ni}_{3,8}$ sem TT.}

Na FIGURA 91 estão mostradas as curvas de absorção de hidrogênio pela liga $\operatorname{Pr}_{0,7} \mathrm{Mg}_{0,3} \mathrm{Al}_{0,3} \mathrm{Mn}_{0,4} \mathrm{Co}_{0,5} \mathrm{Ni}_{3,8}$ sem TT e na FIGURA 92 de (a) e (b) estão apresentadas as micrografias (500x), obtidas por MEV da liga após fragilização sendo: (a) pressão de hidrogênio de 6000 mbar e (b) com pressão de hidrogênio de 9000 mbar.

Com a substituição do La pelo Pr para a liga sem TT, as fases absorvedoras de hidrogênio são $\mathrm{PrNi}_{5}$ e $\mathrm{PrMg}_{2} \mathrm{Ni}_{9}$ (TABELA 33) enquanto que, para a liga $\mathrm{La}_{0,7} \mathrm{Mg}_{0,3} \mathrm{Al}_{0,3} \mathrm{Mn}_{0,4} \mathrm{Co}_{0,5} \mathrm{Ni}_{3,8}$ as fases foram LaNii e $\mathrm{LaMg}_{2} \mathrm{Ni}_{9}$ (TABELA13).

Os resultados indicam que as fases formadas na liga com a substituição do La pelo Pr não são boas absorvedora de hidrogênio nas condições de pressão e temperatura estabelecidas neste trabalho.

Esta substituição provocou a diminuição dos parâmetros de rede e do volume da célula unitária principalmente da fase (AIMn) $\mathrm{Ni}_{3}$, proporcionando uma diminuição na absorção de hidrogênio pela liga e consequentemente diminui o valor da capacidade máxima de descarga como já podemos observar nos itens 5.4 .5 e 5.5.2e (Gao et al, 2008; Liao et. al, 2004).

Estas fases absorveram baixa quantidade de hidrogênio na pressão de 6000 e 9000 mbar, provocando algumas trincas na superfície da liga, não promovendo a decrepitação da liga e para baixa pressão, 2000 e 4000 mbar não ocorreu a absorção de hidrogênio. 
FIGURA 91 - Curvas de absorção de Hidrogênio pela liga $\operatorname{Pr}_{0,7} \mathrm{Mg}_{0,3} \mathrm{Al}_{0,3} \mathrm{Mn}_{0,4} \mathrm{C}_{0,5} \mathrm{Ni}_{3,8}$ sem tratamento térmico.

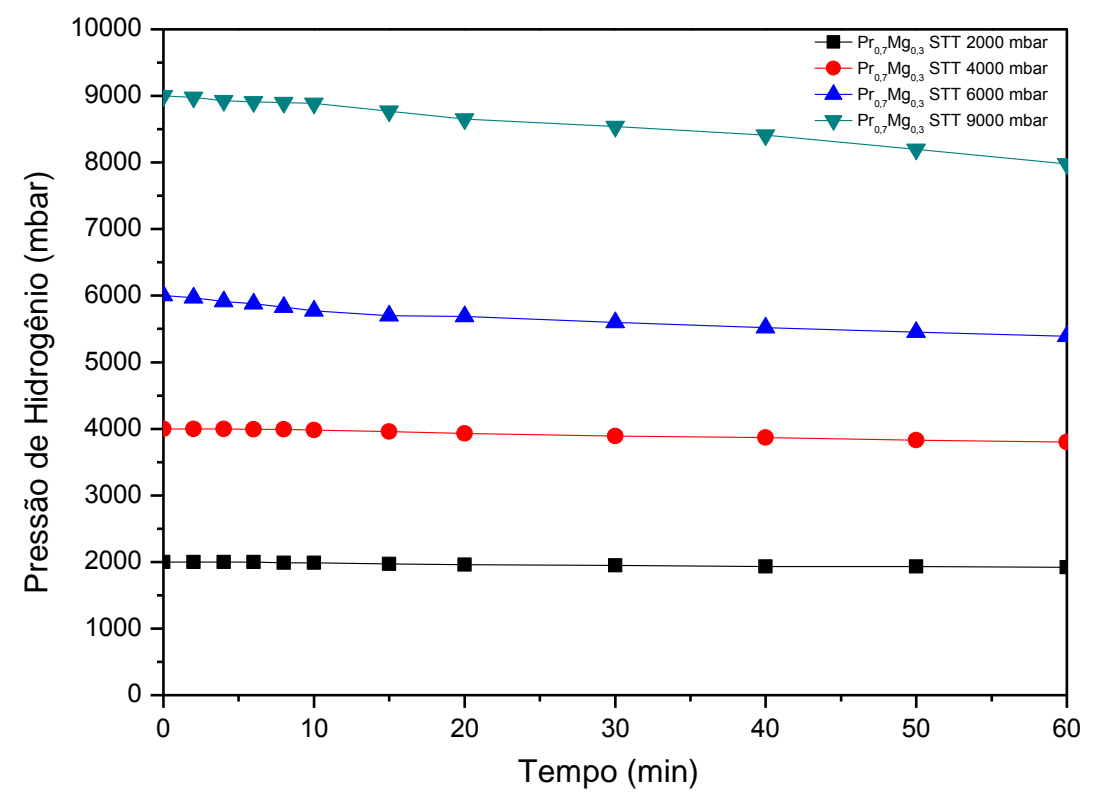

FIGURA 92 - Micrografia com aumento de 500x da liga $\operatorname{Pr}_{0,7} \mathrm{Mg}_{0,3} \mathrm{Al}_{0,3} \mathrm{Mn}_{0,4} \mathrm{Co}_{0,5} \mathrm{Ni}_{3,8}$ fragilizada sem tratamento térmico em 6 e 9 bar de hidrogênio por 60 minutos.
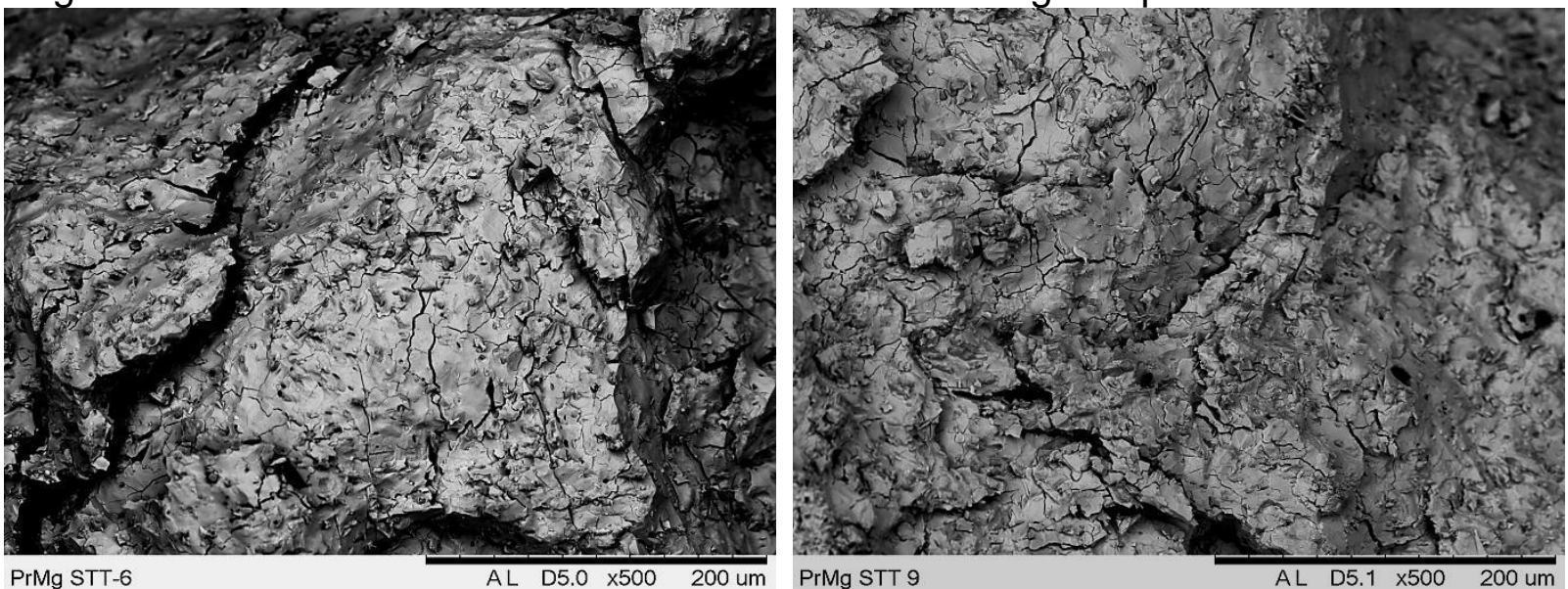

a)

b) 
5.6.22 - Curvas de absorção de hidrogênio e micrografias da liga TT $\mathrm{Pr}_{0,7} \mathrm{Mg}_{0,3} \mathrm{Al}_{0,3} \mathrm{Mn}_{0,4} \mathrm{Co}_{0,5} \mathrm{Ni}_{3,8}$ com TT em $750^{\circ} \mathrm{C}$ por 9 horas.

Na FIGURA 93 estão mostradas as curvas de absorção de hidrogênio pela liga $\operatorname{Pr}_{0,7} \mathrm{Mg}_{0,3} \mathrm{Al}_{0,3} \mathrm{Mn}_{0,4} \mathrm{Co}_{0,5} \mathrm{Ni}_{3,8}$ com TT de $750^{\circ} \mathrm{C}$ por 9 horas e na FIGURA 94 de (a) e (b) estão apresentadas as micrografias (500x), obtidas por MEV da liga após fragilização sendo: (a) pressão de hidrogênio de 6000 mbar e (b) com pressão de hidrogênio de 9000 mbar. Resultados de absorção de hidrogênio foram similares à liga sem TT.

As fases absorvedoras de hidrogênio foram as mesmas da liga sem TT, $\mathrm{PrNi}_{5}$ e $\mathrm{PrMg}_{2} \mathrm{Ni}_{9}$ (TABELA 34), mantendo baixa quantidade de hidrogênio absorvido somente na pressão de 6000 e 9000 mbar.

FIGURA 93 - Curvas de absorção de Hidrogênio pela liga $\mathrm{Pr}_{0,7} \mathrm{Mg}_{0,3} \mathrm{Al}_{0,3} \mathrm{Mn}_{0,4} \mathrm{Co}_{0,5} \mathrm{Ni}_{3,8}$ com tratamento térmico de $750^{\circ} \mathrm{C}$ por 9 horas.

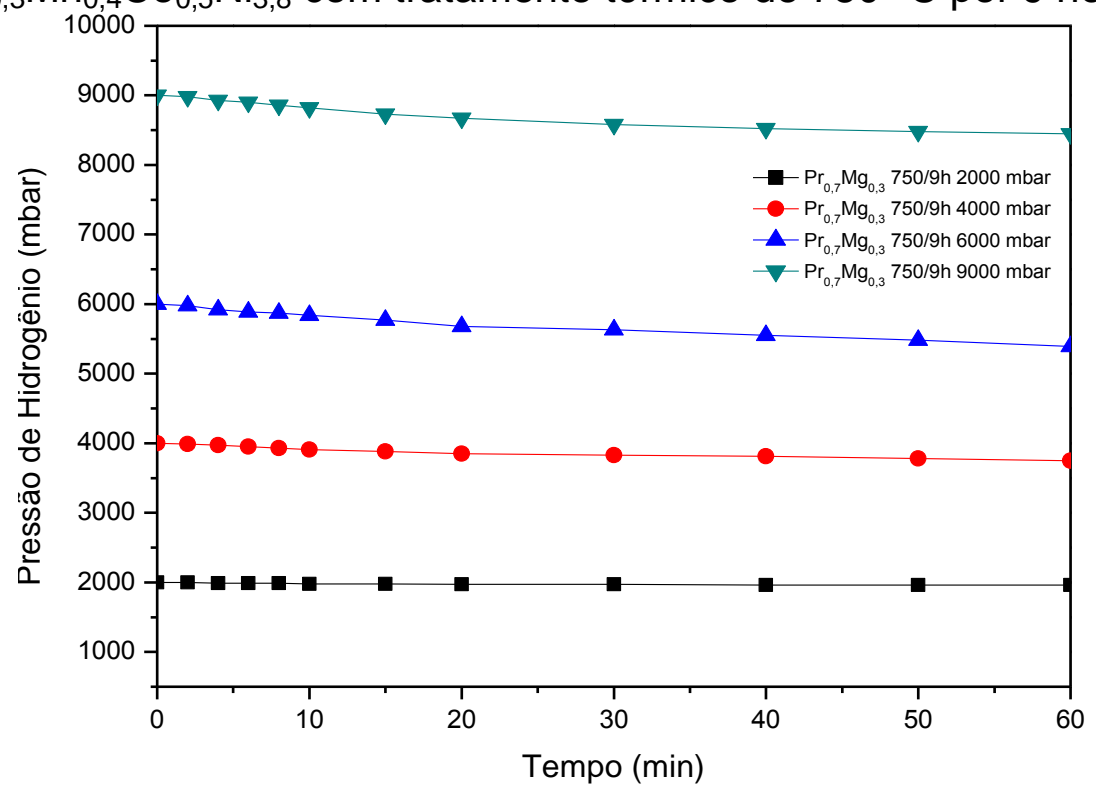


FIGURA 94 - Micrografia com aumento de 500x da liga $\operatorname{Pr}_{0,7} \mathrm{Mg}_{0,3} \mathrm{Al}_{0,3} \mathrm{Mn}_{0,4} \mathrm{Co}_{0,5} \mathrm{Ni}_{3,8}$ fragilizada com tratamento térmico de 750 por 9 horas em 6 e 9 bar de hidrogênio por 60 minutos.

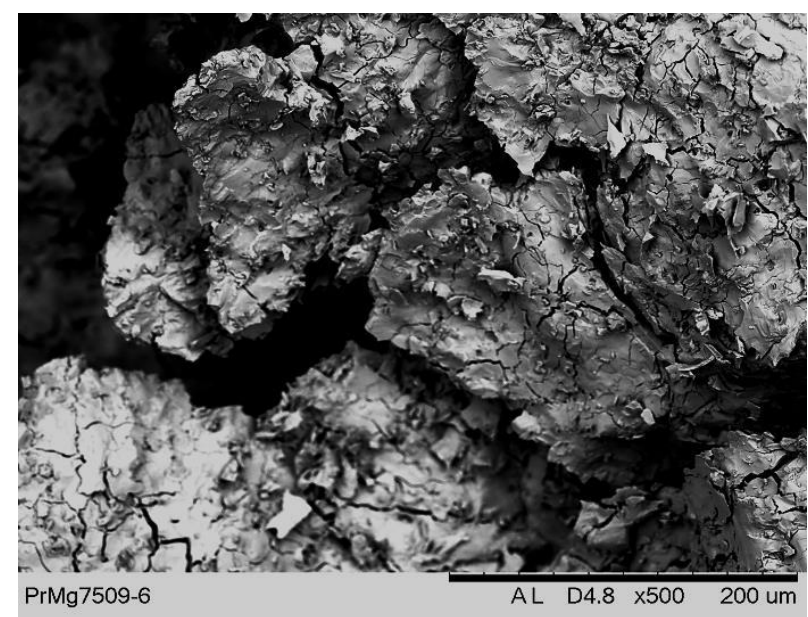

a)

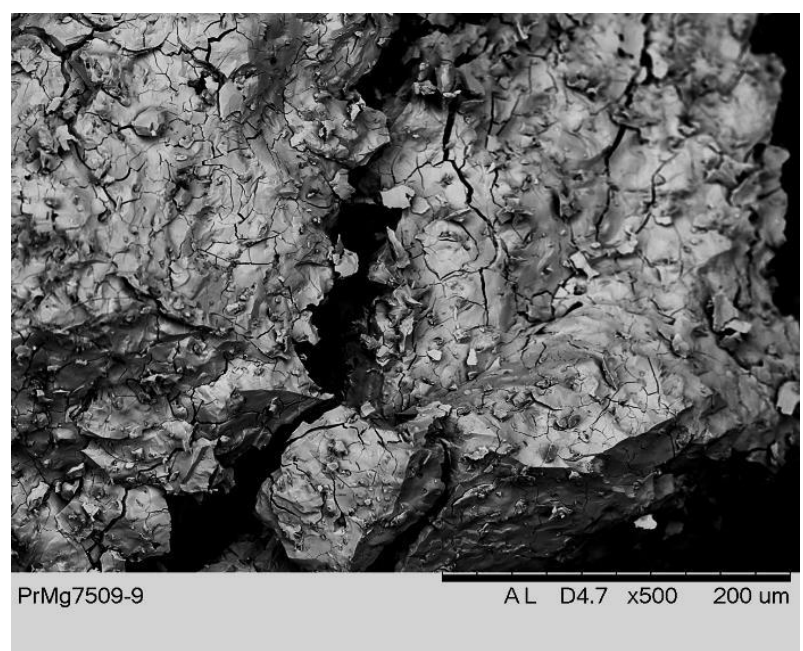

b)

\subsubsection{3 - Curvas de absorção de hidrogênio e micrografias da liga TT $\mathrm{Pr}_{0,7} \mathrm{Mg}_{0,3} \mathrm{Al}_{0,3} \mathrm{Mn}_{0,4} \mathrm{Co}_{0,5} \mathrm{Ni}_{3,8}$ com TT de $750^{\circ} \mathrm{C}$ por 16 horas.}

Na FIGURA 95 estão mostradas as curvas de absorção de hidrogênio pela liga $\operatorname{Pr}_{0,7} \mathrm{Mg}_{0,3} \mathrm{Al}_{0,3} \mathrm{Mn}_{0,4} \mathrm{Co}_{0,5} \mathrm{Ni}_{3,8}$ com TT de $750^{\circ} \mathrm{C}$ por 16 horas e na FIGURA 96 de (a) e (b) estão apresentadas as micrografias (500x), obtidas por MEV da liga após fragilização sendo: (a) pressão de hidrogênio de 6000 mbar e (b) com pressão de hidrogênio de 9000 mbar.

As fases absorvedoras de hidrogênio para estas condições de tratamento térmico foram as mesmas da liga sem TT, $\mathrm{PrNi}_{5}$ e $\mathrm{PrMg}_{2} \mathrm{Ni}_{9}$ (TABELA 35), mantendo baixa quantidade de hidrogênio absorvido somente na pressão de 6000 e 9000 mbar, provocando algumas trincas na superfície da liga apresentadas nas micrografias. 
FIGURA 95 - Curvas de absorção de Hidrogênio pela liga $\mathrm{Pr}_{0,7} \mathrm{Mg}_{0,3} \mathrm{Al}_{0,3} \mathrm{Mn}_{0,4} \mathrm{Co}_{0,5} \mathrm{Ni}_{3,8}$ com tratamento térmico de $750^{\circ} \mathrm{C}$ por 16 horas.

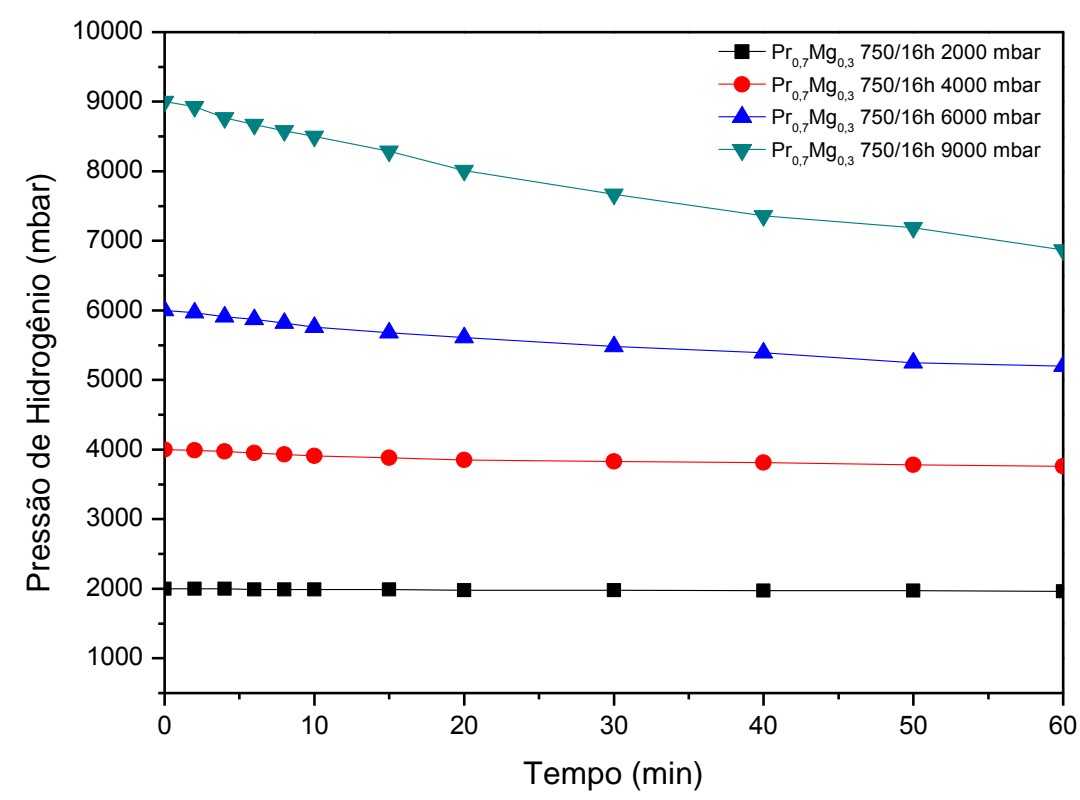

FIGURA 96 - Micrografia com aumento de 500x da liga $\operatorname{Pr}_{0,7} \mathrm{Mg}_{0,3} \mathrm{Al}_{0,3} \mathrm{Mn}_{0,4} \mathrm{Co}_{0,5} \mathrm{Ni}_{3,8}$ fragilizada com tratamento térmico de 750 por 16 horas em 6 e 9 bar de hidrogênio por 60 minutos.

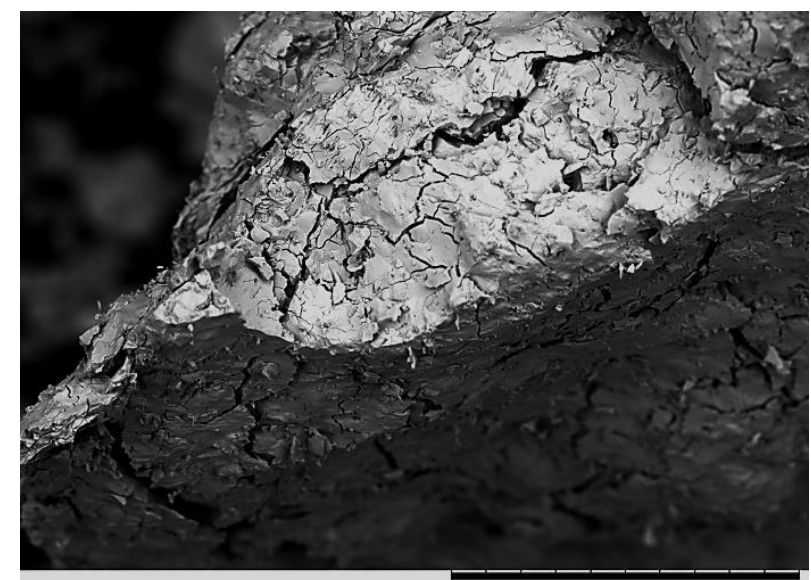

PrMg750166

AL $\quad$ D4.2 $\times 500 \quad 200$ um

a)

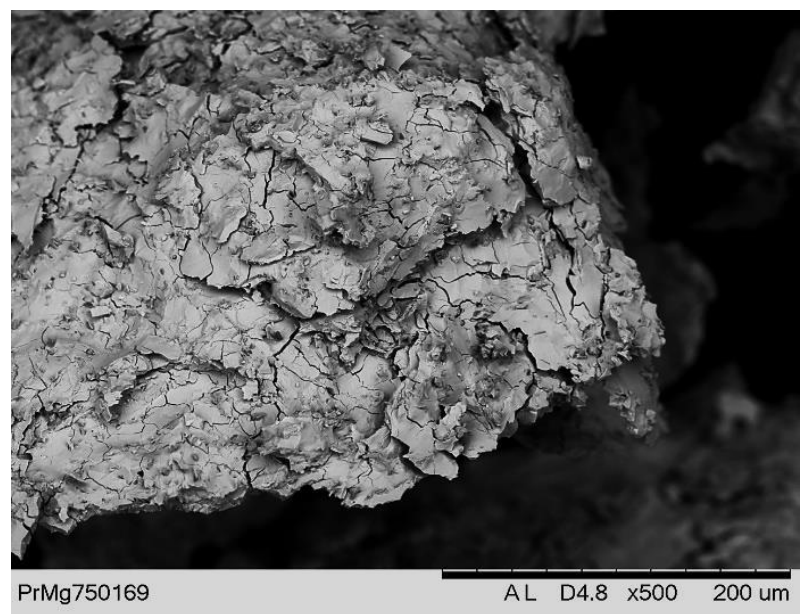

b) 
5.6.24 - Curvas de absorção de hidrogênio e micrografias da liga TT $\mathrm{Pr}_{0,7} \mathrm{Mg}_{0,3} \mathrm{Al}_{0,3} \mathrm{Mn}_{0,4} \mathrm{Co}_{0,5} \mathrm{Ni}_{3,8}$ com TT $850^{\circ} \mathrm{C}$ por 9 horas.

Na FIGURA 97 estão mostradas as curvas de absorção de hidrogênio pela liga $\mathrm{Pr}_{0,7} \mathrm{Mg}_{0,3} \mathrm{Al}_{0,3} \mathrm{Mn}_{0,4} \mathrm{Co}_{0,5} \mathrm{Ni}_{3,8}$ com TT de $850^{\circ} \mathrm{C}$ por 9 horas e na FIGURA 98 de (a) e (b) estão apresentadas as micrografias (500x), obtidas por MEV da liga após fragilização sendo: (a) pressão de hidrogênio de 6000 mbar e (b) com pressão de hidrogênio de 9000 mbar.

As fases absorvedoras de hidrogênio foram as mesmas da liga sem TT, $\mathrm{PrNi}_{5}$ e $\mathrm{PrMg}_{2} \mathrm{Ni}_{9}$ (TABELA 36), mantendo baixa quantidade de hidrogênio absorvido somente na pressão de 6000 e 9000 bar, provocando algumas trincas na superfície da liga.

FIGURA 97 - Curvas de absorção de Hidrogênio pela liga $\mathrm{Pr}_{0,7} \mathrm{Mg}_{0,3} \mathrm{Al}_{0,3} \mathrm{Mn}_{0,4} \mathrm{Co}_{0,5} \mathrm{Ni}_{3,8}$ com tratamento térmico de $850^{\circ} \mathrm{C}$ por 9 horas.

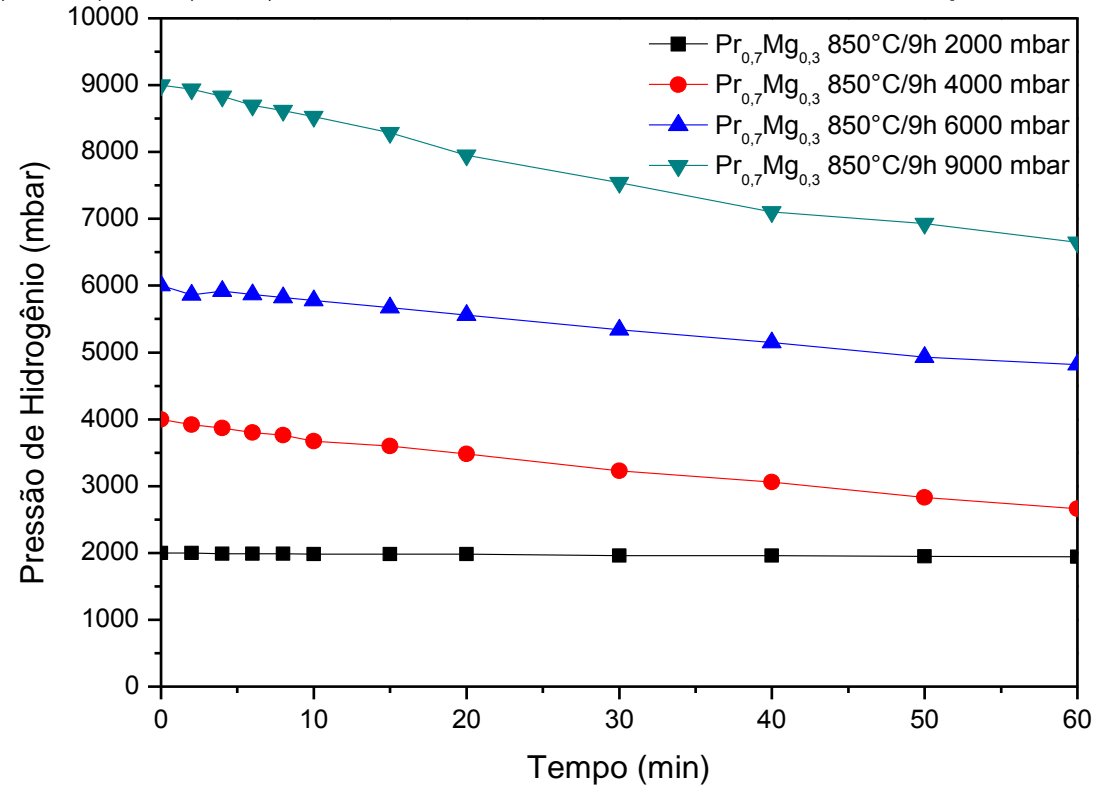


FIGURA 98 - Micrografia com aumento de 500x da liga $\operatorname{Pr}_{0,7} \mathrm{Mg}_{0,3} \mathrm{Al}_{0,3} \mathrm{Mn}_{0,4} \mathrm{Co}_{0,5} \mathrm{Ni}_{3,8}$ fragilizada com tratamento térmico de 850 por 9 horas em 6 e 9 bar de hidrogênio por 60 minutos.

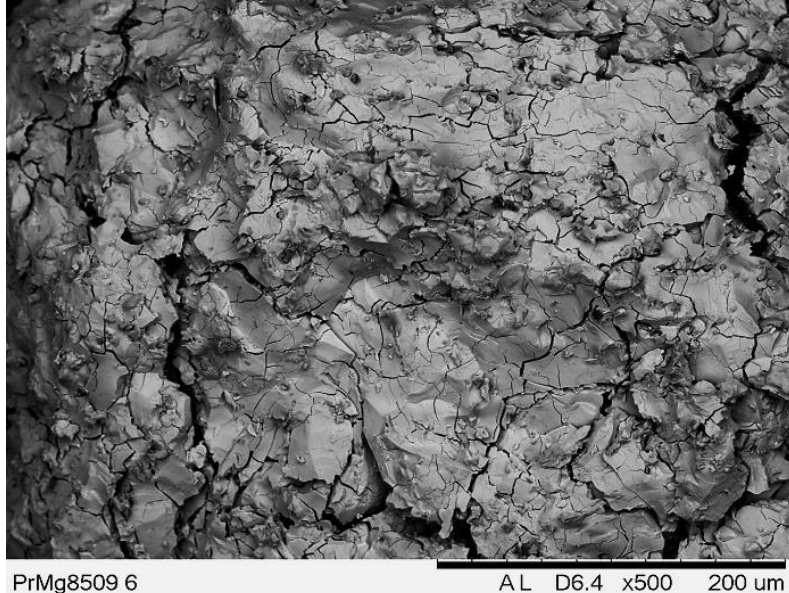

a)

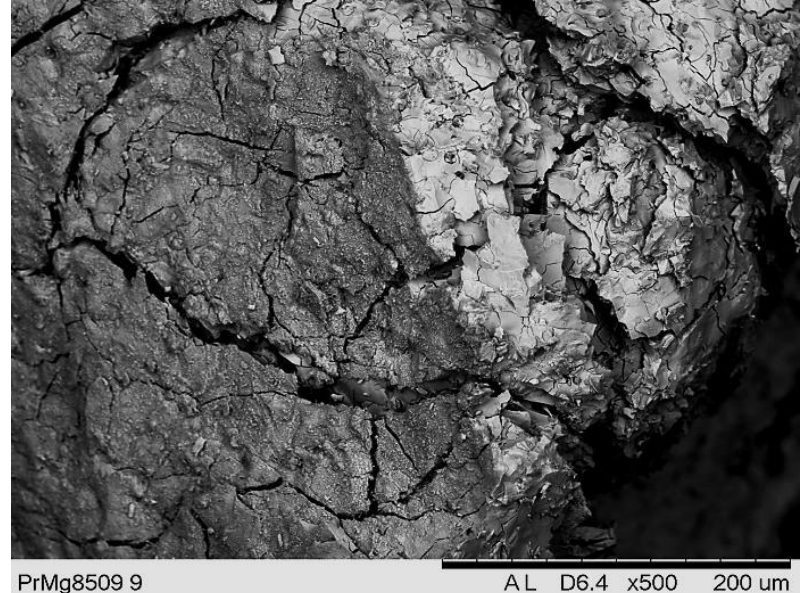

b)

\subsubsection{5 - Curvas de absorção de hidrogênio e micrografias da liga TT $\mathrm{Pr}_{0,7} \mathrm{Mg}_{0,3} \mathrm{Al}_{0,3} \mathrm{Mn}_{0,4} \mathrm{Co}_{0,5} \mathrm{Ni}_{3,8}$ com TT de $850^{\circ} \mathrm{C}$ por 16 horas.}

Na FIGURA 99 estão mostradas as curvas de absorção de hidrogênio pela liga $\operatorname{Pr}_{0,7} \mathrm{Mg}_{0,3} \mathrm{Al}_{0,3} \mathrm{Mn}_{0,4} \mathrm{Co}_{0,5} \mathrm{Ni}_{3,8}$ com TT de $850^{\circ} \mathrm{C}$ por 16 horas e na FIGURA 100 de (a) e (b) estão apresentadas as micrografias (500x), obtidas por MEV da liga após fragilização sendo: (a) pressão de hidrogênio de 6000 mbar e (b) com pressão de hidrogênio de 9000 mbar.

As fases absorvedoras de hidrogênio após o TT foram as mesmas da liga sem TT, $\mathrm{PrNi}_{5}$ e $\mathrm{PrMg}_{2} \mathrm{Ni}_{9}$ (TABELA 37), mantendo baixa quantidade de hidrogênio absorvido somente na pressão de 6000 e 9000 bar, provocando algumas trincas na superfície da liga.

Os TT realizados para a liga $\operatorname{Pr}_{0,7} \mathrm{Mg}_{0,3} \mathrm{Al}_{0,3} \mathrm{Mn}_{0,4} \mathrm{Co}_{0,5} \mathrm{Ni}_{3,8}$ não foram suficientes para alterar a composição da liga mantendo somente as fases $\mathrm{PrNi}_{5} \mathrm{e}$ $\mathrm{PrMg}_{2} \mathrm{Ni}_{9}$ (TABELAS 33 a 37) e, desta forma o comportamento de absorção foram semelhantes em todos os experimentos realizados. Observou-se que para todas as substituições do La e Ni ocorreram absorções de hidrogênio pelas ligas, revelando um aspecto frágil na microestrutura do material analisado. Somente a liga com a 
substituição do La pelo $\operatorname{Pr}$ não houve este comportamento de fragilização, onde ocorre somente a alta pressão, mas, com baixa quantidade de absorção de hidrogênio pela liga.

FIGURA 99 - Curvas de absorção de Hidrogênio pela liga $\mathrm{Pr}_{0,7} \mathrm{Mg}_{0,3} \mathrm{Al}_{0,3} \mathrm{Mn}_{10,4} \mathrm{Co}_{0,5} \mathrm{Ni}_{3,8}$ com tratamento térmico de $850^{\circ} \mathrm{C}$ por 16 horas.

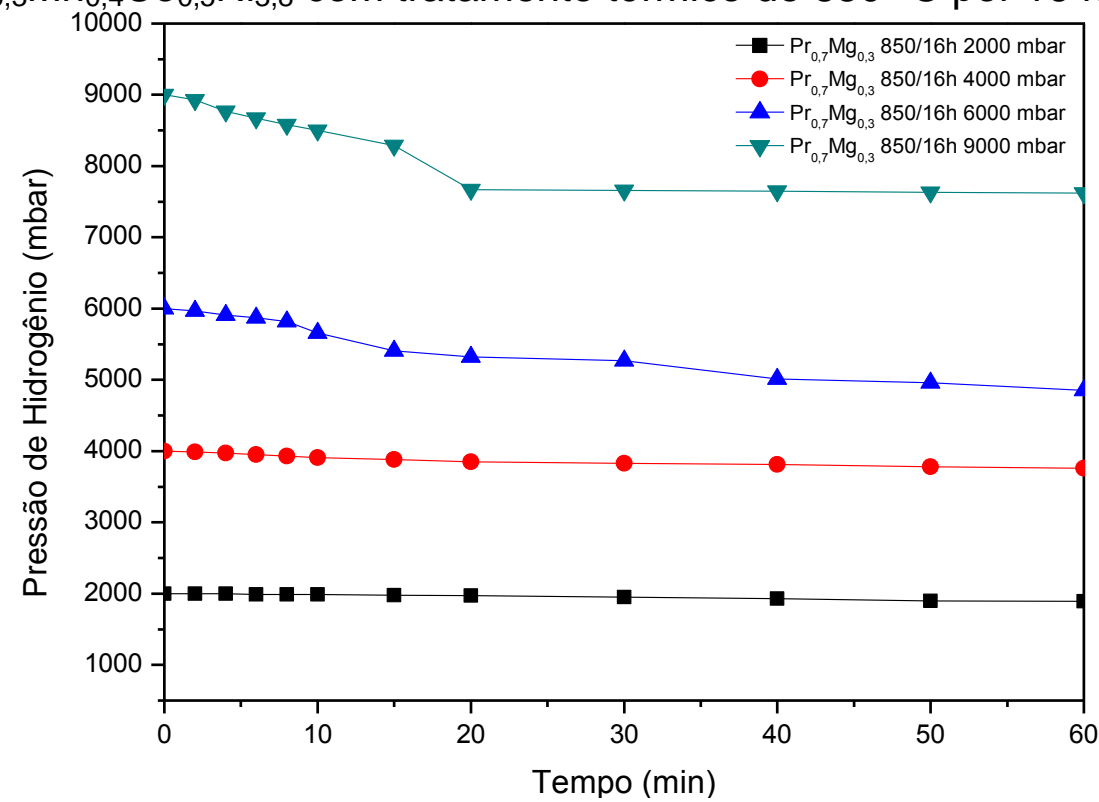

FIGURA 100 - Micrografia com aumento de 500x da liga $\operatorname{Pr}_{0,7} \mathrm{Mg}_{0,3} \mathrm{Al}_{0,3} \mathrm{Mn}_{0,4} \mathrm{Co}_{0,5} \mathrm{Ni}_{3,8}$ fragilizada com tratamento térmico de 850 por 16 horas em 6 e 9 bar de hidrogênio por 60 minutos.
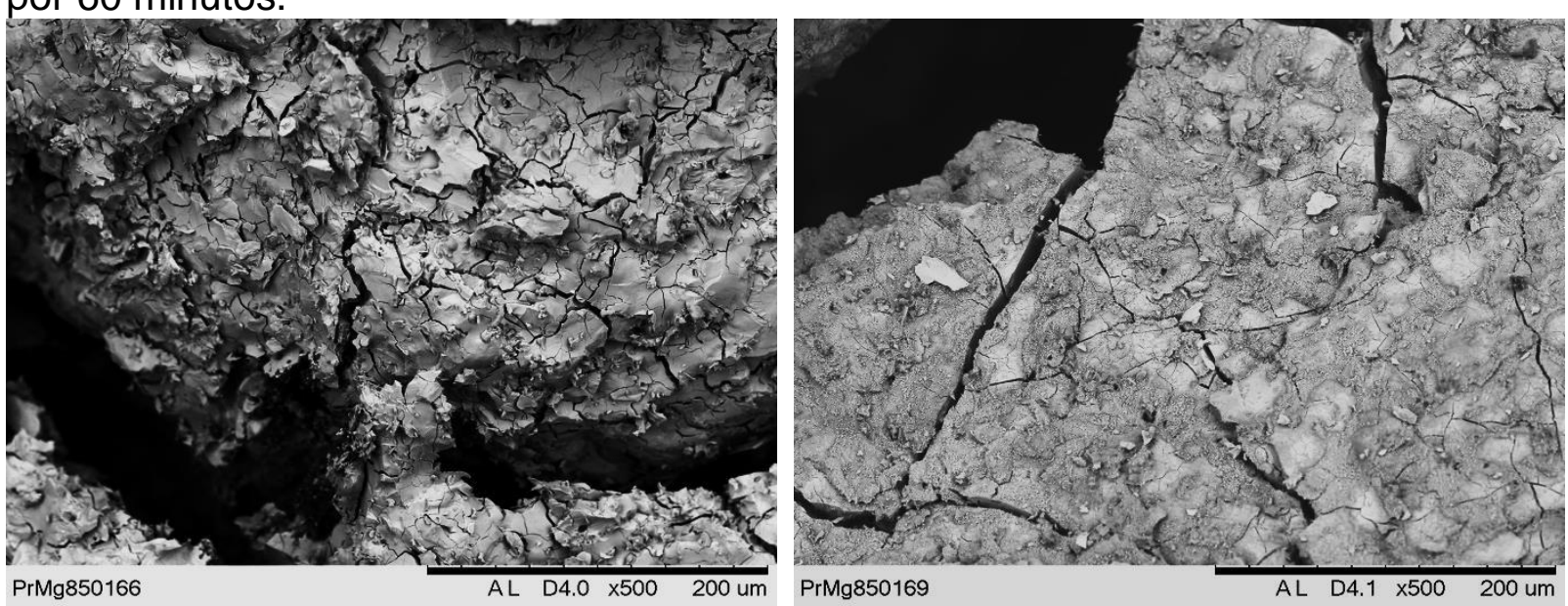

a)

b) 


\section{6 - CONCLUSÕES}

O tratamento térmico influenciou positivamente na capacidade de descarga do eletrodo negativo das baterias utilizando as ligas $\mathrm{Ni}-\mathrm{MH}$ como material ativo.

Os refinamentos por Rietveld e as imagens obtidas por MEV-FEG da liga $\mathrm{La}_{0,7} \mathrm{Mg}_{0,3} \mathrm{Al}_{0,3} \mathrm{Mn}_{0,4} \mathrm{Co}_{0,5} \mathrm{Ni}_{3,8}$ com substituição parcial do Ni pelo Co, apresentaram mudanças de fases na microestrura da liga, após o tratamento térmico mostrando uma modificação na rede cristalina, onde a fase $\mathrm{LaMg}_{2} \mathrm{Ni}_{9}$ com estrutura romboédrica do grupo espacial $\mathrm{R} 3 / \mathrm{m}$ desaparece dando lugar a fase $\mathrm{Al}_{6} \mathrm{Mn}$ com estrutura ortorrômbica pertencente ao grupo espacial $\mathrm{C} / \mathrm{cm}$. Surgindo também outra fase denominada $\mathrm{LaCo}_{13}$ com estrutura cúbica do grupo espacial Fm-3c, essas transformações aconteceram a partir do tratamento térmico $750^{\circ} \mathrm{C}$ por 16 horas.

A melhor capacidade de descarga das baterias foi obtido para a liga $\mathrm{La}_{0,7} \mathrm{Mg}_{0,3} \mathrm{Al}_{0,3} \mathrm{Mn}_{0,4} \mathrm{Co}_{0,5} \mathrm{Ni}_{3,8}$ tratada termicamente a $850^{\circ} \mathrm{C}$ por 16 horas $(406,1$ mAh) e $H / M$ calculado $(0,977)$. Esta liga sem TT também apresentou melhor capacidade de descarga $(326,1 \mathrm{mAh})$ e $\mathrm{H} / \mathrm{M}$ calculado $(0,785)$.

Na liga $\mathrm{La}_{0,7} \mathrm{Mg}_{0,3} \mathrm{Al}_{0,3} \mathrm{Mn}_{0,4} \mathrm{Cu}_{0,5} \mathrm{Ni}_{3,8}$, com a substituição parcial do $\mathrm{Ni}$ pelo $\mathrm{Cu}$ as analises de Raios-X utilizando o método de refinamento por Rietveld mostrou que as fases $\mathrm{LaNi}_{5}$ e $\mathrm{LaMg}_{2} \mathrm{Ni}_{9}$ são mantidas, ocorrendo mudança somente na fase $\mathrm{MgNi}_{2}$ do tipo $\mathrm{AB}_{2}$, formando a fase $\mathrm{MgNiCu}$, com as mesma características com estrutura hexagonal pertencendo ao grupo espacial: $\mathrm{P} 63 / \mathrm{mmc}$, devido a presença do $\mathrm{Cu}$ verificou-se um aumento no volume da célula unitária para esta fase.

Foi possível observar na liga $\mathrm{La}_{0,7} \mathrm{Mg}_{0,3} \mathrm{Al}_{0,3} \mathrm{Mn}_{0,4} \mathrm{Sn}_{0,5} \mathrm{Ni}_{3,8}$, com substituição parcial do $\mathrm{Ni}$ pelo $\mathrm{Sn}$, uma diminuição da concentração da fase $\mathrm{LaNi}_{5}$ e o desaparecimento $\mathrm{LaMg}_{2} \mathrm{Ni}_{9}$ originando uma nova fase $\mathrm{LaNi}_{2} \mathrm{Sn}_{2}$, isto se deu pela substituição parcial do Ni pelo Sn. 
As analises de PCT mostraram que a liga $\mathrm{La}_{0,7} \mathrm{Pr}_{0,3} \mathrm{Al}_{0,3} \mathrm{Mn}_{0,4} \mathrm{Co}_{0,5} \mathrm{Ni}_{3,8}$ sem TT apresentou melhor e capacidade de descarga calculada (317,0 mAh) e H/M (0,832). Enquanto que, a liga $\mathrm{La}_{0,7} \mathrm{Mg}_{0,3} \mathrm{Al}_{0,3} \mathrm{Mn}_{0,4} \mathrm{Co}_{0,5} \mathrm{Ni}_{3,8}$ sem TT apresentou capacidade de descarga calculada de 284,0 mAh e H/M de 0,683.

Os ensaios com 4 ciclos de ativação realizados nas ligas com TT mostraram que a primeira foi o suficiente para ativação da liga.

Nos ensaios de absorção de hidrogênio para fragilização, realizados nas ligas sem e com TT ocorreram de forma espontânea. Somente a liga $\operatorname{Pr}_{0,7} \mathrm{Mg}_{0,3} \mathrm{Al}_{0,3} \mathrm{Mn}_{0,4} \mathrm{Co}_{0,5} \mathrm{Ni}_{3,8}$ se mostrou resistente a absorção de hidrogênio a baixa pressão (2 e 4 bar).

Não houve uma concordância entre as propriedades eletroquímicas resultantes na capacidade de descarga das baterias $\left(\mathrm{C}_{\text {máx. }}\right)$ com as propriedades realizadas no PCT ( $\left.\mathrm{C}_{\text {máx.calc. }}\right)$ para todas as ligas sem e com TT. 


\section{APENDICE A -}

\section{A influência da adição de rGO e CNT nas propriedades eletroquímicas das nas Baterias das Ligas de LaNi}

\section{Resumo}

Neste trabalho estão apresentados os resultados obtidos na investigação onde foram aplicados as adições de 1, 2, 5 e 10\% de óxido de grafeno reduzido (rGO) e nanotubo de carbono de múltiplas paredes (CNT) nas baterias de Ni-MH do tipo $\mathrm{AB}_{5}$ com a liga $\mathrm{La}_{0.7} \mathrm{Mg}_{0.3} \mathrm{Al}_{0.3} \mathrm{Mn}_{0.4} \mathrm{Co}_{0.5} \mathrm{Ni}_{3.8}$ no estado bruto de fusão como material ativo no eletrodo negativo, misturados manualmente, a fim de verificar qual a melhor condição de adição desses materiais, estabelecida através dos resultados da capacidade máxima de descarga. Os materiais de adição foram caracterizados por microscopia eletrônica de varreduras (MEV-FEG) e difração de raios-X. As medidas eletroquímicas foram executadas no aparelho ARBIN T4, utilizando dois eletrodos como célula padrão.

\section{Introdução}

Nos últimos anos, as ligas à base de $\mathrm{LaNi}_{5}$ têm sido objeto de muitos estudos. Uma aplicação bem-sucedida dessas ligas é como o material ativo nos eletrodos negativos das baterias de Ni-MH (Cassini et al 2015). A capacidade das ligas $A_{5}$ para absorver hidrogênio à temperatura ambiente é sua principal vantagem. Quando usado em baterias $\mathrm{Ni}-\mathrm{MH}$, ligas à base de $\mathrm{LaNi}_{5}$ foram parcialmente modificadas pela substituição de certos elementos para melhorar a cinética dos processos de absorção e dessorção de hidrogênio, aumentar o ciclo de vida, melhorar a resistência à corrosão $\mathrm{Co}, \mathrm{Al}, \mathrm{Mn}$ e $\mathrm{Mg}$ estão invariavelmente presentes em tais ligas (Yang et al 2011). O uso mais amplo de baterias de Ni-MH tornou-se uma 
preocupação nos últimos anos devido ao alto custo de alguns dos elementos empregados para criar o eletrodo negativo. A bateria de $\mathrm{Ni}-\mathrm{MH}$ consiste em uma liga armazenadoras de hidrogênio como eletrodo negativo e um hidróxido de níquel $\left(\mathrm{Ni}(\mathrm{OH})_{2}\right)$ para o eletrodo positivo juntamente com uma solução aquosa de hidróxido de potássio $(\mathrm{KOH})$ principalmente para o eletrólito. As ligas de armazenamento de hidrogênio são um novo grupo de intermetálicos funcionais que podem armazenar de forma reversível o hidrogênio (Liu et al 2011, Sakai et al 2011 e Cuscueta et al 2008).

É cada vez mais crítico reduzir o custo de produção e melhorar o desempenho eletroquímico das baterias de $\mathrm{Ni}-\mathrm{MH}$ para sua aplicação em campos de alta potência, por exemplo, veículos elétricos, ferramentas elétricas e assim por diante. Portanto, ainda é imperativo melhorar a capacidade de alta taxa de ligas tipo $\mathrm{AB}_{5}$ baseadas em terras raras para atender aos requisitos adicionais de baterias $\mathrm{Ni}-\mathrm{MH}$ de alta potência. Para melhorar o desempenho de descarga de ligas à base de terra rara $\mathrm{AB}_{5}$ em alta densidade de corrente de descarga, muita pesquisa. Este trabalho irá enfatizar a liga de eletrodo de armazenamento de hidrogênio $\mathrm{La}_{0.7} \mathrm{Mg}_{0.3} \mathrm{Al}_{0.3} \mathrm{Mn}_{0.4} \mathrm{Co}_{0.5} \mathrm{Ni}_{3.8}$ bruto de fusão com adições de 1, 2, 3, 5 e 10\% de rGO e CNT para estudar as melhorias de desempenho no Ni- Baterias $\mathrm{MH}$ (Castillo L.A.B. 2013 e Li et al 2011).

\section{Materiais e Métodos}

Neste trabalho a adição de 1, 2, 5 e 10\% de óxido de grafeno reduzido (rGO) obtido da empresa e o nanotubo de carbono (CNT) Sigma-Aldrich Products, na liga de $\mathrm{La}_{0.7} \mathrm{Mg}_{0.3} \mathrm{Al}_{0.3} \mathrm{Mn}_{0.4} \mathrm{Co}_{0.5} \mathrm{Ni}_{3.8}$ no estado bruto de fusão.

A liga foi produzida por fusão por indução sob atmosfera protetora de argônio, e colocada num molde de cobre retangular refrigerado a água em pedaços de aproximadamente $5 \mathrm{~kg}$. Foi então fraturada em pedaços menores e reduzida a um tamanho de partícula de aproximadamente 200 mesh para confecção dos eletrodos negativos da bateria. Neste trabalho, uma análise das fases presentes na microestrutura da liga fundida, e a composição química foram obtidas por análise de 
espectroscopia de energia dispersiva (EDS), acoplada ao microscópio eletrônico de varredura (MEV-FEG). Padrões de difração de raios-X (XRD) e análise detalhada foram relatados para a liga e os materiais de adição.

Os ensaios eletroquímicos da liga para determinação da capacidade máxima de descarga foram realizados utilizando o aparelho ARBIN-T4, eletrodos negativos para determinação da capacidade máxima de armazenamento da liga foram preparados por prensagem de uma mistura composta de $100 \mathrm{mg}$ de pó de liga com $400 \mathrm{mg}$ de pó de Ni metal e poli (vinilideno) aglutinante e metil-2-pirrolidinona, formando uma massa, e fixados em ambos os lados de uma tela de níquel de $10 \mathrm{x}$ $10 \mathrm{~mm}$. As adições de rGO e CNT feitas durante a preparação do eletrodo negativo, de forma manual, utilizando um almofariz de ágata com pistilo para promover a mistura. Da mesma forma, os eletrodos positivos foram preparados, e os materiais utilizados neste conjunto foram $300 \mathrm{mg}$ de $\mathrm{NiOH}$ e $100 \mathrm{mg}$ de $\mathrm{Ni}$ metálico, adicionando também os elementos de ligação de poli (vinilideno) e metil-2pirrolidinona da mesma maneira como homogeneização dos elementos. Medidas eletroquímicas foram realizadas em uma célula padrão composta de três eletrodos em $\mathrm{KOH} 6 \mathrm{~mol} \mathrm{~L}^{-1}$. Os testes foram realizados carregando o eletrodo catódico com uma corrente de $100 \mathrm{mAg}^{-1}$ por 5 horas e descarregando com uma corrente anódica de $50 \mathrm{mAg}^{-1}$. Usando a capacidade de descarga $\left(C_{\max }\right)$, na qual a capacidade máxima de armazenamento de hidrogênio por célula unitária ( $\eta$ ) foi calculada usando a equação de Faraday (EQUAÇÃO 1) (Hongmei et al 1999). Os valores da taxa de retenção cíclica $\left(\mathrm{C}_{\text {ret }}\right)$ também foram calculados após 40 ciclos de carga/descarga para as baterias (EQUAÇÃO 2) (Reilly et al 1999).

$$
\begin{aligned}
& n=\frac{3600}{9.65 \times 10^{7}} M w \times C \max \\
& C_{\text {ret. }}=\frac{C 40}{C \max \cdot \text { desc }} \times 100
\end{aligned}
$$




\section{Discussão}

O padrão de difração de raios- $X$ da liga de armazenamento de hidrogênio $\mathrm{La}_{0.7} \mathrm{Mg}_{0.3} \mathrm{Al}_{0.3} \mathrm{Mn}_{0.4} \mathrm{Co}_{0.5} \mathrm{Ni}_{3.8}$, utilizando o método de Rietveld para refinamento é mostrado na FIGURA 1. O padrão mostrado que a liga é composta principalmente de $\mathrm{LaNi}_{5}$ (com uma estrutura hexagonal do tipo $\mathrm{CaCu}_{5}$ ), $\mathrm{MgNi}_{2}$ (estrutura hexagonal do tipo $\mathrm{AB}_{2}$ ) e $\mathrm{LaMgNi}$ (com uma estrutura romboédrica do tipo $\mathrm{PuNi}_{3}$ ).

A micrografia obtida pela analise no MEV-FEG da liga de armazenamento de hidrogênio $\mathrm{La}_{0.7} \mathrm{Mg}_{0.3} \mathrm{Al}_{0.3} \mathrm{Mn}_{0.4} \mathrm{Co}_{0.5} \mathrm{Ni}_{3.8}$ esta mostrada na FIGURA 2. Combinando essas micrografias com espectroscopia de dispersão de raios- $X$ durante a análise de microscopia eletrônica de varreduras, foi possível identificar a composição de cada fase presente encontrada nos padrões de difração de raios-X. Onde região clara é a fase $\mathrm{LaNi}_{5}$, a fase $\mathrm{MgNi}_{2}$ mostrada pelas regiões escuras e a região cinza é a fase $\mathrm{LaMg}_{2} \mathrm{Ni}_{9}$.

FIGURA 1. Padrão de Difração de raios-X (DRX) da liga $\mathrm{La}_{0.7} \mathrm{Mg}_{0.3} \mathrm{Al}_{0.3} \mathrm{Mn}_{0.4} \mathrm{Co}_{0.5} \mathrm{Ni}_{3.8}$ no estado bruto de fusão.

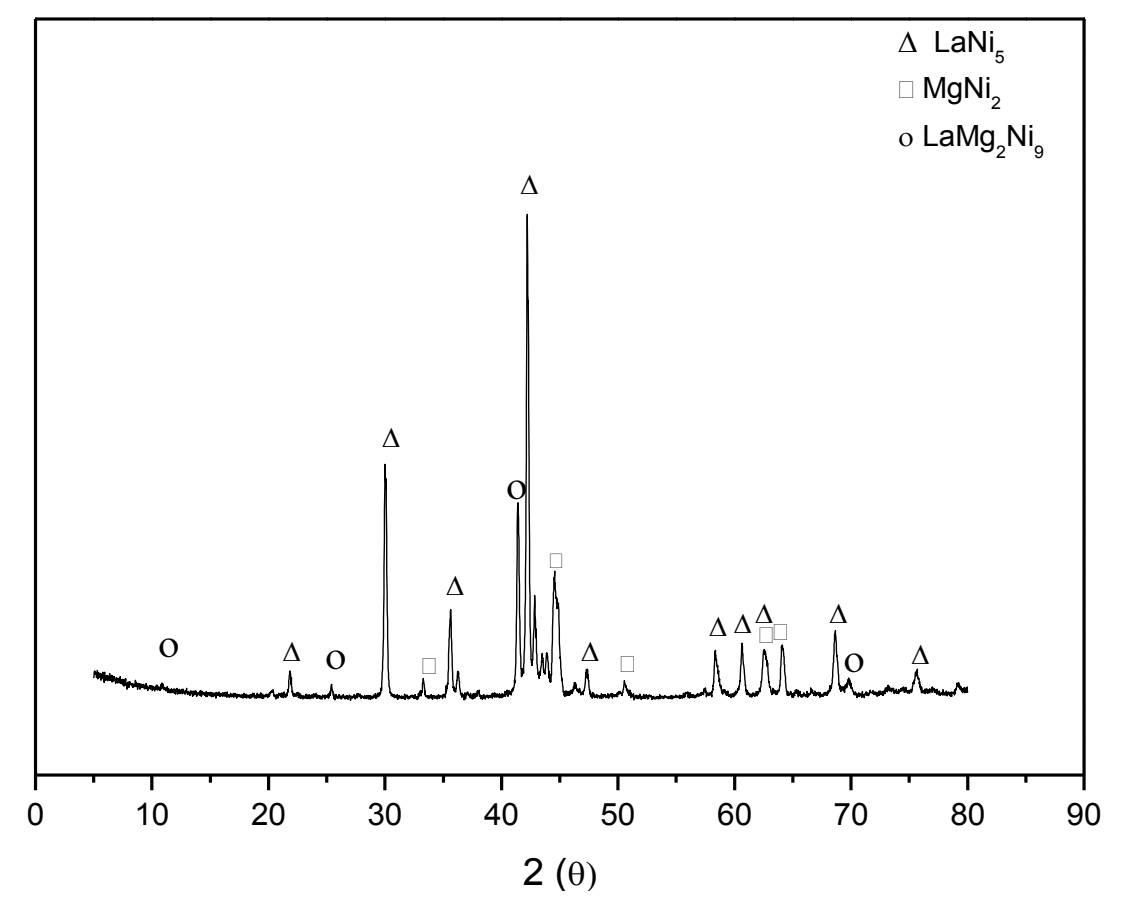


FIGURA 2. Micrografia obtida no MEV da liga $\mathrm{La}_{0.7} \mathrm{Mg}_{0.3} \mathrm{Al}_{0.3} \mathrm{Mn}_{0.4} \mathrm{Co}_{0.5} \mathrm{Ni}_{3.8}$ bruta de fusão.

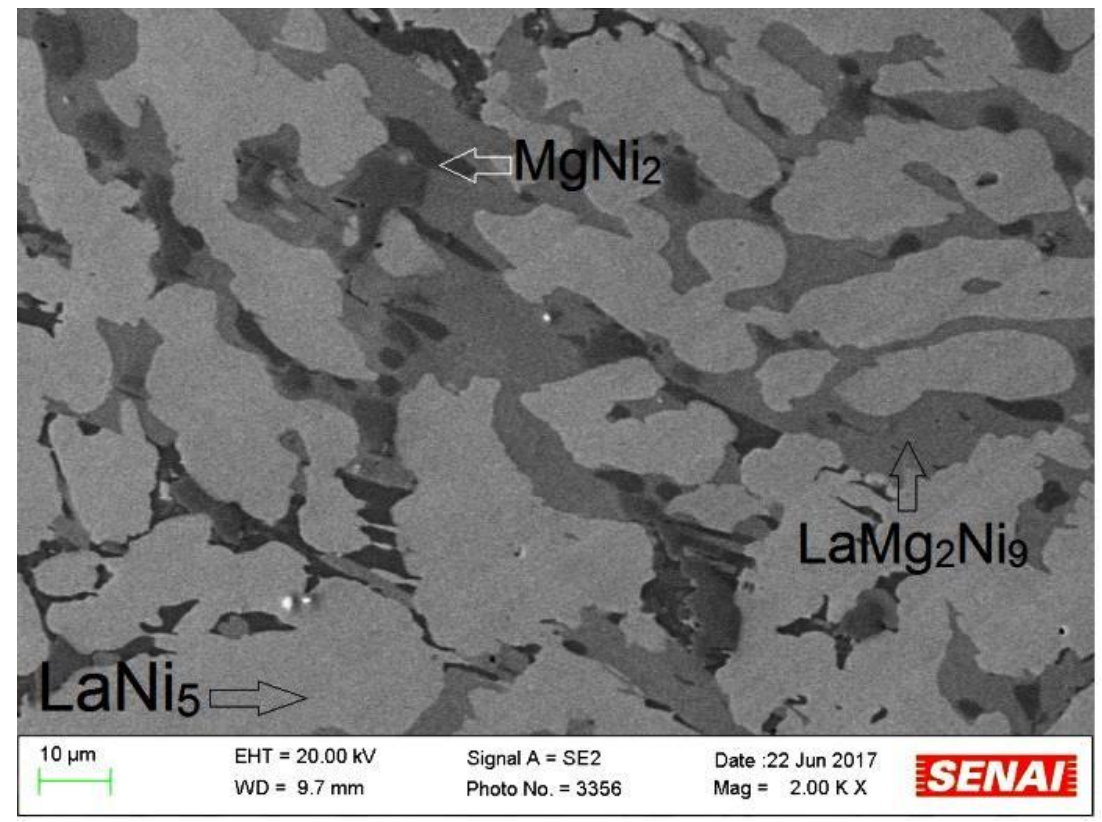

As micrografias obtidas no MEV-FEG do CNT e rGO são mostradas na FIGURA 3 e 4.

Na FIGURA 3 (b) com aumento de 20.000x, observa-se que a estrutura do CNT é do tipo "mult layers" ou camadas não uniformes, com dimensionamentos variados nos diâmetros dos nanotubos.

A FIGURA 4 (a) 6.500x e (b) 41.720x do óxido de grafeno reduzido (rGO), mostra a estrutura do rGO onde se observa as camadas formadas.

FIGURA 3. Micrografia obtida no MEV-FEG mostrando: (a) 5000x e (b) 20000x do nanotubo de carbono (CNT).

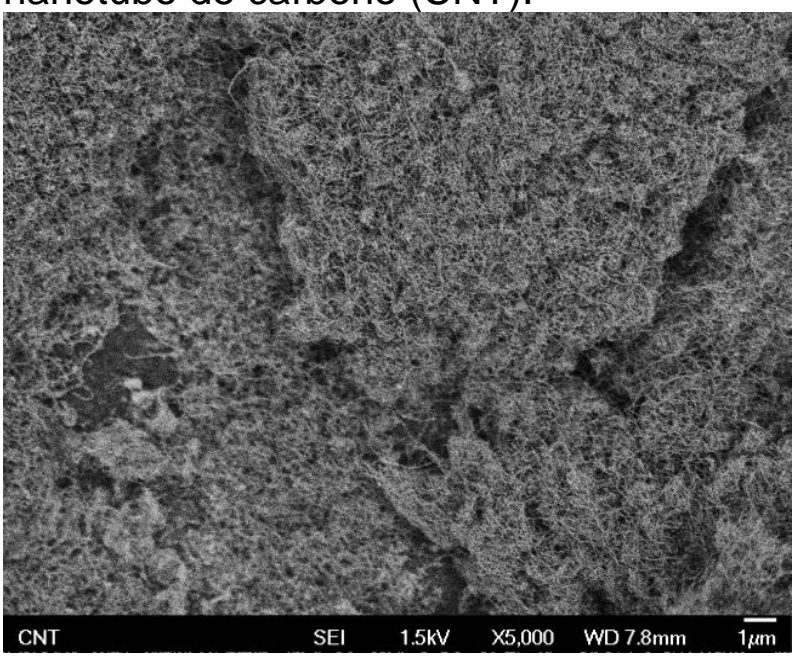

(a)

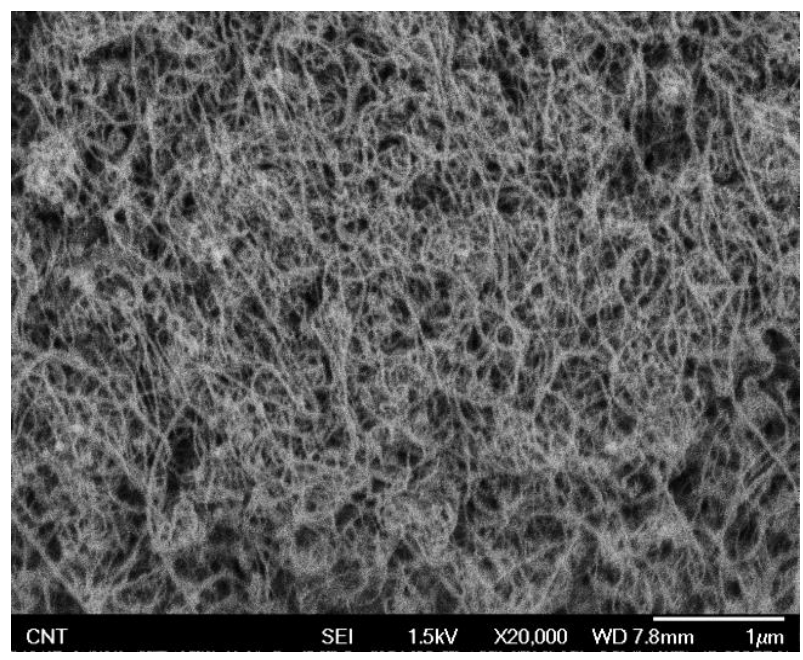

(b) 
FIGURA 4. Micrografia obtida no MEV-FEG mostrando: (a) 6500x e (b) 41720x do do óxido de grafeno reduzido ( $\mathrm{GGO}$ ).

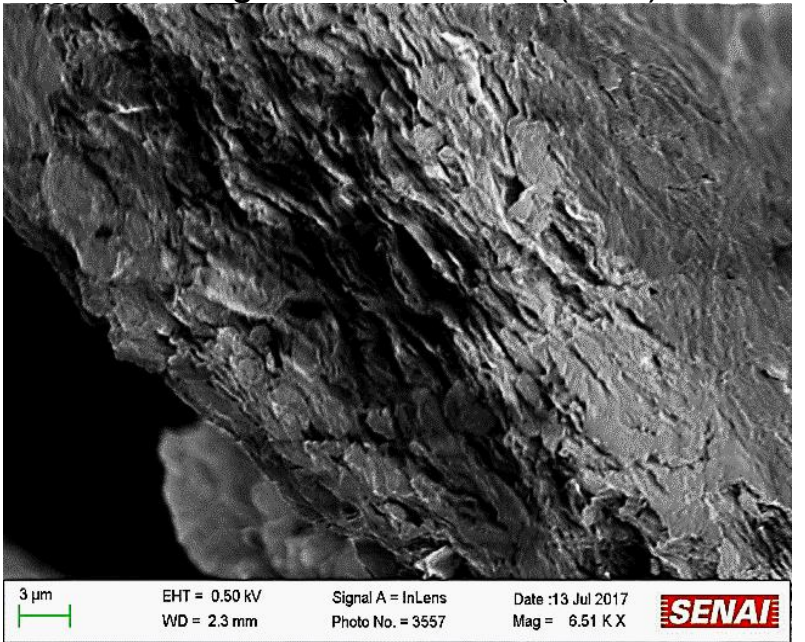

(a)

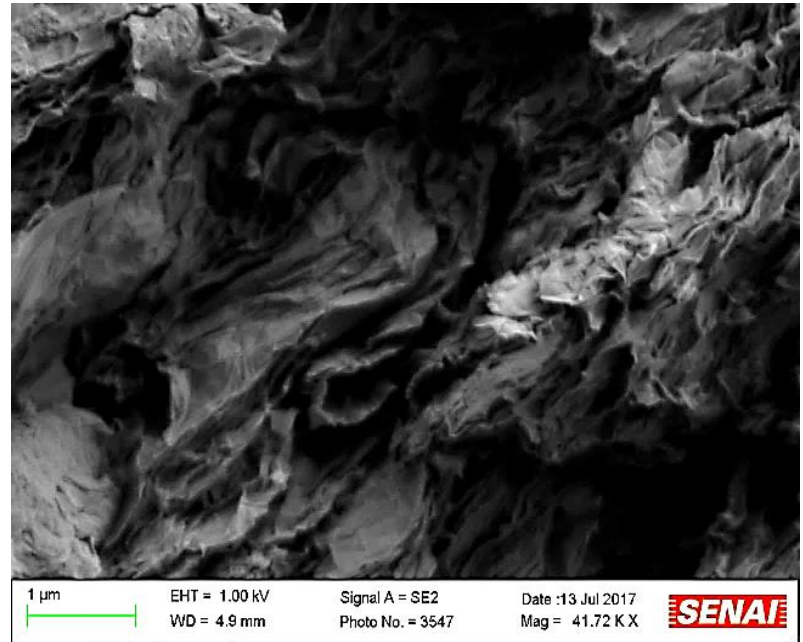

(b)

O aspecto morfológico característico na FIGURA 3 do CNT mostra que os diâmetros dos nanotubos de carbono são heterogêneos, o que pode ter influenciado a manutenção da capacidade de retenção cíclica durante a análise do desempenho eletroquímico.

A estabilidade cíclica é um fator extremamente importante que afeta diretamente a vida útil de uma liga de armazenamento de hidrogênio. As figuras $5 \mathrm{e}$ 6 mostram as curvas de ciclo de vida de $\mathrm{La}_{0.7} \mathrm{Mg}_{0.3} \mathrm{Al}_{0.3} \mathrm{Mn}_{0.4} \mathrm{Co}_{0.5} \mathrm{Ni}_{3.8}$ com adição de CNT e rGO nos eletrodos negativos (Castillo L.A.B. 2013). Observou-se que a capacidade de descarga da bateria com adição de $2 \%$ de rGO e $1 \%$ de CNT apresentaram melhores desempenhos, mas a capacidade de estabilidade cíclica foi mantida nas adições em 1\% para rGO e 10\% para CNT. A TABELA 1 e a TABELA 2 mostram uma relação das propriedades obtidas através das EQUAÇÕES 1 e 2, tanto para as adições de rGO quanto para CNT investigadas neste estudo (Li et al 2011). 
Figura 5. Estabilidade cíclica da liga $\mathrm{La}_{0.7} \mathrm{Mg}_{0.3} \mathrm{Al}_{0.3} \mathrm{Mn}_{0.4} \mathrm{Co}_{0.5} \mathrm{Ni}_{3.8}$ como material ativo do eletrodo negativo com adições de CNT.

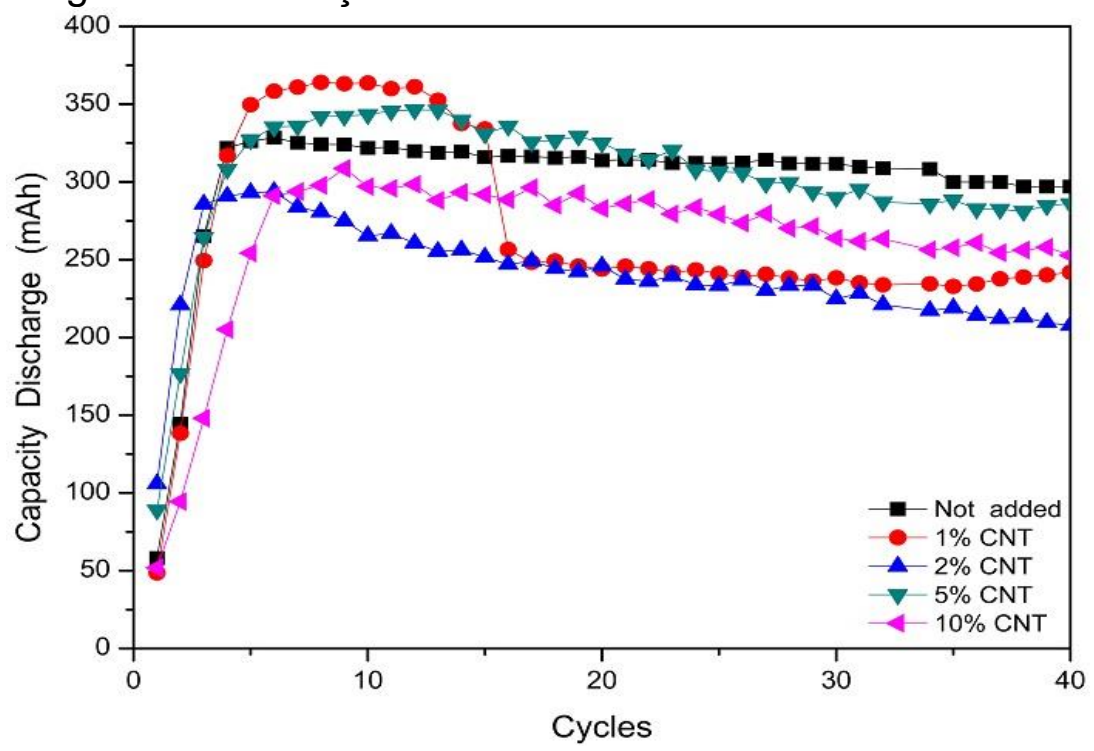

TABELA 1. Propriedades eletroquímicas da liga $\mathrm{La}_{0.7} \mathrm{Mg}_{0.3} \mathrm{Al}_{0.3} \mathrm{Mn}_{0.4} \mathrm{Co}_{0.5} \mathrm{Ni}_{3.8}$ como material ativo do eletrodo negativo com adições de CNT.

\begin{tabular}{ccccc}
\hline CNT (\%) & $\mathbf{C}_{\text {max. }}$ (mAh) & $\mathbf{M}_{\mathbf{w}}$ (g/mol) & $\mathbf{\eta}$ (H/f.u) & $\mathbf{C}_{\text {ret }}(\%)$ \\
\hline Sem adição & 326 & 387.1 & 4.7 & 93.8 \\
1 & 362 & 387.1 & 5.2 & 64.4 \\
2 & 295 & 387.1 & 4.3 & 70.2 \\
5 & 344 & 387.1 & 4.9 & 81.0 \\
10 & 307 & 387.1 & 4.4 & 82.7 \\
\hline
\end{tabular}

Figura 6. Estabilidade cíclica da liga $\mathrm{La}_{0.7} \mathrm{Mg}_{0.3} \mathrm{Al}_{0.3} \mathrm{Mn}_{0.4} \mathrm{Co}_{0.5} \mathrm{Ni}_{3.8}$ como material ativo do eletrodo negativo com adições de rGO.

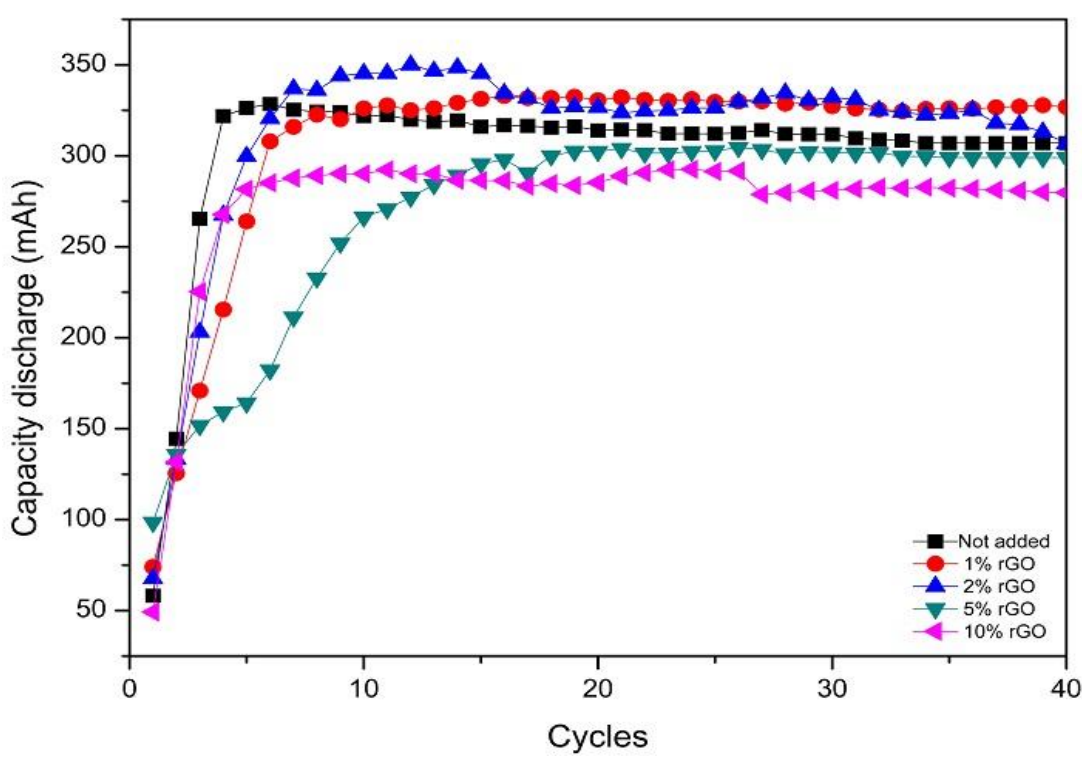


TABELA 2. Propriedades eletroquímicas da liga $L a_{0.7} \mathrm{Mg}_{0.3} \mathrm{Al}_{0.3} \mathrm{Mn}_{0.4} \mathrm{Co}_{0.5} \mathrm{Ni}_{3.8}$ como material ativo do eletrodo negativo com adições de rGO.

\begin{tabular}{ccccc}
\hline rGO (\%) & $\mathbf{C}_{\text {max. }}$ (mAh/g) & $\mathbf{M}_{\mathbf{w}}$ (g/mol) & $\mathbf{\eta}(\mathbf{H} / \mathbf{f . u})$ & $\mathbf{C}_{\text {ret }}(\%)$ \\
\hline Sem adidição & 326 & 387.1 & 4,7 & 93.8 \\
1 & 335 & 387.1 & 4,84 & 97.3 \\
2 & 352 & 387.1 & 4,96 & 88.6 \\
5 & 303.3 & 387.1 & 4,36 & 97.3 \\
10 & 289.6 & 387.1 & 4,2 & 97.1 \\
\hline
\end{tabular}

\section{Conclusão}

O trabalho aqui apresentado investigou os efeitos da adição de CNT e rGO no eletrodo negativo das baterias de $\mathrm{Ni}-\mathrm{MH}$ fabricadas com ligas de armazenamento de hidrogênio $\mathrm{La}_{0.7} \mathrm{Mg}_{0.3} \mathrm{Al}_{0.3} \mathrm{Mn}_{0.4} \mathrm{Co}_{0.5} \mathrm{Ni}_{3.8}$ no estado bruto de fusão. Os resultados mostram que $1 \%$ do CNT elevou a capacidade máxima de descarga de $326 \mathrm{mAh}$ para 362 mAh, porém a capacidade de retenção cíclica durante os 40 ciclos de carga/descarga diminuiu de $93,8 \%$ para $64,4 \%$, para os resultados obtidos com a adição de rGO indicou o aumento da capacidade máxima de descarga e capacidade de retenção nos 40 ciclos com $2 \%$ da adição de rGO. 


\section{7 - REFERÊNCIAS BIBLIOGRÁFICAS}

ADZIC G. D., JOHNSON J. R, REILLY J. J., MCBREEN J., MUKERJEE S., Cerium Content and Cycle Life of Multicomponent ABs Hydride Electrodes. J. Electrochem. Soc. v. 142, issue 10, p. 3429-3433. 1995.

AMBROSIO R. C. e TICIANELLI E. A., Baterias de níquel-hidreto metálico, uma alternativa para as baterias de níquel-cádmio. Quim. Nova. v. 24, p. 243-246. 2001.

BASE DE ESTRUTURAS CRISTALINAS <icsd-fiz-karlsruhe de.proxy01.dotlib.com.br $>2019$.

BINNEMANS K., JONES P.T., BLANPAIN B., GERVEN T.V., YANG, Y., WALTON A., BUCHERT M., Recycling of rare earths: a critical review. Journal of Cleaner Production, v. 51, p. 1-22, 2013.

BLANCO M. V., BORZONE E. M., BARUJ A., MEYER G. O. Hydrogen sorption kinetics of La-Ni-Sn storage alloys. International Journal of Hydrogen Energy, v. 39, p. 5858-5867. 2014.

BORZONE E. M., BLANCO M. V., BARUJ A., MEYER G. O., Stability of LaNi $\mathrm{L}_{5-\mathrm{x}} \mathrm{Sn}_{x}$ cycled in hydrogen. International Journal of Hydrogen Energy, v. 39, p. 87918796. 2014.

BRIKI C., BELKHIRIA S., DHAOU M. H., DE RANGO P., JEMNI A. Experimental study of the influences substitution from $\mathrm{Ni}$ by $\mathrm{Co}, \mathrm{Al}$ and $\mathrm{Mn}$ on the hydrogen storage properties of $\mathrm{LaNi}_{3.6} \mathrm{Mn}_{0.3} \mathrm{Al}_{0.4} \mathrm{Co}_{0.7}$ alloy. International Journal of Hydrogen Energy, v. 42, p. 10081-10088. 2017.

BRONOEL G., SARRADIN J., BONNEMAY M., PERCHERON A., ACHARD J.C., SCHLAPBACH L., A new hydrogen storage electrode. International Journal of Hydrogen Energy. v. 1, p. 251-254, 1976.

BUCHERT, M. Life cycle assessment (LCA) of nickel metal hydride batteries for HEV application. In: International Automobile Recycling Congress, IARC 2010, Basel (Switzerland), 4 de março de 2010. Disponível em: http://www.rechargebatteries.org/wpcontent/uploads/2013/07/LCA_NiMH_in_Toyota

BUSCHOW K.H.J; BOUTEN P.C.B; MIEDEMA A.R.; Rep. Prog. Phys., v. 45, p. 937, 1982.

BUSCHOW, K.H.J and VAN DER GOOT A.S., The crystal structure of rare-earth nickel compounds of the type $\mathrm{R}_{2} \mathrm{Ni}_{7}$. J. Less-Commom Metals. v. 22, p. 419-428. 1970. 
CASINI J.C. S., ZARPELON L. M. C., FERREIRA E. A., TAKIISHI H., FARIA R. N., Hydrogenation and ddischarge capacity of a $\mathrm{La}_{0.7} \mathrm{Mg}_{0.3} \mathrm{Al}_{0.3} \mathrm{Mn}_{0.4} \mathrm{Co}_{0.5} \mathrm{Ni}_{3.8}$ alloy for Nickel-Metal hydride batteries. Materials Science Forum. v. 660-661, p. 128-132. 2010.

CASINI J.C.S., Hidrogenação de ligas à base de terras raras para fabricação de eletrodos negativos de baterias de níquel-hidreto metálico. 2011. Dissertação (Mestrado) - Instituto de Pesquisas Energéticas e Nucleares - Universidade de São Paulo, Brasil.

CASINI J.C.S., Influência da substituição do cobalto por estanho e cobre na microestrutura e propriedades elétricas em ligas a base de LaMgAIMnCoNi. 2015. Tese (Doutorado) - Instituto de Pesquisas Energéticas e Nucleares Universidade de São Paulo, Brasil.

CASINI J.C.S., GUO Z., LIU, H.K., FERREIRA E.A., FARIA R.N., TAKIISHI H. Effect of $\mathrm{Sn}$ substitution for $\mathrm{Co}$ on microstructure and electrochemical performance of $\mathrm{AB}_{5}$ type $\quad \mathrm{La}_{0.7} \mathrm{Mg}_{0.3} \mathrm{Al}_{0.3} \mathrm{Mn}_{0.4} \mathrm{Co}_{0.5-\mathrm{x}} \mathrm{Sn}_{\mathrm{x}} \mathrm{Ni}_{3.8} \quad(\mathrm{x}=0-0.5)$ alloys. Transactions of Nonferrous Metals Society of China, v. 25, p.520-526. 2015.

CASINI J.C.S., SILVA F. M., GUO Z., LIU H. K., FARIA R. N. , TAKIISHI H. Effects of substituting $\mathrm{Cu}$ for $\mathrm{Sn}$ on the microstructure and hydrogen absorption properties of Co-free $\mathrm{AB}_{5}$ alloys. International Journal of Hydrogen Energy. v. 41, p. 1702217028. 2016.

CASTILLO L.A.B., Nanotubos de carbono aplicados al electrode negative de una bateria de Ni/MH. Universidad Nacional del Cuyo - Comissão de energia atômica. Argentina. 2013.

CHANDRA D, CHIEN W., TALEKAR A. Metal Hydrides for NiMH Battery Applications. Material matters, v. 6, p. 48-58, 2011.

CHEN J. High energy storage materials for rechargeable nickel-metal hydride batteries. 1999. Tese (Doutorado) - Institute of Superconducting and Electronic Materials (ISEM). Australia

CHEN J., DOU S.X., LIU H.K., Short Communication Effect of partial substitution of $\mathrm{La}$ with $\mathrm{Ce}, \mathrm{Pr}$ and $\mathrm{Nd}$ on the properties of $\mathrm{LaNi}$,-based alloy electrodes. Journal of Power Sources. v. 63, p. 267-270. 1996.

CHEN J., KURIYAMA N., TAKESHITA H. T., TANAKA H., SAKAI T., HARUTA M., Hydrogen Storage Alloys with PuNi3-Type Structure as Metal Hydride Electrodes. Electrochemical and Solid-State Letters. v. 3, p. 249-252. 2000.

CHENG L. F., WANG R. B., PU Z. H., LI Z. L., HE D. N., XIA B. J., Study on microstructure and electrochemical performance of $\mathrm{La}_{0.7} \mathrm{Mg}_{0.3}\left(\mathrm{Ni}_{0.9} \mathrm{Co}_{0.1}\right)_{\mathrm{x}}$ hydrogen storage alloys. Journal of Power Sources, v. 185, p. 1519-1523. 2008.

CHOW J., KOPP R. J., PORTNEY P.R., Energy Resources and global development. Science. v. 302, p. 1528-1531. 2003. 
CHUMPHONGPHAN S., PASKEVICIUS M., SHEPPARD D. A., C. E. BUCKLEY Cycle life and hydrogen storage properties of mechanical alloyed $\mathrm{Ca}_{1} \mathrm{~L}_{x} \mathrm{Zr}_{x} \mathrm{Ni}_{5} \mathrm{~L}_{y} \mathrm{Cr}_{y}$; $(x=0,0.05$ and $y=0,0.1)$. International Journal of Hydrogen Energy. v. 37, p. 7586- 7593. 2012.

CUEVAS F., JOUBERT J.M., LATROCHE M., PERCHERON-GUEGAN A. Intermetallic compounds as negative electrodes of Ni/MH batteries. Applied Physics A Materials Science \& Processing, v. 72, p. 225-238. 2001.

DENATRAN., Anuário de frota Departamento Nacional de Trânsito. Disponível em:

<http://www.detran.pr.gov.br/arquivos/File/planejamento/2018/FROTAJUNHO_2018. pdfs. Acesso em: 05 de setembro de 2018.

CUSCUETA DJ, MELNICHUK M, PERETTI HA, SALVA HR, GHILARDUCCI AA. Magnesium influence in the electrochemical properties of LaeNi base alloy for $\mathrm{Ni}-\mathrm{MH}$ batteries. Int J Hydrogen Energy. v. 33, p.3566-3570. 2008.

DONG X.P., LU F.X., ZHANG Y.H., YANG L.Y., WANG X.L., Effect of La/Mg on the structure and electrochemical performance of $\mathrm{La}-\mathrm{Mg}-\mathrm{Ni}$ system hydrogen storage electrode alloy. Mater. Chem. Phys, v. 108, p. 251-256. 2007.

DORNHEIM M., Thermodynamics of Metal Hydrides: Tailoring Reaction Enthalpies of Hydrogen Storage Materials. Thermodynamics-Interaction Studies-Solids, Liquids and Gases. p. 891-918. 2011.

EWE, H.; JUSTI, E. W.; STEPHAN, K., Elektrochemische Speicherung und Oxidation von Wasserstoff mit der intermetallischen Verbindung LaNi $i_{5}$, Energy Conversion, v. 13, p. 109-113, 1973.

FAN Y., ZHANG L., XUE C., FAN G., LIU B., HAN S. Phase structure and electrochemical hydrogen

storage performance of $\mathrm{La}_{4} \mathrm{MgNi}_{1} \mathrm{M}(\mathrm{M}=\mathrm{Ni}, \mathrm{Al}, \mathrm{Cu}$ and $\mathrm{Co})$ alloys. Journal of Allo ys and Compounds, v. 727, p. 398-409. 2017.

FARIA R.N., ZARPELON L.M.C., SERNA M.M., Baterias recarregáveis- introdução aos materiais e cálculos. São Paulo: Artlilber, 2014.

FEDERAL TRANSIT ADMINISTRATION - Washington Metropolitan Area Transit Authority (WMATA), http://www.fta.dot.gov/research, 2015.

FENG F., GENG M., NORTHWOOD D.O., Electrochemical behavior of intermetallicbased metal hydrides used in $\mathrm{Ni}=$ metal hydride $(\mathrm{MH})$ batteries: a review. International Journal of Hydrogen Energy. v. 26, p. 725-734. 2001.

FERREIRA E.A. Estudo da Hidrogenação para Pulverização de Ligas à base de Terras Raras com Nb para Eletrodos de Hidreto Metálico. 2013. Tese (Doutorado). Instituto de Pesquisas Energéticas e Nucleares - Universidade de São Paulo, Brasil. 
FERREIRA E. A., SERRA J. M., CASINI J. C. S., TAKIISHI H., FARIA R. N., Microstructure and Electrochemical Properties of a LaMgAIMnCoNi Based Alloy for Ni/MH Batteries. Materials Science Forum, v. 727-728, p. 80-84. 2012.

FERREIRA E. A., SERRA J. M., CASINI J. C. S., TAKIISHI H., FARIA R. N. Microstructure and Electrochemical Properties of a LaMgAIMnCoNi Based Alloy for Ni/MH Batteries. Materials Science Forum. v. 727-728 pp 80-84. 2012.

FERREIRA E. A., ZARPELON L. M. C., CASINI J. C. S., TAKIISHi H., FARIA R. N., The Effect of High Charging Rates Activation on the Specific Discharge Capacity and Efficiency of a Negative Electrode Based on a LaMgAIMnCoNi Alloy. Materials Science Forum, v. 660-661, p. 133-138. 2010.

FIORI C., DELL'ERA A., ZUCCARI F., SANTIANGELI A., D'ORAZIO A., ORECCHINI F., Hydrides for submarine applications: Overview and identification of optimal alloys for air independent propulsion maximization. International Journal of Hydrogen Energy. v. 40, p. 11879-11889. 2015.

FRIEDLMEIER G., MANTHEY A., WANNER M., GROLL M., Cyclic stability of various application-relevant metal hydrides. Journal of Alloys and Compounds. v. 231, p.880-887. 1995.

GALDINO, G. S.; Influência do Pr na microestrutura e propriedades elétricas em ligas a base de LaPrMgAIMnCoNi utilizadas em baterias de NiMH. 2011. Dissertação (Mestrado) - Instituto de Pesquisas Energéticas e Nucleares Universidade de São Paulo, Brasil.

GAO J., YAN X.L., ZHAO Z.Y., CHAI Y.J., HOU D.L., Effect of annealed treatment on microstructure and cyclic stability for La-Mg-Ni hydrogen storage alloys. Journal of Power Sources. v. 209, p. 257-261. 2012.

GAO Z., LUO Y., LI, R.; LIN Z., KANG L., Phase structures and electrochemical properties of $\mathrm{La}_{0.8-\mathrm{x}} \mathrm{Gd}_{0.2} \mathrm{Mg}_{\mathrm{x}} \mathrm{Ni}_{3.1} \mathrm{Co}_{0.3} \mathrm{Al}_{0.1}$ hydrogen storage alloys. J. Power Sources, v. 241, p. 509-516. 2013.

GIBB, T.R.P. Compounds of Hydrogen with Metals and Metalloids. Journal of The Electrochemical Society, v. 93, p. 198, 1948.

GIZA K., ADAMCZYK L., DRULIS H., HACKEMER A., Hydrogen sorption and corrosion properties of $\mathrm{La}_{2} \mathrm{Ni}_{9} \mathrm{CoSn}_{0.2}$ alloy. International Journal of Materials Research, v. 109, p. 99-104. 2018.

GONZÁLEZ E. L., LLERENA F. I., PÉREZ M. S., IGLESIAS F. R., MACHO J. G., Energy evaluation of a solar hydrogen storage facility: Comparison with other electrical energy storage technologies. International Journal of Hydrogen Energy, v. 40 , p. 5518-5525. 2015.

GOODELL P. D., Stability of rechargeable hydriding alloys during extended cycling. Journal of the Less-Common Metals. v. 99, p. 1-14. 1984. 
GUTJAHR M.A; BUCHNER H; BECCU K.D., SAUFFERER in Power sources 4, ed. D.H Collins, Oriel Press, Newcastle Upon Tyne, p.79, 1973.

GUZIK M. N., LANG J., HUOT J., SARTORI S., Effect of Al presence and synthesis method on phase composition of the hydrogen absorbing La-Mg-Ni-based compounds. International Journal of Hydrogen Energy, v. 42, p. 30135-30144. 2017.

HANDA K.; YOSHIDA H., Development of Next-Generation Electric Vehicle “i-MiEV"(Second report). Disponível em: <http://www.evoscan.com/manuals/EvoX/EvoX\%20Technical\%20Perspective\% 20Review/20e_11.pdts. Acesso em: 10 out. 2017.

HILL N., The role of GHG emissions from infrastructure construction, vehicle manufacturing, and ELVs in overall transport sector emissions. In: Diamant Conference Center, Brussels. 2011.

HONGMEI J., GUOXUN L., CHUANHUA Z., RUIKUN W. Factors affecting the characteristics of the negative electrodes for nickel-metal hydride batteries. Journal of Power Sources, 77(2), 123-126. 1999.

HU W.K., DENYS R. V., NWAKWUO C. C., HOLM T., MAEHLEN J.P, SOLBERG J. K., YARTYS V.A., Annealing effect on phase composition and electrochemical properties of the Co-free $\mathrm{La}_{2} \mathrm{MgNi}_{9}$ anode for Ni-metal hydride batteries. Electrochimica Acta. v. 96, p. 27- 33. 2013.

HUANG T., YUAN, X., YU J., WU Z., HAND J., SUN G., XU N., ZHANG Y., Effects of annealing treatment and partial substitution of $\mathrm{Cu}$ for $\mathrm{Co}$ on phase composition and hydrogen storage performance of $\mathrm{La}_{0.7} \mathrm{Mg}_{0.3} \mathrm{Ni}_{3.2} \mathrm{Co}_{0.35}$ alloy. International Journal of Hydrogen Energy. v. 37, p. 1074. 2012.

HUANG T., HAN, J., ZHANG Y., YU J., SUN G., REN H., YUAN X., Study on the structure and hydrogen absorption-desorption characteristics of as-cast and annealed $\mathrm{La}_{0.78} \mathrm{Mg}_{0.22} \mathrm{Ni}_{3.48} \mathrm{Co}_{0.22} \mathrm{Cu}_{0.12}$ alloys. Journal of Power Sources, v. 196, p. 9585-9589. 2011.

INADA R., YASUDA S., HOSOKAWA H., SAITO M., TOJO T., SAKURAI Y., Formation and Stability of Interface between Garnet-Type Ta-doped $\mathrm{Li}_{7} \mathrm{La}_{3} \mathrm{Zr}_{2} \mathrm{O}_{12}$ Solid Electrolyte and Lithium Metal Electrode. Batteries, v. 4, p. 26. 2018.

INOUE H., HIGUCHI E., Electrode materials for nickel/metal hydride (Ni/MH) rechargeable batteries. In: XU, Q.; KOBAYASHI, T. (Ed.). Advanced materials for clean energy. Boca Raton: CRC, p. 201-227. 2015.

ISE T., MURATA T., HIROTA Y., NOGAMI M., NAKAHORI S., The effect of particle size on the electrochemical properties of hydrogen absorbing alloy electrodes. Journal of Alloys and Compounds. v. 298, p. 310-318. 2000. 
IWASE K., MORI K., TERASHITA N., TASHIRO S., SUZUKI T., Crystal Structure of $\mathrm{Pr}_{3} \mathrm{MgNi}_{14} \mathrm{D}_{\mathrm{x}}$ Studied by in Situ Neutron Diffraction. Inorganic Chemistry, v. 56, p. 6933-6937. 2017.

IWASE K., TERASHITA N., MORI K., YOKOTA H., SUZUKI T. Crystal structure and Cyclic hydrogenation property of $\mathrm{Pr}_{4} \mathrm{MgNi}_{19}$. Inorg. Chem., v. 52, p. 14270-14274. 2013.

IWASE K., TERASHITA N., MORI K., ISHIGAKI T. Structural Parameters of $\mathrm{Pr}_{3} \mathrm{MgNi}_{14}$ during Hydrogen Absorption-Desorption Process. Inorganic Chemistry, v. 51, p. 11805-11810. 2012a.

IWASE K., TERASHITA N., MORI K., TSUNOKAKE S., ISHIGAKI T. Crystal structure and cyclic properties of hydrogen absorption-desorption in $\mathrm{Pr}_{2} \mathrm{MgNi}_{9}$. International Journal of Hydrogen Energy, v. 37, p. 18095-18100. 2012b.

JAIN I. P., LAL C., JAIN A., Hydrogen storage in Mg: A most promising material. International Journal of Hydrogen Energy, v. 35, p. 5133-5144. 2010.

JIANG W., MO X., GUO J., WEI Y., Effect of annealing on the structure and electrochemical properties of $\mathrm{La}_{1.8} \mathrm{Ti}_{0.2} \mathrm{MgNi}_{8.9} \mathrm{Al}_{0.1}$ hydrogen storage alloy. Journal of Power Sources. v. 221, p.84-89. 2013.

JOUBERT J. M., ČERNÝ R., LATROCHE M., PERCHERON-GUÉGAN A., SCHMITT B., Hydrogenation of $\mathrm{LaNi}_{5}$ studied by in situ synchrotron powder diffraction. Acta Materialia. v. 54, p. 713-719. 2006.

JUSTI E.H., EWE H.H., KALBERLAH A.W., SARIDAKIS N.M., SCHAEFER, M.H., Electrocatalysis in the nickel-titanium system. Energy Conversion. v. 10, p. 183, 1970.

KABUTOMORI T. and OHNISHI K., Metal hydrides. Energy Carriers and Conversion Systems - v. II, p. 249-262. 2009.

KADIR K., SAKAI T., UEHARA I., Structural investigation and hydrogen storage capacity of $\mathrm{LaMg}_{2} \mathrm{Ni}_{9}$ and $\left(\mathrm{La}_{0,65} \mathrm{Ca}_{0,35}\right)\left(\mathrm{Mg}_{1,32} \mathrm{Ca}_{0,68}\right) \mathrm{Ni}_{9}$ of the $A B_{2} \mathrm{C}_{9}$ type structure. Journal of Alloys and Compounds. v. 302, p. 112-117. 2000.

KADIR K., TANAKA H., SAKAI T., UEHARA I., Hydrogen behavior in the La-Mg-Cu system. Journal of Alloys and Compounds, v. 289, p. 66-70. 1999.

KADIR K., SAKAI T., UEHARA I., Synthesis and structure determination of a new series of hydrogen storage alloys; $\mathrm{RMg}_{2} \mathrm{Ni}_{9}(\mathrm{R}=\mathrm{La}, \mathrm{Ce}, \mathrm{Pr}, \mathrm{Nd}, \mathrm{Sm}$ and $\mathrm{Gd}$ ) built from $\mathrm{MgNi}_{2}$ Laves-type layers alternating with $\mathrm{AB}_{5}$ layers. Journal of Alloys and Compounds, v. 257, p.115-121. 1997.

KAND M., YAMAMOTO M., KANNO K., SATOH H., HAYASHIDA H., SUZ M., Cyclic behavior of metal hydride electrodes and the cell characteristics of nickel-metal hydride batteries. Journal of the Less Common Metals. v. 172/174, p. 1227. 1991. 
KLEPERIS J.,WÓRJCIK G.,CZERWINSK A.,SKOWRONSKI J., KOPEZYK M., BRZEZINSKA M.B., Electrochemical behavior of metal hydrides. J. Solid Stat Electrochem. v. 5, p. 229-249. 2001.

KOHNO T., YOSHIDA H., KAWASHIMA F., INABA T., SAKAI I., YAMAMOTO M., KANDA M., Hydrogen storage properties of new ternary system alloys: $\mathrm{La}_{2} \mathrm{MgNi}_{9}$, $\mathrm{La}_{5} \mathrm{Mg}_{2} \mathrm{Ni}_{23}, \mathrm{La}_{3} \mathrm{MgNi}_{14}$. Journal of Alloys and Compounds. v. 31, p. L5-L7. 2000.

LAMBERT S. W., CHANDRA D., CATHEY W. N., LYNCH F. E., BOWMAN R. C., Investigation of hydriding properties of $\mathrm{LaNi}_{4.8} \mathrm{Sn}_{0.2}, \mathrm{LaNi}_{4.27} \mathrm{Sn}_{0.24}$ and $\mathrm{La}_{0.9} \mathrm{Gd}_{0.1} \mathrm{Ni}_{5}$ after thermal cycling and aging. Journal of Alloys and Compounds. v. 187, p. 113-135. 1992.

LAPTEV R. S., KUDIIAROV V. N., BORDULEV Y. S., MIKHAYLOV A. A., LIDER A. M., Gas-phase hydrogenation influence on defect behavior in titanium-based hydrogen-storage material. Progress in Natural Science: Materials International. v. 27, p.105-111. 2017.

LEMORT L., LATROCHE M., KNOSP B., BERNARD P. Elaboration and characterization of new pseudo-binary hydride-forming phases $\operatorname{Pr}_{1.5} \mathrm{Mg}_{0.5} \mathrm{Ni}_{7}$ and $\mathrm{Pr}_{3.75} \mathrm{Mg}_{1.25} \mathrm{Ni}_{19}$ : a comparison to the binary $\mathrm{Pr}_{2} \mathrm{Ni}_{7}$ and $\mathrm{Pr}_{5} \mathrm{Ni}_{19}$ ones. The Journal of Physical Chemistry C, v. 115, p. 19437-19444. 2011.

LI F., YOUNG K., OUCHI T., FETCENKO M.A. Annealing effects on structural and electrochemical properties of $(\mathrm{LaPrNdZr})_{0.83} \mathrm{Mg}_{0.17}(\mathrm{NiCoAlMn})_{3.3}$ alloy. Journal of Alloys and Compounds. v. 471, p. 371-377. 2009.

LI R., WU J., ZHOU S., WANG X., Effects of rare-earth content and annealing on the electrochemical properties of $\mathrm{Mm}(\mathrm{NiCoMnAl})_{5}$ hydrogen storage alloys. Journal of Alloys and Compounds. v. 363, p. 292-298. 2004.

LI B, CAO H, SHAO J, ZHENG H, LU Y, YIN J, QU M. Improved performances of $\beta-\mathrm{Ni}(\mathrm{OH})_{2} @$ reduced-graphene-oxide in Ni-MH and Li-ion batteries. Chemical Communications. v. 47, p. 3159-3166. 2011.

LI B., REN H., ZHANG Y., DONG X., REN J., WANG X. Microstructure and electrochemical performances of $\mathrm{La}_{0.7} \mathrm{Mg}_{0.3} \mathrm{Ni}_{2.55-x} \mathrm{Co}_{0.45} \mathrm{Al}_{\mathrm{x}} \quad(\mathrm{x}=0-0.4)$ hydrogen storage alloys prepared by casting and rapid quenching. Journal of Alloys and Compounds. v. 425, p. 399-405. 2006.

LI Y., ZHANG Y., REN H., LIU Z., SUN H., Mechanism of distinct high rate dischargeability of $\mathrm{La}_{4} \mathrm{MgNi}_{19}$ electrode alloys prepared by casting and rapid quenching followed by annealing treatment. International Journal of Hydrogen Energy, v. 41, p. 18571-18581. 2016.

LI Y., HAN D., HAN S., ZHU X., HU L., ZHANG Z., LIU,Y., Effect of rare earth elements on electrochemical properties of $\mathrm{La}-\mathrm{Mg}-\mathrm{Ni}$-based hydrogen storage alloys. International Journal of Hydrogen Energy, v. 34, p. 1399-1404. 2009. 
LI S.L., CHEN W., LUO G., HAN X.B., CHEN D.M., YANG K., CHEN W.P.; Effect of hydrogen absorption/desorption cycling on hydrogen storage properties of a $\mathrm{LaNi}_{3.8} \mathrm{Al}_{1.0} \mathrm{Mn}_{0.2}$ alloy. Internatinal Journal Hydrogen Energy. v. 37, p. 3268-3275. 2012.

LIAO B., LEI Y.Q., CHEN L.X., LU G.L., PAN H.G., WANG Q.D., Effect of the La/Mg ratio on the structure and electrochemical properties of $\mathrm{La}_{x} \mathrm{Mg}_{3-\mathrm{x}} \mathrm{Ni}_{9}(\mathrm{x}=1.6-2.2)$ hydrogen storage electrode alloys for nickel-metal hydride batteries. Journal of Power Sources. v. 129, p. 358-367. 2004.

LIAO B.; LEI Y.Q.; CHEN L.X.; LU G.L.; PAN H.G.; WANG Q.D., Effect of Co substitution for $\mathrm{Ni}$ on the structural and electrochemical properties of $\mathrm{La}_{2} \mathrm{Mg}\left(\mathrm{Ni}_{1-\mathrm{x}} \mathrm{Co}_{\mathrm{x}}\right)_{9}(\mathrm{x}=0,1-0,5)$ hydrogen storage electrode alloys. Electrochimica Acta, v. 50, p. 1057-1063. 2004.

LIBOWITZ G. G., HAYES H. F., GIBB T. R. P., Critical Materials Problems in Energy Production. editado por Charles Stein. 1958.

LIM K. L., LIU Y., ZHANG Q. A., LIN K. S., CHAN S. L. I.; Cycle stability of La-Mg-Ni based hydrogen storage alloys in a gas-solid reaction. Internatinal Journal

Hydrogen Energy . v. 42, p. 23737-23745. 2017.

LIM K. L., LIU Y., ZHANG Q.-A., LIN K.-S., CHAN S. L. I., Cycle stability improvement of $\mathrm{La}-\mathrm{Mg}-\mathrm{Ni}$ based alloys via composite method. Journal of Alloys and Compounds, v. 661, p. 274-281. 2016.

LIM K. L., LIU Y., ZHANG Q. A., CHAN S. L. I., Effects of partial substitutions of cerium and aluminum on the hydrogenation properties of $\mathrm{La}_{(0.65-\mathrm{x})} \mathrm{Ce}_{\mathrm{x}} \mathrm{Ca}_{1.03} \mathrm{Mg}_{1.32} \mathrm{Ni}_{(9-\mathrm{y})} \mathrm{Al}_{\mathrm{y}}$ alloy. International Journal of Hydrogen Energy, v. 39, p. 10537-10545. 2014.

LIU J., ZHENG Z., CHENG H., LI K., YAN K., HAN X., LIU, Y. Long-term hydrogen storage performance and structural evolution of $\mathrm{LaNi}_{4} \mathrm{Al}$ alloy. Journal of Alloys and Compounds, v. 731, p. 172-180. 2018.

LIU J., YAN Y., CHENG H., HAN S., LV Y., LI K., LU C. Phase transformation and high electrochemical performance of $\mathrm{La}_{0.78} \mathrm{Mg}_{0.22} \mathrm{Ni}_{3.73}$ alloy with ( $\left.\mathrm{La}, \mathrm{Mg}\right)_{5} \mathrm{Ni}_{19}$ super lattice structure. Journal of Power Sources, v. 351, p. 26-34. 2017a.

LIU J., LI K., CHENG H., YAN K., WANG Y., LIU Y., ZHENG Z., New insights into the hydrogen storage performance degradation and $\mathrm{Al}$ functioning mechanism of $\mathrm{LaNi}_{5-\mathrm{x}} \mathrm{Al}_{\mathrm{x}}$ alloys. International Journal of Hydrogen Energy, v. 42, p. 2490424914. 2017b.

LIU J., HAN S., LI Y., ZHANG L., ZHAO Y., YANG S., LIU B., Phase structures and electrochemical properties of $\mathrm{La}-\mathrm{Mg}-\mathrm{Ni}$-based hydrogen storage alloys with super lattice structure. International Journal of Hydrogen Energy, v. 41, p. 2026120275. 2016. 
LIU J., HAN S., LI Y., YANG S., CHEN X., WUA C., MA C.; Effect of Pr on phase structure and cycling stability of La-Mg-Ni-based alloys with $A_{2} B_{7}$ and $A_{5} B_{19}$-type super lattice structures. Electrochimica Acta. v.184, p. 257-263. $2015 a$.

LIU J., HAN S., LI Y., YANG S., ZHANG L., ZHAO Y., Effect of Al incorporation on the degradation in discharge capacity and electrochemical kinetics of $\mathrm{La}-\mathrm{Mg}-\mathrm{Ni}-$ based alloys with $\mathrm{A}_{2} \mathrm{~B}_{7}$-type super-stacking structure. J. Alloys Compd., v. 619, p. 778-787. 2015b.

LIU J., LI Y., HAN D., YANG S., CHEN X., ZHANG L., HAN S., Electrochemical performance and capacity degradation mechanism of single-phase La-Mg-Ni-based hydrogen storage alloys. Journal of Power Sources. v, 300, p.77-86. 2015c.

LIU J., HAN S., LI Y., ZHANG J., ZHAO Y., CHE L., Effect of crystal transformation on electrochemical characteristics of La-Mg-Ni-based alloys with $\mathrm{A}_{2} \mathrm{~B}_{7}$-type superstacking structures. Int. J. Hydrogen Energy, v. 38, p. 14903-14911. 2013.

LIU Y., CAO Y., HUANG L., GAO M., PAN H. Rare earth-Mg-Ni-based hydrogen storage alloys as negative electrode materials for $\mathrm{Ni} / \mathrm{MH}$ batteries. Journal of Alloys and Compounds, v. 509, p. 675-686. 2011a.

LIU Y., PAN H., GAO M., WANG Q., Advanced hydrogen storage alloys for Ni/MH rechargeable batteries. J. Mater. Chem., v. 21, p. 4743-4755. 2011 b.

LIU Y., PAN H., GAO M., LEI Y., WANG Q., Degradation Mechanism of the La-MgNi-Based Metal Hydride Electrode $\mathrm{La}_{0.7} \mathrm{Mg}_{0.3} \mathrm{Ni}_{3.4} \mathrm{Mn}_{0.1}$. Journal of The Electrochemical Society, v.152, p. 1089-1095. 2005a.

LIU Y. F., PAN H. G., LI R., LEI Y. Q., Effects of Al on cycling stability of a new rareearth Mg-based hydrogen storage alloy. Materials Science Forum, v. 475, p. 24572462. 2005b.

LIU Y., PAN H., GAO M., LI R., LEI Y., Effect of Co content on the structural and electrochemical properties of the $\mathrm{La}_{0.7} \mathrm{Mg}_{0.3} \mathrm{Ni}_{3.4-x} \mathrm{Mn}_{0.1} \mathrm{Co}_{\mathrm{x}}$ hydride alloys II. Electrochemical properties. Journal of Alloys and Compounds. v. 376, p. 304-313. 2004a.

LIU Y., PAN H., GAO M., ZHU Y., LEI Y., Hydrogen storage and electrochemical properties of the $\mathrm{La}_{0.7} \mathrm{Mg}_{0.3} \mathrm{Ni}_{3.825-\mathrm{x}} \mathrm{Co}_{0.675} \mathrm{Mn}_{\mathrm{x}}$ hydrogen storage electrode alloys. Journal of Alloys and Compounds. v. 365, p. 246-252. 2004b.

LIU Y., PAN H., GAO M., ZHU Y., LEI Y., WANG Q., The effect of Mn substitution for $\mathrm{Ni}$ on the structural and electrochemical properties of $\mathrm{La}_{0: 7} \mathrm{Mg}_{0: 3} \mathrm{Ni}_{2: 55-\mathrm{x}} \mathrm{Co}_{0: 45} \mathrm{Mn}_{\mathrm{x}}$ hydrogen storage electrode alloys International Journal of Hydrogen Energy v. 29, p. 297-305. 2004c.

LIU Y, PAN H, GAO M, WANG Q. Advanced hydrogen storage alloys for $\mathrm{Ni} / \mathrm{MH}$ rechargeable batteries. J Mater Chem; v. 21, p. 4743-55. 2011. 
LIU P.; PAN H.; ZHU Y.; LI R.; LEI Y. Influence of Mn content on structural and electrochemical properties of the $\mathrm{La}_{0,7} \mathrm{Mg}_{0,3} \mathrm{Ni}_{3,25-x} \mathrm{Co}_{0,75} \mathrm{Mnx}$ hydrogen storage alloys. Journal Materials Science and Engineering, v. 372, p. 163. 2004.

LOTOTSKYY M. V., TOLJ I., PICKERING L., SITA C., BARBIR F., YARTYS V., The use of metal hydrides in fuel cell applications. Progress in Natural Science: Materials International, v. 27, p. 3-20. 2017.

LV, W., SHI, Y., DENG, W., YUAN, J., YAN, Y., \& WU, Y. Effect of Mg substitution for La on microstructure, hydrogen storage and electrochemical properties of $\mathrm{La}_{1-\mathrm{x}} \mathrm{Mg}_{\mathrm{x}} \mathrm{Ni}_{3.5}(\mathrm{x}=0.20,0.23,0.25$ at\%) alloys. Progress in Natural Science: Materials International, v. 26, p. 177-181. 2016.

MA J., PAN H., CHEN C., WANG Q., Effect of heat treatment on the microstructure and electrochemical properties of $A B 5$-type $\mathrm{MINi}_{3.60} \mathrm{Co}_{0.85} \mathrm{Mn}_{0.40} \mathrm{Al}_{0.15}$ hydride alloy: 1."The microstructure and P-C isotherms. International Journal of Hydrogen Energy, v. 27, p.57-62. 2002.

MA J., PAN H., CHEN C., WANG Q., The electrochemical properties of Co-free $\mathrm{AB}_{5}$ type $\mathrm{Ml}_{(4.45-\mathrm{x})} \mathrm{Mn}_{0.4} \mathrm{Al}_{0.15} \mathrm{Sn}_{\mathrm{x}}$ hydride electrode alloys. Journal of Alloys and Compounds, v. 343, p. 164-169. 2002.

MEENA P., JANGIR M., SINGH R., SHARMA V. K., JAIN I. P., Synthesis and hydrogen storage of $\mathrm{La}_{23} \mathrm{Nd}_{7.8} \mathrm{Ti}_{1.1} \mathrm{Ni}_{33.9} \mathrm{Co}_{32.9} \mathrm{Al}_{0.65}$ alloys. Journal of Materials Research and Technology, v. 7, p. 173-179. 2018.

MØLLER K. T., JENSEN T. R., AKIBA E., Li H., Hydrogen - A sustainable energy carrier. Progress in Natural Science: Materials International, v. 27, p. 34-40. 2017.

MORIMOTO K., NAGASHIMA I., MATSUI M., MAKI H., MIZUHAT M., Improvement of electrochemical properties and oxidation/reduction behavior of cobalt in positive electrode of Ni-metal hydride battery. Journal of Power Sources, v. 388, p. 45-51. 2018.

NWAKWUO C. C., HOLM T., DENYS R. V., HU W., MAEHLEN J. P., SOLBERG J. K., YARTYS V. A. Effect of magnesium content and quenching rate on the phase structure and composition of rapidly solidified $\mathrm{La}_{2} \mathrm{MgNi}_{9}$ metal hydride battery electrode alloy. Journal of Alloys and Compounds, v. 555, p. 201-208. 2013.

Nissan Marketing, 2012. Produced by Nissan. Disponível em: <http://umtri.umich.edu/content/Brendan.Jones. Nissan.Marketing.PT.2012.pdts. Acesso em: 14 set. 2017.

NOTTEN P. H. and HOKKELING P., Double-Phase Hydride Forming Compounds: A New Class of Highly Electrocatalytic Materials. J. Electrochem. Soc., v.138, p. 1877-1885. 1991.

OESTERREICHER H.,.BITTNER H., Hydride formation in $\mathrm{La}_{1-x} \mathrm{Mg}_{x} \mathrm{Ni}_{2}$. Journal of the Less-Common Metals. v. 73, p. 339-344. 1980. 
OKAMOTO, H. "La-Ni (Lanthanum-Nickel)," Journal of Phase Equilibria, v. 23, p. 287-288. 2002.

OUCH T. I, YOUNG K.., MOGHE D., Reviews on the Japanese Patent Applications Regarding Nickel/Metal Hydride. Batteries. v. 21, p.2-30. 2016.

PAN H., CHEN N., GAO M., LI R., LEI Y., WANG Q., Effects of annealing temperature on structure and the electrochemical properties of $\mathrm{La}_{0.7} \mathrm{Mg}_{0.3} \mathrm{Ni}_{2.45} \mathrm{Co}_{0.75} \mathrm{Mn}_{0.1} \mathrm{Al}_{0.2}$ hydrogen storage alloy. Journal of Alloys and Compounds. v. 397, p. 306-312. 2005.

PENG C.H., ZHU M., Microstructure and hydrogen storage properties of a multiphase $\mathrm{Ml}_{0.7} \mathrm{Mg}_{0.3} \mathrm{Ni}_{3.2}$ hydrogen storage alloy. Journal of Alloys and Compounds. v. 375, p. 324-329. 2004.

PETIT FÉREY, M.A.; Élaboration et caractérisation d'alliages hydrurables de type $\mathrm{AB}_{\mathrm{X}}(\mathrm{A}=\mathrm{La}, \mathrm{Mg} ; \mathrm{B}=\mathrm{Ni}$ et $\mathrm{X}=3$ à 4$)$ envue de leur utilization commematière active pour electrode negative d'accumulateur Ni-MH. 2008. Tese (Doutorado) Departamento de Ciência e Engenharia: Materiais, Modelagem e Meio Ambiente Universidade de Paris XII, França.

PLUNKETT RESEARCH LTD., Automotive industry Overview. Disponível em: $<$ <ttp://www.plunkettresearch.com/automobiles-trucks-marketresearch/industryandbusiness-data>. Acesso em: 15 out. 2017.

POLLET B.G.; STAFFEL I.; SHANG J.L. Current status of hybrid, battery and fuel cell electric vehicles: From electrochemistry to market prospects. Electrochimica Acta. v.84, p. 235- 249. 2012.

QI Y., ZHANG Y., ZHANG W., GAO J., YUAN Z., BU W., GUO S., Hydrogen storage thermodynamics and kinetics of RE-Mg-Ni-based alloys prepared by mechanical milling. International Journal of Hydrogen Energy, v. 42, 18473-18483. 2017.

REILLY J.J., ADZIC G.D., JOHNSON J.R., VOGT T., MUKERJEE S., MCBREEN J., The correlation between composition and electrochemical properties of metal hydride electrodes. Journal of Alloys and Compounds. v. 293-295, p. 569-582. 1999.

REILLY J.J. and WISWALL R.H., Formation and properties of iron titanium hydride. Inorganic Chemistry, v. 13, p. 218-222. 1974.

REVISTA GALILEU, Ciência e meio ambiente. https://revistagalileu.globo.com/Ciencia/Meio-Ambiente/noticia/2018/04/japaoencontrou-acervo-de-minerais-que-podem-suprir-o-mundo-por-muito-tempo.html. 2018.

RIBEIRO E.S., Método e instrumentação de caracterização de materiais sólidos aplicáveis no armazenamento de hidrogénio. 2016. Tese de doutoramento. Departamento de Física da Faculdade de Ciências e Tecnologia da Universidade de Coimbra. 
SAKAI T., MIYAMURA H., KURIYAMA N., KATO A, OGURO K., ISHIKAWA H., The influence of small amounts of added elements on various anode performance characteristics for $\mathrm{LaNi}_{2,5} \mathrm{Co}_{2,5}$-based alloys. Journal of the Less-Common Metals. v. 159 , p. $127-$ I 39. 1990.

SAKAI T., YOSHINAGA H., MIGAMURA H., KURIGAMA N., ISHIKAWA H., Rechargeable hydrogen batteries using rare-earth-based hydrogen storage alloys. J Alloys and Compounds. v. 180, p. 37-54. 1992.

SAKAI T., UEHARA I., ISHIKAWA H., R\&D on metal hydride materials and Ni-MH batteries in Japan. Journal of Alloys and Compounds. v. 293-295, p. 762-769. 1999.

SAKINTUNA B., LAMARIDARKRIM F., HIRSCHER M. Metal hydride materials for solid hydrogen storage: A review. International Journal of Hydrogen Energy. v. 32, p. 1121-1140. 2007.

SANDROCK G., A panoramic overview of hydrogen storage alloys from a gas reaction point of view. Journal of Alloys and Compounds. v. 293-295, p. 877-888, 1999.

SANDROCK G.D., In Hydrogen Energy System-Utilization of Hydrogen Aspects, Science. v. 302, p.1528-1531. 2003.

SANTOS S., CASTRO J., TICIANELLI E., Microstructures and electrode performances of $\mathrm{Mg}_{50} \mathrm{Ni}_{(50-x)} \mathrm{Pd}_{x}$ alloys. Open Chemistry, v. 11, p. 485-491. 2013.

SCHLAPBACH L., Surface properties and activation. Hydrogen in Intermetallic Compunds II, p. 15-95. 1992.

SCHLAPBACH, L., ZÜTTEL A., Hydrogen-storage materials for mobile applications. Nature. v. 414. p. 353 - 358. 2001.

SHASHIKALA K., Hydrogen Storage Materials. Functional Materials, p. 607-637. 2012.

SIEGMANN H. C., SCHLAPBACH L., BRUNDLE C. R., Self-Restoring of the Active Surface in the Hydrogen Sponge LaNi ${ }_{5}$. Physical Review Letters, v. 40, p. 972-975. 1978.

SOUZA E.C., Propriedades estruturais e eletroquímicas de ligas de hidreto metálico processadas por moagem de alta energia. Tese (Doutorado) - 2006. Universidade de São Paulo, São Carlos, Brasil.

SONG D., WANG Y., LIU Y, HAN S., JIAO L., YUAN H., Effects of annealing on microstructures and electrochemical properties of $\mathrm{La}_{0.8} \mathrm{Mg}_{0.2} \mathrm{Ni}_{2.4} \mathrm{Mn}_{0.10} \mathrm{Co}_{0.55} \mathrm{Al}_{0.10}$ alloy. Journal of Rare Earths. v. 26, p.398-40. 2008. 
TAKASAKI T., NISHIMURA K., SAITO M., FUKUNAGA H., IWAKI T. SAKAI T., Cobalt-free nickel-metal hydride battery for industrial applications. Journal of Alloys and Compounds. v. 580, p. S378-S381. 2013

TAN S., SHEN Y., ONUR ŞAHIN E., NORÉUS D., ÖZTÜRK T., Activation behavior of an $\mathrm{AB}_{2}$ type metal hydride alloy for NiMH batteries. International Journal of Hydrogen Energy, v. 41, p. 9948-9953. 2016.

TANAKA H., SENOH H., KURIYAMA N., AIHARA K., TERASHITA N., NAKAHATA T., Cycle durability of $\mathrm{Ca}-\mathrm{Mg}-\mathrm{Ni}$ alloys and factors which cause degradation of hydrogen storage capacity. Materials Science and Engineering. v. B108, p. 81-90. 2004.

TIAN X., WEI W., DUAN R., ZHENG X., ZHANG H., TEGUS O., LI X., Preparation and electrochemical properties of $\mathrm{La}_{0.70} \mathrm{Mg}_{\mathrm{x}} \mathrm{Ni}_{2.45} \mathrm{Co}_{0.75} \mathrm{Al}_{0.30}(\mathrm{x}=0,0.30,0.33,0.36$, 0.39) hydrogen storage alloys. Journal of Alloys and Compounds, v. 672, p. 104109. 2016.

VAN MAL H.H., BUSCHOW K.H.I. and MIEDEMA A.R., Hydrogen absorption in $\mathrm{LaNi}_{5}$, and related compounds: experimental observations and their explanation. Journal of the Less-Commom Metals, v. 35, p. 65-76. 1974.

VAN VUCHT J. H. N., KUIJPERS F. A., BRUNINH. C. A. M. G, Reversible roomtemperature absorption of large quantities of hydrogen by intermetallic compounds. Philips Res. Refits. v. 25, p.133-140. 1970

VIRKAR A. V. \& RAMAN A., Crystal structures of ab3 and azb7 rare earth-nickel phases. Journal of the Less-Common Metals. v. 18, p. 59-66. 1969.

VUCHT J.H.N.V., KUIJIPERS F.A., BUNNING H.C.A.M., Philips Research Reports, v. 25 , p. 133.1970.

XIAO L., WANG Y., LIU Y., SONG D., JIAO L., YUAN H., Influence of surface treatments on microstructure and electrochemical properties of $\mathrm{La}_{0.7} \mathrm{Mg}_{0.3} \mathrm{Ni}_{2.4} \mathrm{Co}_{0.6}$ hydrogen-storage alloy. International Journal of Hydrogen Energy. v. 33, p. 39253929. 2008.

XIE S. C., CHEN Z. L., LI Y. T., SI T. Z., LIU D. M., ZHANG Q. A. Hydrogen absorption-desorption features and degradation mechanism of $\mathrm{ErNi}_{3}$ compound. Journal of Alloys and Compounds, v. 585, p. 650-655. 2014.

XUE, C., ZHANG, L., FAN, Y., FAN, G., LIU, B., \& HAN, S. Phase transformation and electrochemical hydrogen storage performances of $\mathrm{La}_{3} \mathrm{RMgNi}_{19}(\mathrm{R}=\mathrm{La}, \mathrm{Pr}, \mathrm{Nd}, \mathrm{Sm}$, $\mathrm{Gd}$ and $\mathrm{Y}$ ) alloys. International Journal of Hydrogen Energy, v. 42, p. 6051-6064. 2017.

YAN H., KONG F., XIONG W., LI B., LI J., Effect of praseodymium substitution for lanthanum on structure and properties. Journal of Rare Earths, v. 27, p. 244-249. 2009. 
YASUOKA S., ISHIDA J., KISHIDA K., INUI H., Effects of cerium on the hydrogen absorption-desorption properties of rare earth-Mg-Ni hydrogen-absorbing alloys. Journal of Power Sources, v. 346, 56 - 62. 2017.

YANG S, HAN S, SONG J, LI Y. Influences of molybdenum substitution for cobalt on the phase structure and electrochemical kinetic properties of $A B_{5}$-type hydrogen storage alloys. J. Rare Earths, v. 29, p. 692 - 697. 2011.

YANG T., YUAN Z., BU W., JIA Z., QI Y., ZHANG Y., Effect of elemental substitution on the structure and hydrogen storage properties of $\mathrm{LaMgNi}_{4}$ alloy. Materials \& Design, v. 93, p. 46-52. 2016.

YARTYS V., DENYS R. Structure-properties relationship in $\mathrm{RE}_{3-\mathrm{x}} \mathrm{Mg}_{\mathrm{x}} \mathrm{Ni}_{9} \mathrm{H}_{10-13}(\mathrm{RE}=$ $\mathrm{La}, \mathrm{Pr}, \mathrm{Nd}$ ) hydrides for energy storage. Journal of Alloys and Compounds, v. 645, p. S412-S418. 2015.

YOUNG K., OUCHI T., NEI J., KOCH J. M, LIEN Y.L., Comparison among Constituent Phases in Super lattice Metal Hydride Alloys for Battery Applications. Batteries. v. 34, p. 2-20. 2017.

YOUNG K.. Research in Nickel/Metal Hydride Batteries. Batteries, v. 2, p. 31. 2016a.

YOUNG K., Electrochemical applications of metal hydrides. Compendium of Hydrogen Energ. p. 289-304. 2016b.

YOUNG K., OUCHI T., SHEN H., BENDERSKY L. A., Hydrogen induced amorphization of $\mathrm{LaMgNi}_{4}$ phase in metal hydride alloys. International Journal of Hydrogen Energy, v. 40, p. 8941-8947. 2014.

YOUNG K., OUCHI T., MAYS W., REICHMAN B., FETCENKO M. A. Pressurecomposition-temperature hysteresis in C14 Laves phase alloys. Journal of Alloys and Compounds, v. 480, p. 434-439. 2009a.

YOUNG K., FETCENKO M. A., OUCHI T., LI F., KOCH J., Effect of Sn-substitution in C14 Laves phase alloys for NiMH battery application. Journal of Alloys and Compounds, v. 469, p. 406-416. 2009b.

YOUNG K., OUCHI T., FETCENKO M. A., Roles of Ni, Cr, Mn, Sn, Co, and Al in C14 Laves phase alloys for $\mathrm{NiMH}$ battery application. Journal of Alloys and Compounds, v. 476, p. 774-781. 2009c.

YOUNG K., Niquel metal hydride Batteries. Technology \& Engineering. 2018.

WIPF, H.. Hydrogen in metals III - properties and applications. Annales de Chimie Science Des Matériaux, v. 24, p. 246-248. 1999. 
WANG D., LUO Y., YAN R., ZHANG F., KANG L., Phase structure and electrochemical properties of $\mathrm{La}_{0.67} \mathrm{Mg}_{0.33} \mathrm{Ni}_{3.0-x} \mathrm{Co}_{x}(\mathrm{x}=0.0,0.25,0.5,0.75)$ hydrogen storage alloys. Journal of Alloys and Compounds, v. 413, p. 193-197. 2006

WANG Y., WANG Y., Recent advances in additive-enhanced magnesium hydride for hydrogen storage. Progress in Natural Science: Materials International, v. 27, p. 41-49. 2017.

WEI F., LI L., XIANG H., LI H., WEI F. Phase structure and electrochemical properties of $\mathrm{La}_{1.7+\times} \mathrm{Mg}_{1.3-\mathrm{x}}(\mathrm{NiCoMn})_{9.3} \quad(\mathrm{x}=0-0.4)$ hydrogen storage alloys. Transactions of Nonferrous Metals Society of China, v. 22, p. 1995-1999. 2012.

WU C., YANG S., LI Y., MA Y., ZHANG L., LIU J., HAN S., Microstructural evolution and electrochemical properties of the ultra-high pressure treated $\mathrm{La}_{0.70} \mathrm{Mg}_{0.30} \mathrm{Ni}_{3.3}$ hydrogen storage alloy. Journal of Alloys and Compounds, v. 665, p. 231-239. 2016.

WU C., ZHANG L., LIU J., LI Y., YANG S., LIU B., HAN S., Electrochemical characteristics of $L_{0.59} \mathrm{Nd}_{0.14} \mathrm{Mg}_{0.27} \mathrm{Ni}_{3.3}$ alloy with rhombohedral-type and hexagonaltype $A_{2} B_{7}$ phases. Journal of Alloys and Compounds, v. 693, p. 573-581. 2017.

WU J., LI R., SU H., WANG X. Structure and electrochemical properties of $\mathrm{LaCo}_{13-\mathrm{x}} \mathrm{Ni}_{\mathrm{x}}$ compounds. Journal of Alloys and Compounds, v. 289, p. 251-256. 1999.

WU Y. F., LIU Y. N., LI C. S., ZHANG Y. P., ZHANG S. N., MA X. B., CHEN Y. Z., XI Z. P., The Effect of Heat Treatments and Degradation Behavior of High-Rate Dischargeability in Ti-V-based Alloys as Anode Materials for Nickel-Metal-Hydride Batteries. Z. Phys. Chem., v. 22, p.389-401. 2013.

WU Z., KISHIDA K., INUI H., ISHIDA J., YASUOKA S., ZHANG, Z., Microstructures and hydrogen absorption-desorption behavior of an $\mathrm{A}_{2} \mathrm{~B}_{7}$-based La-Mg-Ni alloy. International Journal of Hydrogen Energy, v. 42, p. 22159-22166. 2017.

ZARPELON L. M. C., BANCZEK E. P., MARTINEZ L. G., LIMA N. B., COSTA I., FARIA R.N., Effects of Magnesium Content on Structure and Electrochemical Properties of La-Mg-Pr-Al-Mn-Co-Ni Hydrogen Storage Alloys. Advances in Materials Science and Engineering, v. 2018, p. 1-11. 2018.

ZARPELON L. M. C. and FARIA R. N., Microstructure and Electrochemical Characteristics of LaPrMgAIMnCoNi Hydrogen Storage Alloys for Nickel-Metal Hydride Batteries. Materials Science Forum. v. 802 p. 421-426. 2014.

ZENG Q., JOUBERT J.M., LATROCHE M., JUN D., PERCHERON-GUEGAN A., I influence of the rare earth composition on the properties of $\mathrm{Ni}-\mathrm{MH}$ electrodes. Journal of Alloys and Compounds. v. 360 p. 290-293. 2003. 
ZHANG F., LUO Y., CHEN J., YAN R., KANG L., CHEN J., Effect of annealing treatment on structure and electrochemical properties of $\mathrm{La}_{0.67} \mathrm{Mg}_{0.33} \mathrm{Ni}_{2.5} \mathrm{Co}_{0.5}$ alloy electrodes. Journal of Power Sources. v. 150, p. 247-254. 2005.

ZHANG H., ZHENG X., TIAN X., LIU Y., LI X. New approaches for rare earthmagnesium based hydrogen storage alloys. Progress in Natural Science: Materials International, v. 27, p. 50-57. 2017.

ZHANG L., HAN S., LI Y., YANG S., ZHAO X., LIU J., Effect of Magnesium on the Crystal Transformation and Electrochemical Properties of $\mathrm{A}_{2} \mathrm{~B}_{7}$-Type Metal Hydride Alloys. Journal of the Electrochemical Society, v. 161, p. A1844-A1850. 2014.

ZHANG L., ZHANG J., HAN S., LI Y., YANG S., LIU J. Phase transformation and electrochemical properties of $\mathrm{La}_{0.70} \mathrm{Mg}_{0.30} \mathrm{Ni}_{3.3}$ super-stacking metal hydride alloy. Intermetallics, v. 58, p. 65-70. 2015.

ZHANG Q., PANG G., SI T.Z., LIU D.M., Crystal structure and hydrogen absorptiondesorption properties of $\mathrm{Ca}_{3} \mathrm{Mg}_{2} \mathrm{Ni}_{13}$. Acta Materialia. v. 57, p. 2002-2009. 2009.

ZHANG W., HAN S., HAO J., LI Y., BAI T., ZHANG J., Study on kinetics and electrochemical properties of low-Co $A_{B_{5}}$-type alloys for high-power $\mathrm{Ni} / \mathrm{MH}$ battery. Electrochimica Acta, v. 54, p. 1383-1387. 2009.

ZHANG X.B., SUN D.Z., YIN W.Y. , CHAI Y.J., ZHAO M.S., Effect of La/Ce ratio on the structure and electrochemical characteristics of $\mathrm{La}_{0.7-\mathrm{x}} \mathrm{Ce}_{\mathrm{x}} \mathrm{Mg}_{0.3} \mathrm{Ni}_{2.8} \mathrm{Co}_{0.5}(\mathrm{x}=0.1-$ 0.5) hydrogen storage alloys. Electrochimica Acta. v. 50, p. 1957-1964. 2005.

ZHANG, Y., YUAN, Z., YANG, T., FENG, D., CAI, Y., ZHAO, D., An investigation on hydrogen storage thermodynamics and kinetics of $\mathrm{Pr}-\mathrm{Mg}-\mathrm{Ni}$-based $\mathrm{PrMg}_{12}$-type alloys synthesized by mechanical milling. Journal of Alloys and Compounds, v. 688, p. 585-593. 2016.

ZHANG Y., YANG T., ZHAI T., YUAN Z., ZHANG G., GUO S., Effects of stoichiometric ratio $\mathrm{La} / \mathrm{Mg}$ on structures and electrochemical performances of as-cast and annealed $\mathrm{La}-\mathrm{Mg}-\mathrm{Ni}$-based $\mathrm{A}_{2} \mathrm{~B}_{7}$-type electrode alloys. Trans. Nonferrous Met. Soc. China. v. 25, p. 1968-1977. 2015.

ZHANG Y., LI P., YANG T., ZHAI T., YUAN Z., GUO S., Effects of substituting La with $\mathrm{M}(\mathrm{M}=\mathrm{Sm}, \mathrm{Nd}, \mathrm{Pr})$ on electrochemical hydrogen storage characteristics of $\mathrm{A}_{2} \mathrm{~B}_{7^{-}}$ type electrode alloys. Trans. Nonferrous Met. Soc. China. v. 24, p. 4012-4022. 2014.

ZHANG Y., CAI Y., LI B., REN H., HOU Z., ZHAO D., Electrochemical Hydrogen Storage Characteristics of the as-Cast and Annealed $\mathrm{La}_{0.8-\mathrm{x}} \mathrm{Pr}_{\mathrm{x}} \mathrm{Mg}_{0.2} \mathrm{Ni}_{3.35} \mathrm{Al}_{0.1} \mathrm{Si}_{0.05}(\mathrm{x}=0 \sim 0.4)$ Electrode Alloys. Rare Metal Materials and Engineering, v. 42, p. 1981-1987. 2013.

ZHANG Y., CAI Y., ZHAO C., ZHAI T., ZHANG G., ZHAO D. Electrochemical performances of the as-melt $\mathrm{La}_{0.75-\mathrm{x}} \mathrm{M}_{x} \mathrm{Mg}_{0.25} \mathrm{Ni}_{3.2} \mathrm{Co}_{0.2} \mathrm{Al} \mathrm{l}_{0.1}(\mathrm{M}=\mathrm{Pr}, \mathrm{Zr} ; \mathrm{x}=0,0.2)$ alloys applied to Ni/metal hydride (MH) battery. International Journal of Hydrogen Energy, v. 37, p. 14590-14597. 2012a. 
ZHANG Y., HOU Z., LI B., REN H., ZHANG G., ZHAO D., An investigation on electrochemical hydrogen storage performances of the as-cast and -annealed $\mathrm{La}_{0.8-\mathrm{x}} \mathrm{Sm}_{\mathrm{x}} \mathrm{Mg}_{0.2 \mathrm{Ni3.35}} \mathrm{Al}_{0.1} \mathrm{Si}_{0.05}(\mathrm{x}=0-0.4)$ alloys. Journal of Alloys and Compounds. v. 537 , p. $175-182.2012 b$.

ZHANG Y., LI B., REN H., CAI Y., DONG X., WANG X., Investigation on structures and electrochemical performances of the as-cast and -quenched $\mathrm{La}_{0.7} \mathrm{Mg}_{0.3} \mathrm{Co}_{0.45} \mathrm{Ni}_{2.55-\mathrm{x}} \mathrm{Fe}_{\mathrm{x}}(\mathrm{x}=0-0.4)$ electrode alloys. International Journal of Hydrogen Energy, v. 32, p. 4627-4634. 2007.

ZHANG Y. H., DONG X. P., WANG G. Q., GUO S. H., REN J.Y., WANG X. L. Microstructure and electrochemical performances of $\mathrm{La}_{0.7} \mathrm{Mg}_{0.3} \mathrm{Ni}_{2.55-\mathrm{x}} \mathrm{Co}_{0.45} \mathrm{Cu}_{\mathrm{x}}(\mathrm{X}=0$ 0.4 ) hydrogen storage alloys prepared by casting and rapid quenching. Journal of Alloys and Compounds. v. 417, p.224-229. 2006.

ZHANG Y., TANG J., GSCHNEIDNER K., A Redetermination of the LaNi Phase Diagram from $\mathrm{LaNi}$ to $\mathrm{LaNi}_{5}$ (50 to 83.3 at.$\% \mathrm{Ni}$ ), Journal of the less-common metals, v. 169, p. 45-53, 1991.

ZHOU H., WANG Y., YAO Q., The 673 and 1123K isothermal sections (partial) of the phase diagram of the $\mathrm{Ce}-\mathrm{Mg}-\mathrm{Ni}$ ternary system. Journal of Alloys and Compounds, v. 407, p. 129-131. 2006.

ZHOU Z.; SONG Y.; CUI S.; HUANG C.; QIAN W.; LIN, C., ZHANG Y., LIN, Y., Effect of annealing treatment on structure and electrochemical performance of quenched $\mathrm{MmNi}_{4.2} \mathrm{Co}_{0.3} \mathrm{Mn}_{0.4} \mathrm{Al}_{0.3} \mathrm{Mg}_{0.03}$ hydrogen storage alloy. Journal of Alloys and Compounds, v. 501, p. 47-53. 2010.

ZHUANG Y., DING R., LIU J., OU X., DENG H., The isothermal section of the Gd-Mn-Ni ternary system at 803K. Journal of Alloys and Compounds. v. 346, p. 181-183. 2002.

ZHUANG Y., DENG H., LIU J., YAO Q., The $673 \mathrm{~K}$ isothermal section of the La-NiSn ternary system. Journal of Alloys and Compounds, v. 363, p. 228-231. 2004.

ZILSTRA H; WESTENDORP F.F.; Influence of hydrogen on the magnetic properties of $\mathrm{SmCo}_{5}$. Solid State Communications., v.7, p. 857. 1969.

ZÜTTEL A., Materials for hydrogen storage. Materials Today. v. 6, p. 24-33. 2003.

ZUTTEL A., REMHOF A., BORGSCHULTE A., FRIEDRICHS O. Hydrogen: the future energy carrier. Philosophical Transactions of the Royal Society A: Mathematical, Physical and Engineering Sciences, v. 368, p. 3329-3342. 2010. 


\section{Sugestões para trabalhos futuros}

- Estudos a partir de ligas onde ocorram substituições parciais do $\mathrm{Ni}$ por (Co+Cu). Formando a liga $\mathrm{La}_{0,7} \mathrm{Mg}_{0,3} \mathrm{Al}_{0,3} \mathrm{Mn}_{0,4} \mathrm{Co}_{(0,5-x)} \mathrm{Cu}_{x} \mathrm{Ni}_{3,8}(\mathrm{x}=0,1-0,4)$.

- Estudos a partir de ligas onde ocorram substituições parciais do La por Mg em porcentagens menores que as praticadas nas ligas atuais $\mathrm{La}_{(0,7+x)} \mathrm{Mg}_{(0,3-x)} \mathrm{Ni}_{5} \quad(x=0,05-0,25)$.

- Estudos na forma de promover a distribuição do óxido de grafeno reduzido (rGO) nas ligas usadas na fabricação dos eletrodos negativos de $\mathrm{NiMH}$.

- Estudos para aplicação de óxido de grafeno reduzido (rGO) também em eletrodos positivos nas baterias de $\mathrm{NiMH}$. 


\section{PRODUÇÃO CIENTIFICA}

SOARES E.P., ZARPELON L.M.C., DE FARIA JR.,R.N., The Influence of Pr and Mg Content on the Hydrogen Decrepitation of LaNi-Based Battery Alloys. Materials Science Forum, v. 899, p. 148-153. 2017.

SOARES E.P., CASINI J.C.S., VIEIRA L.S., SILVA F.M., DE FARIA JR R.N., TAKIISHI H., Effect of Hydrogen Decrepitation Pressure on the Particle Size of Rare Earth Based Alloys for Ni-MH Battery Production. Materials Science Forum, v. 930, p. 637-642. 2018.

SOARES E. P., FILHO J.C.S., CASINI J.C.S., DE FARIA JR R.N., TAKIISHI H., The influence of the addition of rGO and CNT on the electrochemical properties ofthe batteries the LaNi-Based Battery Alloys. Materials Science Forum, submitted. 2019

CIONE F.C., SOUZA A.C., SENE F.F., GOMES M.P., SOARES E.P., ROSSI J. L., Obtention of WCuNi composite material using powder metallurgy for gamma $(\varphi)$ radiation attenuation. In: VIII Encontro Científico de Física Aplicada, Espírito Santo. Blucher Physics Proceedings. v. viii. p. 25-28. 2018.

FILHO J.C.S., SOARES E.P., VENANCIO E.C., SILVA S.C., TAKIISHI T., Influência do tratamento térmico na redução do óxido de grafeno. In: VIII Encontro Científico de Física Aplicada, Espírito Santo. Blucher Physics Proceedings. v. viii. p. 72-76. 2018.

FILHO J.C.S., SOARES E.P., SILVA S.C., VENANCIO E.C., ANTUNES R.A., TAKIISHI H., Processing of graphene oxide by heat treatment. Journal of Materials Research, submitted. 2019 


\section{PARTICIPAÇÃO DE TRABALHOS EM EVENTOS CIENTÍFICOS}

SOARES E.P., ZARPELON L.M.C., DE FARIA JR R.N., The Influence of Pr and Mg Content on the Hydrogen Decrepitation of LaNi-Based Battery Alloys. Tenth International Latin American Conference on Powder Technology 08th to 11th November 2015 - Mangaratiba - RJ - Brazil.

SOARES E.P., CASINI J.C.S., VIEIRA L.S., SILVA F.M., DE FARIA JR R.N., TAKIISHI $H$., Efeito da pressão de hidrogênio na decrepitação e no tamanho de partícula de ligas a base de terras raras para produção de baterias $\mathrm{Ni}-\mathrm{MH}$. 22 Congresso Brasileiro de Engenharia e Ciência dos Materiais 6 a 10 de novembro de 2016 - Natal - RN- Brasil.

SOARES E. P., FILHO J.C.S., CASINI J.C.S., DE FARIA JR R.N., TAKIISHI H., A influência da adição de rGO e CNT nas propriedades eletroquímicas das baterias das ligas de baterias a base LaNi. 23ํㅡㄹ Congresso Brasileiro de Engenharia e Ciência dos Materiais 4 a 8 de novembro de 2018 - Foz do Iguaçu - PR - Brasil.

FILHO J.C.S., SOARES E.P., SILVA S.C., VENANCIO E.C., ANTUNES R.A., TAKIISHI H., Processamento do óxido de grafeno por tratamento térmico. 23ª Congresso Brasileiro de Engenharia e Ciência dos Materiais 4 a 8 de novembro de 2018 - Foz do Iguaçu PR - Brasil

FILHO J.C.S., SOARES E.P., VENANCIO E.C., SILVA S.C., TAKIISHI H., Influência do tratamento térmico na redução do óxido de grafeno. In: VIII Encontro Científico de Física Aplicada, 2017, Espírito Santo.

CIONE F.C., SOUZA A.C., SENE F.F., GOMES M.P., SOARES E.P., ROSSI, J. L., Obtention of WCuNi composite material using powder metallurgy for gamma $(\varphi)$ radiation attenuation. In: VIII Encontro Científico de Física Aplicada, 2017, Espírito Santo. 